


$$
\text { \% }
$$









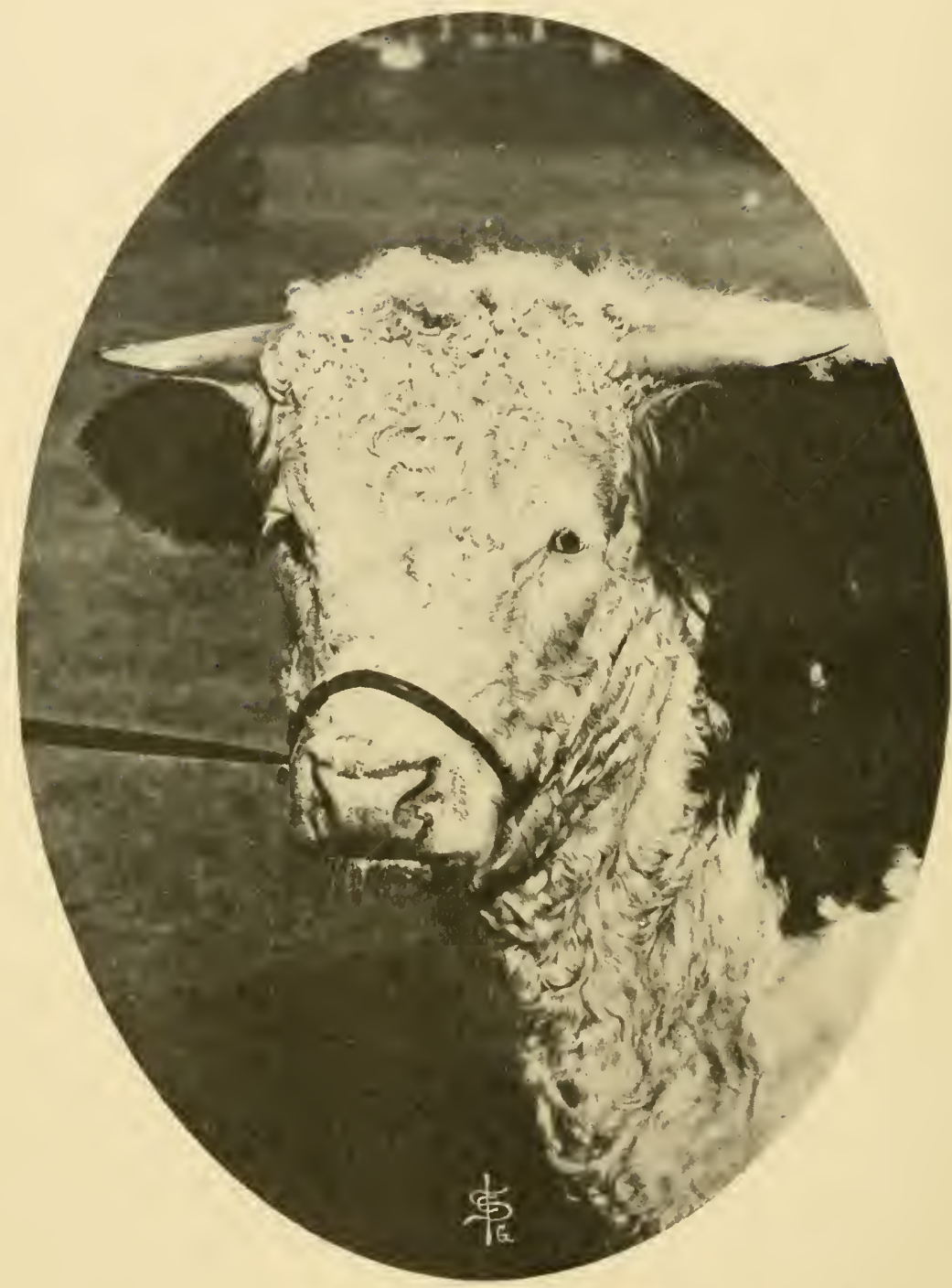

An Ideal Feeder's Head.

Hereford steer, Peerless Wilton 39th's Defender, Grand Champion at the International Live Stock Show in 1906. Bred, fed and exhibited by Mr. F. A. Nave, Attica, Ind. Sold to Iowa State College. 


\title{
Types and Market Classes of Live Stock
}

\author{
By \\ H. W. Vaughan, M. Sc. in Agr. \\ Professor of Animal Husbandry \\ University of Minnesota
}

FIFTH EDITION

Revised

R. G. ADAMS \& CO.

COLumbus, оніо

1919 


$$
\begin{aligned}
& 5 F 10^{5} \\
& \sqrt{3} \\
& 9^{19}
\end{aligned}
$$

COPYRIGHT, 1919

H. W. VAUGHAN

THE CHAMPLIN PRESS

COLUMBUS, OHIO

MAR - 21920

DCl.A565069

$m o \cdot 1$. 


\section{PREFACE TO FIRST EDITION.}

During the past eight years there has been added to the curriculum in most of our agricultural colleges a new course dealing with the types of farm animals, market demands, and market classes of live stock. More properly speaking, it has been inserted at the very beginning of the work in animal husbandry, forming, as it logically does, the foundation course in the study of that important branch of agriculture. This is a soundly practical study; the student is brought to a much clearer conception of values and a much better appreciation of live stock than was possible under the former system of teaching.

Recognizing the need of a text on this subject which could be placed in the hands of students, the writer prepared and printed a loose-leaf edition which has been used at Ohio State University during the past three years. This met with favorable comment, and requests have been made that the material be put into book form. After careful revision and the addition of a number of illustrations, this is now attempted in the hope that students and teachers and the general reader as well may find such a book useful.

The arrangement of the subject-matter corresponds to the order usually followed in teaching, but may be varied as desired, each section of the book-Cattle, Sheep, Hogs, and Horses-being complete in itself.

The writer desires to express his indebtedness to numerous commission men, buyers for the packing houses, and others who have kindly given their assistance during his quests for information, and to numerous experiment station publications, particularly the series of excellent bulletins issued by the Illinois Station setting forth the results of their studies of the Chicago and St. Louis markets. Acknowledgment of valued assistance is due my present co-workers, and also Professors C. S. Plumb and F. R. Marshall at Ohio State University.

Iowa State College,

H. W. VAUGHAN. July, 1915. 



\section{PREFACE TO FIFTH EDITION.}

At most agricultural colleges, the study of beef cattle begins with the fat steer at the market, both on foot and in the carcass, proceeds from that to a study of cattle in the feed-lot, and then considers the selection and operation of the breeding herd. Similar procedures are followed in studying other kinds of live stock. If the student learns his first lesson at the market, he comes to the feed-lot fortified with a knowledge of what the market wants, and he then proceeds to a study of the breeding herd knowing what both the market and the feed-lot demand from the breeder.

This is the most practical method of teaching because the market should serve as a guide to the breeder and feeder; and it is best from a pedagogical standpoint because finished animals for the market are easiest to judge, are judged on practical points, the student begins his judging with the more elementary and proceeds to the more complex types, and as he progresses to each new stage he brings with him a soundly practical viewpoint gained from his previous experience. Finally, in his study of the commercial breeding herd, the produce of which goes direct to the feed-lot or market, he learns the necessity for using good purebred sires, and this leads in logical order to the study of the breeds of farm animals. He takes up the breed studies with a clear understanding that it is the function of these breeds to supply seed to improve all farm and range live stock, he has a firm belief in their power to perform this function, and he is led to compare and value the various breeds as they should be compared and valued, namely on their ability to meet practical requirements. In short, the modern plan of study, which proceeds from the market to the breeds, rather than from the breeds to the market, gives the student the right philosophy of the live-stock business, particularly the purebred live-stock business.

In the first edition of this book, published in 1915, the undersigned endeavored to present clearly and concisely the things a beginner in the field of Animal Husbandry should know, leading up to, but not including, the study of the breeds. The 
favor with which the book was received far surpassed the expectations of those responsible for its appearance, and led to three reprintings of the original edition. Thus encouraged, the book has been rewritten so as to bring it up to date and give it greater clearness and accuracy, yet retaining the original plan without any radical changes.

A number of new illustrations are included. At the suggestion of several instructors at various colleges, three new chapters, III., VII., and XXXVII., have been added. These additions meet the test applied to all parts of the book, namely they treat concisely of subjects concerning which the beginner should be informed before taking up more advanced studies in animal husbandry.

University of Minnesota,

H. W. VAUGHAN.

July, 1919. 


\section{ILLUSTRATIONS.}

An Ideal Feeder's Head. (Courtesy Iowa State College.)-Frontispiece

FIG.

PAGE

1. Points of the Steer. . . . . . . . . . . . . . . . . . . 28

2. Points of the Steer. . . . . . . . . . . . . . . . . . . . 29

3. Correct Type in the Fat Steer. (Photograph by Mr. F. E.

Colburn. Courtesy Iowa State College.)............. 32

4. A Steer with Excellent Lines. (Courtesy Iowa State College.). 34

5. A Feed-Lot Model. (Courtesy Iowa State College.)......... . 37

6. Knocking Cattle........................ 40

7. Wholesale Cuts of Beef...................... 43

8. Cuts of Beef Indicated in the Live Animal. (Courtesy Iowa State College.)....................... 45

9. Beef Ribs. (Courtesy Iowa State College.)............... 50

10. Well-Marbled Beef. (Courtesy Iowa State College.)......... 51

11. Dairy-Type Steer. (Courtesy Iowa State College.).......... 63

12. Dairy-Type Steer. (Courtesy Iowa State College.).......... 67

13. Carcasses of Beef and Dairy Calves. (Courtesy Iowa State College.) .............................. 69

14. Carcasses of Beef and Dairy Calves. (Courtesy Iowa State College.)................................. 70

15. Union Stock Yards, Chicago. (Courtesy Mr. A. G. Leonard and Union Stock Yard and Transit Co.).............. 77

16. Ideal of Early Beef Producers. (Courtesy Iowa State College.) 86

17. Prime Baby Beef. (Courtesy Iowa State College.).......... 88

18. Baby Beeves on Feed. (Courtesy Prof. A. B. Caine, Iowa State College.)...................... 89

19. Prime Fat Heifer. (From Ill. Bul. 78. Courtesy Prof. H. W.

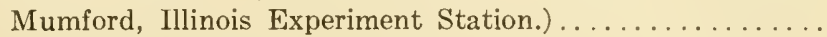

20. Fancy Selected Feeders. (From Ill. Bul. 78. Courtesy Prof. H. W. Mumford, Illinois Experiment Station.) ..........

21. An Average Load of Steers on Feed. (Courtesy Iowa State College.)................................ 101

22. Fancy Feeder Calves............................ 103

23. Prime Fat Steers............................ 108

24. Choice Fat Steers. . . . . . . . . . . . . . . . . . . . 109

25. Good Fat Steers. (From Ill. Bul. 78. Courtesy Prof. H. W. Mumford, Illinois Experiment Station.)........... 110

26. Prime Baby Beeves. (Courtesy Iowa State College.)........ 111

27. Old-Time Texas Long-Horn. (Courtesy Prof. F. R. Marshall, Bureau of Animal Industry, Washington, D. C.) ......... . 112

28. Modern Western Range Cattle...................... 113

29. Good to Choice Heifer. (From Ill. Bul. 78. Courtesy Prof. H. W. Mumford, Illinois Experiment Station.) .......... 
Fig.

30. Good Cutters. (From Ill. Bul. 78. Courtesy Prof. H. W. Mumford, Illinois Experiment Station.)...

31. Common or Inferior Canners. (From Ill. Bul. 78. Courtesy Prof. H. W. Mumford, Illinois Experiment Station.) . . . . . . .

32. Choice Feeder. (From Ill. Bul. 78. Courtesy Prof. H. W. Mumford, Illinois Experiment Station.) .............

33. Good Feeders. (From Ill. Bul. 78. Courtesy Prof. H. W. Mumford, Illinois Experiment Station.) ..............

34. Medium Feeders. (From Ill. Bul. 78. Courtesy Prof. H. W. Mumford, Illinois Experiment Station.) .............

35. Common or Inferior Feeders. (From Ill. Bul. 78. Courtesy Prof. H. W. Mumford, Illinois Experiment Station.) ........

36. Choice Veal Calf. (From Ill. Bul i78. Courtesy Prof. H. W. Mumford, Illinois Experiment Station.) .............

37. Correct Type in the Beef Sire.

38. Correct Type in the Beef Cow . . . . . . . . . . . . . . . . . .

39. An Excellent Breeding Cow. (Courtesy lowa State College.)..

40. Points of the Dairy Cow .

41. A Dairy Cow with Utility Points Emphasized. (Courtesy Iowa State Department of Agriculture.) ................

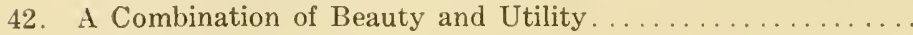

43. Excellent Type in the Dairy Cow . . . . . . . . . . . .

44. An Inferior Dairy Cow ..................................... Excellent Type in the Dairy Bull. Iowa State Departrnent of Agriculture.) .................... 152

46. A Dairy Bull with Strength and Vigor ................

47. Cross-Section of Cow's Udder. (From Sisson's Anatomy of the Domestic Animals. Courtesy Dr. Septimus Sisson, Ohio State University.) . . . . . . . . . . . . . . . . . . . . .

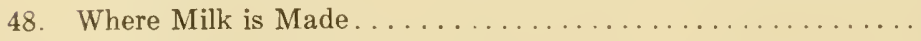

49. Circulation To and From the Udder................

50. What Good Purebred Sires Can Do. (From Iowa Bul. 188. Courtesy Prof. A. C. McCandlish, Iowa State College.) ......

51. The Dual-Purpose Type. (Courtesy Mr. J. J. Hill, St. Paul,

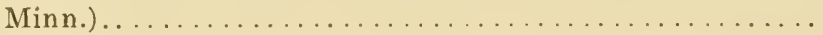

52. The Dual-Purpose Type (Courtesy Mr. Geo. P. Grout, Duluth, Minn.)................................

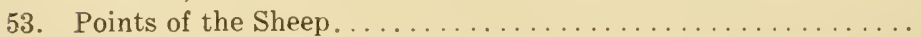

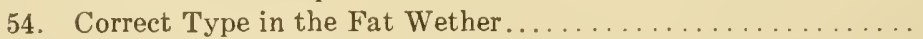

55. Long-Wool Sheep. (Courtesy Iowa State Department of Agriculture.)... . . . . . . . . . . . . . . . . . . . . 199

56. Killing Sheep at Chicago..................... 204

57. Wholesale Cuts of Mutton . . . . . . . . . . . . . . . 206

58. Round-Joint and Break-Joints................... 209

59. Prime Native Lambs. (Courtesy Iowa State College.)...... 216

60. Prime Western Lambs. (Courtesy Armour \& Company, Chicago, Ill.) . . . . . . . . . . . . . . . . . . . . .

61. Choice Western Lambs. (Courtesy Iowa State College.)...... 
FIG.

62. Good Lambs. (Courtesy Prof. W. C. Coffey, Illinois Experiment Station.)........

63. Common or Cull Lambs. (From Ill. Bul. 129. Courtesy Prof W. C. Coffey, Illinois Experiment Station.).

64. Prime Native Yearlings. (Courtesy Iowa State College.)

65. Prime Western Yearlings. (From Ill. Bul, 129. Courtesy Prof. W. C. Coffey, Illinois Experiment Station.).

66. Good Yearlings. (From Ill. Bul. 129. Courtesy Prof. W. C Coffey, Illinois Experiment Station.) . . . . . . . . . .

67. Common Wethers. (From Ill. Bul. 129. Courtesy Prof. W. C Coffey, Illinois Experiment Station.)

68. Fancy Selected Feeder Lambs. (From Ill. Bul. 129. Courtesy Prof. W. C. Coffey, Illinois Experiment Station.) ......

69. Good Feeder Lambs. (From Ill. Bul. 129. Courtesy Prof. W. C. Coffey, Illinois Experiment Station.) .............

70. Common Feeder Lambs. (From Ill. Bul. 129. Courtesy Prof. W. C. Coffeỳ, Illinois Experiment Station.) . . . . . . .

71. Correct Type in the Mutton Breeding Ram. (Courtesy Mr Alan Eltringham, Babraham, Cambridge, England.) . .

72. Correct Type in the Breeding Ewe................ 241

73. A Prize-Winning Flock. . . . . . . . . . . . . . . . . . . 242

74. A Flock of Uniform Type........................ 243

75. Class A Merino Ram. (Courtesy Prof. F. R. Marshall, U. S. Bureau of Animal Industry.). . . . . . . . . . . . . .

76. Class B Merino Ram. (Courtesy Prof. F. R. Marshall, U. S.

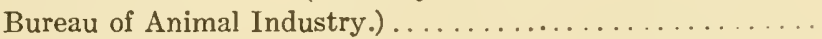

77. Class C Merino Ram. (Courtesy Prof. F. R. Marshall, U. S. Bureau of Animal Industry.). . . . . . . . . . . . . .

78. Class B Merino Ewe. (Courtesy Prof. F. R. Marshall, U. S. Bureau of Animal Industry.). . . . . . . . . . . . . .

79. Rambouillet Ewe. (Courtesy Prof. F. R. Marshall, U. S. Bureau of Animal Industry.) . . . . . . . . . . . . . . . .

80. Wool Fiber Highly Magnified . . . . . . . . . . . . . . .

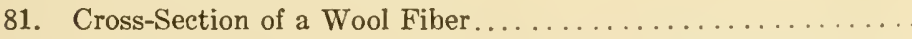

82. Woolen and Worsted Yarns. (From U. S. House of Rep. Doc.

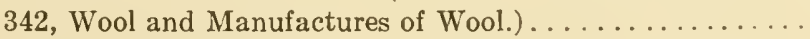

83. Clothing and Combing Wools. (From U. S. Dept. Agr. Bul. 206 Courtesy Prof. F. R. Marshall, U. S. Bureau of Animal Industry.).

84. Grades of Combing Wool. (From U. S. Dept. Agr. Bul. 206. Courtesy Prof. F. R. Marshall, U. S. Bureau of Animal In-

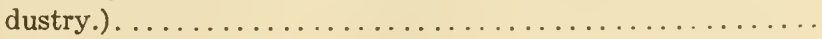

85. Grades of Combing Wool. (From U. S. Dept. Agr. Bul. 206. Courtesy Prof. F. R. Marshall, U. S. Bureau of Animal In-

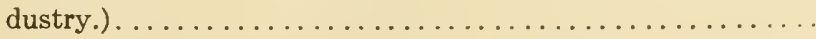

86. Grades of Combing Wool. (From U. S. Dept. Agr. Bul. 206. Courtesy Prof. F. R. Marshall, U. S. Bureau of Animal Industry.) 
FIG.

87. Tender Wool Showing Break. (From U. S. Dept. Agr. Bul. 206. Courtesy Prof. F. R. Marshall, U. S. Bureau of Animal Industry.)

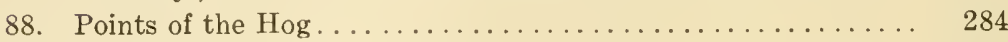

89. Correct Type in the Fat Barrow .................. 286

90. Finished Barrows. (Courtesy National Duroc-Jersey Record

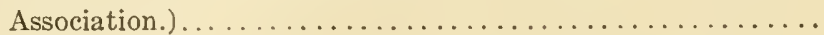

91. Fancy Market Bacon Pig. (Courtesy Iowa State College.)....

92. Correct Bacon Type. (Courtesy Iowa State College.) ........

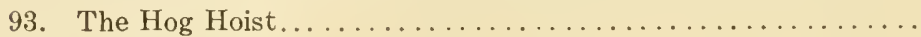

94. Dressing Hogs. . . . . . . . . . . . . . . . . .

95. A View of the Pork Coolers......................

96. Wholesale Cuts of Pork. (After Ill. Bul. 147.)............

97. Effect of Underline on Trimming of Side...............

98. Fat and Bacon Carcasses Compared. (Courtesy Iowa State College.) ............................. 307

99. Unloading Hogs at Chicago....................... 320

100. Prime Heavy Hogs. (Courtesy Iowa State College.) ... . . . . 323

101. Prime Butcher Hogs . . . . . . . . . . . . . . . . . . . . . . . . 324

102. Choice Butcher Hogs. (Courtesy Iowa State College.)...... 325

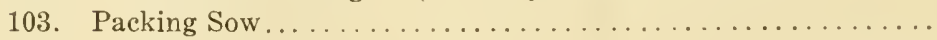

104. An Excellent Boar. (Courtesy Mr. W. H. Robbins, Springfield, Ohio.) .................................

105. Pork Production in United States Closely Related to Corn Pro-

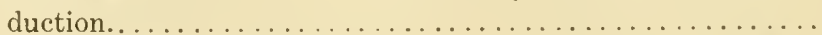

106. Good Type in the Breeding Boar. (Courtesy Iowa State De-

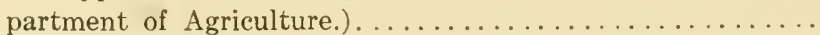

107. Good Type in the Breeding Sow. (Courtesy Iowa State De-

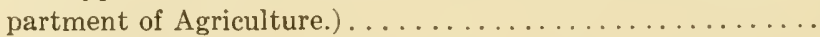

108. Skeleton of the Horse. (From Sisson's Anatomy of the Domestic Animals, after Ellenberger \& Baum, Anatomy for Artists. Courtesy Dr. Septimus Sisson, Ohio State University.) ......

109. Bones of the Fore Leg. . . . . . . . . . . . . . . . . .

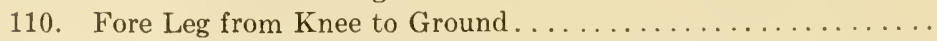

111. Bones, Tendons, and Ligaments of the Fore Leg ..........

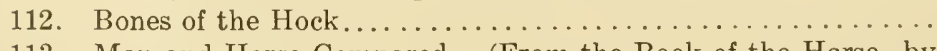

113. Man and Horse Compared. (From the Book of the Horse, by permission of the Gresham Publishing Company, London.). .

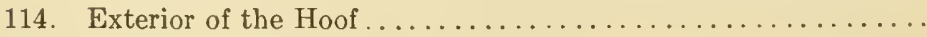

115. Diagram Showing Structure of Foot............. 356

116. The Parts of the Hoof ........................ 358

117. Attachment of Fore Leg to Body. (From the Book of the Horse, by permission of the Gresham Publishing Company,

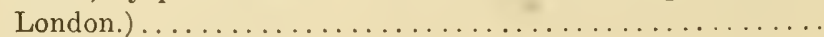

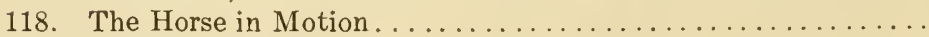

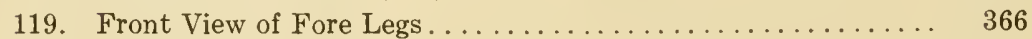

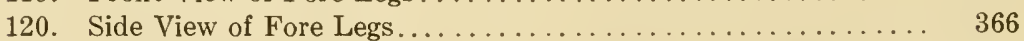

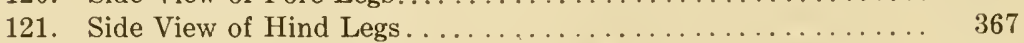

122. Rear View of Hind Legs....................... 367 
123. Defects in Fore Legs and Their Effect on Action .......... 368

124. Sickle Hock. . . . . . . . . . . . . . . . . . . . . . . . . . 370

125. Points of the Horse......................... 387

126. The Draft Type............................ 389

127. Heavy Drafters in Harness . . . . . . . . . . . . . . . . . . 395

128. Before and After Fattening. (Courtesy Mr. B. E. Carmichael, Ohio Experiment Station.)................... 398

129. Carriage or Heavy-Harness Type. (Courtesy Prof. C. N. Arnett, Montana State College.)..................

130. The Heavy-Harness Type in Action. (Courtesy Mr. Wm. Little, Irvington Farm, Sewickley, Pa.). .............

131. The Carriage Horse in Harness. (Courtesy The Spur, New

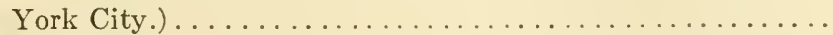

132. Sensational Action. (Courtesy The Spur, New York City.)...

133. Roadster or Light-Harness Type. (Courtesy Hon. John R. Thompson, Libertyville, Ill.).

134. The Light-Harness Horse in Action. . . . . . . . . . . . . .

135. Five-Gaited Saddle Horse. (Courtesy Mrs. R. Tasker

Lowndes, Danville, Ky.) . . . . . . . . . . . . . . . . .

136. The Saddle Horse in Action. (Courtesy Mrs. R. Tasker

Lowndes, Danville, Ky.) . . . . . . . . . . . . . . . . .

400

402

404

407

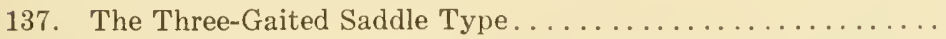

138. A Typical Hunter. (From Nimrod's Condition of Hunters, by permission of the John Lane Company, New York City.)....

139. The Hunter in Action. (Courtesy The Field, New York City.)

140. A Hunt Team and Pack of Fox Hounds. (From Nimrod's Condition of Hunters, by permission of the John Lane Com-

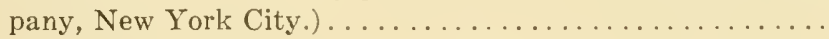

141. Polo Pony of Excellent Type. (Courtesy The Spur, New York

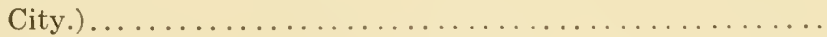

142. The Polo Pony in Action. (Courtesy Mr. Harold A. Taylor, Coronado, Cal.) ..........................

143. Horse Market at Union Stock Yards, Chicago .............

144. Eastern Chunk. (Courtesy Prof. C. N. Arnett, Montana State College.) . . . . . . . . . . . . . . . . . . . . . . .

145. Express Horse. (Courtesy Capt. M. G. Thornburg, Commanding Officer Remount Service Training Camp, Auxiliary Remount Depot, Camp Joseph E. Johnston, Jacksonville, Fla.)

146. Light Artillery Horse. (Courtesy Iowa State College.) .......

147. Heavy Artillery Horses. (Courtesy Capt. M. G. Thornburg, Commanding Officer Remount Service Training Camp, Auxiliary Remount Depot, Camp Joseph E. Johnston, Jack-

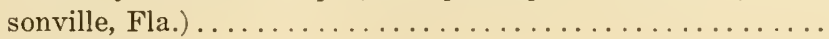

148. Fire Horses . . . . . . . . . . . . . . . . . . . . . . . .

149. Runabout Horse. . . . . . . . . . . . . . . . . . . 452

150. Cavalry Horse. (Courtesy Iowa State College.)...........

151. High-Class Pony. (Courtesy Mr. Geo. A. Heyl, Washington,

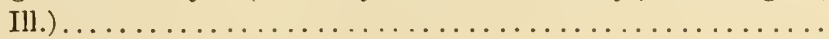

152. Correct Type in the Draft Stallion. 
FIG.

153. Correct Type in the Draft Mare. (Courtesy Iowa State Department of Agriculture.) . . . . . . . . . . . . . . . .

154. A Highly Successful Sire. (Courtesy Mr. Wm. Crownover, Hudson, Iowa.) . . . . . . . . . . . . . . . . . 462

155. Blood Will Tell. (Courtesy Truman Pioneer Stock Farm, Bush-

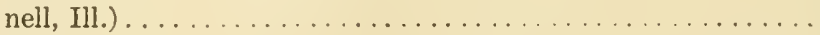

156. Correct Type in the Jack. (Courtesy Mr. L. M. Monsees, Pettis County, Mo.) . . . . . . . . . . . . . . . . . . . . . 469

157. Prize-Winning Mules . . . . . . . . . . . . . . . . . . . 470

158. High-Class Draft Mules. . . . . . . . . . . . . . . . . . . . 473

159. Mining or Pack Mule. (Courtesy Iowa State College.)...... 474

160. Cotton or Lead Mule. (Courtesy Iowa State College.)....... 475

161. Sugar Mule. (Courtesy Capt. M. G. Thornburg, Commanding Officer Remount Service Training Camp, Auxiliary Remount Depot, Camp Joseph E. Johnston, Jacksonville, Fla.) ......

162. Farm or Wheel Mule. (Courtesy Iowa State College.)........

163. Small Pair of Wheel Mules to Army Wagon. (Courtesy Capt. M. G. Thornburg, Commanding Officer Remount Service Training Camp, Auxiliary Remount Depot, Camp Joseph E. Johnston, Jacksonville, Fla.) . . . . . . . . . . . . . . . . .

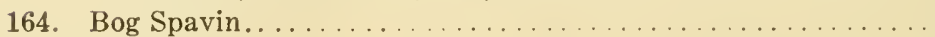

165. Bone Spavin ............................ 483

166. Curb ............................... 486

167. Ringbone and Cocked Ankle...... ............. 489 


\section{CONTENTS.}

PAGE

General Introduction

\section{PART ONE-CATTLE}

CHAFTER

Introduction . . . . . . . . . . . . . . . . . . . . . 23

I. Beef Type............................. 27

II. The Beef Carcass.......................... 40

III. Packing House By-Products from Cattle... . . . . . . . . . 57

IV. The Value of Type in Beef Making. .............. 63

V. American Cattle Markets..................... 71

VI. Fashions in Market Cattle................ 85

VII. Selection of Feeder Steers................. 95

VIII. Market Classes and Grades of Cattle............ 106

IX. Breeding for the Market. . . . . . . . . . . . . . 125

X. Dairy Type............................ 138

XI. The Secretion of Milk .................... 155

XII. Variations in the Usefulness of Dairy Cows . . . . . . . . 164

XIII. Breeding for Milk Production.................... 172

XIV. Dual-Purpose Cattle...................... 180

PART TWO-SHEEP

Introduction . . . . . . . . . . . . . . . . . 189

XV. Mutton Type.......................... 194

XVI. The Mutton Carcass and the Pelt.............. 203

XVII. Sheep Markets and Market Classification............. 214

XVIII. Breeding for the Market...................... 235

XIX. The Merino or Fine-Wool Type................. 245

XX. Wools and Wool Growing.................. 255

\section{PART THREE-SWINE}

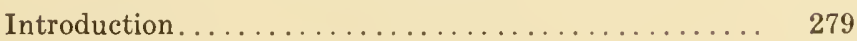

XXI. The American or Lard-Type Hog ............... 282

XXII. The Bacon-Type Hog. . . . . . . . . . . . . . . 290

XXIII. The Hog Carcass...................... 297

XXIV. Hog Markets and Pork Packing-Past and Present..... 314

XXV. Market Classification of Swine . . . . . . . . . . . . . 322

XXVI. Breeding for the Market.................. 332

\section{PART FOUR-HORSES}

Introduction. . . . . . . . . . . . . . . . . 345

XXVII. Brief Anatomical Study of the Horse. . . . . . . . . . . 348

XXVIII. Some Important Facts Concerning the Horse......... 361 
Chapter

PAge

XXIX. Origin of the Types of Horses.

374

XXX. Draft Type..

384

XXXI. The Carriage or Heavy-Harness Horse

400

XXXII. The Roadster or Light-Harness Horse

409

XXXIII. The Saddle Horse.

418

XXXIV. The Hunter and Polo Pony

428

XXXV. Market Classes of Horses

438

XXXVI. Horse Breeding......

457

XXXVII. The Mule.............

468

XXXVIII. Market Classes of Mules .

472

XXXIX. Unsoundness in the Horse.

480

Index....

493 


\section{GENERAL INTRODUCTION.}

Two distinct systems of farming are practiced in the United States-(1) grain farming and (2) live-stock farming. Grain farming is the growing of crops useful for food or clothing, the income being derived from the sale of these crops. Live-stock farming is that system in which the crops are used chiefly or entirely as feed for the live stock which is produced, the income being derived from the sale of animals, milk, and wool.

The maintenance of soil fertility is more difficult under the first of these two systems. Although it has been experimentally demonstrated that fertility may be maintained and increased by the use of commercial fertilizers and green manures without the aid of live stock, nevertheless the keeping of live stock and the utilization of farm manure afford the easiest method of maintaining and increasing the fertility of the soil. Where farming has been practiced for a long period of time, the most fertile and prosperous communities are those in which much live stock has been kept and the manure properly handled and applied to the soil.

Of the two systems, live-stock farming affords much greater opportunity for the development and application of knowledge and skill. The live-stock farmer must be equally competent as a crop producer with the grain farmer, and in addition must know how to handle and feed live stock economically. He must have a certain practical knowledge of animals and their requirements which comes with long experience, but which can be readily acquired by one who has a liking for farm animals.

Dr. C. E. Thorne of the Ohio Experiment Station has said, "While it is true that meat is an extravagantly wasteful food, viewed solely from the economir standpoint, yet it is also true that the ruling peoples of the earth are the meat eaters, and the time is probably far in the future when in this country meat will be banished from the tables of any but the improvident, even though further advance in its cost should take place. The outlook, therefore, is that for a long time to come the farmer who possesses the ability to handle live stock successfully will find ample opportunity for the exercise of his talents and ample reward for the larger ability which such exercise involves." 
The keeping of live stock on the farm provides a means of utilizing as feed or bedding much that would otherwise be wasted. This applies to large amounts of roughage such as straw and corn stalks. Meadow aftermath and rough or stony land unsuited for the plow may be grazed, unmarketable soft corn may be fed, and other similar wastes may be converted into profits where live stock is kept.

Experiments indicate that if animals were kept in stalls or pens throughout the year and the manure carefully saved, the approximate value of the manure produced by each horse or mule would be $\$ 27$, by each head of cattle $\$ 20$, by each hog $\$ 4$, and by each sheep $\$ 2$. The total fertilizing value of the manure produced in the United States in one year would, therefore, be $\$ 2,477,100,000$. In this estimate, no account is taken of the value of the manure for improving the mechanical condition and drainage of soils, which is fully as great as the value of the phosphoric acid, potash, and nitrogen contained in farm manure.

When fed to animals, a large proportion (about 80 per cent.) of the fertilizing element of the feed is recovered in the excrement. For example, if a ton of corn is sold off the farm, it removes fertility to the value of $\$ 6.56$; while if fed to animals, this ton of corn results in manure worth, while fresh, $\$ 524$. If this manure is properly handled and applied to the soil, little of its fertilizing value will be lost. The corresponding figures for one ton of oats are $\$ 7.43$ and $\$ 5.94$ respectively, for timothy $\$ 5.21$ and $\$ 4.16$, red clover $\$ 8.79$ and $\$ 7.03$, alfalfa $\$ 8.76$ and $\$ 7.00$, oat straw $\$ 3.30$ and $\$ 2.64$, corn silage $\$ 1.22$ and $\$ 0.97$, whole milk $\$ 1.96$ and $\$ 1.52$. In many instances the best method of increasing the fertility of a farm is to buy feeds which may be fed profitably to the live stock on hand, and then carefully handle and apply the manure produced. For example, a ton of cottonseed meal or wheat bran used for feed gives manure worth, while fresh, $\$ 19.20$ and $\$ 10.19$ respectively.

The live-stock farmer who fails to harvest the manure crop carefully is surely overlooking a great source of profit. On the other hand, animals should not be regarded merely as fertilizer factories. The manure produced by farm stock, while valuable, is secondary in importance to the value of the animals themselves. The stockman converts his crops into animal products of higher value to man, aiming thereby to reap a larger profit than is possible by the grain-farming system, and at the same time he increases the fertility of his land. 
The advantages of live-stock farming may be summarized as follows:

1. Live-stock production, properly conducted, is a profitable business.

2. It provides a home market and pays better than average prices for farm crops.

3. Makes easily possible the maintenance and improvement of soil fertility.

4. Gives steady employment throughout the year to labor on the farm and thereby helps to solve the farm labor problem.

5. Utilizes as pasture much land unfit for the plow.

6. Utilizes much that would otherwise be waste on the farm, such as straw, corn stalks, soft corn and other unsaleable grain, meadow aftermath, many weeds, and garbage.

7. Affords the best means of utilizing such by-products as tankage, cottonseed meal, linseed meal, gluten feed, and skim milk.

8. Affords opportunity for higher development and application of skill in farming.

9. The care and handling of live stock is intensely interesting work.

The stockman's success depends very largely upon the degree to which his animals meet with favor on the live-stock market. If he is to make a financial success of his business, he must produce what the market wants. Far too many feeders of live stock lack acquaintance with market demands. Far too many breeders devote themselves to a breed simply because it satisfies a hobby and because the breed appeals to their fancy, rather than because they see in their animals any special utility. Unless a breed of beef cattle makes possible the production of better beef for the market; unless a breed of swine is fostered because in it is seen the possibility of improving the quality or cheapening the cost of pork; unless a breed of draft horses is really useful when put to the test in the collar; then such breeds have little excuse for their existence, and those who foster them must sooner or later suffer financially for their efforts. Both the breeder and the feeder must know the demands of the open. market and keep them always in mind.

The word "purebred" has a wonderful charm to many persons, and perhaps rightly so, yet many an animal, very inferior from a utility point of view, has brought a large price merely because it had a pedigree and a registration number. 
The word "imported," when prefixed to an animal's name, lends even greater charm. The greatest breeders of the past refused to be carried away by any charm of family history or lure of names. They rode no hobbies. They were intensely practical; they never overlooked the market requirements of the kind of animals they bred. No animal met with favor in their eyes unless such favor was earned by meat upon the back, milk in the pail, weight and quality of wool, pounds gained for pounds of feed consumed, or some other performance of practical value. With them it was a question of ultimately furnishing better animals for the market or lowering the cost of production. It must be just so with the master breeders of the present and future.

These pages aim to familiarize the reader with the types of farm animals, market demands, and market classes of live stock, such knowledge being fundamental in all live-stock work and study, and valuable not only to breeders and feeders, but to all persons who buy and use animals. 


\section{PART ONE.}

\section{CATTLE.}

\section{INTRODUCTION.}

Cattle are useful to man because they produce meat and milk, both of which are in such demand that the production and marketing of them engage the attention of many thousands of people in America. Over two-fifths of the expenditures of families of medium income is for food. About one-third of the national dietary is composed of meat. Milk, butter, and cheese are produced in vast and increasing quantities, being staple articles of food.

America has been an exporter of beef and dairy products to the value of many millions of dollars annually. During the last few years these exports have declined markedly and we have now begun to import beef from South America. The United States practically dominated the world's export trade in fresh, chilled, and frozen beef with its contribution of over 63 per cent. of the total export trade of the nine surplus countries for the ten years 1895-1904. For the next five years the average fell to 33 per cent., and in the next year. 1910, the fraction was 9.4 per cent.; in $1911,4.9$ per cent.; and in 1912 , only 1.6 per cent. While the United States was experiencing this downfall in exports of beef, Argentina grew from 17 per cent. of the total export trade in the earlier years to 80 per cent. in 1912. If to this be added the 15 per cent. due to Australia, and 3 per cent. due to New Zealand, in 1912, almost the entire export trade in this class of beef is accounted for.

The decline in America's exports of beef is partially due to a decrease in production, but is chiefly due to a population increasing at such a tremendous rate that the increase in home production of food does not keep parallel with it The United States had 7 millions of people in 1810, 17 millions in 1840, 38 millions in 1870, 76 millions in 1900, and 93 millions in 1910. Will it not be 150 millions in 1940 , and 200 millions in 1960? Furthermore, only one-third of the population haring census occupations is agricultural, and the fraction has declined from 
83 per cent. in 1820 to 77.5 per cent. in 1840,47 per cent. in 1870,44 per cent. in 1880, 39 per cent in 1890, 35 per cent. in 1900 , and 32.4 per cent. in 1910. These figures do not mean that our agricultural population has absolutely declined; on the contrary, it was never so large in number as it is today, with over 33,000,000 men, women, and children. The point is that the consumers of food-stuffs in America have increased at a much more rapid rate than have the producers. The producer of live stock in this country is assured of ready sale for all his products at remunerative prices.

Excepting Australia and New Zealand, the inhabitants of the United States are the most liberal eaters of beef, mutton, and pork. The average per capita consumption of dressed beef in this country was 78.4 pounds in 1918 , and the total consumption of dressed beef, veal, mutton, pork, and lard amounted to 193.5 pounds per capita. According to the latest available figures, Cuba follows with 124 pounds, the United Kingdom 119 pounds, Germany 113 pounds, France 80 pounds, Denmark 76 pounds, Belgium 70 pounds, and Sweden 62 pounds. The average for Australia is 262.6 pounds, and for New Zealand 212.5 pounds.

The production of beef, mutton, and pork throughout the world, outside of China, is estimated to be about 50 billion pounds a year, dressed weight, including lard. The United States by far leads all other countries in the production as well as the consumption of meat and meat products. The census of 1910 estimated that the meat produced in the United States in the year was $16,940,000,000$ pounds, embracing beef, veal, mutton, lamb, and pork, including lard. If the extra-edible parts are added, the grand total for 1910 was $19,712,000,000$ pounds. Slaughtering and meat packing ranks first in value of products among all the manufacturing industries of the United States.

Milk may be regarded as more fixed than meat in the family dietary. The number of milk cows in this country has steadily increased from the earliest enumeration in the census of 1850 , when the number of these cows on farms was $6,400,000$, to the last census of 1910 , when the number was $20,600,000$. The estimate for 1919 is $23,467,000$. The yield of milk per cow in 1918 was estimated to be 8.2 quarts per day for 287 days of the year, or 588 gallons. Assuming that 80 per cent. of the total number of dairy cows are of milking age, the total production of 
milk on farms in the United States was 11,044,000,000 gallons in 1918. If the production of cows in towns and villages were included it would add about 5 per cent. to the above estimate.

Experience has shown that it requires a certain kind or type of cow to produce a large flow of milk, and quite a different kind to produce beef. For this reason, two distinct kinds of cattle have been developed-dairy cattle and beef cattle. The dairy cow possesses certain characteristics which make her useful as a machine for producing milk, and we call this combination of characteristics dairy type. Likewise, the beef animal has certain characteristics which stamp it as an animal that will convert feed into flesh rather than into milk, and we call this combination of characteristics beef type. This gives us an understanding of what is meant by type, and we may now define type by saying it is that combination of characteristics desired by the breeder which makes an animal highly useful for a specific purpose.

Some breeders have endeavored to establish what is called a dual-purpose type of cattle. They believe there is need of a cow that can produce both beef and milk, and they have, therefore, tried to combine dairy type and beef type as nearly as possible. The dual-purpose cow does not give as much milk as the dairy cow, nor does she make as much beef as the beef cow. At present the demand for dual-purpose cattle is comparatively limited, but some authorities have predicted that many farms will ultimately adopt the dual-purpose type as the one most profitable.

Various breeds of cattle have been evolved to meet the demands for each of the three types of cattle. Each breed has its own peculiar and special features not found in individuals of other breeds. These special characteristics constitute what is called the breed type. For example, there are six breeds of beef cattle all of which possess beef type, yet each breed is distinctive in certain points which make up the breed type.

The breeds of beef cattle are the Shorthorn, Polled Shorthorn, Hereford, Polled Hereford, Aberdeen-Angus, and Galloway.

The dairy breeds are the Holstein-Friesian, Jersey, Guernsey, Ayrshire, Brown Swiss, Dutch Belted, French Canadian, and Kerry.

Dual-purpose demands are met by the Red Polled and the Devon. The Shorthorn breed is also noted for many individuals and several families of dual-purpose type. 
Years ago, various groups of men in different localities under different conditions and with different sorts of unimproved cattle took up beef production, or dairying, or a combination of the two. In this way originated the various breeds of the three types of cattle as we know them today. Competition does not narrow each type down to a single best breed, because no one breed is best under all conditions of soil, climate, and food supply.

As compared to other kinds of farm live stock, cattle have a special advantage in their ability to utilize coarse roughage such as coarse hay, corn stalks, and silage, and the coarser pastures of ranker growth. No other farm animal will utilize so much of what would otherwise be waste.

\section{Definition of Cattle Terms.}

Bull.-Breeding male, any age.

Cow.-Mature female.

Heifer.-A female under three years old, and usually one that has not produced offspring.

Calf.-Young animal, usually under one year old.

Steer.-Unsexed male, castrated when a calf. The best age to castrate calves is six to eight weeks old, although they may be castrated from a week to six months old. The longer castration is delayed the greater is the risk of loss from the operation and the greater the liability of coarseness developing in head, neck, and forequarters.

Stag.-Unsexed male, castrated when mature or so far advanced toward maturity that masculinity is plainly evident in head, neck, and forequarters. Well-developed masculine character constitutes coarseness in a market animal.

Spayed heifer.-Unsexed heifer. Spaying is performed by making an incision in front of the left hip and removing the ovaries. The scar left after the operation is about the only sure method of identifying such heifers.

Free-martin.-An imperfectly-sexed heifer born twin with a bull. They are infertile. All heifers born twin with bulls are not free-martins. 


\section{CHAPTER I.}

\section{BEEF TYPE.}

The following description applies particularly to the fattened steer. Special or additional features of type which should characterize the beef bull and the beef cow will receive attention later. It should be understood, however, that all good beef animals-steers, heifers, cows, and bulls-are similar in the essentials of beef type; therefore, the description given here applies in almost every respect to all classes of beef animals.

General appearance.-When correct in form and fatness, the beef animal presents a massive, blocky appearance from every angle of view. As viewed from the side, the body is rectangular, very deep, and short from shoulder to hip. The body is very wide, and the legs are short and placed squarely under the body. Two dimensions of the beef animal should be great - width and depth; the third dimension, length, should be relatively small. There should be great smoothness of outline everywhere, all the parts being uniformly developed and so blended as to form a symmetrical and balanced animal. The back is uniformly broad, the more width the better. From a side view, the top line and underline are straight and parallel. A fullness of outline is presented everywhere.

An animal showing too much length of middle is referred to as "rangy," while animals standing high off the ground on long legs are termed "leggy." The head should be short and broad, and the neck short and thick. Such a head and neck are associated or correlated with the desired type of body. Rangy, leggy animals usually have long narrow heads and long thin necks. With only the heads and necks of a number of beef animals in view, the best animals may be picked out with reasonable certainty by the general proportions of the heads and necks. A straight-edge laid against the side of a beef animal should touch the shoulder and hindquarter and all points between them.

The head should be of medium size, short, and broad, with a broad muzzle, indicating capacity for grazing and feeding. The nostrils should be large, indicating capacity for breathing and hence a good constitution. The face line, from a side view, 
should be straight or show a slight inward curve or dish from eyes to muzzle. The head below the eyes should be as short as possible, the eyes themselves being wide apart, large, prominent, bright, and clear, and indicative of a quiet disposition. A quiet expression of the eyes means a quiet, contented feeder that will transform feed into flesh; a nervous, restless expression is evidence of an unsatisfactory feeder that will neither consume enough feed nor store up the energy of the feed consumed, but waste it in nervousness and too much moving about. The forehead should be very wide. The jaws should be broad and well muscled. If horns are present they should not be coarse at their base, but rather fine and nicely shaped and proportioned,

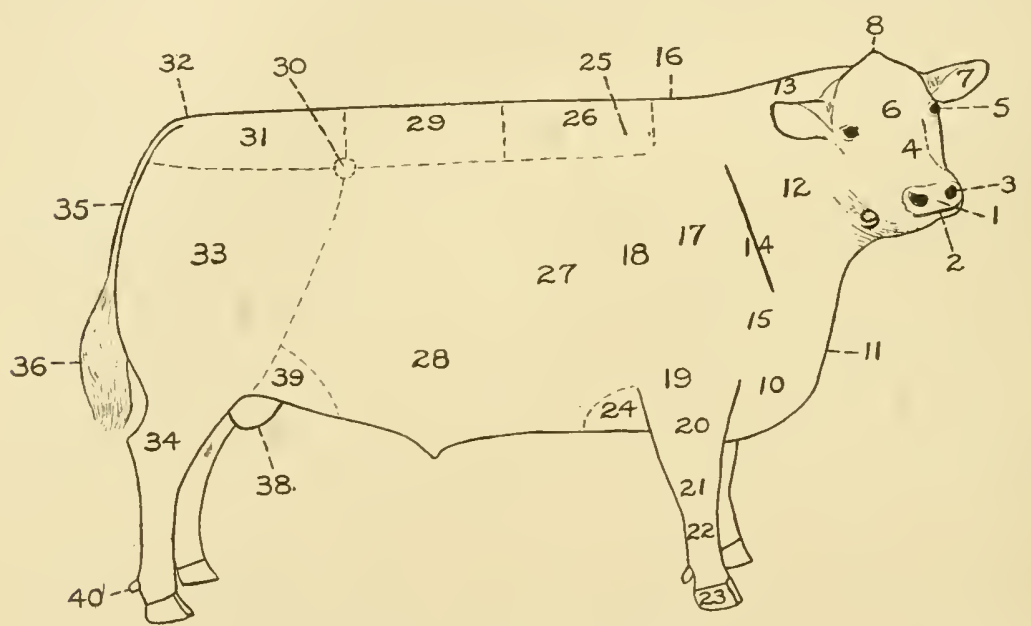

Fig. 1. Points of the Steer.
1. Muzzle
2. Mouth
3. Nostril
4. Face
5. Eye
6. Forehead
7. Ear
18. Poll
9. Tongue root
10. Brisket
11. Dewlap
12. Neck
13. Crest
14. Shoulder vein
15. Point of shoulder
16. Top of shoulders
17. Shoulder
18. Fore-rib
19. Elbow
20. Arm
21. Knee
22. Shank
23. Foot
24. Fore flank
25. Crops
26. Back

27. Ribs

28. Paunch or belly.

29. Loin

30. Hip or hook

31. Rump

32. Tail-head

33. Thigh

34. Hock

35. Tail

36. Switch

38. Cod

39. Hind flank

40. Dew claw

tapering evenly to their tips. The ears should be of medium size, fine texture, and neatly attached to the head. The entire head should be clean-cut, all lines being sharply defined, giving a well-bred appearance, sometimes referred to as "character." 
The neck should be short, thick, and muscular. The throat should be neat and trim, while at the shoulders the neck should show depth and fullness. The line where the neck and shoulder join is called the "shoulder vein," and we like this part to be filled out plump and full. A long neck lacking in thickness is frequently found, and it is undesirable chiefly because it is associated with a rangy type of body. When the animal is standing in natural position, with the head up, the top line of the neck should be slightly arched and the poll of the head should be slightly higher than the top of the shoulders.

The shoulders should be very smooth, blending perfectly with the rest of the body. This conformation is secured when

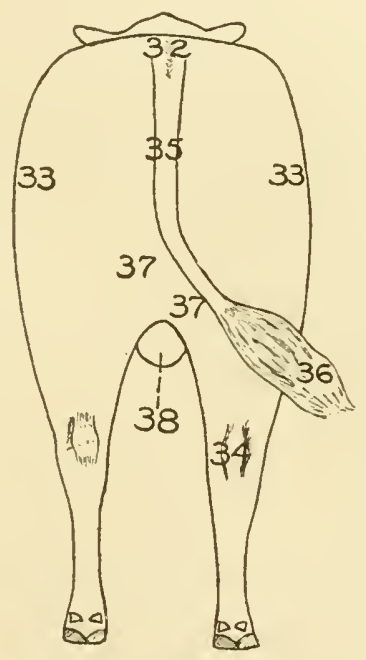

Fig. 2. Points of the Steer.

32. Tail-head

33. Thighs
34. Hocks

35. Tail

36. Switch
37. Twist

38. Cod

the shoulder blade lies snugly against the ribs beneath, and is covered over with a uniformly thick layer of flesh. The top of the shoulders should not be sharp and fine, nor yet so wide that the tops of the shoulder blades are prominent and outstanding, but should be moderately wide and nicely rounded over with flesh. Rough, angular shoulders, unevenly covered, are among the most common defects of beef cattle. When the shoulders are not properly laid in, but are wide and open, the appearance of the animal is injured, the fleshing over the shoulder is not 
taken on properly, and, when slaughtered, the carcass lacks the smooth, tidy appearance so much desired. A prominent shoulder also causes the development behind it to appear insufficient.

The brisket and chest are highly important. The former should carry forward prominent and wide, and be well fleshed, yet neat, presenting a full, well-developed, and trim appearance. The chest, which lies between the shoulders and immediately behind them, ought to be very wide and deep. Too much width and depth are never found. A full, deep chest with large heart-girth indicates a rugged sort of animal possessed of much constitutional vigor. The floor of the chest should be wide, as shown by the distance between the two fore legs, provided width at this point is not due merely to prominent, open shoulders which set the fore legs wide apart. The forerib, lying just behind the shoulder, should not be flat, but should arch boldly so that no flatness or depression exists immediately behind the shoulder. Many beef animals present a hollowness or flatness of fore-rib which detracts much from the desired smoothness of conformation, and reduces the chest capacity. Care should be taken to see that the animal carries down deep and full at the front flanks just behind the elbows. The butcher cares nothing for a beef animal's constitution, but every intelligent feeder places great emphasis on the depth and width of chest, which indicate to him that the steer will be a good doer in the feed-lot. Briefly summing up all the points in the description thus far, we may say that the forequarters should be smoothly laid, smoothly and thickly fleshed, and very wide and deep, showing nc lack of constitution anywhere.

The front legs should be short and placed squarely under the animal. They should come straight down, and the toes should point straight ahead. For reasons already given, the fore legs should be set well apart. The arm should be wide and muscular at its attachment to the shoulder. Fineness of bone and smoothness of joints are evidences of quality, whereas rough, coarse animals have heavy joints and big shank bones.

The back carries great weight, and it is desirable that it be straight and strong. When some people refer to the back they include the entire top of the animal from shoulders to tail. Others mean the top from shoulders to hips. The score card restricts the meaning of this term to that portion of the top lying between the shoulders and the last rib, which is some 
distance in front of the hip. In this description we shall use the word in the score-card sense. The back furnishes one of the high-priced cuts of beef, and always receives critical attention in judging. It is important, first of all, that the back be very wide in order that it may carry the maximum amount of meat. Beef cattle are never criticized for too much width in this part. Width is secured when the ribs arch boldly from the spinal column; if the ribs are not arched, the back must necessarily be narrow.

Fully as important as the width of back is the depth of flesh which covers this part. When touched with the fingers, great depth and mellowness should be found. No mere beauty of outline or stylishness of appearance can ever make up for lack of fleshing in a beef animal. The flesh must be there. Dimples or ties, rough spots, or uneven patches of fat detract from the value because the carcass of such an animal will be rough in appearance and uneven in its covering of flesh. If a wide back furnishes greater space for meat than does a narrow one, then length of back might be advised for the same reason. But a long back is not wanted because one of the outstanding features of correct beef type is compactness, by which is meant shortness from head to tail, and especially shortness from shoulder to hip. We naturally expect the back to be short, because length there is associated with the undesirable rangy type of animal too often found.

The ribs should not only be well sprung, but should also carry down with much depth to help make a roomy or capacious body. A wide, deep middle is essential to digestive capacity. Cattle have thirteen pairs of ribs. In beef cattle they should be placed close together along the sides, and the last pair should come as close to the hips as possible. This provides a framework upon which the fleshing can be smoothly laid. When there is much space between the ribs, a smooth fleshing is not often found, for then the position of the ribs will be marked by ridges and there will be hollows between them. When the distance is great between the last rib and the hip, it is impossible to get that part filled out smoothly; instead there will be a large "hunger hollow" which detracts much from the appearance. Once more, therefore, the necessity for compactness (shortness) of middle is emphasized.

The development along the side of the animal should be such that all points fill out plump and smooth to meet the same 
straight line from front to rear. The fleshing over the ribs should be thick, smooth, and even, and the hind flank should be well filled with flesh so that when the hand is placed under it and lifted, it is found to be thick, full, and heavy. If the front and hind flanks carry down properly, the underline will be straight, as it ought to be.

At this point it is well to state that while the middle of a beef animal should be wide and deep, a distended condition of the paunch is not desirable. When this occurs, the animal is

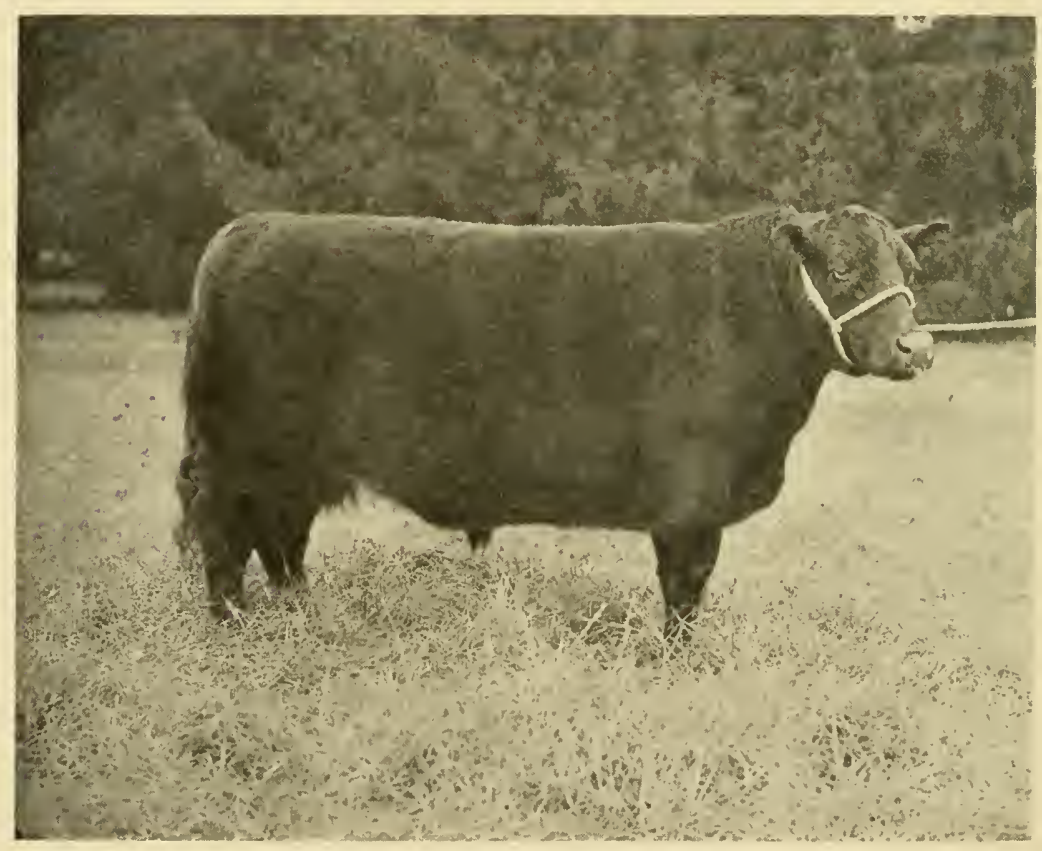

Fig. 3. Correct Type in the Fat Steer.

Two-year-old Aberdeen-Angus steer, Victor, Grand Champion at the International Live Stock Show in 1911. Fed and exhibited by Iowa State College. Sold for ninety cents per pound.

referred to as "paunchy." The lines of the middle, both at the sides and along the belly, should be straight and trim, giving a neat, tidy appearance. Given good arch and depth of rib, a steer may be straight and trim in his middle without sacrificing proper feeding capacity, and such animals suit the butcher much better than paunchy ones, because an excessive paunch means much waste when the animal is slaughtered. 
The loin is that portion of the top lying between the rear edge of the back and the hips. It has no ribs below it, but consists of large muscles, affording the very choicest cuts of the entire carcass - the porterhouse and sirloin. The loin should be very wide and very thickly fleshed to afford as high development of this part as possible. The covering of flesh should also be smooth and firm. We like the loin to be thickly padded and plumped up with muscle having the proper degree of fatness. Such a loin may be described as a "live" loin-one that exhibits resiliency or springiness when handled. A loin that is flat and that handles soft and "dead" is deficient in lean meat and has too much fat. The loin-edge is sometimes rough and patchy, due to an uneven distribution of the fat, whereas it should be smooth and even.

The hips should be laid in snugly, and nicely covered over with flesh. The eye should not be able to locate the hip of a well-fattened animal; only when the hands are used should the point of the hip be possible of location. This helps to give the smoothness desired in both the living animal and the carcass which it ultimately yields. Wide hips cannot be covered over with flesh, and the animal suffers a rough and ragged appearance.

The rump is the top between hips and tail-head. It should be level so as to carry out the top line straight and square to the end of the body. Some animals droop in the rump, and some rise prominently; in each case the conformation is faulty. The rump should be as long as possible and as wide as the rest of the top. This permits a maximum fleshing and provides the most attractive form. The width should be carried as uniformly as possible from hips to end of rump. As the tailhead is approached, there is bound to be some rounding off, yet this does not mean that the end of the rump need be narrow or peaked. Rather it should be wide and plumped out with flesh. Beef cattle very frequently exhibit roughness about the tail-head or at the end of the rump on each side of the tail, due to the accumulation of patches or gobs of fat. Smoothness here indicates better fleshing qualities.

The thigh begins at the border of the rump and extends down the outside of the leg. It should be wide and plump from every angle of view, and come down with some bulge on the outside to where the thigh naturally narrows. The plumpness and thickness should carry down as close to the hock as 
possible; viewed from the side, the thigh should be very wide, and when the animal is viewed from the rear there ought to be much thickness from side to side.

The twist is the fleshing between the hind legs, just as the thigh includes the fleshing on the outside. It should be very deep and full, filling in the space between the legs, and carrying down as far as possible toward the hocks. The thighs and twist furnish the third most valuable cut of the carcass and are worthy of careful examination in judging.

The hocks and legs, by their position, indicate the capacity for fleshing in the twist and also on the thigh. If the hocks are straight and properly placed, showing no special tendency

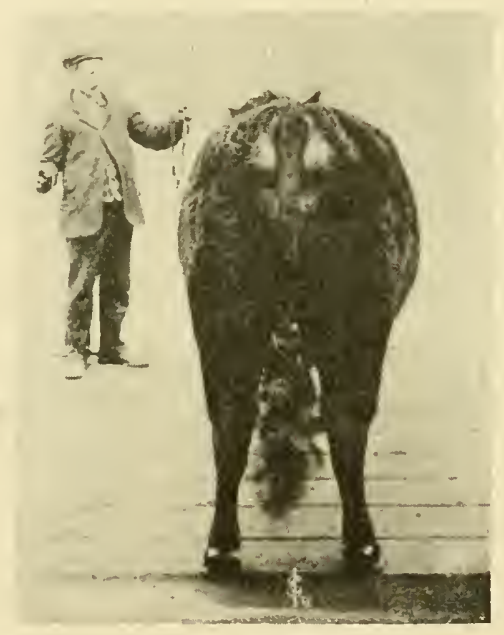

Fig. 4. A Steer with Excellent Lines.

Aberdeen-Angus steer, Blackrock, Grand Champion at the International Live Stock Show in 1905. Fed and exhibited by Iowa State College. This steer has straight side lines and a trim middle. He is free from paunchiness.

to come together, they will be associated usually with more heavily fleshed hindquarters than otherwise. It is important, therefore, that the hocks stand squarely under the animal. The shanks should carry straight down, and, as in front, they should be short and show refinement in bone. The joints of the leg should be clean-cut.

The quality of the beef animal is shown in bone, skin, hair, and head. Quality, which is synonomous with refinement, is essential because it insures against coarseness of texture in all 
parts, especially the texture of the muscles. The head should be of medium size and should be clean-cut, presenting a sort of chiseled appearance. The heads of many animals do not exhibit that "finishing touch" which characterizes the head expressive of refinement. Heavy bone, large rough joints, and heavy horns show lack of quality. One of the best indications of quality is the hide, which should be found pliable, easily stretched, and only medium thick when rolled up in the hand. The hair should be soft and fine.

Quality is again shown by the smoothness of the animal, both in frame and in fleshing. Coarse shoulders, rough hips, and rough, uneven flesh show lack of quality. Quality and good breeding are usually found together, and certainly the animal with quality is the most desirable type for the producer as well as for the consumer. Well-bred animals respond best when fed out for the market. Coarse, rough animals yield unattractive carcasses and inferior cuts of meat.

Animals are sometimes found which possess too much quality. In such cases there is a delicacy of make-up; quality is purchased at the expense of constitution. Extreme quality is also purchased at the expense of size, for over-refined animals are usually undersized. The proper degree of quality represents the middle ground between two extremes, each of which is undesirable. This middle ground is hard to define; it may be said that all the quality is wanted which may be had without sacrifice of constitution and proper size.

The fleshing of beef cattle is of the highest importance. The fact that the butcher's block is the ultimate end, and beef the ultimate product, must never be lost sight of by the breeder, feeder, or judge of beef cattle. All over the body, and more especially in the back, loin, and hindquarters, there should be found a uniformly deep covering of flesh. The flat of the hand pressed along the shoulder, back, or side should find a deep, mellow fleshing, without any patchiness or bare spots. When mature cattle are heavily fed they thicken in their flesh, and this increase in thickness is due to a mixing of fat among the muscle fibers, a storing of fat between the muscles, and a laying on of fat just beneath the skin.

When studying the fleshing of an animal it is well to keep in mind that the fleshing is made up partly of lean meat and partly of fat. The lean meat or muscle which an animal carries is often called the "natural flesh." We want as much natural 
flesh as it is possible to obtain. When a steer is fat it is rather difficult to determine how much natural flesh he has. In order to estimate this it is necessary to examine the development of flesh in those parts which take on very little fat, as for example the thighs, arm, and neck. Width in the crops is another good indication of heavy muscling.

The proportion of muscle in the make-up of an animal is evident at birth (See Fig. 13), and feeding will not increase it beyond a very narrow limit. Henry and Morrison of the Wisconsin Station* discuss this point as follows: "Since the leanmeat tissues of the body are composed mostly of muscular fibers, any gain in these tissues can be caused solely by an increase in the number or by the thickening of these fibers. The fibers increase in number by dividing lengthwise, which process occurs with farm animals only while young and growing. Indeed, recent investigations show that with some animals all increase in the number of muscular fibers occurs before birth, the muscles of the new born young containing as many as those of the mature animal. The fibers of the muscles can thicken to only a limited extent, and hence the muscular tissues, or lean meat, of the mature animal cannot be increased beyond a relatively narrow limit, compared with the great storage of fat which may occur."

A starving animal draws upon its muscular tissue to support life, and will rapidly repair its tissues upon a return to favorable conditions, but from the standpoint of farm and feed-lot conditions this fact does not enter into consideration and therefore does not alter the statements which are here made. The only factors which the feeder has under his control are growth and fatness. If the animal is mature, feeding is almost exclusively a fattening process; if the animal is not mature, fattening is accompanied by growth in bone and muscle. Practically speaking, we can no more increase the proportionate amount of muscle by feeding than we can add quality, or a better head, or a straighter top line. All these are breeding problems-not feeding problems. Feeding will fatten a steer, increase his weight, and improve his form and appearance, but it has little or no effect upon the proportion of natural flesh in his make-up. The degree of fatness shown by a steer is referred to as his "condition," and this feature will now be discussed.

* Feeds and Feeding, p. 75 . 
Condition.-In comparison with dairy cattle, one of the most distinctive features of beef cattle is their ability to fatten easily and to deposit the fat in and around the muscles, thereby making the meat tender and juicy. As pointed out above, the feeding of beef cattle is largely a fattening process. The practical feeder knows, however, that it is not profitable to feed an animal up to his limit of fatness, because the last gains a steer makes are most costly, and such animals do not suit the consumer of beef as well as a steer fattened in moderation. Thin cattle are characterized by a very firm fleshing, so that when the finger-tips are pressed on the back and ribs the flesh is found to be hard and unyielding. When such cattle are

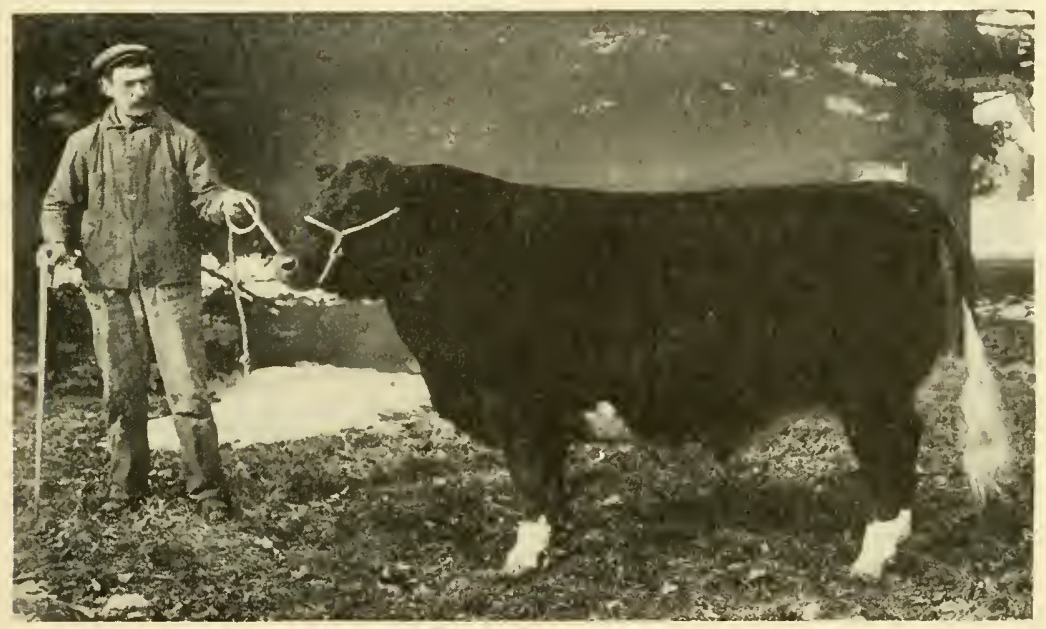

Fig. 5. A Feed-Lot Model.

Prince Rock, a grade Aberdeen-Angus steer, fed and owned by Iowa State College. Note the extreme depth of chest and middle in this steer, giving him a strong constitution and great feeding capacity. His short legs and blocky body indicate large gains on feed and quick maturity.

properly fattened a decided change takes place; the flesh now has a mellow, yet firm and springy feel, and is no longer hard and unyielding. This firm, springy, and mellow condition indicates that the steer is properly fattened from a market stand. point. When feeding for show purposes, the fattening proceeds further, and, if continued to excess, the fleshing becomes soft and blubbery. To the fingers, such an animal seems incased in blubber, and when the animal is slaughtered this is indeed found to be true. 
The best way to determine the state of fatness of an animal is to use the hands in the manner mentioned above. This can be done rapidly, yet thoroughly, by a vigorous handling along the top and down over the ribs and shoulders. Other means of determining the condition consist of examinations of the cod, hind flank, and tongue-root. At these points the fat tends to accumulate extensively, and they are, therefore, good indices of condition. After castration, the scrotum with its content of fat is called the cod. Thin steers show very little fullness of cod, while fat ones have the cod completely filled with fat. Thin animals also exhibit a very light hind flank. At the beginning there may be little more than a fold of skin; when fat, this part fills out remarkably full and heavy. By placing the flat of the hand beneath it and lifting, the quantity of fat in the flank is easily determined. When a fat steer walks, there is a characteristic roll or swell to the flank as the hind leg swings forward. This is not noticeable in a thin animal. The thickness of the tongue-root may be determined by grasping the part with the thumb and fingers.

Some individuals fatten smoothly, with no special tendency to bunch the fat in patches or rolls at certain points, while others become "rolly," or "patchy," in spite of all the feeder's skill. Patches and rolls are most often found about the tail-head and end of the rump, along the ribs, and at the edge of the loin. The occurrence of these is highly undesirable; they indicate an improper distribution of fat, give the animal a rough appearance, and, when the animal is slaughtered, the carcass is discounted, for then the bunches of fat are very evident and the appearance is spoiled. The fatter the steer becomes, the greater is the tendency toward patchiness, yet many animals begin to exhibit this defect before they are really ripe and ready for market.

Style has actual market value in a fat steer. A stylish steer is one that stands squarely on his feet, with his backlevel, head well up, and eyes and ears attentive to what is going on about him. This does not mean a nervous animal, but a wideawake one, full of life, and seemingly interested in the things about him. When he walks, he does it easily and without awkwardness. Other things being equal, such a steer will attract buyers much more quickly than an animal that slouches while standing, showing a pronounced dip in the back, and having an awkward stride when in motion. These two animals 
may dress out equally high, and yield equally valuable carcasses; the difference is that the first steer forces his good points to the attention of the buyer and shows for all he is worth, while in the case of the second steer, the buyer is left to discover the animal's good points without any assistance from the animal. Cattle with style sell more readily and at slightly higher prices than cattle without style.

Size and weight vary according to age, sex, breed, and fatness. Disregarding breed differences, for this factor need not be considered here, the following figures represent fair standards of weight at different ages for well-fattened steers:

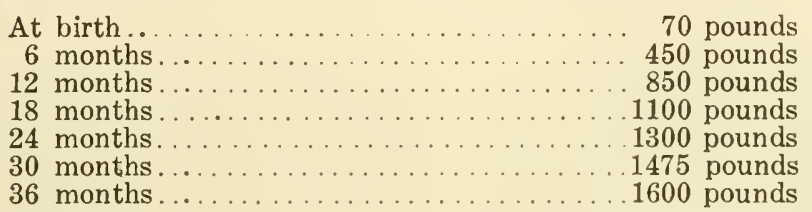

Age from the teeth.-The ages of cattle may be determined with a fair degree of accuracy by an examination of the teeth. There are eight incisors in the lower jaw of mature cattle. There are no incisors in the upper jaw, but a tough fibrous pad instead, amply suited to the grazing habits of cattle. The dentition at various ages is as follows:

12 months. All calf teeth in place.

15 months. Center permanent incisors appear.

18 months. Center permanent incisors in wear.

24 months. First intermediates up.

30 months. Six broad incisors.

36 months. Six broad incisors in wear.

39 months. Corners up.

42 months. Eight broad incisors in wear. 


\section{CHAPTER II.}

\section{THE BEEF CARCASS.}

Buyers of fat cattle at the large market centers make their bids according to their estimates of the kind of carcasses the animals will yield. These estimates are made with considerable accuracy because the buyers have made a study of carcasses and the cuts which they yield. A similar knowledge of meats is essential to the beef producer in order that he may. learn to judge and value beef cattle correctly.

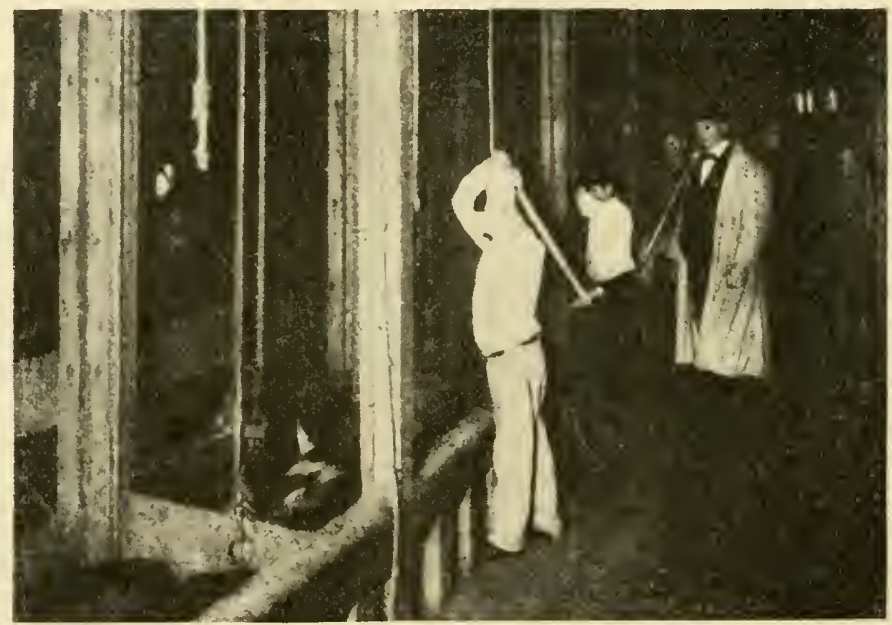

Fig. 6. Knocking Cattle.

Slaughtering.- Upon reaching the packing house, the cattle are driven into knocking pens where they are dealt a sledgehammer blow by the "knocker" who stands on a platform about even with the head of the animal. They are then rolled on the dressing floor, where a shackle is placed about the hind leg. The carcass is raised and bled, and the head removed. Again floored, the feet are removed at knees and hocks, and the hide is stripped. The carcass is then placed on a spreader, known as a "beef tree," where it is disemboweled, the hide removed entirely, and the back split. An endless chain then conveys the sides of beef through a set of washers to the coolers. The time required for 
dressing a carcass is less than 40 minutes. The beef remains in the coolers from one to two weeks before it is ready for the market, the temperature being kept at about 38 degrees Fahrenheit. Prime meats require three to four weeks ageing in a refrigerator to arrive at their best.

The offal.-The feet, head, hide, internal organs, loose fat, blood, and contents of stomach and intestines are collectively called the offal or waste of the steer, so called because formerly, with the exception of the tongue, hide, and tallow, this offal was thrown away. Today all of it is valuable for manufacturing into various by-products. (See Chapter III.)

The dressing percentage.-By comparing the weight of the chilled carcass with the live weight of the animal, the percentage of carcass, or what is called the dressing percentage, is determined. This is a very important point in determining the market price of a steer, and the buyer always estimates the dressing percentage when bidding on a load of cattle. For instance, suppose we have a steer of 1,200 pounds weight on foot. When dressed, the carcass weighs say 720 pounds. The dressing percentage would then be 60 per cent. Now suppose we have two loads of 25 steers each. The average live weight of the steers in each load is 1,200 pounds. When slaughtered one load dresses 60 per cent., and the other $57 \mathrm{r} / 2$ per cent. Each load had a total live weight of 30,000 pounds. When dressed, one load yields $2 \frac{1}{2}$ per cent. higher than the other, a difference of 750 pounds of carcass - a difference exceeding the weight of a single carcass. The total dressed weight of the 25 steers in the best load was 18,000 pounds; 26 steers of the lower dressing kind would not yield this weight of carcasses by 60 pounds. We will suppose each lot of carcasses brought a wholesale price of $\$ 20$ per cwt. Then 750 pounds of carcass amounts to $\$ 150$, which is the difference in the income from the sale of the two lots of carcasses. This amounts to $\$ 6$ per head in favor of the high dressers. In handling thousands of animals, as do the large packing firms, the question of dressing percentage is a very important one. The range in the dressing percentages of cattle is from 35 to 70 per cent.

The chief factors determining the dressing percentage of a steer, in the order of their importance are:

(1) fatness, paunchiness, and (3) quality of bone and hide. Aged dairy cows which have outlived their usefulness as milk producers are sent to market; they are very paunchy and very thin, and 
dress around 45 per cent. Well-bred steers, well fattened and with straight lines, that is, free from paunchiness, dress out 62 to 65 per cent. The highest record known to the writer, where the steer was dressed in the usual manner, is 69.9 per cent. In determining the dressing percentage, the refinement of head, bone, and hide is of less importance as a rule than paunchiness or fatness, although in some animals the weight of hide is a considerable item.

Commission men who sell cattle on the big markets are always careful that the cattle consigned to them get plenty of feed and water before they are offered for sale. This is called the "fill," and it is important because it has a quieting effect on the cattle, corrects the gaunt appearance caused by shipping, and adds weight to the animal. The buyer estimates the fill in various ways, particularly by the degree of paunchiness. Hence the fill does not constitute a fourth factor of the dressing percentage, but is included under paunchiness. On hot days when caicle take a heavy fill of water, buyers stay off the market as long as possible.

The census of this country has provided average live and dressed weights of meat animals killed in the wholesale slaughtering and meat-packing industry, and these averages are derived from an immense number of animals. The average live weight of cattle was 1069 pounds in 1899, 1047 pounds in 1904, 1019 pounds in 1909, and 989 pounds in 1914. The average dressed weight was 583 pounds in 1899, 569 pounds for 1904, 543 pounds for 1909 , and 530 pounds for 1914 . The average dressing percentage was, therefore, 54.5 in $1899,54.3$ in $1904,53.3$ in 1909, and 53.6 in 1914. The average live weight of calves for these four years was 141, 167, 168, and 167 pounds. The average dressed weight was $90,103,105$, and 102 pounds. The average dressing percentage was $63.8,61.7,62.5$, and 61.1 per cent. respectively. Calves dress a higher percentage than cattle because the hide is left on the veal carcass to preserve the color and moisture of the flesh, which dries out and turns dark much more rapidly than beef when exposed to the air.

The wholesale cuts. - When the carcass has been sufficiently ripened in the cooler, it is ready for cutting up into the wholesale cuts. The full side of beef, half the carcass, has the appearance shown in the following diagram. The wholesale cuts are indicated by the dotted lines. 
The first step in cutting up a side of beef is to "quarter" or "rib" it, which means to separate the side into forequarter and hindquarter. Sides are usually quartered or ribbed between the 12th and 13th ribs, leaving one rib on the hindquarter. Such a hindquarter is called a "regular hindquarter," and it contains from 47 to 49 per cent. of the weight of the side, and the forequarter contains from 51 to 53 per cent., the averages being about 48 per cent. hinds and 52 per cent. fores. Hinds are quoted about 25 per cent. higher than fores in cold months, and up to 40 per cent. higher in summer. This variation is due to the large amount of boiling and stewing pieces in the fores, which meats are in greater demand in winter.

The hindquarter is divided into four wholesale cuts-the loin, round, flank, and kidney. The kidney is not shown in the accompanying diagram, as it lies under the loin.

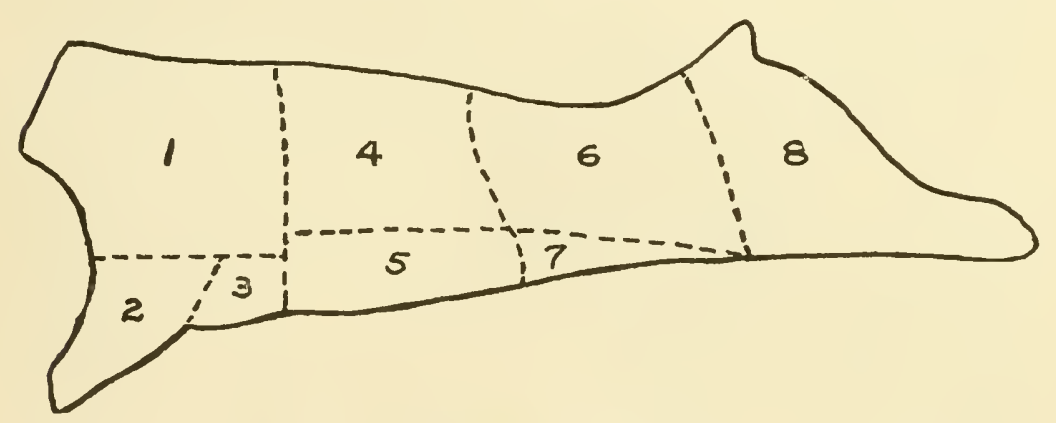

Fig. 7. Wholesale Cuts of Beef.

1. Chuck; 2 , shank; 3 , brisket; 4 , rib; 5 , navel; 6 , loin; 7 , flank; 8 , round; 3 and 5 , plate; 6,7 , and 8 , hindquarter.

The forequarter yields five wholesale cuts-the rib, chuck, navel, brisket, and shank. The navel and brisket are usually not divided, but are sold as one cut called the plate.

The loin is separated from the round at the hip joint, which is a considerable distance back of the hip. Thus much of the rump is converted into loin when the carcass comes under the knife of the butcher. The shank is sawed off just below the shoulder joint. The plate is taken off on a line extending from about the middle of the twelfth rib through the point at which the shank is removed. The rib an'd chuck are separated between the fifth and sixth ribs. This gives five ribs to the chuck and seven to the rib. 
A 720-pound carcass will yield a 360-pound side. When the side is cut up, the weights of the various wholesale cuts, their wholesale prices per pound, and their total values are as given in the following table, the figures for weights representing averages for good steer carcasses. Prices are given for No. 1, No. 2, and No. 3 grades.

\begin{tabular}{|c|c|c|c|c|c|c|c|c|}
\hline \multirow{2}{*}{$\begin{array}{l}\text { Wholesale } \\
\text { cuts }\end{array}$} & \multirow{2}{*}{$\begin{array}{l}\text { Wts. } \\
\text { in } \\
\text { lbs. }\end{array}$} & \multirow{2}{*}{$\begin{array}{l}\text { Wts. } \\
\text { in } \\
\text { per } \\
\text { cent. }\end{array}$} & \multicolumn{3}{|c|}{ Price per lb., cents } & \multicolumn{3}{|c|}{ Total value of cuts } \\
\hline & & & No. 1 & No. 2 & No. 3 & No. 1 & No. 2 & No. 3 \\
\hline $\begin{array}{l}\text { Round... } \\
\text { Loin..... } \\
\text { Flank.... } \\
\text { Rib...... } \\
\text { Plate..... } \\
\text { Chuck.... } \\
\text { Shank.... } \\
\text { Kidney ... }\end{array}$ & $\begin{array}{l}80 \\
65 \\
18 \\
35 \\
50 \\
90 \\
11 \\
11\end{array}$ & $\begin{array}{r}22 \\
18 \\
5 \\
10 \\
14 \\
25 \\
3 \\
3\end{array}$ & $\begin{array}{l}25 \\
52 \\
17 \\
40 \\
181 / 2 \\
21 \\
111 / 2 \\
19\end{array}$ & $\begin{array}{l}24 \\
43 \\
16 \\
34 \\
17 \\
20 \\
11 \\
18\end{array}$ & $\begin{array}{l}17 \\
19 \\
15 \\
17 \\
12 \\
141 / 2 \\
10 \\
17\end{array}$ & $\begin{array}{r}\$ 20.00 \\
33.80 \\
3.06 \\
14.00 \\
9.25 \\
18.90 \\
1.27 \\
2.09\end{array}$ & $\begin{array}{r}\$ 19.20 \\
27.95 \\
2.88 \\
11.90 \\
8.50 \\
18.00 \\
1.21 \\
1.98\end{array}$ & $\begin{array}{r}\$ 13.60 \\
12.35 \\
2.70 \\
5.95 \\
6.00 \\
13.05 \\
1.10 \\
1.87\end{array}$ \\
\hline Total. & 360 & 100 & 28.4 & 25.5 & 15.7 & $\$ 102.37$ & $\$ 91.62$ & $\$ 56.62$ \\
\hline
\end{tabular}

High-priced and low-priced cuts.--The average price for the entire No. 1 carcass is, then, 28.4 cents per pound. From the foregoing table it is seen that the loin, rib, and round constitute half of the carcass weight, but bring a little more than 65 per cent. of the return from the sale of the wholesale cuts. The 180 pounds of loin, rib, and round have an average price of 37.7 cents per pound, while the remainder of the side, also weighing 180 pounds, brings an average of 19.2 cents. Hence the packer wants cattle as highly developed in back, loin, rump, and round as possible. Buyers of cattle for slaughter emphasize this point. They want cattle smoothly and heavily fleshed in all parts, and especially in the four parts mentioned. The selling price of a load of cattle is greatly dependent on this feature.

Variations in carcasses. - A study of the carcasses in any cooler brings out striking differences. Some are large, being from 1,500- to 1,600-pound animals; others are from younger beeves that weighed 800 to 1,100 pounds. Some are compact and wide, others are long and narrow. Some are well developed in the regions of high-priced cuts, while others are deficient in this respect. Some carry heavy fleshing, others are very poorly covered indeed. The layer of external fat is very thick in some, these being highly finished cattle fed on grain. Others show practically no external fat. These are from grass-fed cattlepoor pasture too, for a steer puts on some fat on grass if the 
pasture is good. Some show a nice intermixing of fat and lean, called "marbling," while others exhibit this feature very slightly, or none at all. The lean meat of some carcasses has a pale red color; in others it is very dark. Some carry snow-white fat, others carry fat of a yellow color. Some beef is fine grained, and some is very coarse and fibrous. Some carcasses have soft bones, somewhat cartilaginous in character; others have hard flinty bones. Size of bones varies a great deal in different carcasses.

To sum up these differences we may say that carcasses vary in respect to (1) size, (2) shape, (3) thickness of fleshing,

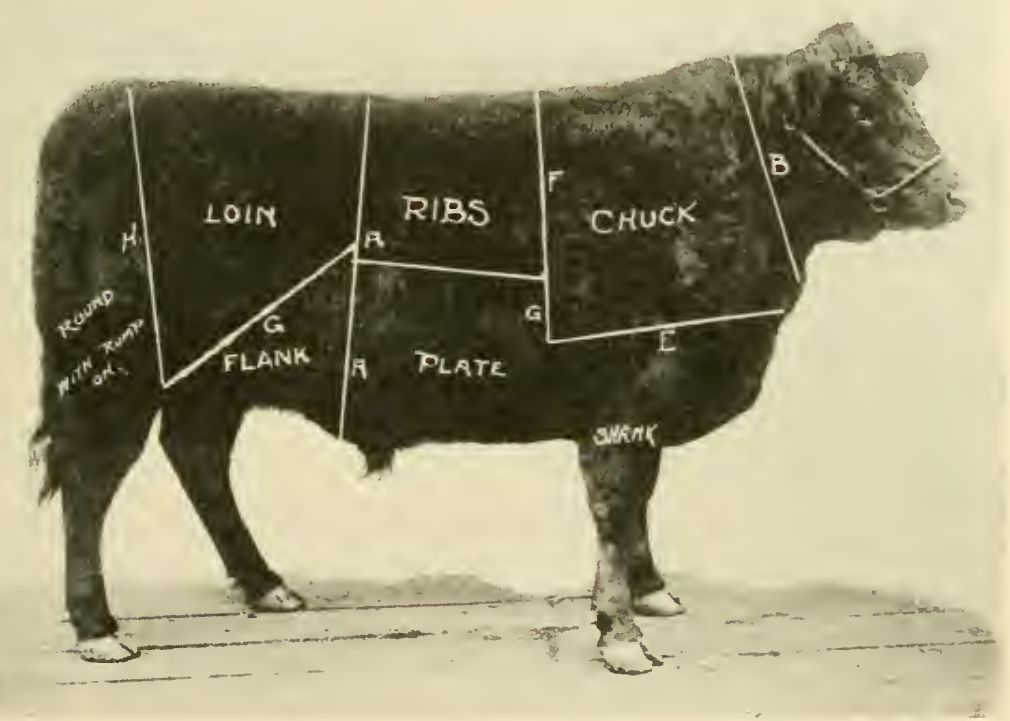

Fig. 8.-Cuts of Beef Indicated in the Live Animal.

(4) thickness of external fat, (5) marbling, (6) color of lean meat, (7) color of fat, (8) grain of meat, (9) flintiness of bones, and (10) size of bones. The butcher or packer is interested in all these things, for each is of considerable importance. The packer grades the wholesale cuts of beef, as they vary in these points, into No. 1, No. 2, and No. 3 grades. No. 1 cuts bring the highest price, and between No. 1's and No. 3's there is a marked difference. These three grades are all used on the butcher's block. Cuts from inferior carcasses not suitable for block use, are called strippers; these are manufactured into boneless cuts, barreled beef, and sausage. 
How the carcass is produced.-Before discussing the qualifications of a good carcass, it will be profitable to consider briefly how an animal grows and builds up the parts of its body which eventually make up the carcass. The carcass consists of bone, muscle, connective tissue, and fat. At birth the calf weighs about 70 pounds. Its bones are soft and elastic, and its muscles are tender. It carries a certain degree of fatness, depending on how well it was nourished before it was born-in other words, on how well its mother was fed. Up to weaning time it subsists largely upon its mother's milk, which is primarily a bone and muscle builder, producing growth.

When weaned, the future of the calf depends upon (1) ancestry, (2) feed, and (3) management. If its ancestors were dairy animals, it will never fatten properly nor make a valuable carcass. However, we are dealing with beef production and will assume the calf is from a good line of beef cattle. If given plenty of feed and good care, in other words every opportunity to develop quickly, the calf rapidly increases in size and its flesh expands and thickens. It also lays on fat. It is hard to fatten young animals because they tend to utilize their feed for growth rather than fat. Growth is increase in bone and muscle. However, with heavy feeding, cattle become fat before reaching maturity, and may be sent to market under 20 months of age weighing 800 to 1000 pounds. Such animals are called "baby beeves."

Another way to handle the calf is to turn it out to pasture and perhaps help it along with a little grain if the pasture is short. In this case the object is to produce growth only, and the animal may then be finished as a two-year-old. Under this plan the animal should be roughed through the winter with care, otherwise it will receive a setback. A third way to manage this calf would be to put it on pasture where it can get grass if there is any, and get thin if there isn't-so thin that it loses what we may call its baby flesh. In winter, under this system, the animal starves along as best it can, and the result is that it never makes a good beef, even though liberally fed at the finish. Once the baby fleshing is lost through setbacks received during development, the steer does not make as desirable a carcass as he would otherwise.

As an animal increases in age, its bones become hard and flinty. The bones which bear the most strain become most flinty, these being the shank bones. In young cattle the tips 
of the spinous processes of the vertebræ are soft and cartilaginous. These "buttons," as they are called, are present up to the age of 18 months; thereafter they gradually ossify, and at about the fifth year the spines are hard to the tips. Similar changes take place in the cartilages on the breastbone before the third or fourth year. The breastbone, backbone, ribs, and pelvis gradually harden and whiten, especially after the age of 18 months. When visiting a beef cooler, the age of the animals from which the carcasses came may be told approximately by the bones. With increase in age the muscles become tougher through use. The muscles which the animal uses most and which do the most work become the toughest in their make-up; these are the muscles of the neck and those used in locomotion, including the muscles of the thigh, shoulder, and arm.

Wild animals store up fat in their bodies as a reserve upon which they rely in times when food is scanty. The bear, for instance, takes on lots of fat during summer and fall, which is resorbed and used to support life during hibernation in winter; he comes out in the spring in very thin condition. The storing of fat is a provision of nature. In the domestic animals which produce meat, man has encouraged this fat-storing tendency by methods of breeding and feeding. That great success has been achieved along this line is shown by the highly finished cattle, sheep, and hogs coming from the hands of the best stockmen. The natural place for the storing of fat is along the back, forming a layer of clear fat just beneath the skin. It is also stored about the internal organs, between the muscles, and within the muscles among the muscle fibers. This storing of fat among the muscle fibers gives the marbled appearance already referred to. Practically no fat is stored up in the muscles which do much work, hence we find the round steak coming from the thigh to be almost completely free from fat, being lean all the way across. The muscles of the loin and back, having little work to do, take on the marbling feature quite easily if the animal is well bred and properly handled. This largely explains why cuts from the loin and back are most tender, although in these muscles there is not the stimulus to the growth of connective tissue such as is the case in working muscles, and this is undoubtedly another reason why the loin and back yield cuts of superior tenderness. 
The following figures show the relative amounts of lean, fat, and bone in the cuts from a good carcass, as compared with those from an inferior carcass:

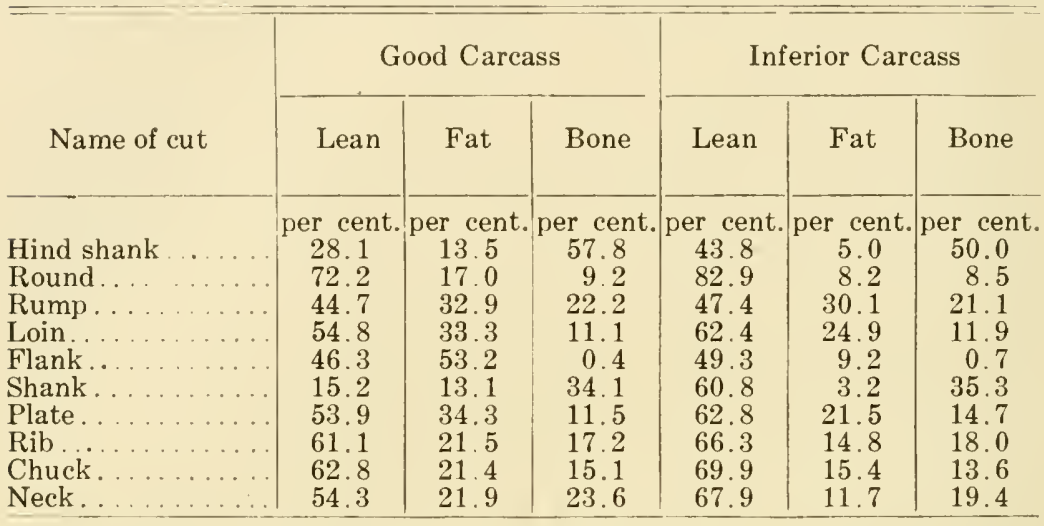

A careful comparison of the figures for the good carcass and the inferior one shows that they have about the same percentage of bone, but the inferior carcass shows a considerably lower percentage of fat and, therefore, a higher percentage of lean.

As stated in the previous chapter, the feeding of mature cattle is essentially a fattening process. This is clearly shown by results at the Missouri Station,* where muscle fibers and fat cells extracted from steers at different periods during the fattening process were examined and measured under the microscope and it was found that while there was very little or no increase in the diameter of the muscle fibers, the fat cells increased enormously both in number and size.

Thus we understand why cattle differ a great deal in the kind of carcasses they yield, depending upon their inherited tendencies and upon their feed and care. The effects of inherited tendencies upon the carcass are discussed in more detail in Chapter IV.

The demands of the butcher and ultimate consumer.- The questions which now come before us are: 1. What kinds of lean meat and fat does the butcher want? 2. How much lean meat does he want, and how much fat? 3. How does he want these two substances arranged with regard to each other?

* Influence of Nutrition upon the Animal Form, paper by Dean H. J. Waters at Thirteenth Meeting of Society for Promotion of Agricultural Science. 
These questions bring up the demands of consumers of meats, for the butcher is guided by what the consumer of beef wants and will pay for. You and I are consumers of meat, and what we like, or dislike, together with the size of our pocketbook, guides the butcher who buys our cattle. Now what do we want? We want meat that is (1) nutritious, (2) tender, (3) juicy, (4) of good flavor, (5) attractive in appearance, and (6) has a small amount of outside fat. Provided beef is well ripened in the cooler and well cooked, there is not much variation in its nutritive or food value. The tenderness depends upon the work the muscle has done and upon the amount of marbling it carries. It is impossible to get too much marbling, the more the better. Meat free from fat shrivels and drys up when roasted, becoming dry and tough. Ageing or ripening in the cooler helps to make meat tender. Juiciness results from the presence of fat and manner of cooking. The flavor depends mostly upon fatness and upon proper ripening of the carcass. The cuts of beef which are most attractive in appearance are those with bright, rich, red lean, snow-white fat, and a high degree of marbling. The consumer desires a maximum of lean meat well marbled, and a minimum of bone and outside fat in the cuts of beef.

All carcasses not suitable for side beef-Carcass beef which is thick and fat enough so that the entire side can be sold over the butcher's block in retail cuts is known as "block beef" or "side beef." Carcasses that are not thick enough in flesh to be entirely utilized by the retailer are called "cutters." The loins and ribs of cutters may be sold over the block. "Canners" are the worst carcasses to be found, from which none of the regular wholesale cuts may be sold over the block, but which must be disposed of as boneless fresh meats and cured beef products. In this chapter our attention is confined to side beef and to a study of the qualifications of a good carcass.

1. Weight of carcass.-The heaviest carcasses seldom exceed 1,050 pounds, and the minimum is about 250 pounds. Sufficient finish and quality are not often found in carcasses weighing less than 800 pounds. No definite line as to weight can be drawn between carcasses of beef and veal, because there are many factors determining the character of the flesh. The greatest demand is for carcasses from 1,200- to 1,400-pound steers, and most of the cattle coming to market are of about these weights. Such carcasses yield retail cuts of a size to 
suit the average family. There is also a demand for heavy carcasses to supply hotels, restaurants, and dining cars, which use large cuts.

2. Shape of carcass.--The ideal carcass of beef is compact and has good width in proportion to length, short shanks and neck, and full rounds, loins, and ribs. Large plates, hollow loins, prominent hips, thin chucks, or rangy, loosely coupled sides are especially discriminated against.

3. Thickness of fleshing.-There is a clear distinction between thickness due to fatness and thickness due to muscular flesh. Only the knife can completely reveal the thickness of a side and the relative thickness of fat and lean; even expert dealers are often mistaken as to the actual thickness of flesh in an uncut side.

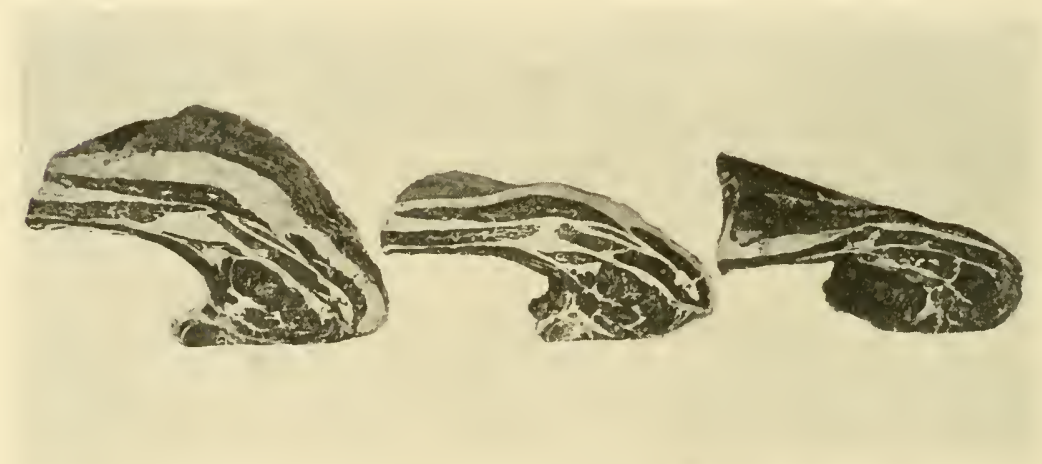

Fig. 9. Beef Ribs.

The rib cut on the left is too fat, the one on the right too lean, and the cut in the center is correctly fattened. Note that the amount of lean meat is practically the same in all three.

4. Thickness of external fat.-This is referred to as the "finish." Perfect finish consists of a smooth covering of firm white fat over the entire carcass, with the greatest depth along the back, a white brittle "kidney" of medium size, and a lining of flaky fat on the inner surface of the ribs. The rounds and shanks are covered last in the process of fattening. Carcasses show variation in thickness of external fat, ranging all the way from zero to four inches. Beef fat is not palatable to most people. The average consumer does not want more than onehalf or three-fourths of an inch of external fat, and if the carcass weighs 500 pounds or less, about one-fourth of an inch is sufficient. It is impossible to secure proper marbling unless a certain amount 
of fat is put on externally at the same time, but the necessary marbling is usually secured when one-half or three-fourths of an inch of fat is laid on externally; after this point is reached, the fat is largely stored externally, between the muscles, and about the internal organs. A certain amount of outside fat is necessary in prime beef in order to insure proper ripening in the cooler, and also for proper roasting. In the lowest grade, such as canners, outside fat is entirely lacking and such carcasses will rot before they ripen. A carcass carrying soft, "gobby" fat sells at a discount. Grass-fed cattle often yield carcasses that are watery and flabby, with a marked lack of finish. Heifers

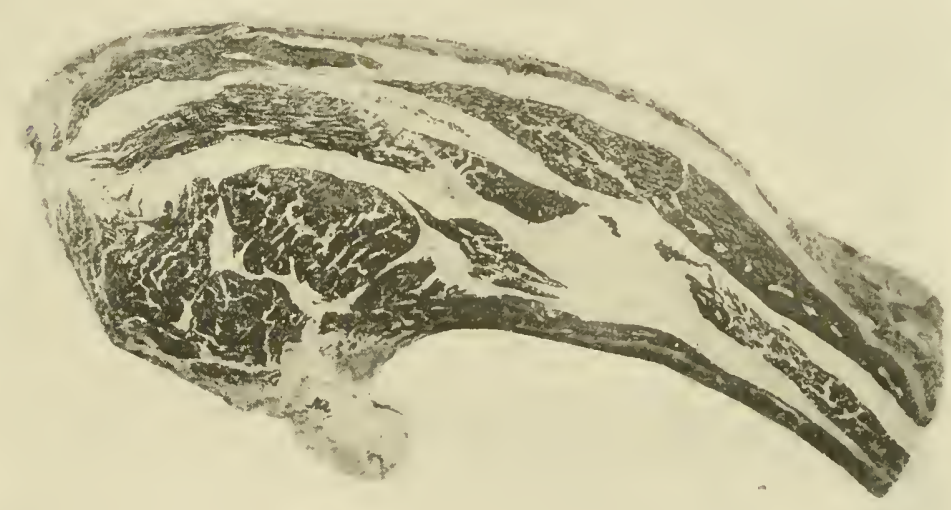

Fig. 10. Well-Marbled Beef.

Rib roast showing correct proportion of fat to lean, and a high degree of marbling.

carry a higher percentage of fat in all cuts than do steers. This is one of the principal reasons why thev often sell at a discount in this country while in England they are not discriminated against because the Englishman likes fatter beef.

Cattle fed to a complete finish, as are the beef cattle exhibited at the larger live-stock shows, carry a great excess of external fat-far too much to suit the average consumer. This excess of tallow adds practically nothing to the value of the carcass as food. In a way, the fat-stock shows set a wrong example for feeders to follow. Such a finish results from a long 
feeding period of 8 to 10 months, and in some cases even longer. A 3 to 6 months feeding period gives a carcass which suits the consumer better, and such a plan is undoubtedly more profitable to the feeder, because the first gains a steer makes are acquired much more cheaply than the last ones. This does not mean that the farmer should send thin cattle to market; it means there is a place to stop in the feeding of a bullock which results in greatest profit to the producer and best satisfaction to the consumer. A smooth and firmly finished steer is the sort this implies. As bearing on the matter of cost of gains, the Kansas Station* found the grain required for 100 pounds of gain with fattening steers for different periods to be as follows:

Up to 56 days

Up to 84 days

Up to 112 days

Up to 140 days

Up to 168 days

Up to 182 days

\section{Grain for $100 \mathrm{lbs}$. gain}

730 pounds of grain.

807 pounds of grain.

840 pounds of grain.

901 pounds of grain.

927 pounds of grain.

1000 pounds of grain.
Increase of feed required

10 per cent.

15 per cent.

23 per cent.

27 per cent. 37 per cent.

These figures indicate the heavy cost of thoroughly fattening a steer, and the importance of selling as early as possible.

5. Marbling.-The highest quality of beef is that which contains the largest proportion of well-marbled lean.

6. Color of lean meat.-The meat from grass-finished cattle is often dark in color. Grain feeding gives the best colora bright, rich red. Dark color is due to the presence of much blood in the tissues. Anything which causes the blood to flow into the tissues in large quantities results in dark color. Exercise or excitement will bring about this condition, hence the dark-colored flesh of western range cattle, and of grass-fed cattle in general, is not due to the nature of the food, but to the amount of exercise made necessary in ranging about at pasture. Stags and bulls kill out dark because of their restlessness, and of heifers in heat the same is true. Dark carcasses break down (decompose) quicker than light-colored ones, and consumers object to the appearance, hence butchers have two good reasons for disliking a dark-colored carcass.

7. Color of fat.-A clear white color of fat is desired. An unattractive yellow color is rather frequently met with. Some packers believe the yellow color is due to the kind of feed upon

* Kan. Bul. 34 . 
which the animal was fattened. Cottonseed meal has been charged with this fault, but experimental work has shown that cottonseed meal does not produce yellow fat. Cattle of Jersey and Guernsey breeding usually kill very yellow.

8. Grain of meat.--When the fresh-cut surface is viewed, it should show a smooth, fine-grained appearance, and should feel "velvety" to the touch. Meat with fine grain comes from the animal with quality, that is, one with fine hide, hair, and bone. Such an animal is finely textured throughout, and if well fed, so that the baby fleshing is preserved, a carcass with fine-grained flesh will result. Some meats are very coarse indeed.

9. Size of bones. - The bones should be as small as the weight of the carcass will allow. From the producer's standpoint, however, such carcasses do not always represent greatest profits, because extremely fine-boned cattle do not usually make the greatest gains on feed.

10. Flintiness of bones.-As already shown, flintiness of the bones is an indication of age. The most desirable carcasses are those of young animals approaching maturity, the meat from old ones being tough, dark-colored, and lacking in marbling. The bones of cows and heifers, and of dairy-bred animals, turn hard and white earlier than those of steers, indicating quicker maturity.

Grading carcasses.-As to the relative importance of the above factors in grading carcass beef, it may be said that finish (by which is meant the thickness and smoothness of outside fat) is particularly essential, with thickness of flesh, fineness of grain, color of lean and fat, fineness of bone, and shape of carcass of about equal importance. From what has been said we now understand why the loin and rib bring such high prices as compared to other parts of the carcass; it is because of their superior tenderness, marbling, and palatability, combined with attractive appearance. The round brings a good price because it contains so much lean and so little bone and external fat. Other parts of the carcass are as nutritious as the loin, rib, and round, but are difficult to cook in such a way that they appeal to us as do the porterhouse, sirloin, and rib roast. But a carcass will yield only so much of these, hence the great variation in the price of the various wholesale cuts. It is perhaps well that there are cheap cuts of meat and cheap carcasses, for there is a great percentage of population not able to buy any other kind. 
The packer does not want all beef to be of highest quality. He must take care of the second- and third-class trade as well as the fancy trade. But the producer of market cattle must aim to produce the highest quality of product, for this work requires skill, and skill always commands a higher reward than unskilled effort. Anybody can produce medium or inferior beef, and the price obtained is in proportion.

Sex differences.- Steer carcasses are identified by the cod fat and generally by their full, fleshy rounds and loins, heavier, coarser bones, and short necks as compared with cows. They show more quality and finish than any other class, and are sold as carcass beef more extensively than any other class, except heifers. Heifer carcasses are distinguished by the udder, and usually they have smaller bones, more prominent hips, more angular rumps, less development of lean meat, and they average lighter in weight. The tendency in heifer beef is to carry the fat more extensively as kidney suet or gobby fat than do steers. They have flatter loins, flatter plates, and longer, thinner necks than steers. Carcasses of cows have the bag trimmed off as closely as possible. The form is angular, the neck long, the bones hard and white, and the majority lack thickness of flesh. Fat cow carcasses often carry an excess of kidney fat and bunches of fat on the back and rump. The flesh is seldom as well marbled as that of heifers or steers. Cow carcasses require more ageing or ripening to make the meat tender. Dressed bulls are easily recognized by the heavy neck and heavy shoulders, thick rounds, dark color, coarse-grained flesh, and absence of cod fat. They have rough shape and the bones show maturity. The coarse dark flesh has no marbling as a rule, and but few bulls are suitable for dressed beef. They are used for sausage and the rounds are made into smoked beef hams. Many stags approach steers in form, quality, and finish; others resemble bulls.

Carcass classes and grades.-All carcasses of cattle are classified and graded as follows:

Classes

Steers

Heifers

Cows.

Bulls and stags.

Cutters

Canners

Veal calves

\section{Grades}

Prime, choice, good, medium, common Prime, choice, good, medium, common Choice, good, medium, common Choice, good, medium, common Good, medium, common Good, medium, common Choice, good, medium, common 
The following wholesale prices* indicate the comparative values of those of the above classes which are suitable for block beef :

Steer carcasses.. Heifer carcasses .. Cow carcasses. . Bull carcasses. Veal carcasses
350 to $700 \mathrm{lbs}$. 400 to $600 \mathrm{lbs}$ 250 to $500 \mathrm{lbs}$. 400 to $600 \mathrm{lbs}$. and up. 50 to 275 lbs., hides on.
$201 / 4$ to $291 / 4$ cents per $1 b$. $221 / 4$ to $281 / 4$ cents per $1 \mathrm{~b}$. $183 / 4$ to $221 / 1$ cents per lb. $171 / 4$ to $173 / 4$ cents per lb. $173 / 4$ to $283 / 4$ cents per $1 \mathrm{lb}$. teaches:

Conclusions. - The study of the beef carcass therefore

1. That well-bred cattle yield the best carcasses and bring the highest price.

2. The market wants young, highly finished cattle.

3. Steers yield the most desirable carcasses.

4. The best results come from a method of management which offers no chance for a setback during growth and fattening.

5. The breeder and feeder of beef cattle should secure as high development of loin, back, and hindquarter as possible.

6. To bring a good price, cattle must dress high.

7. To dress high, cattle must be free from paunchiness and must be fat.

8. Broadly speaking, heredity regulates the lean meat, and man regulates the fat.

9. The feeding of mature cattle is almost entirely a fattening process.

10. Fatness is desirable because it adds weight, makes perfect ripening possible, gives tenderness and juiciness to the meat, and increases the dressing percentage.

11. Cattle may be made too fat.

12. Carcasses vary widely in weight, shape, thickness of fleshing, thickness of external fat, marbling, color of lean, color of fat, grain of meat, and size and hardness of bones.

13. Ancestry, age, sex, feed, and care determine what sort of a carcass an animal will yield.

14. Half of the carcass meets with strong demand and sells high, while the remainder sells low.

15. There is demand for carcasses of all weights, but the strongest demand is for handy-weight carcasses from cattle weighing 1,200 to 1,400 pounds.

* Wholesale price list of a leading Chicago packer, March, 1919. 
16. To secure the greatest returns, the feeder should send his cattle to market well done after a short feeding period, but not in an excessively fat condition resulting from long continued feeding. 


\section{CHAPTER III.}

\section{PACKING HOUSE BY-PRODUCTS FROM CATTLE.}

When slaughtered, the average steer yields over 40 per cent. of offal. In the early days of the packing industry the only by-products of a beef animal which received attention from packers were hide, tallow, and tongue. The remainder of the offal was either thrown away or sold for almost nothing. In some instances, packers even paid for the carting away of offal. In a short time glue works, fertilizer works, soap factories, oil and tallow factories sprang up in the vicinity of the packing plants and grew to be large industries. Soon the packing plants went into the soap business for themselves, then into the glue business, the fertilizer business, and so on, until today packing house by-produts are numbered by the score from what was formerly mere waste. The modern packing house is living and depending for profits on what the packing industry of a quarter century ago was throwing away. The utilization of by-products is one of the chief reasons why packers are able to compete so successfully with the local butchers of the country. Were it not for this conversion of waste material into saleable form, the cost of beef would be considerably higher than under existing conditions.

The most important of all the by-products of the animal is the hide. Cattle hides have increased in value enormously in the last few years. In 1904, the average price for packer hides was $\$ 10.63$ per cwt. In 1918 , the average price was $\$ 24.77$ per cwt. The average cattle hide, which weighs about 75 pounds, therefore brought $\$ 18.57$ in 1918 . Next in value to the hide stand the fats derived from the abdominal region. The fats of the steer bear the general name of "tallow." Out of the finer and better of these fats, those which may be readily detached by cutting and pulling, is made oleomargarine or butterine. This food product appeared in 1866 and has since come into extensive use. The "butter fats" average in weight from 60 to 75 pounds to the animal. One Chicago plant has a capacity of fifteen tons of oleomargarine a day, and in a year this concern has put out between eight and nine million pounds. The production of oleomargarine in the United States has increased 
from about 50 million pounds in 1905 , to 138 million pounds in 1910, 177 million pounds in 1916, 298 million pounds in 1917, and 377 million pounds in 1918. The marked increases in the last two years were due to the scarcity and high price of butter. The per capita consumption increased from a little over half a pound in 1905 to over $31 / 2$ pounds in 1918. After all the oleo has been squeezed from beef suet, there comes another valuable by-product-stearin-largely used in the manufacture of chewing gum.

Lean meat trimmings are made into sausage. Hair sells at a good figure for use in plastering and for other purposes. The horns, at one time considered a rubbish nuisance, are now sold from the packing house at $\$ 100$ to $\$ 200$ per ton. The same is true of hoofs, which bring $\$ 40$ to $\$ 85$ per ton. Hoofs and horns are manufactured into combs, knife, cane, and umbrella handles, buttons, and many other articles. Dried blood sells for blood meal at $\$ 90$ per ton. Fibrous matter and scraps, after all the grease has been extracted, are ground to tankage and sold at $\$ 70$ to $\$ 90$ per ton. From all bone and cartilage the basic substance is extracted from which glue is made. Fully 18 per cent. of dry bones is glue, the rest is ground to fertilizer, worth $\$ 35$ per ton. One Chicago packing plant turns out $8,000,000$ pounds of glue annually. From the intestines are made sausage casings, brewer's hose, and snuff packages, while the bladder yields packages for putty, snuff, and lard. The tail furnishes hair for mattresses and upholstering, and the bone and meat are used for making ox-tail soup. Shank bones are worth from $\$ 65$ to $\$ 85$ per ton, and are cut into buttons, toothbrush handles, and other ariicles. The same use is made of long thigh bones, worth $\$ 150$ per ton. The tongue, cheek, tripe, brains, heart, liver, and sweetbreads are sold for food. Tripe is pickled stomachs. Sweetbreads are the thymus and pancreatic glands. The contents of the stomach are burned under packing house boilers and the ashes are used for fertilizer. Nothing is wasted but the water in the carcass. 
A Chicago packer has computed from numerous tests the following percentages of yields from a steer:

\begin{tabular}{|c|c|}
\hline Pounds & $\begin{array}{l}\text { Per cent. of } \\
\text { live weight }\end{array}$ \\
\hline 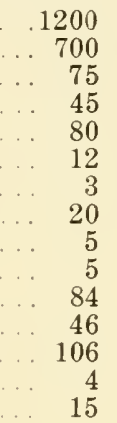 & $\begin{array}{l}58.3 \\
6.2 \\
3.7 \\
6.6 \\
1.0 \\
0.25 \\
1.6 \\
0.41 \\
0.41 \\
7.0 \\
3.8 \\
8.8 \\
0.3 \\
1.2\end{array}$ \\
\hline & 99.57 \\
\hline
\end{tabular}

The following table, giving the weights of the offal of steers, was compiled from slaughter tests conducted by the Iowa Experiment Station:

\begin{tabular}{|c|c|c|c|c|c|c|c|c|}
\hline $\begin{array}{l}\text { Products of dress- } \\
\text { ing steers }\end{array}$ & $\begin{array}{l}\text { Here- } \\
\text { ford }\end{array}$ & $\begin{array}{l}\text { Here- } \\
\text { ford }\end{array}$ & Angus & Angus & $\begin{array}{l}\text { Hol- } \\
\text { stein }\end{array}$ & $\begin{array}{l}\text { Hol- } \\
\text { stein }\end{array}$ & Jersey & Jersey \\
\hline 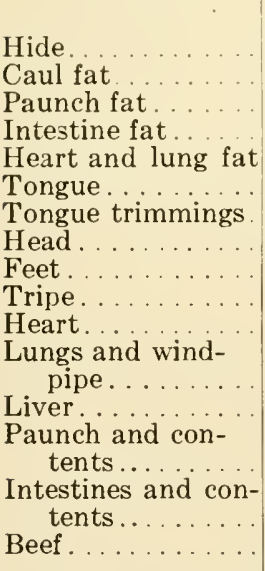 & $\begin{array}{c}\text { Lbs. } \\
90 . \\
24 . \\
24 . \\
28 . \\
11 . \\
4 . \\
4 . \\
28 . \\
16 . \\
22.5 \\
3.5 \\
6 . \\
13 . \\
151 . \\
78.5 \\
792 .\end{array}$ & $\begin{array}{c}\text { Lbs. } \\
102.5 \\
23.5 \\
26 . \\
22 . \\
7.5 \\
4 . \\
5 . \\
25 \\
17 . \\
17 . \\
6 . \\
8 . \\
18 . \\
132 . \\
66 . \\
777 .\end{array}$ & $\begin{array}{l}\text { Lbs. } \\
80 . \\
23 . \\
11 . \\
19 . \\
6 . \\
2 . \\
1.5 \\
25.5 \\
19 . \\
16 . \\
2.5 \\
6.5 \\
10 . \\
115.5 \\
54 . \\
812 .\end{array}$ & \begin{tabular}{|c|} 
Lbs. \\
62.5 \\
22.5 \\
18. \\
21.5 \\
8.5 \\
3.5 \\
2.5 \\
20.5 \\
10.5 \\
20. \\
3. \\
7.5 \\
12. \\
101.5 \\
52. \\
680.
\end{tabular} & \begin{tabular}{|l|} 
Lbs. \\
83. \\
14. \\
12.5 \\
17.5 \\
7.5 \\
4.5 \\
2.5 \\
25. \\
17. \\
19. \\
3.5 \\
11. \\
11.5 \\
133. \\
50.5 \\
773.
\end{tabular} & $\begin{array}{l}\text { Lbs. } \\
61.5 \\
11.5 \\
10 . \\
15 . \\
3 . \\
3.5 \\
2.5 \\
23.5 \\
15 . \\
16 . \\
1.5 \\
8.5 \\
11 . \\
125 . \\
63.5 \\
602 .\end{array}$ & \begin{tabular}{|c|} 
Lbs. \\
66. \\
25. \\
20. \\
53.5 \\
18. \\
4. \\
3.5 \\
24.5 \\
8.5 \\
16. \\
4.5 \\
10. \\
11. \\
129.5 \\
76. \\
592.
\end{tabular} & $\begin{array}{l}\text { Lbs. } \\
77 . \\
41.5 \\
21.5 \\
36 . \\
11.5 \\
4.5 \\
3.5 \\
28 . \\
15 . \\
11 . \\
4 . \\
10 . \\
15.5 \\
\\
133 . \\
79.5 \\
636 .\end{array}$ \\
\hline Total...... & 1295.5 & 1256.5 & 1203.5 & 1045.5 & 1185.0 & 972.5 & 1062.0 & 1127.0 \\
\hline Live weight... & 1338. & 1320 . & 1324. & 1142. & 1316. & 1090. & 1100 . & 1182. \\
\hline $\begin{array}{l}\text { Difference, in- } \\
\text { cluding blood } \\
\text { and shrink... }\end{array}$ & 42.5 & 63.5 & $\mid 120.5$ & 96.5 & 131. & 117.5 & 138 & 55. \\
\hline
\end{tabular}


A carload containing eighteen prime and uniform AberdeenAngus steers, bred and fed by the owner in Henry County, Illinois, were sold at the Union Stock Yards, Chicago, August 26, 1914.* They were reshipped to New York City on the same date, where they were slaughtered August 30, 1914. They had been calved in the spring of 1912, suckled their dams on pasture until weaning time, and received grain and hay through the following winter. The next summer they ran on pasture and were then fed clover and alfalfa hay until January 15, 1914. One-half corn ration was fed the steers until March 1 , when a full feed of corn with alfalfa hay was given in the dry lot until marketing.

It is of interest to know the story of these steers in detail as they passed through the market and through the hands of the packer, and to know the weights and values of the numerous products secured from their slaughter. The following table, giving the figures for a single steer representing an average of the 18 head, tells the story:

\section{Marketing.}

Live weight at Chicago, pounds ....................... 1483

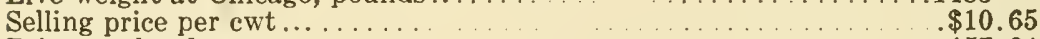

Price per head..................................... $\quad .157 .94$

Marketing expenses-

Freight and terminal switching.

Yardage...................

Feed and insurance..

Commission......

Proceeds to producer.

Slaughtering and Wholesaling.

Cost of live steer to packer.

Freight, bedding, and feed to New York City ...

Gross cost of steer at New York.

Live weight at New York, pounds.

Shrinkage in shipment, Chicago to New York, pounds

Shrinkage in shipment, Chicago to New York, percentage.

Chilled carcass weight, pounds ..

\section{Proceeds to Packer.}

Dressed beef, 899.4 lbs., average $16.86 \mathrm{c}$. 


\begin{tabular}{|c|c|c|c|}
\hline Offal & $W t$. in lbs. & Price & Value \\
\hline Liver & 12.47 & 12c per lb. & $\$ 1.50$ \\
\hline Heart & 4.28 & $6 \mathrm{c}$ per $\mathrm{lb}$. & .26 \\
\hline Tail & & $10 \mathrm{c}$ each & .10 \\
\hline Tongue & 10.50 & $10 \mathrm{c}$ per lb. & 1.05 \\
\hline Brains & $\ldots \ldots$ & $8 \mathrm{c}$ each & .08 \\
\hline Sweetbreads & .39 & $30 c$ per $1 b$. & .12 \\
\hline Melts & $\ldots \ldots$ & $6 \mathrm{c}$ each & .06 \\
\hline Lungs & $\cdots$ & $5 c$ per set & .05 \\
\hline Raw tripe & 22.00 & $11 / 2 \mathrm{c}$ per lb. & .33 \\
\hline Switch & & $3 \mathrm{c}$ each & .03 \\
\hline Cheek meat & 5.33 & $91 / 2 \mathrm{c}$ per lb. & .51 \\
\hline Head meat & 1.17 & $81 / 2 \mathrm{c}$ per lb. & .10 \\
\hline Ox lips & .51 & $5 \mathrm{c}$ per $\mathrm{lb}$ & .03 \\
\hline Skull bones & 13.00 & $\$ 20$ per ton & .13 \\
\hline Feet & 19.11 & $\$ 27$ per ton & .26 \\
\hline Heart cap & .43 & $31 / 2 \mathrm{c}$ per lb. & .02 \\
\hline Blood, estimated & 8.00 & $\$ 40$ per ton & .16 \\
\hline Tankage & 4.00 & $\$ 20$ per ton & .04 \\
\hline Tallow & 5.00 & $51 / 2 \mathrm{c}$ per lb. & \\
\hline & & & $\$ 5.11$ \\
\hline
\end{tabular}

Green value edible offal

Casings-

Rounds, at $22 \mathrm{c}$ per set . . . . . . . . . . \$ .22

Middles, at $72 \mathrm{c}$ per set. . . . . . . . . . 72

Bungs, at 22c per set.................. .22

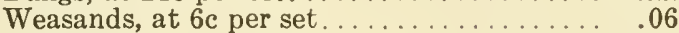

Bladder, at $31 / 2 \mathrm{c}$ per set.............. .04

$\overline{\$ 1.26}$

Less expense, $42 \mathrm{c}$ per set..............42

Green value casings ................. $\$ .84$

Total value of offal.................. $\$ 5.60$

Total proceeds to packer.............................. $\$ 179.43$

Gross margin to packer . . . . . . . . . . . . . . . . . $\$ 16.99$

Retailing.

Cost of beef to retailer.

Proceeds of beef at retail

Gross margin to retailer...

It would seem that the packer is now doing his share in supplying the people with good meat at a fair price. There can be no further expansion in the line of getting more product out of the animal, the limit in that direction having been reached. Further improvement in the quality and cheapening of the price of beef rests largely with the grower or producer of live stock. Much may be done on the production side of the business to bring about these results. More feed must be grown per acre, 
feeding must be done more economically, and better animals must be bred and fed for the market in order that greater returns may be secured for the feed consumed. The scrub animal must be eliminated through the multiplication in numbers and extension of territory of the improved breeds of cattle. Thus more good purebred sires will be made available for grading up the common cattle of the country, and meats of better quality will be produced at lower cost. 


\section{CHAPTER IV.}

\section{THE VALUE OF TYPE IN BEEF MAKING.}

In order to determine just what advantages are possessed by the beef-type steer as compared with dairy-type steers, some experiments have been carried out which have resulted in interesting findings. It has long been known that beef steers suit feeders and butchers better than steers of dairy breeding. It has been claimed that beef steers gain faster in proportion

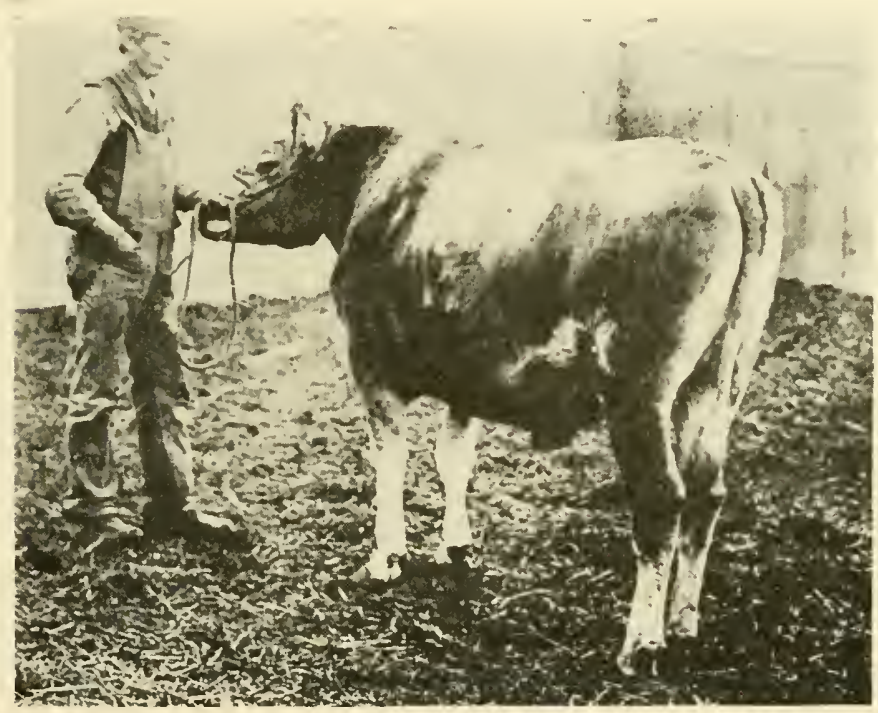

Fig. 11. Dairy-Type Steer.

Jersey steer in the Iowa experiment at end of feeding period. Note the slack crops and fore-rib, paunchiness, and lack of muscling in this steer.

to feed consumed, that they fatten more readily, dress out higher, yield a more valuable carcass, and hence bring a higher price on the market. Experimental results have upheld some of these views and disproved others.

In 1903, the Iowa Experiment Station* conducted a series of experiments dealing with the comparative merits of the two types for beef production. The object was to provide answers

* Ia. Bul. 20. 
to the following questions: 1. Which type of steer makes the greater gains from pounds of feed consumed? 2. In the gains made, what differences exist between the two types as to distribution of such gains over the body? 3. Which type of steer yields the greater profit to the feeder? 4. Which type shows the greater amount of offal? 5. Which type carries the higher percentage of tallow? 6. Which type carries the higher percentage of valuable cuts? 7. In considering the various commercial cuts from the two types, what differences are to be found as regards: weight, thickness, covering of fat, marbling, color, and fineness of grain? 8. Is the low price paid for dairytype steers due to prejudice, or to an actual inferiority in the value of the carcasses?

Four beef-type steers and four dairy-type steers were put on feed January 1, 1903, and fed one year. The steers were on dry feed during the entire time, so that the exact amount of feed consumed by each lot might be known. Of the four beef steers, two were high-grade Herefords, and two, purebred Angus. The four dairy steers consisted of two Jerseys and two Holsteins. The ages at the beginning of the test were approximately as folows: Average of Herefords, 16 months; of Angus, 18 months; of Holsteins, 24 months; and of Jerseys, 18 months. The feeds given were mixed hay, sorghum (during July and August), corn meal, bran, oil meal, and gluten feed. The conditions were alike for all the animals, and the feed was the same, but each animal was given all he would clean up regularly. At the end of the feeding test the cattle were bought in separate lots by the head buyer of a packing company of Des Moines, Iowa. The prices given were the market prices for such steers, December $28,1903$.

Following is a summary of the first part of the investigation:

\begin{tabular}{|c|c|c|}
\hline & $\begin{array}{l}\text { Beef } \\
\text { steers }\end{array}$ & $\begin{array}{l}\text { Dairy } \\
\text { steers }\end{array}$ \\
\hline Average weight at beginning, lbs & .685 & 574 \\
\hline Average gain per steer, lbs......... & .606 & 598 \\
\hline Average value of feed consumed per steer & $\ldots \$ 47.27$ & $\$ 45.18$ \\
\hline Average cost of one pound of gain..... & . $7.81 \mathrm{c}$ & $7.63 \mathrm{c}$ \\
\hline Percentage of dressed weight in slaughter test. & . 61.7 & 57.15 \\
\hline Selling value, average price per pound . ...... & . . $4.888 \mathrm{c}$ & $3.752 \mathrm{c}$ \\
\hline
\end{tabular}

1 The dairy-type steers made their gains at a trifle less cost per pound than did the beef steers, indicating that their digestive and assimilative functions were slightly more vigorous in this 
inslance. The gains made by the dairy steers were not distributed on the body in such a way as to command the highest prices. The beef-type steers made a large proportion of their gains on the back, loin, and hindquarters, while the dairy-type steers showed but little increase in thickness on these parts.

The beef-type steers were far more profitable to the feeder, for although both lots made approximately the same total gains, and although the average of the four dairy-type steers compared with the average of the four beef-type steers shows that the former made his 600 pounds of gain cheaper by $\$ 1.70$ than did the latter, nevertheless this 600 pounds gain of the beef steer brought $\$ 7.18$ more on the market. When $\$ 1.70$ is deducted from $\$ 7.18$, there is left $\$ 5.48$ profit in favor of the beef animals, or a total of nearly $\$ 22$ for the four head. Nor does this represent all the financial advantage of the beef-type steer, for the value of the initial weight $(685 \mathrm{lbs}$.) of the beef steer was increased to a greater degree by feeding than was the value of the initial weight of the dairy-type steer. The report of the experiment furnishes no initial valuations, hence a complete accounting in this regard cannot be made.

Following are given the weights of the cuts from the carcasses, expressed in percentages of the total carcass weight; also the wholesale and retail prices of these cuts:

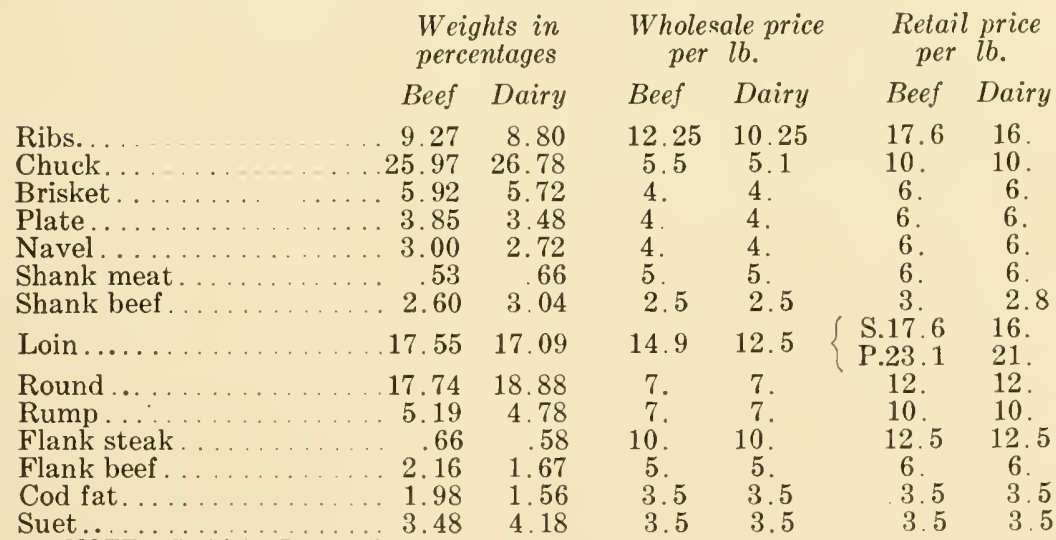

It will be observed that the carcasses were cut up into a greater number of parts than result from the regular method of catting explained in the previous chapter, but the differences in the cuts are not great enough to prevent a full understanding of the above table. 
On the basis of the above figures we are able to determine the relative profits of the beef- and dairy-type steers to the wholesaler or packer. This is shown as follows:

\begin{tabular}{|c|c|c|}
\hline $\begin{array}{l}\text { Cost of } 4 \text { live steers } \ldots \ldots \text { per head } \\
\text { Cost of killing at } \$ 1.50 \text {. }\end{array}$ & $\begin{array}{l}\text { Beef steers } \\
. \$ 242.52 \\
\quad 6.00\end{array}$ & $\begin{array}{l}\text { Dairy steers } \\
\$ 170.64 \\
6.00\end{array}$ \\
\hline $\begin{array}{l}\text { Cost of carcasses and offal.................. } \\
\text { Received from sale of hides, tallow, and tongue. }\end{array}$ & $\begin{array}{r}. \$ 248.52 \\
. \quad 36.13\end{array}$ & $\begin{array}{r}\$ 176.64 \\
30.27\end{array}$ \\
\hline $\begin{array}{l}\text { Cost of dressed beef } \ldots \\
\text { Cost of dressed beef per lb } \\
\text { Actual wholesale returns when beef was sold... } \\
\text { Margin between cost and selling price of dressed } \\
\text { beef . }\end{array}$ & $\begin{array}{c}\$ 212.39 \\
.0715 \\
232.61\end{array}$ & $\begin{array}{c}\$ 146.37 \\
.0583 \\
179.83\end{array}$ \\
\hline
\end{tabular}

The last item in the above table is interesting. It shows that there was $\$ 20.22$ margin for the beef-type steers and $\$ 33.46$ for the dairy-type steers, or a difference of $\$ 13.24$ in favor of the dairy-type cattle. If this difference in margins were applied to the live-weight price of the dairy-type steers, their price per cwt. would have been 28 cents higher; in other words the dairytype steers would have brought 4 cents per pound, instead of $33 / 4$ cents.

At a meat demonstration in January, 1904, conducted by Mr. John Gosling, some further important differences were brought out between the cuts from the dairy- and beef-type carcasses. Mr. Gosling is recognized as one of the leading authorities on meats in this country. In grading the carcasses, he placed three of the beef-type carcasses as No. 1, and the other as No. 2. Two of the dairy-type carcasses were graded No. 2, and the other two as No. 3. The color of the flesh was fairly good in all eight of the carcasses, although in the Jersey carcasses it was somewhat dark. The external color (or color of the fat) was good in all except one-a Jersey-which killed very yellow. The other Jersey killed very white, although, as a rule, carcasses of Jerseys or grade Jerseys are very yellow. The spines in the backbone of the dairy-type carcasses were hard, indicating the early maturity of the dairy type. They were much more cartilaginous in the beef-type carcasses, although the ages were nearly the same. The fore-ribs from the dairytype steers were light and lacking in marbling. The Holstein ribs lacked depth, and were very irregular and rough. The dairy-type steers carried more kidney fat or suet; this is a cheap product which increases the dressing percentage, but reduces the value of the carcass when excessive. 
The answers to the questions asked at the beginning of the experiment are, therefore, as follows: 1. The gains from pounds of feed consumed are practically the same for both the beef and dairy types. 2. The beef-type steer uses his gains to slight advantage as compared with the dairy-type, placing a slightly greater percentage of his gains in the valuable cuts. 3. The beef-type steer yields the greater profit to the feeder. 4. The dairy-type steer shows the greater amount of offal. 5. The dairy-type steer carries the higher percentage of tallow. 6. As regards the percentage of valuable cuts, there is very little difference; if any, it is in favor of the beef-type steer. 7. The beef-type steer yields cuts that are heavier, thicker, usually

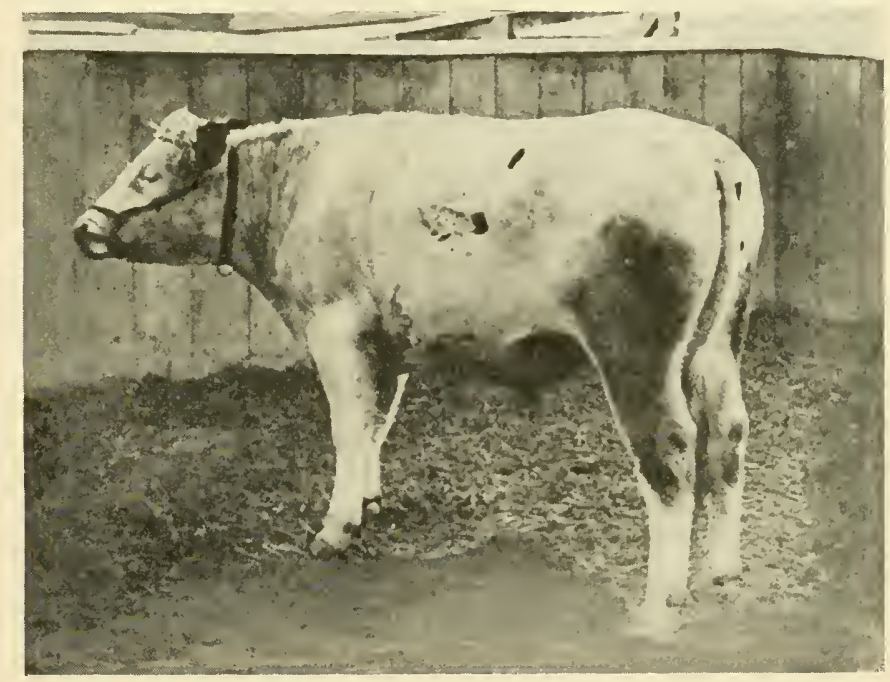

Fig. 12. Dairy-Type Steer.

Holstein steer in the Iowa experiment. His flat ribs, ridgy back, and angular appearance are characteristic of steers of dairy breeding.

covered with whiter fat, nicer in marbling, and a little better in color of muscle. There is no apparent difference in fineness of grain. 8. The low price paid for dairy steers may be due partially to prejudice, and to the greater expense of carrying and selling the low-grade carcasses, but it is chiefly due to an actual inferiority in the carcasses. They are unsatisfactory to the consumer, because they do not furnish thick and well-marbled cuts; they are unsatisfactory to the butcher, because they furnish low-grade carcasses which are difficult to dispose of; and 
they are decidedly unsatisfactory to the feeder, because they yield him little or no profit, and both breeder and feeder waste their time in producing such a type of steer for beef purposes.

In an earlier experiment at the Iowa Station, James Wilson and C. F. Curtiss found the quantity of fat about the internal organs of fat steers of the various breeds to be as follows:

\begin{tabular}{|c|c|c|c|}
\hline Breed & $\begin{array}{c}\text { Average dressed } \\
\text { weight }\end{array}$ & $\begin{array}{l}\text { Loose } \\
\text { tallow }\end{array}$ & $\begin{array}{l}\text { Per cent. of loos } \\
\text { tallow to beef }\end{array}$ \\
\hline Shorthorn & $\ldots \quad 1,092$ & 145 & 13.3 \\
\hline Hereford. & 1,022 & 129 & 12.6 \\
\hline Red Poll. & 990 & 125 & 12.6 \\
\hline Galloway. & 1,088 & 147 & 13.5 \\
\hline Angus... & 1,137 & 157 & 13.8 \\
\hline Devon. & 815 & 123 & 15.0 \\
\hline Swiss ... & 1,017 & 119 & 11.7 \\
\hline Holstein. & 862 & 155 & 17.9 \\
\hline Jersey . . . & 880 & 166 & 18.8 \\
\hline
\end{tabular}

This table gives further evidence of the tendency of the dairy breeds to deposit proportionately more fat about the intestines, paunch, kidneys, and caul. Experiments at the Kansas Station substantiate the results of the Iowa investigations. (See also table on page 59.)

Why the dairy steer lacks thick flesh.-The experimental results set forth above emphasize the lack of thickness in the cuts from the dairy steer. In other words, the dairy steer is decidedly lacking in muscular development. Mr. John Gosling has continually emphasized this point in his annual meat demonstrations at the Iowa State College. He has conclusively shown that there is a very marked difference in the amount of muscle or lean meat present at birth in calves of dairy ancestry as contrasted with those of good beef breeding, and he has also shown that from a practical standpoint, at least, feeding does not increase the relative proportion of muscle in the make-up of an animal. His demonstration in January, 1918, included a beef calf and a dairy calf, less than a week old, which were not selected for veals, but were used to demonstrate the vast difference in the natural flesh or muscle present at birth in these two types of cattle. The accompanying illustrations show the difference. There was no visible fat on either of them, but the beef calf was thick, plump, and rounding, with muscles like the breast of a quail, while the dairy calf was flat and thin in all parts. The beef calf was thick in neck and arm, broad of back and loin, full in rump, bulging in thighs, and carried his beef to the hocks. The dairy calf was scrawny in his neck, ridgy along the spine, narrow and shabby over the rump, and light and tapering in 
his rounds. The evidence is unquestionable. Fat can be put on by feeding, but the muscle comes only by inheritance. The dairy calf is "born wrong" from a beef standpoint, and no known method of feeding and management can correct its deficiency.

Professor W. A. Henry, of the Wisconsin Station, has written the following pointed statement* relative to the comparative merits of beef-type and dairy-type steers:

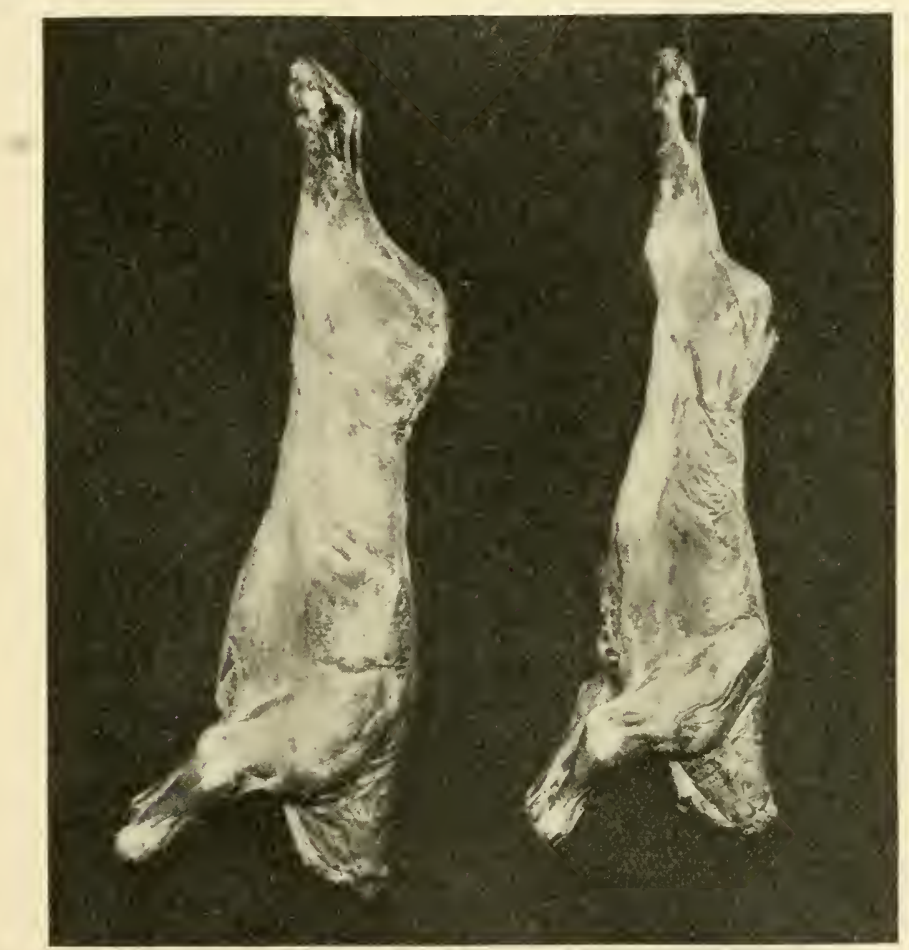

Fig. 13. Carcasses of Beef and Dairy Calves.

These calves were slaughtered when less than a week old. Neither carcass showed any degree of fat. Note the muscling in round, rump, loin, rib, shoulder, arm, and neck of the beef calf on the left as compared to the dairy calf on the right.

"Beyond that which can be expressed in figures or stated percentagely lies that indefinable something described by the word 'quality' which enters into all objects of barter. No one can compare a bunch of well-fed beef-bred steers with one representing the dairy breeds without being impressed by a difference

\footnotetext{
* Feeds and Feeding, p. 443.
} 
not measured by the scales....... The matter at issue may be illustrated by a condition in the fruit world: No orchardist will hold that the Baldwin apple tree necessarily grows faster than the seedling apple tree, or that it will make wood and fruit on less material from soil and air. Neither will he hold that Baldwin trees necessarily yield more barrels of fruit than seedlings, nor that a given measure of Baldwin apples contains more juice or human food than the same measure of common seedling

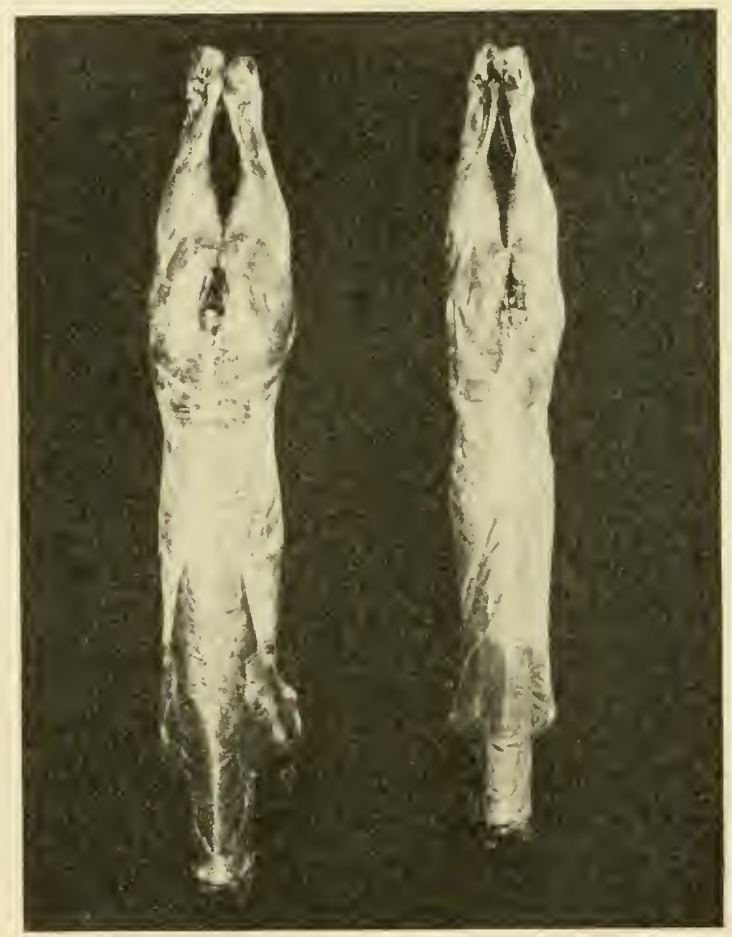

Fig. 14. Carcasses of Beef and Dairy Calves.

Back view of carcasses shown in Fig. 13. Beef calf on left, dairy calf on right. Note the rounds, rumps, loins, backs, shoulders, and necks. The marked difference in the muscling inherited by these two calves is plainly evident.

apples. Fruit growers do rightfully assert, however, that the market wants Baldwin apples and will pay more for them than for common seedling fruit, and that from this judgment of the market, be it reasonable or unreasonable, there is no appeal. Beef cattle have been bred for meat production-it would be passing strange if they did not excel for that purpose." 


\section{CHAPTER V.}

\section{AMERICAN CATTLE MARKETS.}

The largest live-stock markets of the United States are located in the central part of the country. With the West and Central West on the one hand as the great breeding and feeding ground, and with the East on the other as the chief region of consumption, it is logical that the large markets have a central location. Following are the fourteen largest cattle markets and their receipts of cattle, including calves, during 1918:
1. Chicago
2. Kansas City
3. Omaha.
4. Fort Worth
5. St. Louis .
6. St. Paul
7. St. Joseph

Total
8. Sioux City

9. Denver. .

10. Oklahoma City.

11. Buffalo.

12. Pittsburg.

13. Indianapolis

14. Cincinnati.
817,593

728,268

690,109

667,671

522,683

504,190

455,291

The U. S. Bureau of Markets reports the total receipts of cattle and calves at 53 markets during 1918 at 24,955,111. The fourteen markets listed above received over 78 per cent. of this total.

From the above figures we see that the Chicago market is the largest in the United States, in fact Chicago is the largest cattle market in the world. In 1918, Chicago received 3,789,922 cattle and 657,767 calves, the largest year's receipts since the opening of the yards in 1865. Cattle weighing 300 pounds. or less per head are classed as calves. The 3,789,922 cattle received during 1918, if placed in a procession, allowing ten feet of space for each animal, would form a line 7100 miles long. Their total value was $\$ 463,038,180$. Their average value per head was $\$ 122$. 'Their average weight was 941 pounds. Their average price per cwt. was $\$ 13$. The number of western range cattle received at Chicago in 1918 was 434,300 , the largest on record. These cattle constituted about $11 \mathrm{I} / 2$ per cent. of all cattle received. The total value of the calves was $\$ 14,400,162$; their average value per head was a little less than $\$ 22$; their average weight was 139 pounds; and their average price per cwt. was a little less than $\$ 16$. 
The census of 1909 estimated that $13,611,422$ cattle and $6,515,976$ calves were slaughtered in the United States in that year. It is estimated that about three-fifths of the beef cattle marketed in the United States pass through the large central markets, that about one-third are sold for local slaughter, and that about one-tenth are slaughtered on farms and ranges. Considering that the animals which are shipped to the centralized markets generally are of heavier weights and of higher grades than stock slaughtered locally, it is apparent that probably two-thirds or more of the beef consumed is the product of animals which pass through the large central markets. About two-fifths of the calves are slaughtered by the large packers, a little less than half are slaughtered locally, and about onesixth are slaughtered on farms and ranges.

The great markets of the Middle West are points of focus of never-ending processions of beef animals moving from western ranges and cornbelt feed-lots. Upon reaching market, the cattle are either slaughtered at the great packing houses located at the stock yards, or are shipped out of market on the hoof. Both dressed carcasses and live animals are shipped to various cities and towns to fill the orders of retail butchers. For example, the Chicago packing houses slaughtered 2,800,051 cattle in 1918, and the remaining 989,871 head were shipped out alive. Of the latter number, 586,557 were shipped to various parts of the country for slaughter, and 403,314 were taken out for feeding.

An investigation by the U. S. Office of Markets and Rural Organization in 1915, indicated that 42 per cent. of cattle are marketed in the fall, 19 per cent. in the winter, 21 per cent. in the spring, and 18 per cent. in the summer. Both the buying of stockers and feeders and the selling of fat stock are confined to a few months of the year. Movements of live stock are largely controlled by such factors as the limits of the grazing season, the maturity of crops for feeding, distribution of labor, etc., and it is not advisable that monthly shipments of live stock to market be absolutely equalized, yet it is at the same time true that a more even distribution is, within limits, desirable to both producer and consumer.

Zone system of marketing at Chicago.-At Chicago, in 1915, 42 per cent. of cattle were received on Mondays, 10 per cent. on Tuesdays, 33 per cent. on Wednesdays, 10 per cent. on Thursdays, 4 per cent. on Fridays, and less than 1 per cent. on Saturdays. A similar, though less marked, condition prevailed 
with respect to hogs and sheep. In order to more nearly equalize receipts, the zone system of marketing was applied to the Chicago Union Stock Yards on December 10, 1917, and has been continued to the present time. This system was inaugurated by the U. S. Food Administration as a war measure. Under this plan a circle is drawn on the map so as to include Eastern Iowa, Illinois, and most of Wisconsin. The regulations provide that those who live within the circle may ship their stock so as to arrive on the Chicago market on Tuesday, Thursday, and Saturday, and that those outside the line may ship so as to arrive at Chicago on Monday, Wednesday, and Friday. The stabilizing effects of this system are shown by the fact that, during 1918, 30 per cent. of cattle were received at Chicago on Monday, 23 per cent. on Tuesday, 14 per cent. on Wednesday, 19 per cent. on Thursday, 10 per cent. on Friday, and 4 per cent. on Saturday.

Early cattle markets.-A century ago cattle markets were small and largely local in character. The "West" at that time comprised what we now designate as the Middle West, embracing Kentucky, Ohio, Indiana, and Illinois, and the live-stock business and the meat business of that time were far different propositions than today. There were no railroads, no live-stock cars, no refrigerator cars, no steamships, and no large live-stock markets. Every large town had its own stock yards or cattle market to which cattle were driven from the surrounding country and sold to butchers. The cattle business and the meat business were local affairs of small dimensions depending upon the size of the town. In time, New York, Philadelphia, Boston, and Baltimore became rather large markets, and in some instances cattle were driven long distances to supply them.

Early methods of transportation.- This was before the days of railroads, and even after the railroads came, very few live animals were carried until about 1860 . Prior to 1850 , it was the general practice to drive live stock to market on foot. At that time, in many parts of the country, pasturage was free along the routes, and the animals were driven by easy stages, reaching market without very much depreciation. George Renick, of Ohio, was perhaps the first man to find an outlet for cattle fattened in what was then "The West." He was one of the first settlers of the Scioto Valley, having come in with his brother, Felix, from Virginia, and selected large tracts of land. near the present site of Chillicothe, Ohio. In 1805, against 
the advice of his neighbors, he successfully drove sixty-eight head of cattle from the Scioto to Baltimore, and disposed of them at a profit. This gave a great impetus to the western cattle business of that time, and afforded a means of marketing corn. In 1817, Felix Renick drove one hundred head of prime Shorthorn steers to Philadelphia, receiving $\$ 134$ per head for them. He became the leading producer of high-class cattle in Ohio, and one of the most extensive breeders and feeders in the United States. R. R. Seýmour, of Ohio, fed 100 to 700 annually, and in 1841 drove 840 head to Philadelphia.

One route from Kentucky to New York City covered about 800 miles and required over ten weeks to complete it. Another route from Lexington extended to Charleston, S. C., a distance of 550 to 600 miles. Drives to the eastern seaboard were made from as far west as Iowa, and even Texas cattle passed eastward in this manner. There is record of a drove of several hundred cattle from Texas passing through Pennsylvania, on the way to New York City, which had left Texas four months previously. Sheep were driven across country also, notably from Vermont to Virginia. Large numbers of hogs were driven to market, but they were a more active type than the modern fat hog. By 1860 , few hogs were driven any considerable distance. Today we do not even drive hogs from the farm to the shipping point, but haul them in wagons.

Development of large markets.-The large live-stock markets grew up with the country. As long as the market was simply the scene of barter in live animals for local use, no large markets were developed. About 1830 pork-packing was begun, and this furnished the first impetus to the creation of large markets of more than mere local importance. Pork could be pickled, salted, and smoked, and the fat rendered into lard, and the products thus produced could be shipped to distant points. As these products met with good demand, porkpacking was the natural beginning of a vast meat-manufacturing business, tending to centralize the hog markets, and much increase them in size. So far as cattle were concerned, however, the development was not parallel. Outside of an article known as barreled beef, which was put down in salt, packers had found no method of handling beef as they did hogs. Not until the era of the refrigerator car, beginning in 1875, were cattle of much interest to packers, and not until that time did the large cattle markets reach a maximum development. 
The advent of railroads marked a decided turning point in the development of the live-stock industry and the live-stock markets. However, it was a long time after the hauling of live stock had been taken up by railroads before it was done efficiently. An account of one of the first shipments of cattle from Kentucky to New York City, made in 1852, shows how crude and expensive were the first attempts at transporting cattle by rail. One week was consumed in driving the cattle, one hundred in number, from near Lexington, $\mathrm{Ky}$., to Cincinnati, where they were loaded in box cars and shipped to Cleveland. They were taken to Buffalo by boat, where they were given several days rest and then driven to Canandaigua, N. Y. They were at once hauled to Albany in immigrant wagons, rested two days in a feed-yard, and sent to New York by boat. The cost of the shipment from Kentucky to New York City was $\$ 14$ per head.

The cattle markets of the United States migrated from east to west, following closely upon the settling up of the country. It was at one time believed that Albany was to be the final gateway for western cattle. Next Buffalo, Pittsburg, and Cincinnati were in turn regarded as the future great market of the country; but eventually it became evident that Chicago, by virtue of location and railroad facilities, was to become and remain the largest cattle market in America. This fact was clearly established by 1870 .

Chicago's early cattle trade.-The history of Chicago as a cattle market extends back many years to the time when a few hundred animals were driven in to supply the garrison at old Fort Dearborn. It was not until the advent of railroads, however, that Chicago took prominence as a live-stock center. When railroad communication with the Atlantic seaboard was established and lines were built from Lake Michigan toward the Mississippi, a revolution was brought about. Half a dozen stock yards were located in various parts of the city, and when these became glutted, the cattle were grazed on the surrounding prairie until a price could be realized. Mess pork and barreled beef were staple articles known to the trade under the appetizing names of "sow belly" and "salt horse." Dressed beef was then unknown to commerce, artificial refrigeration was not even speculated upon, the refrigerator car existed merely as an idea, if at all, and the canning of meats had not been attempted. Armour was not a prominent name at that time, 
Swift had not yet discovered Chicago, and nearly every concern then engaged in the manufacture of meats has since gone out of business.

Prior to 1870 , the Chicago cattle business was almost exclusively a matter of buying, selling, and shipping live animals. Then there were no market papers to inform the producer of the state of the market, and no well-organized commission firms to attend to the disposal of his stock. The producer did most of his own selling. There was danger of finding the market glutted, or shipping facilities swamped. Since that time a trade mechanism and a trade demand have grown up, bringing a constant market and quick, sure sales for the cattleman. The loss by wear and tear in shipment from farm to market has been reduced to a minimum.

In the early days it was all guesswork-guesswork as to how long it would take to reach the market, guesswork as to the freight charges, guesswork as to promptness in handling the stock by railroads, guesswork as to the condition of the market, guesswork as to the price the animals would bring. Luck usually counted for more in determining the profits than did skill in the preparation of cattle for market.

Founding of the Union Stock Yards.--Prior to 1865, Chicago had several stock yards of minor importance and located in different sections of the city. The first was the old Bull's Head Stock Yards, opened in 1848, at the corner of Madison Street and Ogden Avenue. At this time Chicago had a population of only 20,000 , but was growing rapidly. In 1865 , John B. Sherman organized the Union Stock Yard and Transit Company, which purchased 320 acres at 39 th and Halsted streets and opened the present Union Stock Yards, thus laying the basis for a greater live-stock trade at Chicago. In 1876 the Union Stock Yards comprised 475 cattle yards, 675 covered hog and sheep pens, 375 chutes, 15 corn cribs, and 10 hay barns. The company owned and operated 24 miles of railway, had put down several miles of macadamized streets and alleys, and installed a drainage system. The market could then accommodate at one time 20,000 cattle, 100,000 hogs, 15,000 sheep, and 1000 horses-in all, 136,000 animals. About one hundred commission firms were then doing business.

The Union Stock Yards today.--The Union Stock Yard and Transit Company receives, unloads, yards, feeds, waters, weighs, and delivers or reships live stock, but neither buys, 
sells, nor slaughters animals. It is a great transportation and marketing corporation, which connects all the twenty-six railway systems entering Chicago with the Union Stock Yards, and provides unloading platforms, chutes, pens, buildings, and all necessary facilities for doing an immense daily business in handling live animals, but takes no part in the transaction of the market. The Chicago yards now occupy an area of 500 acres, 450 of which are paved. There are 25 miles of streets, and 300 miles of railway tracks. The number of pens is 13,000 , of which 8,500 are double-decked and covered; there are 725 chutes, 25,000 gates, 25 miles of watering troughs, and 450 commission and other offices. The water system has a reservoir holding 10,000,000 gallons, and pumps with a daily capacity of $8,000,000$ gallons, of which $7,000,000$ gallons are consumed on hot days. Separate accommodations are provided for each kind of stock; sheep and hogs are kept in sheds of two or more stories each, and cattle occupy open pens holding from one to several carloads. These yards would hold at one time 75,000 cattle, 125,000 sheep, 300,000 hogs, and 6,000 horses and mules. It is estimated that 50,000 people earn a living at the stock yards and the packing plants, and that 250,000 of Chicago's population are more or less dependent on the live-stock industry.

Since 1900 , a yearly average of more than 15,000,000 animals have found a cash market at Chicago. Since 1865, $116,153,488$ cattle, $9,832,996$ calves, $328,293,317$ hogs, $132,627,438$ sheep, and 3,536,796 horses have been handled, making a grand total of $590,444,035$ animals, the value of which was $\$ 12,498,228,223$. Sixty per cent. of the cattle received at Chicago are slaughtered there, also 83 per cent. of the calves, 77 per cent. of the hogs, and 74 per cent. of the sheep. The business often amounts to $\$ 5,000,000$ in a day, and averages well over $\$ 2,000,000$ for every business day of the year. Not infrequently 2,000 carloads of stock are received on Monday or Wednesday, the largest market days. When unloaded, the stock is taken in charge by some one of the many commission firms who sell to the packer, shipper, speculator, or feeder, and remit the proceeds to the consignor. Prices established on this leading market form the basis of values for live stock at other markets and throughout the country.

Average carloads.-Reports of stock yards and railroads show that the average number of meat animals to the carload is for cattle about 25, hogs in single-deck cars about 75, and 
sheep about 120 per deck. These figures represent mere averages. The number of animals per car varies greatly depending on the age and size of the animals. For example, a stock car 36 feet long will hold 55 calves weighing 400 lbs. each, 35 yearlings weighing $700 \mathrm{lbs} ., 25$ cattle averaging $1000 \mathrm{lbs} ., 21$ cattle weighing $1200 \mathrm{lbs}$, or 19 cattle weighing $1400 \mathrm{lbs}$. each.

Sources of receipts.-The corn-growing area of the Mississippi and Missouri valleys affords the best facilities for the production of meat animals, and this area is tapped at many points by lines of railway centering in Chicago. The corn-fed cattle of Iowa, Nebraska, Missouri, Kansas, Illinois, Indiana, and Ohio, and the grass-fed cattle of Montana, Wyoming, the Dakotas, and Texas, have easy access to Chicago. Steers are sold in Chicago that were born in Texas, matured in Montana, and finished in an Iowa feed-lot. Sheep often experience similar wanderings before reaching market, but hogs usually come direct from the farm on which they were farrowed.

Federal inspection.-Federal inspection for disease is rigid and includes live animals, carcasses, and packing-house products intended as food. In 1915, the federal inspection conducted at all the large packing plants and at numerous other establishments throughout the country resulted in the condemnation at slaughter of 3.44 per cent. of cattle, .51 per cent of calves, 3.40 per cent. of hogs, .15 per cent. of sheep, and .41 per cent. of goats. The average of all animals was 1.83 per cent. Meat condemned after slaughter, including all meat and meat food products, prepared and processed, amounted to .36 per cent. Nothing has done more to instil confidence in packers' meats than has the rigid governmental inspection. Packers' losses are frequently heavy on account of this inspection, mainly owing to tuberculosis. Crippled animals may go into the food supply. Diseased animals, diseased meats, and dead animals are consigned to the rendering tank, the products of which are grease, glue, and fertilizer.

Development of the packing industry.-No explanation of the rise of the large live-stock markets in America is complete without some reference to the development of the immense packing industry. The history of the meat business is closely interwoven with the history of the live-stock markets, the two enterprises being mutually dependent upon each other. The Chicago market benefitted not only from its location and shipping facilities, but to a great extent also because of the large 
packing interests which centered there. That part of the yards where the group of packing plants is located is called "Packingtown." The various plants composing it are owned by Armour \& Co., Swift \& Co., Morris \& Co., Wilson \& Co., Libby, McNeill \&.Libby, Anglo-American Packing Co., Roberts \& Oake, Hammond Packing Co., Western Packing Co., Louis Pfaelzer \& Co., Boyd-Lunham Packing Co., Miller \& Hart, Independent Packing Co., Brennan Packing Co., and others. Many of these firms do a big business in dressed beef, thereby increasing the demand and helping to sustain prices for live cattle at Chicago.

The numbers of cattle and calves slaughtered by leading Chicago packers in 1917 and 1918 were as follows:

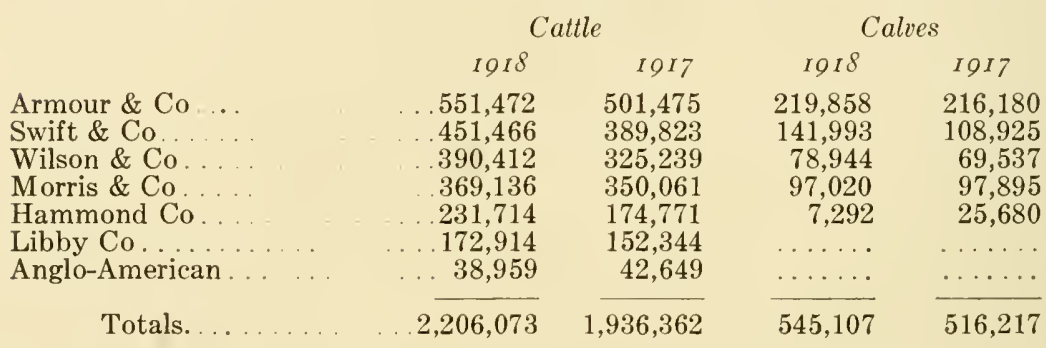

As already pointed out, hogs benefitted from the packing industry long before cattle, because beef did not interest packers to a great extent until the invention of artificial refrigeration and the substitution of the tin can for the oak barrel. Arthur Libby introduced canned corn beef in 1874 , which was followed by dozens of palatable canned preparations. Previous to the installation of ice machines, packing operations were largely confined to the season of low temperatures.

In 1876 , about 250,000 cattle were slaughtered in Chicago, and more than three-fourths of these were handled by two firms - the Wilson Packing Co., and Libby, McNeill \& Libby. The Wilson Packing Co. canned 15,000 to 16,000 head of cattle annually, and Libby, McNeill \& Libby over 180,000, about onehalf being canned and the other half put in barrels and tierces. Three-fourths of the product went to Great Britain.

The refrigerator car.- There have been three eras in the evolution of the American meat industry: (1) The era of pickled meats, such as hams, pork products generally, and salted beef; (2) the era of artificial refrigeration and the refrigerator car; (3) the era of complete utilization of by-products. The supremacy during the first era was first at Cincinnati, but 
it shifted to Chicago in the early sixties. In the early days, packing houses were operated only during the winter months, and no meats were packed in summer until large chill rooms were made possible through successful artificial refrigeration. In 1875, Philip D. Armour erected in Chicago the first really largescale chill room in the world, although small ice boxes had previously been used by others. As early as 1868 a refrigerator car had been invented, but it was not until 1869 that the first through-line railroad was opened up between Chicago and New York so that cars of western meat could be shipped through to eastern markets without unloading. In 1869 the first consignment of dressed beef was shipped from Chicago to Boston, but the attempt was not successful. In 1875, G. F. Swift, who had come to Chicago that year, and who founded what is now Swift $\&$ Co., fitted up a car and shipped it east successfully. Thereupon, this branch of the packing business was entered into rapidly, thus eliminating freight charges on the 40 to 44 per cent. waste of the live animal, the shrink on cattle during the long haul, the expense of feeding and watering en route, and the loss of those which died in transit. It cost $\$ 4.00$ to $\$ 4.40$ to ship a steer of 1,250 pounds weight from Chicago to New York, while the freight on the 700 pounds of fresh beef yielded by the animal would amount to only $\$ 3.15$, not including the expense of icing. From Kansas City to New York the saving amounts to about $\$ 2.50$ per head.

The total number of refrigerator cars in the United States is in excess of 100,000 . Of this number, about 38,000 are under private as distinguished from railroad ownership. About twothirds of the privately owned refrigerator cars are controlled by four leading packers, Armour, Swift, Morris, and Cudahy, and nearly one-half are used chiefly in the meat trade.

Shrinkage of beef cattle in transit.-In an investigation made in 1913 by W. F. Ward of the U. S. Bureau of Animal Industry,* cattle in transit less than 24 hours shrank from 2.05 to 3.91 per cent. Those in transit from 24 to 36 hours shrank from 3.46 to 6.37 per cent. Those in transit from 36 to 72 hours shrank 3.88 to 5.40 per cent. Those in transit over 72 hours shrank from 3.96 to 7.00 per cent. These figures are based_on live weight at origin and "filled" weight at market.

* U. S. Dept. Agr. Bul. 25, pp. 73, 74. 
Pioneer exports of beef.-Still greater savings have been effected by changes in the export trade. Mr. John J. Bate, of New York, was the first to undertake shipments of dressed carcasses to Europe. On February 11, 1875, he made a small shipment to Liverpool which arrived in good condition. This was followed, on June 6, by a larger shipment, and on August 10, a still larger consignment to Liverpool was made, all arriving in good condition. In October, 1875, Mr. Timothy C. Eastman began his first shipments of fresh beef from America to England; Mr. Eastman is generally regarded as the pioneer in this enterprise. He built up a very large business which continued many years. Others entered into the industry, and shipments were made from New York, Philadelphia, and Portland, Me. American beef was found in no way inferior to British beef, and was sold at from four to six cents lower retail rates. The advent of American meats caused considerable excitement among British farmers and stockmen, and considerable prejudice against our meats was aroused at some points, which has never been wholly overcome. The business increased rapidly, meats being successfully shipped from Chicago to England. A saving of more than one-half in shipping expenses is effected by exporting dressed beef rather than its equivalent in live animals. From Argentina to England, two-thirds of the live-weight expenses are saved by sending dressed beef.

The modern packing plant.-No better illustration of the growth of the packing industry can be had than that afforded by the rise and present proportions of one of the large packing companies at Chicago. In 1885, this concern was capitalized at $\$ 300,000$; in 1886 , at $\$ 3,000,000$; in 1896 , at $\$ 15,000,000$; later at $\$ 35,000,000$; in 1906 at $\$ 50,000,000$; and in 1918 it was $\$ 150,000,000$. It has packing plants in several American cities and also in South America and Australia, but the figures here presented apply only to its business in the United States. It has over 400 branch houses in the principal cities and towns of the United States, and owns and operates 7000 refrigerator cars. Its output of meat of all kinds in 1918 was almost 3 billion pounds. Its sales in 1918 totalled over $\$ 1,200,000,000$. It paid $\$ 682,000,000$ to live-stock producers. Its profit on meat sales was only about 2 per cent., but the capital was turned over several times during the year. It earned 7.6 per cent. on the capital employed. It paid its 25,000 stockholders a 6 per cent. dividend amounting to $\$ 9,000,000$. In the year, it shipped $760,000,000$ 
pounds of meat to the American Army and Navy at home and abroad and to the Allied nations. In 1918, its Chicago plant converted into dressed meat 450,000 cattle, 142,000 calves, $1,200,000$ sheep, and $1,144,000$ hogs.

The American packing industry has made the outlet for American meats practically world-wide, and has afforded to the American grower of live stock an opportunity not enjoyed by producers elsewhere. The development of the American meat industry made a demand for cattle; cattle made a demand for corn, and increased its price; corn land rapidly increased in value, and with it all have come better farmers, better farming, and a more prosperous American agriculture.

The cattle business of today.-The unknown quantities of shipping and marketing, which were the bugbear of the cattleman of earlier times, have been reduced to a minimum. The producer of cattle knows, or ought to know, if he is to succeed in his business, just what grade his cattle will be classified under when they come before the buyer. Each class has its own price, varying from day to day in response to supply and demand. Daily market reports put the producer in touch with conditions and prices, and commission men advise him by letter whether it is a good time or a bad time to ship. Whereas charges were formerly uncertain, now they are definitely fixed, and the feeder can figure out all expenditures to the cent before his cattle start for market. Railway rates are much lower than twenty-five years ago, transportation is more direct and fast, there is much less cruelty to the animals in transit, less loss in transit, and less shrink between feed-lot and market.

Yardage at Chicago is 30 cents per head for cattle and 20 cents for calves. Hay is $\$ 40$ per ton. The commission charges for selling cattle at Chicago are as follows: Cattle in car lots, 70 cents per head; minimum per car $\$ 14$, maximum $\$ 18$. Calves in car lots, 30 cents per head; single-deck cars, minimum $\$ 14$, maximum $\$ 18$; double-deck cars, minimum $\$ 20$, maximum $\$ 23$. Less than 15 cattle in one car, $\$ 1$ per head. Less than 28 calves in one car, 50 cents per head.

As success in the commission business rests upon soundness of judgment, honesty, and skill, very few consignors undertake to do their own selling, but do it more profitably through the medium of the commission man. Today it is almost entirely a question of intelligence and industry in the business of cattle 
breeding and feeding. The market still fluctuates, to be sure, yet not in the violent fashion of old, and, as compared with early conditions, certainty has displaced uncertainty, giving stability and foundation to a great permanent cattle industry. 


\section{CHAPTER VI.}

\section{FASHIONS IN MARKET CATTLE.}

England and America, and other countries inhabited by English-speaking people, lead in meat consumption, especially in beef consumption. "The roast beef of old England" is well known as characteristic of the Englishman's culinary tastes, but Youatt records that in the time of Henry VIII. the English people were "strangers to beef and mutton." The consumption of beef was confined principally to the summer months, and it sold at a very low price, so that there was no encouragement toward the production of beef cattle or beef. Instead, cattle were valued for milking purposes and most of all for field labor, and not until they had served a number of years as draft animals were they fattened for the butcher. Six-year-old oxen were sold from the plow to be fattened and then brought $\$ 50$ to $\$ 75$. There is record of an ox that was worked until fifteen years old and then fattened fairly well. Those most certainly were not days when men talked of baby beef. Size, usefulness for field labor, and for dairy purposes were the qualities chiefly sought. Prior to the close of the eighteenth century, there was little exercise of care in the breeding of cattle, and feeding was an unknown art. But conditions gradually became better; England became more prosperous and wealthy, and there arose a demand for more and better beef, for which higher prices were paid. This impetus gave rise to the formation of the breeds of beef cattle, all of which originated in England and Scotland, unless we consider the Polled Shorthorn and Polled Hereford real American breed creations, which, of course, they are not, being the result of slight modifications of English breeds.

When beef production was begun in earnest, more attention was given to size and quantity than to quality. Judging from the records of early weights of cattle, and from drawings made at that time, cattle were ponderous, rough, slow-maturing beasts, and very patchy with great lumps of tallow. The ideals of those days were exemplified by such famous animals as the Durham Ox, weighing 3,024 pounds at five years of age, and The White Heifer That Traveled, weighing 2,300 pounds. These were early Shorthorns. Among early Hereford catıle, a bull, 
The General, weighed 3,640 pounds at six years. Another bull, Wellington, weighed 2,912 pounds, had a girth of 11 feet, 3 inches, and measured 11 feet, 4 inches, from muzzle to tail-head. Another Hereford bull, Hamlet, weighed 2,800 pounds, and a steer reached 2,912 pounds. At the first Smithfield Fat Stock Show held in London in 1799, a Hereford bullock described as 8 feet, 11 inches, in length, 6 feet, 7 inches, in height, and 10 feet, 4 inches, in girth, won first prize and sold for $\$ 500$. Another ox at the same show measured 7 feet in height, and 12 feet, 4 inches, in girth.

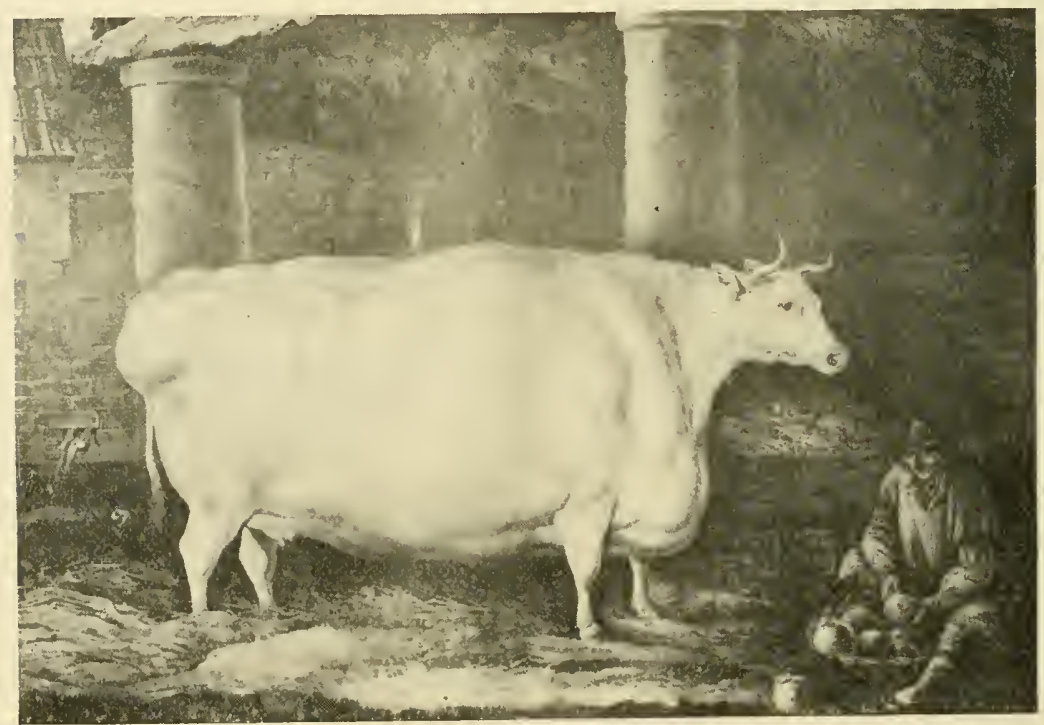

Fig. 16. Ideal of Early Beef Producers.

The noted "White Heifer That Travelled," a Shorthorn, calved about 1806, bred and fed by Robert Colling, of Barmpton, near Darlington, in the county of Durham, England. A free-martin heifer, a non-breeder, fed to a weight of 2300 pounds, completely finished, and publicly exhibited through the principal agricultural counties of England to advertise the beef-making qualities of the Shorthorn breed, particularly the herds of Charles and Robert Colling, first noted improvers of the breed. From an engraving made when she was seven years old. The artist has undoubtedly refined the head, horns, and bone to a considerable degree, yet the picture typifies in the size, massiveness, extreme fatness, and small bone of this animal the ideals of early beef producers.

In England and America the attainment of large weights continued to be the aim of beef producers until rather recent times. Early maturity was not given much attention. It was simply a matter of making each animal as large as possible 
before consigning it to the butcher. Cattle were grown and fattened cheaply in those days, and the advantages of young, quick-maturing, highly-finished cattle were not so marked, nor was a good price offered for any except matured beeves. Stockmen at Albany, N. Y., offered $\$ 1,000$ to anyone who would deliver a bullock weighing 4,000 pounds. Prior to 1856, two Illinois cattlemen fed one hundred head of high-grade Shorthorn steers and marketed them at an average weight of 1,965 pounds. About the same time, another feeder collected a lot of one hundred grade steers and fed them to the enormous average of 2,377 pounds as four-year-olds. These feats are said to have widely advertised the Shorthorn as a beef-making breed, the paramount consideration of cattle feeders at that time being the attainment of great weight and immense bulk.

Fat-stock shows are, in most respects, criterions of market demands in cattle. The champions of early days were big, matured steers. In 1891, the Chicago Fat Stock Show eliminated classes for three-year-old cattle; that date marked the turning point toward what has since become known as "baby beef." In 1918 the International Live Stock Exposition at Chicago abolished the class for two-year-old steers. The tendency is more and more toward the finishing of younger, quickermaturing animals. The changes that are being wrought are not plainly evident unless comparisons are made extending over a period of years, or unless the operations of some of the more progressive feeders have been followed during recent times.

Breeders and feeders now put much stress on quickness of maturity. This they have secured by selecting short-legged, blocky, compact animals, which type reaches maturity much more rapidly than the long-legged, more rangy type, popular in the early days. Some sacrifice has been made of size and weight in order to produce a type that will make beef quickly, yet the better breeders are careful to maintain a proper degree of size along with the low-set, blocky type of body. The change has been vastly beneficial to the breeder, feeder, butcher, and ultimate consumer.

Baby beef are choice and prime fat cattle, between 12 and 20 months of age, weighing 800 to 1000 pounds. Yearlings make 25 to 50 per cent. more meat for the grain consumed than the same animals would make if kept until two or three years of age. The small, compact carcasses cut up with less waste, and furnish thick, light steaks such as are most in demand, be- 
cause they are cheaper and of a size adapted for domestic use. Such cattle will not dress out quite as high as older cattle, but the difference in percentage yield of carcass is due to a greater amount of tallow in the older animal, which materially lessens the older animal's superiority in this regard. The production of baby beef necessitates starting the fattening process at birth and carrying it on simultaneously with growth; the animal receives full feed from start to finish. As stated by the Breeder's Gazette: "The making of baby beef is a continuous performance which shows 365 days in the ordinary year and 366 days in the

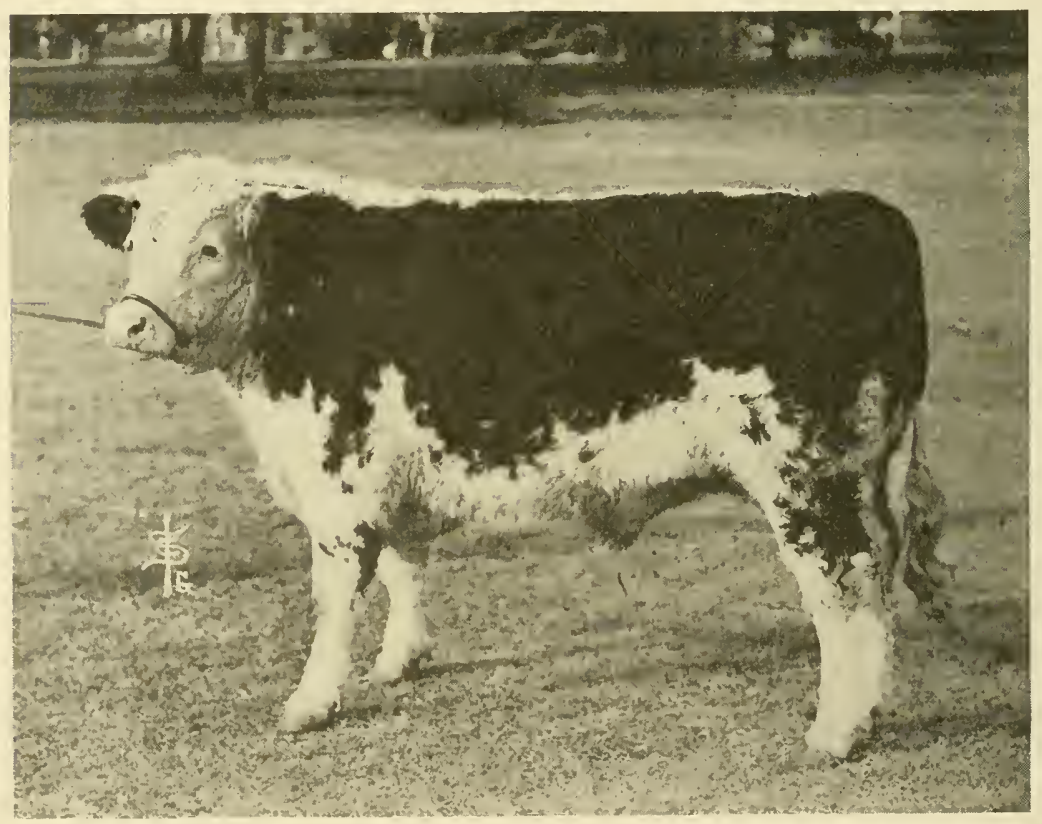

Fig. 17. Prime Baby Beef.

Hereford steer, Peerless Wilton 39th's Defender, Grand Champion at the International Live Stock Show in 1906. Bred, fed, and exhibited by Mr. F. A. Nave, Attica, Ind.

leap year. It is readily observable that there is no such thing as 'warming-up' or 'short-feeding' calves intended for the buyers of prime baby beef. Cattle may be 16 to 18 months of age and afterward warmed up a bit, but they will not class as baby beef and they will not bring the prices of that article."

Baby beef can only be produced from well-bred calves, as only well-bred ones mature early enough to meet the market 
requirements for this kind of cattle. Such calves are hard to buy and the producer of baby beef cannot feel assured of obtaining them season after season by purchase, but is practically compelled to breed them for his own use. As breeding and feeding are rather distinct lines of enterprise, and as few feeders care to maintain a breeding herd, or have facilities for doing so, baby beef production is much less followed than would be the case if good calves were readily available. Furthermore, it has been shown that only those feeders skilled in the art of finishing cattle, and fully equipped to give the animals every chance, can successfully produce baby beef.

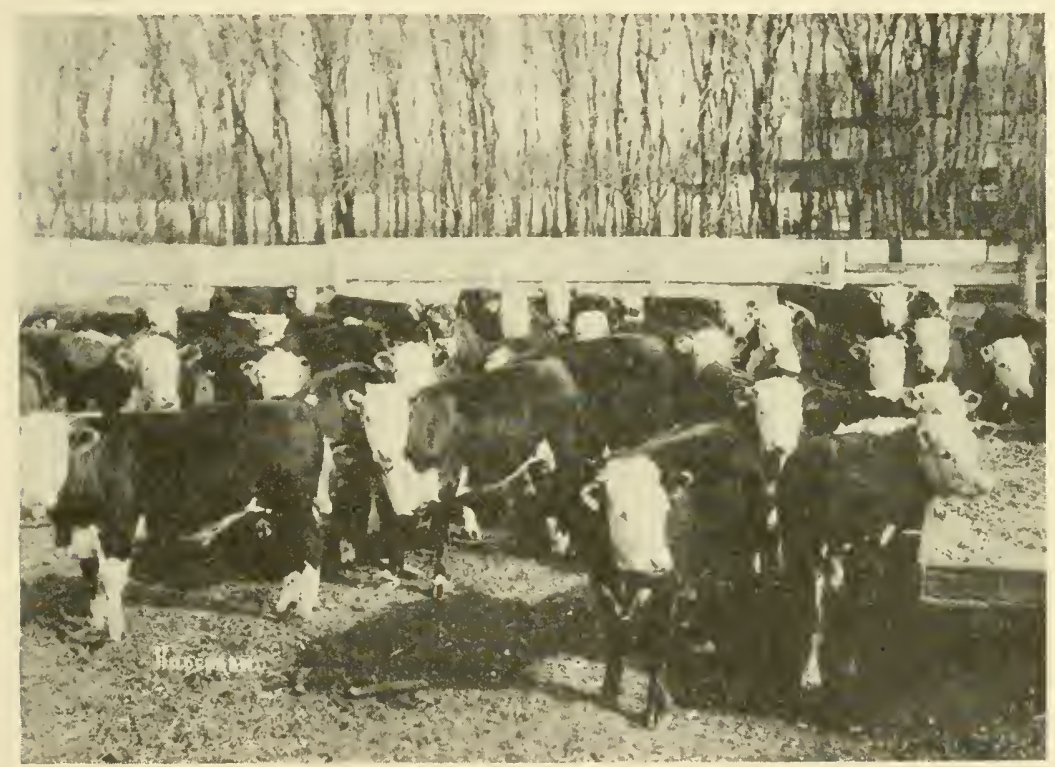

Fig. 18. Baby Beeves on Feed. ing, Ia.

Grade Hereford calves in the feed-lot of E. M. Cassady \& Sons, Whit-

As long as thin two- and three-year-old steers may be purchased for feeding, there will be no marked increases in baby beef production. The time is now at hand, however, when a large percentage of beef cattle must not only be fed on the farms of the Mississippi and Missouri valleys, but bred there also. As it is no longer profitable for the farmer to first grow a steer and then fatten him, the growing and fattening processes must 
be combined, and the cattle sent to market under 24 months of age; in other words, beef production must be placed very largely on a baby beef basis.

Clay, Robinson \& Co., of Chicago, in a communication to the writer, had the following to say concerning baby beef production: "There has been marked increase in the production of this class of cattle for the reason that the public demands them. For years the tendency has been toward the maturing of cattle at a younger and younger age. It was not so many years ago when an animal was not considered ready for the market under four years old, but evolution in beef production started, and the most desirable beeves in the market today are prime, fat yearlings."

The above quotation is good evidence of the buyer's attitude toward baby beef. As showing the possibilities for profit to the producer of such cattle, the Kansas Station fed 130 grade Shorthorn, Hereford, and Angus calves that had just been weaned, and during seven months' feeding secured an average monthly gain of 56 pounds per head. The average weight at the beginning was 408 pounds; when sent to market seven months later, the average weight was 800 pounds, and the age was a little over one year. All except 32 head were heifers. The remarkable feature of this demonstration was the small amount of feed consumed. It required only 503 pounds of grain and 509 pounds of hay to make 100 pounds gain in weight. The best record was made by 10 skim-milk calves that were fed alfalfa hay and corn. They consumed only 439 pounds of grain and 436 pounds of hay for every 100 pounds of gain. When older cattle are fed, it usually requires about twice these amounts of grain and roughage to secure 100 pounds of gain.

E. M. Cassady \& Sons, of Whiting, Iowa, made a test of the cost and rate of gains made by Hereford steers started on feed as calves and yearlings. These steers were of the same breeding, having been bred on the Cassady farm from the same sire and dams. The calves weighed 475 pounds when put on feed, and were charged at $\$ 6.00$ per cwt.; the yearlings weighed 775 pounds, and were charged at $\$ 5.70$ per cwt. Although the calves were fed for a longer period than the yearlings, the average cost of 100 pounds of gain was $\$ 10.80$ for the calves, as compared with $\$ 15.65$ for the yearlings. The calves made a profit of $\$ 20.00$ per head, and the yearlings made a profit of $\$ 14.00$. 
In three years work, including three trials, the Indiana Experiment Station found that when feed prices were such that it cost $\$ 7.74$ to produce 100 pounds of gain on baby beeves, it cost $\$ 9.09$ to make the same gain on yearlings, and $\$ 9.37$ on two-year-olds.

\section{Steer and Heifer Beef.}

The heading of this chapter, "Fashions in Market Cattle," implies that the demands of the cattle market are subject to change. The truth of this has been shown by the preceding discussion of the trend away from the old-time, heavy, matured

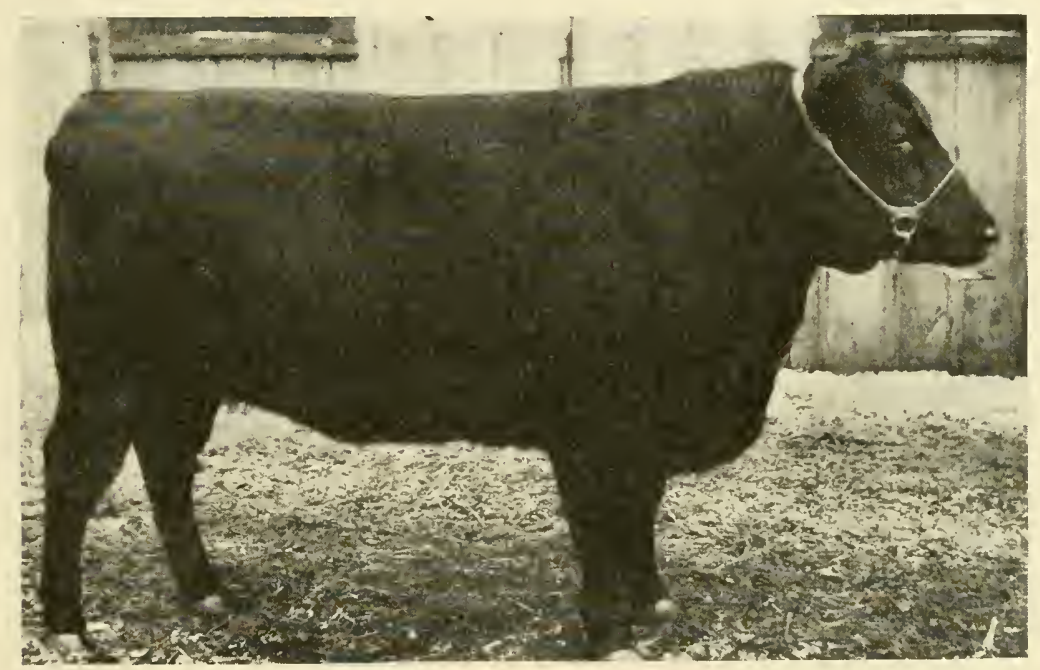

Fig. 19. Prime Fat Heifer.

beeves, and toward the finishing of younger cattle. The word, "fashions," also implies that the market indulges in some practices that are not entirely utilitarian and practical, but are more or less fanciful and whimsical. That this is true will be shown by a consideration of the cattle market's discrimination against fat heifers as compared with fat steers. When the heifer is well fed, she is consigned to a lower class than a steer of the same breeding, same fatness, same quality, same age and form. In some countries, heifers outsell steers for beef purposes. In this country there is discrimination in price against heifers on the market, and for that reason heifers are rarely as well fed as steers. 
In September, 1892, Wilson and Curtiss, of the Iowa Experiment Station,* purchased five steers and ten heifers and began an experiment to determine whether a discrimination against fat heifers is justifiable. All of these cattle were yearling grade Shorthorns, all sired by the same bull. Five of the heifers were spayed soon after purchase, and all fifteen head were roughed until January 4, 1893, when they were grain-fed for eleven months, and then shipped to Chicago. There they were sold on the open market to Swift \& Co., who made slaughter and block tests of the animals. The results of the experiment are condensed into the following table:

\begin{tabular}{|c|c|c|c|}
\hline Weights, costs, gains, prices, yields, profits. & $\begin{array}{c}\mathbf{5} \\
\text { Steers }\end{array}$ & $\begin{array}{c}5 \\
\text { Open } \\
\text { heifers }\end{array}$ & $\begin{array}{c}5 \\
\text { Spayed } \\
\text { heifers }\end{array}$ \\
\hline 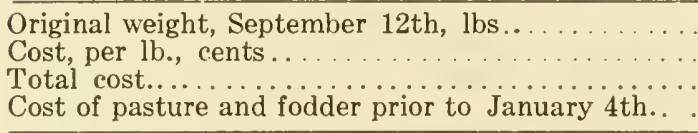 & $\begin{array}{r}4005 \\
3.5 \\
\$ 140.18 \\
20.00\end{array}$ & $\mid \begin{array}{r}3455 \\
2 \\
\$ 69.10 \\
20.00\end{array}$ & $\begin{array}{r}3998 \\
2 \\
\$ 79.96 \\
20.00\end{array}$ \\
\hline 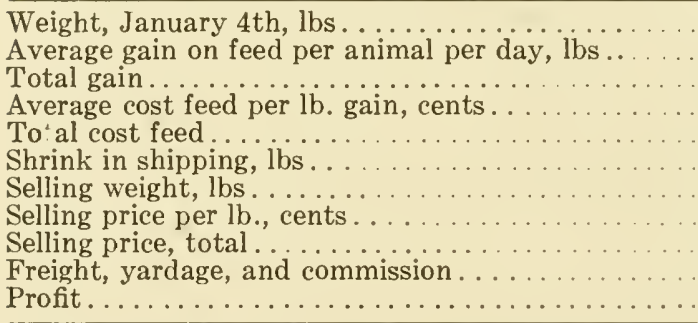 & $\begin{array}{r}4093 \\
2.44 \\
4032 . \\
5.02 \\
\$ 202.47 \\
215 \\
7910 . \\
5.75 \\
\$ 454.82 \\
24.71 \\
67.46\end{array}$ & $\mid \begin{array}{c}3592 \\
1.99 \\
3288 \\
6.04 \\
\$ 198.70 \\
290 \\
6590 \\
4.75 \\
\$ 313.02 \\
24.71 \\
.51\end{array}$ & $\begin{array}{l}3994 \\
2.07 \\
3416 \\
5.86 \\
\$ 200.32 \\
280 \\
7130 \\
4.75 \\
\$ 338.67 \\
24.71 \\
13.68\end{array}$ \\
\hline 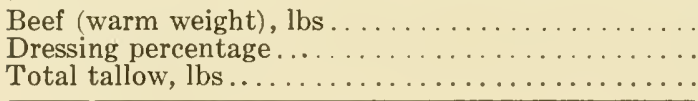 & $\begin{array}{r}4997 . \\
63.2 \\
969.5\end{array}$ & $\begin{array}{c}4110 . \\
62.4 \\
648.75\end{array}$ & $\begin{array}{r}4475 \\
702.8 \\
701.5\end{array}$ \\
\hline 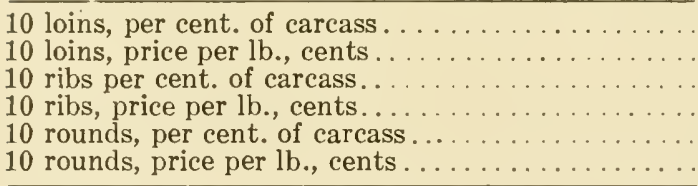 & $\begin{array}{l}16.7 \\
15 . \\
10.1 \\
15 . \\
24.1 \\
6 .\end{array}$ & $\begin{array}{l}17.6 \\
13.5 \\
10.8 \\
13.5 \\
21.5 \\
5.75\end{array}$ & $\begin{array}{l}17.7 \\
13.5 \\
10.9 \\
13.5 \\
21.7 \\
5.65\end{array}$ \\
\hline $\begin{array}{l}\text { [argin betw } \\
\text { product } \\
\text { handlin }\end{array}$ & & & \\
\hline
\end{tabular}

The returns made by the heifers to Swift \& Co. would have justified a purchase price of $\$ 5.37$ per cwt. for the spayed heifers and $\$ 5.32$ for the open heifers, instead of $\$ 4.75$ for each, and still have left the same margin of profit as in the steers. It is clear, then, that the difference in the live-weight value of the 
steers and heifers was only about 40 cents per ewt., instead of $\$ 1.00$ a cwt. made by the buyers. Expert opinions secured from Chicago packers as to why the heifer carcasses sold at less price per pound than the steer carcasses were to the effect that heifers make more fat where the steers make lean meat. There is said to be more lean meat in a steer loin and a larger tenderloin. Otherwise, the carcasses were said to be of equal value.

It is a well-known fact that Englishmen make no discriminations against heifer beef, indeed they pay more for it than for steer beef. Wilson and Curtiss corresponded with several Englishmen concerning this matter, and the substance of the replies was that heifers yield meat of finer grain and better quality, are good cutters, and yield little rough meat. Rib and loin cuts from spayed heifer carcasses were valued two cents per pound higher than the same cuts from steer carcasses equally well fattened. Plate cuts from heifers were valued one cent higher. Heifer beef was said to be better marbled, more pleasing in appearance, more juicy, and more palatable.

In 1894, the Iowa Station* conducted a second experiment with steers and spayed and open heifers. The same plan was followed as in the first experiment and the results were practically the same, thus verifying the results of the first test.

Evidently English and American standards for meats vary somewhat, and public preference has been cultivated along different lines in the two countries. So far as our American markets are concerned, it seems that the difference in prices paid for fat steers and heifers may not be justified by any real difference in the cuts of meat, yet the condition must be accepted nevertheless, and producers must shape their operations accordingly. There is, however, one logical objection to heifers; it is that they are frequently pregnant, which lowers the dressing percentage and may affect the value of the carcass. At the present time the discrimination against heifers amounts to 50 or 75 cents per cwt. for open heifers, and about 25 cents per cwt. in the case of spayed heifers. There is not as much discrimination in price against fat young heifers as against fat heifers of older age.

The question of spaying.-As the experiment just discussed dealt with spayed and open heifers, a word may be said here about the comparative merits of the two from the stand-

* Ia. Bul. 33 . 
point of the feeder. As a rule, open heifers make greater gains because of the setback caused by the operation of spaying. Once recovered from the operation, the spayed heifers gain faster, but do not reach as large weights as open heifers. The recurrence of heat in open heifers and their restlessness at that time retards the gains made, as compared with spayed heifers recovered from the operation. Spayed heifers are said to yield beef of slightly higher quality. Spaying entails a certain expense and there is danger of mortality. The general practice is not to spay when it is possible to separate the heifers and feed them in a lot by themselves. When it is desired to feed heifers along with steers, it is desirable that they be spayed, otherwise the recurrence of heat causes considerable commotion among the cattle, decreasing the gains made and increasing the cost. 


\section{CHAPTER VII.}

\section{SELECTION OF FEEDER STEERS.}

Beef producers may be divided into two groups-(1) men who grow beef, and (2) cattle feeders. In the first group are those who maintain breeding herds for the production of steers for the market. This group includes the western cattle man on the range and also the farmer who keeps a small herd of beef cows. The beef grower has a year-round job. Furthermore, he usually follows the business steadily for a period of years. The very nature of the business demands that it be established on a permanent basis. It cannot be followed one year, given up the next year, and begun again the next, with any fair expectation of profits. The second group includes those who follow the practice of buying thin cattle to be fattened. This is simply a finishing process, and is more speculative in character than that of growing beef. It may be followed intermittently, although most successful feeders are in the business regularly each year. Furthermore, in the cornbelt states, where grain feeding is practiced, it is usually limited to a few months of the year and usually to those months when other farm work is slack.

In an investigation of methods of marketing live stock and meats, made by the U. S. Department of Agriculture* in 1915, reports were received from 2072 special live-stock and price reporters of the Bureau of Crop Estimates which indicated that 74 per cent. of stockers and feeders are bought in the fall, 19 per cent. in the spring, 3 per cent. in the summer, and 4 per cent. in the winter. It was also indicated that 55 per cent. of stocker and feeder cattle purchased are bought in the district in which they are fed or grazed, 27 per cent. at the centralized markets, and 18 per cent. in the country, other than locally.

As shown in the preceding chapter, the cornbelt beef grower finds baby beef production profitable. On his high-priced land he cannot afford to raise steers to two years old or older and then fatten them. The cornbelt cattle feeder, however, is not bound by the same rules. He usually buys western steers raised on cheaper lands, and so long as thin two- and three-year-

* U. S. Dept. Agr. Report 113, p. 17. 
old steers may be bought at prices low enough to make them profitable, the feeder will continue to make use of them as well as of calves and yearlings.

Profits in cattle feeding come from skill in feeding and management, and also from intelligent buying and selling. There is practiced what is known as "speculative cattle feeding" in which feeders emphasize the buying and selling more than they do the actual feeding of the animals, the object being to buy on a low market and sell when the market is high. Omitting this speculative feature from consideration, it may be said that the sources of profit in feeding a steer are (1) the increase in

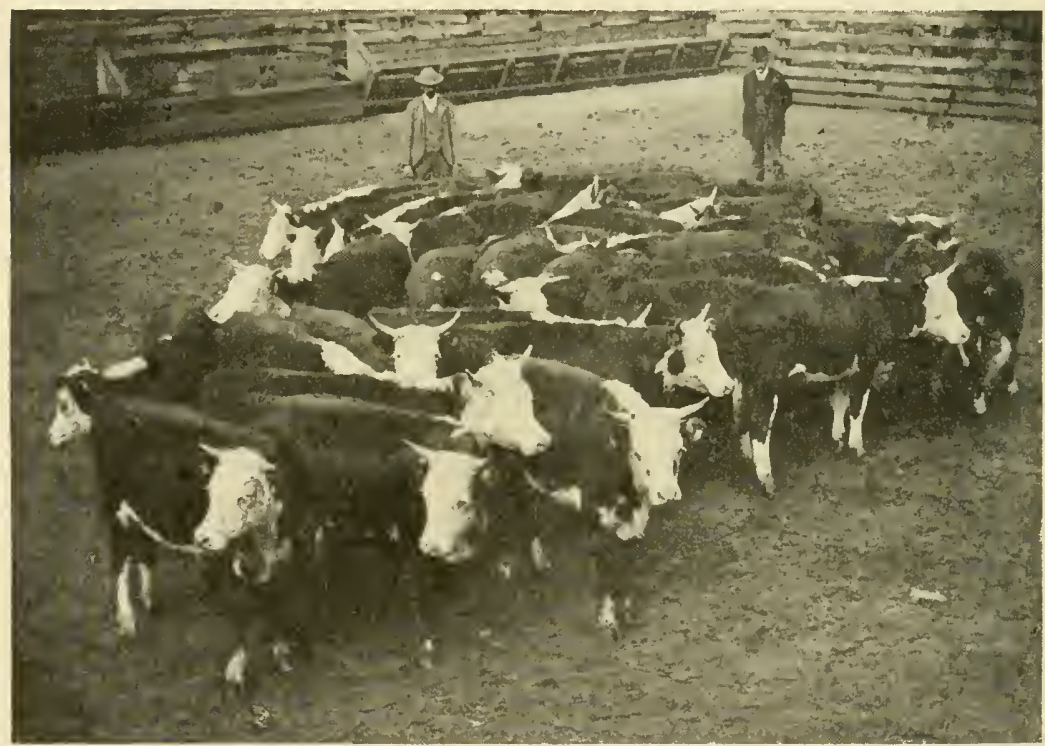

Fig. 20. Fancy Selected Feeders.

weight of the animal, and (2) the increase in the value of the animal's initial weight. For example, if we buy a thin steer at 8 cents per pound, and fatten him during four or six months feeding, we increase not only his weight, but also his value per pound. If the initial weight was 1000 pounds, and the final weight was 1325 pounds, he should sell at 10 cents per pound without any rise of the cattle market during the feeding period. Then the net income to the feeder would be as follows:

325 pounds at $10 \mathrm{c} \ldots \ldots \ldots \ldots \ldots \ldots \ldots \ldots \ldots \ldots \ldots$

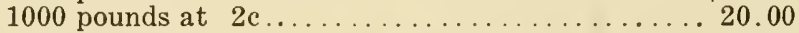

Net income. . . . . . . . . . . . . . \$52.50 
The difference between the cost price and selling price per pound is spoken of as the "margin." The steer feeder counts on at least 2 cents per pound margin, and when cattle and feedstuffs are very high in price a greater margin is necessary. As shown by the above calculation, heavy cattle may be handled on narrower margins than light ones, for if the initial weight of the steer had been 600 pounds instead of 1000 pounds, other factors remaining the same, then the net income would have been less by $\$ 8.00$. As a matter of fact, however, the younger steer would probably make his 325 pounds of gain somewhat cheaper than the older steer, thus compensating, in part at least, the advantage of the older animal.

Success in fattening cattle requires a thorough knowledge of two classes of cattle-fat steers of the better grades, and stockers and feeders, - the beginning and the end of the feeding process. The cattle feeder must be an expert judge of a thin animal, as well as a good judge of the finished product. "Well bought is half sold." Failure to select the right kind of steers for feeding is alone sufficient to cause failure in the business. The cattle feeder must have a good knowledge of the values of the various grades of feeders, and must use judgment as to whether or not to buy, and if he buys it is again a matter of judgment as to which grade of feeders may be purchased, fed, and sold with the greatest profit. The actual buying, however, is usually put in the hands of a commission firm; such firms also freely and intelligently advise the purchaser concerning the matters here discussed.

The points which determine the value of feeder steers are age and weight, form, quality, constitution and thrift, natural fleshing, condition, breeding, disposition, style, and uniformity. Each of these is briefly discussed.

1. Age and weight.-Calves and yearlings require a longer feeding period, as a rule, than two- or three-year-old steers. This is due to the fact that young animals grow while they fatten, and hence fatten more slowly than older animals. Most cattle feeders prefer two- and three-year-old steers for feeding purposes, and this is especially true where a "short feed" of from 60 to 90 days is given. For the "long feed" of 120 to 180 days or more, calves and yearlings may be satisfactory if cårefully selected and properly handled. Some feeders prefer the older steers even for the longer feed. The common practice is to buy feeders that weigh from 900 to 1000 pounds, or even heavier. 
Such steers are 18 months old, or over. A thrifty steer, well developed for his age is usually more profitable than a stunted animal.

A considerable amount of experimental work has been done to determine the relative advantages in feeding calves, yearlings, and two-year-olds at the Kansas, South Dakota, Missouri, Iowa, Illinois, and Indiana experiment stations. These experiments have been based entirely upon the finishing period or, in other words, have been planned from the standpoint of the cattle feeder rather than the grower, and the results indicate that under present conditions it is more profitable to feed twoyear-old cattle than calves. This conclusion is based upon the difficulty of securing calves of the type, breeding, and quality necessary for fattening at an early age, the greater margin between buying and selling prices, the shorter feeding period, more rapid gains, greater production of pork from hogs following the cattle, smaller proportion of grain to roughage, and broader demand for finished heavy steers.

In three different trials at the Indiana Experiment Station* the calves required 90 days and the yearlings 20 days longer feeding period than the two-year-olds, to make them prime. The average daily gain of the calves was .61 pound per head less than that of the two-year-olds and .34 pound less than that of the yearlings. The following conclusions were drawn from the Indiana experiments:

1. The initial cost per cwt. of calves is greater than that of older cattle.

2. The length of time necessary for finishing steers decreases with increased age of the cattle.

3. The rate of gain and the cost of gain increases with the increased age of the cattle.

4. The proportion of roughage to concentrates consumed increases with the increased age of the cattle.

5. The amount of gain necessary in finishing cattle of equal condition decreases as their age increases.

6. The difference in total quantity of feed necessary for finishing cattle of different ages and fed to the same marketable finish is negligible.

7. The calves made an average profit of $\$ 4.25$ per head, the yearlings $\$ 6.43$, and the two-year-olds $\$ 7.95$.

*Ind. Bul. 146. 
8. The increase in live weight necessary to make calves prime was 103 per cent.; yearlings, 54 per cent.; and two-yearolds 43.6 per cent. of their initial weights at the beginning of the feeding period.

9. The difference in cost of one hundred pounds of gain between calves and yearlings was $\$ 1.35$ in favor of the calves; between yearlings and two-year-olds, 28 cents in favor of the yearlings.

10. The experienced farmer who feeds cattle should handle older cattle in preference to calves, while the farmer who produces and finishes his own cattle may find calves profitable.

The Missouri Experiment Station* drew the following conclusions from feeding 300 cattle of various ages on heavy grain rations in connection with bluegrass pasture:

1. Two-year-old cattle make larger average daily gains than yearlings.

2. Two-year-old cattle consumed from 13 to 22 per cent. more grain per day per head than did yearlings.

3. Two-year-old cattle consumed more grain per day per thousand pounds live weight than yearlings.

4. Yearlings require less grain for each pound of gain than do two- or three-year-old cattle. Other things being equal, the younger the animal, the less grain is required to make a pound of gain. The condition of the animal at the beginning of the feeding period is an important factor, and may to a large extent counteract the influence of age in determining cheaper gains.

5 . In these investigations, the fattening of two- and threeyear-old cattle has been generally more profitable than fattening yearlings. The chief reasons are:

(a) The margin between the buying and selling price is less in the case of yearlings. The older cattle fatten in a shorter period.

(b) It is not generally advisable to try to finish the cheaper grades of yearlings. In our investigations, the quality of the yearlings has generally been higher than that of the older cattle. In spite of this fact, the financial results have seemed to favor the feeding of older cattle.

When all evidence as to the comparative merits of calves, yearlings, and older cattle for feeding purposes is summed up, the outstanding points are as follows:

* Mo. Bul. 90 . 
1. Young animals, which are fattened as they grow, make cheaper gains than older animals. This is the chief advantage of the young animal.

2. The older animals enjoy a wider margin between cost price and selling price per pound, they fatten in less time, and the cost of feed per head is practically the same as for the younger animals. These are the chief advantages of the older animal.

In the investigations which have been made by our state experiment stations, the advantages of the older animal outweighed the advantage of the younger animal, making the twoyear-olds more profitable than the yearlings or calves. Furthermore, a table of costs and prices does not fully emphasize the marked ability of the older animal to consume roughage during the fattening period. Where considerable quantities of silage, hay, or other roughage must be utilized, and this is very frequently the case, older steers are desirable. Nevertheless, in some instances and in certain years the younger animals may be preferable. For example, with higher cost of older steers, and lower price of feeds, calves may be purchased and fed at a greater profit. Another point which is frequently of practical importance is the fact that the initial cost of calves per head is much less than that of older cattle. Three or four calves may be bought for the price of one two-year-old steer, and the feed-lot may be filled at a much smaller outlay of capital. For this reason, some farmers must feed calves if they are to feed at all.

2. Form.-The form should be as nearly identical as possible with the description given for the fat steer. Allowances must, of course, be made for the absence of fat in the thin animal, for we cannot expect a thin steer to appear extremely blocky and low set. Yet even in thin condition the steer should be low set, deep, broad, compact, and balanced; such conformation insures feeding capacity and early maturity. Broad, level tops make possible a maximum development of high-priced cuts, and are indicative of superior form in the feeder. High-grade feeders have a straight top line and straight underline, the two being nearly parallel. For best results, a large feeding capacity is of very great importance. The muzzle should be broad, the barrel wide and deep, and the flanks well let down. An excessive paunch is undesirable, as it rarely disappears during fattening and shipping and will lessen the price paid for the finished steer on the market. Some degree of paunchiness may be termed 
a good fault in a feeder, but the best feeders have much depth and fullness of middle without being objectionably paunchy. The feeder should have as much smoothness as is consistent with thinness. Too great prominence of shoulder, hips, and tail-head should be avoided. There should be nothing in his form that will prevent a high degree of smoothness being secured when he is fattened. It should be remembered that the proportions of the head and neck correspond with the type of body, and in making selections of young thin cattle these are dependable indicators of the turn the form will take during development and finishing.

The head demands far more attention in the feeder than in the finished steer. We look for what is termed the "feeder's

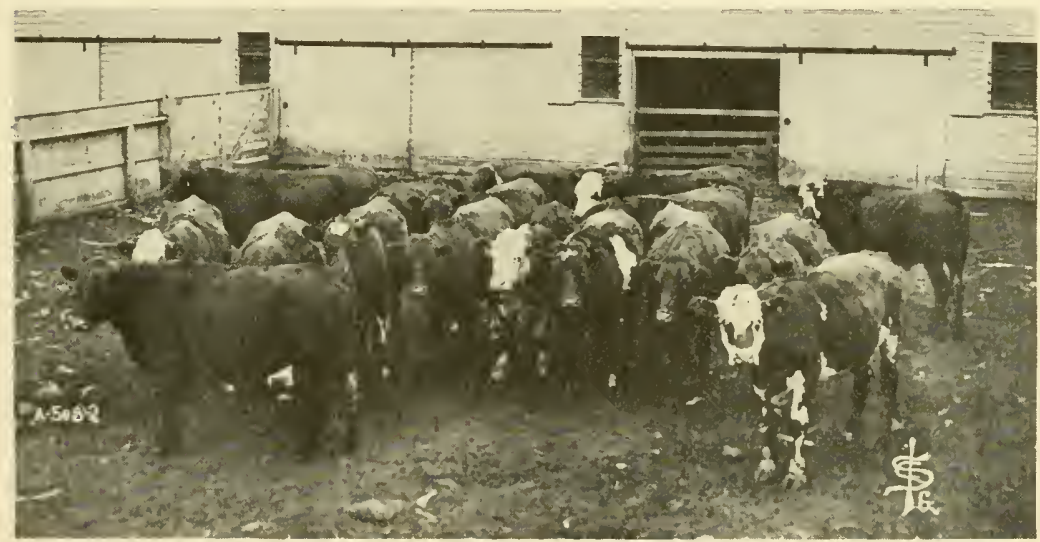

Fig. 21. An Average Load of Steers on Feed.

head," that is, a head of much width between the eyes, short and clean-cut from eyes to muzzle, very broad at the muzzle, but not coarse, large of nostril, and strongly muscled and well developed in cheeks and jaws. The eye should be large, prominent, bright, clear, and placid. Polled or dehorned cattle are preferred by feeders, although this feature does not affect the grading of the animal on the market. More hornless cattle can be put in the feed-lot or car, and they make more rapid gains on feed because of less commotion and less difficulty in getting up to the feed-racks. Hornless cattle shrink less in shipment, the carcasses show fewer bruises, and the hides are more valuable. Being in greater demand, they sell at slightly higher prices. Dehorning gives cattle a setback, causes wild- 
ness for a time, and is not advisable if cattle are to be put on feed immediately, except in the case of calves or yearlings that are to be given a long feed.

3. Quality.-The indications of quality in beef cattle have been discussed. Quality and good breeding are usually found in company, and good breeding surely "tells" in the feed-lot. Quality also insures smoothness and a higher dressing percentage, points of much importance in the eyes of the buyer of fat cattle. Coarse, staggy heads and necks indicate late castration. Stags sell at a discount on the fat steer market.

4. Constitution and thrift.-A wide, deep chest, full heartgirth, and deep, broad body are evidences of a strong constitution. Avoid that steer which has quality carried to the point of delicacy, as only vigorous, rugged cattle make big gains on feed. When choosing between two steers, one of which is too refined in head, hide, and bone, and the other a trifle too rugged, or what might be termed slightly on the coarse order, it will usually be wisest to select the more rugged steer; he will usually consume more feed, gain more consistently, and make his gains at less cost than will the over-refined animal.

A thrifty, healthy steer makes known the fact in a bright, clear eye, sleek coat of hair, and a loose, sappy hide. He is wide awake and gives evidence that he "feels good." Avoid the steer with the small, dull eye, tight hide, dry, staring coat, hanging head, and lifeless gait. Red blood and good health indicate ability to assimilate feed and make gains.

5. Natural fleshing.- This refers to lean meat or muscle. As previously pointed out, feeding does not add muscle to an animal; the muscle must be born on the steer. The cattle feeder's job is to fatten beef, and he must buy the beef or muscle when he buys his steers. Look for muscular necks, backs, loins, and rounds. Such steers bring the best prices when properly fattened.

6. Condition counts in judging feeders. The more fat a feeder steer carries, the quicker and cheaper he may be finished. Other things being equal, fleshy feeders are more desirable than very thin ones. Furthermore, if the steer is too thin he cannot class as a feeder, but instead is classed as a stocker. Stockers are thin enough to make gains in condition on grass or roughage. Feeders carry more flesh and are ready for the feed-lot. Experienced cattle men buy as much condition as possible when they buy their feeders. 
7. Breeding.-Steers of good beef breeding are much preferred over those which have more or less of a scrub or dairy ancestry. We look for evidences of beef breeding in the form, quality, fleshing, and color of the animals. The beef-bred animal is more rectangular in build, more compact and blocky, and lower set than the dairy-bred steer. The steer of beef breeding is plumper and thicker in his muscles throughout. The dairy-bred steer stands high off the ground, has a long, narrow head, cuts up in the flank, is split up in the twist, cathammed, and rough in conformation over the hips and rump. His bone is usually too fine, and his hide too thin and "papery" in texture. Coarse, rough steers, with coarse, plain heads, show lack of good ancestry. The wide, short, clean-cut head, with

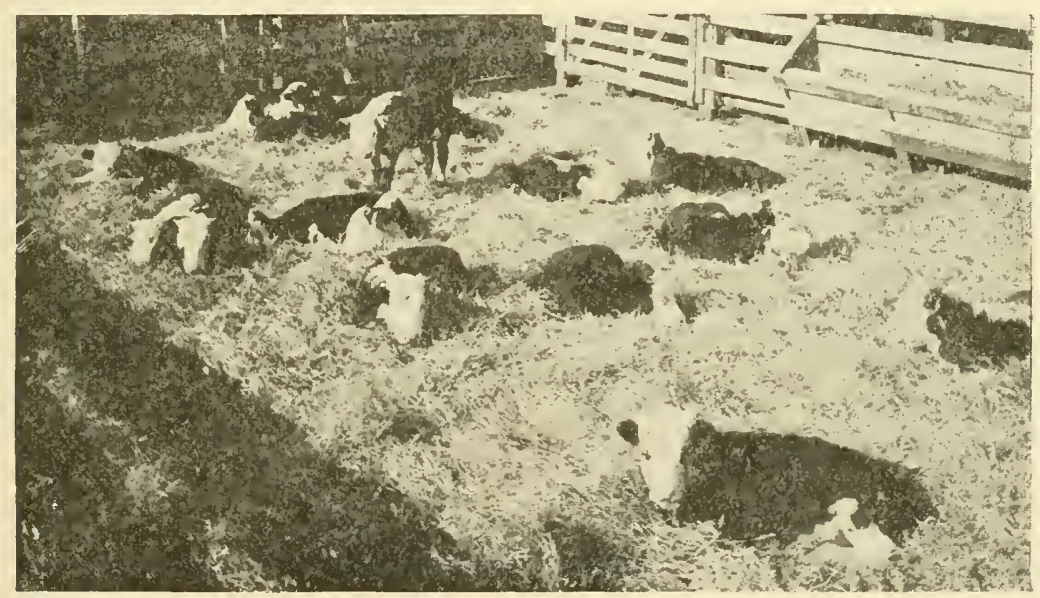

Fig. 22. Fancy Feeder Calves.

broad muzzle, good eye, and marked indications of what is often termed "character," may be accepted as one of the very best evidences not only of beef breeding, but of good beef breeding. The more one deals with feeder cattle the more one learns to study heads and to place reliance on what the head indicates as to form, quality, feeding capacity, constitution, thrift, breeding, and disposition.

The colors of the beef breeds are certainly preferred in feeder steers, but many scrub animals masquerade under these colors. Red, roan, or black are frequently found in animals carrying a very small percentage of Shorthorn, Hereford, Aberdeen-Angus, or Galloway blood. The same is true of the polled 
head of the Aberdeen-Angus, Galloway, Polled Durham, and Polled Hereford. Well-bred beef steers carry the colors of the beef breeds, but these colors do not always cover well-bred beef steers. Color alone is not a safe guide to good breeding. Color gives unmistakable evidence, however, if it is the fawn, or spotted white and fawn, of the Jersey and Guernsey, or the black and white markings of the Holstein. In such cases, color furnishes all the evidence we need as to the breeding of the animal. As to which of the beef breeds should be given preference when selecting feeders, that is almost entirely a matter of personal fancy. They are all good, and there is no best. There are differences to be sure, but none great enough to claim attention here.

8. Disposition.-Nervous, restless cattle are profit-losers on feed. In many instances, with proper handling, such steers quiet down a great deal as the feeding period progresses, but in many other instances this is not true. The eye and the carriage of the head, ears, and tail are indications of the disposition. A high-headed, wild-eyed steer, with ears in motion to catch the slightest sound, stampedes on the least provocation. The poll of the head should be carried on a line with the back, and the eyes should be placid in expression, indicating a quict, contented feeder that will make gains in proportion to the feed he consumes, instead of wasting his energy in nervousness and frightened antics.

9. Style.-A low-backed, awkward, slouching kind of a steer may feed as well and yield as good a carcass as a wideawake, straight-lined steer that stands squarely on his legs, but other things being equal the latter steer looks much better and attracts more favorable attention on the market than the former. A steer of good style shows for all he is worth. The other kind fail to make a good impression at first sight, and on a crowded market this may mean much.

10. Uniformity in size and color adds much to the attractiveness of a load of cattle, and in buying feeders this point is worthy of attention. They look better in the feed-lot, and an even load of steers attracts more attention on the market than does a mixture of all sizes, colors, and sorts.

In addition to the foregoing, other points may well be considered in selecting feeders. Avoid cattle that have cuts, sores, or lumps on them anywhere, especially those showing lumpy jaw. Avoid blind steers, lame ones, and those with crooked 
legs. Big, sprawling brands affect the value of the hide. When determining upon the price, remember to consider the amount of fill the cattle will carry to the scales. In buying at the large markets, avoid "stale" cattle, which means those that have been on the market several days and are too well filled. Watch the droppings for evidence of grain feeding, and give preference to grass-fed cattle as they are usually more thrifty and respond better to grain feeding. A steer that has had grain to put him in feeder condition may be looked on with suspicion. He may be a hard feeder and poor doer. Go to the market and accompany the commission man when he selects and buys your feeders. You will learn much from your visit to the market and the commission man will be aided by knowing exactly the kind of cattle you want.

Advantages of cattle feeding.-The reasons for fattening a steer are many and important, even though feeding does not increase the lean meat or muscle. They are as follows:

1. Feeding increases the value of the steer.

(a) Adds weight to the animal.

(b) Improves the form and appearance.

(c) Increases the dressing percentage.

(d) Covers the carcass with fat so that it may be held in the cooler long enough to ripen.

(e) The marbling expands the lean meat, making the steer thicker in all his cuts.

(f) Makes the beef more tender and juicy.

(g) Fat beef cooks much better than lean beef.

(h) Fat meat is more nutritious than lean meat.

2. Utilizes as feed much that would otherwise be waste on the farm.

3. Gives employment to labor when other farm work is slack.

4. Makes easily possible the maintenance and improvement of soil fertility.

5. Cattle feeding, properly managed, is a profitable enterprise. 


\section{MARKET CLASSES AND GRADES OF CATTLE.}

The large live-stock markets classify their receipts of cattle into various classes and grades, depending upon the quality, condition, weight, age, and sex of the animals. A market class may be defined as a group of animals on the live-stock market, all of which are suitable for a certain commercial use.

There is a clear distinction between type and market class. A type represents an ideal which the breeder or feeder is endeavoring to produce. Types represent only the most highly desirable or profitable sorts of animals, while there are market classes for all sorts of animals-profitable and unprofitable from the producer's standpoint. 'The market classification represents the practical outcome of producers' attempts to reach ideals, and a visit to any market will show that often they do not reach them. Hence, some market classes have counterparts among the types, and some have not. The latter might be termed the by-products or misfits of the breeder's art. Of these there is always a percentage, depending upon how difficult a task the producer set for hinself; the more extreme the type, the greater the percentage of misfits. Most of these misfits are useful, and some return a profit to the producer.

There will always be some market classes which return a maximum profit to the breeder and feeder, and these the breeder will try to produce by adjusting his type accordingly and selecting animals for breeding purposes which nearest approach the ideal,-in other words, typical animals. The less profitable market classes are filled incidentally, not through any design on the part of the breeder. Some market classes are composed of animals that have already served one or more purposes; having outlived their usefulness, they are discarded and sent to market. The market is accommodating; it provides a place for all sorts of odds and ends, and hunts up a use for them. Thus, some market classes persist which at first thought have no excuse for being. Everything classifies somewhere. The types are logically much fewer than the market classes.

On the large live-stock markets, cattle are handled according to the following classification: 
1. Fat steers, including all fat steers suitable for block beef.

2. Western range cattle, including all grass-fed branded cattle direct from western ranges.

3. Butcher stock, including the better grades of heifers, cows, and bulls suitable for block beef.

4. Cutters and canners, including mostly thin cows and bulls, but also inferior steers and heifers, in fact anything not suitable for feeding, and too inferior to yield a carcass suitable for block use.

5. Stockers and feeders, including thin calves, yearlings, two-year-olds, and older cattle. It may include steers, heifers, cows, or bulls.

6. Veal calves, including all grades of veal calves.

7. Milkers and springers.-These are cattle of dairy breeding which are usually more valuable for milking purposes than for beef. They are sorted out and sold for dairy purposes.

\section{Fat Steers.}

The fat steer class represents the cream of the market, including only those steers which show the effects of good feeding. In this class condition and quality are of more importance than weight. The demand comes from two classes of buyers: (1) Packers for dressed beef slaughtered in Chicago, and (2) eastern buyers who ship fcr slaughter to Boston, New York, Philadelphia, Pittsburg, Baltimore, Cleveland, Albany, Detroit, and many other cities. The cattle which classify as fat steers may be divided into five grades. A grade is a division of a market class or sub-class, the division depending upon value. The grades of fat steers are: (1) Prime, (2) choice, (3) good, (4) medium, and (5) common. Each market class is divided up into various grades. For example, we speak of "prime steers," "medium steers," "good cows," "common canners," "choice feeders," etc. Fat steers dress from 55 to 67 per cent. and supply the highest class of trade.

Prime steers. - This is the most select grade of the fat steer class. Buyers for eastern markets take most of this grade, and packers take the rest. Prime steers are practically above criticism in form, quality, and fatness. They show a high development of flesh in loin, back, thighs, twist, and rump, are very broad and deep, and are free from paunchiness. The head is medium-sized and clean-cut. The bone is clean and 
fine, the skin pliable and medium thick, and the outlines are smooth and well rounded. The flesh is abundant in all parts, and is firm, yet mellow and springy to the touch. There are no ties, rolls, or patches of flabby fat, but a smooth, even, deep, firm fleshing everywhere. Prime steers weighing from 1200 to 1400 pounds are in greatest demand, although they may weigh up to 1600 pounds. Very few steers come to market which grade as prime. At the conclusion of the International Live Stock Exposition, which is held at the Union Stock Yards in December, most of the fat steers are sold, and these are usually prime, but it requires much searching to locate cattle of this sort at other periods of the year.

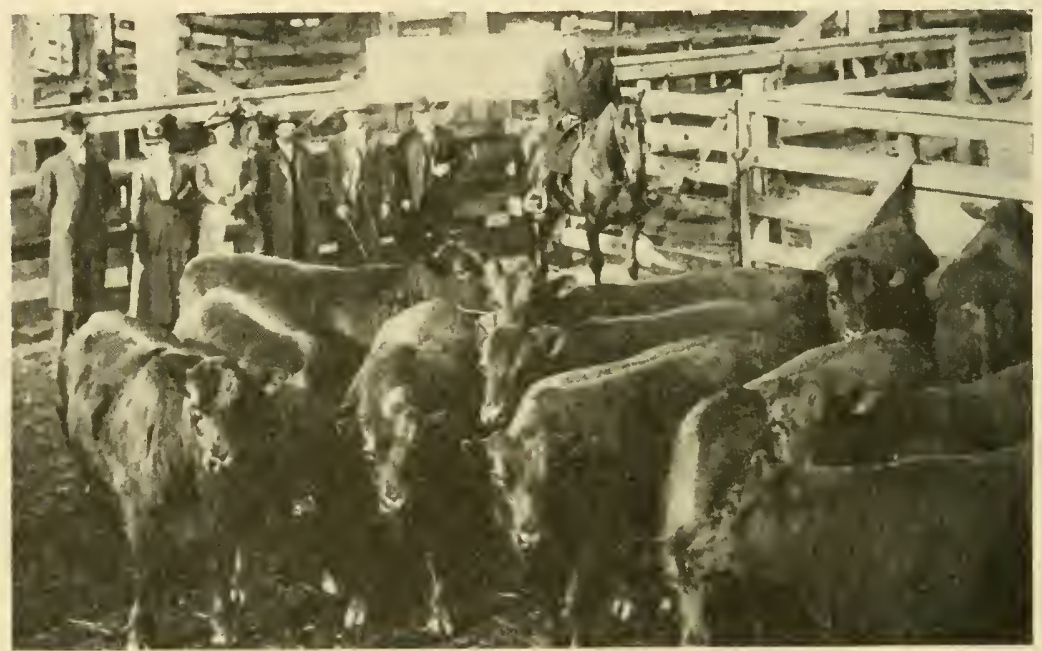

Fig. 23. Prime Fat Steers.

Choice steers.- If a steer is not quite right in quality or condition, but still possesses to a marked degree the characteristics most sought by packers and shippers, he is called a choice steer.

Good steers.-Good fat steers may be of very good quality, but noticeably lacking in condition or finish; they may be finished or in prime condition, yet lacking in quality; or they may be noticeably deficient in both quality and condition, but still good enough to be above the average grade of fat cattle reaching the market. By far the largest number of steers belonging to the good grade may be said to be a little on the coarse order; they are fat and of good weight, but rather plain. 
Medium steers. - These are of about average quality and condition, lacking to a marked degree the finish and quality demanded in a prime steer. They are generally too paunchy and too lacking in condition and quality to dress a high percentage of beef or show a good proportion of fat. The beef from such steers is not good enough to meet the demands of dealers in beef of the best quality, nor is the proportion of the high-priced cuts large.

Common rough steers. - This is the lowest grade of steers coming to the market. They are very much lacking in form,

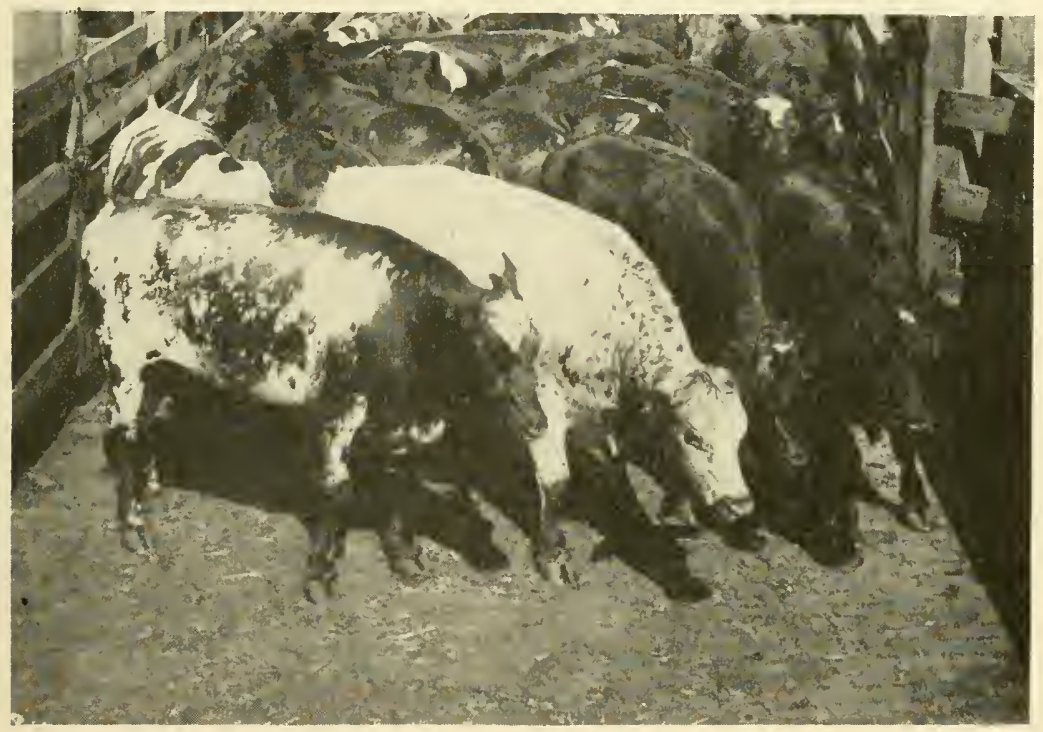

Fig. 24. Choice Fat Steers.

quality, and condition. Steers of good quality that are not fat enough to be classed as beef steers are classed among the better grades of stockers and feeders; therefore, this grade includes only those steers which are too thin to sell among the higher grades of beef cattle, and too coarse and rough to be sold as stockers and feeders.

Heifers. - Two to four heifers mixed in with a load of fat steers may be passed without any cut in price if they are similar to the steers in all respects except sex. However, this class is a fat-steer proposition, and market reports always give separate quotations for fat steers and fat heifers. 
Sub-class baby beef.- Choice and prime fat steers between 12 and 20 months of age and weighing from 800 to 1000 pounds are styled "baby beef" or "fat yearlings" upon the market. These are not separated from the fat steer class, but constitute a sub-class within it. As pointed out in the preceding chapter, the fat yearling is becoming the most prominent feature of the cattle market. Beginning in 1904, fat yearlings have steadily increased in numbers, this increase having been most marked during the past few years. Most market reports now give separate quotations for this sub-class.

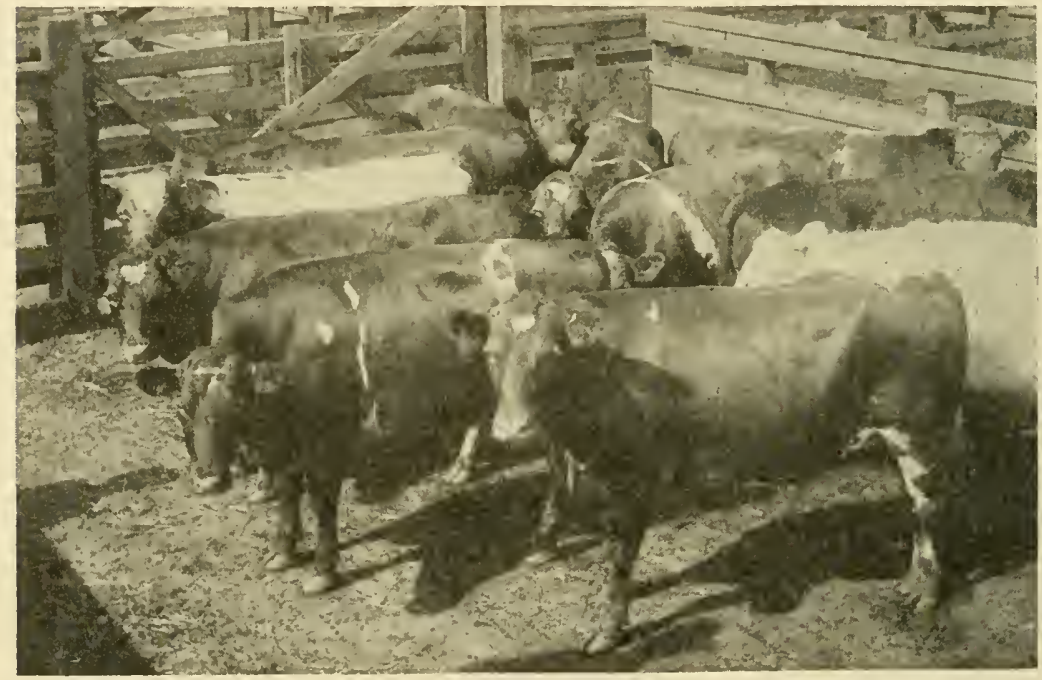

Fig. 25. Good Fat Steers.

Source of the fat steer class.-Cattle which classify as fat steers come from the feed-lots of the cornbelt states. They are steers which have been grain-fed. The class includes steers that were bred and raised in the cornbelt, known as "native" steers, and also branded steers bred and raised on western ranges and then taken to cornbelt farms to be fattened. The latter are sometimes called "fed Westerns."

\section{Western Range Cattle.}

Not so many years ago, western cattle were distinguished by very long horns, long legs, thin flesh, narrow bodies, and large, deep brands. This type was known as the "Texas long- 
horn." So many purebred beef bulls have been taken to the ranges, however, that today the long-horned Texan is rarely seen. Western cattle now carry a high percentage of the blood of the improved beef breeds, and the heads are either naturally polled or have short or medium-length horns. Many prizewinning bulls have been bought by western cattlemen and turned loose upon the range, and today range cattle usually have the low-set, blocky form and flesh-making qualities of their sires. There were no cattle in America prior to its discovery; the old-fashioned Texas and western cattle undoubtedly sprang from animals which escaped from the hands of early Spanish explorers or were left behind when they were forced to make a retreat.

The best western cattle are used for the same purposes as

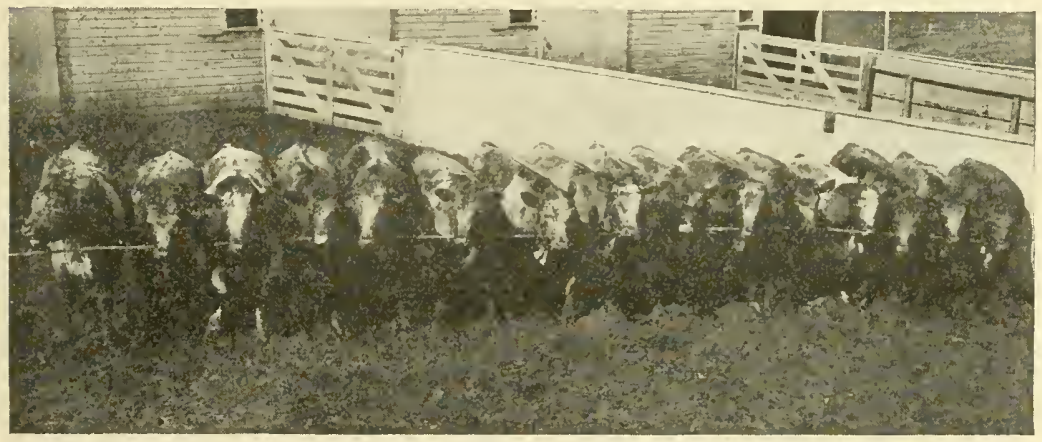

Fig. 26. Prime Baby Beeves.

These are representatives of the famous "blue-grays" so popular in the British markets. They were sired by a Shorthorn bull, and their dams were Galloway cows.

the best native cattle, but being largely grass-fed, they are more subject to shrink during shipping. All Texas and western range cattle are branded, and are sometimes spoken of as "branded cattle." As a rule, branded cattle sell at a discount because of the damage to the hide. In cases of brands on the body, the damage to the hide is estimated anywhere from five to fifteen cents per cwt., according to size and location, and in extreme cases where there is a big, sprawling side brand, covering a large part of the surface, the discount will be very much higher, as it practically spoils half the hide.

The range country furnishes grass from the middle of July until the middle of November, and cattle coming to market 
from the grass of western ranges are known upon the market as "grass westerns." When grass gives out on western ranges, the cattle are sent to market. Texas cattle begin to appear in May and make a heavy run from that time until October, while other branded cattle from the West make a heavy run from August 1 to December 1. During the five months from November until May, very few such cattle reach Chicago.

\section{Butcher Stock.}

Butcher stock and cutters and canners may be looked upon as by-products of the cattle-feeding industry. Butcher stock has the same relation to the fat steer class which skim milk

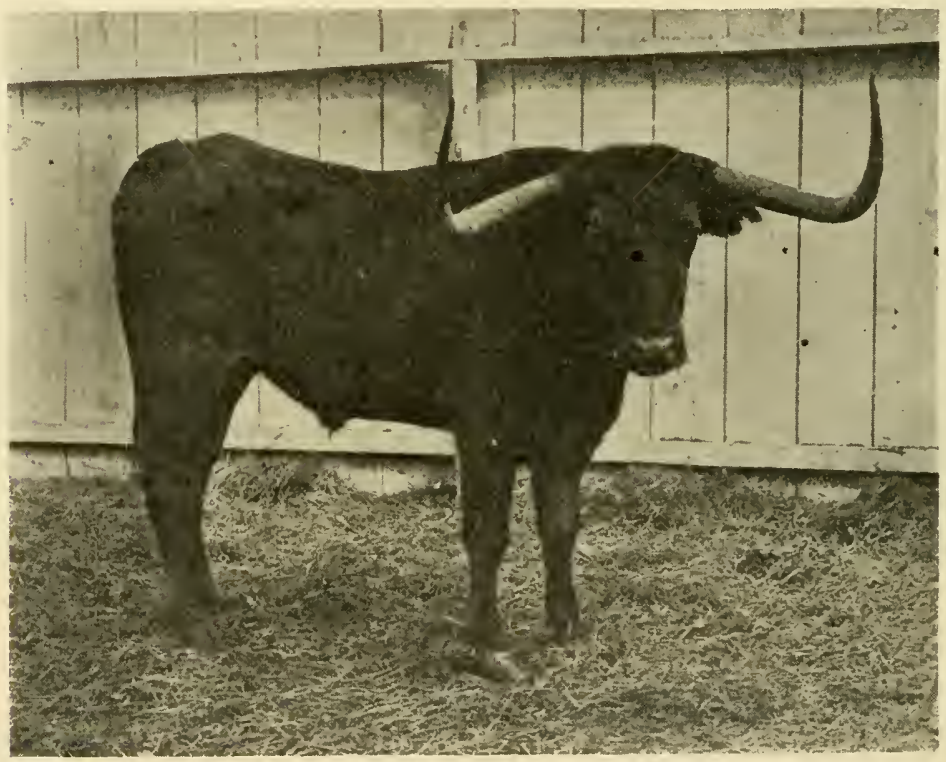

Fig. 27. Old-Time Texas Long-Horn.

Formerly a prominent feature on the large cattle markets.

has to cream. The bulk of butcher stock is made up of fat cows, heifers, and bulls. They dress out from 50 to 61 per cent. and the carcasses are used to supply the trade in small towns, and the medium class of trade in cities. The grades within this class are: Prime, choice, good, and medium heifers; prime, choice, good, and medium cows; and choice, good, and medium bulls. 
Heifers.-The same conformation, quality, and condition are demanded in prime heifers that have already been noted as characteristic of prime steers. The only noteworthy difference is that of sex. (See Fig. 19.) Choice, good, and medium heifers are similar to steers of the same grades.

Cows.-The prime grade includes a very small number of strictly fancy, well-bred cows, in prime condition. Choice cows are prime in condition, but are somewhat deficient in quality. Good cows lack in both condition and quality, but are fat enough to be reasonably good killers. Medium cows

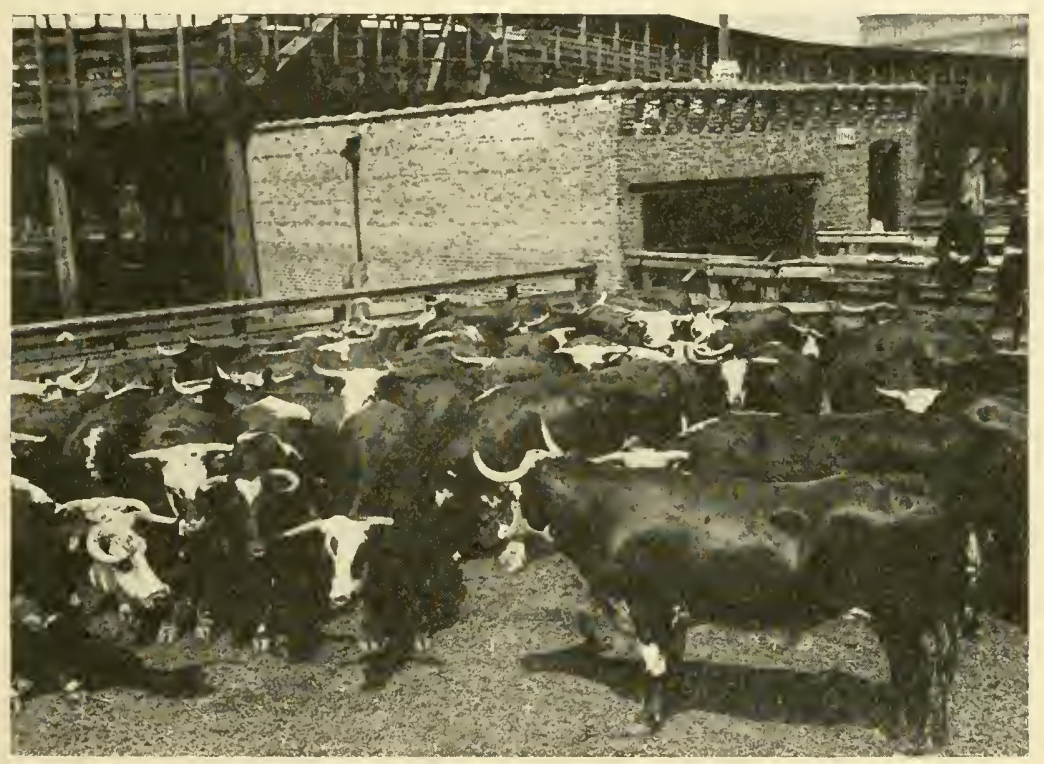

Fig. 28. Modern Western Range Cattle.

These cattle were sired by purebred bulls and were fattened on grass. In the background appears a scales-house where cattle are weighed to the buyer when sold.

are poor in form, low in condition, and deficient in quality. This is the lowest grade suitable for block beef.

Bulls and stags.- There are very few choice bulls; the supply is made up of good beef bulls which have become too aged for further use as breeders. Bulls of the good grade lack in quality and condition. Medium bulls are thin, long legged, and coarse, and are just good enough to escape bologna or the tin can. Very few stags come to market. They are classed and graded the same as bulls. 


\section{Cutters and Canners.}

Cutters carry sufficient flesh to permit of the loin or rib, or both, being used for block purposes, the remainder of the carcass being canned. The cutter and canner class is made up mostly of old thin cows that are very paunchy, indicating a high percentage of offal when dressed. Many of them are cast-off dairy cows which are sent to market without any attempt being made to fatten them. They dress from 35 to 55 per cent. The lowest grade of canners furnishes a sort of comic supplement

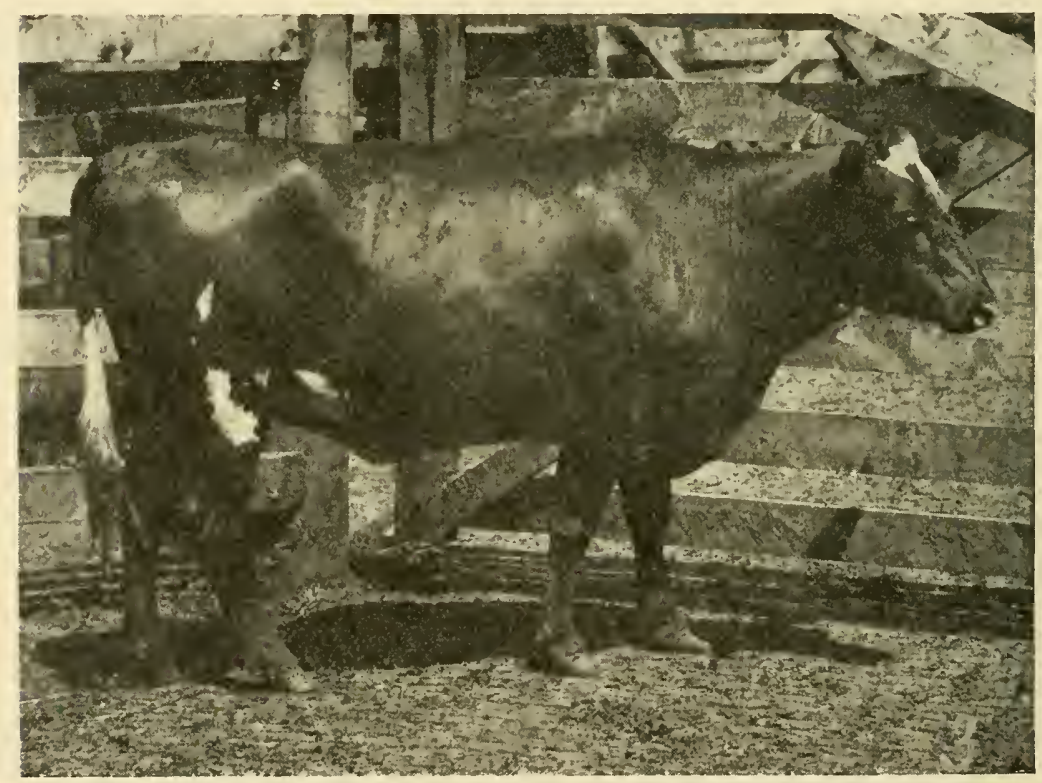

Fig. 29. Good to Choice Heifer.

to a cattle market; marketmen refer to them as "Dairy Maids," "Nellies," "Hat Racks," "Skins," "Dogs," and "Sea Horses," thus showing their lack of appreciation for such cattle.

Canners include thin cows, inferior steers, heifers, bulls, and stags, and in fact anything of a very low, inferior grade that is too lacking in flesh to permit of even a part of the carcass being sold over the butcher's block. They are also too old and unthrifty, and of such inferior type and breeding as to render them unfit for the stocker and feeder trade. They are the very lowest grade of cattle coming to market. 
The grades within the cutter and canner class are good, medium, and common cutters; good, medium, and common canners; and bologna bulls.

\section{Stockers and Feeders.}

Stockers and feeders include calves, yearlings, two-year-olds, and older cattle. The difference between a stocker and a feeder is that the stocker is usually a younger and thinner steer or heifer, used mostly for grazing purposes and possibly fed out after being grazed for a time, while a feeder is usually a steer, older and in higher flesh than the stocker, and suitable for placing

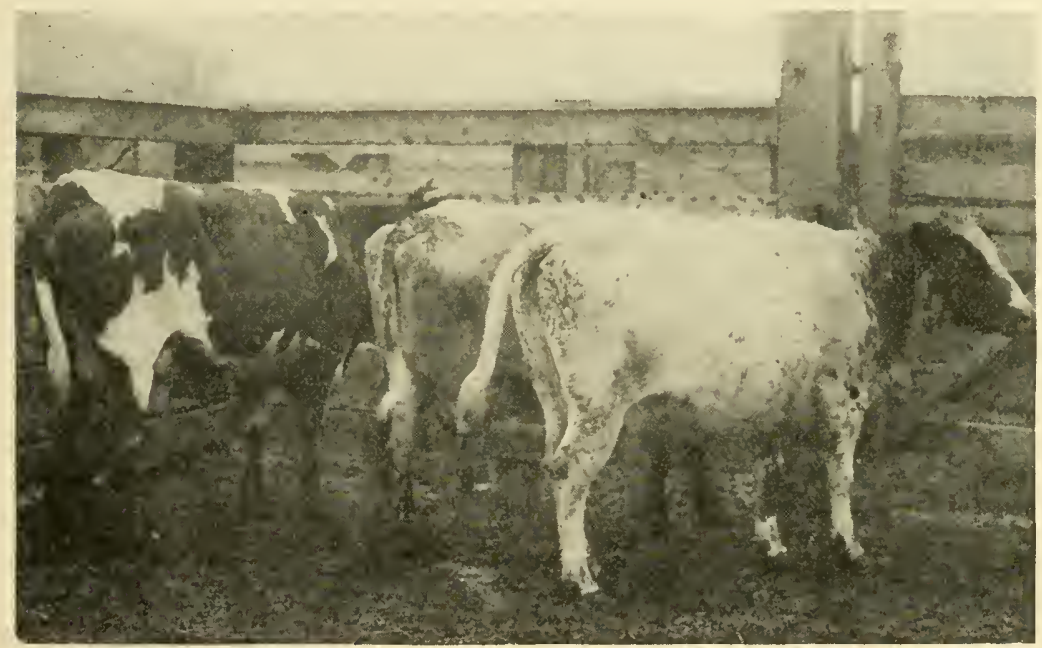

Fig. 30. Good Cutters.

in the feed-lot immediately and feeding upon a grain ration. Heifers are not commonly classed as feeders. The grades of stockers and feeders are: Fancy selected, choice, good, medium, and common feeders; feeder bulls; fancy selected, choice, good, medium, and common yearling stockers; good, medium, and common stock heifers, and stock and feeding cows.

Fancy selected feeders.-Very few of the fancy grade reach the market, as breeders fortunate enough to own thin steers of such quality usually hold them until finished as prime steers, or sell them direct to neighboring feeders at good strong prices. Fancy selected feeders must be uniform in size, type, and color, and show unmistakable signs of good breeding. They 
are practically above criticism, possessing in a high degree the form, quality, constitution, fleshing, and disposition of an ideal feeder as described in Chapter VII.

Choice feeders.--Steers of this grade will, under proper management, develop into choice and prime fat steers. They possess the ability to make economical gains in flesh. Choice feeders compared to fancy selected feeders are somewhat deficient in some one point, such as form, quality, or uniformity, or they are slightly deficient in several points. They must show evidence of good breeding, and everything considered they are excellent cattle for feeding purposes. Most of the best feeder steers on the market grade as "choice" rather than as "fancy selected."

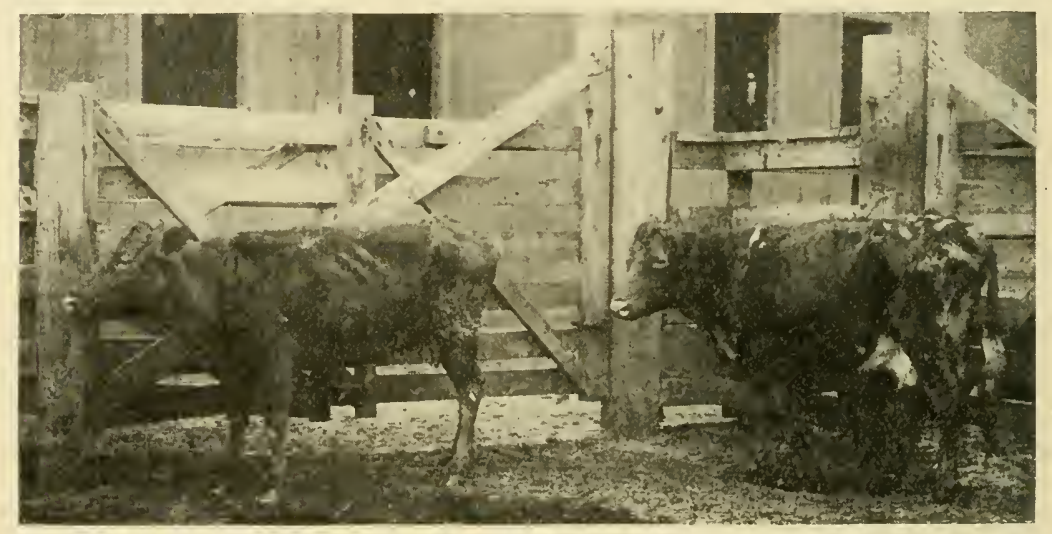

Fig. 31. Common or Inferior Canners.

Good feeders.-These possess in less degree the qualities which characterize choice and fancy selected feeders. They are not so thrifty, have not as good conformations, and carry a smaller precentage of good breeding. They are easily criticized, for they are too long of leg, too narrow across the back, and either too fine or too heavy in bone. Good feeders will finish into good fat steers, or perhaps may make the choice graile.

Medium feeders.-These are very much lacking in form, quality, and constitution, and very seldom grade higher than medium when fattened. Many of them are off-colored and spotted and bear little promise of accomplishing anything noteworthy on feed. Marketmen refer to such cattle as "doggy."

Common feeders. - These are common in quality, conformation, and condition. It seldom pay's to feed them. Dairytype steers classify here. 
Feeder bulls.-These are young bulls of good beef type. Both the supply and the demand are limited.

Stockers.-Thin yearling steers are not in much demand as feeders so long as the supply of two-year-olds is large enough to satisfy feeder demands. The yearlings are mostly available for stocker purposes and are quoted in market reports as "yearling stockers." They are such cattle as will, after a summer on grass and wood wintering, be suitable to put on grain feed. Most of the stocker trade, however, is in heifers which when sent to the country are used for grazing and for breeding pur-

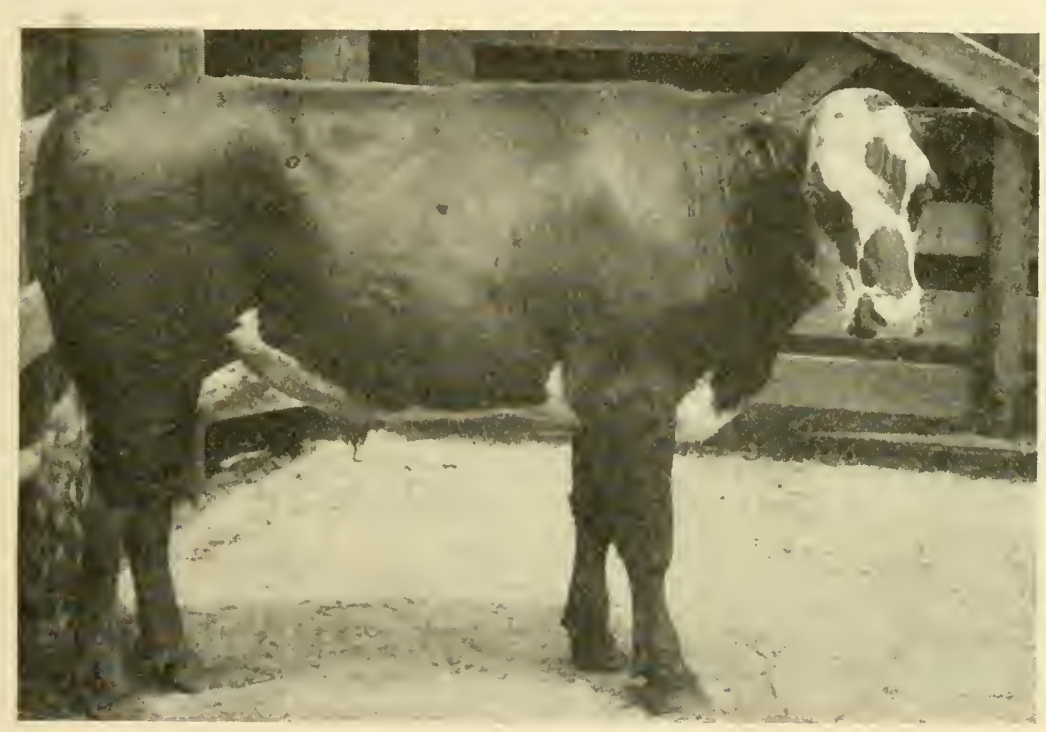

Fig. 32. Choice Feeder.

poses. The better ones have considerable beef blood and good square frames. They are too thin to classify as butcher stock, and are too good in form and quality to sell at the low prices paid for cutters and canners. Stockers are graded on the same basis as feeders.

Stock and feeding cows.-A rather common practice is to buy thin cows showing evidences of beef breeding, turn them on pasture and breed them, rough them through the winter, and the next season, after their calves are weaned, fatten them off for market, retaining the calves for feeding purposes. Such cows are called stock and feeding cows. 


\section{Veal Calves.}

Veal calves are a by-product of the dairy industry. Most of them are of dairy type and breeding, and are not profitable to raise for beef. The veal calves annually slaughtered in the United States are nearly half as many as the cattle slaughtered for beef, but their dressed weight is only one-tenth of the dressed weight of the cattle. Veal calves are dressed with the skin on, and a well-fattened veal dresses from 65 to 70 per cent. The desired type is a blocky, sleek, smooth calf, with comparatively small head. The neck should be thick, the brisket full, ribs well covered, loin wide, flanks full, rump plump and meaty,

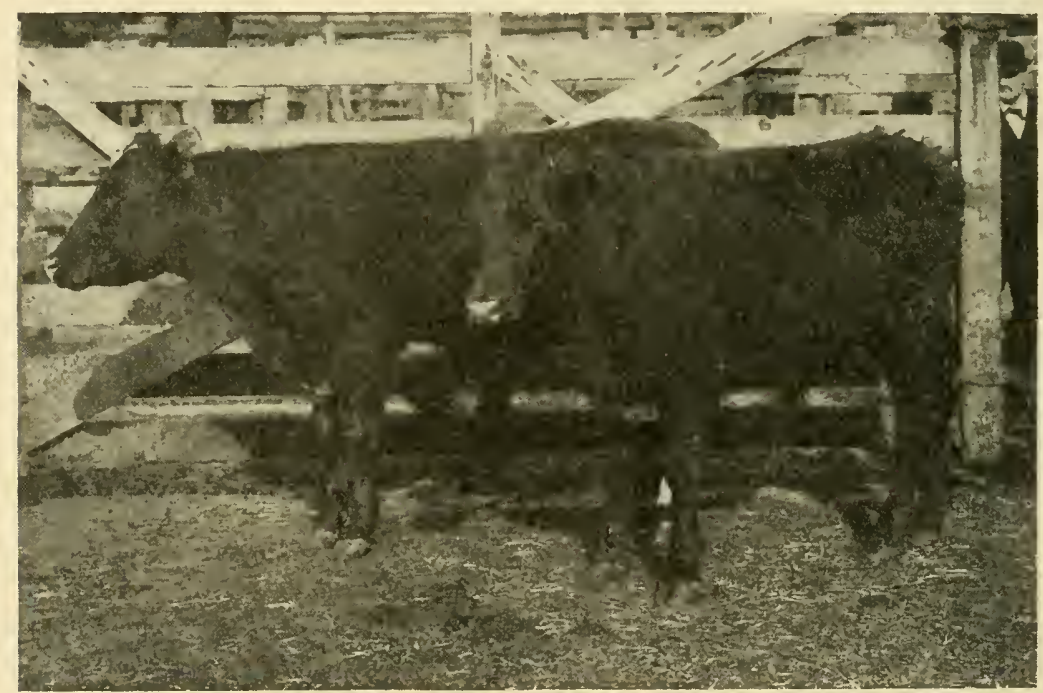

Fig. 33. Good Feeders.

thighs plump, and scrotum or udder full. The skin should be sleek, mellow, and easily lifted.

The most important factors determining the value of a veal calf are age, condition, and weight. Weight is not so important as age and flesh. To command the highest price, a young calf should carry high finish, weigh from 140 to 160 pounds, and be about eight weeks old. A strictly fat calf of 150 pounds at seven weeks of age is the sort that tops the market. Veal calves range in weight from 80 to 450 pounds, and in age from 5 to 20 weeks. The grades are choice, good, medium, and common. Following are the requirements of the various grades as to fatness, weight, and age: 
Choice... . . . well fatted .. . . . 120-160 lbs...............6-8 weeks Good........ fat...........110-200 lbs ..............6-10 weeks Medium .....medium fat. ....100-240 lbs............5-12 weeks Common.....thin........ $80-450 \mathrm{lbs} \ldots \ldots \ldots \ldots$ wide range

\section{Milkers and Springers.}

These are cows and heifers of dairy type and breeding which are sorted out of the run of cattle at the market and sold to dairymen. They are sold by the head, whereas all other classes of cattle are sold by the hundredweight. The only difference between a milker and a springer is that the former is in milk while the latter is heavy in calf and will freshen soon.

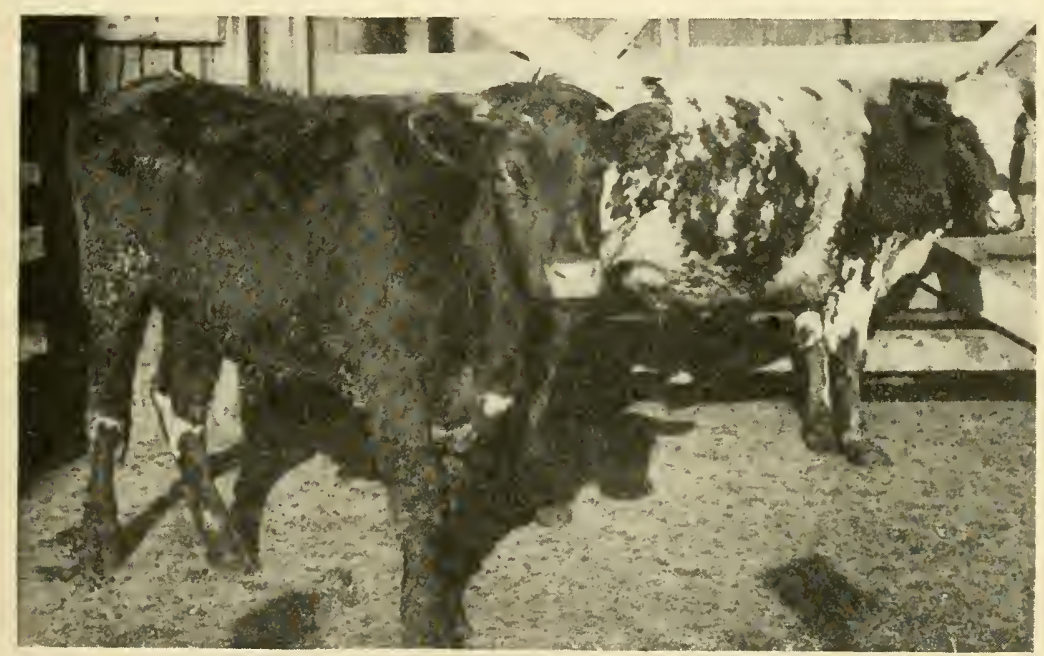

Fig. 34. Medium Feeders.

The springer gives evidence in her type, color, and mammary development that she will be a useful milk cow after calving. The value of this class of cattle depends partly on their age, and this is determined from the teeth.

How are cattle classed and graded?-Persons who are not familiar with the large markets sometimes ask by what method the thousands of cattle arriving daily at the yards are divided up into the various classes and grades. To reply that cattle are classified according to the use made of them, while true, is not a satisfactory answer, for another question then arises as to who or what decides how they shall be used. It may be said that the class and grade of any particular animal or carload of animals on the market will be finally determined by the com- 
petition on that day's market and by the price paid; in other words, supply and demand largely determine the limits of each class. For example, certain steers received at the market are of a type and carry a degree of fleshing which place them at about the dividing line between stockers and feeders on the one hand and fat steers on the other. The class these steers will make will depend on who will bid the highest for them. If there is a big run of feeders that day and not many fat steers, the fat cattle buyers will probably bid higher for them than anyone else, and so they go as fat steers. If the fat steer market is dull and the feeder market active, they will in all probability be sold as feeders.

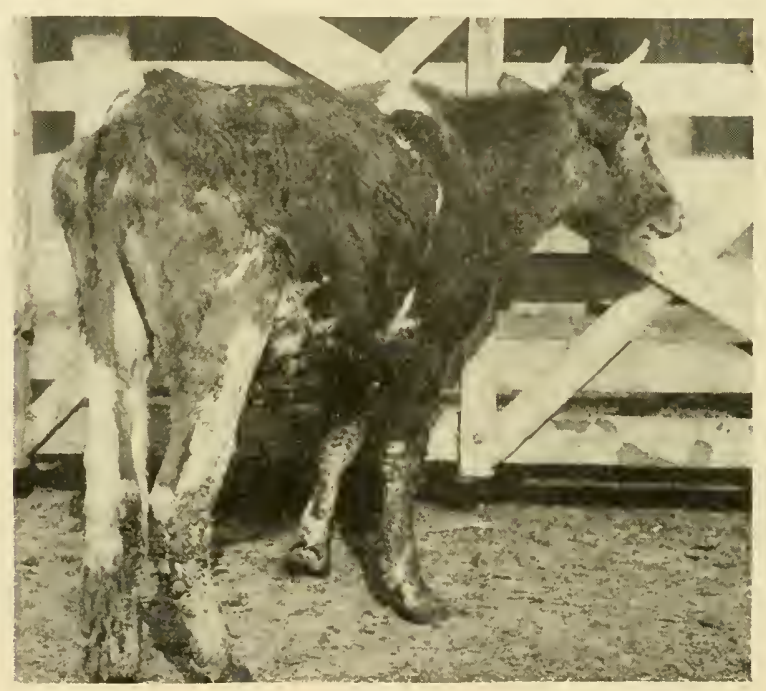

Fig. 35. Common or Inferior Feeder.

There is the same indefinite line of division between the poorest grade of butcher cows and the best grade of cutters. The former shade off by degrees into the latter. Cows may sell one day as butcher cows that would sell the next day as cutters, depending on the fluctuations in supply and demand. It is again impossible to fix absolutely the line of division between cutters and canners. One merges with the other. Likewise stockers and feeders cannot be sharply separated. Butcher bulls and bologna bulls furnish still another example. It is possible that an animal might be almost equally eligible to three classes. For instance, a heifer of a certain type and degree of 
flesh might at some seasons of the year, class among the poorest butcher heifers, the best cutters, or as a stock heifer, with the chances of each about even on an average market. Such a case is not decided until the animal is sold. If a buyer of butcher stuff bids the most, she will be used that way. If the cutter buyer for the packer gets her, she is a cutter. If she is bought by a commission firm for a farmer, she is a stock heifer. She will sell to the highest bidder on that day's market.

Commodities such as hardware, dry goods, metals, and many other articles may be bought and sold in large quantities without examining the articles because they are standardized so that the buyer knows exactly what he will get. Even the

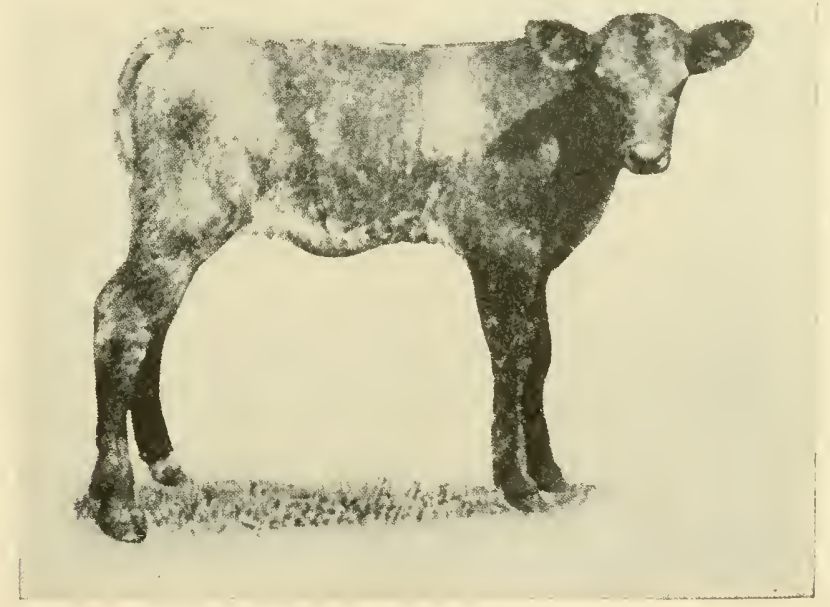

Fig. 36. Choice Veal Calf.

grain market has been standardized. But not so the live-stock market. So many factors enter into consideration in determining the value of an animal, and these factors vary so much, that live stock must be bought and sold in the presence of the parties concerned in the transaction, or their agents. The men engaged in buying and selling on any market differ considerably in their opinions as to the exact requirements of the various classes and especially of the various grades in each class. They usually agree very closely on the price, yet one prominent buyer may call a certain fat steer a typical "choice" steer, and another equally well-qualified buyer may call him a typical "good" steer. This difference of opinion is largely explained by the fact that 
they are accustomed to express values in terms of dollars and cents rather than in the grade names used in reporting the markets in the newspapers. There is no close agreement on the exact application of these terms. Even the reporters for the papers are not themselves agreed on the application of many terms they use.

Between one market and another there are still other differences in the application of terms. The best fat steers of a certain market will be quoted as prime steers in the daily reports of that market as given in the newspapers, yet these same steers on some other large market where a better class of cattle are regularly received would never be called better than choice steers. Admittedly there is opportunity for, and need of, greater uniformity in the use and meaning of market terms, yet the market classifications as they now exist at various markets, with all their inaccuracies and lack of uniformity, serve a valuable purpose. They furnish at least some sort of a "handle" to the market. Without them it would be next to impossible to report the markets to country stock buyers, stockmen, and farmers. For example, the term "canner cow" has come to have a pretty generally accepted meaning. So has "fat steer," "veal calf," "feeder steer," and many other class names, but the requirements of the various grades within each class are far from being definitely agreed upon by various individuals, and various markets.

\section{Cattle Prices at Chicago.}

Chicago prices during 1918. - The average price for fat steers on the Chicago market* during 1918 at $\$ 14.65$ stood as a new record in that market. Butcher stock reached a new record average at $\$ 9.50$, and the same was true of grass western steers at $\$ 14.40$, cutters and canners at $\$ 7.25$, veal calves at $\$ 15.75$, and stockers and feeders at $\$ 10.25$. The lowest and highest prices paid at Chicago for the various classes of cattle in 1918 were as follows: Fat steers, $\$ 9.00-\$ 20.50$; western range steers, $\$ 7.25-\$ 18.50$; western cows and heifers, $\$ 4.85$ $\$ 14.50$; fat native cows and heifers, $\$ 5.50-\$ 18.00$; native bulls, $\$ 5.50-\$ 16.00$; cutters and canners, $\$ 3.50-\$ 8.35$; stockers and feeders, $\$ 5.50-\$ 14.50$; and veal calves, $\$ 4.25-\$ 19.75$.

\footnotetext{
* Year Book of Figures, 1919.
} 
Market values of the various classes. - In determining the comparative market values of the various market classes, averages for one year are not sufficient as a basis for comparison. The following table gives the yearly average prices at Chicago for the several market classes from 1909 to 1918, and also the averages for the entire ten-year period:

\begin{tabular}{|c|c|c|c|c|c|c|c|c|c|c|c|c|}
\hline \multirow[b]{2}{*}{ Year } & \multicolumn{6}{|c|}{ Fat Steers } & \multicolumn{2}{|c|}{ West'n Range } & \multirow{2}{*}{ 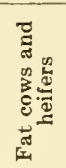 } & \multirow[b]{2}{*}{ 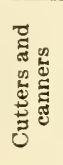 } & \multirow{2}{*}{ 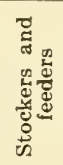 } & \\
\hline & 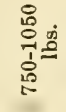 & 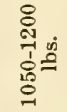 & 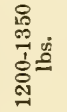 & 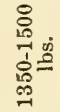 & 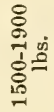 & 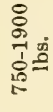 & 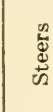 & 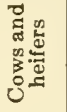 & & & & \\
\hline
\end{tabular}

$1909|\$ 5.40| \$ 0.90 \$ 6.30|\$ 6.90 \$ 7.30| \$ 6.3 \mathrm{E}|\$ 5.25 \$ 4.10 \$ 4.2 \xi \$ 2.75 \$ 4.50| \$ 7.10$ \begin{tabular}{l|l|l|l|l|l|l|l|l|l|l|l|l|l}
1910 & 5.90 & 6.40 & 6.95 & 7.35 & 7.70 & 6.80 & 5.40 & 4.20 & $4.6 C$ & 3.10 & 4.85 & 8.10
\end{tabular} $\begin{array}{lllllllllllllllll}1911 & 5.65 & 6.00 & 6.50 & 6.75 & 7.00 & 6.40 & 6.65 & 5.00 & 4.35 & 2.85 & 4.75 & 7.60\end{array}$

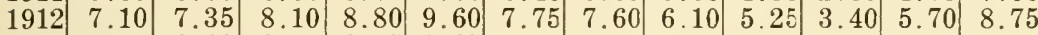

$\begin{array}{llllllllllllllll}1913 & 8.00 & 8.10 & 8.30 & 8.65 & 8.85 & 8.25 & 7.40 & 6.05 & 6.10 & 4.25 & 7.05 & 10.10\end{array}$

\begin{tabular}{llllll|l|l|l|l|l|l|l|l}
1914 & 8.10 & 8.30 & 8.70 & 8.95 & 9.75 & 8.65 & 7.65 & 6.40 & 6.55 & 4.60 & 7.35 & 9.90
\end{tabular}

\begin{tabular}{llllll|l|l|l|l|l|l|l}
1915 & 7.70 & 8.05 & 8.55 & 8.75 & 9.25 & 8.40 & 7.75 & 6.00 & 6.10 & 4.25 & $*$ & $*$ \\
& 10.15
\end{tabular}

\begin{tabular}{ll|l|l|l|l|l|l|l|l|l|l|l|l|l}
1916 & 8.45 & 8.85 & 9.40 & 10.25 & 10.75 & 9.50 & 8.40 & 6.25 & 6.75 & 4.80 & 7.20 & 10.85
\end{tabular}

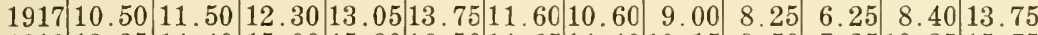

\begin{tabular}{l|l|l|l|l|l|l|l|l|l|l|l|l|l|l}
1918 & 13.25 & 14.40 & 15.00 & 15.90 & 16.50 & 14.65 & 14.40 & 10.15 & 9.50 & 7.25 & 10.25 & 15.75
\end{tabular}

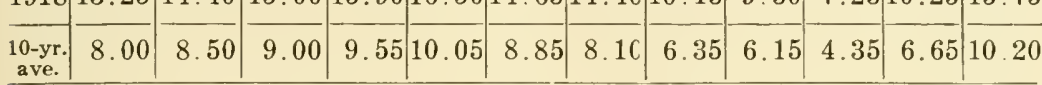

* No outlet, due to outbreak of foot-and-mouth disease and quarantine of the yards.

From the standpoint of averages, it will be observed that the price of a fat steer bears a constant relation to his weight, the heavier the steer, the higher the price per cwt. This is due to the fact that as a steer becomes older he fattens more easily; and in dealing with groups of very large numbers of fat steers of different weights, all factors determining value are equalized except the factor of fatness. Between the average prices of 900-pound and 1,125-pound fat steers, there is a difference of 50 cents per cwt.; between 1,125-pound and 1,275-pound steers, the difference is also 50 cents; between 1,275 and 1,425 pounds, it is 55 cents; and between 1,425 and 1600 pounds, it is 50 cents. The sum of all these differences is $\$ 2.05$, which is the difference between the average prices of the lightest and heaviest groups of fat steers. All fat steers together sell 75 cents higher than western range steers, and $\$ 2.70$ higher than butcher stock. Between stockers and feeders and fat steers, there exists a margin of $\$ 2.20$ based on the Chicago figures. Butcher stock sell $\$ 1.80$ higher than cutters and canners. Veal calves bring the highest price of any class, exceeding the price of fat steers by $\$ 1.35$. 
Highest and lowest monthly prices.-It is true of Chicago and of the six leading cattle markets that beef steers are usually highest in price in late August or early September. They are usually lowest about the last of January or first of February. The fewest receipts occur in April and the most in October.

Highest prices for stockers and feeders are made in April and May, which mark the opening of the pasture season. Lowest prices occur in October, November, December, and January, January being the lowest. The movement of stockers and feeders is greatest in October, November, September, December, and August, and smallest in May.

Fat cows and heifers sell highest in May, and lowest in December and January.

Cutter and canner prices exhibit no marked high and low spots, and the high points in prices are the most irregular in occurrence of any class of cattle.

Largest receipts of veal calves arrive from March to May. Highest prices are made in September and lowest prices in April. One reason for the low price in April is that a large majority of spring calves are too small to yield high-class veal. 


\section{CHAPTER IX.}

\section{BREEDING FOR THE MARKET.}

There were $67,866,000$ eattle on farms in the United States in 1919. Of this number, $23,467,000$ were dairy cattle and the remaining 44,399,000 were reported as "other cattle." The average value of dairy cows was given as $\$ 78.24$, and of "other cattle," \$44.16. The leading states in numbers of cattle other than dairy animals on farms were as follows:
1. Texas............. $3,961,000$
6. California .
$1,650,000$
2. Nebraska ..........2,940,000
3. Iowa ................. 2,861,000
4. Kansas . . . . . . . . 2, 2401,000
5. Missouri . . . . . . 1,782,000
7. Minnesota . ........1,632,000
8. South Dakota .......1,496,000
9. Oklahoma.......... 1,444,000
10. Wisconsin ........1,436,000

The distribution by geographical divisions was as follows:

North Atlantic.

$2,337,000$

$3,390,000$

South Atlantic

$5,414,000$

North Central, East of Mississippi River

North Central, West of Mississippi River

$13,724,000$

South Central

$9,518,000$

Far Western

$10,016,000$

Total United States

$44,399,000$

In the United States the cattle slaughtered in 1910 were 42 per cent. of the stock of cows on hand. The slaughtered calves as related to the stock of cows on hand were 20.3 per cent. For cattle and calf slaughter combined, the ratio to the number of cows was 62.3 per cent. An average of 249 pounds of beef, including veal, was produced during the year per head of stock cows. If veal is excluded, the ratio of beef to stock of cows was 228 pounds. The veal production was 21 pounds per stock cow.

Market cattle are bred on the farms of the East and Central West, and also upon the large ranches of the West and Southwest. A national shortage of beef cattle, together with a world shortage, has served to elevate beef prices, and the breeding of beef cattle for the market has become increasingly attractive both in the cornbelt and on the range. The first live-stock census was taken in 1840 , at which time the number of cattle, excluding calves, to each inhabitant was .88 of an animal. It was .81 of an animal in $1860, .72$ in $1880, .82$ in $1890, .89$ in 1900 , and .71 in 1910. By the use of better and better animals for 
breeding purposes, however, the average value of all our domestic animals has been constantly increased, so that loss in numbers has been partially equalized by increase in quality.

In partial explanation of the decline of beef cattle in this country since 1900 , it may be said that, in the cornbelt, cattle breeding has largely changed to cattle feeding since thirty years ago. Range and ranch began to supply feeders cheaper than they could be raised on the farm. But limitations to the production of feeders began to appear. In the West, decline in production of feeders was caused by the enforcement of the nofence law on the public land, by homesteading, and by dry farming, while in the cornbelt the raising of steers for feeding declined because of increase in dairying; increased cost of stockers and feeders, and in neglect to feed roughage.

As the supply of feeders from western ranges and ranches is certain to become more and more limited, there never was a better time for the cornbelt farmer to engage in the business of beef production; the time is ripe for the man who wants to breed as well as feed cattle for the market.

In Iowa during 1911-1912, 24 farms produced 816 calves and fed them out as baby beeves at a profit of $\$ 7.00$ per head. The cost of keeping the cow a year, the cost of feeds at full market prices, and the interest on the investment were all figured in. In 1912-1913, 36 farms bred, fed, and sold 983 calves at an average weight of 876 pounds. The average age of these calves was 16 months. They sold at $\$ 8.60$ per cwt., or $\$ 75.30$ per head. The cost per head was $\$ 59.20$; this left a profit of $\$ 16.10$ per head. A comparison of crop yields during five years on ten beef cattle farms in ten counties in Iowa, and on ten grain farms in the same neighborhoods showed that the cattle farms averaged $14 \mathrm{bu}$. more corn per acre, $7 \mathrm{bu}$. more oats, and 1 ton more hay. Baby beef production has the following advantages: 1 . There is money in the business at present and prospective prices. 2. It pays better than average market prices for farm crops. 3. It makes use of rough lands otherwise wasted. 4. It helps to maintain soil fertility. 5. Helps solve the labor problem.

When breeding for beef, the producer must use good cattle of the beef type. Attention must be given to the selection of both the cows and the bulls, and an effort must be made to breed for market what the market wants and will pay for in amount sufficient to return a profit. In some years, feeders of cattle find it more profitable to buy rather a low grade of 
cattle for feeding purposes, although as a general rule, it pays best to feed high-class cattle that will sell at the top of the market, or near the top, when finished. Breeders of cattle are confronted with no such problem as to what to aim for in breeding; they should always try to breed the best. Breeding herds are not so easily or quickly changed to suit fluctuations in market demands as are cattle in the feeder's hands; hence, breeders abide by the general rule that greatest returns come from the production of the highest grade of cattle.

When the object of the breeder is to produce calves to be fed for the market, the cows in the herd are purebred only in rare instances. Purebred cattle are not so numerous as to permit their widespread use, and it is impracticable to advise that purebred cows shall constitute the common herds of the country, nor would it be possible to bring about that condition for many years to come. By all means, however, the cows in such herds should be high grades of some one of the beef breeds.

At this point some definition of terms is necessary. A purebred animal is a member of some breed, and is registered or eligible to registry in the herd book of that breed. Second, it is an animal possessing a distinctive and useful type. Third, it is descended from a long line of ancestors specially selected by the men who founded and developed that breed, these ancestors being of the same type as itself, which fact explains why the animal may be termed a purebred. Fourth, being backed up by an ancestry of useful animals like itself, it has the power to reproduce this useful type in its offspring, this power or ability being called prepotency. As it is a rule of breeding that what goes into an animal from its ancestors will come out in its offspring, we at once realize the purebred's power for good when used as a breeder. The terms "full blood" and "thoroughbred" are often erroneously used in place of the word purebred.

A cross-bred animal is one whose sire and dam were both purebred, but belonged to different breeds. A cross between a Shorthorn bull and a Hereford cow, for example, produces a cross-bred calf.

A scrub animal is one that bears no evidence of good breeding-one without any purebred ancestors, or, at most, very few and very distant ones. Its ancestors were a miscellaneous lot, of all shapes, sizes, colors, and sorts, few if any of which were useful animals. Hence, scrub animals are usually of indeterminate type and little value. 
When a scrub female is mated with a purebred male, the offspring is called a grade. If this grade animal is in turn mated with a purebred of the same breed as its own purebred parent, or with one of some other breed, the result will still be a grade. When three or more crosses have been made upon a scrub foundation by sires from the same breed, the resulting offspring will possess 87.5 per cent. or more of purebred ancestry and may be referred to as high grades.

Returning to the point under discussion, cows in market beef breeding herds should be high grades, preferably with all the purebred ancestors members of the same breed. From this breed also, a purebred bull should be selected to mate with the cows, thus insuring a uniform lot of calves for feeding. The herd bull should be selected with great care. It is often said that the "bull is half the herd," and some one has added the equally true statement that "an inferior bull is all of the herd." In breeding all kinds of farm live stock we expect the offspring to be better than the dam, and we rely upon the sire to bring about this improvement. In breeding beef cattle for the market, it is well to have good cows, but it is an absolute essential to have a good bull. We pin our hopes on him. He must be a good individual, he must be purebred, and he should come from a good line of ancestry. These three points are guarantees as to his breeding ability. No progress whatever will be made by using other than a purebred bull and continuing in the same breed when future herd-headers are selected. The grading-up process must be continued, and where this has been done through a number of generations, herds will be found that are, for all intents and purposes, purebred so far as production for the market is concerned.

One of the most notable exampies of the value of purebred bulls as herd improvers is that afforded by the history of cattle breeding on western ranges. Beginning with the old Texas long-horn stock which formed the foundation of range herds, successive crosses of purebred sires brought remarkable improvement in the beef-making qualities of western cattle. (See Figs. 27 and 28 in preceding chapter.)

As to what price the breeder is justified in paying for a bull, that will vary depending upon the conditions. Some very satisfactory bulls have been bought at very moderate prices. In grading up western range cattle, high-priced, prize-winning bulls have been purchased in a number of instances and the 
bull turned out on the range as his pedigree burned in the office stove. If a full quota of cows is at hand for breeding, not less than $\$ 150$ should be invested in a bull, and more often it will be advisable to pay $\$ 200, \$ 250$, or more, rather than $\$ 150$. A small increase in the value per head of one season's crop of calves by the use of the higher-priced bull, as compared with the cheap one, will return the difference in the price of the two animals. Furthermore, when the heifer calves by the higher-priced sire are gone over with a view to keeping out certain ones for use in the breeding herd, there will result a herd of higher average merit than otherwise, and improvement thereafter will be doubly fast. The man who sees no further than first cost when purchasing a bull is surely doomed to failure. As to which breed of beef cattle to use for market production, that is a matter to be decided somewhat by the conditions, but it is largely a matter of personal preference. Each breed has its own special advantages, and there is no best breed of beef cattle.

The following table* gives the averages by states of answers made by western stockmen in 1915 to the questions indicated by the headings of the various columns in the table. This table furnishes ample proof of the fact that the average value of the live stock of a community is in direct proportion to the value of the sires used. "A stream can rise no higher than its source."

\begin{tabular}{|c|c|c|c|c|c|}
\hline \multirow[t]{2}{*}{ State } & \multirow{2}{*}{$\begin{array}{c}\text { Average } \\
\text { no. of bulls } \\
\text { per } 100 \text { cows }\end{array}$} & \multirow{2}{*}{$\begin{array}{c}\text { Average } \\
\text { value } \\
\text { of bulls }\end{array}$} & \multirow{2}{*}{$\begin{array}{c}\text { Average } \\
\text { no. of calves } \\
\text { per } 100 \text { cows }\end{array}$} & \multicolumn{2}{|c|}{$\begin{array}{l}\text { Average weight of } \\
\text { steers sold from } \\
\text { range or pasture }\end{array}$} \\
\hline & & & & $\begin{array}{l}\text { Long } 2-y r \\
\text { old }\end{array}$ & $\begin{array}{l}\text { Long 3-yr.- } \\
\text { old }\end{array}$ \\
\hline Ariz. & 6.00 & $\$ 82.00$ & 57.00 & 774.0 & 935.0 \\
\hline Cal. & 3.73 & 94.75 & 73.55 & 968.2 & 1141.6 \\
\hline Col. & 4.16 & 131.90 & 69.30 & 883.0 & 1084.5 \\
\hline Idaho & 4.00 & 100.00 & 75.00 & 1000.0 & 1200.0 \\
\hline Mont. & 3.44 & 138.00 & 75.80 & 991.0 & 1211.0 \\
\hline Nev.. & 4.00 & 93.00 & 70.00 & 940.0 & 1140.0 \\
\hline N. M & 5.00 & 83.00 & 66.00 & 725.0 & 934.0 \\
\hline Ore & 4.04 & 113.35 & 75.74 & 975.7 & 1186.0 \\
\hline Ut: & 4.00 & 93.00 & 69.00 & 900.0 & 1085.0 \\
\hline Wash. & 3.72 & 124.15 & 79.48 & 1032.0 & 1225.0 \\
\hline Wyo. & 5.52 & 160.50 & 73.20 & 937.0 & 1155.0 \\
\hline
\end{tabular}

Arizona and New Mexico use the most bulls and the cheapest bulls. These states are credited with the fewest calves and the steers produced are markedly inferior in weight at two and

* Compiled from U. S. Dept. Agr. Report 110, by W. C. Barnes and J. T. Jardine. 
three years of age. Such factors as climate, feed supply, and method of management affect the character and value of cattle produced on the range, yet the predominating factor, as shown by the above table, is that of good breeding. Those states rank highest which use the best breeding stock. The importance of good breeding is again shown by the fact that in Arizona and New Mexico the more progressive stockmen have spent large sums in purchasing good bulls and this has resulted in a decided improvement in the grade of stock on the public ranges in those states within the last few years. On the other hand, many of the smaller men either turn out scrubs or else have no bulls at all, and this keeps down the averages.

The producer of feeding cattle secures his bulls from breeders who maintain herds of purebred and registered beef cattle. These are the sources of all that is good in beef cattle, their function being to produce sires to be used to grade up the common cattle of the country. Hence a knowledge of market requirements is very essential to the breeder of pedigreed beef cattle, for he is engaged, indirectly, but most certainly, in the production of cattle for the open market. The breeder of registered cattle who ignores the requirements of the open market will never be able to build up an active demand for his stock, because the mere fact that an animal is purebred and registered does not suffice. Buyers usually insist that a thoroughly useful animal shall accompany the pedigree, and the inferior animal, no matter how glowing his family history, does not receive serious attention or approval.

Fancy, purebred, registered beef cows and bulls frequently sell for $\$ 1,000$ or more, and wonder is sometimes expressed that a bull or cow can command such a price. Only when it is understood that the sons and daughters of these high-priced animals will not be sold to the butcher, but will be used as breeding animals in herds that produce cattle for the butcher, is it realized that such prices do not necessarily represent a foolish waste of money. It may be several years before many descendants of such an animal reach the market, they being multiplied in the meantime, but when the market finally feels the good influence of such an animal, the benefits usually more than justify the price of the original bull or cow.

In selecting beef animals for breeding purposes, the breeder must not only emphasize those points which are important to the feeder and butcher, but must keep in mind his own interests 
as well. The features which are of particular interest to the breeder are: 1. The possession of a good constitution. 2. Thick natural flesh. 3. Quick maturity. The first of these is also of much importance to the feeder, the second interests all parties concerned with beef cattle, and the third interests both the breeder and feeder. Constitution is of the greatest importance, for it guarantees thrift and vigorous reproduction. It is the cornerstone of the successful herd. By thick natural flesh is meant a full muscular development such as will expand into a maximum fleshing when the animal is fattened. Quick maturity makes possible a finish at an early age, and this prime essential in present-day beef production is characteristic of cattle that have the blocky, compact, low-set type. Long bodied, long legged animals attain large size, but are difficult to fatten before they are mature, and they mature late.

When cattle intended for breeders are in high condition, the standards for weights at various ages are as follows:

\begin{tabular}{|c|c|c|}
\hline Months & $\begin{array}{c}\text { Weights of } \\
\text { bulls }\end{array}$ & $\begin{array}{c}\text { Weights of } \\
\text { cows }\end{array}$ \\
\hline 6 . & 600 & 500 \\
\hline 12 & 1075 & 750 \\
\hline 18. & 1275 & 975 \\
\hline 24. & 1500 & 1150 \\
\hline 30. & 1800 & 1350 \\
\hline 36. & 1975 & 1475 \\
\hline $42 \ldots$ & 2100 & 1550 \\
\hline
\end{tabular}

The above figures are for purebred bulls and high-grade cows such as should be used in market beef breeding herds. The weights given for bulls thus represent higher standards than those for the cows. The difference in the matured weights of the two sexes as given above, while largely due to sex, is due in part to higher average merit in the bulls than in the cows.

The beef bull.-In general appearance the beef bull is identical with the steer, being wide, deep, compact, and low set. When in use as breeders, bulls are seldom kept in high condition, hence in studying the form certain allowances should be made for lack of fatness, as this has much to do with the appearance of blockiness and massiveness presented by the animal. The bull should have plenty of size and we should not demand the same degree of refinement in bone that is desired in the steer, yet quality should be easily apparent. The hide should roll up mellow and loose in the hand, showing medium thickness, and the hair should be soft and fine. Even when in a medium- 
fat condition, the fleshing should be abundant and smooth. The head should be clean-cut, wide, and short, but larger than the steer's, with heavier horns, and a more burly appearance generally. The eye shows more animation or spirit, and a more resolute expression. Such a head is indicative of masculinity which is insisted upon by all breeders, it being an evidence of potency or breeding capacity. The bull at maturity should show a powerfully muscled neck with a pronounced arch or crest, this also indicating masculinity. The crest should come forward close to the head, and the neck should be short.

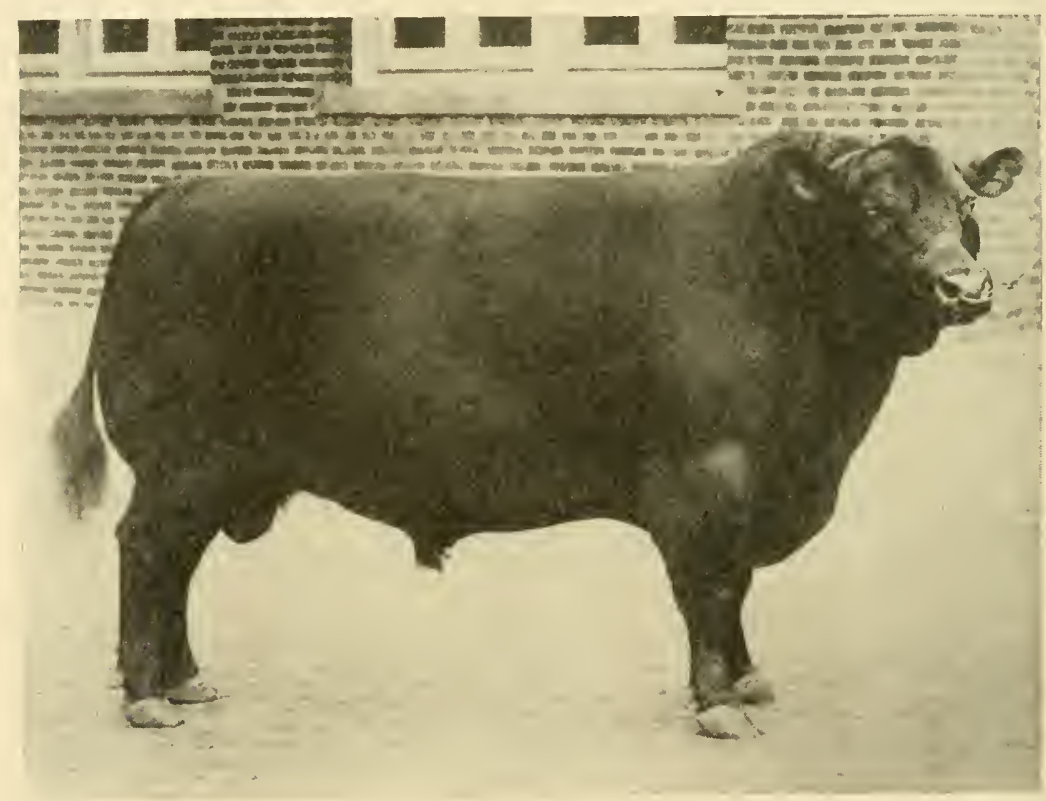

Fig. 37. Correct Type in the Beef Sire.

Erwin C., Champion Aberdeen-Angus bull at the 1913 International, owned by Mr. W. A. McHenry, Denison, Ia.

Masculinity is again shown in the shoulders by a heavier, more massive development than is found in the steer, yet this does not excuse a rough, prominent shoulder such as would be troublesome in the offspring when they are fed for market.

The entire front of the bull is well developed and massive, a condition which is inherited by domesticated bulls from their wild ancestors. In the wild state, a bull became the head of the herd only by right of conquest, and his burly head, heavy 
horns, muscular neck, and massive front were needed to defeat his male rivals, and to protect the herd from its enemies after he had gained leadership. It was a survival of the fittest, which is nature's method of improving the wild animals. Under domestication, the masculine characters have not the same values as in the wild state, yet they are none the less valuable, because they indicate a rugged, vigorous, and potent animal-qualities highly prized by any breeder. A wide, deep chest and full middle insure a good constitution. The middle is identical in form with the middle of the steer, but more emphasis is placed upon straightness and strength of back. The hips should be smooth, and the hindquarters should be long, level, wide, and heavily fleshed.

Great variation will be found in the manner in which bulls walk, some doing it awkwardly and clumsily, with the back humped to a marked degree, and with the legs sprawling; others are active in their movements, keeping their legs under them, and carrying themselves with little apparent effort, the latter of course being much preferred. Style has market value in a bull as in a steer, and between an animal that stands and walks gracefully, and one that slouches, other things being equal, the former will sell much more readily if they are priced the same, and his calves will more quickly attract buyers when they reach the market. Before purchasing a bull, the cows in the herd should be carefully studied and their weaknesses noted, so that a bull may be selected that is strong in the points where the cows show weakness.

A beef bull, well developed at a year old, may serve a few cows, but should as a rule be eighteen months old. An ordinarily vigorous mature bull will get 100 calves a year if the cows come to him at proper intervals, but when they are nearly all bred in the spring and in the fall probably 60 is about the usual limit.

The beef breeding cow or heifer.-Cows reach maturity quicker than bulls, but do not attain as much size or weight. They show more refinement at all points than do males, but in form and fleshing are nearly identical with all good beef animals regardless of sex. In selecting cows, emphasis is placed upon constitution, thick natural flesh, quick maturity, and feminine character. The head shows marked refinement, and there is a calm expression of the eye, showing a much milder disposition than the bull. As compared with steers, the horns are less developed, and the neck is not so thick and perhaps 
not quite so short. The shoulders are well laid in and smooth, and throughout the forequarters there is an absence of the great strength and massiveness found in the bull. The refinement of the cow's head, neck, and shoulders is an evidence of femininity, which, like masculinity in the male, is evidence of breeding capacity. "Motherly" looking cows, not too compact in form, are wanted. A coarse, "steery" headed female is seldom a successful breeder. Although she may produce a calf each year, her stock is not likely to possess the high qualities that one expects.

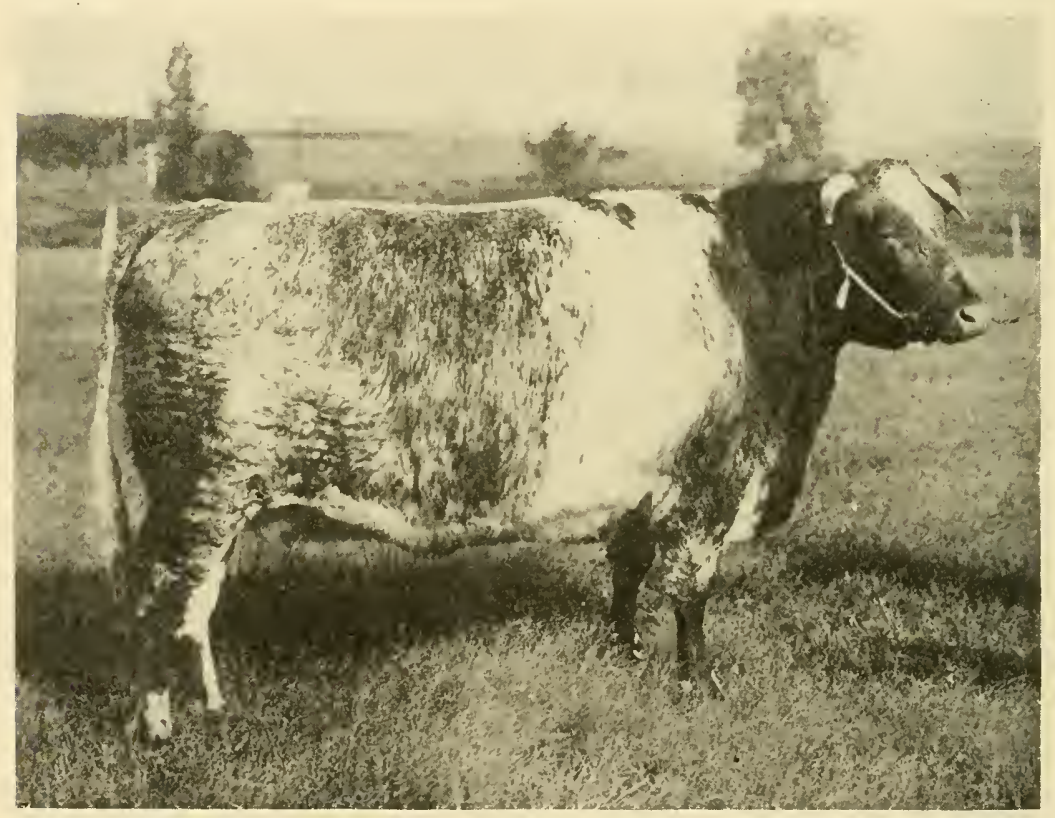

Fig. 38. Correct Type in the Beef Cow.

Fair Start 2d., a famous Shorthorn show cow, owned by Mr. George J. Sayer, McHenry, Ill.

A straight, strong back and wide, deep middle are as desirable in the cow as in the bull or steer, indeed even more so, as a capacious middle provides ample room for carrying the calf. Cows should be a little longer in the middle, a little less compact in other words, than steers and bulls. The hips are notably different, showing more width and prominence, and this feature is often so pronounced as to cause criticism. While a wider hip is accepted in cows than in other beef animals, nevertheless care should be taken to guard against undue prominence. Cows are 
also usually shorter and rougher in the rump than bulls, but the rump should be as long, level, wide, and smoothly fleshed as possible.

So far as condition is concerned, it must be remembered that the breeding cow is more valuable on account of the progeny she produces than on account of her own excellence as an animal suitable for slaughter, hence we do not fault her if she lacks in fatness, provided her constitution, form, and quality are good. However, the beef cow must possess the ability to fatten readily when put on heavy feed, for "like produces like," and if the cow will not take on flesh readily, then we cannot expect her calves to be profitable in the feed-lot. It is on this account that beef breeding bulls and cows are shown in heavy flesh in the show ring, thus indicating their capacity as beef producers. Beef cows are sometimes made so fat for showing that their usefulness as breeders is injured by a heavy deposit of fat about the generative organs. The practice has, therefore, been severely criticized, yet the danger is not great if the feeding is carefully managed, and the advantages so far outweigh the disadvantages that the showing of breeding animals in high condition seems destined to continue.

In the show ring, little or no attention is paid to the udder of the beef cow, but the man who breeds beef cattle cannot ignore the cow's milk-producing qualities. The udder should be of good size and shape, with well-placed teats, and the cow should be able to furnish ample milk for her calf during at least the first six months of lactation. E. S. Bayard, a breeder of beef cattle and Editor of the National Stockman and Farmer, has the following to say regarding the selection of beef cows and the importance of good milking qualities*- "Good-sized, roomy, robust cows; with breadth but not coarseness; big of barrel, loose of hide, short of leg, neat of head, mild of manner, placid of countenance, with a decidedly feminine expression, are the kind. Cows that are good milkers, as a rule, are good and regular breeders-they do not get too fat to breed. Her calf is started well, is kept going, and develops rapidly, for there is no feed for a calf or any other animal that will take the place of mother's milk. The cows which milk most and lose flesh most rapidly when suckling calves are the quickest-fleshing cows. They milk down rapidly and they recover flesh quickly when relieved of the strain of milk production. This character-

* Penn. Dept. Agr. Bul. 235. 
istic of quick fleshing usually accompanies good milking, but not persistent milking of course. Beef-bred cows are not, as a rule, all-the-year milkers, nor is it desirable that they should be. Milk enough is vital to success, and breeders of beef cattle cannot afford to neglect it any more than they can afford to make it a leading object of their breeding. So get lady cows, feminine type, with good udders, and they can be found in all the beef breeds. Let the steery cow alone as you would the bull that lacks masculinity."

The cows which raise good calves should be retained in the herd as long as they are useful, and those which fail to produce

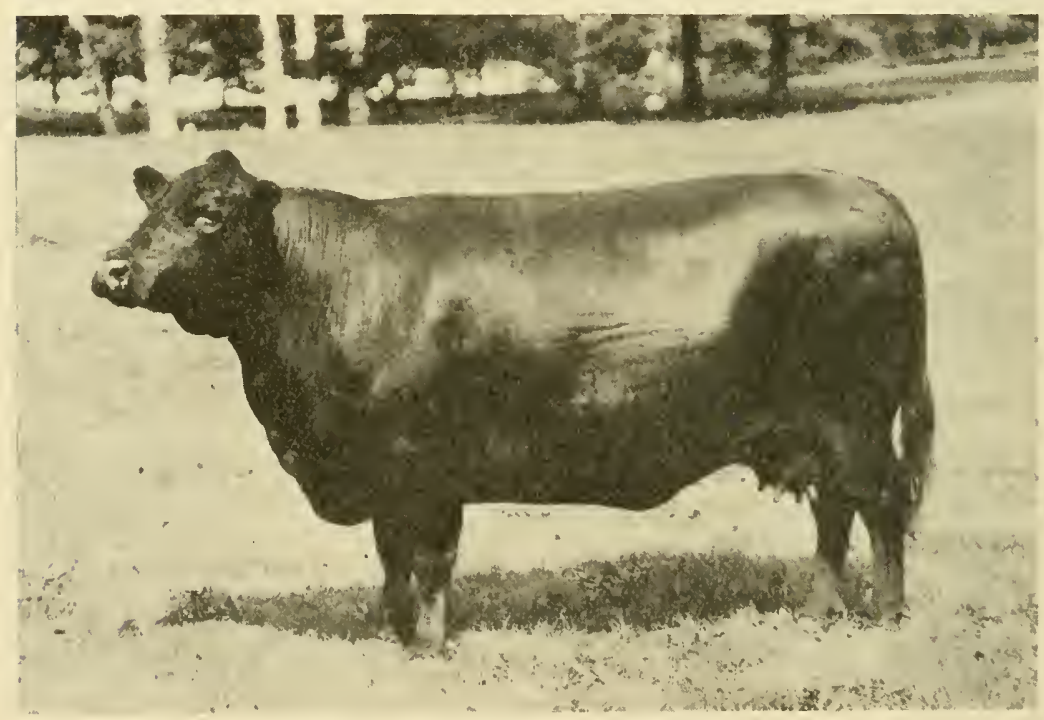

Fig. 39. An Excellent Breeding Cow.

Blackbird Perfection 2d., Aberdeen-Angus cow owned by Iowa State College. Beefy throughout, yet not milkless. She has good udder development and can raise her calf.

good offspring should be sent to the butcher no matter how attractive they may be individually. The attractive fat cow that gives no milk and raises a small, scrawny calf is not worthy of a place in the herd, whereas some of the good mothers may nurse down pretty thin and look rather unattractive after they have suckled their calves for a time. When a cattle breeder designates his plainest-looking cows as the best producers in his herd, he is often fully justified in doing so. Save those that are best by test, and replace the unprofitable cows with the best of the crop of heifers. 
In many instances, heifers are bred at 15 to 18 months old, but it is better practice to begin breeding them at about 21 months so that they drop their first calves at about 30 months. The period of gestation often varies from 274 to 287 days, and the average is about 280 days.

Value of records.- The possibilities for better agriculture through the application of business methods to farming are very great, and this is especially true of live-stock farming. The feeder ought to weigh his cattle regularly, and keep careful and complete records of the weights and of all items of expense incurred in finishing and marketing, so that he may know whether his cattle return him a profit or were fed at a loss. In either case, the records are available for study, and when the next lot is fed, comparisons may be made and benefits derived from past experiences. This is all the more important in the case of feeders who breed their own calves, for then such records are doubly valuable as they greatly assist in determining the producing qualities of the various animals in the breeding herd. If the breeder has records showing the gains made, the cost of the gains, the market prices received, and the dressing percentages of various calves from various cows and by various bulls, he has the best possible measure of the worth of his herd bull and his breeding cows. If such records are complete they permit comparisons of one cow with another and one bull with another, thus indicating what animals should be retained as breeders and what ones discarded. If the breeder has a chance to see the carcasses yielded by fat cattle of his own breeding, he should most certainly avail himself of it and talk with some well-qualified butcher regarding their merits and faults. By such progressive methods will the breeder forge ahead and obtain the maximum profit and satisfaction from his business.

In conclusion, there is good opportunity for profit in beef production, and the soil needs the fertility which comes from the keeping of live stock. The factors necessary to insure success in beef production are (1) good blue-grass pastures, (2) better care of pastures, (3) utilization of corn stalks through the use of a silo-build a silo, (4) the growing and feeding of alfalfa, (5) keeping the best heifer calves for breeding purposes, (6) buying only good, purebred, beef bulls to mate with them, and (7) staying by beef production year in and year out, making it a permanent part of farming operations. 


\section{CHAPTER X.}

\section{DAIRY TYPE.}

Dairy animals that are correct in type present a marked contrast to beef animals. The body and back are longer and much narrower, the thighs are thin, the neck longer and more slender, and in all parts the animal is lean and angular, whereas the beef animal is thick-fleshed and smooth. The dairy animal should present a muscular appearance, without being at all beefy, but should not be so low in flesh as to present an emaciated appearance. Both males and females are rather sharp at the withers, deep ribbed, fairly short of leg, and are well divided between the hind legs. There should be no bulge to the thigh, and no tendency toward the development of what is called the twist in beef cattle. There is a limit to an animal's feeding and digestive capacity, hence one animal cannot produce both beef and milk in maximum quantities. Breeders of dairy cattle want the dairy cow to do one thing only; they discriminate against beefiness just as sharply as they favor evidences of large milking capacity.

\section{The Dairy Cow.}

Dairy cows may be judged by two distinct methods. One method consists of keeping records of the cow's production, including the duration of the lactation periods, the pounds of milk given at each milking, and the results of the Babcock tests for butter-fat. Records may also be kept of the quantities of feed consumed and the cost of the feed-stuffs used, so that at the end of each year an accounting may be made with each cow, and her profitableness or unprofitableness accurately determined. This method gets right at the cow's producing capacity and removes all doubt concerning her right to a place in a producing herd. It is also much used in estimating a cow's value for breeding purposes. This method may be called judging by performance.

Breeders of dairy cattle have an advantage over breeders of beef cattle, it being difficult for the latter to obtain complete records of performance. A slaughter test fully reveals a beef 
animal's capacity as a meat producer, and records of the cost of feed and labor may be as easily kept as for dairy animals, but after the beef animal has demonstrated its value on the block it is no longer available for breeding purposes. However, calves by a certain bull or from a certain cow may be slaughtered and records made which will help to reveal the worth of that particular bull or cow; but this is much more troublesome and expensive than the testing of dairy cows, and the resulting records are more meager and less significant. Beef producers must rely upon the hand and eye in valuing their cattle, and upon such records as the gains made, costs of gains, prices received for animals sent to market, and the dressing percentages.

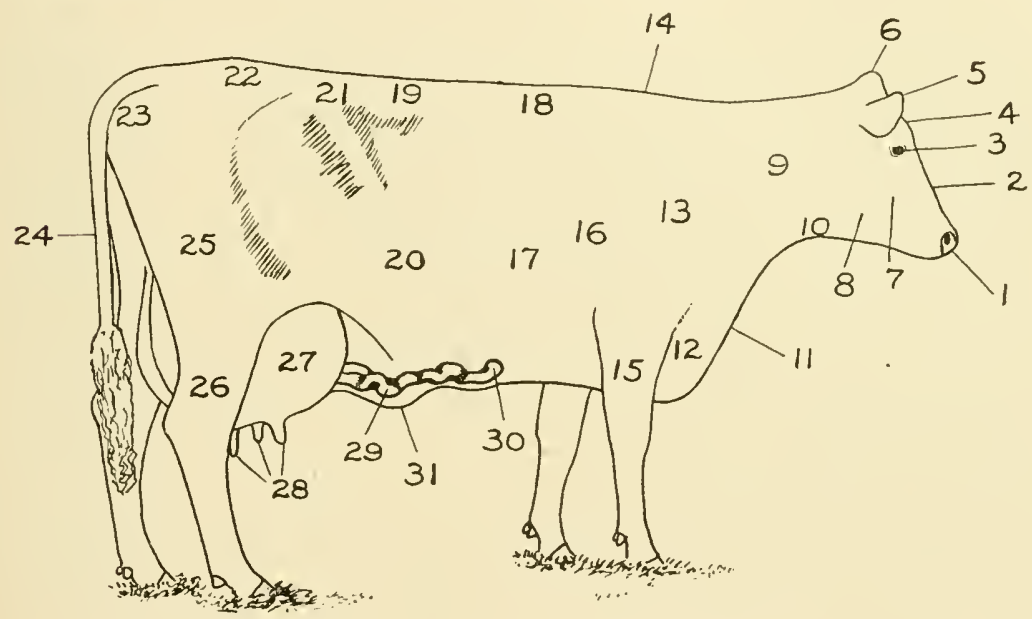

Fig. 40. Points of the Dairy Cow.
1. Muzzle
2. Face
3. Eye
4. Forehead
5. Ear
6. Poll
7. Cheek
5. Jaw

9. Neck
10. Throat
11. Dewlap
12. Brisket
13. Shoulder
14. Withers
15. Fore leg
16. Fore-rib

9. Neck

10. Throat

12. Brisket

13. Shoulder

15. Fore leg

16. Fore-rib
25. Thigh

26. Hind leg

27. Udder

28. Teats

29. Milk-vein

30. Milk-well

31. Navel

The other method of judging dairy cows consists of a detailed study of the animal, and an examination for certain characteristics which are evidences of milk-producing capacity. If the fifty highest-producing dairy cows in the United States were assembled so that comparisons might easily be made, considerable variation would be found among them in form, quality, udder, and other points. Yet through all these cows 
would run certain well-defined characteristics which dairymen have come to know are associated with heavy production. These characteristics may be causes of the heavy yield, or merely incidental correlates, but in either case they are evidences of productive capacity, and are valuable aids in judging dairy cows. Many dairymen keep no records of the production in their herds, and rely solely upon an examination of the individuality when additional cows are purchased. There are other men who ridicule the idea of judging a cow by any other means than records of her performance; they will tell you of cows which score high but are poor yielders, and of other cows which score low but are big producers. However, such instances are exceptional and should not dislodge one's faith in the value of studying the individuality of dairy cows. No doubt it is wrong to rely solely upon either method of judging, for the two methods may be combined to the advantage of each, and in this way the best estimate of the value of a dairy cow is made.

The form of the high-class dairy cow is that of a triplewedge. One wedge is apparent from a side view; the cow is much deeper behind than in front, so that if the top line and underline were continued on forward they would meet at a point not far in front of the animal. The second wedge is formed by a widening from breast to hindquarters, so that the side lines rapidly converge if they are carried out in front of the cow. These two wedges are sometimes secured, in part at least, by a lack of width and depth in the chest, whereas they should result solely because of much width and depth of barrel, thus giving the needed digestive capacity. Although the wedge form is characteristic of the dairy cow, it is not valuable in itself, and the mere fact that a cow has it is not sufficient. The examination should go deeper; the wedges should be analyzed and their causes determined. The third wedge is formed by the shoulders and withers; the withers constitute the point of the wedge, and the shoulders widen out below to provide the necessary chest capacity. This wedge insures against coarseness at the withers and heavy fleshing on the shoulders. The general form of the cow is very angular throughout, due to a well-developed frame and the presence of but little flesh to give smoothness to the parts. Some allowance, however, must be made for sex and age; we naturally expect more fleshing in the bull than in the cow in milk, and the same is true of young heifers before their first calving, and also of dry cows. Some dairymen make an 
effort to fatten dry cows, for the added body fat is resorbed and converted into butter-fat when the cow again comes in milk, thus temporarily raising the percentage of butter-fat above the normal. These features, however, do not excuse any persistent beefy tendency in dairy animals, it being distinctly objectionable.

The head of the dairy cow should be lean, and have a broad muzzle, large nostrils, and a dished face. Compared with the head of the beef animal, there is less width and more length, the proportions of the head being described as medium long and medium broad. The eyes should be prominent, bright, calm, and wide apart, and the forehead should be fairly wide. The jaws should be strong, and the cheeks well muscled. The

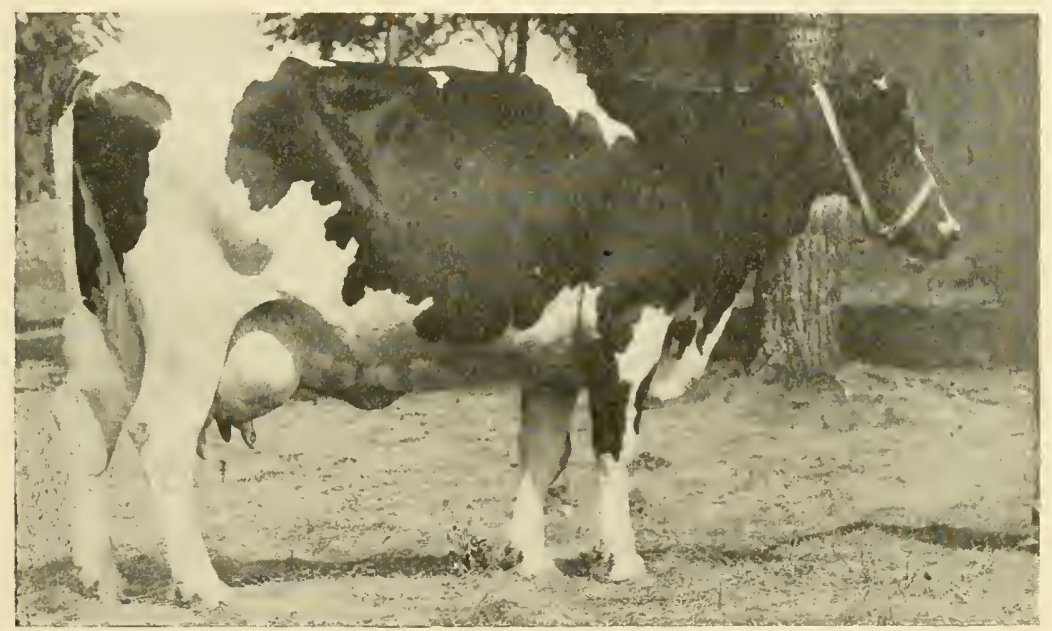

Fig. 41. A Dairy Cow with Utility Points Emphasized.

Holstein-Friesian cow, Chloe Artis Jewel. Correct form, strong constitution, large feeding capacity, good quality, good dairy temperament, and exceptional mammary development are all evident in this cow. Note especially her wonderful mammary veins. Owned by Mr. C. A. Nelson, Waverly, Ia.

ears should be fine in texture, and of medium size. The horns should be fine and have a curve that adds to, rather than detracts from, the appearance. In Guernsey cattle, a yellowish secretion of the skin inside of the ear, and a waxy color of the horn are often regarded as evidence that the butter will have a rich, golden color. The head should have a distinctly feminine expression, and in all its features should be clean-cut and sharply defined. Such a head has a chiseled appearance indicative of quality and good breeding. 
The neck should be long and fine. The upper edge has a slight concave curve, and the lower border has a thin fold or edge of skin, called the "dewlap," extending upwards from the brisket. If the neck is short and thick, or has much depth, so as to make it appear heavy, there is a lack of true dairy type. The throat should be neat and trim, rather than full. Naturally we do not want the neck and shoulders to blend smoothly as in beef cattle, for this results from heavy fleshing.

The brisket of the dairy cow is much narrower and sharper than in beef cattle, and does not carry forward so prominently, the difference being mainly due to the heavy fleshing of the beef animal.

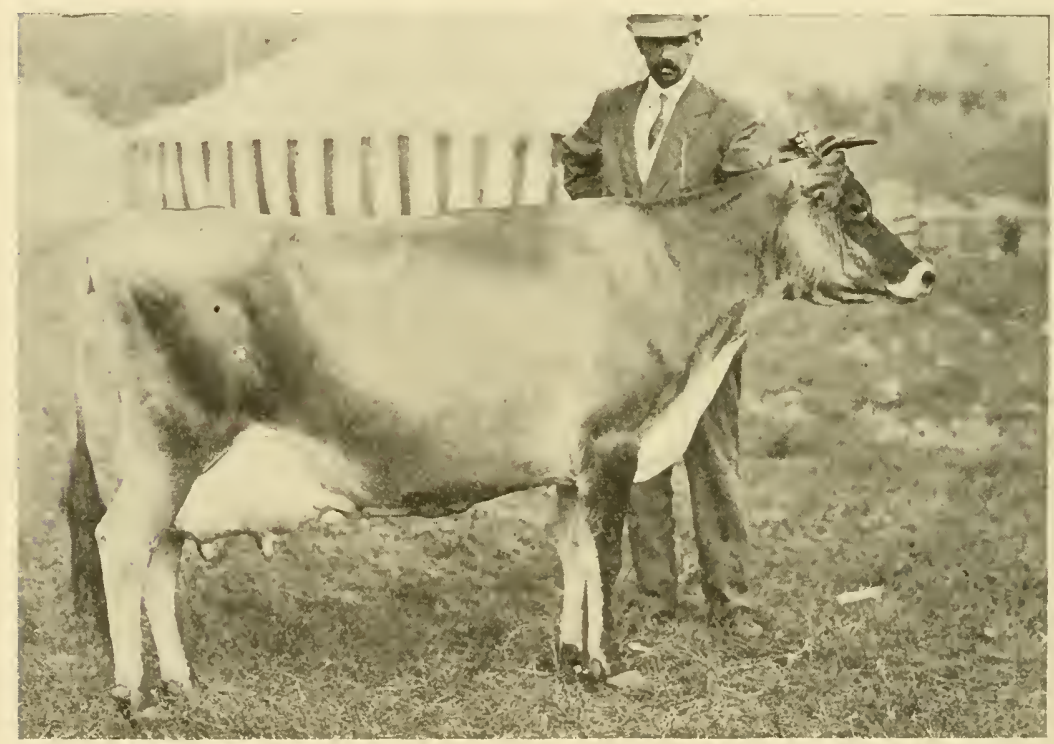

Fig. 42. A Combination of Beauty and Utility.

Jersey cow, Bosnian's Anna, Champion at the National Dairy Show. Her chiseled, feminine head, straight top line, deep rib, nicely balanced udder, and large veins are all noteworthy. She is especially strong in temperament and quality. Note also the correlation between levelness of rump and levelness of udder. Owned by Mr. C. I. Hudson, East Norwich, L. Y., N. Y.

The shoulders should be light, that is, free from heavy fleshing, and the tops of the shoulder blades and the spines of the vertebræ should form rather sharp and refined withers. The shoulders will not appear smooth, but they should not be rough and coarse. A rather open, loosely connected shoulder is asso- 
ciated with the open-jointed conformation desired in the dairy animal, and is a feature found in many of the record-holding cows.

The front legs should be fairly short, should come down straight, and the toes should point straight ahead. The pasterns should be strong. There should be no coarseness of shanks or joints. Very often the knees come quite close together, the legs being crooked, and the toes turning out, but this is a faulty position and often indicates a narrow chest and lack of constitution.

The chest gets its capacity from depth more than from width. However, the fore-rib should have at least a medium degree of arch; breeders of Holstein-Friesian cattle place much emphasis upon a pronounced arch of rib. The fore-rib should carry down deep to give plenty of room for the heart and lungs. Beef cattle should fill up full and smooth with flesh behind the shoulder, but dairy cattle typically show some slight depression just behind the shoulder, although the heart-girth must be very large to insure a strong constitution. The distance between the front legs is a fairly accurate measure of the width of the chest floor, which should not be cramped, but ample, with the front flanks well filled out. In making a large flow of milk, the heart has to pump great quantities of blood which the lungs must purify, thus demanding that the dairy cow have an excellent constitution.

The back should be straight and strong, and have moderate width, and a fair degree of length. Dairy cattle seem put together somewhat loosely; it is not desired that they should be closely coupled or short in the back. A sway-back is sometimes said to indicate true dairy type, but there is no good argument in support of this view; it is logical that cows with big middles should have straight, strong tops. Some dairymen also desire that the backbone shall stand up prominently along the back, loin, and rump, and terminate in a long tail. The argument is that a well-developed backbone encloses a large spinal cord, and as a large nerve branches off at the last dorsal vertebræ and goes to the udder to control operations there, a large spinal column is accepted as evidence of proper development of the nervous system, which, in turn, is supposed to signify increased efficiency on the part of the cow as a milk machine. Whether the size of the brain, spinal cord, and branching nerves, rather than their quality and texture, determines 
the efficiency of the nervous system may be questioned, and as for the course of reasoning showing the relation between length of tail and quantity of milk yield, the reader may take it for what he deems it worth and form his own conclusions. In any event, there are many other ways of estimating a cow's value, the reliability of which are better substantiated. However, a prominent backbone is valuable as an evidence of true dairy temperament, or freedom from beefiness.

The loin should be rather long, should carry up level and strong, and show a fair degree of width.

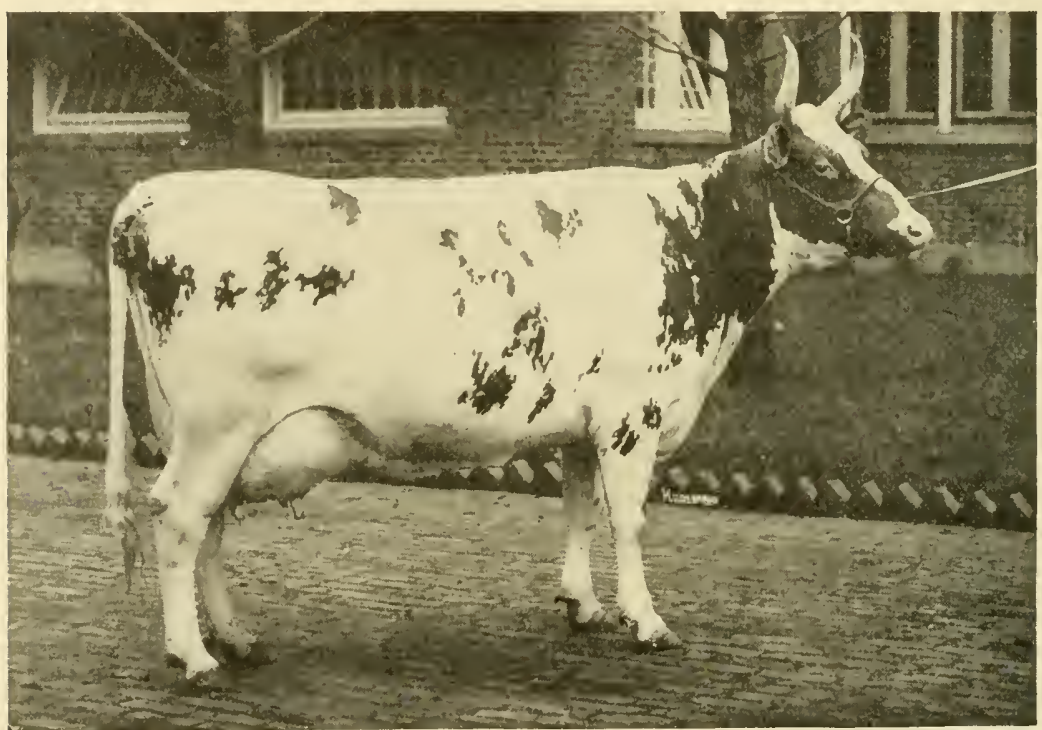

Fig. 43. Excellent Type in the Dairy Cow.

Ayrshire cow, Kilnford Bell 3d., Champion at the National Dairy Show in 1913 and 1914. Note the beautiful head of this cow, and her large, shapely udder. Her conformation indicates strength and vigor without coarseness. Owned by Mr. Adam Seitz, Waukesha, Wis.

The barrel ought to be very deep and wide, and this is secured when the ribs are very long and reasonably well arched. There will be no such degree of rotundity as is found in beef cattle; there should be a well-developed paunch with a capacity for lots of feed. A flat-sided conformation means a restricted capacity for food. The ribs do not lie close together along the side as in beef cattle, and there is more space between the last rib and the hip. Of all the points discussed thus far, two are of vast importance; these are constitution and digestive capacity. The 
dairy cow is a milk machine and should be studied and operated as such. It is thus much easier to put emphasis where it belongs and so arrive more quickly at the true worth of the animal. Milk is manufactured in the udder from nutriment derived from the feed, and if the cow has the true dairy temperament and does not tend to take on fiesh, the quantity of her milk yield will be in direct relation to the quantity and quality of the feed consumed. A heavy milk flow therefore necessitates full development of the organs of digestion, respiration, and circulation, the external evidences of which are a large heart-girth, a large barrel-girth, and a rather lengthy middle.

The hips are very prominent, and should be as wide as possible. Narrowness across the hips is often associated with a lack of width in barrel, and when the hips and rump are narrow, the hind legs often set close together, leaving little space for the udder.

The rump should be wide and level to insure against difficulty in calving, and should not rise strongly at the tail-head as that conformation usually goes with the sway-back. A level rump is usually associated with a level udder. Length of rump is also very desirable; it gives symmetry to the form, and provides room for a long udder-attachment below. A narrow, peaked rump is liable to cause trouble at calving time, and, as pointed out, it brings the hind legs too close together. At the end of the rump on either side of the tail are the pin-bones. They should be wide apart, for reasons similar to those just mentioned. From the point of the hip to the end of the rump there should be a well-marked hollow, insuring against beefiness of rump.

The tail performs a part in milk production by protecting from the annoyance of flies. The fleshy part of the tail should extend to the point of the hock and the brush should be heavy and long. The root of the tail should be carried on a line with the rump, showing no undue prominence or roughness.

The thighs should be muscular, but not fleshy. From a rear view they should be fine and there should be no fleshing between the legs to take up the space that should be filled by the udder. It is desirable that the thighs be long, and that the conformation inside the thigh be incurving. Much variation in rumps and thighs will be found in dairy animals, ranging from decided beefiness to the trim, clean-cut conformation shown by the best dairy cows. 
The hind legs should be placed well apart, and they should come down straight. If the toes point outward and the hocks come close together, the conformation is weak and there is not sufficient room for the udder.

The udder of the dairy cow comes in for special attention, ranking in importance with the chest and barrel, the three being fundamental in the make-up of a sucessful dairy cow. The udder's size, texture, shape, and teats should be carefully studied.

Size of udder.-The udder should be large in circumference, carrying well forward along the belly, and extending by a graceful curve high up between the hind legs. When a side view of the cow is taken as she stands in natural position, the udder should carry out far in front of the hind legs, and the swell of the rear quarters of the udder should be plainly evident back of the leg. A measurement of nearly six feet around the udder has been reported, just two inches less than the cow's heart-girth. The udders of heifers are often deceptive, having much greater capacity than the exterior indicates. This is because the udder is held snugly against the abdominal wall; but with increase in age and yield of milk, the added weight produces some relaxation of the supporting tissues, and the udder becomes more pendulous and prominent.

Texture of udder.- Two sorts of tissue mainly compose the udder - glandular tissue and connective tissue. The former is the seat of secretory activity, and the latter serves the purpose of a framework or support. More or less fatty tissue is also present. Naturally, it is very important that there be a large proportion of glandular tissue and a relatively small amount of connective tissue. This is determined by examining the udder with the hands for mellowness, which indicates that the udder is largely glandular; or still better by having the cow milked, when the udder should show much decrease in size, and the skin covering it should shrivel. When the udder is composed largely of connective tissue, if feels firm and is referred to as "meaty," and when it is milked out, the yield of milk is small and the udder shows little or no decrease in size. Unfortunately, meaty udders usually excel in shape and appearance, while the most glandular ones have not sufficient connective tissue to properly support them, the heavy weight causing them to hang down rather loosely to form what is called a "pendant" udder. Many large producers have such udders, whereas it is a fact that the type of udder that wins in the show ring is 
often lacking in milk capacity. The skin and hair covering the udder should be very soft and fine. Texture of udder is one of the most important considerations in judging dairy cows.

Shape of udder.-All sorts of sizes, textures, and shapes are presented. The most desirable shape is an evenly balanced udder, with all four quarters fully developed, and having a flat floor, instead of being cut up between the halves and quarters. There is a natural tendency for the rear quarters to develop much more than the front quarters, the latter often terminating abruptly, but the most desirable shape is one extending well forward to make what is termed a balanced udder. Udders which carry neither forward nor backward, but are small and tapering from base to teats, without any fullness, are termed "funnel-shaped" udders. Undoubtedly there is considerable correlation between shape of rump and shape of udder. A long rump goes with a long udder, a wide rump with a wide udder, and a level rump is associated with a level udder in contrast to the tipped-up form of udder so often associated with a drooping rump. Shape and balance of udder are important, but subsidiary to size and texture.

The teats and their placement.--The teats should be cylindrical, perpendicular, hang on the same level, and be placed at least six inches apart each way, so as to be easily grasped in the hand. They should be three or four inches long and of a size to make milking easy, but not too large, for udders with very large teats are usually cut up between the halves and quarters, and this occurs at the expense of glandular tissue. When dairy cows are judged, a small amount of milk is drawn from each teat to make certain that the teat is unobstructed and free from defects not evident to the eye. Leaky teats are due to weakness of the muscles of the teat, this being an undesirable trait rather commonly met with, especially in heavy milkers just before milking time. Some udders have not only four large teats, but also one or more small or rudimentary ones. A small amount of milk may sometimes be drawn from them, as they usually spring from rudimentary glands. It is preferred that the udder have four full-sized teats, and four only.

In conclusion it may be said that the udder, first of all, should be large; second, it should be mellow and glandular; third, it should be well-balanced and of good shape; fourth, the teats should be of medium size and placed well apart. 
The milk-veins are large veins passing forward from the udder along the belly just beneath the skin, and disappearing through openings in the body-wall known as milk-wells. The position of the milk-wells varies; some are near the fore flanks, and some midway between the udder and the front legs. As will be explained more fully later, nutriment derived from the food is carried to the udder by the blood and is there utilized in the manufacture of milk. After the udder has absorbed those elements necessary in making milk, the blood returns to the heart through the milk-veins. It is evident that the size and

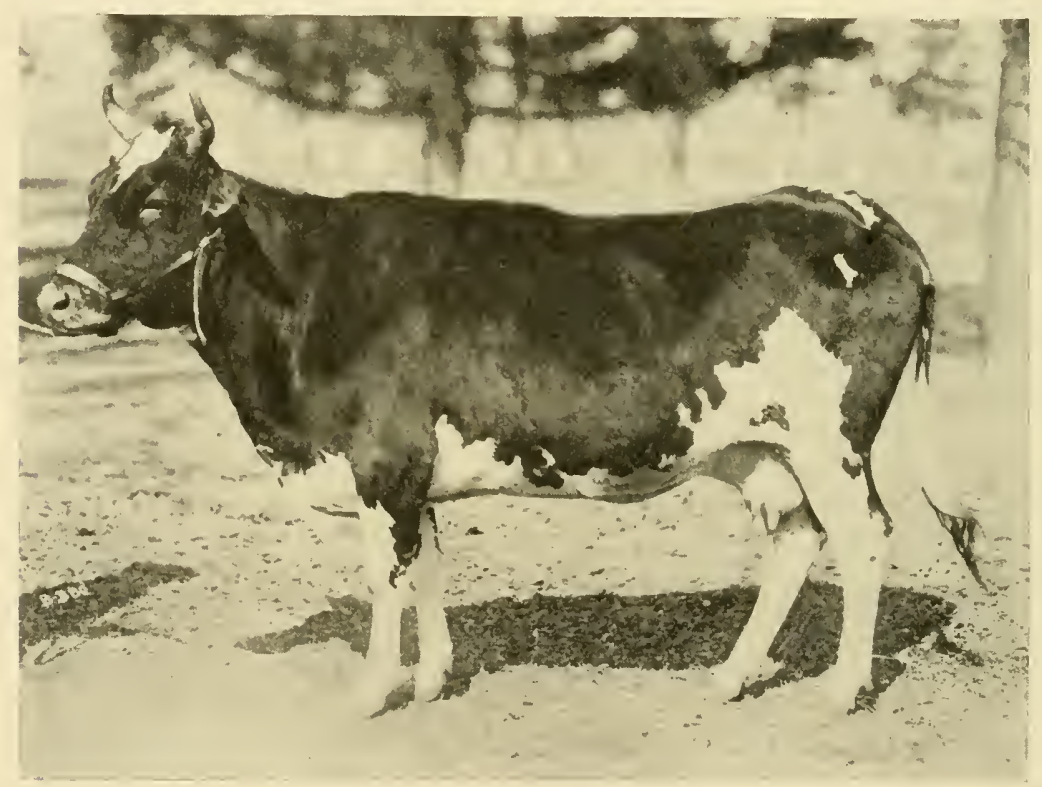

Fig. 44. An Inferior Dairy Cow.

Note the staggy head, coarse neck, uneven top line, small barrel, coarse sloping rump, beefy thighs, and small funnel-shaped udder. Her wedge from the side view points the wrong way.

development of these veins is a good index to the cow's milking capacity, hence they are highly useful in judging dairy cows. The milk-veins of young heifers are small in diameter and are straight. As the heifer develops and her milk flow increases, the veins show increase in diameter, sometimes to an inch or more, they often become crooked or tortuous, and may extend forward toward the fore flanks. The degree of tortuousness varies according to the vein's diameter, small veins being nearly 
straight and large ones very crooked indeed. There will be at least two milk-veins, one on each side of the belly, and sometimes there will be three, the third one having a position on the middle of the abdomen between the two side veins. They sometimes show more or less branching, each branch passing forward and disappearing through its own milk-well. Although diameter of veins is probably most important, length and extension of veins are also regarded as important, indicating an increased venous development and capacity for a larger flow of blood, due to the added number of milk-wells which make easy the work of handling a large circulation. Nearly all phenomenal producers have veins not only of large diameter and decided tortuousness, but also of many branches and forward extensions. Small veins, called udder veins, occur on some udders, their presence being further evidence of a well-developed mammary circulation.

The milk-wells vary in size to correspond with the veins, and are taken into account in judging. They should be large and easily indented when the finger is applied to them. They are especially valuable in estimating the milking qualities of dry cows, for while the udder and milk-veins are much decreased in size during the dry period, the wells maintain their usual diameter.

The escutcheon or "milk mirror" is that portion of the udder and thighs that is covered with hairs turning up and out, in place of down, as on the rest of the body. A Frenchman, Francois Guenon, beginning in 1814 as a boy of fourteen years, worked out in great detail what is known as the Guenon or escutcheon theory. He classified cows and bulls into ten orders and each of these again into four grades, depending on the size and shape of the escutcheon. To each of these orders and grades he ascribed certain values. He also attached certain values to the location of the tufts, ovals, or swirls in the hair on the thighs, making seven additional classes of these. Guenon claimed to be able to tell accurately the producing ability of the cow, and it is said that in tests before various agricultural societies in France he was very successful in proving his theory. The escutcheon theory was formerly highly credited by many dairymen, and in rather recent years at least one agricultural college published a score card for dairy cows that gave about fifty points out of one hundred to the escutcheon.

Modern tests have found this theory to be altogether lacking in accuracy. At the present time most score cards used by 
colleges allow only one or two points to the escutcheon. Some have omitted it from consideration altogether, and this seems entirely justifiable, as the escutcheon theory may be rightly regarded as a quack theory.

The quality of dairy cows is shown in the hide, hair, ear, horn, head, and bone, the same as in beef cattle. The dairy cow has a thinner skin than the beef cow, and it should also possess a maximum of mellowness and unctuousness or oiliness. An oily hide is something of an evidence of milk rich in fat; and an abundant yellowish secretion about the udder, inside the thighs, around the eyes, inside the ears, at the root of the tail, and below any spots of light-colored hair indicates a rich butter color. Opinions differ on the question of quality in dairy cattle. Some breeders aim at a very rugged type having great constitution, rather large bone, and a medium thick hide. This type is exemplified by many Holstein-Friesians and by the St. Lambert family of Jerseys. Other breeders desire extreme quality, and this may result in some delicacy of constitution. Perhaps this type is best illustrated by what is known as the "Island-type" of Jersey, which is the type developed in the native home of the breed on the Island of Jersey, and also fostered by many breeders of Jersey cattle in the United States. The average dairyman will be wise to steer a course midway between the two extremes, insisting upon constitution first and then upon as much quality as may be had without delicacy.

The temperament is of much importance. Temperament is a term used to express differences in the mental and physical constitutions of individuals. Temperaments are of two kinds -sanguine and lymphatic. The sanguine temperament is characterized by a strong, frequent pulse, firm flesh, soft and light hair, active movements, and sensitiveness. The lymphatic temperament is featured by a rather sluggish circulation, fleshiness, thicker skin and coarser hair, slow movements, and quietness. The sanguine temperament is possessed in marked degree by the best dairy cattle, while beef cattle have the lymphatic temperament. The best evidence of true dairy temperament is a lean, angular appearance in all parts of the animal. A dairy bull, a young heifer, or a dry cow may show some degree of fleshiness without being seriously faulted for it, but a cow in milk should be free from beefiness even when well fed. This is a good indication that she is an economical milk producer. 
The disposition varies greatly in different individuals. An irritable, kicking, fence-jumping cow is not expected to make much of a record as a milk and butter-fat producer. She uses too much of her energy in performance that has no market value; the making of milk is a secondary matter with her. Such cows consume little feed and exhibit a fastidious appetite; in short, they are not useful cattle, there being too much waste of energy in nervousness and bad temper. In contrast to such cows is the cow that never moves faster than a walk and is gentle and pleasant to handle. She is a good feeder and is easily suited with her feed. She spends lots of time chewing her cud and is always busy making milk. She is a useful, profitable cow, provided she has the conformation which enables her to work successfully. The irritable cow has an uneasy and wild expression of the eye, and carries her head high. She is usually switching her tail whether it is fly-time or not. Proper disposition is indicated by a calm eye, and by a carriage of the poll of the head no higher or lower than the withers. If the head is carried high it indicates nervousness, while a head carried low indicates quietness carried to the extreme of sluggishness.

The size of dairy cows varies between wide limits. The holders of the world's records in milk and butter-fat production are large cows, which is a condition naturally to be expected, but does not signify that small cows are necessarily less profitable. The beef producer must keep up a certain degree of size in his cattle in order that the cuts of beef will have the size and weight desired, but with dairy cattle it is different. The dairyman cares not so much that his cows are large and hence large yielders, as that the yield be made economically; he studies the production in relation to the feed consumed. Small cows not only yield less, but eat less, and may be as profitable as large cows. The latter have an advantage in that they can profitably consume proportionately more roughage, and fewer of them need be kept to produce a given quantity of milk, requiring fewer stalls and slightly less labor. On the other hand, if the calves can be sold at a profit, as would be true of a purebred herd, the smaller cows will realize more profit from this source. The question of size is of minor importance and may be almost ignored so far as the production of market milk is concerned.

\section{The Dairy Bull.}

The features of dairy type as they apply to the dairy cow having been fully discussed, and the fundamental points of 
dairy type having been set forth in that connection, the requirements for the bull may be presented more quickly. In form the bull should be rather long and moderately wide, with a deep rib, rather short leg, and rather angular body. His build should impress one with its strong constitution, barrel capacity, strength of back, and muscularity without beefiness. The head should be decidedly masculine in its proportions and expression, and have a wide muzzle, large nostrils, large, bright eyes with a courageous expression, and clean-cut features. In all breeds except the Ayrshire, the masculine head will have short, stubby horns. The neck should be strong and the crest heavily developed.

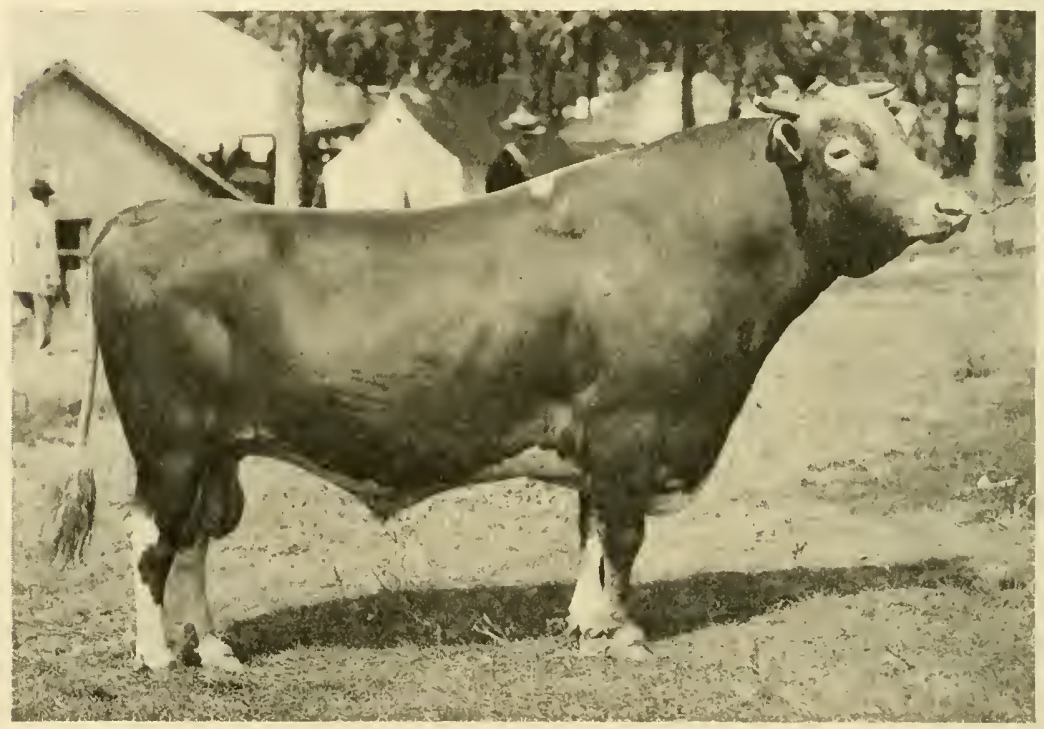

Fig. 45. Excellent Type in the Dairy Bull.

Guernsey bull, Holden 4th, a noted breeding and show bull. Masculinity, depth of body, quality, and freedom from beefiness are his outstanding good points. Owned by Wilcox \& Stubbs, Des Moines, Ia.

The brisket shows more width, depth, and prominence than in the cow, in keeping with a masculine development of the forequarters. The shoulders are deeper and more heavily developed, but should not be beefy. The withers show more width than in the cow, yet tend to be fine and free from flesh. The front legs should be straight, rather short, and have fair width between. The chest should be moderately wide and very deep. The back should be moderately wide and fairly long, but carried up straight and strong. The top line of the 
dairy bull usually rises higher over the withers and neck than over the back and loin, and the first impression may be that the animal is sway-backed, but upon further study the observer often finds he has been misled by the rise over the withers and crest. No marked covering of flesh should be found on the back, but the backbone should be plainly evident.

The loin should be long, level, and medium wide. The barrel should be deep and well developed, but need not show as much capacity as demanded in the cow. The hips are only moderately wide, the points being much less prominent than

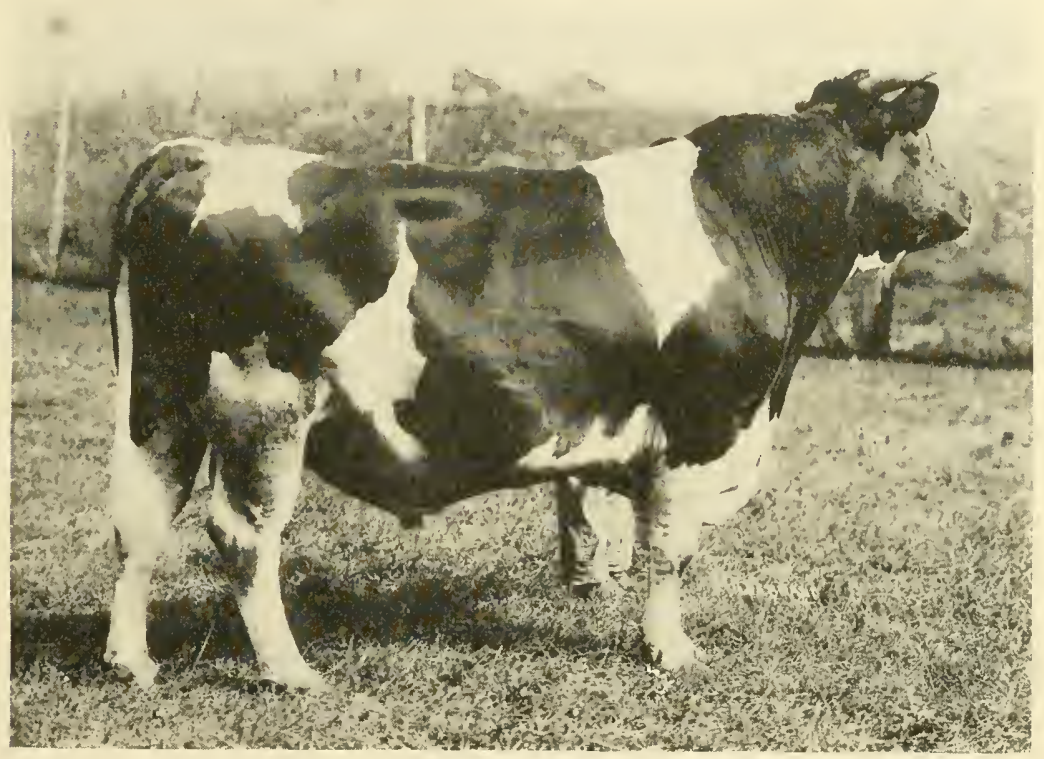

Fig. 46. A Dairy Bull with Strength and Vigor.

Holstein-Friesian bull, King Homestead DeKol, Champion at many state fairs and at the Waterloo and National Dairy Shows in 1911. His masculinity, ruggedness, and length and depth of body are marked. Owned by Mr. John B. Irwin, Minneapolis, Minn.

in the female. The rump should be long, level, and medium wide. The thighs may be slightly heavier than in the female, but any considerable degree of thickness is sharply criticized. Some dairy bulls almost rival beef bulls in the amount of fleshing shown in the hindquarters, and such animals are distinctly not of true dairy type in conformation and temperament. A dairy bull should carry no more fleshing than is permissible in a dry cow or in a heifer before her first calving. The bull should be well divided between the hind legs, and should have rather flat, 
trim thighs. The hind legs should be placed rather well apart, and should be straight and medium short.

In common with the males of nearly all species of animals classed as mammals, the dairy bull has miniature teats called rudimentaries. These are located in front and on each side of the scrotum, there being two on a side. They vary in length from mere buttons to an inch or more. Some persons attach much significance to the rudimentaries, believing that their position and size indicate the shape and capacity of udder which will be shown by the bull's daughters. It is not established that the rudimentaries really have such a significance, and many persons give them no attention in judging. Dairy bulls also have small veins on the belly corresponding to the large milk-veins of the dairy cow.

The quality of the bull is very important; it should be easily apparent in a loose, mellow hide, and a reasonable degree of quality is also wanted in head and bone. Coarseness is an evidence of lack of good breeding. In disposition, dairy bulls are much less quiet and trustworthy than beef bulls, often being ill-natured and sometimes unruly. This does not subject them to criticism unless they become dangerous and difficult to handle, but is accepted as an evidence of masculinity.

The individuality of the dairy bull is certainly somewhat significant of his value, but it reveals less of the animal's ability to perform his function than does the cow's individuality when it is studied in relation to function. The bull is only valuable as a progenitor of heifer calves that will develop into heavy milkers. What points, therefore, in the individuality of the bull are evidence that he will sire high-producing cows? It may as well be stated first as last that it is impossible to determine in any accurate manner from the bull's individuality what his breeding qualities, as they relate to milk flow, will be. There are far more reliable sources from which to form such an estimate and these will be discussed later. Nevertheless, it is important that the dairy bull show a rugged constitution, great digestive capacity, strength of conformation, and absence of beefiness, these being essential points desired in his female offspring. If he is faulty in any of these respects, we may reasonably suppose that his daughters will be similarly deficient. He should be masculine in order to insure potency. Having all these points of individuality, it is still a question as to what sort of performance may be expected from his daughters. 


\section{CHAPTER XI. \\ THE SECRETION OF MILK.}

Milk is secreted by the mammary glands or udder of the female after the birth of young, the secretion continuing until the young are mature enough to live on ordinary food. All animals which have mammary glands are classed as mammals, and this group of animals presents wide variations in the number, position, capacity, shape, and prominence of the glands. The mammary glands are present in the male in rudimentary condition, although, in abnormal cases, milk is secreted by males. Milk is easily digested and very nutritious, and no food for the young animal is equal to its mother's milk. The highest development of the udder is found in the dairy cow, the extreme development having been largely secured by careful breeding; the lactation period has become prolonged, and the daily yield and quality of milk have been much improved. Cows have been known to secrete over one hundred and fifty pounds of milk in a day, their own weight in less than two weeks, and over fifteen tons in a year.

Exterior of the cow's udder.-The cow's udder consists of four mammary glands, usually referred to as the "quarters," and sometimes there are one to four rudimentaries, all arranged in pairs on opposite sides of the median line of the body. The udder begins a few inches behind the umbilicus and continues backward and upward between the legs. The right and left sides are divided on the exterior by a well-defined line or groove, but the line of separation between the front and rear quarters is not so pronounced. The appearance of size depends partly upon the strength and shape of the abdominal wall; if the wall is loose, the udder is forced downward and backward and there is a seeming increase in size. This sometimes accounts for the apparently sudden development of a good udder after the second or third calving. The skin covering the udder is very thin and elastic, and the hair is finer, softer, and shorter than on the rest of the body. The skin covering the teats bears little or no hair, and is often of a darker color than upon other parts.

Structure of the cow's udder.-When dissected, the right and left halves of the udder are found to be enveloped in strong, 
fibrous capsules. The fibers of the two capsules intermingle somewhat, and are prolonged upward to the median line of the body to form a ligamentous support and partition, the two halves thus being made distinct. The quarters on each side are not so distinctly separated, there being no such well-developed partition as between the halves, nor can the line of separation be seen unless the tissues are stained. Dr. A. W. Bitting of the Indiana Experiment Station injected different colored liquids through the teats and found that the liquids did not leave the

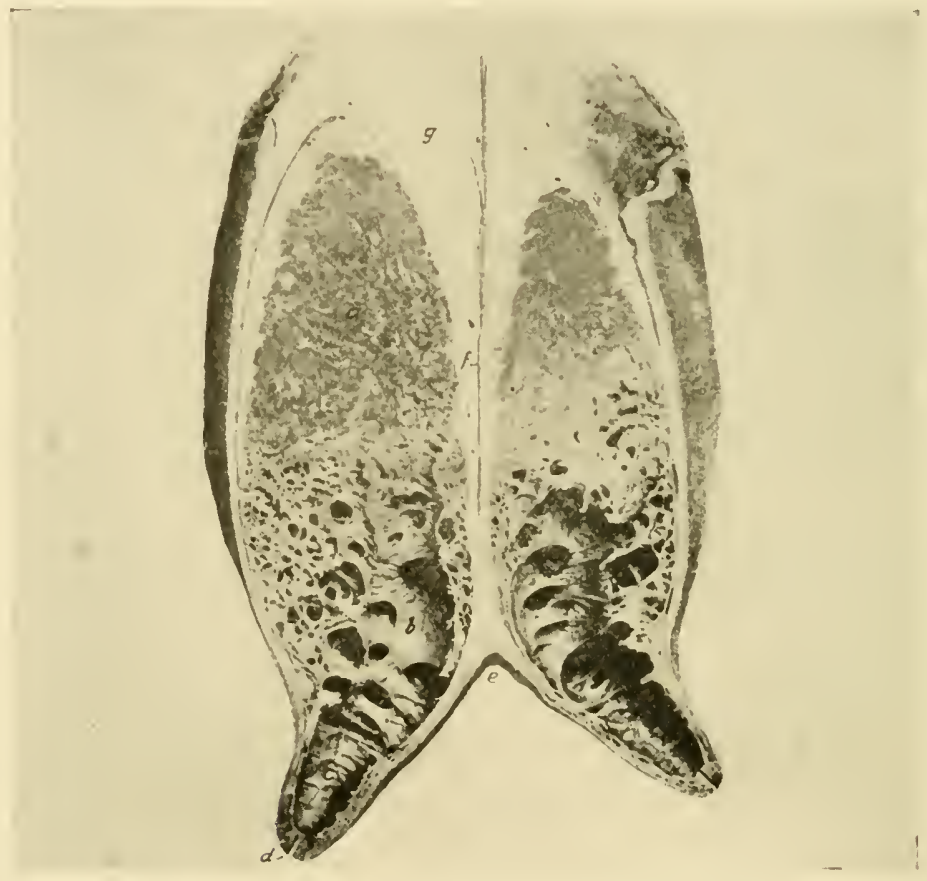

Fig. 47. Cross-section of Cow's Udder.

a, Body of gland; b, milk cistern; c, cavity of teat; d, duct of teat; e, intermammary groove; $f$, septum between glands; $g$, supramammary fat.

quarter, his investigation showing that a rather distinct transverse partition exists. It follows that milk drawn from any teat must be produced in its quarter, although there is slight communication between the smaller ducts in the upper parts of the two quarters on a side. Between the quarters of the same half, the capsule sends off a rather incomplete transverse partition common to both, and there are numerous other reflections 
of the capsule inward from all sides to serve as a supporting framework for the gland tissue and to form the milk cisterns and ducts.

Structure of the teat.--The tissues of the capsule are prolonged downward, becoming greatly thickened, to form the walls of the teats. The teat is cylindrical or conical in shape, variable in length and diameter, and placed at the lowest portion of the gland. Its shape and size are independent of the size of the gland. It is very elastic and is covered with a tough, close-fitting, thin skin. Through its center runs a duct called the teat-canal, having a capacity, when distended, of from one to one and one-half ounces in moderate-sized teats. There are both circular and longitudinal muscle fibers, and at the lower end the circular fibers form an involuntary sphincter muscle, the function of which is to keep the teat-canal closed under ordinary pressure. At the upper end of the teat is another involuntary sphincter muscle, but it does not completely close the canal, and sometimes a third is found farther above. The sphincters are sometimes so relaxed that very slight pressure is sufficient to open them, and the cow leaks her milk; of other cows the reverse is true, making them hard milkers.

The milk-cistern, ducts, and alveoli.-Above the teat is a reservoir, called the milk-cistern, seldom holding more than half a pint. This cistern is divided into pockets of various sizes into which the large milk-ducts empty. At the point of entrance of these ducts are sphincter muscles, and while they cannot entirely close the openings, they may very nearly do so, and in this way the cow is enabled to "hold up her milk." These large ducts ramify to all parts of the gland and anastomose (intercommunicate) freely; and at the intersections are still other voluntary sphincter muscles. A strong effort on the part of the cow is required to close the larger ducts in the lower part of the udder, but a slight effort will close the smaller canals further up in the glands. Cows differ greatly in their control over these muscles and in their disposition to exert it. The most common causes of holding up milk are fright, the presence of strangers in the stable, lack of familiarity with surroundings, irregularity in the time or manner of feeding or milking, and sexual heat. With some cows it becomes a habit, much injuring the usefulness and milking capacity of the animal. The large ducts subdivide into smaller ducts, and these again into smaller ones, until they terminate in groups of small sac-like bodies 
known as the ultimate follicles, acini, or alveoli. The teat-canal, milk-cistern, and ducts are lined with columnar epithelium.

The alveolus (plural, alveoli) is the sacculated distention found in groups of three to five on the end of the minute milkducts. It is the essential part of the gland. It is lined by a single layer of epithelial cells which are especially concerned in milk production. The alveolus is only 1-30 of an inch in diameter, and its cavity is from 1-250 to $1-100$ of an inch in length and from 1-1300 to 1-800 of an inch in diameter. New ducts and alveoli may be formed up to about the fifth or sixth year, thereby increasing the producing capacity of the cow.

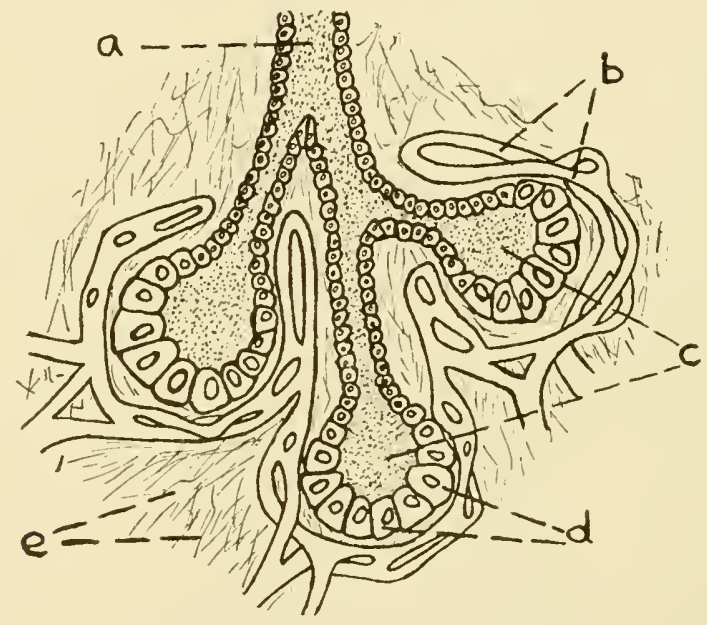

Fig. 48. Where Milk is Made.

Group of alveoli. a, Duct; b, capillary network; c, alveoli; d, epithelial cells; e, fibrous tissue. (After Hough \& Sedgwick.)

The entire gland may be compared to a large bunch of grapes; the main duct of the gland branches very much as the stem of the bunch of grapes branches; and just as the branches and sub-branches of the stem lead to the grapes, so the branches of the duct lead to the alveoli of the gland. If we pack the bunch of grapes in a small basket of sawdust, so that the sawdust fills up loosely the spaces between the individual grapes and the branches of the stem, we may develop our comparison further; the sawdust stands for the connective tissue in which the ducts and alveoli are embedded, and the basket stands for the capsule 
The arterial circulation.-The mammary glands are abundantly supplied with blood. The blood leaves the heart through the posterior aorta, common iliacs, and external iliac, which carry backward to the region of the hips. The external iliac there divides into two arteries, one of which, the prepubic, divides into the two pudic arteries, the external one of which passes down the thigh and gives off a branch, known as the mammary artery, which enters the top of the udder from the rear. The mammary artery has four large branches, one for each quarter of the udder, and there is also a small branch for each rudimentary gland. The large branches subdivide within the gland tissue.

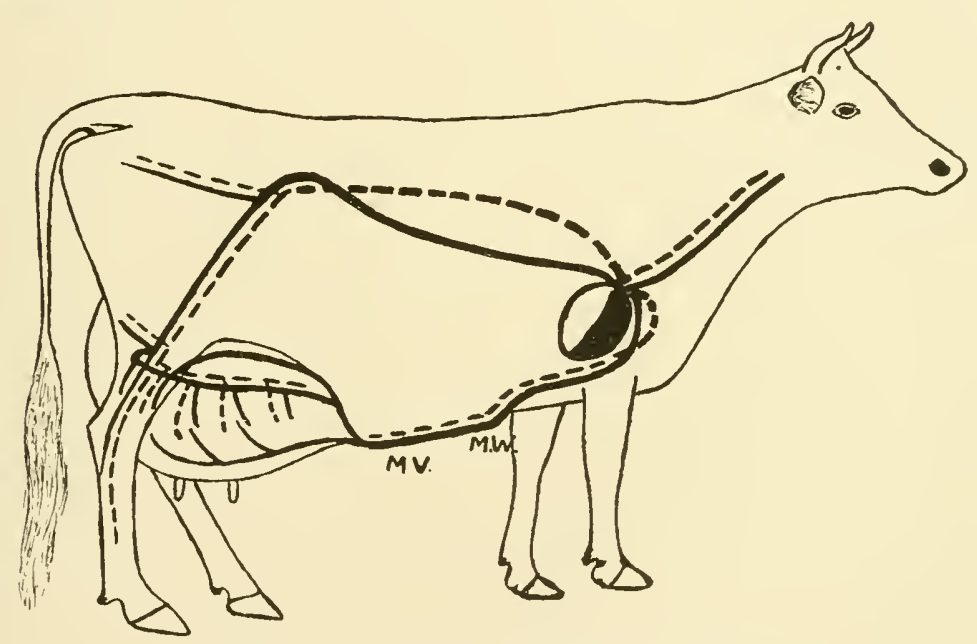

Fig. 49. Circulation To and From the Udder.

The broken lines represent the arteries which earry blood containing the nutritive material to the udder where it is manufactured into milk. The heavy black lines represent the veins which carry the blood back to the heart. Note that there is but one route from the heart to the udder, whereas there are two routes from the udder to the heart. M. V., milk-vein; M. W., milkwell. (After Bitting of the Indiana Station.)

The venous circulation is more complex than the arterial. The blood is collected from the capillaries by from 14 to 17 large veins which empty into the mammary vein running parallel with the mammary artery at the top of the udder. The mammary vein is divided into two parts which encircle the top of the udder and connect in front and behind like a rope tied around it. From this circuit of veins the blood returns to the heart by two routes. One route leads out to the rear of the udder, then 
up to the region of the hips, and thence to the vena cava and the heart, the veins along the route being parallel to the arteries through which the blood came, and being similarly named. The other route is already familiar, leading out in front of the udder through the large subcutaneous abdominal veins (milk-veins) which pass through the chest wall and become a part of the internal thoracic vein, reaching the heart by way of the anterior vena cava. The direction of the blood in the encircling veins at the top of the udder is determined by the valves in the vessels. The larger volume of blood passes through the milk-veins, thus bringing them into great prominence. During pregnancy, the pressure of the uterus tends to interfere with the circulation through the posterior vessels, and this tends to further increase the size of the milk-veins. Inasmuch as the blood may return to the heart posteriorly, it is possible to have a large milker with small milk-veins, but this is not likely to occur. Cows with large milk-veins are large producers, and cows with small milkveins may be large producers.

Nature and composition of milk.-Cow's milk is an opaque, yellowish-white fluid devoid of odor except for a short time after its extraction. When fresh, it is slightly sweet and has a slightly alkaline reaction. Under the microscope, milk is found to be a fine emulsion of fat, a quart of milk being estimated to contain 2,000,000,000,000 fat globules, and the cow that gives two gallons of milk per day must therefore secrete at the rate of over 175,000,000 fat globules per second. The composition of milk varies a great deal; there are differences between breeds, differences between individuals, and differences in the milk from the same cow at different times. As lactation advances, the daily milk yield decreases, but the percentage of fat constantly increases as does the percentage of all solids. The specific gravity of average milk is 1.032 and its composition is as follows:

Milk $\left\{\begin{array}{l}\text { Water } 87 \% \\ \text { Solids } 13 \%\end{array}\left\{\begin{array}{l}\text { Solids not } \\ \text { Fat } 9.1 \% \\ \text { Fat } \quad 3.9 \%\end{array}\left\{\begin{array}{l}\text { Ash } \\ \text { Casein } \\ \text { Albumin } \\ \text { Sugar }\end{array}\right.\right.\right.$

The results of various American experiments indicate that the average composition of the milk of the various breeds is as follows: 


\begin{tabular}{|c|c|c|}
\hline Breeds & $\begin{array}{l}\text { Solids } \\
\text { per ct. }\end{array}$ & $\begin{array}{c}\text { Fat } \\
\text { perct }\end{array}$ \\
\hline Jersey. . . & .14 .70 & 5.35 \\
\hline Guernsey ... & .14 .71 & 5.16 \\
\hline Shorthorn... . & .13 .38 & 4.05 \\
\hline Ayrshire....... & .12 .61 & 3.66 \\
\hline Holstein-Friesian & .11 .85 & 3.42 \\
\hline
\end{tabular}

The quantity of milk given by the different breeds is almost inversely proportional to the fat content, so that the total quantity of solids and fat is nearly the same for all dairy breeds. The highest average percentage of fat in a regular milking that has been reported is 10.7 , and the cow did not give milk of this richness regularly. In a few cases, tests showing 9 per cent. have been made and it is only rarely that a cow averages 7 per cent.

Secretion of milk. - The udder is a true organ of secretion. Milk is not merely strained from the blood, but contains substances not found in the blood, these being formed in the gland itself. Surrounding the alveoli are capillaries, and through the walls of the capillaries the fluids of the blood pass freely into the cavity of the alveoli by osmosis. At the same time, the epithelial cells lining the alveoli are the seat of secretory. activities which produce some of the most important constituents of the milk. Thus milk is formed partly from the osmosis of blood serum and white blood corpuscles directly into the cavity of the alveolus, and partly by a chemical elaboration by the epithelial cells. The water from the blood serum passes out of the alveolus, carrying with it some of the mineral constituents of the blood in solution, and a part of the albumin of the blood serum. During its passage from the capillaries to the cavity of the alveolus, by far the larger part of the albumin of the blood is changed by the epithelial cells to the casein of milk. These cells also secrete globules of fat, having an average diameter of about 0.0001 of an inch. Small amounts of fat may also be carried over directly by the blood and appear in the milk without change. Only minute quantities of sugar are found in the blood, hence milk-sugar is no doubt also elaborated by the secretory cells of the udder.

Milk secretion is not perfectly understood in all its details. In some of its phases, milk secretion is undoubtedly a continuous process, but the agitation of the udder at milking time seems to be very essential in completing the process of milk manufacture. Between milkings, the udder is engaged in certain important preliminary steps which make possible the rapid 
culmination of the act of secretion when the stimulus afforded by agitation is given. (The theory that milk secretion is largely the result of cell growth, division and degeneration, is no longer held by leading physiologists.)

If an udder is cut open just before milking time, it is found that the milk-cisterns and ducts are distended with milk containing a very low per cent. of butter-fat. The quantity of this milk is only a small part of the total yield which the cow would give at a milking. Agitation of the udder is necessary to complete the process of secretion. Observation of a calf, lamb, or kitten when nursing shows that considerable agitation is a prominent feature of nature's method of milking. Under this stimulus the water of the blood rushes through the walls of the alveoli and carries the butter-fat, which has been manufactured by the epithelial cells, down into the milk-ducts and cisterns, and finally through the teats. Other products of secretion, namely casein and lactose (milk-sugar), are brought down also. The last milk drawn from the udder is the richest in fat; in one experiment, four successive samples taken during the course of milking tested $0.76,2.60,5.35$, and 9.80 per cent. of fat respectively.

Experiments made at the Wisconsin Experiment Station in manipulating the udders of cows, after the regular milkings, resulted in bringing down considerable milk very rich in butterfat. It was estimated that if the udders of the million cows in Wisconsin at that time were manipulated after the customary operation of milking, and if butter-fat is worth only twenty cents per pound, the value of the extra product would amount to $\$ 6.00$ per head annually, or $\$ 6,000,000$ for all the cows in the state.

Colostrum.-Because of more or less incompleteness of the various processes of secretion at the start of the lactation period, the first milk differs in composition from that afterwards secreted, and is called colostrum. It is thick and viscous, contains less water than normal milk, five times as much albumin, twice as much ash, slightly more fat, and about one-half the usual percentage of sugar. It has a laxative effect on the calf, useful in properly starting the work of digestion. In about one week following birth, the yield of milk usually increases and becomes normal in composition.

Stimuli to secretion.- The cow has no control over the secretion of milk, it being involuntary. During the latter part of pregnancy, the embryo calf makes very rapid growth, and 
the blood supply to the placenta is much increased. At that time the cow does not ordinarily secrete milk, her excess of energy being given to the growth of the embryo. When the calf is born, the demand through the placenta ceases, and the large volume of blood is turned toward the udder. A short time previous to calving, the udder of the cow shows considerable increase in size, and by the time the calf is born the mammary glands are fulfilling their function nearly to the maximum capacity. In young heifers that have never had a calf, the udder contains a watery, saline fluid. Regular attempts at milking, or manipulation of the udder with the hands, or allowing a calf to suck, may stimulate the secretion of considerable normal milk in such young heifers. The same methods have been known to cause the secretion of a milk-like fluid by the rudimentary glands of males. Thorough milking furnishes a stimulus that causes prolongation of the lactation period, while incomplete removal of milk tends to check the secretion and shorten the milking period, and it may also cause serious inflammation. Frequent milkings tend to increase the flow of milk, but there is no special advantage in milking more often than twice a day unless the cow is a high producer and the udder becomes very much distended between milkings, as such distention acts as a check to further secretion. Regularity in milking is essential to best results, both in the amount secreted per day and in the length of the lactation period. 


\section{CHAPTER XII.}

\section{VARIATIONS IN THE USEFULNESS OF DAIRY COWS.}

The census of 1910 showed that the average cow kept for milk production averaged 3,113.2 pounds of milk per year. If this milk tested four per cent. fat, each cow produced 124.5 pounds of butter-fat. Assuming that average butter contains 85 per cent. of butter-fat, the average American dairy cow is found to have had 146.5 pounds of butter to her credit. Rather it was a discredit. It is generally agreed by dairymen that an annual production of at least 200 pounds of butter is necessary to pay for feed, labor, taxes, insurance, and interest on the investment in keeping one cow. The average dairy cow in the United States in 1919 was estimated to be worth $\$ 78.24$. The cow that yields 200 pounds of butter in a year is not worth more than that, if as much. If the 250 -pound cow gives 50 pounds for profit, or $\$ 20$, she will pay 10 per cent. interest on $\$ 200$. If the 200-pound cow is worth $\$ 75$, the 250 -pound cow is worth $\$ 275$, the 400 -pound cow is worth $\$ 875$, and the few exceptional cows that produce enough butter-fat in a year to make 1000 pounds of butter are each worth $\$ 3,275$. These figures might be further increased by including the values of the calves produced by each class of cows. As a matter of fact, however, cows yielding 200 pounds of butter or less are not worth anything as dairy cows, but only what they will bring for beef, and the 250 -pound cow will not bring $\$ 275$, yet she may pay a reasonable per cent. of interest on that sum. These figures are valuable only as indications of the wide variations in the usefulness of dairy cows. It is estimated that one-fourth of the cows in the entire country kept for milk do not pay for the cost of keeping, and nearly one-fourth more fail to yield an annual profit.

The following tables are compiled from the results of the classic tests of purebred dairy cows at the Pan-American and Louisiana-Purchase expositions. These tables are presented to show variations in the profitableness of different individuals rather than of different breeds: 
Pan-American Exposition, Buffalo, IgoI; six-months test.

\begin{tabular}{|c|c|c|c|c|c|c|c|}
\hline $\begin{array}{l}\text { Breed and } \\
\text { individual }\end{array}$ & $\begin{array}{l}\text { Av. } \\
\text { daily } \\
\text { yield } \\
\text { of } \\
\text { milk }\end{array}$ & $\begin{array}{c}\text { Per } \\
\text { cent. } \\
\text { of } \\
\text { fat }\end{array}$ & $\begin{array}{c}\text { Daily } \\
\text { return } \\
\text { over } \\
\text { feed } \\
\text { cost }\end{array}$ & $\begin{array}{l}\text { Breed and } \\
\text { individual }\end{array}$ & $\begin{array}{l}\text { Av. } \\
\text { daily } \\
\text { yield } \\
\text { of } \\
\text { milk }\end{array}$ & $\begin{array}{l}\text { Per } \\
\text { cent. } \\
\text { of } \\
\text { fat }\end{array}$ & $\begin{array}{c}\text { Daily } \\
\text { return } \\
\text { over } \\
\text { feed } \\
\text { cost }\end{array}$ \\
\hline Guernsey- & & & & Shorthorn- & Lbs. & & Cents \\
\hline Best cow... & 31.2 & 5.4 & 33.0 & Best cow & 38.3 & 3.7 & 23.9 \\
\hline Poorest cow & 23.5 & 4.4 & 16.3 & Poorest cow.. & 33.6 & 3.4 & 16.0 \\
\hline Red Polled- & & & & Polled Jersey- & & & \\
\hline Best cow... & 34.2 & 4.5 & 28.9 & Best cow.... & 22.3 & 5.6 & 23.8 \\
\hline Poorest cow & 30.1 & 3.7 & 17.6 & Poorest cow. & 13.7 & 4.3 & 8.6 \\
\hline Jersey- & & & & Brown Swiss- & & & \\
\hline Best cow.... & 25.8 & 5.6 & 27.9 & Best cow ... & 32.2 & 4.1 & 22.9 \\
\hline Poorest cow... & 30.3 & 4.0 & 21.4 & Poorest cow. & 34.6 & 3.3 & 16.9 \\
\hline $\begin{array}{l}\text { Holstein- } \\
\text { Best cow }\end{array}$ & 45. & 3.4 & 27.4 & Fr. Canadian- & $\begin{array}{lll}30 & 0\end{array}$ & 40 & 226 \\
\hline Poorest cow. & 41.1 & 3.3 & 20.3 & Poorest cow. & 21.4 & 3.7 & 12.7 \\
\hline Ayrshire- & & & & Dutch Belted- & & & \\
\hline Best cow... & 39.1 & 3.6 & 26.2 & Best cow... & 29.5 & 4.2 & 21.1 \\
\hline Poorest cow. & 36.8 & 3.4 & 21.5 & Poorest cow. & 21.8 & 3.1 & 6.4 \\
\hline
\end{tabular}

Louisiana-Purchase Exposition, St. Louis, Igo.f; I20-day test.

\begin{tabular}{|c|c|c|c|c|c|c|c|c|}
\hline \multirow{2}{*}{$\begin{array}{l}\text { Breed and } \\
\text { individual }\end{array}$} & \multicolumn{3}{|c|}{$\begin{array}{l}\text { Average daily } \\
\text { yield per cow }\end{array}$} & \multirow{2}{*}{$\begin{array}{l}\text { Per } \\
\text { cent. } \\
\text { fat }\end{array}$} & \multirow{2}{*}{$\begin{array}{c}\text { Feed } \\
\text { cost } \\
100 \mathrm{lbs} \\
\text { milk }\end{array}$} & \multirow{2}{*}{$\begin{array}{c}\text { Feed } \\
\text { cost } \\
1 \mathrm{lb} . \\
\text { fat }\end{array}$} & \multirow{2}{*}{$\begin{array}{c}\text { Gain } \\
\text { in live } \\
\text { wt. }\end{array}$} & \multirow{2}{*}{$\begin{array}{l}\text { Daily } \\
\text { return } \\
\text { over } \\
\text { feed } \\
\text { cost }\end{array}$} \\
\hline & Milk & Fat & $\begin{array}{l}\text { Total } \\
\text { solids }\end{array}$ & & & & & \\
\hline Jersey- & Lbs. & Lbs. & Lbs. & & Cents & Cents & Lbs. & Cents \\
\hline Best cow...... & 48.4 & 2.3 & 6.7 & 4.8 & 55.0 & 9.7 & 77 & 42.1 \\
\hline $\begin{array}{l}\text { Poorest cow.... } \\
\text { Holstein-Friesian- }\end{array}$ & 38.8 & 1. 6 & 5.1 & 4.1 & 65.0 & 13.2 & 85 & 22.3 \\
\hline $\begin{array}{l}\text { Best cow ...... } \\
\text { Poorest cow... }\end{array}$ & $\begin{array}{l}67.5 \\
47.1\end{array}$ & $\begin{array}{l}2.4 \\
1.5\end{array}$ & $\begin{array}{l}7.5 \\
5.1\end{array}$ & $\begin{array}{l}3.5 \\
3.2\end{array}$ & $\begin{array}{l}45.0 \\
61.0\end{array}$ & $\begin{array}{l}11.0 \\
16.5\end{array}$ & $\begin{array}{r}54 \\
147\end{array}$ & $\begin{array}{l}38.4 \\
15.0\end{array}$ \\
\hline Brown Swiss- & & & & & & & & \\
\hline $\begin{array}{l}\text { Best cow ....... } \\
\text { Poorest cow... }\end{array}$ & $\begin{array}{l}51.0 \\
38.5\end{array}$ & $\begin{array}{l}1.8 \\
1.5\end{array}$ & $\begin{array}{l}6.1 \\
5.1\end{array}$ & $\begin{array}{l}3.4 \\
3.8\end{array}$ & $\begin{array}{l}54.5 \\
69.5\end{array}$ & $\begin{array}{l}13.7 \\
15.5\end{array}$ & $\begin{array}{r}74 \\
147\end{array}$ & $\begin{array}{l}23.1 \\
16.5\end{array}$ \\
\hline $\begin{array}{l}\text { Shorthorn- } \\
\text { Best cow ...... } \\
\text { Poorest cow... }\end{array}$ & $\begin{array}{l}43.4 \\
21.4\end{array}$ & $\begin{array}{l}1.7 \\
0.8\end{array}$ & $\begin{array}{l}5.5 \\
2.7\end{array}$ & $\begin{array}{l}4.0 \\
3.9\end{array}$ & $\begin{array}{r}54.5 \\
107.5\end{array}$ & $\begin{array}{l}11.7 \\
23.5\end{array}$ & $\begin{array}{l}139 \\
23.4\end{array}$ & $\begin{array}{r}27.1 \\
1.6\end{array}$ \\
\hline
\end{tabular}

The tests at the two expositions cannot be compared, except in the most general sort of way, because different prices were charged for feed and credited for milk and butter-fat produced. All of the tests plainly show that greater variations in economy of production exist within the various breeds than between the breeds. This is a point often forgotten by those who argue upon the comparative merits of breeds. At the Pan-American Exposition, the best Guernsey cow returned five times as much profit as the poorest Dutch Belted cow. At the Louisiana- 
Purchase Exposition, the best Jersey returned twenty-six times the profit returned by the poorest Shorthorn. In both tests it will be observed that in the majority of instances the best cow of a breed returned twice as much profit as the poorest cow of the same breed.

At the Louisiana-Purchase Exposition, a Holstein cow was the leader in total production of milk and butter-fat, and a Jersey led in economy of production. The following facts from the complete, detailed reports are of much value in showing the possibilities for profit from well-bred dairy cows of real dairy type. Although varying considerably in the quantity and quality of milk produced, it will be observed that they were nearly equal from the standpoint of net profits:

\begin{tabular}{|c|c|}
\hline Name. . . . . . . . . . . . . . . . . . Shadybrook Gerben & Loretta D \\
\hline$\ldots \ldots \ldots \ldots$ Holstein & Jersey \\
\hline Duration of test, days .......... & 120 \\
\hline Days in milk at beginning of test. & 71. \\
\hline Total pounds milk............ & 5802.7 \\
\hline Total pounds butter-fat.. & 280.2 \\
\hline Total pounds butter. .... & 330.0 \\
\hline Average per cent. fat. & 4.82 \\
\hline Average per cent. total solids. . . . . . . . . . . & 13.83 \\
\hline Average pounds milk per day ............ & 48.4 \\
\hline Pounds milk to make $1 \mathrm{lb}$. butter . . . . . . . . & 17.58 \\
\hline Average value milk per day, cents. . . . . . . . & 83.11 \\
\hline Average value butter per day, cents . . . . . . . & 68.75 \\
\hline Average grain ration, pounds. . . . . . . . . . & \\
\hline Average hay and silage, pounds.......... & 36 . \\
\hline Cost of ration per day, cents............. & 26.65 \\
\hline Cost of feed in 100 lbs. milk, cents . . . . . . . & 55. \\
\hline Cost of feed in $1 \mathrm{lb}$. butter, cents . . . . . . . . & 9.69 \\
\hline Average net profit milk per days, cents . . . . . & 56.45 \\
\hline Average net profit butter per day, cents...... & 42.09 \\
\hline Pounds gain in weight during test........... & 77. \\
\hline
\end{tabular}

The highest records in milk and butter-fat production are useful in showing the possibilities in the breeding, feeding, and management of dairy cattle. Sometimes these records are made regardless of economy in production, no expense being spared to give the cow every opportunity to make a high record; sometimes they have been secured at the expense of the cow's future usefulness, her constitution being undermined and her digestion permanently deranged by the forcing methods that are practiced. Hence the value of such records is sometimes overestimated.

Following are the leading records of the various dairy breeds, the world's records over all breeds being indicated by an asterisk $(*)$. 
Holsteins.

*One day, 1917, May Echo Sylvia (Ontario, Can.)..... 152.10 lbs. milk

*One day, 1919, Rolo Mercena D'eKol (Ontario, Can.).. 6.86 lbs. fat

*7 days, 1917, May Echo Sylvia (Ontario, Can.) ..... 1,005.10 lbs. milk

*7 days, 1919, Rolo Mercena DeKol (Ontario, Can.)... 41.54 lbs. fat

*30 days, 1917, May Echo Sylvia (Ontario, Can.)...... 4,196.90 lbs. milk *30 days, 1919, Rolo Mercena DeKol (Ontario, Can.)... 160.27 lbs. fat

*One year, 1919, Tilly Alcartra (California)..........33,428.80 lbs. milk

*One year, 1915, Duchess Skylark Ormsby (Minnesota). . 1,205.09 lbs. fat

Guernseys.

One year, 1915, Murne Cowan (Ohio) ............24,008.00 lbs. milk

One year, 1915, Murne Cowan (Ohio) .............. 1,098.18 lbs. fat

Jerseys.

One year, 1915, Passport (Pennsylvania)...........19,694.80 lbs. milk One year, 1919, Vive La France (Oregon) ........... 1,031.64 lbs. fat

Ayrshires.

One year, 1915, Garclaugh, May Mischief (Pennsylvania)25,329 .00 lbs. milk One year, 1915, Lily of Willowmoor (Washington)..... $955.56 \mathrm{lbs}$. fat

\section{Brown Swiss.}

One year, 1913, College Bravura 2d. (Michigan)...... 19,460.60 lbs. milk One year, 1913, College Bravura 2d. (Michigan)...... 798.16 lbs. fat

An Ayrshire cow, Crocus, is reported to have given over 45 tons of milk during her 17 years of life. Another Ayrshire cow, Annie Bert, is reported to have given over 45 tons of milk during twelve lactation periods. She also had a record of nearly 2 tons of butter. The University of Missouri had a Jersey cow, Hope of Ramapo, that in 17 years produced 78,585 pounds of milk, 4,147 pounds of butter, and 15 calves, thus bringing $\$ 1,341.72$ into the treasury. The noted Jersey cow, Jacoba Irene, in 37 months produced 42,373 pounds of milk and 2,331 pounds of butter-fat. Another noted Jersey, Sophie 19th. of: Hood Farm, in 6 years produced 75,920 pounds of milk and 4,433 pounds of fat. Lily of Willowmoor, an Ayrshire owned in the state of Washington, produced 84,991 pounds of milk. and 3,362 pounds of fat in 5 years. The most notable longdistance record is that of the Holstein cow Tilly Alcartra, owned in California, that has produced in 6 consecutive years a total of 4,913 pounds of butter-fat and 156,776 pounds of milk.

Cause of wide variation in production.-Prof. C. H. Eckles of the Missouri Station* has determined why dairy cows vary so widely in production and profit. Two cows in the station herd showing striking difference in ability were selected for the

*Mo. Res. Bul. 2. 
investigation. They were registered Jerseys, sired by the same bull, from dams distantly related, and they had been raised under practically the same conditions. The following table gives the facts regarding these two cows during the first two milking periods prior to the investigation:

Name

Date of birth

Age at first calving.

Pounds milk, first lactation period.....

Pounds fat, first lactation period.

Number of days in milk.

Pounds milk, second lactation period

Pounds fat, second lactation period. .

Number of days in milk...........
Pedro's Ramaposa

Sept. 4, 1902

$29 \mathrm{mo}$.

4552

238.8

337

7174

377

365
Pedro's Elf

May 11, 1903

$18 \mathrm{mo}$.

878

44.1

131

3189

114.8

232

During these two lactation periods, Pedro's Ramaposa produced 2.8 pounds of milk and 3.9 pounds of fat for each pound produced by Pedro's Elf. While the second milking period was in progress, an investigation was planned to determine the cause of this difference in efficiency as dairy cows. The cows were therefore bred so that the calves might be born as near the same time as possible; Pedro's Elf calved October 4, 1907, and Pedro's Ramaposa calved October 7.

Complete records were kept of the amount and composition of the feeds consumed Each cow was fed a ration of the same composition at all times, but the amount was varied to suit the individual. As there was a possibility of the inferior cow using part of her feed for depositing fat on her body-a characteristic of inferior dairy cows-each cow was fed such an amount as would keep her at a uniform body weight. Thus the feed consumed could be studied in relation to dairy qualities only. They were fed all they would consume, unless they began to lay on flesh and gain in weight. The refused feed was collected, analyzed, and deducted from the records. Complete records were kept of the milk produced and of its composition. The same man always milked both cows. In order to eliminate another disturbing factor from such an experiment, the cows were kept farrow; had they carried calves, it would have been impossible to have accurately measured the feed requirements for milk production. A digestion trial was conducted when the cows were at their maximum production to ascertain whether any difference existed in the efficiency of digestion.

At the end of the milking period the cows were kept farrow and the same ration was fed as during the milking period; this was continued for 90 days, the feeding being so regulated 
in quantity as to maintain the cows at a uniform body weight In this way the requirement for maintenance was determined for each cow. A maintenance ration is one that will maintain a resting animal at a uniform body weight; such a ration keeps up the body heat, makes repairs in the tissues, and furnishes energy for the working of the heart, lungs, digestive and other organs, and for slight movements of the body. If the dairy cow is pregnant, she requires enough feed above maintenance to furnish nourishment for the foetus. Still more feed in excess of maintenance is necessary if she is giving milk as well as carrying a calf. Cows vary somewhat in their maintenance requirements, hence two cows consuming the same amounts of feed may have different proportions of their feed available for milk production. For instance, a restless cow has a greater maintenance requirement than a quiet one; when standing up, more feed is required for maintenance than when lying down. Many other factors affect the requirement for maintenance. It is therefore apparent that an investigation into the cause of differences in the economy of production is not complete unless the requirement for maintenance is determined. This the Missouri Station did by finding how much feed was necessary to maintain each cow at a constant body weight while dry and farrow. Other experiments have shown that a well-fed dairy cow uses about 43 per cent. of her feed for maintenance, 30 per cent. in the work of converting feed into milk, and about 20 per cent. finally appears as milk. These percentages vary, depending on the nature of the feed and the individual, but a good dairy cow is more efficient as a machine than either the horse or the steam engine. In the Missouri experiment it was found that the higher-producing cow required slightly more feed for maintenance; hence, the wide variation in production could not be accounted for by a superiority of the high-producing cow in regard to maintenance.

During the year of the investigation, Pedro's Ramaposa produced 8,522 pounds of milk and 469.9 pounds of fat. Pedro's Elf produced 3,188 pounds of milk and 169.3 pounds of fat. The former produced 2.67 pounds of milk and 2.77 pounds of fat for each pound produced by the latter. The digestion trial showed practically identical results, the co-efficient of digestion being 64.39 per cent. for the best cow and 64.99 for the poorest cow. Pedro's Ramaposa consumed 1.75 pounds of feed for each pound used by the other cow, and the real cause of the differ- 
ence in production was found to be the amount of feed consumed above maintenance. The maintenance requirement being practically the same, Ramaposa had 65 per cent. of the total feed consumed available for milk production, and Elf had only 44.2 per cent. thus available.

It was observed that Ramaposa, when producing the maximum milk yield, was practically to the limit of her capacity for handling feed. Her maximum capacity for feed seemed to coincide closely with the amount necessary to maintain her at uniform weight. Elf consumed all her feed, and would have taken slightly more had it been offered, although she never showed lack of feed. Ramaposa had much the stronger appetite; she ate rapidly, swallowed the grain with much less chewing, and always showed by her impatience to get her feed a much keener appetite than did the latter. Both cows remained in excellent physical condition throughout the investigation.

After deducting the maintenance requirement, one cow produced milk as economically as the other. The ratio between the feed available for milk production and the milk produced was practically the same for each cow. The experiment showed that cows vary but little in the maintenance requirement, or in their ability to digest feed. A superior dairy cow is one with a large capacity for feed above maintenance, and one that is not disposed to take on fat, but uses the feed above maintenance for milk production. This once more emphasizes the importance of a large, well-developed barrel and its significance in judging dairy cows, provided the cow also has a high degree of dairy temperament as shown by her lean appearance when heavily fed while in milk.

Effect of feed on quantity and composition of milk.-The general statement may be made that the quantity of milk is dependent upon the amount of feed and upon the inherent milkgiving qualities of the cow. Feed has an effect on the quantity of the milk yield, in that an underfed cow cannot produce to the limit of her ability. As shown in the Missouri experiment, however, heavy feeding does not increase the cow's ability, it merely makes possible a production that is up to the limit of her natural, inherited ability. The composition of the milk cannot be permanently changed by any known method of feeding; the composition is regulated by the udder of the cow, each cow having her own characteristic quality of milk. By fattening dry cows, the fat content of the milk is temporarily raised 
when the cows freshen. It is known that cows fed cottonseed meal yield butter that is hard and tallowy, with a high melting point, while linseed meal produces a soft butter with a low melting point. In spite of these and other minor exceptions, it may be said that improvement in the composition of milk is a breeding, rather than a feeding, problem. The feeder can only supply feed in such amount as will permit the cow to give a maximum flow of milk. But as we have seen, two cows may produce far different quantities of milk when given the best of care, so that increase in the quantity of milk is also a problem for the breeder. Cows are born with certain inherent abilities; feeding can assist these inherent abilities to reveal themselves, but cannot permanently alter them. Great cows are born great. Their greatness will not be realized, however, unless they are given good care and plenty of the right kind of feed to use in manufacturing milk. No matter how large and efficient a factory may be, it cannot turn out much product unless it has available an abundant supply of the raw material, but an abundant supply of raw material will not raise the output of a poorly equipped or inefficient plant above a certain low maximum. It is far more correct to say that a well-fed dairy cow eats because she gives milk, than it is to say that she gives milk because she eats. 


\section{CHAPTER XIII. \\ BREEDING FOR MILK PRODUCTION.}

In 1919 , there were $23,467,000$ dairy cows on farms in the United States, and they were valued at $\$ 78.24$ per head. If put in single file, allowing ten feet of space for each animal, they would make a line over 44,000 miles long, or would form a procession fourteen abreast from New York to San Francisco.

On January 1, 1919, the leading states in numbers of dairy cows, and their average prices per head, were as follows:

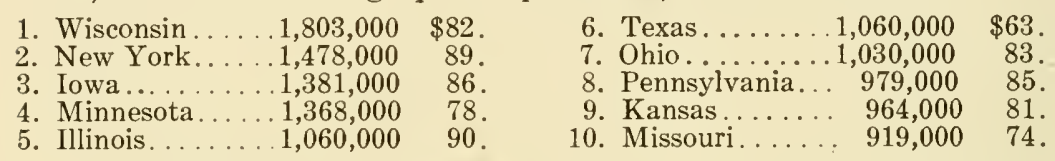

The distribution of dairy cows, by geographical divisions, on January 1, 1919, was as follows:

North Atlantic...

$3,515,000$

South Atlantic

$1,963,000$

North Central, East of Mississippi River.

$5,454,000$

North Central, West of Mississippi River..

$6,284,000$

South Central.

$4,294,000$

Far Western..

$1,957,000$

Total, United States..

$23,467,000$

No greater strides have been made in animal breeding during recent years than have been made by breeders of purebred dairy cattle. The methods used are very practical because they are based on accurate knowledge of the producing ability of the animals bred, such knowledge being secured by tests of the various cows in the herd. The dairyman engaged in the production of market milk or butter-fat has, in many instances, seen the benefits arising from keeping records and using them as a basis for improving his herd and has greatly benefited by adopting the methods used by the more progressive breeders of purebred dairy cattle. There is great need for the improvement of the average dairy cow of the country. The small number of purebred dairy cows makes it inadvisable to recommend that this improvement shall be accomplished by replacing the average cow with a purebred cow, and that all milk and butterfat shall be produced by purebred cattle. However, this ideal is easily possible of close approximation by using purebred dairy 
bulls to grade up the ordinary dairy cows of the country. There is no good argument in behalf of keeping any except a purebred dairy bull at the head of any dairy herd. No progressive dairyman will take chances in raising a heifer calf for milk purposes whose sire is either a beef bull or a mongrel. The necessity for using purebred sires to breed to common cows and the financial advantage of such a policy was pointed out in Chapter IX., in which the breeding of beef cattle for the market was discussed. The arguments there presented apply with equal force to the breeding of dairy cattle.

Tests which strikingly illustrate the effect of a purebred sire in improving a herd of scrub dairy cows have been conducted at the Iowa Station* by Kildee and McCandlish. The results presented in the following table show the average yearly production of the original scrub cows and the greatly increased ability of their daughters and granddaughters sired by good purebred dairy bulls. All were fed and cared for alike, and no animals were weeded out during the experiment, so that the improvement secured can be credited only to the use of good purebred sires:

\begin{tabular}{|c|c|c|c|c|c|c|}
\hline \multirow[b]{2}{*}{ Sire } & \multicolumn{2}{|c|}{ Scrub dams } & \multicolumn{2}{|c|}{ Daughters } & \multicolumn{2}{|c|}{ Granddaughters } \\
\hline & $\begin{array}{l}\text { Milk } \\
\text { lbs. }\end{array}$ & Fat, lbs. & $\begin{array}{l}\text { Milk, } \\
\text { lbs. }\end{array}$ & Fat, lbs. & $\begin{array}{l}\text { Milk, } \\
\text { lbs. }\end{array}$ & Fat, lbs. \\
\hline $\begin{array}{l}\text { Guernsey } \\
\text { Holstein .. } \\
\text { Jersey ... }\end{array}$ & $\begin{array}{l}3687 \\
3782 \\
3463\end{array}$ & $\begin{array}{l}168 \\
176 \\
168\end{array}$ & $\begin{array}{l}5102 \\
6840 \\
5009\end{array}$ & $\begin{array}{l}241 \\
273 \\
264\end{array}$ & $\begin{array}{r}5810 \\
11127 \\
5411\end{array}$ & $\begin{array}{l}301 \\
420 \\
287\end{array}$ \\
\hline Average of all. & 3660 & 172 & 5999 & 261 & 8402 & 358 \\
\hline
\end{tabular}

If the results are expressed on the percentage basis, the percentage increase in production of the daughters and granddaughters over the original scrub cows may be determined. The following table shows this percentage increase:

\begin{tabular}{|c|c|c|c|c|}
\hline \multirow{2}{*}{ Sire } & \multicolumn{2}{|c|}{ Daughters } & \multicolumn{2}{|c|}{ Granddaughters } \\
\hline & $\begin{array}{c}\text { Milk } \\
\text { per cent. }\end{array}$ & $\begin{array}{c}\text { Fat } \\
\text { per cent. }\end{array}$ & $\begin{array}{c}\text { Milk } \\
\text { per cent. }\end{array}$ & $\underset{\text { per cent. }}{\text { Fat }}$ \\
\hline $\begin{array}{l}\text { Guernsey . . . . . . . . } \\
\text { Holstein . . . . . . . . } \\
\text { Jersey . . . . }\end{array}$ & $\begin{array}{l}38 \\
81 \\
45\end{array}$ & $\begin{array}{l}43 \\
55 \\
57\end{array}$ & $\begin{array}{r}58 \\
194 \\
56\end{array}$ & $\begin{array}{r}79 \\
138 \\
71\end{array}$ \\
\hline Average & 64 & 52 & 130 & 109 \\
\hline
\end{tabular}

${ }^{*}$ Iowa Buls. 165 and 188. 
Scrub Cow No. 56. Average yearly production 3874.6 lbs. of milk and $192.62 \mathrm{lbs}$. of fat.

Half-blood Holstein No. 77 , out of Scrub No. 56. A verage yearly production 6955.5 lbs. of milk and $266.25 \mathrm{lbs}$. of fat.

Three-quarterblood Holstein No. 233 , out of half-blood Holstein No. 77. Average yearly production 12804.2 lbs. of milk and 482.54 lbs. of fat.
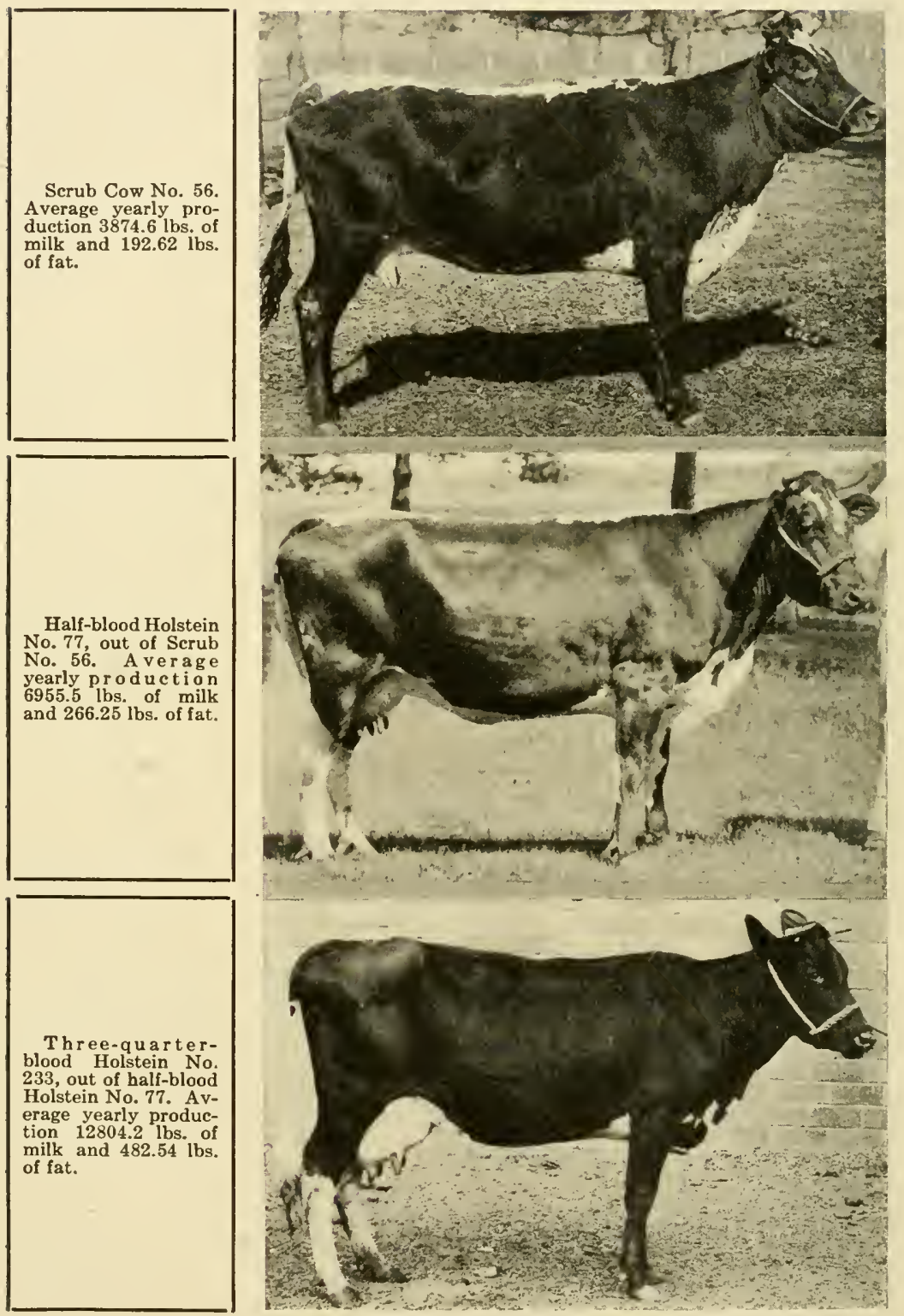

Fig. 50. What Good Purebred Sires Can Do.

Improved production in two generations through the use of purebred Holstein sires. From the Iowa experiment 
The half-blood daughters, carrying 50 per cent. of improved breeding, showed an increase of 52 per cent. in butter-fat production as compared to their scrub dams. The granddaughters, carrying 75 per cent. of improved breeding, showed an increase of 109 per cent. in butter-fat production as compared to their scrub grandams. In other words, the production of this herd was doubled in two generations through the use of good dairy sires.

By going to the same breed each time a sire is selected, the dairyman soon acquires a herd of very high-grade cows, having only a very small percentage of scrub ancestry. Good grade dairy cows often rival their purebred cousins in production, and many have sold at prices considerably above $\$ 200$. By using purebred sires, and by weeding out the poor producers and retaining the high-producing cows and their heifer calves, an inferior herd may be revolutionized and made to yield a profit. In this way the dairyman is enabled to raise his standards higher and higher, each year eliminating from his herd those cows which fail to reach the mark. Eventually a herd is built up in which every cow returns a large profit on the feed and care invested in her during the year.

12 The following records made by the herd of Peder Pedersen \& Son in the Benson Cow Testing Association, Cedar Falls, Iowa, in three consecutive years show what may be accomplished by the use of good sires, the keeping of records, weeding out the poor cows, and by proper feeding and management:

$\begin{array}{ccc}\text { Average milk per cow } & \begin{array}{c}\text { Average } \\ \text { butter-fat }\end{array} & \text { Net income } \\ \text { per cow over }\end{array}$

19115665 pounds.................... $207.7 \quad \$ 22.12$

Largest net income cow in herd.......... $\quad 54.22$

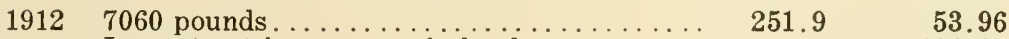

Largest net income cow in herd .......... $\quad 106.30$

$1913 \quad 9697.47$ pounds ................. $341.98 \quad 75.00$

Two largest net income cows, each........ 144.00

This herd was made up of grades and a few purebred Holsteins, and the number of cows remained about the same during the three years reported. At the end of the first year it was found that 40 per cent. of the cows were unprofitable. They were sent to the butcher, and their places in the herd were taken by two-year-old heifers sired by a purebred sire out of common cows. At the end of the second year, 30 per cent. of the cows 
were "weeded out" and their places taken by two-year-old grade heifers, one purebred cow, and one purebred two-year-old heifer. The end of the third year's work showed that the average milk production had been increased over 71 per cent., the butter-fat 60 per cent., and the average net profit per cow increased from $\$ 22.12$ to $\$ 75.00$, or 239 per cent.

Selection of the dairy bull.-If fifteen or twenty dairy bulls are brought before a judge recognized as competent, and he is asked to pick out the bull that will sire the highest-producing cows, he will be unable to do so with any degree of certainty by studying their individualities. He may easily eliminate some of them because of lack of constitution, weak masculinity, or because they show a decided tendency towards.fleshiness. Having such faults, he is reasonably certain that they will not prove sure breeders, or that their heifer calves will not develop into high producers. Having eliminated certain ones, there will probably be several bulls remaining that have no serious faults in conformation, and among these it is mere guesswork to attempt to select the most successful sire. Whereas the beef bull carries his evidence of merit upon his back, the true value of the dairy bull can only be judged by the kind of cows in his ancestry, the kind of cows he sires, or by both. The judging of dairy bulls in the show ring is much less conducive to good results in the improvement of cattle than is the judging of beef bulls.

As a general rule, when valuing a purebred animal, more emphasis should be placed upon individuality than upon pedigree; but the dairy bull is an exception. On a basis of 100 points given to the bull's selection, it is conservative to state that 40 points should be allotted to his individuality, and 60 points to the records of performance in his pedigree. All purebred dairy bulls have pedigrees, but in many cases no records were kept of the production of their female ancestors; in such cases the pedigree has no special significance, and little importance can be attached to it. When records of performance of the ancestors are available, the bull is said to have a "pedigree with performance," and to such a pedigree much attention should be given when selecting a bull.

If the bull is matured and has been long enough in service so that he has heifers in milk, they furnish the best evidence of the bull's value as a breeder. In this connection, however, the dams of the heifers must be studied, as the seeming success of 
the bull may be very largely due to the excellence of the cows with which he is mated. If the dams are inferior and the heifers are good, all the more credit is due the sire. Most of the trade in purebred dairy bulls is in bull calves, for only rarely will a successful bull, as shown by actual trial, be offered for sale.

The best indication of the future breeding value of a dairy bull calf is furnished by the milk and butter-fat records of his

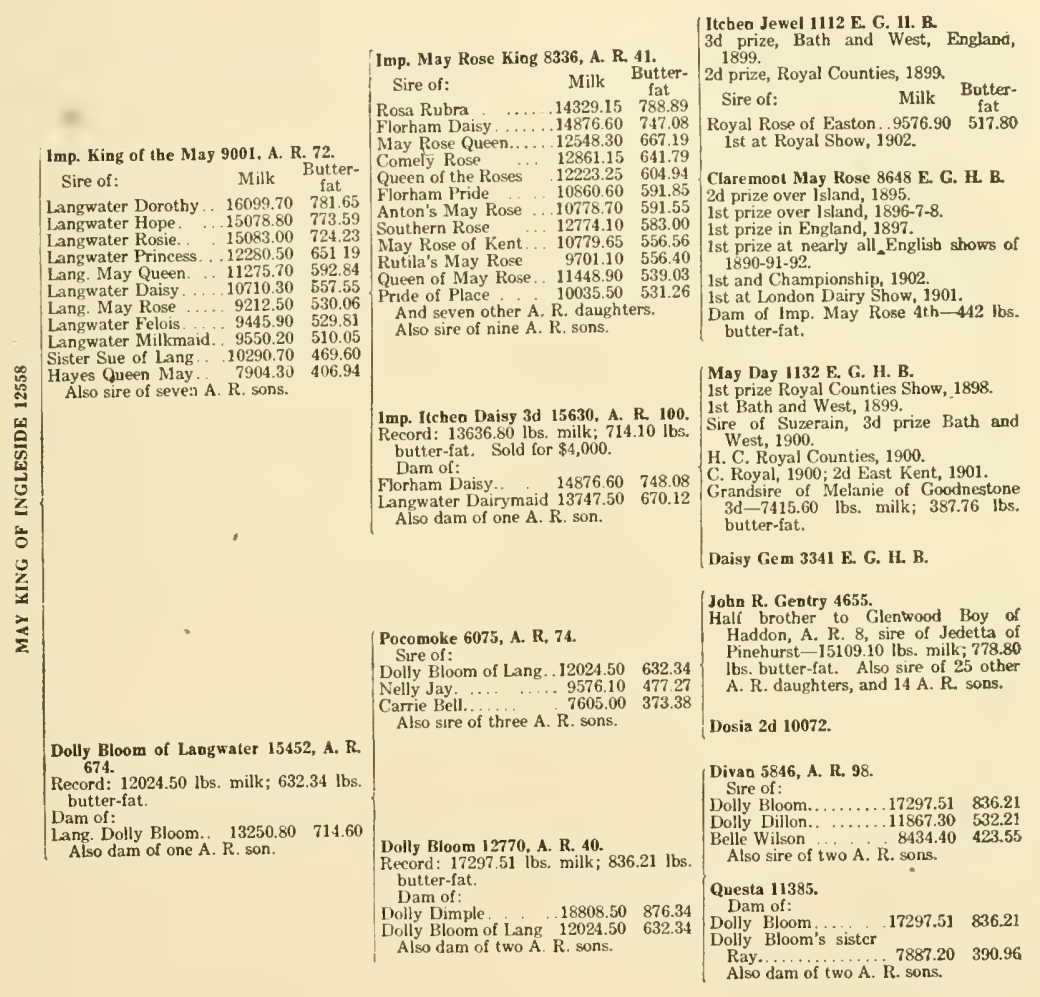

dam. If any of her female offspring have records of production, these also furnish valuable evidence. Next, the records of the cows sired by his sire should be studied, if such records are available. After that, the performance of the paternal and maternal grandams should be noted, together with the performance of their female offspring. The grandsires' lists of performers should be studied also, and, if possible, similar studies should be made of the great-grandams and great-grandsires. The fundamental principle underlying breeding is that "like 
begets like," and if the bull has a high-producing ancestry, high-producing sisters, and the other female members of his family are high producers, we are reasonably certain that he has inherited true dairy qualities of a high order which he will transmit to his offspring.

As a fine example of a pedigree with performance, the pedigree of the Guernsey bull, May King of Ingleside 12558, is herewith presented. Such a bull commands too high a price to permit using him on grade cows, and the average dairyman seeking a sire cannot expect to obtain a bull with a pedigree equal to this one, although he may be able to secure $a^{\circ}$ son or grandson of such a bull at the price he can afford to pay.

There is danger of over-emphasizing the importance of pedigrees when breeding any kind of live stock, and this is especially true if records of tests are included in the pedigrees, as is the case with many trotting horses and dairy cattle. Some breeders have selected and mated their animals solely upon the basis of records, without any consideration of individuality. Animal breeding is not successfully supervised when the owner decides upon matings from pedigrees spread out before him in his office or by the parlor lamp. If this is done, and individuality is neglected, defects of conformation may gain a foothold in his herd and eventually defeat his plans. For instance, two animals may be selected for mating because of the excellence of their breeding; in other words, the mating looks good on paper; but weakness of constitution may be common to both of them, and if so, it is probable that their offspring will exhibit this defect in greater degree, so as to prevent the fulfillment of the offspring's inherited tendency to high production.

Enough attempts at selecting and mating animals purely on the basis of records have met with failure to show that such procedure is very liable to wreck the herd. The breeder must refuse to be carried away by performance to the extent of buying merely a pedigree. Choose several good individuals, and then let the pedigrees be the basis for the final choice. A meritorious individual should accompany the meritorious pedigree.

Advantages of dairy farming.-Dairy farming has the following advantages:

1. The dairy cow is well adapted to diversified and intensive farming where the farmer strives to produce the greatest possible income from a small acreage. Striking examples of this fact are found in Holland, Denmark, and the Island of Jersey. 
2. If the manure is properly conserved and used, dairy farming increases soil fertility. A ton of butter removes only 64 cents' worth of plant food from the farm, while a ton of corn removes $\$ 6.56$ worth of plant food. By feeding the crops and purchased supplementary feeds to dairy cows, the land may be made more productive.

3. The dairy cow is a continuous source of revenue. The cream or milk checks come in at frequent and regular intervals.

4. Skim milk is a most excellent feed for hogs and poultry. sale.

5. Good grade and purebred dairy cows meet with ready

It is also true that the dairy cow yields about six times as much edible solids in her milk for every 100 pounds of digestible nutrients consumed as the beef steer or mutton sheep in its carcass. The dairy cow is a more economical producer of food for human beings than is the steer, sheep, or pig. 


\section{CHAPTER XIV.}

\section{DUAL-PURPOSE CATTLE.}

Dual-purpose cattle are all-purpose or general-purpose cattle. They occupy a position midway between the beef and the dairy types, the aim being to combine the good points of both beef and dairy cattle as nearly as possible. The dualpurpose cow, however, does not give as much milk as the dairy cow, nor does she make as much beef as the beef cow. At present the demand for dual-purpose cattle is comparatively limited, although it has been predicted that many farms will eventually adopt the dual-purpose type as the one most profitable. It is also believed that those who maintain beef breeding herds will in the future pay more attention to the milking qualities of their cows.

Perhaps no subject relating to cattle has aroused so much discussion as has the type, economic importance, and probable future of the dual-purpose cow. It has been argued that the day of general-purpose animals is past. It is said that this is a day of specialization in all things, and that better results and more profit are obtained from animals which do one thing and do it well, than are obtained from animals which do two or three things in a mediocre way. While it is true that the tendency in the live-stock world is more and more toward highly specialized types of animals, it is also true that there are good arguments in favor of a dual-purpose type of cattle. Of these arguments, the best one is that there is need of a farmer's cow; that is, a cow for the farmer who is neither a beef producer nor a dairyman, but who wants to produce enough meat and milk for his own use. Such a man wants a cow that gives a good flow of milk, and yet one that has a strong enough beef tendency to produce a calf that will feed out well and make a good carcass; in other words, this man wants a dual-purpose cow. There can be no doubting this argument and it was this demand which made the old-time Shorthorn the popular cow with farmers fifty or sixty years ago.

Another argument frequently advanced in behalf of dualpurpose cattle is that beef production on high-priced land must, in the future, come from a dual-purpose type of cattle. On west- 
ern ranches where land is cheap, a calf is all the return a cow need give in order to make her profitable, but the cornbelt farmer on $\$ 100$ and $\$ 200$ land cannot conduct a business on the same basis as the western ranchman. It is argued that a farmer on high-priced land cannot afford to keep a cow that produces calves suitable for feeding into beef unless she pays for her board, in part at least, with a fair amount of butter-fat. It is argued that he can no more afford this than he can afford to keep mutton sheep which produce lambs, but no wool. The advocates of the dual-purpose cow claim that she will be the

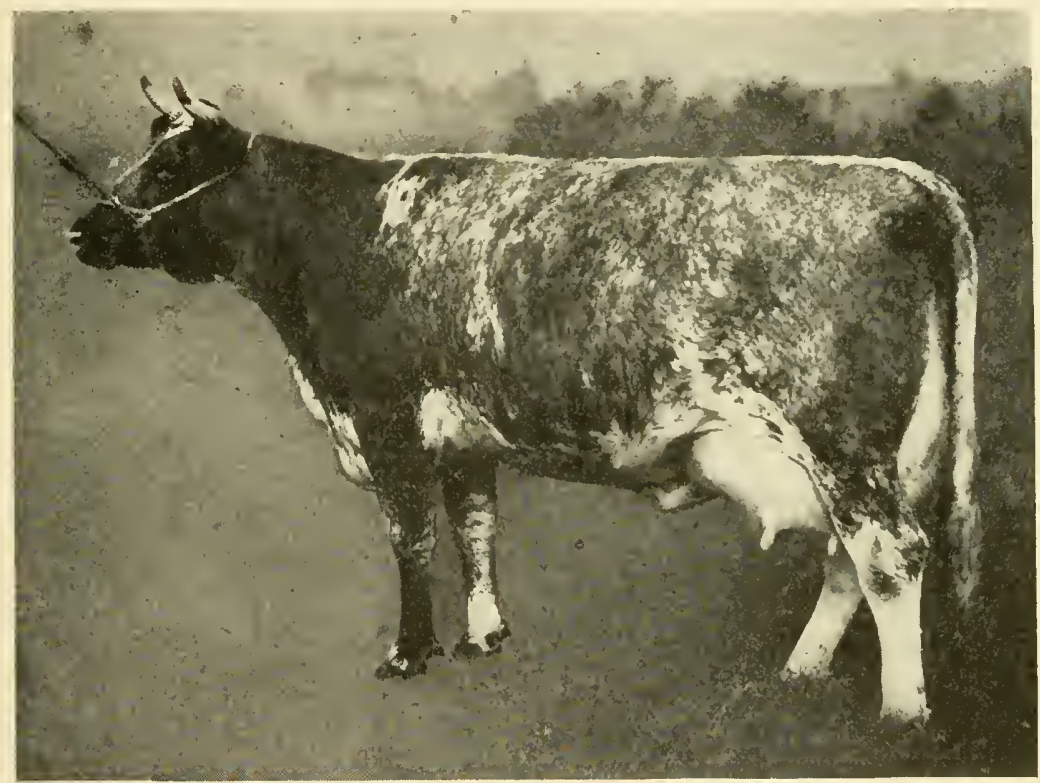

Fig. 51. The Dual-Purpose Type.

Milking Shorthorn cow, Pansy 2d., first prize winner at Carlisle, England, in 1914. Imported and owned by Mr. J. J. Hill, St. Paul, Minn.

salvation of future beef production. However this may be, changes will come gradually and it seems probable that the beef-type animal is destined to continue popular for some years to come.

The methods of management where dual-purpose herds are kept vary considerably. Sometimes the production of beef is given most attention and the milking qualities of the cows are esteemed only as a source of feed for the calves. At the other extreme are herds managed as dairy herds, the beefiness 
of the cows making possible a good income from choice veal calves reared on skim milk and supplemental feeds. Neither of these plans represents true dual-purpose management. The dual-purpose cow is at her best when the plan calls for the sale of milk or butter-fat and the rearing of calves to be fed and marketed as fat steers and heifers, or sold into other hands for feeding. All of the cows may be milked, the butter-fat sold, and the skim milk fed to the calves; or half of the cows may be milked and the rest allowed to raise the calves. The writer knows of one successful herd of grade cows where the practice is to put four calves on one cow, the other three cows being milked. The development of the calves is somewhat restricted by this method, for they do not make as rapid growth nor present as good appearance as would be secured by more liberal feeding, but in this instance the financial return has justified the plan.

It is considerable trouble to rear calves on skim milk, but it is being done with good results on many farms. The skim milk should be supplemented by oats, bran, corn meal, hay, and good pasture until weaning time, and the calf should be wintered on grain, silage, and hay. When weaned and placed on regular rations, skim-milk calves usually advance rapidly and often overtake calves reared on whole milk to such an extent that they cannot be distinguished from the latter.

Dual-purpose type.-Descriptions of the beef and dairy types having been given in detail, dual-purpose type may be described in a few words by comparisons. The true dualpurpose type of animal is distinguished from the beef animal by certain well-marked differences in form and appearance. The dual-purpose animal is not so wide as the beef animal, nor so smooth, and the fleshing is not so thick. The neck is longer, the withers are not so wide and rounding, the middle is less blocky and compact, and the legs are longer. The udder receives considerable attention and should be large, mellow, and of good shape. The dual-purpose cow should bear indications of creditable performance at the pail.

Compared with the dairy type, the dual-purpose animal shows more squareness and fullness of forequarters, more width and compactness of body, more fleshing and smoothness. The spring of rib is more pronounced, the back is wider, the withers are thicker, the shoulder is heavier fleshed and smoother, and the thigh and twist are much more heavily fleshed. Dualpurpose cows that give a generous milk flow will carry less 
flesh during the milking period, but when dry they take on flesh readily. Their calves have a reasonably good fleshing when fed for market, especially if sired by a beef-type bull.

When dual-purpose cattle are brought into the ring at fairs and expositions, it is readily observable that marked variations in type exist, ranging from near the dairy type to the lower limits of beef type. What is regarded as a typical dual-purpose animal by one man will not always suit another, but will be criticised as leaning too much toward the beef type or the dairy type. Some men accept a beef cow with a larger udder than usual as a typical dual-purpose animal; others have in mind a dairy cow showing more beefiness than common. In the show

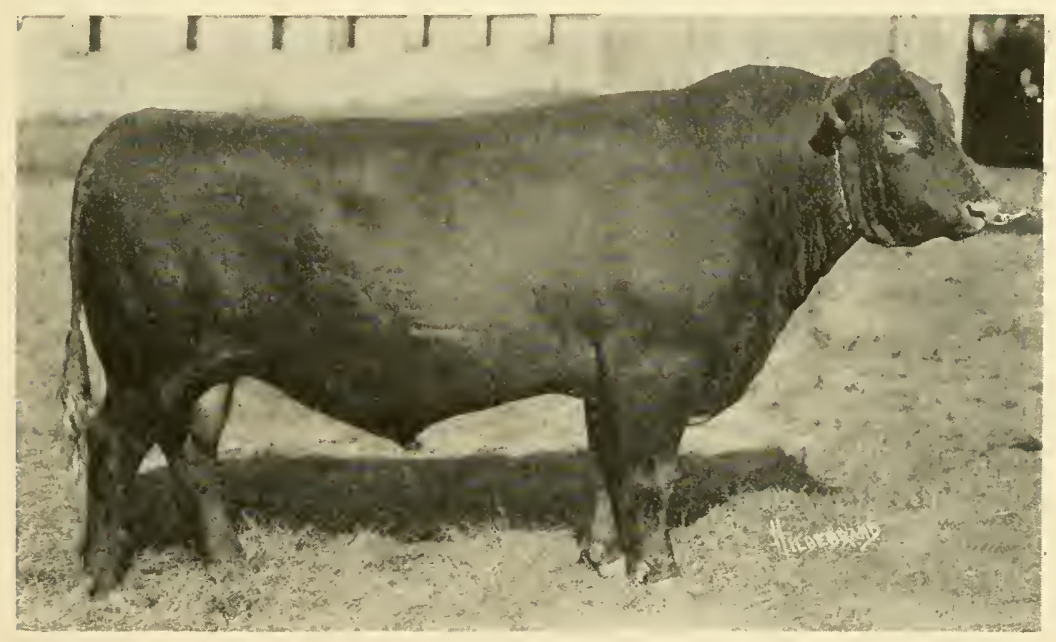

Fig. 52. The Dual-Purpose Type.

Red Polled bull, Teddy's Best, thirty-two times a Champion, and a very noted sire. Owned by Jean Du Luth Farms, Duluth, Minn.

rings of this country much dissatisfaction has arisen over the judging of dual-purpose cattle; some judges have apparently awarded the prizes upon the beef qualities of the animals shown, while other judges have leaned almost as such the other way. A judge at one show will select certain animals as prize winners, and at another show, with the same cattle on exhibition, an almost complete reversal will be made in the awards-hence the dissatisfaction. As time goes on, breeders are getting closer together in their ideals of a dual-purpose animal, although there can never be the uniformity of ideals which prevails among 
breeders of either beef or dairy cattle. This is true because beef and dairy types represent extremes, while the dual-purpose type is an average of these two, or represents the middle ground.

Profits from dual-purpose cattle.-In an investigation into the methods and cost of growing beef cattle in the cornbelt states in 1914 and 1915, the U. S. Department of Agriculture obtained 596 records from farms in Indiana, Illinois, Minnesota, Iowa, Missouri, South Dakota, Nebraska, and Kansas.* Farms where cows were kept for distinctly dairy purposes or where the herds were maintained only for the production and sale of purebred animals for breeding purposes were omitted. Records were procured on 14,634 cows and 621 bulls, and on 12,591 calves produced from them, of which 2,023 were fattened for baby beef. Six distinct practices in beef production were noted, as follows:

Beef.-Farms where all the cows are kept strictly for beef (not including farms producing baby beef).

Baby beef.-Farms maintaining breeding herds for the production of high-grade calves which are fattened on the same farm and sold at from 12 to 18 months of age as baby beef.

Dual-purpose.-Farms on which all of the cows are milked, and either cream or butter-fat sold, the calves being weaned at birth and raised on skim milk.

Mixed.-Farms on which the best cows are milked, their calves being weaned at birth and fed skim milk. Calves from the other cows are allowed to run with their dams as in the beef group.

Partially milked.-Farms on which the calves are not weaned, but on which a part of the milk is drawn from the cow, the calf taking the remainder.

Double nursing.-Farms where some of the cows are milked and their calves given to other cows, the latter raising two calves each.

The cost of calves at weaning time, the cost of raising yearlings, and the profit or loss on the yearlings was determined for each of the six groups. The accompanying table, showing the various factors that make up the cost of producing a yearling and summarizing the results of the investigation, indicates the economy of dual-purpose herds as beef producers. However, as this table is studied, it is well for the reader to keep in mind

*U. S. Dept. Agr. Report 111, by Cotton, Cooper, Ward, and Ray. 
Types and Market Classes of Live Stock

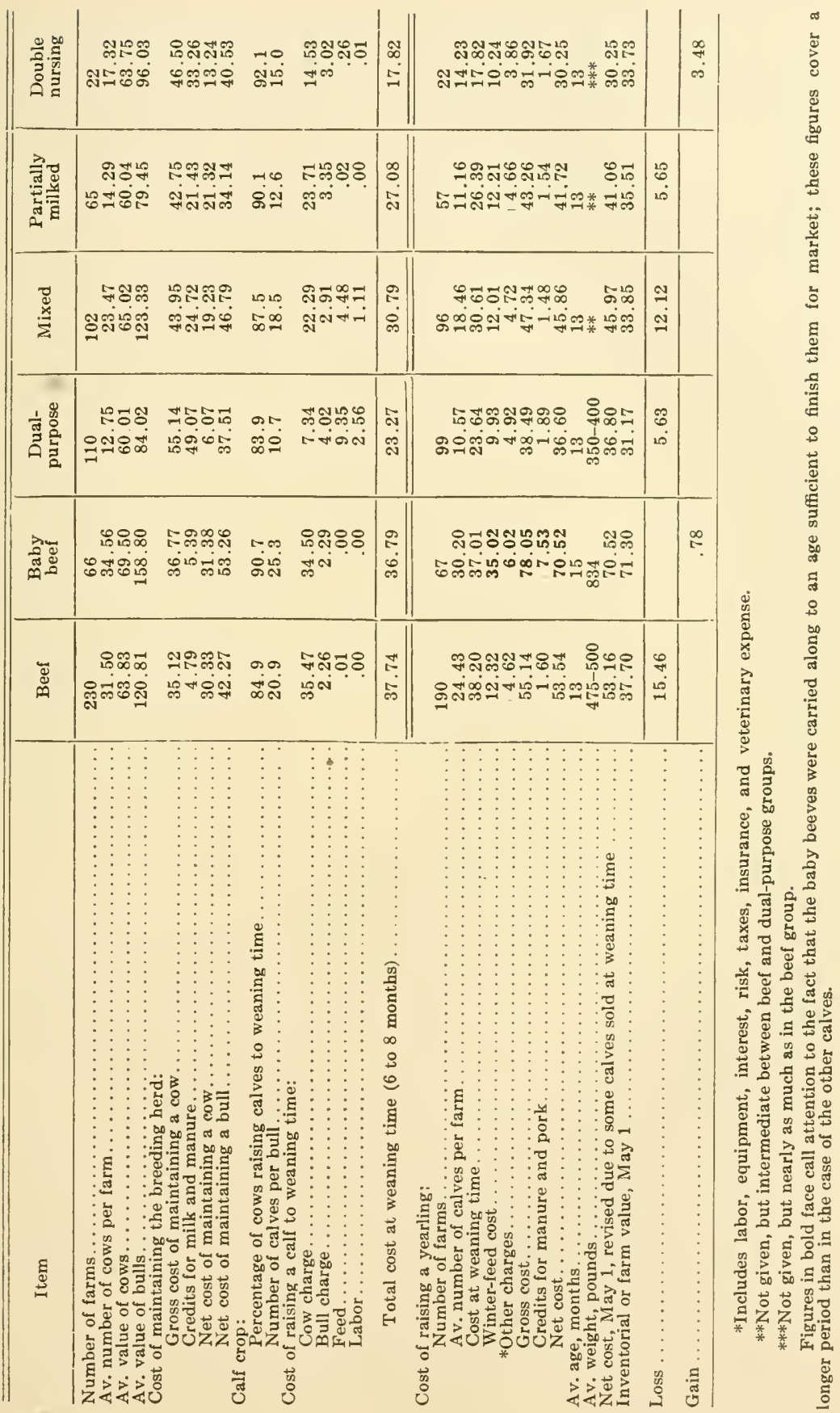


the fact that no profits were allowed for the dairying practiced by the owners of the dual-purpose, mixed, partially milked, and double nursing herds; instead, the returns, including profits, from the sale of milk have been used to lower the cost of the calf. Robbing one department of a farm of profit in order that another department may be credited so as to show a profit may represent skillful book-keeping, but results based on such a method of cost accounting are somewhat misleading. In this case it should be remembered that dairying was conducted at cost, the profits being eredited to beef production.

The greatest item of expense in raising a calf to weaning time, except in the dual-purpose group, is the cow charge, or net cost of keeping a cow a year. The net cost of maintaining a cow varied greatly, depending largely upon the sale of milk products from cows that were milked. It was therefore lowest in the dual-purpose group.

The cost of the calf at weaning time is lowest in the doublenursing group. While the cow charge was lowest in the dualpurpose group, the addition of the cost of feed and labor for the skim-milk calves made the cost of the calf somewhat greater than in the double-nursing group.

The cost of the calf at one year was lowest in the doublenursing group.

The calves in the dual-purpose group, although poorest in merit and value, ranked third in profit.

The calves in the double-nursing group were relatively of good quality and showed the greatest profit.

The data obtained indicate that the keeping of cattle for beef purposes alone is adapted to the more extensive types of farming, while the keeping of cattle primarily for beef purposes, but where an income is also obtained from milk products, is better adapted to the more intensive types of farming.

The averages would seem to indicate that profits from raising calves on cornbelt farms are very small. However, these facts must be taken into consideration:

1. Good returns have been obtained for a large quantity of roughage which, had it not been utilized by live stock, would have been waste.

2. A home market was provided for saleable crops.

3. On many farms a large acreage suitable to pasture only has been utilized. 
4. Profitable employment is provided for a season of the year when labor otherwise might be idle.

5. A return is obtained for capital invested in equipment which, in many instances, were it not utilized by live stock, would return nothing.

6. When the farmer merely breaks even he has at least made 6 per cent. interest on the money he has invested in the cattle business. 



\section{PART TWO.}

\section{SHEEP.}

\section{INTRODUCTION.}

The United States ranks as one of the principal muttonproducing and wool-growing countries of the world. The sheep industry in America dates back to early times. It has experienced more ups and downs, due to changing conditions and varying prices than has the cattle industry or the hog industry. At the present time the sheep business is in a transitional stage. The number and size of flocks in most of the western range states continue to decline. In the farming states increased interest in sheep and increased production are now noticeable. Lamb and wool production is a profitable business at the present time and promises to continue so, not only under range conditions but also in intensive farming.

Lamb and wool production require a smaller use of grain feeds than is required with other kinds of live-stock farming. A majority of lambs are marketed at weaning time and without having had any feed other than the milk of their dams and a slight amount of grazing. The lamb carcass requires less fat to render it suitable for the table than is necessary in any other class of meat. This fact adapts sheep raising to sections that are not adapted to the production of grains but can furnish good pasturage and forage crops. Lambs born late in the season, lambs raised by ewes which are not good milkers, and lambs raised under conditions which do not produce a good milk flow in the ewes go into the hands of feeders and consume considerable grain, but their finish is largely produced from hay and other roughages of comparatively lower value. Breeding ewes require little grain, and good fleeces are produced without the use of concentrated feeds.

Sheep have been advocated on the ground that no labor or attention is needed. It has been said that they are farm scavengers, that they will clear the farm of weeds. It is true that sheep will eat most weeds, and that farms which have a flock of sheep usually give evidence of that fact in cleaner fence 
rows and corners and a tidier appearance generally. It is also true that sheep raising requires comparatively little lábor. The labor cost per dollar's worth of wool or lambs is lower than in any other farm-animal product. It should be emphatically stated, however, that sheep will not do well unless they are given constant attention and the care necessary to maintain thrift, yet the amount of work required is by no means heavy except at lambing and shearing time. One competent man can care for from 300 to 500 ewes during winter.

Sheep raising, properly managed, is profitable on the cornbelt farm, while the New England states, and large areas of cutover timber lands in Michigan, Wisconsin, and Minnesota are suitable for sheep as soon as provision is made for the production of winter feed. Many millions of acres in this country not now in farms and which are largely unfit for the plow and not suitable for grazing by other animals, will eventually return a revenue in lambs and wool. The sheep's ability to prosper on grass and roughage, with little grain, gives it first call under these conditions.

The advantages of sheep, as compared to other live stock on the farm, have been most ably presented by the late Prof. John A. Craig.* He calls attention to the following:

1. Compared with cattle, sheep produce more liberally in proportion to what they consume. They consume more feed in proportion to their weight, and a larger proportion of what is eaten goes into increase. However, sheep are not so well fitted as cattle to utilize large quantities of coarse roughage.

2. The form in which sheep manure is dropped and the way it is tramped into the soil insure a smaller waste than is possible under any other system of stock farming. The sheep's habit of lying upon the highest spot of the field or pasture leaves the larger part of the droppings at the place where they are most needed. land.

3. Sheep farming utilizes what would be otherwise waste

4. They convert into mutton and wool much material that cannot be utilized by other animals. This is particularly true of grain lost in stubble. Volunteer growth or aftermath too scanty for other stock is just suited to the grazing habits of sheep.

* Sheep Farming in North America, pp. 3-8. 
5. Sheep are the best weed destroyers. Of the numerous plants regarded as weeds, cattle and horses eat about 50 per cent., while sheep eat over 90 per cent. of them.

6. The income from wool and that from the lambs and mutton come in in different parts of the year, and it seldom happens that both products sell at bottom prices the same year.

7. The wool clip is easily stored with practically no waste or deterioration if it is desirable to hold for a higher price.

8. The returns come quickly. Lambs may be marketed eight months after the ewes are bred.

9. The ewe's fleece usually pays for her keep. This puts the fat lamb on the market at low cost of production.

10. With good management, the increase in the flock may be safely counted at one hundred per cent.

Sheep breeders in the various countries have developed two distinct kinds of sheep-mutton sheep and wool sheep, the latter being commonly called fine-wool sheep. Mutton sheep naturally divide into two groups known as (1) long- or coarse-wool sheep, and (2) medium- or middle-wool sheep.

Fine-wool sheep bear wool that is $11 / 2$ to 4 inches long after twelve months' growth, medium-wool fleeces vary in length of fiber from 2 to 5 inches, and the long-wool fiber measures 5 to 12 inches. The fiber of the fine-wool fleece is very fine in diameter and has a large number of waves or crimps to the inch, usually from 16 to 22 . The long-wool fiber is coarse and lashy, being rather straight and hairy in appearance. The fiber of the medium-wool fleece occupies a position between the fineand long-wool fibers, but with fewer crimps per inch than the fiber of fine-wool sheep.

The three groups are separated by other marked differences besides length and fineness of wool. Fine-wool sheep are usually of small or medium size, and have a rather narrow form, long neck, uneven top line, white face, more or less wrinkled skin, a compact fleece often dark on the exterior, poor mutton qualities, and active dispositions. Medium-wool sheep are medium to large in size, have a wide, compact, blocky, meat-producing form, straight top line, usually have brown faces, a smooth skin, a compact fleece that is light colored on the exterior, thick flesh, excellent mutton qualities, and active dispositions. Long-wool sheep are large, with blocky bodies, straight lines, rather upstanding, white face, smooth skin, shaggy light-colored fleeces 
hanging in long locks or curls, thick but somewhat coarse flesh, lay on much fat, and are more sluggish and indolent in their habits.

The breeds of long-wool sheep are the Lincoln, Cotswold, and Leicester. The medium-wool breeds are the Southdown, Shropshire, Oxford Down, Hampshire Down, Suffolk, Dorset Horn, Cheviot, and Tunis. The breeds of fine-wool sheep are the American Merino, Delaine Merino, and Rambouillet. All of these breeds except the Merinos and the Tunis originated in Great Britain. The American Merino and Delaine Merino were developed in the United States, the Rambouillet in France, and the Tunis in the province of Tunis in Northern Africa.

Although variations in fleece, size, form, and other points permit the division of all sheep into three groups, there are at basis only two types of sheep-mutton type, and fine-wool type. The former includes both the long- and medium-wool groups. The breeds of sheep are therefore classified according to type as follows:

\begin{tabular}{|c|c|c|}
\hline & Long-wool breeds & $\left\{\begin{array}{l}\text { Lincoln } \\
\text { Cotswold } \\
\text { Leicester }\end{array}\right.$ \\
\hline MUTTON TYPE & Medium-wool breeds & $\begin{array}{l}\text { Southdown } \\
\text { Shropshire } \\
\text { Oxford Down } \\
\text { Hampshire Down } \\
\text { Suffolk } \\
\text { Dorset Horn } \\
\text { Cheviot } \\
\text { Tunis }\end{array}$ \\
\hline Fine-Wool Type & Fine-wool breeds & $\begin{array}{l}\text { American Merino } \\
\text { Delaine Merino } \\
\text { Rambouillet }\end{array}$ \\
\hline
\end{tabular}

The mutton-type sheep is chiefly valued on account of its ability to make good mutton economically, although the woolproducing ability of the mutton-type sheep constitutes an important part of its value to the farmer. Some of the best muttonproducing breeds have failed to gain much popularity mainly because of their deficiency as wool producers. It is not expected that one type of sheep will excel in both mutton and wool production, any more than one type of cattle is expected to excel in both beef and milk production, yet it is important that the mutton-type sheep grow a fleece of good density, length, weight, and quality.

The fine-wool type is mainly a wool proposition. The American Merino is of no more value for mutton than are dairy 
cattle for beef. The Delaine Merino and Rambouillet have better mutton qualities, though not equaling the mutton breeds in this respect, and this largely explains their greater popularity as compared to the American Merino.

The American farmer, and likewise the rangeman, has declared that the most profitable sheep to grow in this country is, as a rule, a combined wool-and-mutton type. Among the mutton breeds, and also among the fine-wool breeds, those which yield the most and best of both mutton and wool rank highest in popularity, while those breeds which are more highly specialized so as to be superior in one line of production and very inferior in the other are not so popular. The popularity of a breed depends also upon other factors such as constitutional vigor, prolificacy, quietness of disposition, feeding qualities, grazing qualities, ease of shearing, and early maturity, but first and fundamentally the breed must produce both a good carcass and a good fleece if it is to be popular with the farmer. Every breed has its place, however, and to eliminate all except two or three breeds from American farms and ranches would be poor policy. Some of the less popular breeds are highly valued for producing rams to use in cross-breeding or grading-up to produce the desired type. Other less popular breeds have special features which give them the preference under certain special conditions of climate, food supply, or method of management.

\section{Definition of Sheep Terms.}

Ram or buck.-Breeding male, any age.

Ewe.-The female, any age.

Lamb.-Any sheep under twelve months of age.

Wether.--Unsexed male, castrated when a young lamb. The best age to castrate lambs is from 7 to 10 days old at the same time they are docked.

Stag.-Unsexed male, castrated when mature or so far advanced toward maturity that masculinity is plainly evident in head, neck, and forequarters. This constitutes coarseness in a market animal.

Shearling.-A yearling.

Two-shear.-A two-year-old.

Two-tooth:-A yearling.

Four-tooth.-A two-year-old. 


\section{CHAPTER XV.}

\section{MUTTON TYPE.}

Although the breeds of sheep classed as mutton breeds may be grouped into two distinct classes-long-wooled and middle-wooled-and although the breeds within each class differ considerably in color markings, fleece, and appearance, nevertheless all of them belong to the mutton type. The following description applies particularly to sheep or lambs fattened for the market.

The general appearance of the mutton-type sheep is almost identical with the beef type of cattle. The mutton sheep should be markedly short legged, broad, deep, and symmetrical. The top line and underline should be straight and parallel, and the top should be broad and level from end to end. The side lines should be straight, and the middle wide and deep, yet neat and trim. Leggy and rangy conformations are as objectionable in mutton sheep as in beef cattle. There should be pronounced blockiness of conformation, combined with neatness, fullness, and great smoothness of outline.

The head should be short and broad, the mouth of ample width, the nostrils large, the face short, the eyes prominent and clear, the forehead broad, and the ears rather fine, short, neatly attached, and well carried. The mutton type does not have horns as a rule, the Dorset breed being the only exception. The head should have a clean-cut appearance, indicative of quality and good breeding.

The neck should be short and plump, arched, trim at the throat, and should join the shoulders full and smooth.

The shoulders should be compact, smooth, and nicely covered over with flesh, making the forequarters very even and smooth. The tops of the shoulders should come fairly well together and be rounded over with flesh.

The breast ought to be prominent, broad, and filled out plump with flesh. A wide breast is an evidence of strong constitution, and plumpness of this part is one of the indications of proper finish and fatness in the market sheep.

The chest should be very wide and deep, and have a full heart-girth. There should be considerable distance between 
the front legs, and also between the shoulders, and no depression of the side should exist just back of the shoulder. The front flanks should earry down deep and be well filled out.

The front legs should be short and straight, the shanks fine, and the joints not too large. The knees show some tendency to come together, but this should not be marked. Attention should be given to the pasterns which should carry up strong, and to the toes which should be well developed, strong, and point directly forward.

The back furnishes one of the valuable cuts of the carcass. It should be very wide, short, and straight, and should be thickly, firmly, and evenly fleshed. When the hand is pressed down upon the back it should exhibit no dip or weakness, but carry

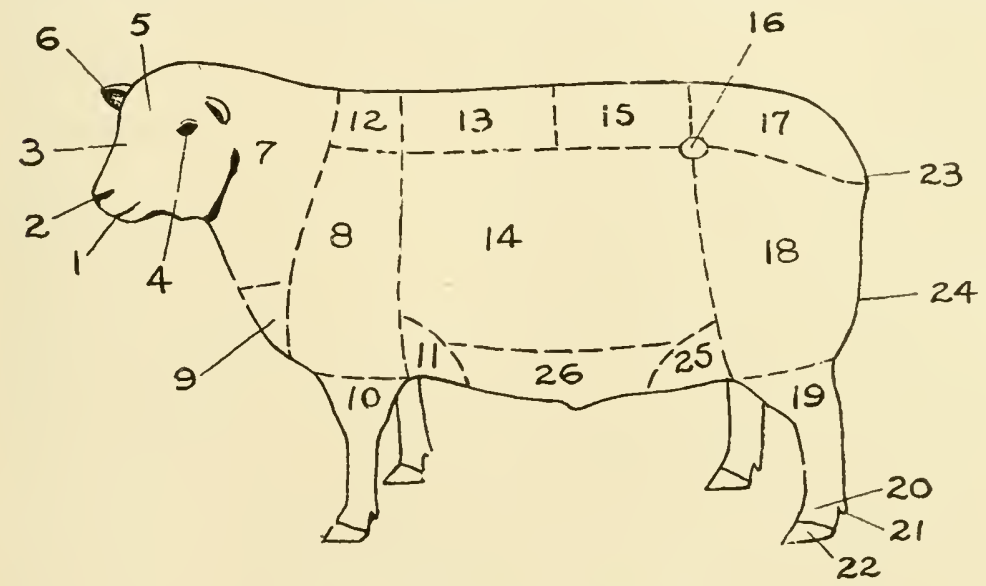

Fig. 53. Points of the Sheep.

$\begin{array}{llll}\text { 1. Mouth } & \text { 8. Shoulder } & \text { 15. Loin } & \text { 21. Dew claw } \\ \text { 2. Nostril } & \text { 9. Breast } & \text { 16. Hip } & \text { 22. Foot } \\ \text { 3. Face } & \text { 10. Fore leg. } & \text { 17. Rump } & \text { 23. Dock } \\ \text { 4. Eye } & \text { 11. Fore flank } & \text { 18. Thigh } & \text { 24. Twist } \\ \text { 5. Forehead } & \text { 12. Top of shoulders } & \text { 19. Hind leg } & \text { 25. Hind flank } \\ \text { 6. Ear } & \text { 13. Back } & \text { 20. Pastern } & \text { 26. Belly } \\ \text { 7. Neck } & \text { 14. Ribs } & \text { 18 and 24. Leg of mutton }\end{array}$

up level and strong. In thin sheep the backbone is marked by a sharp ridge, in well-fattened animals the back is smooth, the backbone being covered, while in very fat animals the flesh may be thickened on either side of the middle line to such an extent that a groove is found down the middle of the back instead of a ridge.

The ribs must have a strong arch to give width to the back, and they should carry down deep to afford a large chest and 
good digestive capacity. They should be placed close together along the side, the last pair coming close to the hips. The covering of flesh on the ribs should be thick, even, and firm. The side should be straight and even, the belly should be straight and trim, and the hind flanks should be well let down.

The loin yields the highest priced cut of the carcass. Like the back, it should be very wide, straight, strong, and covered evenly with thick, firm flesh. The backbone should be covered. Sheep may be well covered over the back and poorly covered over the loin, therefore careful handling all along the top is necessary in order to judge of the fleshing.

The hips should not be prominent; they should be well laid in and smoothly covered over with flesh.

The rump ought to be long, level, and wide, the top line carrying out straight to the end of the body. One of the most common faults of mutton sheep is a poorly shaped hindquarter, the rump frequently rounding off or drooping on top, and the sides cutting in to give a peaked conformation. Squareness and fullness should characterize the hindquarter. The covering of flesh should be abundant, yet smooth and free from softness or bunches of gobby fat.

The thighs and twist, often called the leg of mutton, should be broad and plump as viewed from the rear, and the fleshing should carry well down toward the hocks, as in beef cattle. The leg of mutton, loin, and back constitute the valuable parts of the carcass, and they must carry a high degree of fleshing. Wide variations in the development of thigh and twist will be found, although a maximum development is always demanded.

The hocks and hind legs should be strong and placed well apart. When the hocks are close together, the thigh and twist usually lack a full development. Crooked, weak hocks, either badly sickled or bowed, are rather common and are very undesirable. The legs should be short and straight, and show refinement of bone and joints. The hind pasterns are also given attention in judging, for it is by no means uncommon to find them broken down and weak so as to impair the usefulness of the animal to a marked degree. They should carry up strong, so as to bring the weight full on the toes.

The skin should be of a bright pink color and free from dark-colored spots. The pink color is an indication of health and thrift, while a white or bluish color shows an unthrifty condition. Some breeds excel in this respect, and others char- 
acteristically show a rather dark color due to the presence of pigment in the skin, in which case the dark color is not necessarily an evidence of unthriftiness. The dark-faced breeds often have a pigmented skin over the body, and with this fault is often associated the fault of having black fibers in the fleece.

The quality of the mutton-type sheep is shown by the fineness of the head and bone, fineness of the wool, and fineness and softness of the hair on the face and legs. Quality is also shown by the smoothness of the animal, both in frame and in fleshing. Coarse shoulders, an angular build, and uneven flesh show lack

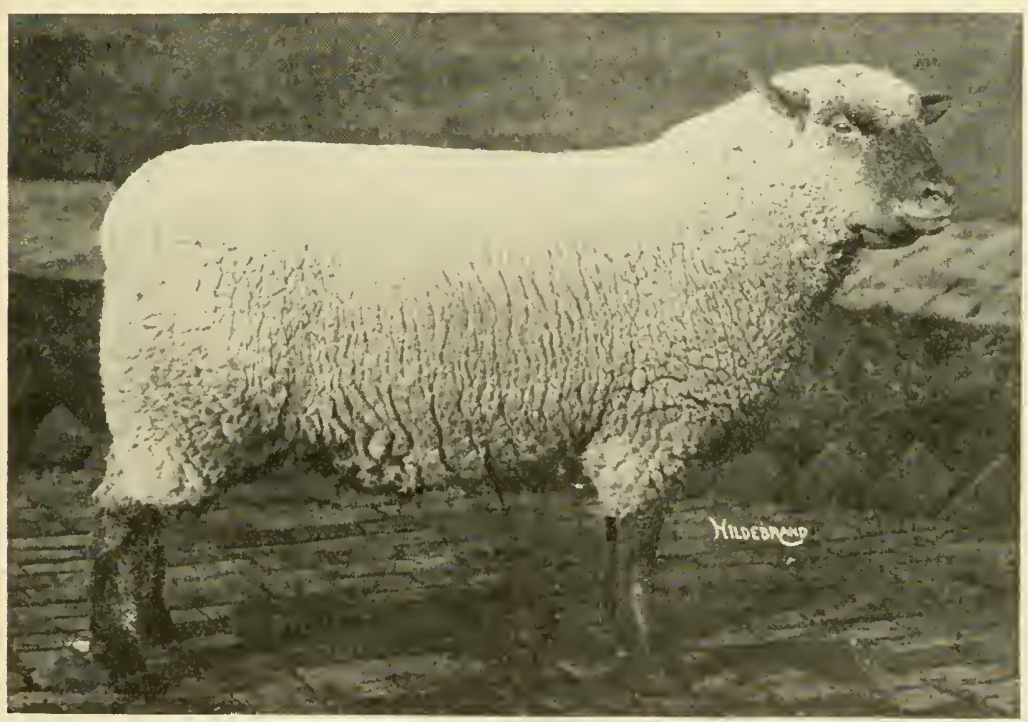

Fig. 54. Correct Type in the Fat Wether.

Grade Shropshire, Grand Champion at the 1913 International. Bred and exhibited by J. \& D. J. Campbell, Woodville, Ont., Can. Neat in form, excellent in quality, and thickly and firmly fleshed. His fatness, trim middle, and good quality insure a high dressing percentage. This sheep belongs to the medium-wool class.

of quality in a mutton sheep. These are important features in either breeding or fat sheep. Quality and good breeding are usually associated. Well-bred animals respond best when fed and fattened for the market. The butcher likes quality because it insures high quality of meat, and indicates little waste when the sheep is killed and dressed. A sheep of good quality yields an attractive carcass with smooth, even outlines. 
The condition, or fatness, of a sheep may be determined by an examination of six points, these being the spinal covering, the neck, the breast, the fore flank, the dock, and the purse. The first of these is by far the most important, as it insures a covering where it is most valuable, namely on the high-priced cuts. The covering over the back and loin should be such that the top is smooth and the backbone not easily felt. The neck and breast of a well-finished sheep are plump, the fore flank is well filled, the dock is found thick when grasped in the fingers, and the purse is well filled with fat. Sheep that have been over-fed often have bunches of soft fat at the end of the rump, and a blubbery mass of fat at the fore flank. Sheep that have much loose fat at the fore flank are referred to as "slipped," it being commonly, but erroneously, supposed that this condition is due to a very heavy formation of fat along the back which becomes excessive and slips down the ribs to the fore flank. The butcher sharply discriminates against such an excessively fat condition, and the breeder has found that slipped ewes are frequently barren. The market wants a thick, firm covering. Softness indicates a "wasty" carcass. Lambs very seldom become too fat, but yearlings and older sheep may be easily fed until they become soft and overdone.

The style which some mutton sheep possess has an importance similar to style in beef cattle. Furthermore, feeders testify that the lamb or wether with stylish appearance and sprightly gait is usually vigorous and a good feeder, style being to some extent an evidence of constitutional vigor and thrift.

The fleece of the mutton-type sheep is of secondary importance, yet constitutes an important item of value. The value of the fleece depends upon its length, weight, quality, and uniformity. Weight of fleece depends upon covering, density, length of staple, and the amount of oil, or grease, called "yolk.". The quality of fleece refers in a strict sense only to fineness of fiber, but in a general way may also include softness, soundness, luster, color, cleanness, purity, and freeness. These various factors of weight and quality will now be discussed.

The covering of wool has reference to the completeness of covering over all parts of the body. Some animals are very devoid of wool on the belly and around the flanks. The breeds differ widely in the extent to which the poll, ears, face, and legs are covered with wool, such features forming a prominent part of some breed types. The tendency in recent years, especially 
with some breeds, has been to secure a more complete covering of wool, and thus produce a fleece of somewhat more weight. In all breeds, the under parts of the body, including the scrotum of the ram, should be well wooled.

A dense fleece is one that is compact, or has a large number of fibers growing on a square inch of skin. As much density is desired as is possible to attain.

The length of fiber varies greatly among the mutton breeds, so that it is difficult to fix requirements for length of fleece for

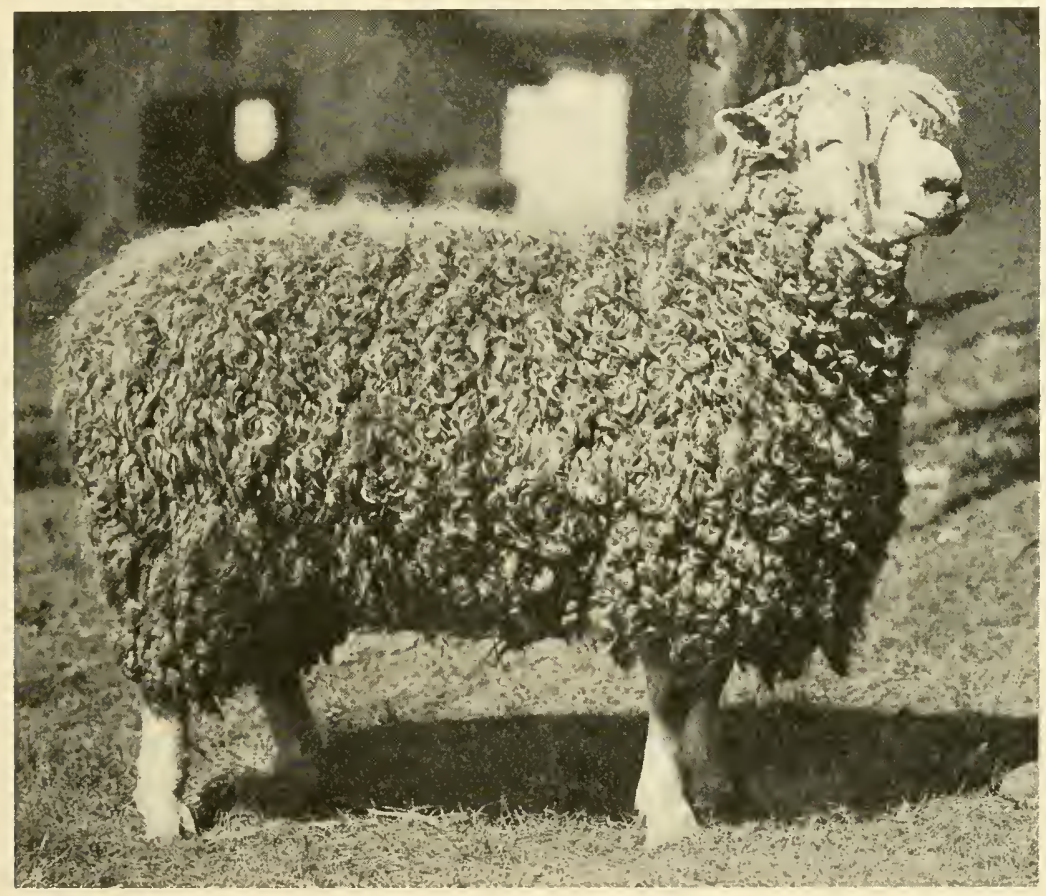

Fig. 55. Long-Wool Sheep.

Lincoln ram, Champion at the Iowa State Fair. Owned by Mr. A. W. Arnold, Galesville, Wis.

the mutton type in general. However, a length of less than 3 inches for a year's growth should subject a mutton-type animal to criticism, and if it is less than $2 \frac{1}{2}$ inches the wool sells at a lower price per pound on the wool market, as it is then not adapted to the manufacture of worsted cloth. As a rule, the longest fleeces are the coarsest and most lacking in density; maximums of fineness, length, and density cannot be secured in 
one animal. The medium-wool breeds vary in length of staple from 2 to 5 inches, while the long-wool breeds vary from 5 to 12 inches.

The yolk is a variable feature and a highly important one. It is secreted by glands in the skin, and passes out over the fibers, giving them an oily coating that is valuable because it makes the wool soft, protects and preserves the fibers, and, by causing the fibers to lie even and regular, insures against matting, or "cotting," of the fleece. A plentiful supply of yolk also tends to prevent the entrance of dust, chaff, and other foreign material into the fleece. Incidentally, the yolk adds weight to the wool, although an excessive amount of oil that merely adds weight to the fleece is not desirable. The yolk should be in a fluid condition and should be uniformly distributed throughout the fleece from skin to tip of fiber. It should not be so abundant as to collect in drops in the fleece, nor should any flakes of dried yolk be in evidence.

The fineness of fiber, from the earliest days of wool growing, has been esteemed one of the most important requirements of wool. It varies a great deal among the breeds of mutton sheep, and also among the individuals within a breed. It is not expected that the mutton type will produce a fiber with the high degree of fineness shown by the Merinos, yet as much fineness is wanted as may be had without sacrifice of weight or quantity of fleece. The crimp, or waved condition, of wool furnishes an easy and accurate measure of fineness. All wool is more or less crimped, and it is a fact that the finest wools are finely crimped, that is, have a large number of crimps per inch, while the coarsest wools are almost devoid of crimp, being lashy or broadly waved. The crimp of the medium-wool fleece should be fine, pronounced, and uniform from skin to tip of fiber. A single fleece yields several sorts of wool, differing considerably in fineness. The finest wool grows on the belly, shoulders, and back; that next in fineness, on the neck, breast, and along the sides, while the coarsest wool is found on the thighs and lower parts of the legs.

Wool that has softness, yet is firm and elastic, is far more valuable than that which is dry, stiff, and harsh. On the other hand, mushy wool having a soft, lifeless feel with no recoil when handled is very often lacking in strength. Softness depends upon fineness of fiber and amount of yolk. Ill health, exposure to rough weather, or lack of feed results in loss of softness. 
The soundness of wool refers to its freedom from weak spots. Sickness, a sudden shock from a blizzard, lack of feed, a rapid change from green to dry feed, or vice versa, and overfeeding often cause the secretion of wool to be lessened for a time, thus producing tender wool. Under the microscope the fibers are found to be narrow in those parts produced under adverse conditions. Yarn made from such wool will be lacking in strength. Sickness will often cause a distinct break in the fiber throughout the fleece. (See Fig. 87.)

Wool is said to have luster when the fibers glisten as though thinly varnished. This feature is especially prized in longwooled sheep. A luster wool takes a dye more readily than does a dull, or lusterless, wool. Furthermore, the luster is plainly apparent in the finished cloth, improving its appearance.

The color of the wool fiber should be a clear white. The occurrence of brown or black fibers mixed in the fleece subjects the animal to much criticism. Such wools cannot be used in the manufacture of white goods or those of light shades. Unless the fiber has perfect whiteness, a rich, brilliant dye cannot be secured by the manufacturer.

As regards cleanness, all sorts and conditions of fleeces are found, ranging from those above criticism, to those that are a mass of burs, sand, bits of straw, manure, and other rubbish-the whole fleece being matted together and constituting a product of no commercial value. Cleanness depends mostly upon the conditions under which the sheep are kept, although some fleeces, on account of their oiliness and density, tend to keep free from foreign material, while others, on account of their open, dry, fluffy character, offer no resistance to the entrance of foreign matter.

By purity of fleece is meant its freedom from hair, called "kemp," and from dead fibers. With unfavorable conditions of keep and inferior breeding there is often a reversion of the fleece to the covering worn by early sheep; that is, hair begins to appear in place of wool. Dead fibers and kemp do not absorb dyes, hence they injure the cloths into which they find their way.

The fleece is said to have freeness when the locks and fibers are not entangled, but part off readily from one another. When the fibers are tangled, or matted together, the fleece is said to be "cotted."

A fleece with uniformity is one having sameness in character throughout. Although there is a natural tendency for 
the wool on different parts to vary in density, length, and fineness, the aim of the breeder is to produce a fleece as nearly uniform throughout as possible.

Age from the teeth. - The teeth are a fairly reliable indication of the age of a sheep. The lamb has eight temporary incisors, or milk teeth, in the lower jaw. There are no incisors in the upper jaw. At 14 months of age, the middle pair of milk teeth is supplanted by a pair of larger, permanent incisors. At 2 years, the second pair of permanent incisors appears; at 3 years, there are three pairs; and at 4 years, all eight permanent incisors are in place. At five years, the teeth show more width between, and at six, the corner teeth may be broken out or the mouth may show signs of wear. Broken-mouthed sheep have their usefulness much impaired, and should not be kept unles: for special reasons. 


\section{CHAPTER XVI.}

\section{THE MUTTON CARCASS AND THE PELT.}

Mutton and lamb supply a wealthier class of consumers than beef, pork, or veal. Lamb is ordinarily considered something of a delicacy, while beef and pork are looked upon as staple articles of food. For this reason, the American meat industry was not much concerned with mutton and lamb until rather recent years, or since the country has become more prosperous and wealthy. The proper handling of mutton and lamb necessitates more careful and quick slaughtering than is required in the case of beef or pork, and good refrigeration facilities are also very essential. The public taste for mutton and lamb was not created until the development of the refrigerator car nor until the erection of large-scale chill rooms was made possible by artificial refrigeration. The year 1875 marked the advent of these great aids to the packing business. Mutton differs from pork and beef in that it is strictly a fresh meat product and does not lend itself to salting, pickling, smoking, or drying as do pork and beef. Hence mutton became a world commodity only after the development of artificial refrigeration and refrigerated transportation. Still another reason for the comparatively recent demand for mutton and lamb is found in the fact that, up to 1870, the great majority of all sheep in America were either purebred or grade Merinos. Good mutton became plentiful only after the use of mutton rams became general on farms and ranges.

Lamb is usually superior to mature mutton in flavor and general palatability, and the demand for lamb far exceeds the demand for mutton; the wholesale trade consists of two or three times as much lamb as mutton. During the past fifteen years the wholesale trade in lamb and mutton has increased to such an extent as to have doubled during that period; this may be partly due to general prosperity and a larger housewife's allowance, and partly to an improvement in the quality of lamb and mutton through better methods of slaughtering and handling.

Slaughtering.- Sheep purchased by packers are driven to the packing plant and allowed to rest a few hours, because animals killed while in an excited condition do not bleed out thor- 
oughly. They are then driven into a small shackling pen, and a shackle is placed around the hind leg. Two at a time, the sheep are raised by a large revolving wheel to a point overhead where the shackle automatically unhooks from the wheel and starts down a gently inclined rail. The animal moves to the "sticker," who quickly dispatches the sheep by a single thrust of a doubleedged knife, one man killing 600 to 700 sheep .per hour. After passing through many hands, the carcass reaches the cooler, the dressing requiring about twenty-six minutes.

Method of dressing.--Prior to the World War, a number of styles of dressing sheep and lambs were used, but during the period of the war, as a conservation measure, the U. S. Food

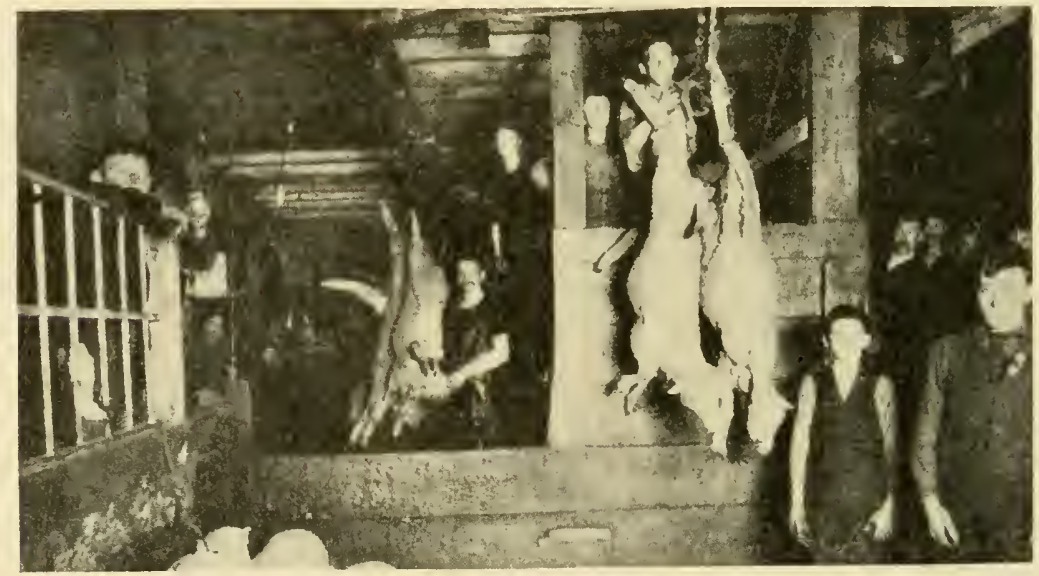

Fig. 56. Killing Sheep at Chicago.

Administration instructed all packers that sheep and lambs must be dressed by the plain or round method, and without caul or pluck. This method of dressing, which is the most economical, has been continued since the war to the present time, and there is no indication that the other styles of dressing will be practiced in the future. Plain- or round-dressed sheep and lambs have the pelt, head, and toes removed, and the fore legs are folded at the knees. They are opened from the cod or bag to the breast, and are split through the breastbone. A spread stick is placed in the breast to hold it open and properly shape the carcass.

Formerly, in dressing the lowest grades of mutton and most lambs, the caul (a fatty membrane investing the internal organs) 
was wrapped about the legs and laid over the inside of the carcass thus improving the appearance, preventing drying out, and, in some cases, furnishing the fat necessary for proper cooking of the meat. The caul contains considerable fat, and as it was usually discarded by the retailers of mutton and lamb, the Food Administration rightly designated this style of dressing as wasteful and caused it to be discontinued. Cauls are now sent to the rendering tank for the extraction of fats and oils. The pluck consists of the heart, lungs, liver, windpipe, a portion of the diaphragm, or "skirt," and more or less adhering fat. Formerly, most lambs were sold "pluck in," and sheep were usually sold "pluck out." The pluck is now used principally in the manufacture of different kinds of sausage.

The offal.- In the plain- or round-dressed style of dressing, the sheep loses the following parts in the order named:- blood, head, pelt, internal organs, and toes. The pelt is the skin with the wool on, and it is a valuable product.

The dressing percentage.-From what has been said of slaughtering and dressing, it is apparent that in order to dress a high percentage of carcass, sheep must be (1) light in pelt, (2) fat, and (3) neat in form, or free from paunchiness. The dressing percentage of sheep is not so important as that of cattle, because the waste has a higher value than the waste from cattle, on account of the high value of the pelt. If a sheep is fat in condition, and neat and trim in form, it will tend to dress high, but the pelt should be as heavy as is consistent with the production of mutton of high quality. As a general rule, the choicest sheep and lambs, from a carcass standpoint, do not wear heavy pelts, although a heavy pelt in itself is valuable, as will be shown later, and between two sheep otherwise equal, the one with the heavier pelt will bring the higher price on the market, even though its heavier pelt lessens its dressing percentage to some extent. Sheep and lambs range in dressing percentage from 40 to 65 per cent., but ordinarily dress from 45 to 55 per cent. Sheep and lambs are combined in the census statements of meat animals slaughtered in the United States. Their average live weight for the four years $1899,1904,1909$, and 1914 was $84,86,81$, and 79 pounds. Their average dressed weight was $43,43,41$, and 39 pounds. Their average dressing percentage was 51.2, 50, 50.6 , and 49.36 per cent. respectively. Mutton carcasses usually weigh from 45 to 85 pounds, while most lamb carcasses weigh from 35 to 50 pounds. 
The wholeșale cuts. - The following diagram represents a side view of a carcass of lamb or mutton, the dotted lines indicating the location of the wholesale cuts.

The leg and loin together are called the saddle, and the combined short rack, chuck, and brisket are called the rack. The saddle and rack are almost equal in weight. One rib is left on the loin. The short rack includes from 9 to 11 pairs of

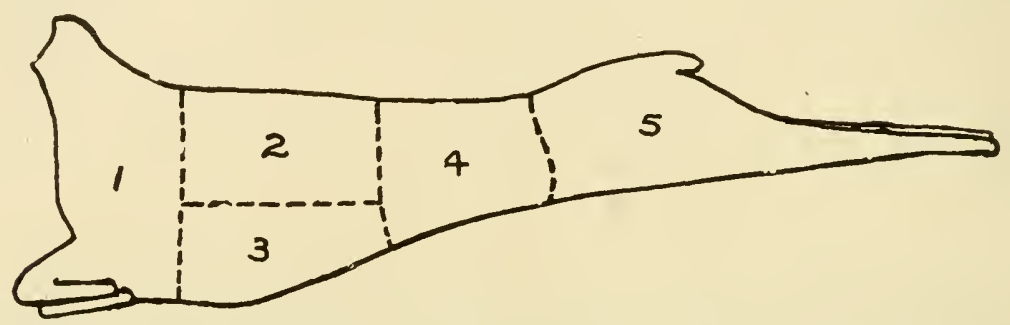

Fig. 57. Wholesale Cuts of Mutton.

1, Chuck; 2 , short rack; 3 , breast; 4, loin; 5 , leg; 1 and 3, stew; 1,2 , and 3 , rack; 4 and 5 , saddle.

ribs, depending on how the carcass is divided between short rack and chuck. The chuck and brisket are usually sold together as one cut, called the stew. In average 45-pound carcasses of lamb and mutton, round dressed, and pluck out, the weights of the various wholesale cuts, their wholesale prices per pound, and total values are as given in the following table:

\begin{tabular}{|c|c|c|c|c|c|c|}
\hline \multirow{2}{*}{ Wholesale cuts } & \multirow{2}{*}{$\begin{array}{l}\text { Wts. } \\
\text { in } \\
\text { lbs. }\end{array}$} & \multirow{2}{*}{$\begin{array}{c}\text { Wts. } \\
\text { in } \\
\text { per cent. }\end{array}$} & \multicolumn{2}{|c|}{ Price per pound } & \multicolumn{2}{|c|}{ Total value of cut } \\
\hline & & & Lamb & Mutton & Lamb & Mutton \\
\hline 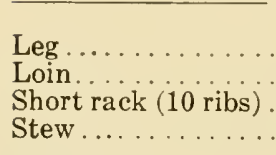 & $\begin{array}{r}13.7 \\
9.6 \\
6.4 \\
15.3\end{array}$ & & & & $\begin{array}{r}\$ 4.66 \\
3.79 \\
3.17 \\
3.60\end{array}$ & $\begin{array}{r}\$ 3.90 \\
3.02 \\
2.34 \\
2.52\end{array}$ \\
\hline Rack..... & $\begin{array}{l}23.3 \\
21.7\end{array}$ & & & & & $\begin{array}{l}6.92 \\
4.86\end{array}$ \\
\hline Totals & 45.0 & 100.0 & $33 \frac{4}{5}$ & $26 \frac{1}{5}$ & $\$ 15.22$ & $\$ 11.78$ \\
\hline
\end{tabular}

High-priced and low-priced cuts.-The average price for the entire lamb carcass is $33 \frac{4}{5}$ cents per pound, while the mutton carcass averages $26 \frac{1}{5}$ cents per pound. As in the beef carcass, the back, loin, and hindquarter yield high-priced cuts, while the breast and belly, constituting the chuck and brisket cuts, are low in price because they lack thickness, the quantity of flesh elements being relatively small. 
Carcass classes and grades.-Carcasses of sheep and lambs are classified and graded as follows:

\begin{tabular}{|c|c|c|}
\hline Classes & Sub-classes & Grades \\
\hline \multirow{2}{*}{ LAMB } & Lambs & Choice, good, medium, common, culls \\
\hline & Yearlings & Choice, good, medium \\
\hline \multirow{3}{*}{ MUTTON } & Wethers & Choice, good, medium, common \\
\hline & Ewes & Choice, good, medium, common, canners \\
\hline & Bucks & Good, medium, common \\
\hline
\end{tabular}

The following wholesale prices* indicate the comparative values of the above classes:

Special Selected Round-Dressed Lambs,

pluck out........................ 30 to 40 Ibs....341/4 cents per lb. Good Lambs, Round-Dressed, pluck out... 30 to $40 \mathrm{lbs} . . .333 / 4$ cents per lb. Medium Lambs, Round-Dressed, pluck

out............................ 30 to 40 lbs... Common Lambs, Round-Dressed, pluck

out...............................

Yearling Lambs, Round-Dressed, pluck

out.......................... 40 to $45 \mathrm{lbs} . . .313$ cents per $1 \mathrm{lb}$.

Wether Sheep, Round-Dressed, pluck out. . 45 to $55 \mathrm{lbs} . .263 / 4$ cents per lb.

Ewe Sheep, Round-Dressed, pluck out....45 to $60 \mathrm{lbs} . \ldots .25 \frac{2}{4} \mathrm{k}$ cents per lb.

Common Sheep, Round-Dressed, pluck out...........

Qualifications of a good carcass.-The value of the carcass depends chiefly upon (1) form, (2) quality, (3) covering, (4) weight, and (5) maturity. These various factors will now be discussed.

1. Form.-The essential points of desired shape are good width in proportion to length, compactness, and smooth, even outlines. This implies a thick loin, broad back, well-fleshed ribs, a full, thick middle from shoulder to leg, plump, thick legs filled down well, and smoothly covered shoulders. The most common faults of form are long, slender legs, narrow backs, lack of development over ribs and loin, and too much paunch, or belly. Long necks in ewes, and heavy "bucky" necks, shoulders, and briskets in wethers are objectionable.

2. Covering.- It is essential that the carcass be smoothly and evenly covered with fat, because of its influence on the appearance of the dressed sheep, the quality of meat, and the shrinkage both in storage and in cooking. Only in the most highly finished sheep are the legs and shanks completely covered. The kidney fat should be well developed, but not exces-

*Wholesale price list of a leading Chicago packer, March, 1919. 
sive. A light kidney usually indicates lack of finish, while a very heavy one is evidence of overdone condition or uneven distribution of fat. The purse, udder, rump, flanks, and brisket are other points at which the amount of fat is plainly apparent, but it should not be excessive on any of these parts. The lowest grades have practically no outside fat, the amount of covering varying more or less directly with the grades of mutton from common to choice. The external and kidney fat should be firm, brittle, and white. As with beef, the English consumer desires fatter mutton than would suit the American trade.

3. Quality.-The term "quality" is here used somewhat broadly, to include not only refinement of bone and fineness of texture of flesh, but also color of lean and fat. The flesh should be firm and fine grained, without the stringy, coarse texture of aged or inferior mutton. The color of flesh varies from light pink in lambs to dull red in mature mutton, and is less variable than in beef. The fat should be clear and white. General quality is more important in mutton and lamb than in other branches of the meat trade, on account of the custom of using the carcasses for display purposes in retail markets.

4. Weight.-This is of more importance in grading mutton than in grading beef, as it is often a strong indication as to whether a carcass is a lamb, yearling, or mature sheep. The extreme ranges in weights of carcasses are, lambs, 15 to 50 pounds; yearlings, 40 to 60 pounds; wethers, 40 to 120 pounds; bucks, 45 to 200 pounds; ewes, 50 to 200 pounds. The most desired weights for a lamb carcass are 40 to 45 pounds; for mutton carcasses, 50- to 65-pound weights are most desired. As with beef, heavy carcasses are demanded by hotels, restaurants, and dining cars.

5. Maturity.-As has been mentioned, the demand for lamb far exceeds the demand for mutton, and the price of lamb has been shown to be considerably higher. The packers' interpretation of the word "lamb" is broader than the ordinary understanding of the term, for both lambs and yearlings yield a "lamb" carcass. Mutton carcasses are those of wethers two years old or over, ewes, bucks, and stags. The maturity of the carcass may be easily determined with a fair degree of accuracy from the bones; in lambs the brisket is soft and red, and the ribs and shank bones are colored with blood vessels; in mature sheep the bones are white and hard. However, the breakjoint furnishes the best means of distinguishing lambs and year- 
lings from mature sheep. The break-joint or lamb-joint is a temporary cartilage which forms in the head of the shank (shin bone) immediately above the ankle. In dressing lambs, yearling wethers, and some yearling ewes, the foot can be broken off at this cartilage, giving the end of the shank a saw-tooth shape. In lambs the broken surface is smooth and moist, and in yearlings it is more porous and dry. The shanks of mature sheep will not "break," because the cartilage is knit or ossified, and the foot is taken off at the ankle instead, making a "roundjoint." Shanks of female or ewe sheep outside the lamb class are, as a rule, too mature to break. Consequently, 80 to 90 per cent. of "yearling lamb" carcasses are wethers, the remainder being ewes and a small proportion of bucks and stags. Yearlings

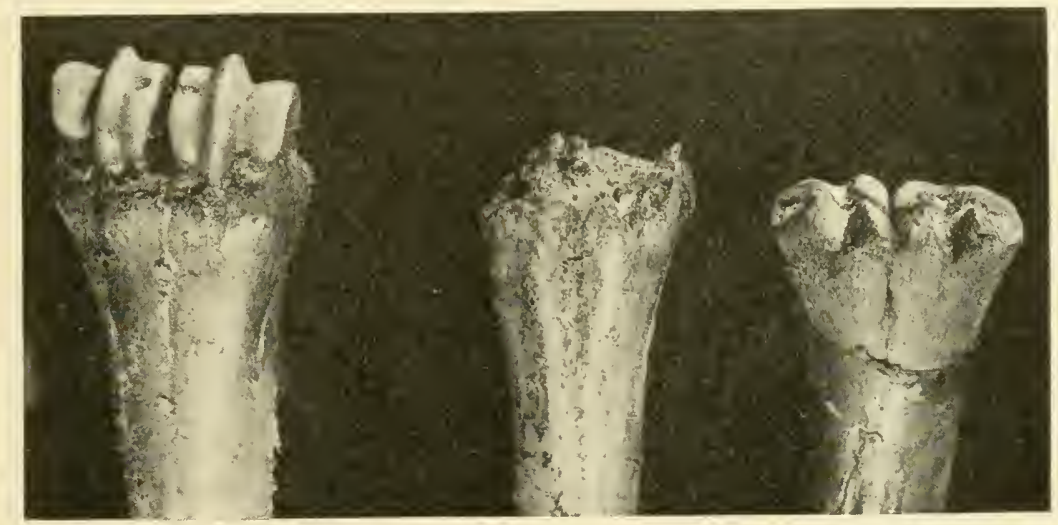

Fig. 58. Round-Joint and Break-Joints.

In dressing mature sheep, the feet are taken off at the ankle, leaving a round-joint on the end of the shank bone. Immediately above the ankle in immature stock is a temporary joint, called the break-joint, at which the feet are removed. Thus the head of the shank bone as well as the foot is removed, leaving the saw-toothed break-joint on the end of the shank bone. As the animal matures, the break-joint ossifies or knits. Pincers are sometimes used to crush off those which are partly ossified. This leaves an imperfect break-joint. The shank bones of mature sheep will not break. At the left above is a round-joint, at the right a true break-joint, and in the center a crushed break-joint from a nearly mature sheep.

substitute for genuine lamb, and we see that they may easily do this because they possess the break-joint.

Goat carcasses.-Dressed goats are occasionally sold in connection with mutton and lambs, and are frequently substituted for them, especially in the retail markets. They are similar to the lowest grades of western sheep in form, quality, 
and finish. Long shanks, coarse, dark flesh, long necks, and thin caul, however, render them quite easily distinguished from sheep carcasses.

\section{The Value of the Pelt.}

The market value of a mutton animal rests not only upon the carcass it yields, but also upon the pelt. Information has been given out from various sources that buyers of sheep for the packers prefer animals wearing light pelts. It has been said that the slaughtering departments of packing houses without exception dispose of sheep pelts at a fixed price per pelt, consigning them to the wool-pullery department of their own plant, or to some independent pullery. Buyers have been reported to prefer light-wooled lots in order to obtain high dressing percentages; it has been said that buyers have no particular interest in the welfare of their own pulleries, or in other firms that buy the pelts for pulling. Farmers have been advised that the highest market price is obtained for sheep and lambs that are light in pelt and which consequently dress high.

Can it be possible that the packer, with all his genius for the utilization of by-products, is overlooking such an important item as wool? If the shank bones of cattle may be profitably converted into buttons and other articles, is it not inconsistent and unbusinesslike to discount well-wooled lots of sheep? With wool worth 25 to 50 cents per pound, is it not strange that the buyer should refuse to bid higher on a well-wooled band of sheep than upon a lot with light fleeces, other things being equal, especially as the fleece is secured at the live-weight price of the animal, namely 10 to 20 cents per pound? In handling thousands of sheep, the wool reaches a considerable valuation. If light pelts are wanted, why do shorn sheep sell at a discount?

Such questions as these led the writer to make an investigation which included interviews with the principal buyers at Chicago, and an inspection of a modern wool-pulling establishment owned by one of the packing firms. It was found that a few buyers do give preference to light-pelted lots, but that class of buyers is decidedly in the minority. Swift, Armour, Wilson, and New York butchers have for some time realized the added value of a heavy fleece, and this has enabled them, in many instances, to outbid competing firms who consider only the dressing percentage as an index of the value of 
sheep for slaughter. The fact that New York butchers have been able to dispose of pelts profitably very largely explains their survival in the face of keen competition with packers.

The slaughtering departments of those packing houses equipped with wool pulleries are credited each day with the value of the pelts sent from the killing floor. The value per pelt varies, depending upon (1) size of pelt, (2) weight of fleece, (3) quality of fleece, (4) cleanness of fleece, (5) amount of grease, (6) color of wool, and (7) thickness of skin. On this basis the value per pelt at the present time (March, 1919) ranges as low as 80 cents for lambs, and as high as $\$ 6.50$ for sheep pelts in full fleece, depending mostly upon age, breeding, and season of the year. The average price of Chicago pelts is now about $\$ 3.90$ per pelt. This is extremely high, due to the present high values of wool and skins. The value of the pelt plays an important part in determining the value of a sheep to the packer. The buyer's appreciation of the value of the pelt results, in most instances, in a much fairer price than would otherwise be paid.

Packing houses and other wholesale butchers not equipped with wool pulleries have two methods of disposing of the pelts; they may either contract them in advance at a fixed price per pelt, or they may allow them to accumulate and then solicit bids. In the latter case, the bidders make an examination and the pelts sell on their merits. In the former case, the packer or butcher has no incentive to pay a premium for well-wooled sheep, but, on the contrary, it is to his advantage to select those with light pelts. One prominent sheep buyer on the Chicago market designated the contract plan as "slipshod," and he stated that "eventually it must cease as competition becomes more keen." He also said, "I instruct my men to consider wool as well as meat, and when they make bids, you may be sure they have estimated the value of the pelt as well as the carcass."

Pelts are most valuable in the spring just before shearing time. Shorn sheep sell at a discount because the wool cannot be pulled at a profit until it has a growth of three-quarters of an inch or more. When the staple measures less than this, the pelts are tanned with the wool on, and the price received is small compared with pelts which can be pulled. The time of shearing marks the close of winter and the opening of pasturage, hence shorn sheep are often gaunt, and this is another reason for the lower price. 
Pulled wool has the same uses as ordinary clipped wool. The weight of wool from an average pelt is 4 to 5 pounds. This seems a low figure, but the pelts are scrubbed before pulling, which takes out nearly all the dirt and grease, and causes a decided loss in weight.

After the wool is pulled, the skins are prepared for the tannery. Untanned sheep and lamb skins are worth from $\$ 5.50$ to $\$ 17.00$ per dozen, with an average of $\$ 7.25$ per dozen for lamb skins and $\$ 8.50$ for sheep skins. The value depends upon the size, quality, and thickness. The Merino yields a thin, porous skin which makes a leather that scuffs easily and wears out very quickly. These bring the lowest price. The best-wearing and highest-priced sheep leather is made from skins of the longwooled breeds. Sheep leather is used for making cheap shoes, shoe linings, gloves, bags, book bindings, cheap saddles, suit cases, sweat bands for hats, and many other articles. Chamois skins are now made entirely of sheep skins. Goat skins are much in demand for furniture leather and are more valuable than sheep skins, the best untanned bringing $\$ 21.00$ per dozen. They average a little larger in size than sheep skins and wear much better.

\section{By-Products of Sheep.}

The by-products from the slaughter of sheep may be classed as edible and inedible. The edible by-products include the tongue, which is used for cooking or sausage; the pluck, which is usually ground up and used in different kinds of sausage; and the paunch, about one-half of the paunches being used for "tripe," made by boiling and pickling the paunches.

Because of the high value of the pelt, the inedible by-products of the sheep are more valuable than those of the steer or the hog, considering their proportion to the carcass. The bones, stomach, and any trimming are tanked, thus extracting fats and oils, and the residue is treated to make glue. The final residue is made into tankage and fertilizer. The blood, dried and ground, makes blood meal and fertilizer. Hard bones yield bone charcoal for bleaching purposes, black pigment for paint, shoeblacking, etc., bone dust for fertilizer, vitrified bone for making glass, cement for billiard balls, and knife handles, combs, buttons, and other articles. The intestines, windpipe, and bladder are cleaned and made into sausage casings. Musical strings, clock cord, and surgical ligature for sewing up wounds, 
as well as casings for little sausages, are made exclusively from the intestines of sheep. A class of oleo oil is made from the better grade of mutton tallow, and enters into the composition of oleomargarine. Inedible greases are used in soaps. Some valuable chemicals used in medicine are obtained as by-products from sheep. Among these are thyroidin, used as a cure for cretinism, and suprarenalin, a powerful astringent used in cases of severe bleeding. More than 130,000 sheep are required to make a pound of suprarenalin. 


\section{CHAPTER XVII.}

\section{SHEEP MARKETS AND MARKET CLASSIFICATION.}

The census of 1910 estimated that 14,724,699 sheep and lambs and 285,553 goats and kids were slaughtered for food in the United States in 1909. From reports of the Census Bureau it is estimated that 83 per cent. of the sheep and lambs marketed in the United States pass through the large central markets, 13 per cent. are sold for local slaughter, and only 4 per cent. are slaughtered on farms and ranges. The corresponding percentages for goats and kids are 12, 46, and 42. The U.S. Bureau of Markets and Rural Organization* conducted an investigation in 1915 which indicated that 43 per cent. of sheep and lambs are marketed in the fall, 13 per cent. are marketed in winter, 18 per cent. are marketed in the spring, and 26 per cent. are marketed in summer. Maximum receipts occur in September and October, at which time large numbers of western sheep and lambs arrive at the markets. Minimum receipts are usually registered in May:

The fourteen largest sheep markets and their total receipts during the year 1918 were as follows:

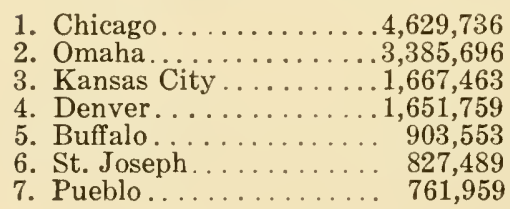

8. St. Paul

9. Pittsbur.............6.6.

10. St. Louis................ 536,406

11. Salt Lake City ...........423,664

12. Sioux City ............387,423

13. Fort Worth...........334,596

14. Cleveland...........287,422

The Chicago sheep market is easily the largest in the world. The total value of sheep and lambs received there during 1918 was $\$ 57,273,848$. Their average value per head was $\$ 12.37$. Their average live weight was 78 pounds. Their average price per cwt. was $\$ 15.86$. Of the $4,629,736$ sheep received, $3,424,526$ were slaughtered by Chicago packers, and the remaining $1,205,210$ were shipped out alive. Of the latter number, 237,204 were shipped to other points for slaughter, and 967,996 were bought for feeding purposes and sent to the country.

*U. S. Dept. Agr. Report 113, p. 19, by Hall, Simpson, and Doty. 
At Chicago, during 1918, Swift \& Co. slaughtered 1,205,835 sheep; Armour \& Co., 1,078,190; Morris \& Co., 520,531; and Wilson \& Co., 517,938. These four companies slaughtered 97 per cent. of all sheep killed by Chicago packers in 1918 .

The commission charge for selling straight carloads of sheep or goats at Chicago is 20 cents per head, with a minimum charge of $\$ 10.00$ and a maximum of $\$ 12.00$ on single-deck cars, and a minimum of $\$ 15.00$ and a maximum of $\$ 18.00$ on doubledeck cars. On less than 40 head of sheep or goats shipped in one car, the commission charge is 25 cents per head. The charge for yardage is 7 cents per head.

\section{Market Classes and Grades of Sheep.}

The market classes of sheep are three in number, their names indicating the use to which the sheep in each class are put. These are (1) mutton sheep, (2) feeder sheep, and (3) breeding sheep. Each of these classes is divided into sub-classes, and these are again divided into grades. W. C. Coffey of the Illinois Station* made a detailed study of the market classification of sheep at the Union Stock Yards, Chicago, and outlines the market classes, sub-classes, and grades as follows:

\begin{tabular}{|c|c|c|}
\hline Classes & Sub-classes & Grades \\
\hline $\begin{array}{l}\text { MUTTON SHEEP } \\
\text { (Native and Western Sheep) }\end{array}$ & $\left\{\begin{array}{l}\text { Lambs ........ } \\
\text { Yearlings....... } \\
\text { Wethers...... } \\
\text { Ewes........ } \\
\text { Bucks and Stags. }\end{array}\right.$ & $\begin{array}{l}\text { Prime, choice, good, } \\
\text { medium, common or } \\
\text { culls. } \\
\text { Prime, choice, good. } \\
\text { Prime, choice, good, } \\
\text { common, } \\
\text { Prime, choice, good, } \\
\text { medium, common or } \\
\text { culls. } \\
\text { Choice, good, common }\end{array}$ \\
\hline $\begin{array}{l}\text { FEEDER SHEEP } \\
\text { (Western Sheep) }\end{array}$ & 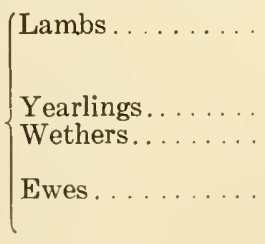 & $\begin{array}{l}\text { Fancy selected, choice } \\
\text { good, medium, com } \\
\text { mon. } \\
\text { Choice, good, common } \\
\text { Choice, good, medium } \\
\text { common. } \\
\text { Choice, good, medium, } \\
\text { common. }\end{array}$ \\
\hline $\begin{array}{l}\text { BREEDING SHEEP } \\
\text { (Native and Western Sheep) }\end{array}$ & $\left\{\begin{array}{l}\text { Ewes ... . . . . . } \\
\text { Bucks ........ }\end{array}\right.$ & $\begin{array}{l}\text { Fańcy selected, choice, } \\
\text { good, common. } \\
\text { (Not graded.) }\end{array}$ \\
\hline MISCELLANEOUS & $\left\{\begin{array}{l}\text { Hot-House Lambs } \\
\text { Throw Outs } \\
\text { Dead Sheep } \\
\text { Goats }\end{array}\right.$ & \\
\hline
\end{tabular}

* Ill. Bul. 129 . 
The division of the sheep in each class into sub-classes is determined either by age or sex. The division of the sheep in each sub-class into grades depends upon their comparative merits and faults and is more arbitrary than the division into classes and sub-classes.

Native and western sheep.-Before taking up a description of the various classes, sub-classes, and grades, it is necessary to explain the differences between native sheep and western sheep. Broadly speaking, native sheep are those kept in small flocks on the farms of the central, southern, and eastern states, while western sheep are those coming to market from large bands on the ranges of the western states. There is also a difference in the breeding; western sheep have a large proportion of Merino blood, whereas natives have mostly a mutton ancestry. Western

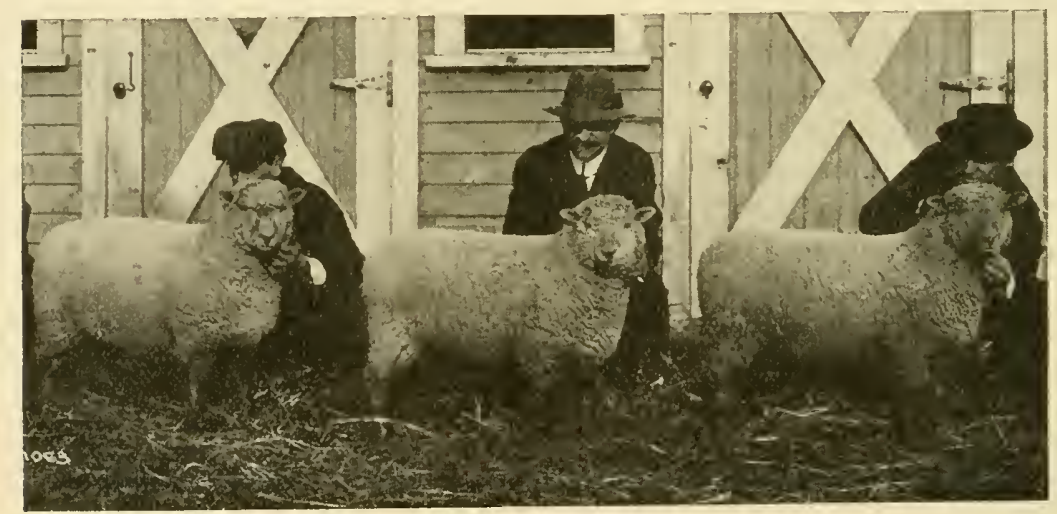

Fig. 59. Prime Native Lambs.

Bred and fed by the Iowa State College.

sheep are white faced and usually show more or less wrinkles, particularly below the neck; native sheep are mostly brown faced and are usually free from wrinkles. Range methods of feeding and management, as compared with farm methods, result in further differences in appearance and make easy the distinction between natives and westerns. The mutton and breeding classes include both native and western sheep, but the feeder class is composed of western sheep only. Although thin natives are bought up in the country and successfully fed, those that reach the market in low condition do not sell as feeders because they are usually infested with internal parasites, thus making it difficult and often impossible to fatten them. 
The stomach worm of sheep, Haemonchus contortus, is one of the most serious pests affecting live stock. Sheep of all ages are subject to it, but infested lambs show much more serious effects than do mature animals. The lambs become infested from the older sheep through the medium of the pasture. The symptoms are anemia, loss of flesh, general weakness, dullness, thirst, loss of appetite, and diarrhea. When the fourth stomach of an infested animal is opened and the contents allowed to settle, the parasites may be seen actively wriggling about. They are $1 / 2$ to $11 / 4$ inches long and about as thick as a pin. The worms in the stomach produce eggs which pass out in the droppings onto the pasture, and, if the season is spring or summer, a tiny worm, nearly one-thirtieth of an inch long, hatches out and crawls up a blade of grass. Uninfested sheep or lambs soon become infested on such pastures. No treatment has been found that will rid a flock of this pest, although dosing with a solution of copper sulphate or with gasoline* is fairly satisfactory and will hold stomach worms in check so that they will not injure the flock. The best means of combating the parasite is by preventative measures. Rotation of pastures is imperative. Permanent pastures for farm flocks are almost certain to cause trouble. Rape should be sown as early in the season as possible. It is easily grown, has a high value as feed for sheep and lambs, and helps prevent stomach worms, especially when temporary fences are used and the flock is changed to fresh ground frequently.

The western rangeman with great areas of pasturage is able to keep his flocks on fresh ground, while on farms this is

\footnotetext{
* It is advisable to treat infested sheep when they go into winter quarters and again in the spring after they have been on pasture for a short time, and at any other time during the summer when they show symptoms of attacks.

Only clear blue crystals of copper sulphate should be used, dissolving 1 ounce in 2 quarts of water. Care must be used in preparing the solution, for too strong a solution will kill the sheep and too weak a solution will not be effective. The sheep should be kept off feed for 18 to 24 hours before treating. On the day they are treated they should receive no water either before or after treating. The size of the dose is as follows:
}

For a lamb 3 months old give $2 / 3$ of a fluid ounce (about 20 c. c.).

For a lamb 6 months old give $11 / 3$ fluid ounces (about 40 c. c.).

For a yearling give 2 fluid ounces (about 60 c. c.).

For sheep 2 years old give 3 fluid ounces (about 90 c. c.).

(From Ohio Experiment Station's Monthly Bulletin, June, 1918, p. 174.)

The gasoline treatment consists in giving a tablespoonful each of gasoline and raw linseed oil in about 6 ounces of cow's milk for a lamb, and half as much again for a sheep, giving three doses, one dose a day for three days, on an empty stomach. 
possible but, unfortunately, is not often practiced. Hence, western sheep have a great advantage over native sheep for feeding purposes.

At the large markets and in live-stock reports, western sheep are frequently distinguished by the name of the state in which they are supposed to have been produced or fed, such as "Montanas," "Colorados," "Mexicans," "Idahos," etc. The word "fed" when prefixed to the name of a class indicates that the sheep were fattened on grain rather than on grass alone.

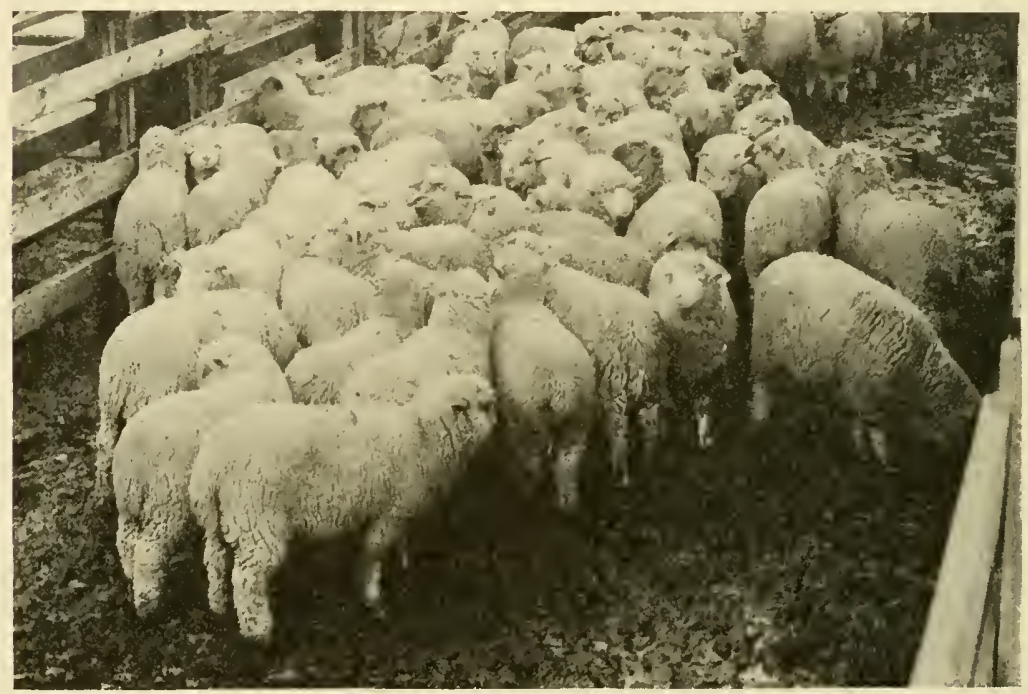

Fig. 60. Prime Western Lambs.

\section{Mutton Sheep.}

All sheep and lambs sent to market, no matter what the condition, age, or weight, are classed as mutton sheep if they are suitable for immediate slaughter. They are either slaughtered at Chicago packing houses or reshipped to Philadelphia, New York, Baltimore, Washington, Buffalo, and other cities. Only the better grades are shipped. The sub-classes of mutton sheep are lambs, yearlings, wethers, ewes, and bucks and stags.

Lambs.-Of the various sub-classes of mutton sheep, the lamb sub-class is by far the most important, both to the producer and to the consumer. The producer finds the marketing of lambs more profitable than the marketing of older animals, while the consumer has developed a strong and increasing pref- 
erence for lamb. Seventy-five per cent. of the ovine receipts at Chicago are lambs, and the percentage is increasing. Nevertheless, mature mutton sheep will never disappear from the market, because surplus and spent breeding stock will always be available for slaughter. At from 12 to 14 months of age, lambs pass into the yearling or ewe sub-classes. No definite age limit can be drawn about the lamb sub-class, for the distinction is based upon the degree of maturity exhibited by the young animal. For this reason native lambs pass out of the sub-class at a younger age than western lambs, because they are better fed and are usually free from Merino blood. The western lamb's slower approach to maturity, due to its breeding and feeding, is something of an advantage, enabling it longer to

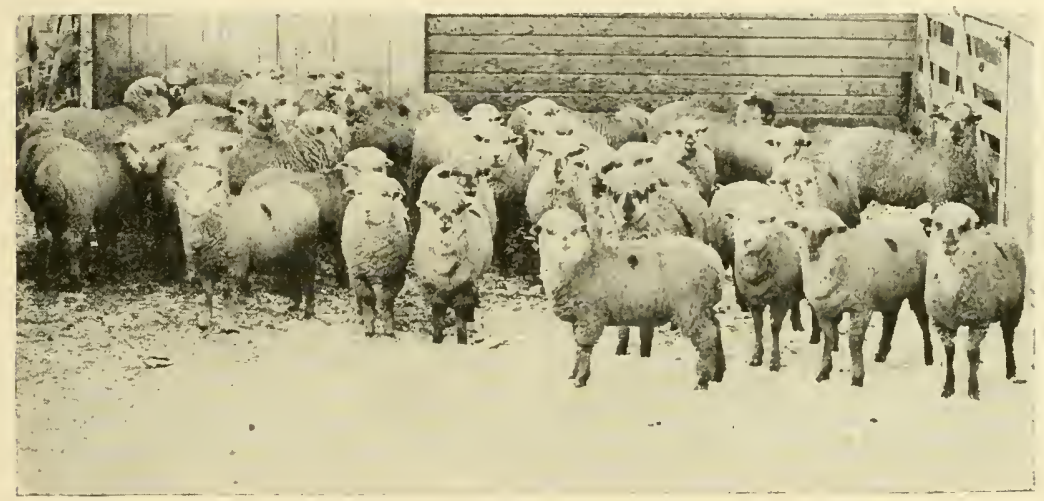

Fig. 61. Choice Western Lambs.

enjoy the advantage in price that lambs have over older animals. A feeder may buy light western lambs in the late fall and feed them until the following May, at which time they will still be classed as lambs; while native lambs of the same age and similarly managed would be classed as sheep upon their return to market.

This makes clear why for several weeks in the year it is necessary to make two separate quotations on lambs, one of which is for those known as "spring lambs," referring to those born in the year the quotations are made, as distinguished from those born the year previous. These separate quotations first appear about May 20, and continue until July 1. After July 1, all animals born in the spring of the previous year are known as yearlings or ewes. The first run of spring lambs to western markets is from Tennessee where pastures are green very early 
in the spring and where lambing is somewhat earlier than farther north. The run starts about the middle of May, and continues regularly after June 1. These Tennessee lambs are followed by Kentucky lambs during July, and the central states and western range lambs from July 15 to November 1 . Then come grain-fed spring lambs from about November 1 to June 1 . These are mostly range-bred stock fed in Colorado or in the cornbelt. Colorado uses peas and alfalfa extensively in lamb feeding. In Idaho, Montana, and other western states, lambs are frequently kept over and finished during fall and winter on hay.

The grades of fat lambs are prime, choice, good, medium, and common or culls. The grade of a lamb depends upon its form, quality, condition, and weight.

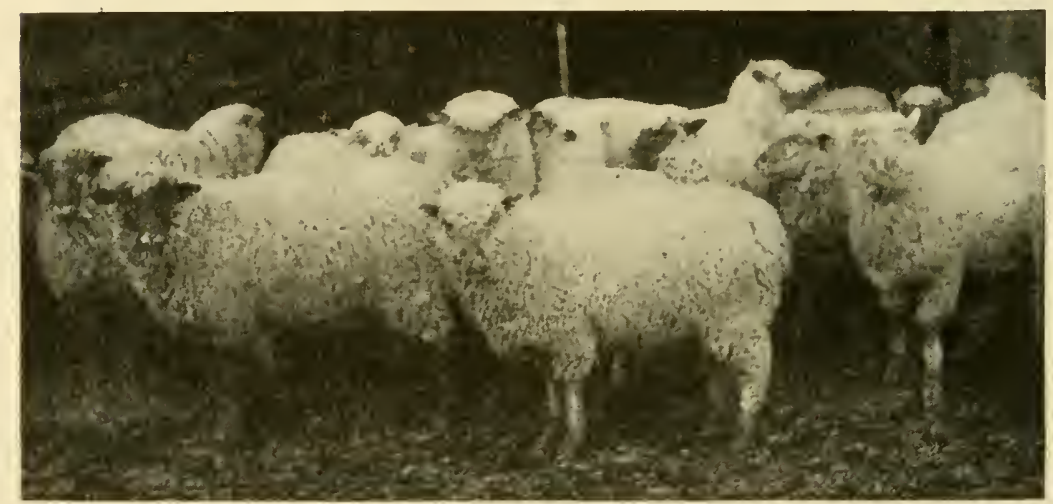

Fig. 62. Good Lambs.

Prime lambs.-Only the best lambs, or those that are superior in form, quality, condition, and weight, are graded as prime. They are used to supply the demands of the fancy city market, hotel, and restaurant trade.

1. Form.-The buyer demands the form that shows the most development of loin, back, and leg of mutton, these being the regions of high-priced cuts. The lamb should be deep, broad, short of leg, and free from paunchiness. Fullness and smoothness of outline are important as indications of thickness and evenness in fleshing. A rough, ungainly lamb dresses out low and yields an unattractive carcass. Undocked lambs are discriminated against on the market.

2. Quality.-The indications of quality are a mediumsized, clean-cut head; fine ears; fine bone; and smooth, well- 
rounded outlines. These features insure fineness in texture o flesh, increase the dressing percentage, and add to the attractive appearance of the carcass; hence, quality is an important factor in determining price.

3. Fatness and fleshing.-The reasons why a lamb should be fat are: (1) Other things being equal, a fat lamb will dress a higher percentage of carcass than a half-fat or thin lamb; (2) the fat adds to the attractiveness of the carcass, making it more inviting to the purchaser; (3) the fat carcass shrinks less in weight in cooling out in the refrigerator, and the same is true in cooking; (4) some external fat and fat deposited through the lean meat improves the juiciness and flavor of the flesh. The fleshing of the lamb should be deep, even, and firm, yet "springy."

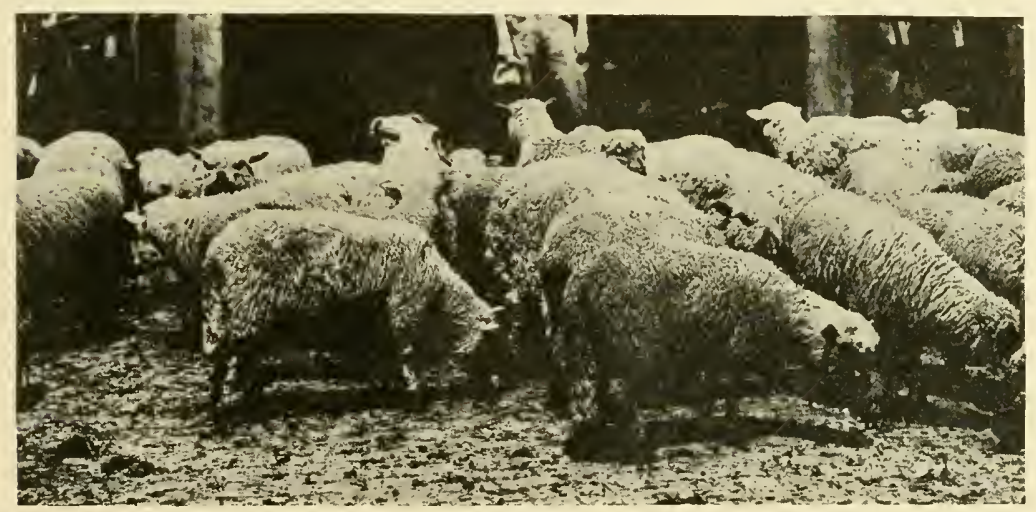

Fig. 63. Common or Cull Lambs.

Lambs are seldom made too fat, but in the finishing of older animals this is easily possible. The proper degree of fatness is indicated by a thick dock, a mellow purse, thickness and smoothness over the back and ribs, fullness at the neck and flanks, and a plump, well-filled breast.

4. Weight.- The most desirable weight for the prime lamb is 80 pounds. When spring lambs first appear on the market they weigh little more than 60 pounds, but if they have quality and finish they easily command top prices. During summer months, consumers of mutton desire small cuts, and this gives rise to a strong demand for lambs weighing 65 to 70 pounds. Native lambs showing the best form, quality, and condition, and weighing 100 pounds occasionally sell as prime lambs, although this is exceptional. As a rule, weight is of less 
importance than quality or condition, but in making selections from the lighter carcasses the average consumer feels more fully assured he is getting lamb and not mutton.

Foreign material and moisture in the wool add to the weight. Should lambs be very wet, buyers may withhold bids until they are more nearly dry, and if bids are made on animals having wet fleeces, the buyer trys to allow for the extra weight in the price he offers. Foreign material, such as mud, sand, or manure, may be lodged in the fleece, and such offerings always command a lower price. It pays to market all sheep in clean condition.

Choice lambs.- This grade includes most of the better lamb offerings upon the Chicago market. Lambs cannot be very

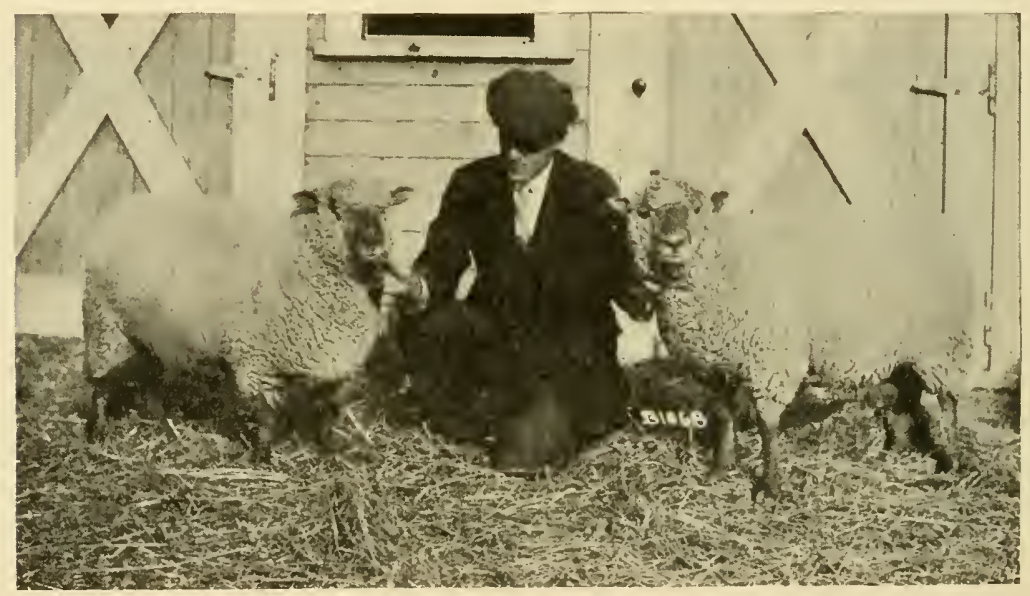

Fig. 64. Prime Native Yearlings.

Bred and fed by Iowa State College.

deficient in form, quality, fatness, or weight, and grade as choice. Deficiency in quality or in weight frequently accounts for failure to grade as prime, but lack of condition is the most common cause.

Good lambs.-Marked deficiency in form, quality, condition, or weight, or a slight deficiency in each, puts the lamb into the good grade. Lack of quality and lack of condition are the most frequent causes of failure to grade higher than good.

Medium lambs.- Here the form is frequently faulty, and the condition and quality fall far below the standard. Long, narrow, rough lambs much lacking in flesh grade here. They 
are often paunchy. Western lambs answering to this description classify as feeders unless they are very coarse, hence this grade is mostly filled by native lambs.

Common or cull lambs.-Coarse, ill-shaped, thin lambs grade as common or culls. With one exception they are very light in weight, ranging from 30 to 50 pounds. The exception is found in the case of coarse, "bucky" lambs, the result of too late castration. The development of sex explains their coarseness and heavy weight, as they are heavier than the bulk of common lambs, sometimes weighing as much as 100 pounds. Common lambs are mostly natives. Their lack of flesh is often due to infestation by internal parasites.

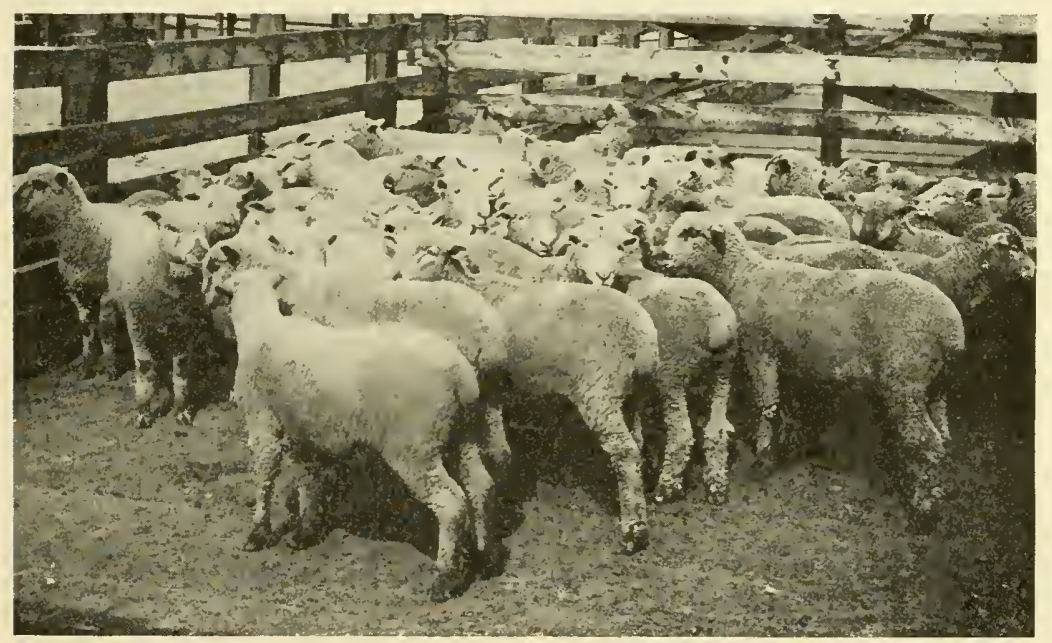

Fig. 65. Prime Western Yearlings.

Many uncastrated lambs still come to market, but principally from the small farms-never from large farms or ranches where sheep raising is recognized as a business. They are discriminated against rather severely at times by buyers. Ram lambs are so restless that they do not acquire the finish of wether lambs. This is especially true after they have reached the age of 3 or 4 months. Tests have shown that wether lambs make 11 per cent. more gains in weight than do ram lambs under similar conditions, and the difference in fatness is much more marked. Lambs should be docked and castrated when from 7 to 10 days old. 
Yearlings.-This sub-class includes yearling wethers only. Yearling ewes are excluded. Yearlings are used as a substitute for lambs in the meat trade. The ability to substitute for lamb depends upon weight, quality, condition, and immaturity; for the nearer the yearling approaches the prime lamb in these respects, the better he fulfills his function. An index greatly depended upon for identifying the carcass of a young sheep, or lamb, is the "break-joint," which was described in Chapter XVI. Most yearling wethers will "break," whereas most yearling ewes will not. This explains the inability of the yearling ewe to substitute for lamb, and hence the term "yearling" on

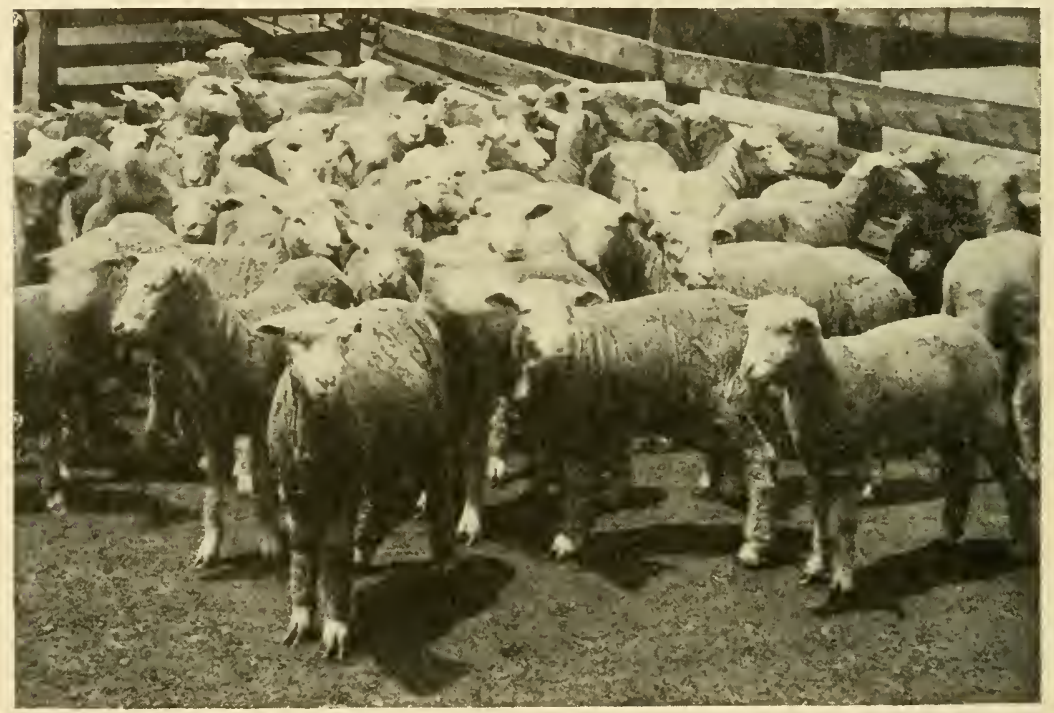

Fig. 66. Good Yearlings.

the sheep market includes wethers only. Yearlings are commonly referred to as "lights" and "heavies," according to weights. Each year there are a number of lambs that for one or more reasons should not be marketed as lambs, and hence the production and marketing of yearlings is economically justifiable. The grades are prime, choice, and good.

Prime yearlings. - To grade as prime, yearlings must be highly developed in form, quality, and condition, and of a light, handy weight, ranging from 70 to 90 pounds. Correct form in the prime yearling necessitates symmetry, compactness, roundness, and smoothness, with no suggestion of uneven lines 
or prominent parts. In quality, the requirements are fine, cleancut features, fine bone, and a smooth form. Sharp discrimination is made by buyers against those not showing a high finish, this being the first essential in prime yearlings.

Choice yearlings. - Yearlings of the choice grade outnumber those grading as prime. A weight of more than 90 pounds is usually alone sufficient to exclude a yearling from the prime grade. Any noticeable departure from correct form, quality, or condition is sufficient to place a yearling in the choice grade. The difference between prime and choice yearlings is small.

Good yearlings. - When the weight is 110 pounds or more, or when there is marked lack of those qualities sought in the

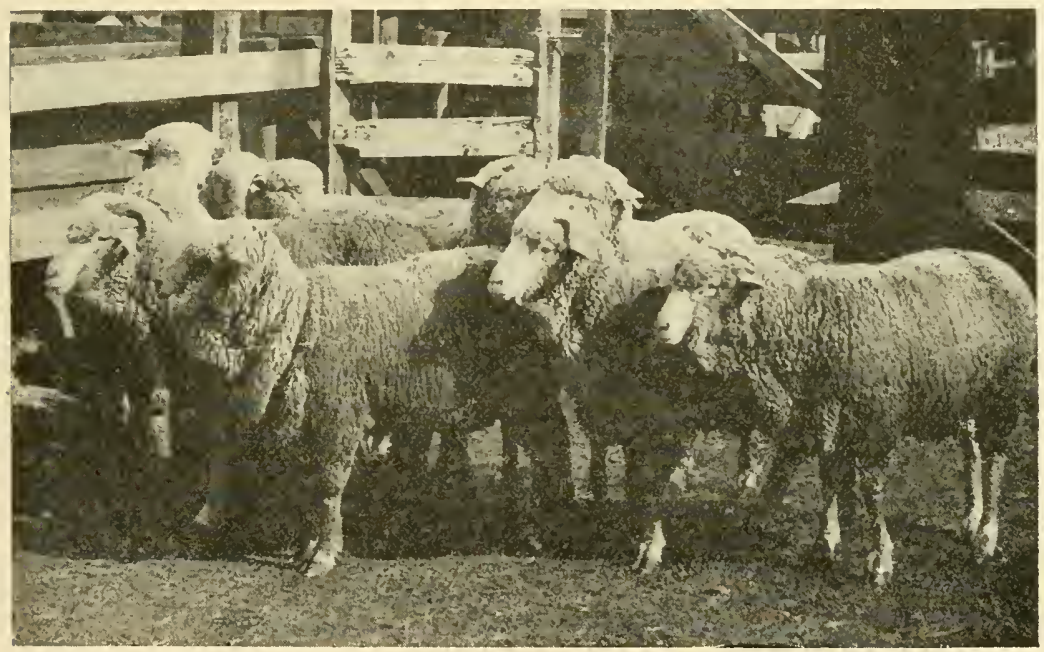

Fig. 67. Common Wethers.

yearling sub-class, the animals grade as good, this being the lowest grade of yearlings. Excepting those that are badly off in form or quality, or both, the good grade of mutton yearlings merges with the yearling feeder sub-class.

Wethers.-This sub-class is composed of mature, castrated males. Comparatively few native wethers appear upon the market, this sub-class being chiefly a western product. It is claimed that there are fewer wethers reaching the market each year, and, as the demand for dressed lamb seems destined to increase, the proportionate number of wethers will undoubtedly continue to decrease, especially when transportation lines are 
further extended through the range districts. At present, the rangeman has a place for wethers if his location is such that the shipment of animals is difficult and expensive, if he has very cheap grazing lands and can produce his animals at very low cost, or if he has too few breeding sheep to run his ranch at its full capacity. As a mutton product, wethers are used in hotel, restaurant, dining car, and steamship trade, or in any place where the heavier cuts may be advantageously used. The grades of wethers are prime, choice, good, and common.

Ewes.-Yearling ewes, ewes discarded as breeders, and surplus breeding ewes compose this sub-class. Wide differences are therefore noticeable in age, condition, and weight of offerings. As a rule, ewes dress out lower and yield proportionately less lean meat than wethers, and hence bring a lower price. The higher grades of ewes are utilized for hotel and restaurant trade, while the lower grades supply the demand for cheap mutton in cities, mining camps, and other places. The grades of ewes are prime, choice, good, medium, and common or culls.

Bucks and stags. - The supply of these is limited and hence they are not graded. This sub-class is of no special importance to the producer of mutton.

\section{Feeder Sheep.}

The chief distinction between mutton sheep and feeder sheep is the degree of fatness. Other distinctions are noticeable, however, for a study of the two classes discloses the fact that thinness of flesh is not alone sufficient to gain ready admission to the feeder class. The animal should also be free from extreme coarseness, and should not be much lacking in vitality because of disease or old age. The supply of feeder sheep is greatest during September, October, and November, at which time rangemen are thinning their flocks in preparation for winter. An investigation conducted by the U. S. Department of Agriculture* in 1915 indicated that 64 per cent. of feeder sheep and lambs are purchased in the fall, 26 per cent. in the spring, 9 per cent. in the summer, and 1 per cent. in the winter. Furthermore, 47 per cent. of feeder sheep and lambs purchased are bought locally in the district in which they are fed or grazed, 39 per cent. at centralized markets, and 14 per cent. in the coun-

* U. S. Dept. Agr. Report 113, p. 17. 
try, other than locally. As previously explained, practically all sheep sold from the markets as feeders are those grown on western ranges. The sub-classes of feeder sheep are lambs, yearlings, wethers, and ewes.

Feeder lambs.-Illinois Bulletin 129 has the following to say regarding feeder lambs: "Feeder lambs are those thin in flesh left after sorting out those in a band in suitable condition for the mutton trade. A great percentage of the feeder lambs reaching the markets fall into that class because of certain influences under which they have been placed. It may be that they have had an unequal chance with those in highest condition in the band on account of not being so well nourished by

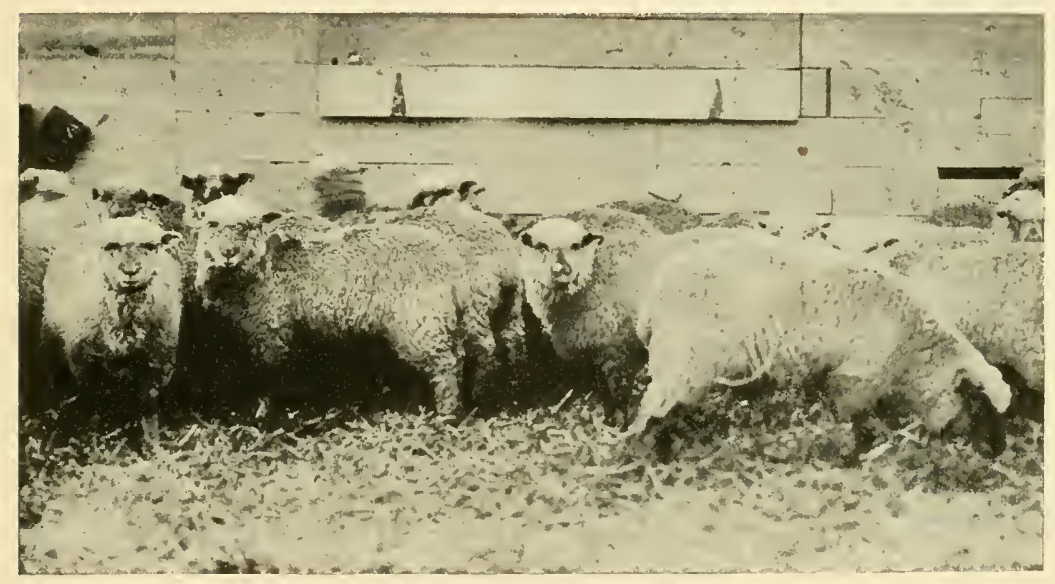

Fig. 68. Fancy Selected Feeder Lambs.

their dams; they may have been born too late to reach that degree of condition, finish, and weight demanded by the packer; or, they may have been held too long at the shipping place on the range or on the road by poor train service without the necessary amount of feed, so that the deterioration in condition placed what would have been mutton lambs in the feeder class." Feeder lambs are graded fancy selected, choice, good, medium, and common or inferior.

Fancy selected feeder lambs. - This grade includes only a relatively small number of lambs, because they must meet not only the requirements for choice feeder lambs, but must also show very good breeding, great uniformity in appearance and markings, and a degree of quality that justifies no adverse criticism. 
They show slightly more fatness than the general run of feeder lambs, and are heavier, weighing from 65 to 70 pounds. Such lambs are quickly finished into prime lambs.

Choice feeder lambs. - This grade of feeder lambs will develop into choice or prime mutton lambs, provided they are properly managed. The buyer looks for evidences of ability to make economical gains and to reach a high state of finish. Such evidences are manifested in the form, quality, constitution, condition, and weight.

1. Form.-The form should be low set, broad, deep, compact, and free from paunchiness. Such a conformation is especially important as an indication of quick maturity and is the form the butcher prizes most in a carcass.

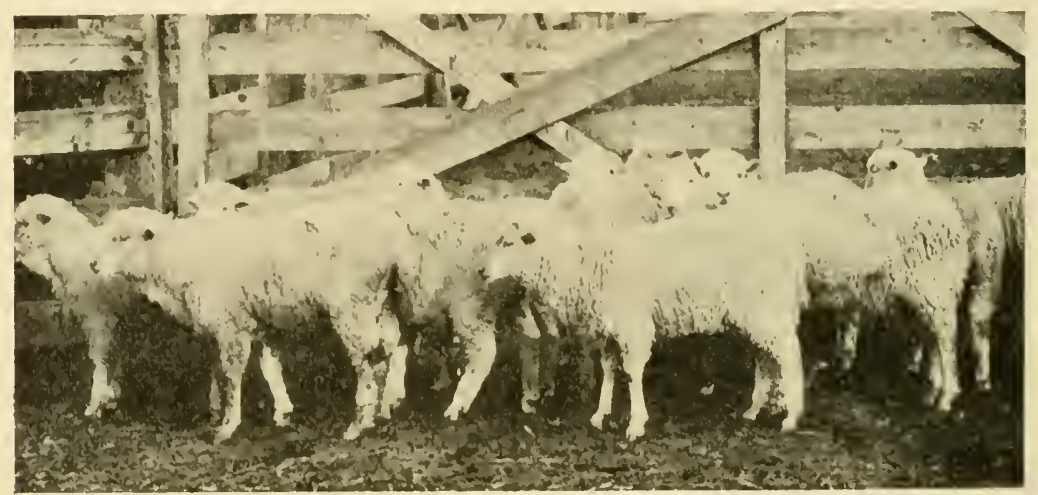

Fig. 69. Good Feeder Lambs.

2. Quality.-The head should be medium sized and cleancut, the bone fine, and the skin free from folds or wrinkles.

3. Constitution and thrift.-A wide, deep chest and roomy middle are essential to constitutional vigor. Buyers desire a thrifty, active lamb and hence look with disfavor on those that are lame or inactive.

4. Condition.- - It is not expected that feeder lambs will be fat, yet they should be fairly full in their outlines, and there should be no suggestion of emaciation, as this means a weakened, inactive lamb.

5. Weight.-Feeder lambs that grade as choice weigh from 55 to 62 pounds. Those below this range of weight may be regarded as too young or too much retarded in development to respond to feeding as a choice lamb should. In a normal 
feeding period of from 90 to 120 days, choice lambs are expected to finish into the weights most desirable on the mutton market; hence, the initial weight cannot be much under 55 pounds.

Good feeder lambs.-These are often somewhat leggy and coarse, yet capable of making satisfactory gains. They average a little light in weight, and are not so high in condition as choice feeder lambs, hence require a longer feeding period to finish them. Buyers of this grade feed them all winter and shear before marketing. This grade especially appeals to buyers who take out lambs a few weeks before shearing time to shear and feed for a short period.

Medium feeder lambs. - This grade is deficient in breeding, form, quality, and weight. They are long, leggy, and angular

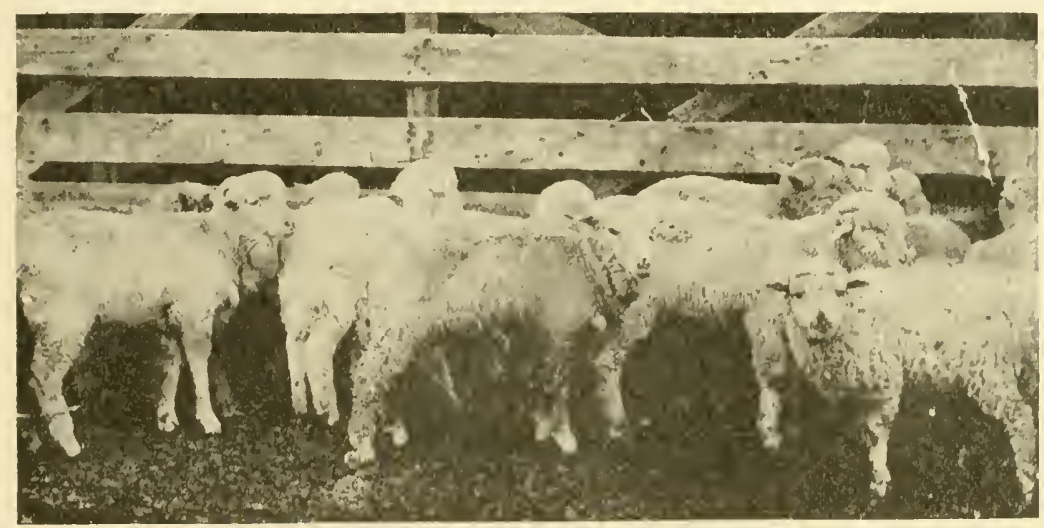

Fig. 70. Common Feeder Lambs.

in form, and their wrinkled skins are evidence of much Merino blood.

Common or inferior feeder lambs.-Little, light, late-born, weak lambs grade as common or inferior. The market calls them "bums," "culls," "pewees," and "peanuts." They weigh from 25 to 45 pounds and require five or six months feeding and careful management to make the feeding profitable. Extremely coarse lambs also grade as common.

Yearling feeders.-This sub-class is composed only of yearling wethers, and, as the mutton yearling should be able to substitute for lamb, quality and weight are of great importance in grading yearling feeders. They are not a prominent feature in the feeder trade, as but few appear on the market. The grades are choice, good, and common. 
Feeder wethers.--The supply is very small. The grades are choice, good, medium, and common.

Feeder ewes.--Most ewes suitable for feeding bring a higher price when sold for breeding purposes, hence the supply of feeder ewes is small. They exhibit considerable variation in condition, quality, and thrift, and are graded choice, good, medium, and common.

\section{Breeding Sheep.}

Both native and western ewes are included in this class, but breeding bucks are exclusively natives. Bulletin 129 of the Illinois Station has the following to say concerning this class: "The ewes most sought after are two-, three-, and four-year-old dark-faced natives in ordinary field condition. Dark-faced ewes sell better than those that are otherwise their equals, because their lambs, being dark faced, sell better than light-faced lambs on the eastern markets. Western ewes are very popular for breeding purposes in certain localities, as Ohio, Michigan, and Western New York, and many engaged in the trade think they should be preferred over natives, because they are more hardy and comparatively free from internal parasites. Many of the ewes offered for breeding purposes are yearlings, but they are not as desirable as two- or three-year-old ewes because they are immature and likely to be unsatisfactory at their first lambing. The native yearling is heavier and more nearly mature than the western yearling, and she meets with a correspondingly better sale." Breeding ewes are graded fancy selected, choice, good, and common.

Fancy selected breeding ewes.-This grade of ewes is composed of the few high grades of the middle-wooled breeds, usually grade Shropshires, which reach the market. They must be not only thrifty and sound, but uniform in quality, form, fleece, and style.

Choice breeding ewes.--Most of the desirable breeding ewes found on the market belong to the choice grade. Eligibility to this grade is based upon form, constitution, age, soundness, breeding, quality, and condition. Below, the writer again quotes from Illinois Bulletin 129.

1. Form.- "The smooth, low-set, symmetrical ewe is preferred over the angular, upstanding ewe with uneven top and lower lines. $* * *$ Choice ewes, unlike fancy selected, do 
not necessarily have to be of stylish carriage. From the standpoint of breed type, they are often plain about the head, with rather long necks, and long in the coupling to the extent that they could hardly be regarded as compact."

2. Constitution.- "Since the breeding ewe is to produce and nourish lambs, it is essential that she be deep and wide in the chest, and that she have a roomy middle, all of which indicates that she has a strong constitution and well-developed assimilative powers."

3. Age.- "The most desirable ages are two, three, and four years, and more particularly two and three years. When breeding ewes go to the country it is the thought of the purchaser that they are to produce, on the average, three crops of lambs before they are sent back to the market as old mutton ewes, hence, if the age is any greater than four years, the ability to produce profitably for three years is very doubtful."

4. Soundness.- "Soundness refers to the condition of the mouth and udder. A broken mouth, which means missing teeth or teeth worn down short, indicates advanced age, and although ewes may otherwise look desirable for breeding purposes, they cannot grade as choice if the teeth are not intact. It is necessary that the choice breeding ewe have a sound udder, and it is pronounced sound when it is soft and pliable to the touch, without abnormal development on either side. Any ewe not having a sound udder should be rejected as a breeder, but in the good and common grades some carelessness is exhibited in this respect."

5. Breeding. - "The breeding most sought after is some one of the Down breeds, chiefly because of the dark color upon the face and legs. Early in the season of the breeding ewe trade, when Kentucky, Tennessee, and Virginia are taking large numbers of breeding ewes, color has a pronounced influence upon the desirability of a ewe. Of two ewes, one with light markings and the other with dark, but equal in all other respects, the one with dark markings is placed a grade higher than the other. It is also desirable that the breeding of choice ewes be such that they have abundant fleeces of medium wool, which means that the wool be of medium fineness and length, dense, and evenly covering all parts of the body. Since they are to remain in the country for three seasons, the quality and quantity of wool they produce is no inconsiderable item."

6. Quality.- "Choice breeding ewes should have smooth, rather refined features, and bone of medium size. Ewes of this 
grade are used to produce choice and prime lambs for the spring and early summer markets, and without a great deal of general quality, they could scarcely fulfill their mission. It is well to distinguish between good general quality and over-refinement, as delicate, over-refined ewes are without sufficient constitution to be profitable producers."

7. Condition.- "While choice breeding ewes should be thrifty and active, fat is not desirable as the purchaser prefers to place these ewes on pasture and cheap forage feeds which will secure the condition desired at a lower cost than the price demanded on the market. Breeding ewes are somewhat like feeder lambs in that they are the result of a sort where those ewes of desirable form, quality, breeding, age, soundness, and thrift, but somewhat lower than mutton condition, are selected out from those that are fatter and desirable for mutton."

Good breeding ewes.-Undesirable markings, age, weight, form, and condition cause breeding ewes to grade as good.

Common breeding ewes.-This grade is characterized by mixed breeding and advanced age. The common grade of breeding ewes merges with the feeder class.

Breeding bucks.-Rams are taken out of the Chicago and other markets for breeding purposes, but most of them are of poor form and mixed breeding. Anyone who has visited the sheep pens at Chicago or at any other large live-stock center will testify that the breeder who goes to the open market to select sires will never succeed in raising the merit of his flock above the level of mediocrity. The practice is unjustifiable and unprofitable.

\section{MISCELLANEOUS.}

Hot-house lambs.-These are lambs produced early and marketed before the general run of spring lambs starts to market, which is about May 20. A few shipments reach the Chicago market, where they are called "spring lambs," but the open market is not the best place to dispose of such a product. The men who have made the most profit from the production of hothouse lambs are those who cater directly to the eastern hotel and restaurant trade. The practice is to slaughter the lambs on the farm where they are produced, and pack the carcasses in ice for shipment, small shipments being made regularly during the winter and early spring. They are in most demand from Christmas until Easter. They must be fat and weigh between 40 and 55 pounds. 
Throw outs. - When bands of lambs reach Chicago, they are at once sorted into the mutton and feeder classes. The buyer of the feeders usually has the privilege of rejecting those not suitable for feeding purposes. The rejections, called "throw outs," are made up of lambs that are lame, unthrifty, blind, uncastrated, undocked, over weight, under weight, badly wrinkled, sore mouthed, burry, black, low backed, or open fleeced. They are purchased by small city butchers who have a cheap trade. They sell at cull-lamb or medium-lamb prices.

Dead sheep.- Sheep which die in transit are valued chiefly for their wool. If mangled and badly trampled, they are worthless, and fifty per cent. of dead sheep reach the market in this condition.

Goats.-These are sold for slaughter if they are in good condition, but do not bring as high price as sheep. The supply is limited. Thin goats are often taken to the country to clean up brush land.

\section{Sheep Prices at Chicago.}

Chicago prices during 1918. - The lowest and highest prices paid in Chicago* on the open market for the various classes of sheep in 1918 were as follows: Native mutton lambs, $\$ 8.00$ $\$ 21.50$; western mutton lambs, $\$ 8.00-\$ 21.50$; spring lambs, $\$ 6.00$-\$22.00; mutton yearlings (natives and westerns), $\$ 8.50$ $\$ 20.00$; native mutton sheep, $\$ 2.50-\$ 17.50$; western mutton sheep, $\$ 3.00-\$ 17.00$; feeder lambs, $\$ 10.50-\$ 21.75$; feeder sheep and yearlings, $\$ 4.50-\$ 16.00$; breeding ewes, $\$ 8.00-\$ 19.00$. In each instance the highest price listed above represents a new high record on the Chicago market, except breeding ewes which established a record of $\$ 20.00$ at Chicago in 1917.

Market values of the various classes.-The comparative market values of the sub-classes of mutton sheep are shown by the following table, giving the yearly average prices at Chicago for the several sub-classes from 1909 to 1918, and also the averages for the entire ten-year period:

* Year Book of Figures, 1919. 


\begin{tabular}{|c|c|c|c|c|c|c|c|}
\hline \multirow{2}{*}{ Year } & \multicolumn{2}{|c|}{ Lambs } & \multirow{2}{*}{$\begin{array}{l}\text { Year- } \\
\text { lings }\end{array}$} & \multicolumn{2}{|c|}{ Sheep } & \multirow{2}{*}{$\underset{\text { lambs }}{\text { All }}$} & \multirow{2}{*}{$\begin{array}{c}\text { All } \\
\text { sheep }\end{array}$} \\
\hline & Natives & Westerns & & Natives & Westerns & & \\
\hline $\begin{array}{l}1909 \\
1910 \\
1911 \\
1912 \\
1913 \\
1914 \\
1915 \\
1916 \\
1917 \\
1918\end{array}$ & $\begin{array}{r}\$ 7.30 \\
7.40 \\
5.70 \\
6.90 \\
7.50 \\
7.75 \\
8.85 \\
10.35 \\
15.35 \\
16.25\end{array}$ & $\begin{array}{r}\$ 7.50 \\
7.65 \\
6.05 \\
7.35 \\
7.85 \\
8.15 \\
9.15 \\
10.90 \\
15.80 \\
16.85\end{array}$ & $\begin{array}{r}\$ 6.00 \\
6.30 \\
4.50 \\
5.65 \\
6.35 \\
6.55 \\
7.45 \\
9.25 \\
13.00 \\
13.75\end{array}$ & $\begin{array}{r}\$ 4.95 \\
5.10 \\
3.80 \\
4.40 \\
5.00 \\
5.35 \\
6.10 \\
7.70 \\
10.90 \\
11.75\end{array}$ & $\begin{array}{r}\$ 5.00 \\
5.35 \\
4.05 \\
4.75 \\
5.30 \\
5.70 \\
6.45 \\
7.95 \\
11.15 \\
12.35\end{array}$ & $\begin{array}{r}\$ 7.40 \\
7.55 \\
5.95 \\
7.20 \\
7.70 \\
8.00 \\
9.00 \\
10.75 \\
15.60 \\
16.60\end{array}$ & $\begin{array}{r}\$ 5.00 \\
5.25 \\
3.95 \\
4.60 \\
5.20 \\
5.55 \\
6.30 \\
7.85 \\
11.00 \\
12.15\end{array}$ \\
\hline $\begin{array}{l}10 \text {-year } \\
\text { average }\end{array}$ & $\$ 9.35$ & $\$ 9.75$ & $\$ 7.90$ & $\$ 6.50$ & $\$ 6.80$ & $\$ 9.60$ & $\$ 6.70$ \\
\hline
\end{tabular}

The above table shows that western lambs outsell native lambs by 40 cents per cwt., and western sheep outsell native sheep by 30 cents per cwt. All lambs together have averaged $\$ 2.90$ more per cwt. than all sheep during the ten years from 1909 to 1918 inclusive. Lambs sell $\$ 1.70$ higher than yearlings, and yearlings outsell sheep by $\$ 1.20$. The inability of thin natives to sell for feeding purposes largely explains the difference in prices between native sheep and western sheep in the mutton class.

As a rule, the lowest prices for sheep and lambs are paid the first week in November, and the highest prices are paid the last week in March. 


\section{CHAPTER XVIII.}

\section{BREEDING FOR THE MARKET.}

In colonial times, sheep were all of the coarse-wooled type, brought with the settlers from England and Holland. They were the unimproved original stock from which the present English breeds have sprung. Later, George Washington and other leading agriculturists of the time, introduced sheep representing the early breeding improvement in Europe. After the organization of the national government the Merinos made their appearance. In 1860, the Merino was the outstanding feature among American sheep. In 1870, more than four-fifths of American sheep were Merinos or their grades. There were a few middle-wooled sheep and a very few flocks of the long-wooled breeds in the middle states and in the Ohio valley. The old coarse wools were scattered through the South. Kentucky had the largest number of long wools. Importations were made from England and Canada. In Texas and New Mexico were Mexican sheep of Spanish origin that had degenerated and almost reverted to the wild state. Their fleeces were coarse and hairy and weighed only one or two pounds.

When the first exports of beef were made to England, about 1875, the "Scotsman," a Scottish newspaper, sent Mr. James. Macdonald to America to investigate the American live-stock industry and render a complete report. The results of this investigation were published by $\mathrm{Mr}$. Macdonald in 1878 in a book entitled, "Food from the Far West." His remarks upon the state of the sheep industry in the United States at that time were as follows:

"No one in political or agricultural circles, or elsewhere, seems so confident of the export of mutton becoming or continuing so extensive or so profitable as that of beef. Mutton is not considered an important article of food in America, and the feeding of sheep has received but very little attention from its farmers. Sheep-farming is certainly carried on very extensively all over America, especially in the Western States of the Union and on the Pacific slopes; but, with a few exceptions in the older and Eastern States, the sheep-farmer's whole harvest is his "clip" of wool. There is no demand for mutton, and there- 
fore he prepares none. He keeps a class of sheep specially adapted for producing wool, and allows his old sheep to die away naturally, or go where they may - that is, if he cannot dispose of them, even for a mere trifle, before they reach the ripe old age of eight or nine years."

Sheep grew in number from $19,000,000$ in 1840 to $22,500,000$ in 1860 , to $35,000,000$ in 1880 , to $36,000,000$ in 1890 , to $61,500,000$ in 1900 , and to $63,000,000$ in 1910 . The number in 1919 was $49,863,000$ The loss since 1910 is $13,137,000$ in nine years.

There has been a steady increase since 1860 in the proportionate number of mutton sheep. This has been mostly due to the increased demand for meat, and partly to the demand for wools other than the Merino, that is, the combing wools. The flocks of mutton sheep increased in all parts of the country, though Merino improvement was still the predominating feature in sheep husbandry in Vermont, New York, Pennsylvania, Ohio, Michigan, and elsewhere, and the great flocks of the ranges became Merino grades of a high order of merit. In recent years many Merino flocks in the eastern part of the country have been made over into mutton flocks by several succeeding crosses of mutton blood, while on the western ranges increasing numbers of mutton rams have been used for crossing on range flocks to produce a more practical wool-and-mutton type. East of the Missouri River the majority of sheep are of the mutton type, while on western ranges Merino blood predominates.

The sheep census.-The U. S. Department of Agriculture estimated that on January 1, 1919, there were 49,863,000 sheep and lambs in the United States, and that their average value per head was $\$ 11.61$. The leading states in numbers of sheep were as follows:
1. Wyoming ...
$.4,018,000$

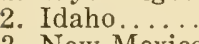
$.3,234,000$
3. New Mexico
$3,135,000$
4. Montana...
$2,984,000$
5. Ohio.
$2,980,000$

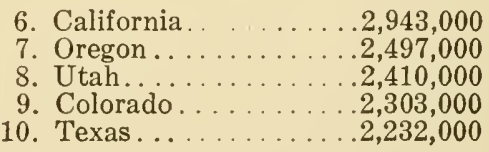

The distribution by geographical divisions was as follows:

North Atlantic.

$2,216,000$

South Atlantic . . . . . . . . . . . . . . . . . . . . . . . . . . . . . $2,179,000$

North Central, East of Mississippi River . . . . . . . . . . . 7,941,000

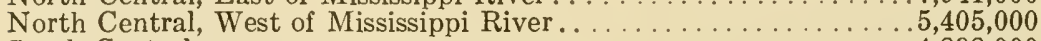

South Central . . . . . . . . . . . . . . . . . . . . . . . . . . . 4,898,000

Far Western.

$27,224,000$ 
The foregoing figures show that the far western division, which includes the range states, has more sheep than all other divisions combined.

In the United States* the sheep slaughter, including lambs, was 44.9 per cent. of the stock of ewes in 1900 , and 46.1 per cent. in 1910. The census of 1900 indicated that the average amount of mutton and lamb produced during the year was 18 pounds per head of stock ewes. The figure for 1910 was 19 pounds. Sheep have a lower ratio than cattle or swine. The reason for this is found in the low meat productivity of sheep kept for wool.

Source of improvement.-A certain few men have collected the very choicest purebred and registered mutton sheep that may be had, almost regardless of price, and have established magnificent flocks upon which they have used rams that were selected with great care and at considerable expense. The owner of such a flock makes it his business to supply breeding rams and some breeding ewes to breeders of less prominence than himself. Year after year he slowly improves his flock by careful selection and mating, and he is thus enabled to send out better rams each year to head the flocks of less prominent breeders. In turn, these less prominent flocks supply better breeding animals to more numerous and still less noted breeders, and so the scheme works out, improvement slowly, but surely, flowing downward and outward from a few flocks to the many. There is a third class of breeders who are producing directly for the market. The produce of their flocks is sold to feeders, or else they themselves feed out the lambs for market. We may: therefore, classify all flocks of sheep as follows:

1. A few flocks solely for improvement.

2. Numerous flocks primarily for propagation and secondarily for improvement.

3. Many flocks solely for mutton production.

The breeders of the third class secure their rams from the second-class flocks, and their ewes are generally grades.

The mutton breeding ram.- The selection of the breeding ram should be most carefully made as he affords the chief opportunity for improvement in the flock. For this reason it is wise to invest several times the average value of the ewes in the purchase of a ram to mate with them. However, it is not so

* U. S. Dept. Agr. Report 109, p. 124. 
much a matter of securing a ram at such or such a price as it is of selecting a sire of merit that is strong in the points wherein the ewe flock is weak, and whose offspring will possess a higher standard of merit than the ewes from which they came. It is a breeding-up process, and this fact justifies more careful selection and greater expenditure of money in each succeeding purchase of a ram. It is always a matter of locating the sort of ram desired, and the price demanded for him should not stand in the way of a purchase unless it is really exorbitant.

The breeding ram of mutton type must be, first of all, a good mutton animal, including as high development of the form,

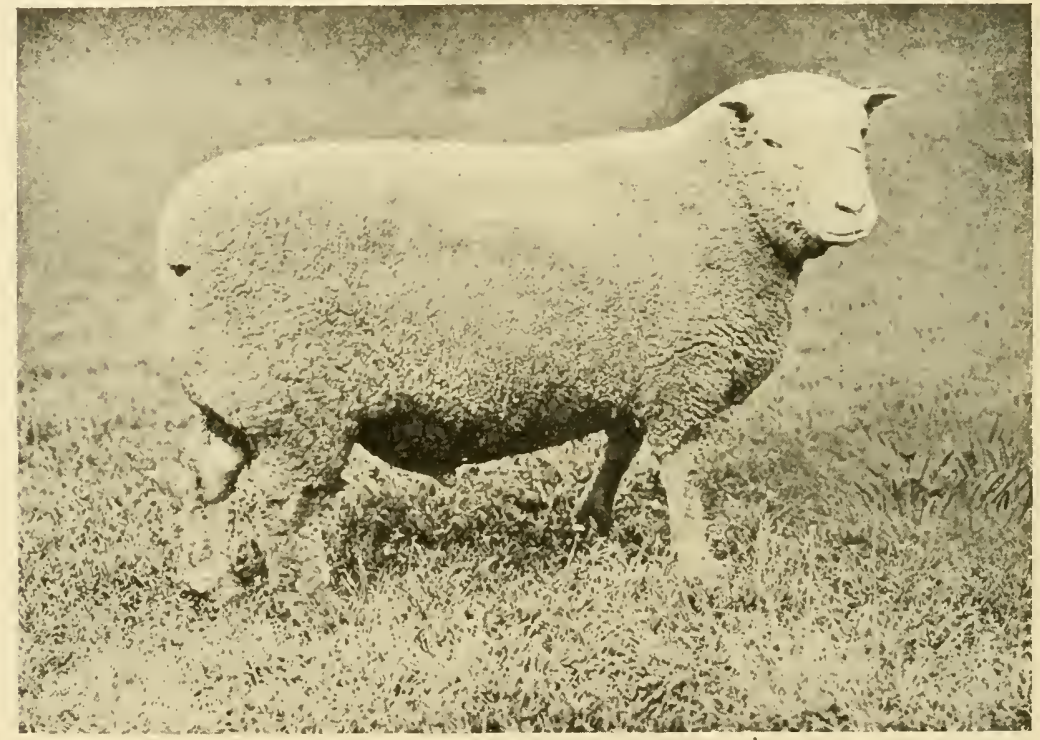

Fig. 71. Correct Type in the Mutton Bireeding Ram.

Southdown ram, Babraham Bumper, Champion at the English Royal Show in 1909. Bred and shown by Mr. C. Adeane, Babraham Hall, Cambridge, England. Note the masculine head and neck, blocky body, heavy leg of mutton, and good bone of this ram.

quality, and fleshing as may be secured. He must, in addition, have a strong, robust constitution as evidenced by a wide, deep chest and middle and good feeding qualities. The story is told of an English shepherd who visited a certain flock to purchase a yearling ram. After much deliberation, he found himself unable to decide among several of the offerings, all of which suited him. Suddenly his serious expression changed to one of 
renewed interest, and turning to the owner he said, "Feed 'em." Grain was placed in a trough in full view of the rams, at sight of which one pricked up his ears and marched quickly to the trough, the others following more leisurely. "That's him," said the buyer, pointing to the ram in front, for in common with all experienced feeders he recognized the significance of good feeding qualities. A strong appetite is evidence of constitution, thrift, lustiness, and health, and indicates a disposition to develop quickly and make economical gains.

The ram should exhibit strong sexual characteristics, these being a strong head with distinctly masculine features and expression, a well-developed crest or scrag similar to the crest of the beef bull, a sufficiency of bone, and general ruggedness of build throughout. Style in the ram, including an active gait and bold presence, is an evidence of masculinity and breeding usefulness. Particular attention should be given to the shape, position, and strength of feet, pasterns, and legs. These points should receive attention in any sheep, but in the breeding ram their importance is magnified. The feet should be well formed, the pasterns strong, the bone ample, and the legs straight. Weakness in the hind legs is of more consequence than weakness in front, as it injures the breeding usefulness to a greater degree. The hocks should not be bent so as to give the hind leg a sickled appearance as viewed from the side; and when viewed from the rear, the hind legs should not be bowed outward, but placed straight and square beneath the quarters. Weak or broken down hind pasterns are particularly objectionable in a breeding ram.

The ram's fleece should be heavy and of good quality according to his breed, special attention being given to the wool in case the ewe flock averages below desired standards for fleece.

So far as the fatness of the ram is concerned, greater satisfaction will ordinarily result from the purchase of a ram in medium condition, or what shepherds call a field ram, than one that has been much pampered in preparation for sale or show. The latter may present a more attractive form and appearance at the time of purchase, but must be let down in flesh before he can be used for breeding purposes, and it is often true that with loss of fat there are revealed some rather disappointing points in form. This more often happens when the buyer is a novice and the ram has had the additional advantage of the correcting power of shears in expert hands. In any case, the purchase 
price of a fitted ram must include the cost of fitting, which may be a considerable amount. It is, of course, a fact that the very choicest rams are highly fitted before being offered for sale, as no flock owner expects to realize full value for an exceptional ram unless he is presented in finished and fitted form; however, this applies to the best offerings and is somewhat outside of the matter under consideration. When rams are purchased to head ordinary flocks the produce of which are sent to market, it will usually be best to pay up to the limit of price for a field ram that suits, rather than invest the same amount in a fitted sheep.

Only purebred sires should be used on any flock, and the same breed should be patronized each time a ram is purchased; in other words, breeding for the market should not result in a mixture of breeds, but the owner should breed in line, grading up his flock by consecutive crosses of the same breed. Thus will the good features of that breed be so strongly stamped upon the flock as to give it a high average of individual merit and great uniformity.

In farm flocks one ram may be used for every 35 to 50 ewes. On the range it is customary to use one ram for every 35 to 40 ewes. A ram lamb should not be used for heavy service. The period of gestation for ewes is somewhat variable, but is usually 146 days. Although ewe lambs are sometimes bred in the fall so that they will lamb the next spring at a little over a year old, the usual plan is to allow the ewe lambs to grow and develop into their yearling form, breeding them in the fall to drop their first lambs the following spring at two years old. The breeding of ewe lambs is not ordinarily considered good practice.

The mutton breeding ewe.-Assuming that there is an established ewe flock to which additions are made from the best ewe lambs of each year, the problem of the breeder is to weed out the less desirable ewes and send them to the butcher. Herein lies a second advantage from the use of good males, for if the sire proves a successful breeder, the owner is furnished with excellent material with which to replenish his ewe flock, thus permitting closer culling of the aged ewes than would be possible had an inferior ram been used. Hence, the use of a good ram not only results in direct improvement in the first crop of lambs, but there is the added advantage of the indirect improvement which is realized when the best ewe lambs reach breeding age. 
It is easiest to cull the flock a short time after shearing, allowing a few days to elapse in order that the ewes may recover from the shabby appearance and somewhat disorganized state common to many of them immediately after being shorn. Aged ewes and broken-mouthed ewes should have been weeded out the previous fall, the cost of wintering them being a needless expense inasmuch as they are difficult to winter without becoming very low in flesh. The wintered ewes may then be sorted two or three weeks after shearing; faulty forms and lack of size are easily detected at that time. It is an easy matter to part with ewes that

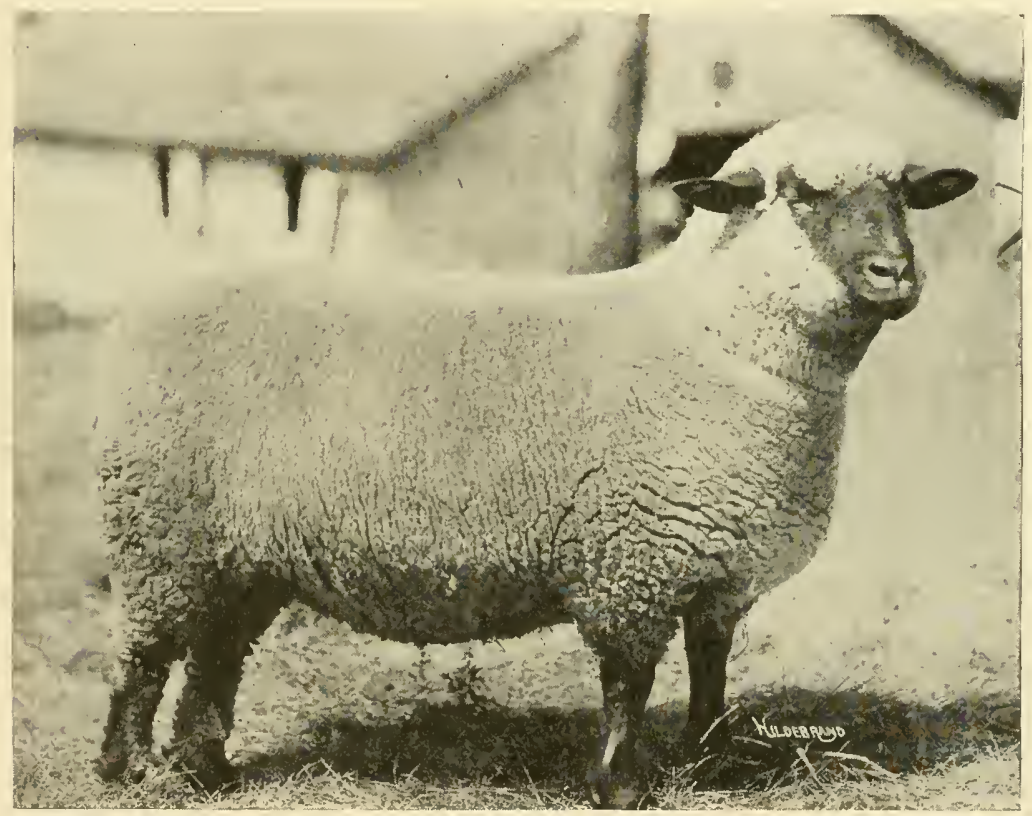

Fig. 72. Correct Type in the Breeding Ewe.

Champion Hampshire ewe at the 1913 International, owned by Mr. A. W. Arnold, Galesville, Wis. This ewe has strength and vigor, combined with femininity and quality. Her dark points are an asset, and her roomy middle and dense fleece are valuable attributes in the breeding ewe.

are aged, broken in mouth, ruptured, crippled, or defective in udder, but it sometimes requires strong determination to give up ewes that are sound, but nevertheless unworthy because of faults in form, quality, size, or fleece. This is especially true when close culling will not leave as large a flock as it is desired to carry, but in the long run it will be best to err on the side of too close 
culling rather than to carry certain individuals that do not measure up to desired standards. Close scrutiny should be made of heads, necks, breasts, shoulders, backs, ribs, rumps, quarters, and legs. Form, size, quality, constitution, muscling, and smoothness of outline should receive much consideration, the requirements for which have been set forth in preceding chapters. One word more, however, may well be added on heads and necks. The following by Prof. John Wrightson,* of the Royal College of Science, London, England, is much to the point:

"Nothing looks better than good heads, and, strange as it may seem, a sheep's head, which is only worth $9 \mathrm{~d}$. at the butcher's is worth a lot of money when carried on a good ram or ewe. A muscular neck indicates strength of constitution and good mus-

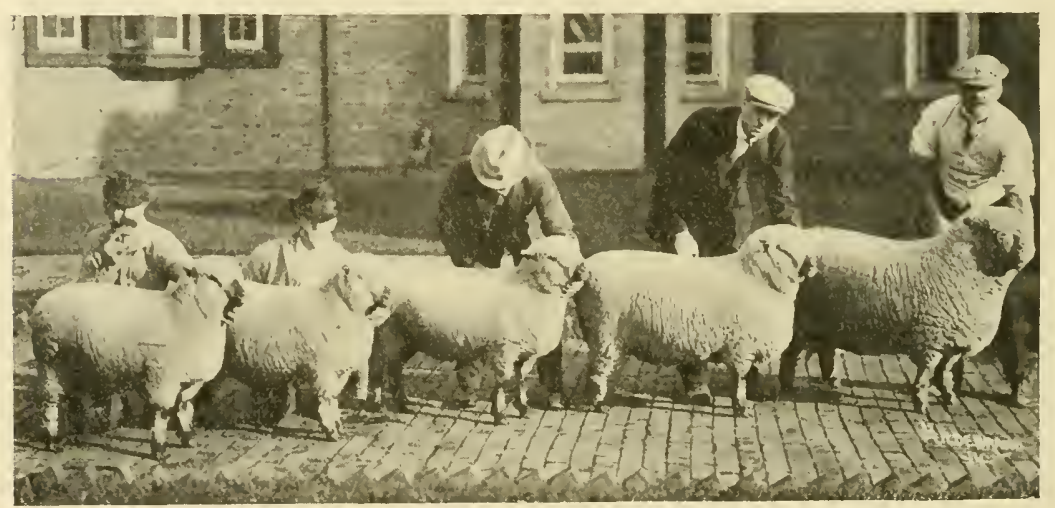

Fig. 73. A Prize-Winning Flock.

Champion Shropshire flock at the 1913 International, owned by A. Broughton \& Sons, Albany, Wis.

cular development, and I have never known a sheep breeder who did not strongly object to a shabby neck. Mr. Ellman, the father of the Southdown breed, insisted on the importance of this point. Mr. James Rawlence, of Bulbridge, one of the oldest of our noted breeders, would not keep a weak-necked ewe, and no man who values his flock would buy a ram with this fault. The neck ought to be muscular, arched, tapering, and neat."

Uniformity in shape, size, color markings, and general appearance is a valuable attribute in any flock. When the produce is intended for the open market, this insures a uniform lot

* Sheep, Breeds and Management, p. 126. 
of lambs for feeding, and it adds much to the attractiveness of the finished lot when presented to the buyer. The market's preference for dark color markings may well be kept in mind in this connection.

The breeder who aims to supply the open market must emphasize the matter of wool when building up a breeding flock. Although meat production is the principal object in view, the clip of wool from such a flock ought to be an important source of revenue. Furthermore, the ewe with the heavy fleece is better protected from the weather, remains more healthy for that reason, and the density of her fleece keeps it free from dirt,

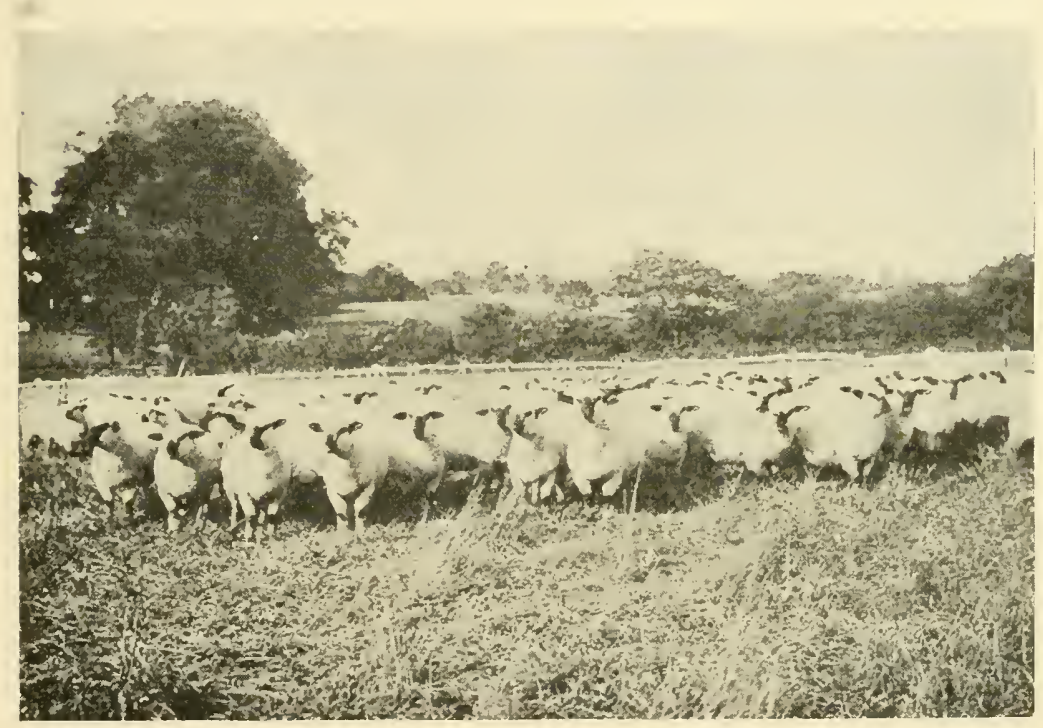

Fig. 74. A Flock of Uniform Type.

sand, manure, bits of straw, and other foreign matter. Moisture is better excluded and the yolk thus becomes abundant, protecting the fibers and preventing a cotted fleece. Her offspring, being heavily wooled, is less subject to chills and colds which hinder rapid growth and development. And lastly, the heavy fleece finds an appreciation on the live-stock market. All along the line, therefore, from breeding flock to packing house, the fleece with density, length of staple, and quality meets with approval and increases the value of the animal it covers.

It is evident that it takes years to build up a flock of much uniform merit and value. It is not a difficult matter to stock 
a farm with sheep, but whether or not the undertaking will be successful depends very largely upon the wisdom displayed in the culling of ewes, selection of rams, and general management of the flock. In no other kind of live stock does the individuality of the man in charge display itself so strongly as with sheep. Sheep respond quickly to good care, and deteriorate rapidly when neglected.

Although some essential points in flock management have necessarily been touched upon in discussing the elements that constitute a good breeding ram and breeding ewe, nevertheless a detailed discussion of sheep management cannot be presented here, as it would require a great deal of space and is outside the range of the general subject in hand. However, such important subjects as winter management and feeding of ewes, feeding as a factor in getting ewes in lamb, dipping, management at lambing time, feeding and management of ewes and lambs, docking and castrating, the feeding of lambs, shearing, control of internal parasites, the sheep-killing dog; crops to grow for sheep-these and many other subjects relating to sheep feeding and management should be carefully studied by anyone who contemplates entering the sheep business. 


\section{THE MERINO OR FINE-WOOL TYPE.}

All sheep are wool bearing, but the Merino excels in weight and fineness of fleece. The Merino is the foundation of American sheep husbandry. It is the most important sheep in America today, though less so than formerly. By far the greater number of grade flocks, especially in one section centering in Ohio, and another comprising the territory west of the Missouri River, are of fine-wool origin. Of the 50,000,000 sheep in the United States, over 27,000,000 are in the Western Division, and these are largely of Merino breeding. Many western sheep are brought into the cornbelt for fattening.

The Merino is native to Spain, and from the Spanish Merino have come all present breeds of Merino sheep. This stock existed in Spain prior to the Christian era, but in all its history in Spain there is practically no record of attempts at improvement. In the eighteenth century, Spanish Merinos were taken to Saxony, France, United States, South Africa, Australia, and other countries in which distinct types and breeds have been developed by selection from the old Spanish stock. Over 20,000 Merino sheep were imported into the United States prior to 1811, and these formed the foundation of the breed known as the American Merino. Beginning in 1840, importations of the French Merino or Rambouillet were made to America, and this breed is now bred extensively to supply rams for western flocks.

The American Merino is the outcome of efforts to develop a sheep with a fleece of the greatest possible value. Some breeders carried their efforts so far as to ignore the meat-producing qualities of the animals they bred, centering practically all their attention on the fleece. At best, the improvement of any kind of live stock is a difficult and slow undertaking. When improvement is sought in one or a few respects, the desired results are secured more readily and in greater perfection than when an attempt is made to improve the animal in a rather large number of ways. It is still more difficult to improve a breed of live stock along two or more opposing or antagonistic lines, such as beef and milk, mutton and wool, strength and speed, or size and quality. It was for this reason that many breeders 
of Merino sheep in America willingly sacrificed the meat-producing qualities of their flocks in order that the production of wool might be made as large as possible. These breeders developed what was formerly known as the Vermont Merino, a type that contrasts with mutton type as strongly as dairy cattle contrast with beef cattle.

Other breeders of fine-wooled sheep did not entirely ignore the mutton qualities of their animals, but placed some emphasis upon a good conformation and a reasonable degree of fleshing; at the same time they gave most attention to the weight and quality of fleece. Efforts of this kind in America resulted in

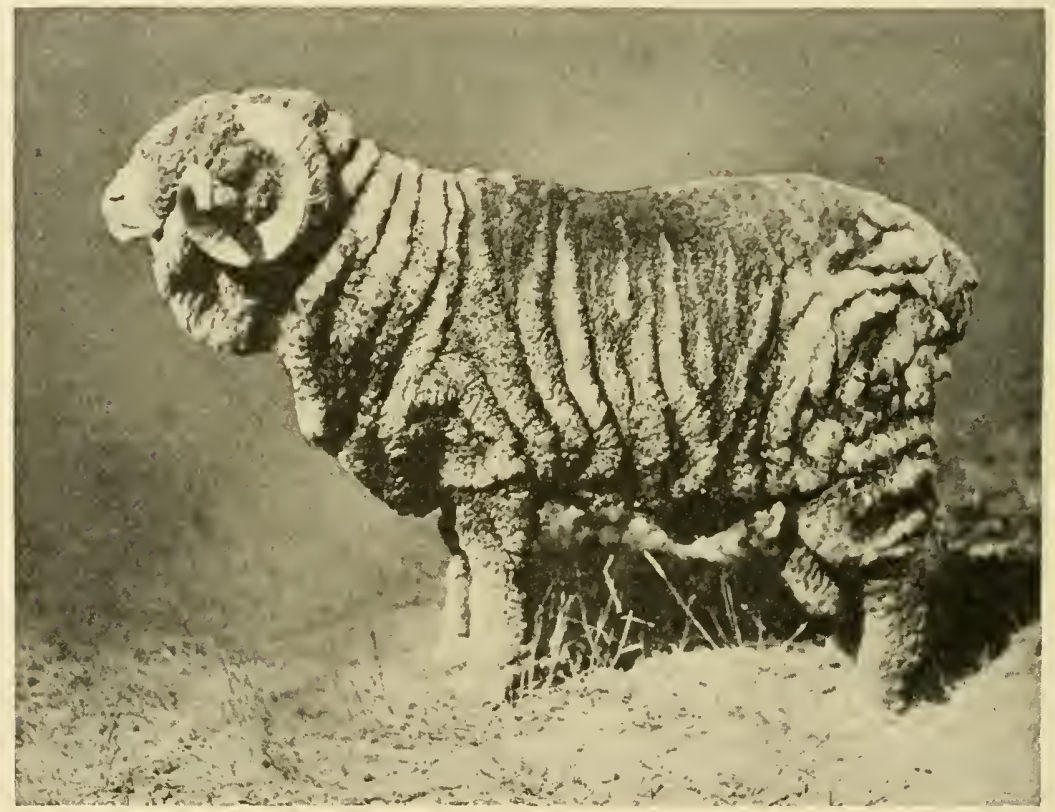

Fig. 75. Class A Merino Ram.

the creation of what is known as the Delaine type of the American Merino; in France similar efforts resulted in the breed known as the French Merino or Rambouillet. Thus a type was established having better mutton qualities, a smoother skin, a fleece of greater length and uniformity, and a type that is shorn much more easily because of its freedom from wrinkles. Broadly speaking, however, the differences mentioned in the ideals of breeders of fine-wooled sheep have not resulted in enough variation in type to prevent a satisfactory study of fine-wooled sheep as a single group or type. 
The general appearance of the fine-wooled sheep is very distinctive. In a general way, the conformation closely resembles that of the dairy cow. There is the same narrowness of forequarters and moderate width of back and body, the same muscular rather than fleshy covering, and the same tendency to be somewhat rangy of body and long of leg. As compared with the mutton type, there is proportionately more length and narrowness of head, more length and thinness of neck, less arch of rib, and less development of thigh and twist. These differences are marked, so that shorn of their fleeces, the two types of sheep present striking differences in form. When viewed in the wool, further variations are manifest. The fleece of the fine-wooled sheep is more compact and is often very dark in color, the latter being due to the very heavy secretion of yolk which catches dust and dirt and produces a black gum on the exterior of the fleece. The mutton-type sheep has a smooth skin, but the fine-wooled type has a loose skin lying more or less in folds or wrinkles. Sometimes there are only a few folds about the breast and lower border of the neck, while the middle and hindquarters are smooth; but a large class of fine-wooled sheep present a very wrinkled appearance over the entire body.

The head should be rather short, medium wide, and well defined or clean-cut in its features. The muzzle should be broad and the nostrils should be large. Rams should have a Roman nose with more width than ewes. The eyes of both sexes should be rather wide apart, large, and clear, and have a quiet expression. The forehead should be somewhat prominent and have a fair degree of width. The ears should be fine, short, covered with silky hair, and actively carried. The horns of the ram should be placed rather well apart so as to give width and strength to the top of the head. At maturity the horns attain a strong development. They have a corkscrew shape, turning backward from the base, then downward, around forward, and up, making about one and one-half turns. The ewes are hornless. Wool covers the poll, forehead, upper part of the face, and cheeks, while the ears and lower part of the face are covered with white hair, which should be very soft and fine. The skin about the nose is often wrinkled. The head of the ram should be very masculine as shown by heavy horns, wide poll, Roman profile, and heavy nose, all parts being well developed or massive and the expression resolute. The ewe should have a refined head and a feminine expression. 
The neck should be moderately short and rather muscular. The neck and shoulders do not blend smoothly as in the mutton type, although extreme angularity or roughness is undesirable. Males should show a heavily muscled neck; a pronounced crest or scrag just behind the poll indicates a strongly sexed animal.

The shoulders should be well laid in, and should be muscular. The depth of fleshing is not great enough to give that smoothness of form which characterizes a good mutton-type animal. The tops of the shoulders are often sharp and high, especially in those individuals showing the more extreme devel-

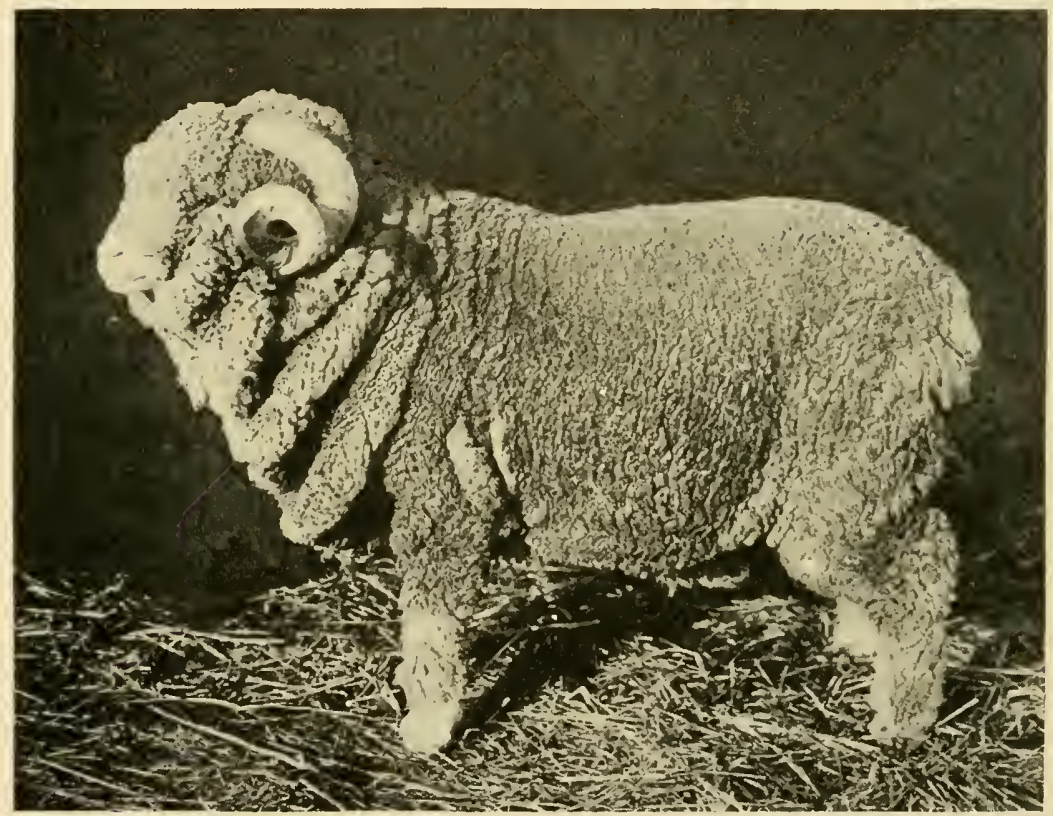

Fig. 76. Class B Merino Ram.

opment of the type; but a neat, rather rounded conformation with a fair degree of smoothness is more to be desired, especially in rams.

The breast should be deep and have moderate width. The absence of heavy fleshing makes impossible the development of any marked degree of plumpness or width, yet a very narrow or peaked breast indicates a cramped chest cavity and lack of strong constitution.

The chest gets its capacity from depth more than from width. Extreme narrowness is a serious fault; the fore-rib 
should arch sufficiently and carry down far enough to provide a roomy chest. The fore flank should be reasonably well filled out. Every type of animal needs a robust constitution, one of the best evidences of which is a large heart-girth, proper allowance being made, when judging, for the thickness of fleshing which covers the forequarters.

The front legs are often very crooked at the knees, too close together, and too long. They should be reasonably straight, moderately wide apart, and fairly short. The feet are often poorly formed and rather weak, whereas they should be well developed and strong. The shanks should be reasonably fine and rather short, and the pasterns should be free from weakness.

The back and loin vary somewhat according to the ideals of breeders. In the very wrinkly Merinos in which the mutton qualities are ignored, the top is noticeably long and narrow, and this may be carried to an undesirable extreme. In the Delaine Merino and Rambouillet, the back is proportionately shorter and wider. In any case the top should be straight from shoulders to hips, showing a fair degree of width of back and a rather wide, strongly muscled loin.

The ribs should be fairly well arched and should show good length in order to provide proper feeding, breeding, and chest capacity. The middle is not very compact, but is moderately long.

The hips are somewhat prominent on account of their width and lack of deep fleshing throughout, but ragged hips are undesirable. Much smoothness cannot be expected in a Merino, yet a rather neat, tidy conformation is demanded.

The rump is often peaked and drooping, but the best form embodies a rump that is long, level, and medium wide.

The thighs and twist vary with respect to the class of finewooled sheep under consideration. Generally speaking, the thigh should be medium thick, and the muscling between the legs should be sufficient to afford at least a moderate development of the twist.

The hind legs should be straight, medium long, reasonably fine, strong in the pastern, and placed somewhat apart. A large percentage of Merino sheep have crooked hind legs, the hocks being close together and the feet too wide apart, or the hocks much bent so as to place the hind feet too far under the body, instead of carrying straight downward from hock to ground. The feet should be well formed and strong. 
The skin should have a bright pink color, indicating health. Fine-wooled sheep usually show an excellent color of skin superior to the mutton type. As already mentioned, the skin is more or less folded or wrinkled. The Merino has not only a thinner skin than the mutton breeds, but is more richly furnished with oil glands and secretes a great deal more yolk. Fineness of skin and fineness of wool are correlated characters.

The quality of fine-wooled sheep is evidenced by fineness of fleece, fineness of bone, fineness of hair on face and ears, and by a medium-sized, clean-cut head with fine ears.

The style of the fine-wooled type is usually rather marked. Merinos have good carriage of head and ear and are quick and active in their movements, walking rapidly and covering ground with more ease and speed than the mutton-type sheep. Their greater activity partly explains their popularity on western ranges where Merino blood forms the basis of most flocks.

The fleece of the Merino has a very high degree of fineness, varying, however, in different flocks and in different individuals. The skin has many more fibers to the square inch than any of the mutton breeds; in other words, the fleece is ordinarily very compact and dense. Density and fineness are outstanding features in a good fine-wooled fleece, the crimp being very fine and regular from skin to tip of fiber. The very finest woolen fabrics are made from this wool. A third striking feature of the Merino fleece as compared with mutton sheep is the large amount of oil or yolk it contains. This gives a generous coating to each fiber so as to preserve its soundness and pliancy. Merino wool commonly undergoes a shrinkage of 65 per cent. in scouring, and this figure is not infrequently exceeded. When the secretion of yolk is very excessive, the fleece is made subject to criticism and the wool buyer makes allowance for the extra weight in the price he offers.

The wool should cover the head in the fashion already described, only the nose and ears being bare. The fleece should cover all of the body and extend down the legs to the feet. The belly and under parts vary a great deal in the covering of wool. It is important that the belly be well wooled, and that the natural bareness occurring at the armpits be as limited in area as possible. The scrotum of the ram should be covered with wool. The wool on the under parts of the animal should be as nearly like the rest of the fleece in density and length as possible. A good Merino flock should average 11 to 15 pounds of unwashed wool. 
Classification of fine-wooled sheep.-Breeders of finewooled sheep and the managers of the larger sheep shows group or classify American Merinos into three classes or sub-types, known respectively as $\mathrm{A}, \mathrm{B}$, and $\mathrm{C}$. As already pointed out, breeders of Merinos have differed in their ideals for a number of years, and this has resulted in three fairly well-defined classes. The classification is based chiefly on the character of the fleece, the number and position of the folds or wrinkles, the size and weight of the animal, and the development of mutton qualities.

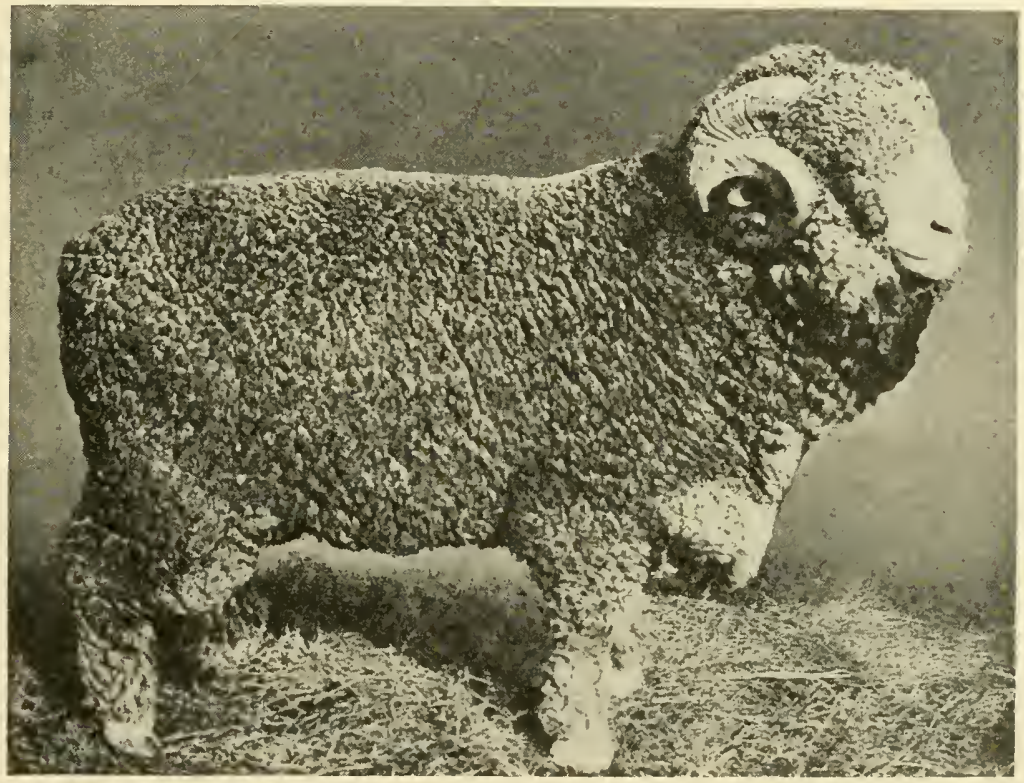

Fig. 77. Class C Merino Ram.

Class A.- These are the smallest and most wrinkly of the three classes, and have the finest, densest, and heaviest fleeces, the shortest wool, the most yolk, the poorest mutton qualities, and the poorest form. Rams weigh about 140 pounds, fleece off; and ewes about 100 pounds. There are heavy folds all over the sheep, except over the back. A good ram should shear close to 30 pounds, and a ewe about 20 pounds. These weights for fleeces represent high standards. The length of fiber is from $11 / 2$ to $2 \frac{1}{2}$ inches. The wool shrinks about 70 per cent. on the average when scoured. The form of the A Merino is most narrow, rangy, leggy, and irregular in lines of the three classes, 
and mutton qualities are practically wanting. It is entirely a wool proposition, with weight of fleece esteemed above everything else. The wrinkly skin results in considerable variation between the wool on top of the wrinkles and that between. The wool on the tops of the wrinkles, being opened out and more exposed, is much less oily, considerably coarser, and slightly shorter.

Class B.-This class is wrinkled on the neck, breast, flanks, and about the dock. It has better mutton qualities and better

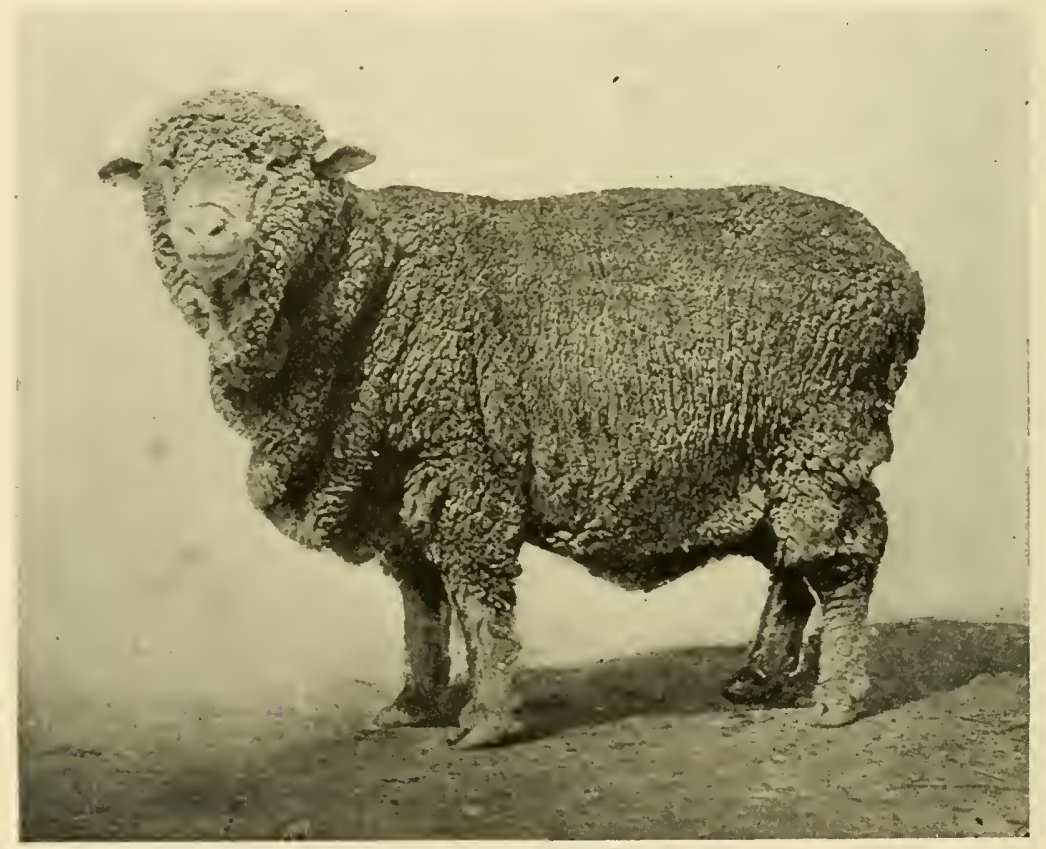

Fig. 78. Class B Merino Ewe.

form than A. Rams weigh 150 to 175 pounds; ewes, 100 to 115 pounds, fleece off. Strictly good rams of this class should shear 25 pounds, and ewes 15 pounds. The fiber measures from $21 / 2$ to 3 inches, and the wool shrinks about 65 per cent. It sells from 2 to 3 cents higher per pound than the wool of A.

Class C.-This is also called the Delaine class. These sheep are free from folds, unless to a slight extent on the neck and breast. The head, legs, and body are not so well wooled as $\mathrm{A}$ and $\mathrm{B}$. It is the largest of the three classes, has the best form, being more blocky and-low set, and has the best mutton 
qualities. It is a creditable meat producer, but not equal to the mutton breeds. The ram should weigh about 175 pounds, and the ewe about 125 pounds, fleece off. Rams should shear 18 pounds, ewes 11 pounds. The fleece has less crimp and fineness and less density than the fleece of $\mathrm{A}$ or $\mathrm{B}$, but is longer, measuring from 3 to 4 inches. The wool shrinks about 60 per cent., and sells from 2 to 3 cents higher per pound than B.

The Rambouillet breed, developed in France, excels all other Merinos in size, constitution, and mutton qualities. The

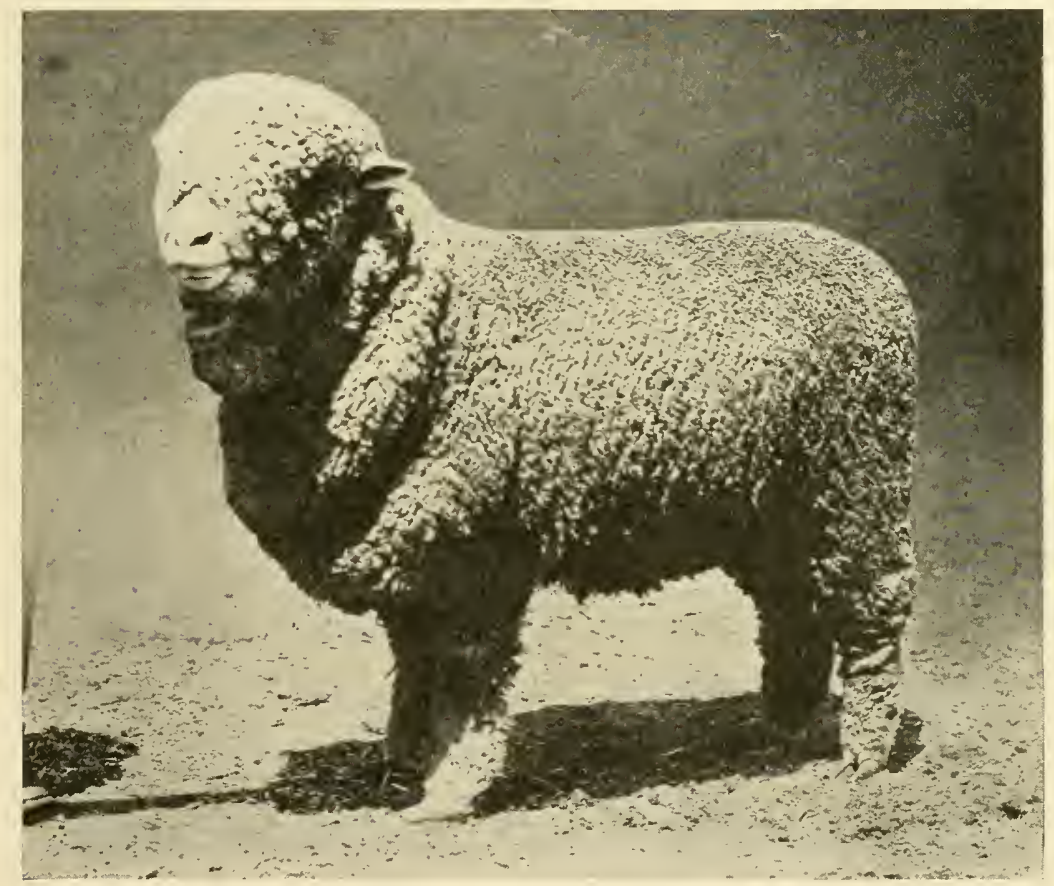

Fig. 79. Rambouillet Ewe.

ram should weigh 185 pounds or over, and the ewe 155 pounds or over. Some of them are very large, rams weighing up to 300 pounds and over, and ewes up to 250 pounds. They have strong frames, heavier bone than the American Merinos, considerable length of leg, and the top line is usually straighter than the American Merino. The head has a bold appearance, is carried higher, and has a more complete covering of wool. The Rambouillet has a smooth body with only a few large folds over the breast, and possibly a few light folds at the flanks and 
dock. Rams should shear from 15 to 20 pounds, and ewes 10 to 12 pounds. These figures are surpassed by the very best of the breed. The weight of fleece averages less than that of the American Merino, mainly because of less oil or yolk. The length of fiber should be from $21 / 2$ to 3 inches, although much of it falls short of this length. The wool has great fineness, but not quite equal to that of the American Merino. 


\section{CHAPTER XX.}

\section{WOOLS AND WOOL GROWING.}

No animal has a covering entirely of wool; even sheep have hair upon the face and lower parts of the legs. Wool served as a necessary protection to sheep in the wild state, the original home having been in the higher parts of mountainous regions. Wool ranks next to cotton as a source of textile fabrics, the temperate regions universally using woolen products. The per capita consumption of wool has increased very greatly. It was about 3 pounds in early times in the United States when all spinning and weaving was done in the home; in 1850 it was 4 pounds; it is now about $61 / 2$ pounds. No other people use as much wool as do Americans, nor as much cotton. The world's clip of wool averages about 2 pounds for each person.

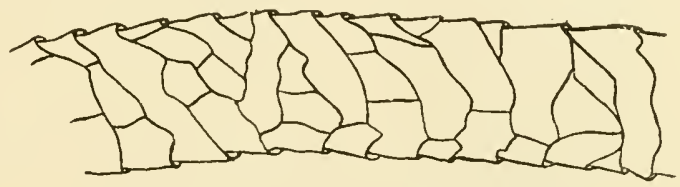

Fig. 80. Wool Fiber Highly Magnified.

This drawing shows the scaly surface of the wool fiber; the tips of the overlapping scales project outward and point toward the tip of the fiber.

As a rule, sheep are shorn only once a year. The coming of mild weather in the spring marks the time of shearing. Both hand and machine shearing are practiced, preferably the latter. As the wool is sheared off it is usually kept in one piece so far as possible, and as soon as the fleece is removed it is spread out, with the flesh or cut side down, any loose pieces are thrown into the center, and the fleece is then rolled up with the flesh side out and is tied with twine. Prior to shipment the fleeces are packed in large sacks, in which condition they arrive at the various wool markets of the country.

Growth and structure.-Wool is modified hair. The term hair is ordinarily used to designate a smooth, straight fiber or filament like horse hair. Wool differs from hair in being more or less crimped and in having a much more serrated or ridged surface. The surface of the fiber is composed of a single layer 
of irregular, overlapping scales, apparent only under the microscope, forming the wool cuticle, there being from 1200 to 3000 exposed points of these scales to an inch. The scales open or point toward the tip of the fiber, like shingles put on the wrong way. Beneath the covering of scales is the cortex or body of the fiber, made up of greatly elongated cells united into bundles, and in the center of the fiber there is sometimes a cavity or canal which may contain granules of pigment.

Hair and wool are very similar in growth and structure, but wool is crimped, has more scales, the points of the scales are more open or projecting, and the entire fiber is more soft

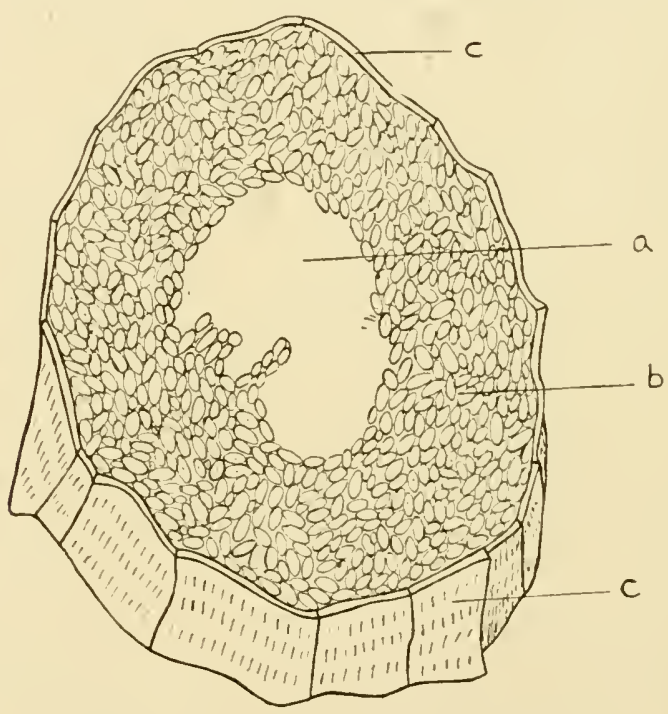

Fig. 81. Cross-Section of a Wool Fiber.

$a$, Central canal, which is not present in most wools; b, cortex or body of fiber, composed of long, spindle-shaped cells which here appear oval because they are cut transversely; c, wool cuticle, composed of scales. (After McMurtrie.)

and flexible than hair. These small differences give to wool its special commercial values. Hair will not retain the twisted state given to it in spinning, but the crimp of wool causes the fibers to become entangled, and the minute scales hook together and hold the fibers in position when wool is spun into yarn. Thus wool has a thread-forming quality which hair has not, preventing slipping and separation of the fibers in the yarn. The entanglement and locking of the fibers is referred to as the felting quality of wool. 
The peculiar structure of the wool fiber was first determined by Youatt, a famous English observer and writer. In Merino wool, the scales or projections are very distinct and sharply pointed, and it was by an examination of Merino wool that Youatt determined the structure of the wool fiber. In the medium-wool breeds, the scales are less distinct and sharp, and in the long-wool breeds, they are rounded off and indistinct. In Merino wool, about 2400 of these scale ends are found to the inch; in the Southdown there are 2000 to 2080; and in the Leicester, 1850 to 1860 . Hence, Merino wool is superior in felting quality, the others standing in a relation proportional to the figures given.

Fineness of fiber.-Dr. William McMurtrie, who conducted extensive investigations of wools for the U. S. Department of Agriculture, ${ }^{*}$ found the average diameter of the Merino fiber to be $1 / 1194$ of an inch, while the Southdown had an average diameter of $1 / 865$, the Hampshire Down $1 / 769$, the Lincoln 1/685, the Leicester 1/654, the Cotswold 1/605, and the Oxford Down 1/581. In 1860, American Merino fibers with a diameter of $1 / 1572$, and American Saxon Merino fibers measuring $1 / 1875$ of an inch in diameter were exhibited in London, showing the extreme fineness which may be secured in wools.

Secretion and composition of yolk.-Opening into each wool follicle are a couple of sebaceous or oil glands, furnishing a profuse secretion of an oily or fatty material, called the yolk, which is thrown out at the same time the fiber is formed. This secretion consists largely of a soapy matter having a potassium base, together with an animal oil which gives to the yolk its peculiar odor. Yolk, then, is not strictly a grease or oil, but is a soap with an excess of oil. This explains why it dissolves freely in warm water and may be washed almost entirely out of the fleece, and why it cleanses and whitens the hands as soap does. The quantity and fluidity of the yolk vary greatly, being greater when the sheep are healthy and well fed, and varying also according to the breed. The yolk maintains the softness and pliancy of the fibers, and protects the scaly surface from injury such as might result from friction of the fibers against one another during the movements of the animal. It also helps Fibers.

* U. S. Dept. Agr. Report, Examination of Wools and Other Animal 
to keep the fleece clean and free from a cotted or matted condition. The wool manufacturer removes the grease from wool by the scouring process. This is the first step in wool manufacture.

Woolens and worsteds. - When scoured wool is combed, that is, drawn through metal teeth, the fibers are made to lie parallel to each other and foreign matter and short fibers are combed out. This waste is called the "noils," and the remaining long fibers are called the "top." Wool used for combing under the Bradford or English system of manufacture must be strong and at least $2 \frac{1}{2}$ inches long in order to give the yarn sufficient strength. Such wool is called combing wool. The yarn made from combed wool (top) is called worsted, and the cloths made of it are known as worsted goods.
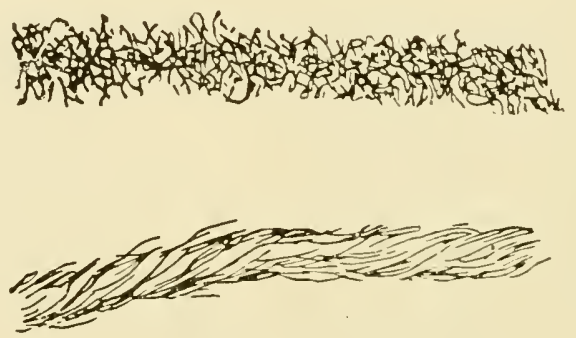

Fig. 82. Woolen and Worsted Yarns.

In the woolen yarn above the short wool fibers are crossed in every direction, while in the worsted yarn below the fibers are longer and are laid parallel to each other.

Wools which are short and much crimped and serratured are called clothing or carding wools. They have a high felting quality. In preparation for spinning they are put through carding machines which jumble the fibers together in any and every direction, forming a mixed mass from which the yarn is eventually drawn. The cloths made from such yarn are known as woolens.

The difference between woolens and worsteds is largely due to the way the yarn for each is spun. In worsted yarn the fibers are arranged as parallel as possible by the combing process; in woolen yarn they are crossed in every direction so as to assist the felting or milling of the cloth. Yarn for woolen cloth is very slightly twisted, so as to leave the fibers as free as possible for the felting process; worsted yarn, on the contrary, is hard spun and made into a much stronger thread. By the process of manufacture, woolens are felted so as to leave little or no 
appearance of the thread, while in worsteds the threads are plainly evident. Woolens usually have a fuzzy, downy surface, while worsteds have a smooth, hard finish. Worsteds hold their shape better than woolens. Worsted cloths have a more clearly defined pattern and more firmly woven appearance than woolens. Woolen cloths are softer and the various colors are not so distinct in the cloth. The principal worsted cloth is Serge, while woolens include several leading varieties such as Tweeds, Cheviots, and Broadcloths. The manufacture of woolen underwear is also essentially a woolen process.

Shoddy, obtained by tearing up woolen rags by machinery, now enters into the composition of all except the very finest woolen yarns, but cannot be used in the manufacture of worsted yarn under the Bradford or English system. However, a varying proportion of cotton threads are often woven into worsted cloth.

Worsteds may be dyed in the top, the yarn, or the cloth. Woolens may be dyed in the wool, the yarn, or the cloth.

Pounds of wool per pound of cloth.-For woolen goods, from 3 to 4.64 pounds of grease wool, with an average of 3.73 pounds, are required to make 1 pound of cloth. The average amount of scoured wool required is 1.37 pounds. For worsted cloths, from 2.56 pounds to 4.55 pounds of grease wool is required, with an average of 3.66 pounds. The average amount of scoured wool for 1 pound of worsted cloth is 1.55 pounds.*

Classification of wools.- Wools may be classified according to their origin and also according to their value and adaptability for different uses. The classifications in common use in this country are as follows:

Clipped wools and pulled wools. - The first distinction made in wools is to divide them into fleece or clipped wools and pulled wools. The former are the ordinary clipped wools coming to market in separate fleeces. These are the more valuable and constitute by far the greater portion of the wool of commerce. Pulled wools are those derived from the pelts of slaughtered sheep in the manner described later on. They are marketed in 500 pound bales. Pulled wools constitute about one-seventh of all the wool produced in the United States.

Domestic, territory, and carpet wools.-Domestic wools are wools coming from the small farm flocks east of the Missouri

* U. S. Dept. Agr. Bul. 206, by F. R. Marshall and L. L. Heller. 
river. For the most part, the sheep are of mutton type and breeding. As compared to territory wools, these wools are usually clean and bright, due to the better protection and care given the sheep. Territory wools are those produced west of the Missouri river, and they derive their name from the fact that this section was formerly made up of Territories in distinction to the States of the central and eastern sections. Territory wools are produced by the large flocks of range sheep which contain much fine-wool blood, though the use of medium- and long-wooled mutton rams is increasing. They shrink from 63 to 70 per cent. on the average when scoured, and sometimes over 80 per cent., due to the presence in fleeces of sand, dirt, and considerable yolk. Carpet wools are inferior and lowpriced wools containing much kemp or dead fibers, and are used in the manufacture of carpets and coarse blankets. Very little carpet wool is produced in this country.

Domestic wools may be subdivided into two groups or subclasses, known as "bright" and "semi-bright," depending on the whiteness and luster of the fiber. Bright wool is produced by Ohio, Pennsylvania, New York, West Virginia, Kentucky, Indiana, Illinois, Iowa, Michigan, Wisconsin, and Minnesota. Semi-bright wool comes from the Dakotas, western Kansas, and Nebraska. They are midway between the bright and the territory in condition, having more sand and dirt than the bright but not as much as the territory. The best bright wools are those known as "Ohio" wools, produced not only in Ohio but also in Pennsylvania and West Virginia. More than half of the flocks of this region are of Merino breeding. Ohio wool is famous for strength, cleanliness, and general quality, and commands a premium on the market.

The states which produce territory wool are Montana, Wyoming, Idaho, Utah, Nevada, Colorado, and Washington. These are mainly range states. Sand storms deposit much sand and dirt in the fleeces. When the range is bare of snow in winter the wool often shrinks 5 per cent. more than when the ground has been covered. Because of the varying shrinkage of territory wools, they are sold on the market upon a clean or scoured basis.

The clips of California, Oregon, Texas, Arizona, and New Mexico are no longer classed as territory wools due to the fact that they have rather distinct characteristics. In Texas, shearing is often practiced twice a year, in which case the wool comes 
to market untied. In California, the northern counties shear once a year, but the middle and southern counties often shear twice a year, the wool shrinks more than that of the northern counties, and it comes to market untied. Oregon produces some excellent wool, though somewhat high in shrinkage. The state also produces what are known as valley wools, largely from long-wooled sheep. New Mexico and Arizona wools are very uneven in character and often kempy, due to lack of care of the sheep and inferior breeding. They come to market untied and are poorly put up.

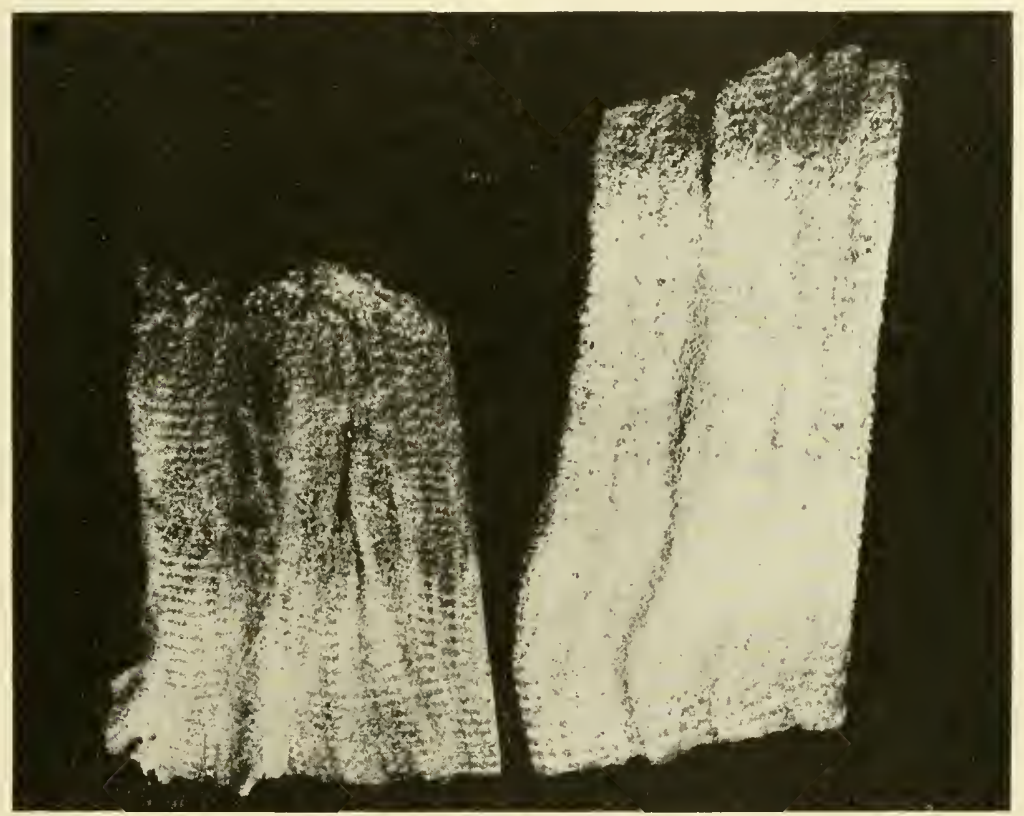

Fig. 83. Clothing and Combing Wools.

Washed, unmerchantable, and unwashed.-Formerly the practice of washing sheep just prior to shearing was extensively followed in the eastern states. This gave rise to the terms of washed, unmerchantable, and unwashed. Unmerchantable wool is not unsaleable wool, but that which has been poorly washed. Fleeces may be unmerchantable for other reasons. The practice of washing is almost a thing of the past, and the use of these terms does not necessarily imply that the washing operation has actually taken place, but sometimes refers solely to shrinkage. Washed wools are lighter in color and condition, 
shrinking 3 or 4 per cent. less ihan unmerchantable, and the latter shrinks about 3 or 4 per cent. less than the unwashed.

Market classes and grades of wool.-Most Americangrown wool is sacked just as the fleeces come from the sheep and sold at home to dealers. Before offering the wool to the manufacturer the dealer opens the sacks and makes up from his various purchases a number of piles, each containing only fleeces of similar character and value. This is called grading, and it is performed without untying the fleeces.

The first division which the market makes in wools is to divide them into the Domestic and Territory classes. The advantages of domestic over territory wool have been mentioned. Each of these is again divided into the Combing and Clothing classes. Combing wool is usually worth about 10 per cent. more than the short or clothing wool, and the aim of the woolgrower is to produce combing wool. Each class is divided into grades, and in grading fleeces the main factor is fineness of fiber, although other factors such as length, shrinkage, and general character are considered. The various grades are adapted to the manufacture of different kinds of fabrics. Thus the wool dealer is enabled to supply the manufacturer not merely a certain general class such as combing wool or clothing wool, but a particular kind or grade of fleeces within that class specially adapted to his mill. The complete classification may be represented in outline as follows:

DOMESTIC WOOLS.

Combing wools

Delaine $\left\{\begin{array}{l}\text { Fine } \\ \text { Medium }\end{array}\right\}$ often one grade Half-blood

Three-eighths-blood

Quarter-blood

Low quarter-blood

Braid

\section{Clothing wools}

$\mathrm{XX}$ and $\mathrm{X}$, washed or fine unwashed Half-blood clothing

Three-eighths-blood clothing

Quarter-blood clothing

\section{TERRITORY WOOLS.}

\section{Combing wools}

Fine staple

Fine medium staple $\}$ usually one grade

Half-blood staple

Three-eighths-blood staple

Quarter-blood staple

Low quarter-blood staple

Coarse, common, low, or
braid
Clothing wools

Fine clothing)

Fine medium usually one grade clothing

Half-blood clothing

Three-eighths-blood clothing

Quarter-blood clothing, or short quarter-blood 
As previously explained, combing wools are at least $21 / 2$ inches long without stretching, while clothing wools are all under that length. It will be noticed that much the same names are given to the grades within each class. The term "staple" as applied to territory wools means the same as the term "combing wool"

If a Merino sheep east of the Missouri river grows a fleece that measures at least $2 \frac{1}{2}$ inches long without stretching, it

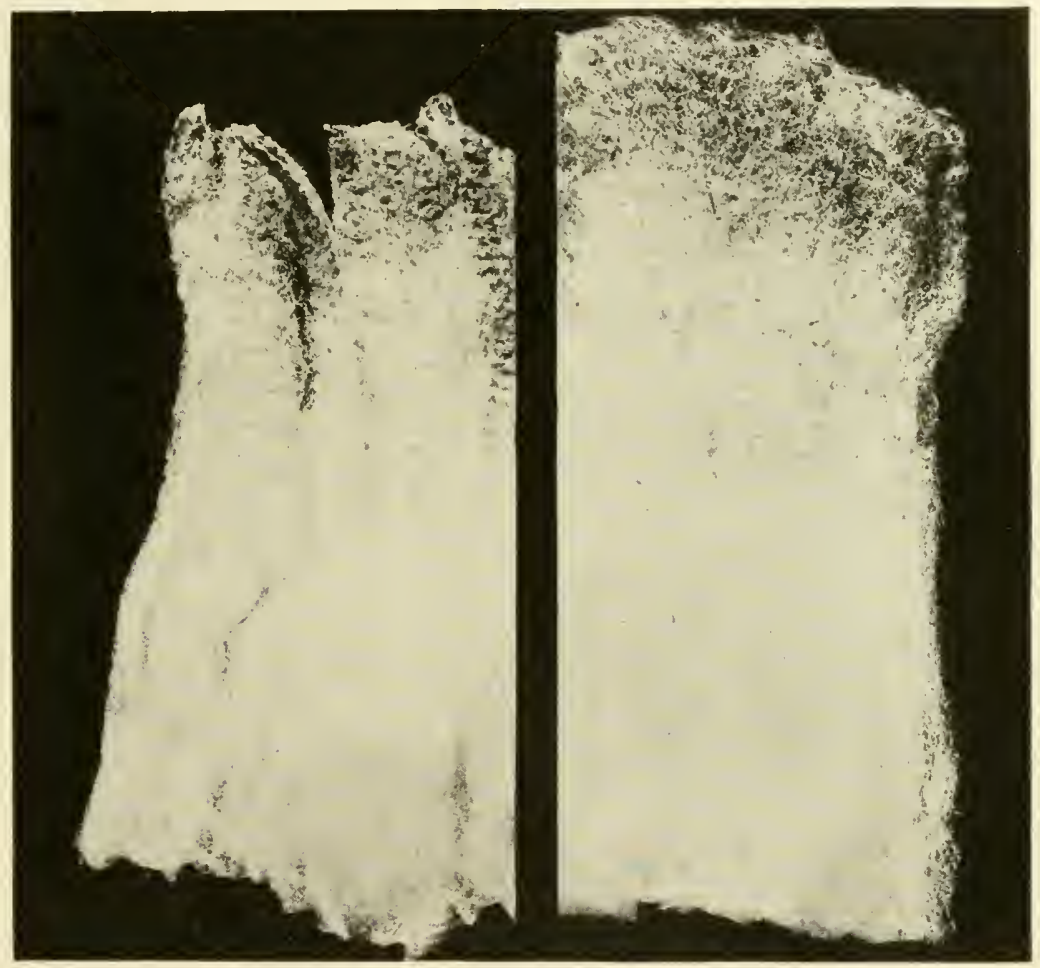

Fig. 84. Grades of Combing Wool.

Fine combing at left and half-blood combing at right.

grades as Delaine on the wool market. The same sheep west of the river grows a fleece that grades as Fine Staple or Fine Medium Staple. The Fine Staple or Fine Medium Staple fleece has a greater shrinkage than the Delaine fleece. This is the main distinction between the two. When scoured, the wools have much the same value. The eastern wool may be somewhat stronger, but in a general way the wool is the same in both fleeces. 
If a Merino sheep in the east grows a fleece less than $21 / 2$ inches long, it grades as XX or X, or as Fine Unwashed. Market usage has decreed that $\mathrm{XX}$ and $\mathrm{X}$ as grade names shall be used only in referring to washed clothing wools. XX is a somewhat finer wool than $\mathrm{X}$. Fine Unwashed corresponds to XX and $\mathrm{X}$, but shrinks more in scouring. The same sheep in the west grows a fleece that grades as Fine Clothing or Fine Medium Clothing. Fine Clothing corresponds to XX, and Fine Medium Clothing corresponds to $\mathrm{X}$, except that the territory wool shrinks more than the domestic.

Similar comparisons might be made for the half-blood grade, the three-eighths-blood grade, etc. If we substitute the general term "Fine" for all the grades thus far discussed, we may say that each class of wool has the following grades:

\author{
Fine \\ Half-blood \\ Three-eighths-blood \\ Quarter-blood \\ Low quarter-blood \\ Low, coarse, common, or braid.
}

In the early days of the American wool trade, the halfblood, three-eighths-blood, and quarter-blood grades referred supposedly to wools from sheep of half, three-eighths, and quarter Merino blood, but they have no such significance now. Wools grading as high as half-blood can come from sheep having no trace of Merino blood. On the other hand, quarter-blood would rarely come from a sheep containing any Merino blood. Low quarter-blood is a grade lower than quarter-blood, and braid is the lowest grade of all. It usually refers to luster wool such as might come from a Lincoln or a Cotswold sheep. The grading of wool in the wool houses is done by expert graders who know wools so well that at a glance they can determine the grade to which the wool belongs and the kind of material into which the wool will be made. Many of these wool graders may never have seen a sheep in fleece, neither do they know the breeds of sheep and the characteristic fleeces. Hence, the wool grade does not depend upon the breed of sheep, and the wool from different individuals of the same flock and breed may be graded differently Wool, then, is graded on the market according to its merit, regardless of the breeding of the sheep which grew it, although some of the names of the various grades may seem to indicate the breeding of the sheep. 
Half-blood wool approaches fineness, but is not so finely crimped as the fine grade. It is also somewhat longer in its class, and usually shrinks less in its class. Three-eighths-blood has a tendency toward the coarser wool. It is less crimped than half-blood and less elastic. It also shrinks less when scoured because it is less oily as a rule. Quarter-blood represents the next step down the scale in fineness and crimp, with still less

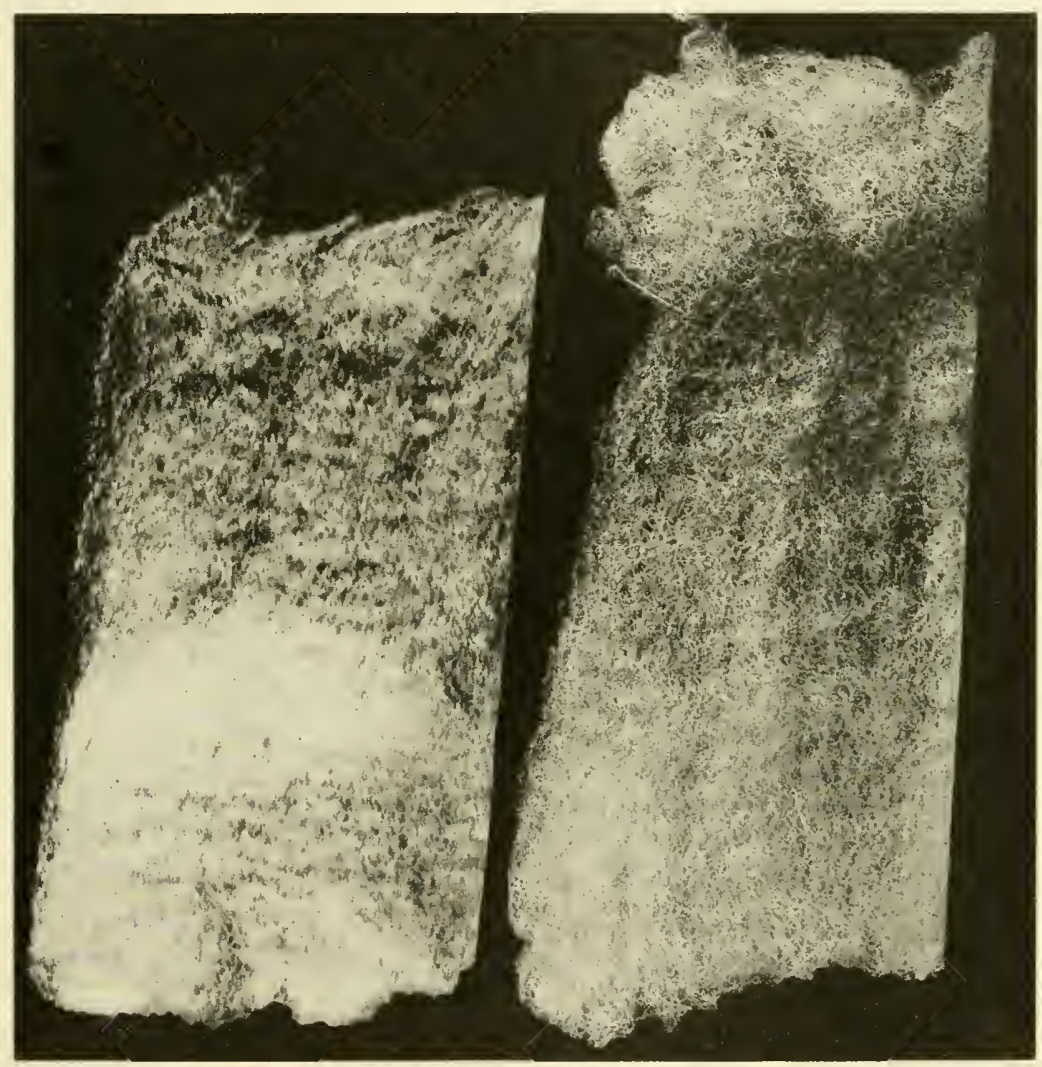

Fig. 85. Grades of Combing Wool.

Three-eighths-blood combing at left and quarter-blood combing at right.

shrinkage. It is longer than three-eighths-blood. Practically all three-eighths-blood and quarter-blood wools are of combing length. Braid wool varies from $4 \frac{1}{2}$ inches up to 12 or 13 inches in length. Its name comes from the fact that it is particularly suitable for the manufacture of braids. It is generally used, 


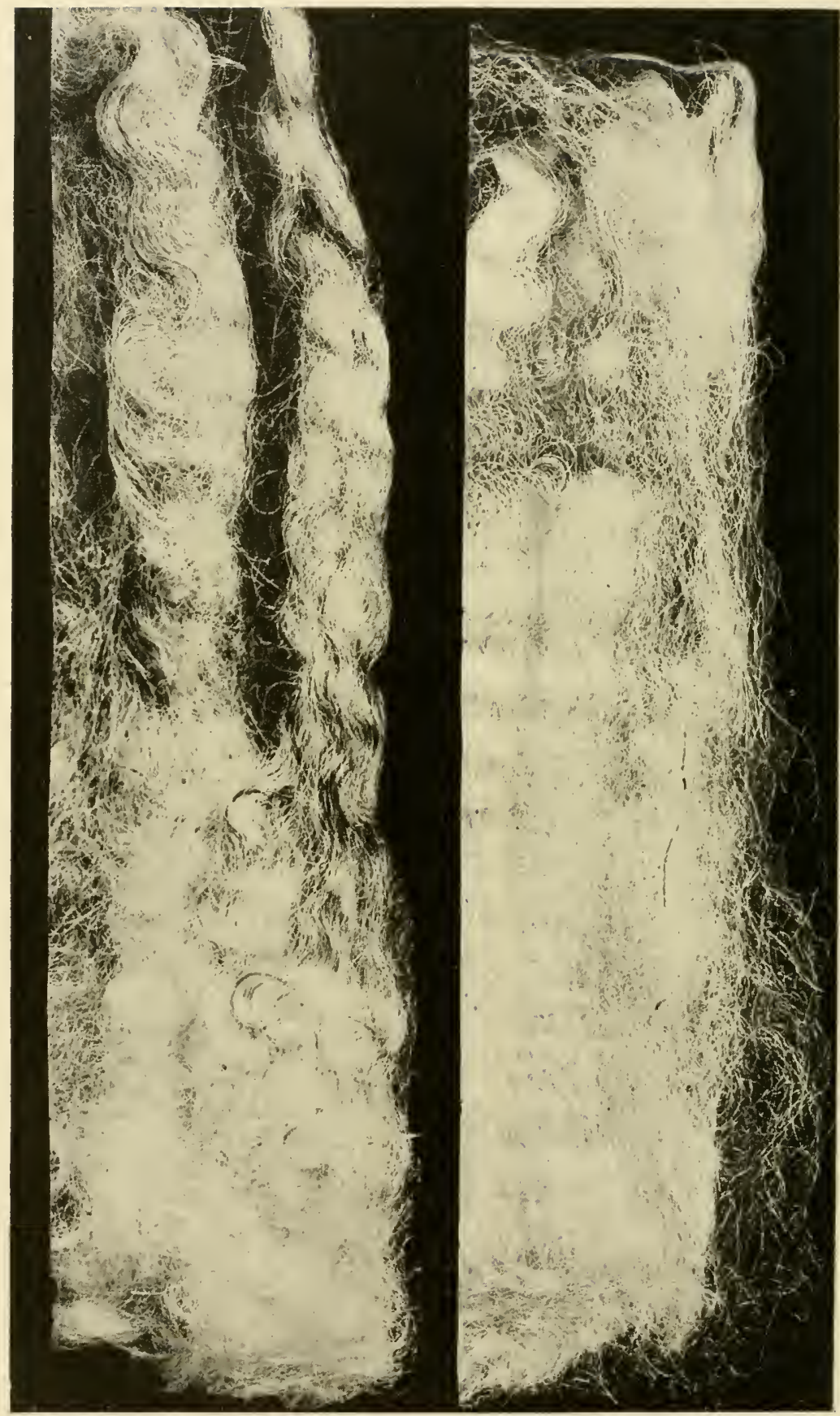

Fig. 86. Grades of Combing Wool.

Low quarter-blood combing at right and braid wool at left. 
however, in fabries requiring long and coarse fibers. For bunting or flags there is no other wool its equal. Because of its length and coarseness it does not appear as one of the grades of clothing wool.

The foregoing statements regarding the comparative lengths and shrinkages of the various grades of wool may be illustrated by the following table* giving the most acceptable length and the estimated average shrinkage of each grade of Montana combing wools:

\section{Grade}

Acceptable length

for an average grade-inches.

Fine and Fine Medium ............ $1 \frac{1}{2}$

Half-blood ........................

Three-eighths-blood ....................

Quarter-blood ......................... 4

Braid.....................

\section{Shrinkage- per cent.}

$64-65$

$61-62$

$55-57$

$51-53$

$46-48$

Classes and grades of wool from various breeds of sheep.The following list $\dagger$ shows in a general way how wool from the various breeds would be likely to grade. This table is presented because it will be of interest and because it will assist the reader who knows the fleeces characteristic of some or all of the breeds of sheep, but does not know the characteristics of the classes and grades of wool, to gain a clearer understanding of the latter.

\section{Breed}

Merino (eastern states).

Merino (range states)

Rambouillet

Southdown .

Shropshire

Hampshire.

Dorset

Suffolk

Cheviot

Oxford.

Corriedale.

Cotswold .

Lincoln.

Leicester

\section{Class and Grade of wool produced}

Delaine, XX, X, or fine unwashed.

Fine and fine medium staple or clothing.

Fine and fine medium staple or clothing and a small amount of half-blood.

Half and three-eighths-blood (chiefly threeeighths combing or clothing, chiefly clothing.)

Mainly three-eighths-blood, combing or clothing. Some quarter-blood.

Three-eighths and quarter-blood combing or clothing.

Three-eighths and quarter-blood combing or clothing.

Three-eighths-blood combing and clothing.

Quarter-blood combing.

Quarter and low quarter-blood combing.

Three-eighths-blood combing.

Low quarter-blood combing or braid. 1915

* Compiled from Nat'l. Wool Warehouse \& Storage Co's. Bulletin, Dec., † U. S. Dept. Agr. Bul. 206. 
Sorting wool.- The wool manufacturer buys from the wool dealer the grade of wool which he desires and thus secures fleeces which have a certain average degree of fineness. However, each fleece varies more or less in fineness. Wool from the lower thighs, called the "britch," is usually the coarsest part of the fleece. The shoulder wool is best in strength, quality, and length; the sides are next best, and quality decreases passing backward to the britch. Wool from the back is likely to contain hayseed and chaff. The belly wool is finer than any, but is short, frowzy, not so strong, and lacks character. A "frowzy" wool is one that appears lifeless, and is badly mussed, the fibers and locks lying topsy turvy. The wool from the head is short, coarse, and in dark-faced breeds is likely to contain black fibers. A fleece may be three-eighths-blood or half-blood on the shoulder, while the britch would be quarter-blood. For these reasons, the wool manufacturer usually sorts the wool which he buys. The fleece is untied, shaken out, and thrown upon a table having a slatted or wire-mesh top so that the loose dirt in the fleece will fall through.

The following table giving the results of an actual case of sorting a bag of wool will be of interest.* This bag contained fleeces that had been graded in the warehouse as half-blood. The gross weight was 245 pounds; weight of bag, $41 / 4$ pounds; net weight of wool, $2403 / 4$ pounds.

Results of sorting a bag of half-blood Montana wool.

\begin{tabular}{|c|c|c|c|}
\hline Sort & Weight & Percentage & $\begin{array}{c}\text { Value per } \\
\text { pound }\end{array}$ \\
\hline & Pounds & Per cent. & Cents \\
\hline Regular sorts: & & & \\
\hline $\mathrm{X}$ or three-quarters-blood & 11.21 & 4.66 & 21.0 \\
\hline Half-blood combing...... & 88.69 & 36.84 & 22.7 \\
\hline Half-blood clothing . ........... & 12.90 & 5.36 & 21.6 \\
\hline Three-eighths-blood combing . . & 64.76 & 26.90 & 23.0 \\
\hline Three-eighths-blood clothing. & 24.33 & 10.11 & 20.0 \\
\hline 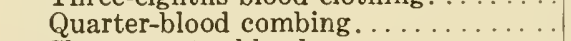 & 12.90 & 5.36 & 19.0 \\
\hline Short quarter-blood.............. & 4.55 & 1.89 & 17.0 \\
\hline Low quarter-blood.. & .55 & .23 & 16.0 \\
\hline Off sorts: & & & \\
\hline Stained and gray . & .55 & .23 & 14.0 \\
\hline Shorts......... & 3.90 & 1.62 & 10.0 \\
\hline Fribs .......... & 3.32 & 1.38 & 5.0 \\
\hline Clips. . & 2.76 & 1.15 & 1.0 \\
\hline String ........ & 1.37 & .57 & $\ldots$. \\
\hline Loss in sorting. & 8.90 & 3.70 & \\
\hline
\end{tabular}

*U. S. Dept. Agr. Bul. 206. 
The stained and gray sort is not usually made unless white goods are to be manufactured. Shorts consist of short wool such as grows about the face, or it may be due to double cutting in shearing. Fribs are short, sweaty, and dungy locks. Clips are locks so incrusted with foreign material that they cannot be scoured clean, but must be clipped off. The string is that used in tying the fleeces. Loss of weight in sorting depends upon the amount of sand and loose dirt in the wool.

Other off sorts are often made from wools of various sections. Some of these are tags, paint locks, and seedy. Tags are large dung locks which are badly stained and have a very high shrinkage. Paint locks require clipping off the painted ends of the locks. Seedy wool contains weed seeds, soft burs, etc. It must often be carbonized before using, as explained in a later paragraph.

Wool pulling.-Wool pulleries may be divided into two groups - those owned by packers and forming a part of the byproducts division of packing plants, and those owned and operated independent of packing establishments. The wool pullery of a packing plant receives pelts daily, direct from the killing floor. They are at once placed in vats of cold water, which takes out all of the animal heat and removes some of the dirt and blood. The soaking continues from 12 to 24 hours. Packing plants not equipped with pulleries salt their pelts, and when a quantity has accumulated send them to a pullery. Salted pelts are soaked 36 hours, as it requires considerable time to dissolve the salt out of the hide. When removed from the vats, the pelts are given mechanical treatment in a scrubbing machine which washes them in a spray of water, completing the removal of dirt, and leaving the fleece in an attractive, white condition. The wet pelts are then put in a centrifugal wringer which throws out the water to such an extent that the fleece is made very nearly dry. The pelts are next taken to a room where they are spread, fleece downward, upon wire screens and painted on the inner surface with a thick liquid bearing the trade name of "Depilatory," consisting of a mixture of sodium sulphide and slaked lime. Within 2 to 4 hours after this treatment the wool fibers become loosened and easily part from the hide, coming out by the roots when pulled.

Before pulling, however, the pelts are taken to large rooms where they are spread out on the floor, fleece upwards, being grouped or classified according to the nature of the fleece. The 
pelts are then taken up and the wool pulled by hand. Coincident with the pulling the operator sorts the wool. Furthermore, the pullery keeps each month's product by itself, thus multiplying the assortments by twelve, and resulting finally in over two hundred kinds of pulled wool, each having a distinct trade name.

Wool pulleries report a strong demand from wool manufacturers for black wool which is used to produce various shades of natural gray by mixing it with white wool. Black wool thus sells at a premium, for the supply is small. Pelts that vary in color through various shades of gray and brown are not in the class of black pelts because the varying color makes them an unknown quantity in color mixing where definite results are wanted. Very few black fleeces are uniformly black. They often contain white, gray, and brown fibers mixed with the black. This explains why the so-called black fleece sells at a discount, while the locks of black wool collected by the wool pullery bring a premium.

The growth of wool must be at least three-fourths of an inch before it may be profitably pulled. Some pelts are not pulled, no matter how long the fleece may be, because the wool is not saleable, or not valuable enough to pay for pulling.

Scouring.--Scouring is the first process in wool manufacturing. The purpose of the scouring process is the removal of dirt and grease from the wool. It does not remove paint, burs, seeds, chaff, nor twine. Paint is clipped from the wool before scouring. If the grease wool comes to the scouring plant in bales, it is first put through a shredding machine which loosens it. This machine is equipped with a blower for the removal of dust, and a screen for the removal of heavy dirt. Scouring is accomplished by passing the wool through a series of four bowls or vats, each containing a different liquor. These liquors are composed as follows:

Bowl No. 1-Mild alkaline solution, preferably potassium; temperature 130 degrees Fahrenheit.

Bowl No. 2-Same alkaline solution as first bowl, plus soap; should be a potash soap; temperature 120 degrees.

Bowl No. 3-Soap solution only; temperature 110 degrees.

Bowl No. 4-Luke warm water.

Nearly all the yolk or grease is removed from the wool in the first bowl. This is done by the saponification of the oil, the soap readily dissolving in the warm liquid. The action of 
the soap in the second and third bowls is to whiten the wool and give it "life" which it loses in bowl No. 1. After rinsing in the fourth bowl, the wool is passed through a dryer.

During treatment in the bowls, automatic rakes keep the wool moving slowly, for if it is moved rapidly through the liquids it forms a ropy mass. The yolk forms an emulsion in the bowls and may be recovered by chemical processes. It is known as "lanolin," and is much used in salves and ointments. Clipped wools shrink as much as 65 per cent. or more in scouring, while pulled wools shrink about 27 per cent. on the average and often shrink only 10 per cent. The difference is due to the very thorough washing given to pelts before pulling.

Carbonization.-Burs and much other vegetable matter cannot be taken from wool in scouring. In the combing process, by which worsteds are made, this vegetable matter is combed out with the noils (short fibers not suitable for worsted yarn). It can be eliminated from the noils or from clothing wools intended for carding or woolen purposes only by carbonization. This consists in immersing the wool in a dilute sulphuric acid or aluminum chloride solution, and then drying it at about $200^{\circ} \mathrm{F}$. This chars the burs and vegetable matter which are then removed by crushing and dusting with little or no change in the wool fiber. The process costs from $11 / 2$ to 3 cents a pound and results in an average loss of about 10 per cent. in weight. Thus we see why the manufacturer and the wool dealer have a right to object to burry wool, and why they offer a much lower price for it than for clean wool.

Wool clip of world.-Australia and New Zealand combined produce about 25 per cent. of the world's wool clip, the Russian Empire 15 per cent., the United States 12 per cent., Argentina 6 per cent., the Union of South Africa 6 per cent., Uruguay 5 per cent., The United Kingdom 4.5 per cent., Turkey in Asia 3.3 per cent., and France 2.8 per cent.

American wools and wool growing.-American sheep are said to have no superior in constitutional vigor and strength of wool fiber. The average weight of fleece of American sheep has shown much improvement. In 1840 it was only 1.9 pounds; in 1850 it was 2.4 pounds; in 1860 it was 2.7 pounds; in 1870 it was 3.5 pounds; in 1880 it was 4.4 pounds; in 1890 it was 4.8 pounds; in 1900 it was 6 pounds; in 1910 it was 6.7 pounds; in 1918 it was 7.1 pounds. The annual wool clip since 1840 is shown by the following figures: 
1840

$35,802,114$ pounds

1850

$52,516,959$ pounds

1860

$60,264,913$ pounds

1870

$162,000,000$ pounds

1880

1890

$232,500,000$ pounds

1900

1910

$276,000,000$ pounds

1918

\section{$288,636,621$ pounds}

$336,896,903$ pounds

$257,921,000$ pounds

According to the estimates of the National Association of Wool Manufacturers, the leading states in number of sheep, average weight of fleece, and pounds of wool produced during 1918 were as follows:

\begin{tabular}{c|c|c|c|c|c}
\hline States & $\begin{array}{c}\text { Number } \\
\text { of } \\
\text { fleeces }\end{array}$ & $\begin{array}{c}\text { Average } \\
\text { weight } \\
\text { of fleece }\end{array}$ & $\begin{array}{c}\text { Wool } \\
\text { product, } \\
\text { raw }\end{array}$ & $\begin{array}{c}\text { Per cent. } \\
\text { of } \\
\text { shrinkage }\end{array}$ & $\begin{array}{c}\text { Scoured } \\
\text { wool }\end{array}$ \\
\hline 1. Wyoming... & $4,051,000$ & 8.4 & $34,026,000$ & 67 & $11,228,580$ \\
2. Montana.... & $2,847,000$ & 8.2 & $23,342,000$ & 64 & $8,403,120$ \\
3. Idaho...... & $2,468,000$ & 7.9 & $19,500,000$ & 63 & $7,215,000$ \\
4. Ohio....... & $1,726,000$ & 7.3 & $12,600,000$ & 53 & $5,922,000$ \\
5. Utah ...... & $2,052,000$ & 7.7 & $15,800,000$ & 65 & $5,530,000$ \\
6. New Mexico. & $3,059,000$ & 5.6 & $17,132,000$ & 68 & $5,482,240$ \\
7. California... & $1,792,000$ & 7.0 & $12,545,000$ & 64 & $4,526,200$ \\
8. Michigan.... & $1,184,000$ & 7.4 & $8,765,000$ & 50 & $4,382,500$ \\
9. Oregon..... & $1,562,000$ & 8.0 & $12,500,000$ & 67 & $4,125,000$ \\
10. Texas....... & $1,607,000$ & 7.0 & $11,250,000$ & 67 & $3,712,500$ \\
\hline
\end{tabular}

This table brings out some important distinctions in wools. The figures for shrink are interesting; the western states exceed the eastern states by 13 to 17 per cent., due to the greater percentage of Merino blood in range flocks and hence a more greasy wool with a greater shrink. Western wools also contain more sand and dirt. The introduction of mutton sheep into the cornbelt has decreased the average weight of fleece, but has improved the shrinkage. The entire clip of the United States is estimated to shrink 60.8 per cent. Wool buyers fix the price on a scoured basis, this being the fairest method of dealing and also the fairest basis on which to compare production by states. Wyoming has the most sheep, and Rhode Island the fewest. Washington has the highest average weight of fleece, which is 8.6 pounds, and Georgia is lowest with 2.9 pounds. Virginia has the lowest per cent. of shrinkage, which is 38 per cent., and Nevada with 70 per cent. has the most.

Imports and exports of wool.-During the fiscal year, 1913'14, the United States imported 195,293,255 pounds of wool 
valued at $\$ 35,579,823$. The average value per pound would thus be 18.1 cents. We export less than 100,000 pounds of wool annually. American wool growers produce slightly more than one-half of the wool used by American wool manufacturers. Australia is the largest exporter of wool, the figure for the calendar year, 1912, being 693,496,000 pounds; Argentina ranked second with $363,680,000$ pounds; South Africa was third with $185,471,000$ pounds; and New Zealand was fourth with $175,982,000$ pounds. The four countries mentioned furnish over threefifths of the exports of the world. The principal importing and wool-manufacturing countries are France, Great Britain, Germany, United States, and Belgium, in the order named. These five countries annually consume over four-fifths of the total imports of the world.

Principal American wool markets.-The principal wool markets in the United States are Boston, Chicago, Philadelphia, St. Louis, and New York. During the past few years Boston has handled nearly 75 per cent. of the total wool crop of this country, and nearly 60 per cent. of the foreign wool shipped into this country. Wool is purchased from the producer by different methods depending upon the size of the clip. Domestic wools are largely sold to local wool buyers who take the whole clip of the neighborhood regardless of quality or cleanliness. Sometimes the country storekeeper buys wool and resells to the travelling buyer. Cooperative wool-selling agencies have been formed in certain localities, particularly in Minnesota and Wisconsin. The advantages of these organizations are discussed in a later paragraph. Territory wools are sold mostly to buyers representing eastern wool dealers. In a few cases they are sold to buyers representing manufacturers. The western wool grower may also consign his clip to a commission house to be stored and sold for a certain commission charge.

Factors that determine the value of wool. - The value of wool depends upon certain well-established factors, many of which have been indicated and discussed in the foregoing paragraphs on wools and wool manufacture. Following is a list of these factors.*

1. Shrinkage.-American wools may shrink from 25 to 80 per cent. The loss in scouring is a complete loss to the manufacturer. Grease wools are valued on a scoured basis. Sand, 
dust, dirt, burs, and seeds lower the yield and affect the value of the clean wool. The following table shows the important part that shrinkage plays in fixing prices. At the top are various prices per pound of clean or scoured wool. In the column to the left are various percentages of shrinkage. By the use of this table we find, for example, that if clean wool is worth $\$ 1.00$ per pound and the shrinkage is 65 per cent., the wool is worth 35 cents in the grease, whereas, if the shrinkage is 60 per cent., the grease wool is worth 40 cents.

Relative prices of scoured and raw wool at varying percentages of shrinkage.

\begin{tabular}{|c|c|c|c|c|c|c|c|c|c|c|c|c|c|}
\hline \multirow{2}{*}{ Shrinkage } & \multicolumn{13}{|c|}{ Price of clean or scoured wool (cents) } \\
\hline & 30 & 40 & 50 & 60 & 70 & 80 & 90 & 100 & 110 & 120 & 130 & 140 & 150 \\
\hline per cent. & cts. & cts. & cts. & cts. & cts. & cts. & ets. & cts. & cts. & ets. & cts. & cts. & cts. \\
\hline & 23 & 30 & 38 & 45 & 53 & 60 & 68 & 75 & 83 & 90 & 98 & 105 & 113 \\
\hline 30 & 21 & 28 & 35 & 42 & 49 & 56 & 63 & 70 & 77 & 84 & 91 & 98 & 105 \\
\hline 35 & 20 & 26 & 33 & 39 & 46 & 52 & 59 & 65 & 72 & 78 & 85 & 91 & 98 \\
\hline 40 & 18 & 24 & 30 & 36 & 42 & 48 & 54 & 60 & 66 & 72 & 78 & 84 & 90 \\
\hline 45 & 17 & 22 & 28 & 33 & 39 & 44 & 50 & 55 & 61 & 66 & 72 & 77 & 83 \\
\hline 50 & 15 & 20 & 25 & 30 & 35 & 40 & 45 & 50 & 55 & 60 & 65 & 70 & 75 \\
\hline 55 & 14 & 18 & 23 & 27 & 32 & 36 & 41 & 45 & 50 & 54 & 59 & 63 & 68 \\
\hline 60 & 12 & 16 & 20 & 24 & 28 & 32 & 36 & 40 & 44 & 48 & 52 & 56 & 60 \\
\hline 65 & 11 & 14 & 18 & 21 & 25 & 28 & 32 & 35 & 39 & 42 & 46 & 49 & 53 \\
\hline 70 & 9 & 12 & 15 & 18 & 21 & 24 & 27 & 30 & 33 & 36 & 39 & 42 & 45 \\
\hline 75 & 8 & 10 & 13 & 15 & 18 & 20 & 23 & 25 & 28 & 30 & 33 & 35 & 38 \\
\hline 80 & 6 & 8 & 10 & 12 & 14 & 16 & 18 & 20 & 22 & 24 & 26 & 28 & 30 \\
\hline
\end{tabular}

2. Class and grade of the wool.-Ordinarily combing wools are worth about 10 per cent. more than the short or clothing wools.

3. Character in wool.- This refers to the color or whiteness of the fiber, the soundness, luster, evenness of distribution of yolk, and the degree of crimp which gives elasticity to the fiber. A fine Merino fiber may be easily stretched by hand 30 per cent. beyond its crimped length, and by gradual pressure on a machine fully that much more. A white fiber may be used in the manufacture of white cloth, or may be dyed any desired color. Black, brown, or gray wool can be used only in dark-colored fabrics, and furthermore it is difficult to stain these wools exactly the same shade as white wool. Kemp, which are hair-like fibers, found mostly on the thighs of coarse-wooled sheep, will absorb little dye, if any at all, and fleeces containing kemp are discriminated against as lacking in character. In kemp the outer scales lie so closely against the body of the fiber that the dye cannot penetrate. The body of the fiber alone absorbs the dye. 
4. Strength of fiber.-Tender spots and breaks affect the value of the wool, may change its class or grade, and lessen the strength of the yarn.

5. Use of paint for branding sheep.-This lowers the value of the fleece, necessitates an extra sort at the mill, and requires that the painted ends be clipped off the fibers before scouring.

6. Tags.-These are worth about one-third as much as good wool. At time of shearing they should be sacked separately. They are objectionable in the fleece because they shrink

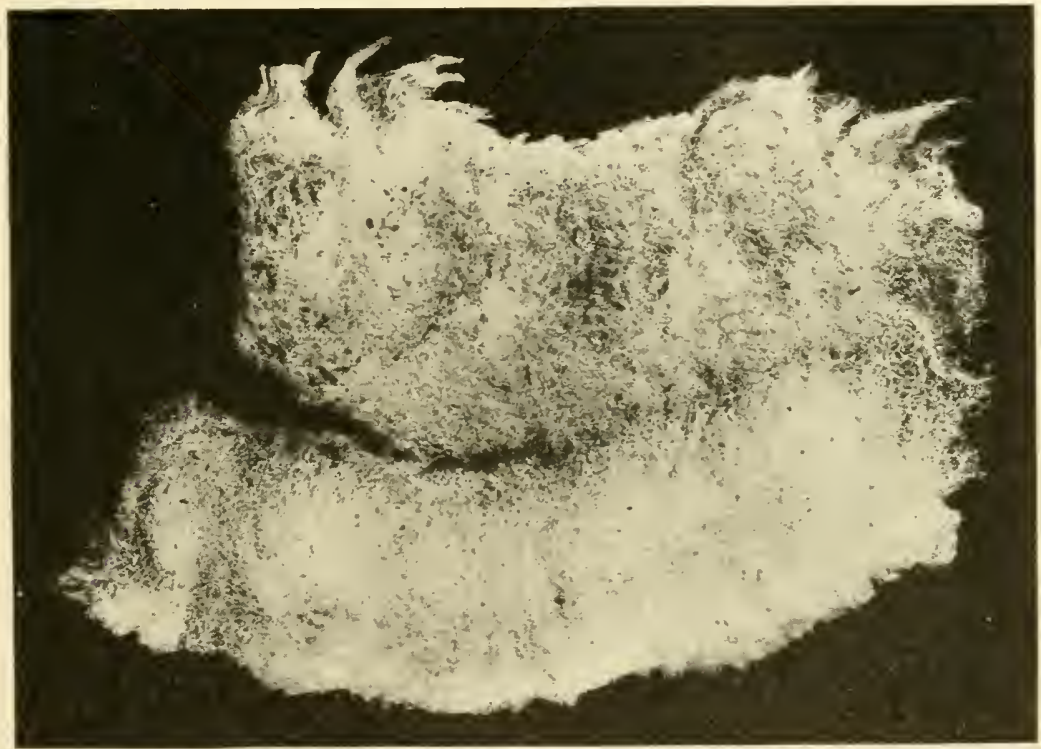

Fig. 87. Tender Wool Showing Break.

much more in scouring than the rest of the fleece, and are liable to stain the surrounding wool, especially when wet.

7. Wet wool.--In wet wool the fibers may be weakened, and there is danger of spontaneous combustion. It may also cause staining, especially when tags are present.

8. Burs.-As has been pointed out, burs cause much trouble and extra expense in manufacture, and hence lower the value of the fleece considerably.

9. Improper tying.- The fleece should be tied so that no locks or pieces fall out. These are difficult to sort and buyers object to them when present in large quantities. The use of 
sisal or binder twine is seriously objected to by dealers and manufacturers because the fibers of the twine shred off and become mixed with the wool and blemish the fabrics made from it. A small, light twine of twisted paper, especially intended for the use of wool growers, is now on the market and should be used exclusively.

10. Buck fleeces.-These contain more grease than other fleeces and hence shrink more in scouring. They should be kept separate.

11. Black wool.-A black fleece packed with white ones is almost certain to contaminate the latter due to some of the black fibers becoming mixed in the white. Black wool should be packed separately. Black fleeces sell at a discount because they are usually not an even black, but contain white, gray, and brown fibers, often more of these than of black.

12. Cotted or matted fleeces.-It is necessary to run these through an opener, which is not done with ordinary wool.

13. Hand and machine shearing.-Machine shearing results in a heavier fleece, longer fibers, and freedom from second cuts. Machine shearing may even result in changing the class from clothing to combing.

14. Packing wool.-Lamb, ewe, and wether fleeces should be packed in separate bags if possible. Lambs' wool is usually more valuable because of lighter shrinkage. Sewing bags with sisal or other unsuitable twine creates a bad impression. The bag should be sewed securely with a stout, hard-finished twine so as not to burst open.

Marketing wool properly.-Poor methods of sheep husbandry annually result in the loss of many thousands of dollars to wool growers. Neglect of flocks in winter, filthy conditions of keep, carelessness in handling, weedy pastures, the use of oil paint or tar to mark sheep, failure to separate the tags when the sheep are shorn, and improper tying of fleeces are factors which greatly lessen the returns to wool producers. The loss is large because of the presence in fleeces of seeds, burs, dust, chaff, sand, manure, and other foreign material, and because unnecessary quantities of unreasonably large twine are used, or because a kind of twine is used that injures the cloth made from the wool. Sometimes there is enough twine around one fleece to tie a half-dozen or more fleeces. Even baling wire has been used in some instances. 
The Animal Husbandry Division of the U. S. Bureau of Animal Industry* suggests the following rules as of fundamental importance in the improvement of American wools:

1. Adhere to a settled policy of breeding the type of sheep suitable to the locality.

2. Sack lambs', ewes', wethers', and all buck or very oily fleeces separately.

3. Shear all black sheep at one time, preferably last, and put the wool in separate sacks.

4. Remove and sack separately all tags, and then allow no tag discount upon the clip as a whole.

5. Have slatted floors in the holding pens.

6. Use a smooth, light, and hard glazed (preferably paper) twine.

7. Securely knot the string on each fleece.

8. Turn sacks wrong side out and shake well before filling.

9. Keep wool dry at all times.

10. Make the brands on the sheep as small as possible and avoid tar brands.

11. Know the grade and value of your wool and price it accordingly.

12. Do not sweat sheep excessively before shearing.

13. Keep the floor sweepings out of the wool.

14. Do not sell the wool before it is grown.

15. When all these rules are followed place your personal brand or your, name upon the bags or bales.

The Australian plan of handling the wool clip has recently been strongly advocated by the U. S. Bureau of Animal Industry and has already been adopted by a few ranchmen in Wyoming, Montana, and Nevada. Under this plan the wool is graded at time of shearing, resulting in standard grades of wool which may be bought and sold like any other standard commodities. The belly wool is separated from the fleece by the shearer, and all bellies from the same kind of sheep are baled together. The fleece, minus the belly, is thrown spread out upon a table having a slatted top to allow loose, heavy pieces of wool and dirt to reach the floor. The fleece is then "skirted." This consists in removing some of the wool from the edges of the fleece. In cross-bred sheep and in some Merinos the lower thigh wool is materially coarser than the body of the fleece, and when this is

*U. S. Dept. Agr. Bul. 206. 
removed, an even quality of wool is left in the fleece. The fleece is then graded into one of several grades according to length, fineness, shrinkage, and character. The fleece is not tied before baling. When opened in the East the wool has lost nothing by baling and makes a good appearance.

The Australian system, so-called because it is universally practiced by Australian wool growers, is educational to the western wool grower who learns much regarding the kinds and values of wools produced by his sheep, and it eliminates the usual further handling undergone by most clips in dealers' warehouses before sale to manufacturers is attempted. Many growers realize for the first time the great amount of clothing wool they are producing and realize as well the variety of grades of wool that come from sheep of supposedly uniform type but in the breeding of which they had not adhered to a distinct standard of fleece in the selection of rams.

Advantage of pooling farm-grown wools.- During the last few years a few counties in the farming states have marketed their wools through their farm bureaus on a pooling basis. In 1915, Otsego County, N. Y., pooled and sold 20,000 pounds of wool at an advance of $41 / 2$ cents per pound over prices offered at the same time by the local dealers. Because of the success of this method of marketing, Ohio and Iowa have organized state wool growers' associations with the object of pooling all the wool of the state. The plan is meeting with marked success. Under this plan of selling collectively small lots of farm wools, it becomes practicable to do the grading needed to secure fair prices to all members. The farmer who produces a good clip of wool will receive a just price instead of the usual flat price offered by the local dealer for all fleeces, good, bad, and indifferent.

Mohair.--This is the product of the Angora goat. The fiber is coarse, very long, exceedingly lustrous, and has very little crimp. It is used in the manufacture of braids, felts, linings, and plushes. It is also used extensively as a substitute for human hair in switches and wigs. 


\section{PART THREE.}

SWINE.

\section{INTRODUCTION.}

The hog is universally known as the "Mortgage Lifter." No other animal has contributed more toward the success of farming in the United States. This country leads the world in hog breeding and pork production. The money-making ability of the hog is based on the following advantages of the hog and of hog raising:

1. Hogs are the most efficient converters of grain and certain other feeds into meat. They make larger gains in weight in proportion to feed consumed than other farm animals.

2. They are most prolific, commonly farrowing from 6 to 10 pigs, and will raise two litters per year.

3. Returns come quickly. The pigs may be marketed within ten months after the sows are bred. The sow may be bred when eight months old, farrowing her first litter at twelve months of age.

4. Of all meat-producing farm animals, the pig is best adapted to diversified and intensified farming where a large income is desired from a small acreage.

5. The hog has a higher dressing percentage than any other animal, and a larger proportion of the live weight is edible than of any other animal.

6. Pork is the most nutritious meat and has better curing and keeping qualities than any other meat.

7. No other animal equals the hog in its fat-storing ability, and hog fat is the most valuable fat produced by domestic animals.

8. Hogs are the most efficient farm animals in converting certain wastes and by-products into profits. This statement applies to grain wasted by fattening cattle, utilization of garbage, and utilization of dairy by-products such as skim milk. In some wooded sections of the country, pigs convert acorns, other mast, and roots into saleable form. 
9. Hog raising requires a smaller investment in animals and equipment and yields quicker and relatively larger results than any other branch of animal husbandry.

Swine are useful as a source of meat and lard. Some swine produce meat only, and some produce lard as well as meat. Differences in the demands of consumers of pork, together with differences in the kinds of feed available for pork production, have resulted in the establishment of two distinct types of swine -lard type and bacon type. The lard hog is an American production found chiefly in the cornbelt states where corn is the principal feed for all farm animals. Corn is a great fattening feed, and when fed to hogs it is converted into fat from which lard is made. Breeders have therefore developed a type of hog specially adapted to converting feed, principally corn, into fat, and at the same time growing a carcass highly valued for the various cuts of meat which it yields.

The bacon hog is also found in America, principally in Canada, however, which is outside the cornbelt. In Canada the feeds available for pork production are peas, barley, wheat, oats, rye, skim milk, and roots. As compared with corn, these feeds are not so fattening; they are muscle builders, and hogs produced with such feeds take on relatively little fat and are not useful as a source of lard. Canadians have made no effort to compete with the hogs of the cornbelt; instead they produce a hog suitable for the English and Canadian trade - a hog whose carcass yields the largest proportion of high-grade bacon.

From what has been said it may appear that there is no real hereditary difference in the temperaments and make-ups of the two types of hogs, but that the differences between them are solely the result of differences in the feeds upon which they are produced. This is largely true, yet it is a fact that when pigs of the bacon type are brought into the cornbelt and fed along with lard hogs, they never entirely lose the bacon type; and when the lard hog is taken into a bacon-producing section and fed with bacon hogs, there is the same degree of change, but the lard hog does not lose his identity under such a system of feeding. Therefore we must conclude that there is something besides the difference in the feeds which accounts for the two distinct types; in other words, there is an hereditary difference between the two kinds of swine.

These facts in regard to swine are no more unique than the results of efforts by some men to produce milk from beef 
cattle, or beef from dairy cattle, or mutton from fine-wooled sheep. In such instances, we find dairy-bred steers tending toward the form of the beef animal, we find beef cattle taking on somewhat the appearance of the dairy animal, and we find that the Merino approaches nearer to mutton type. Careful selection and breeding and the establishment of definite types of animals suitable to special purposes cannot accomplish the desired ends unaided. The feeding and care must receive as much attention as the breeding. No matter how well bred an animal may be, and no matter how great may be its tendency to conform to a given type, it must enjoy a favorable environment before its inherited good qualities can fully assert themselves and thereby enable the animal to fulfill its mission.

In America the lard type of swine is represented by the Poland-China, Duroc-Jersey, Chester White, Berkshire, and Hampshire breeds. The bacon type includes two breeds, the Yorkshire and Tamworth. The Berkshire and Hampshire do not possess true fat or lard type, but occupy a position about midway between the bacon and lard types, being general-purpose breeds.

\section{Definition of Hog Terms.}

Boar.-Breeding male, any age.

Sow.-The female, any age.

Gilt.-A young sow, usually under twelve months and before she has farrowed a litter.

Barrow.-Unsexed male, castrated when a young pig. The best age to castrate pigs is from 6 to 8 weeks old, before weaning.

Stag.-Unsexed male, castrated when mature or so far advanced toward maturity that masculinity is plainly evident in head, neck, and forequarters. This constitutes coarseness in a market animal.

Shote.-A young hog weighing from 100 to 150 pounds. 


\section{CHAPTER XXI.}

\section{THE AMERICAN OR LARD-TYPE HOG.}

The United States has created comparatively few of the breeds now found within her borders. By the time this country reached that stage in her live-stock development when improvement in domestic animals became imperative, European nations had met and solved a similar problem by the creation of numerous useful breeds. It was but natural, therefore, that many of these foreign breeds were imported to this country, and it was fortunate indeed that most of them proved fully capable of fulfilling the requirements of our stock growers. We were thus afforded an easy short cut across what would have been a long, laborious period in the development of our livestock industry. We borrowed whenever such procedure was practicable, and the fact that we have never found it really necessary to create a breed of draft or carriage horses, beef, dairy, or dual-purpose cattle, mutton sheep, or bacon hogs shows how great is our indebtedness to the breeders of Europe.

Our needs were not entirely met, however, for we have created a breed of trotting horses, a breed of saddle horses, a breed of fine-wooled sheep, and a number of breeds of lard-type swine. We have also found it necessary to modify slightly some of the breeds we have adopted, and to our credit it may be said that we have made certain changes in some of these adopted breeds which, as viewed from the standpoint of American conditions and requirements, represent decided improvements. The Polled Shorthorn, the Polled Hereford, the "American-type" Hereford, and the "American-type" Berkshire are examples of such modifications.

The extended patronage which we have given to foreign stock and the lack of necessity for developing breeds of our own, while highly advantageous, has tended to dim our own glory as a live-stock breeding nation. If, because of this fact, our live-stock industry needs a redeeming feature, it is furnished by the creation of a distinctly American type of hog, which includes several breeds. European breeds of swine proved so fully incompetent to make pork under American conditions that our breeders found it necessary to create distinctly new breeds. 
of a new type, and this work has been so well done as to give us a clear title to the distinction of leading the world in swine breeding and in pork production.

Our conditions demand a type of swine possessing a moderate degree of compactness of form, great breadth of back, much fullness of ham, medium shortness of leg, rapid and heavy fattening qualities, and quickness of maturity. Such a type has been developed and maintained by American swine breeders. On account of its heavy and easy fattening qualities, it is comnionly referred to as the lard-type hog. Its ability to assimilate the carbohydrates of corn and build up a valuable fat from which lard is made has played no small part in the rapid development of American agriculture and in the prosperity of our farmers. "King Corn and the American Hog" have always constituted an invincible combination, creating a channel of disposal for the former in the early days when there was a great surplus of that food stuff, and supplying the people of this country with highly palatable and nutritious meat at a moderate price.

The following description applies particularly to the fat barrow raised and fattened for the market. The type desired in lard hogs for breeding purposes is described in Chapter XXVI.

The general appearance of the lard-type hog fattened for the market embodies a broad, deep, fairly compact, and rather short-legged conformation, together with great smoothness. Both the head and neck are short and wide, the top is very broad and slightly arched, the sides are deep, and the hams are massive. As viewed from the side the lard-type hog shows great depth of body, moderate length, a slightly arched top line from head to tail, and a straight underline that tends to be rather close to the ground. He should be as deep in front as behind, in other words, symmetrical. When viewed from behind, the hams show great breadth or thickness, not only at the top but also at the lower part just above the hocks. When a view is taken directly down upon the top of the hog, he should exhibit great width at all points along the top from shoulders to tail. The shoulders should not be wider than the rest of the hog, nor should the hog taper in width from front to rear, but be uniformly very wide from one end to the other, thus presenting a balanced or symmetrical conformation and increasing the value of the carcass. Much quality should be shown in head, ear, coat, skin, smoothness of form, and fineness and smoothness 
of bone and joints. This type is disposed to be mild and quiet in disposition, but a sluggish, inactive hog is an objectionable extreme.

The head is of medium size, rather short, broad between the eyes, and short of snout. A narrow head and finely pointed snout are indications of a poor feeder. The shape and length of head vary according to the breed, but in none of the lard breeds is much length or narrowness desirable. The eyes should be as large, prominent, and clear as possible, a small, sunken eye obscured by rolls of fat around the socket being objectionable. The carriage of the ear varies according to the breed, being erect in some and drooping or broken in others. All the breeds, however, should have a fine and medium sized ear neatly attached to

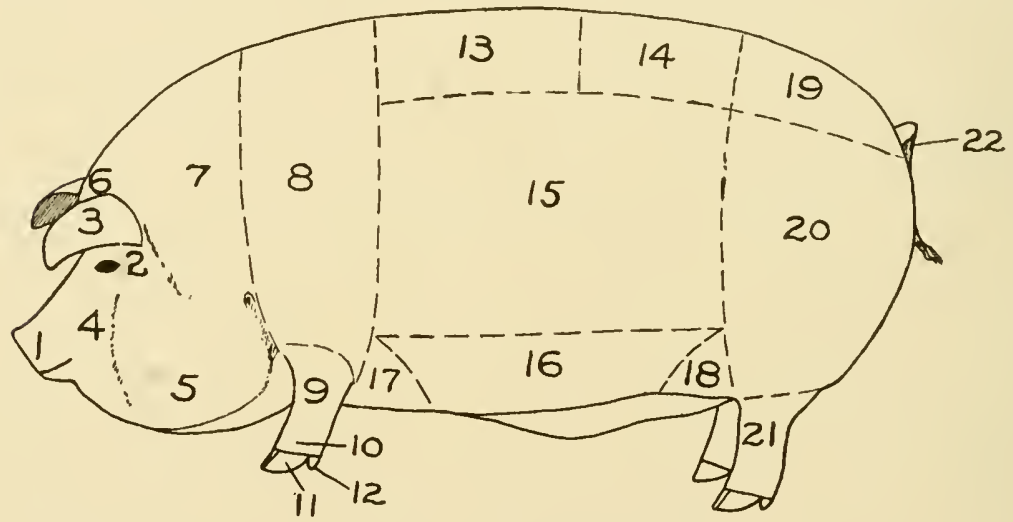

Fig. 88. Points of the Hog.
1. Snout
7. Neck
13. Back
8. Shoulder
14. Loin
9. Fore leg
3. Ear
10. Pastern
11. Toes
15. Side
4. Cheek
5. Jowl
12. Dew claw
16. Belly
17. Fore flank
18. Hind flank
19. Rump
20. Ham
21. Hind leg
6. Poll

the head. The jowl should be well developed or full, and should extend back into the shoulder. It should not be loose and flabby, but rather trim and firm. The cheeks and jowl should be free from wrinkles or seams. The poll of the head should be broad and carry forward prominently.

The neck should be short and wide, and blend smoothly with the shoulder. The neck should be broad on top, and it should be deep. A neck that is narrow or peaked on top and rather long is not often associated with a body of the desired conformation. 
The shoulders are very frequently too open and prominent, so that as one looks down at the top of the hog the shoulders are found to be much the widest part of the animal. They should be well laid in, very smooth, and have no greater width than the rest of the body, such a hog being much more desirable from a market and carcass point of view. The tops of the shoulders should not stand open and apart, but should be laid together and thickly fleshed so as to present a broad, smooth surface in harmony with the rest of the top.

The front legs should be medium short or short, this being a somewhat variable feature depending on the breed, and they must also be straight. It is especially important that the pasterns shall be short, upright, and very strong, and that the toes shall be strong also. These points should be particularly emphasized, for it is a fact that weak, broken-down pasterns and weak, spreading toes are among the most common and most serious faults to be found in swine of the lard type. Weak legs may be due to a natural or inherited weakness, or to improper feeding during the growing period. If growing pigs are fed on corn exclusively, they are liable to develop weakness of the legs, because corn does not carry sufficient bone- and musclebuilding constituents to satisfy the demands of the animal during the growing period. The bone of the market hog should be fine, yet sufficient to carry the weight of the hog. Refinement of bone is pleasing to the butcher because it is associated with general refinement of the entire animal, thus insuring a clean-cut carcass of quality.

The chest is an evidence of the constitutional vigor possessed by the animal. It should be wide and deep, filling out behind the shoulders and elbows and affording a large heartgirth. The underline should not cut up between the fore legs, but carry straight forward so as to give as much depth through the chest as through the middle of the body.

The back and loin of the lard hog are very important parts. They should be medium long and very wide, and, as the animal is viewed from the side, they should be slightly arched. The top of the hog should be very deeply fleshed so as to build the back and loin out level and square on either side of the middle line, thus forming a rather well-marked corner at the junction with the upper border of the side. There will thus be no marked rounding off from the middle line, but a gentle arch over the top from side to side and great width of top due to well-sprung ribs 
and very heavy fleshing. A "ridgy" back is an evidence of lack of fleshing, and a narrow, "sunfish" conformation is very faulty for the same reason. A dip in the back, or sway-back conformation, greatly detracts from the appearance of the animal and may indicate weakness of muscling; hence the cuts from the back and loin may be lacking in lean meat.

The sides of the hog should carry down straight and deep from top to bottom, and should be neither long nor short, but moderate in length. Very short hogs raised and fed for market are open to objection because such a type does not grow rapidly. On the other hand, extreme length is secured at the expense of

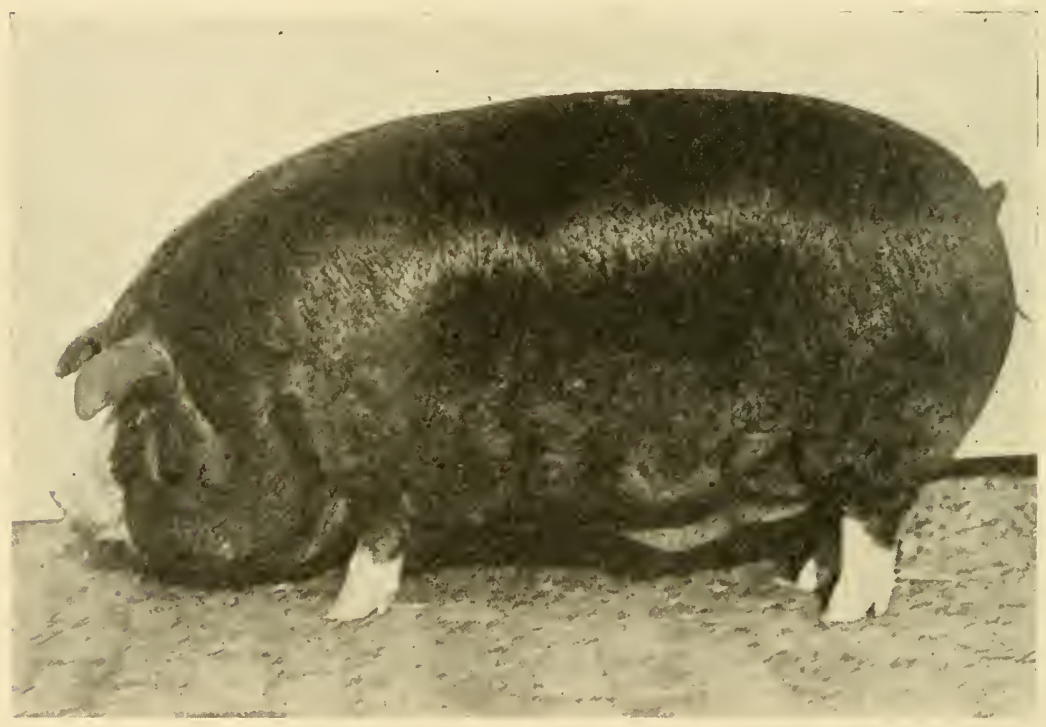

Fig. 89. Correct Type in the Fat Barrow.

Poland-China barrow, Grand Champion at the 1913 International. Bred and exhibited by John Francis \& Sons, New Lenox, Ill Lengthy, deep, symmetrical, and smooth. This hog has remarkable quality in head, ear, hair, and bone. His legs are short and his pasterns strong.

width and depth, and also at the expense of quick fattening qualities. For these reasons, extremes in either direction are to be avoided. When fattened for the market, the sides should be thickly and smoothly fleshed so that every point along the side fills out to meet the same straight line from shoulder to ham. Wrinkles in the skin along the side are objectionable because they injure the smoothness of appearance which is so desirable, and if the wrinkles are very deep and are permanent, 
that is, do not disappear when the hog changes position, they are called creases or seams and are highly undesirable. These seams most often occur just behind the shoulder, but they may occur all along the side. They are due to creases in the skin and in the flesh underlying the skin, so that when the fingers are inserted into them they are found to be deep and pronounced. They indicate lack of quality and lack of evenness in fleshing, and are especially objectionable because they remain in the side meat even after it has been pressed and cured by the packer, thereby injuring the appearance of such cuts and affecting their selling price.

The belly should be straight or "well tucked up," thus insuring a good dressing percentage when the hog is killed. The belly should be firm, not flabby, and should be wide rather than narrow or V-shaped.

The rump should be long and as wide as the rest of the top, and it should carry out from hips to end of body with a slight curve downward to coincide with the slight arch of the entire top from head to tail. Very often the rump will be found very steep or drooping, the hips being carried too high and the tail set very low. Accompanying this kind of a rump, and to a certain extent causing it, is a faulty position of the hind legs, the feet being set too far under the body. This constitutes a weak conformation of the hindquarter, and gives the animal an ungainly appearance. The rump should carry out wide on either side of the tail to form rather square corners, and should not taper in width from hips to end of body, but be uniform in width throughout. When the hog is fat, the tail sets in a socket.

The hams really include the rump as well as the thighs and twist. They should be very large and well developed, being plump and thick from every point of view. The thickness should carry down to the hocks, and the space between the hind legs and above the hocks should be filled with flesh. Loose, flabby hams are undesirable because they carry too much outside fat and require too much trimming off before they can be sold. Some hams lose fifteen per cent. in trimming at the packing house. The hams should be reasonably firm in fleshing and neat in form, yet very plump, wide, and deep.

The hind legs should be medium short, or short, and should carry down straight and vertical from the hocks to the ground. The pasterns should be short, upright, and very strong, the feet well formed, and the toes strong. The bone of the market hog should exhibit considerable refinement. 
The hair should be straight rather than curly, and should be fine. A harsh, bristly coat is an evidence of coarseness. A curly coat is objectionable because curly hair is usually coarser than straight hair, and curly-coated hogs do not shed their coats properly, which injures the appearance. A swirl or rose in the hair on the back or rump detracts from the appearance, and is objectionable for that reason. The hair should be abundant and smooth, and should lie close to the skin. Such a coat affords the most protection and adds to the attractiveness of appearance.

The quality of a fat-type hog is determined by the refinement of the head, hair, and bone, smoothness of finish, and free-

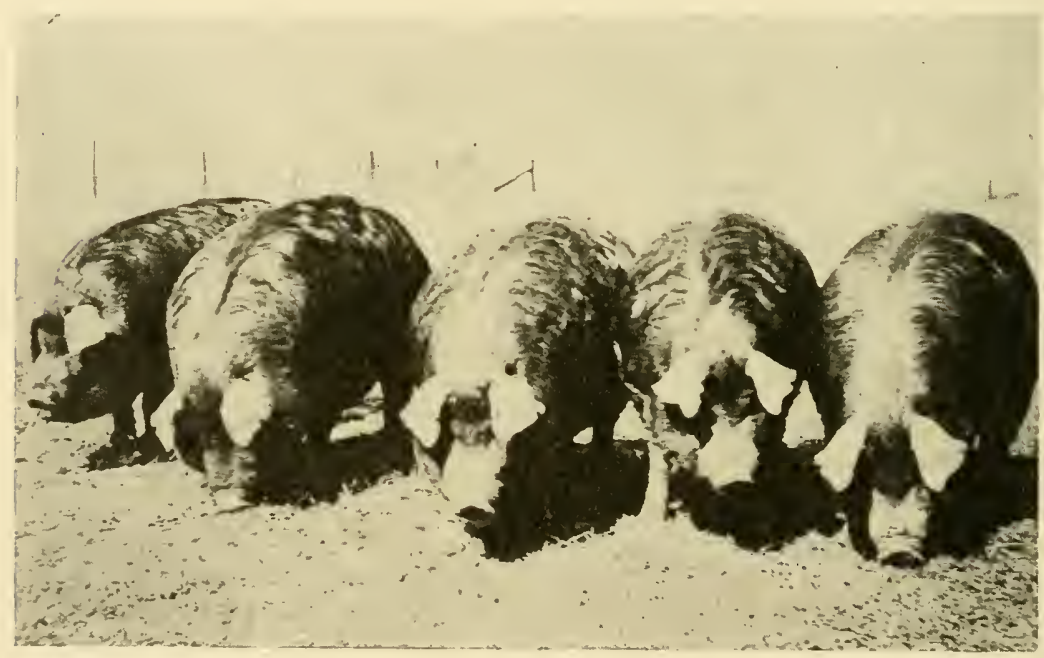

Fig. 90. Finished Barrows.

Duroc-Jersey barrows that won Grand Championship on pen of five barrows at the 1917 National Feeders' and Breeders' Show, Ft. Worth, Tex. Average weight, 386 pounds; age, 12 months. Bred, fed, and exhibited by the Texas A. \& M. College. Note the excellent heads, arched backs, broad tops, high finish, and uniformity of these hogs.

dom from wrinkles and seams. The hog with quality has a clean-cut, well-bred appearance that pleases not only the producer and hog fancier, but also the butcher, because such a hog yields a neat, tidy carcass that attracts buyers, and the cuts of meat show a refined texture that is not to be found in the cuts from a coarse, rough hog.

The proper finish of a lard-type hog is secured by a high degree of fattening, but the feeding should not be continued 
long enough to give the hog a soft, flabby covering. When handled along the back, below the shoulders, and at the lower border of the hams, the fleshing should be rather firm instead of soft as is often the case, especially in some breeds. Some hogs become lumpy in their covering of fat, which is objectionable. When the fattening has proceeded far enough to round out the lines of the animal and give him a smooth, springy, mellow covering of flesh, he is in just the right condition to meet with most favor from the butcher.

The temperament of the fat-type hog is quite different from that of the bacon hog, being less active and more inclined to quietness, lying down, and the taking on of fat. Ideas as to what is most desirable in the temperament of this type of swine are tending somewhat away from the one formerly in favor, namely, that a hog should eat and lie down, and that a minimum of exercise is conducive to greatest economy in pork production. Many producers are now coming to believe that better results are secured if the hog is disposed by temperament to take considerable exercise, especially during the growing period; they are selecting more active hogs for breeding, and are managing their young stock in such a way as to induce them to take a large amount of exercise. This results in growthy pigs of robust constitution and lessens the danger of disease. Exercise also develops the muscles and strengthens the pasterns and legs. Notwithstanding this present-day tendency to select a more active hog than in the past, there must always be considerable difference between the fat type and bacon type in this respect, the former being more quiet, slower in movements, and having much greater natural aptitude to fatten.

The weight for age is an important consideration because it is a measure of the profit-making ability of the hog. Pigs weighing over 150 pounds, fattened for the market, should have at least one pound of weight for every day of their age. On this basis, a pig six months old should weigh not less than 180 pounds. It is not unreasonable to fix the standard of weight for fat hogs six months old at 200 pounds; nine months, 300 pounds; twelve months, 400 pounds. Hogs are matured at about twenty-four months of age. Mature boars in high condition should weigh 800 pounds or over; sows, 600 pounds or over. The average weight of hogs received at the large markets at the present time is about 225 pounds. Hog growers are agreed that weights from 200 to 275 pounds for market hogs are most profitable. 


\section{THE BACON-TYPE HOG.}

The bacon hog presents some very marked differences when compared with the lard hog in form, fleshing, and temperament. These differences are very necessary because the bacon hog yields a product that is quite different from that of the fat or lard hog. The foremost countries in bacon production are England, Denmark, and Canada, the first mentioned consuming the surplus production of the other two. It is a superior product to that with which the American public is furnished, being the finest that is produced. American bacon is the belly meat of the lighter and thinner hogs of the lard type, but English bacon is supplied by a hog the entire side of which is suitable for bacon. Denmark and Canada ship bacon to England in the form of what is called the "Wiltshire" side. A Wiltshire side represents half the carcass of the hog, minus the head and legs. The neck, shoulder, back, loin, side, belly, and ham are included, and all of these parts are retailed as bacon except the ham and shoulder.

The best bacon contains a relatively large amount of lean meat and small amount of fat. The price charged for bacon at wholesale or retail is very largely regulated by these features, a cheap slab of bacon always being characterized by greater thickness, little lean, and much fat. The production of highquality bacon therefore necessitates a different kind of hog than the lard hog, a hog disposed to be muscular and active, but not a hog that fattens readily. The production of the best bacon also necessitates feeding this hog on such feeds as will furnish nitrogenous or muscle-building materials in abundance, the carbonaceous or fat-forming elements of the ration being supplied in much less amount than would be advisable if lard hogs were being fed. This fact explains why but few bacon hogs are found in the cornbelt, and also why the United States is able to produce the lard hog at lower cost than he can be produced elsewhere. Whereas corn plays a large part in the production of lard-type swine for the market, the bacon hog is fed on such feeds as peas, barley, and skim milk, which are much better 
suited to bacon production than is corn, because they contain a larger percentage of protein.

It is important that the producer of bacon hogs turn them off to market at that period in their development when the character of the flesh will be nearest the bacon ideal. To be more explicit, if the hog is marketed too young its flesh will be watery and flabby, whereas further feeding and more age result in a more desirable carcass. Young pigs have a very strong tendency to utilize their feed for growth, and as they become older and are more matured they fatten much more readily. It is for this reason that the best bacon comes from hogs within certain limits of weight. Experience has shown that a weight of 160 pounds is the minimum weight at which to market a bacon hog and that the upper limit is 220 pounds. These figures represent the extremes; the best bacon carcasses are from hogs that weighed 175 to 190 pounds. This does not mean that the bacon hog reaches maturity at a weight of 190 or 220 pounds, or that it is desirable that he should do so. The matured weight for boars in good flesh should be not less than 700 pounds, and for sows not less than 500 pounds.

When the carcass of a bacon hog is split down the back. the layer of fat along the spine and back should be not less than one inch or more than one and one-half inches in thickness, and it should be as uniform in thickness as possible from one end to the other. The production of the best Wiltshire sides is possible only from hogs that are long from shoulder to ham, light and smooth in the shoulder, neck, and jowl, and very straight and trim along the belly.

When thinking of a bacon hog we usually have in mind such a hog as the market wants, in other words, a hog suitable for slaughtering and cutting up into Wiltshire sides. Also, from what has been said of the importance of certain weight requirements, it is at once apparent that boars and breeding sows are not desired by the packer. If, however, their form, quality, and temperament are such as will cause them to transmit to their pigs the characteristics which are necessary in order that these pigs may be fed out successfully for the bacon market, then the boar and sow are said to possess bacon type. In judging breeding stock, certain allowances must therefore be made and certain points must be emphasized which do not concern us in judging bacon hogs for slaughter. The same general principles and the same general type apply in both cases, but the 
judge must emphasize certain points that are peculiar and essential in each.

The form of the bacon hog is strikingly different from that of the lard hog. There is much less thickness and depth of body, greater length of leg, a lighter shoulder, neck, and jowl, and greater length from snout to tail, especially from shoulder to ham. From the snout to the rear border of the shoulder the hog should be comparatively short, this being the low-priced end of the carcass. There is considerable difference between the retail prices received for the front and hind ends of the Wiltshire side. Length of side from shoulder to ham and length

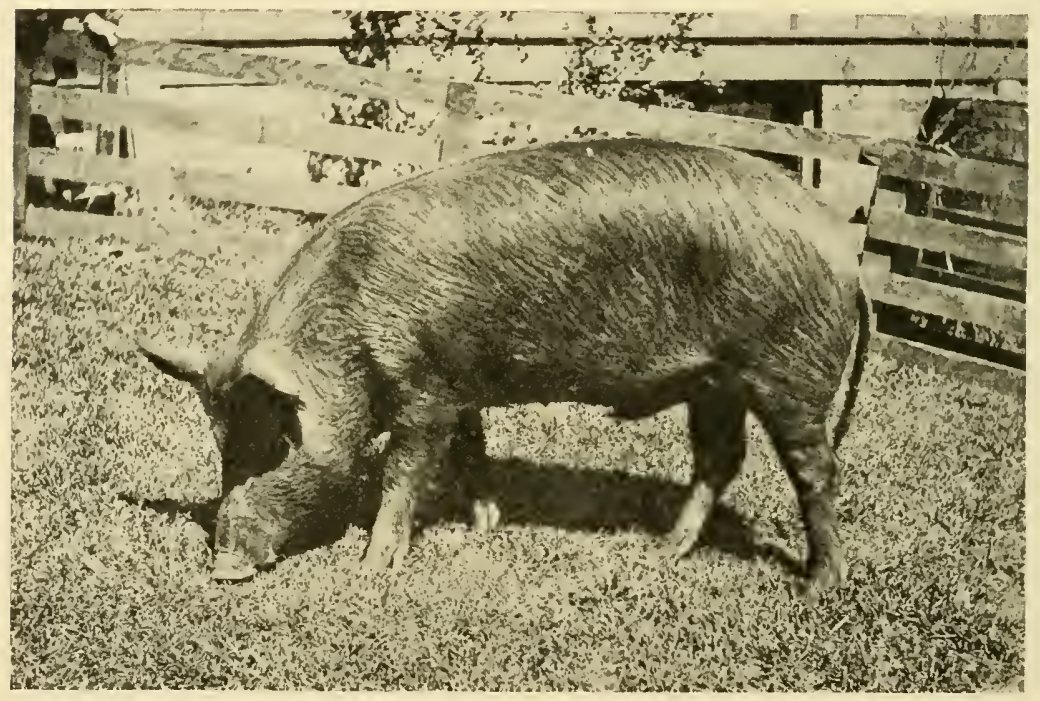

Fig. 91. Fancy Market Bacon Pig.

of ham from front to rear are of very great importance, but it is a mistake to make everything else secondary in importance to length; length should not be carried to the greatest possible extreme. The hog should have enough depth and width of body to give him a strong constitution in a well-developed chest and middle. This applies both to the market hog and the breeding animal. There should be as much depth of body in front as behind, and as much width at one point as another-in other words, the hog should be symmetrical or balanced in his conformation. Great smoothness from one end to the other is a prime essential, and smoothness must be secured without the 
assistance of very much outside fat, such as greatly assists in giving smoothness to the lard hog.

Proper quality in a market bacon hog is very important because a rough or coarse appearance detracts much from the price, and because it is desired that the flesh be fine in texture. In both market hogs and breeding stock, a fine, smooth coat of hair denotes quality. Well-developed wrinkles or seams in the skin indicate coarse-grained flesh, and injure the appearance of the finished product. The snout, face, jowl, and ear should show refinement yet not to an extreme that indicates lack of vigor and feeding qualities. The bone should be flinty and smooth, rather than porous and rough. Coarse bone is very objectionable because it indicates hard feeding qualities and slow maturity. The butcher prefers a fine-boned hog, but the breeder wants the boar to stand on heavy, clean bone covered with skin that shows no coarseness. The brood sow should have finer bone than the boar, but it should be in every way proportionate to her weight, plus the added weight resulting from pregnancy.

Proper condition for a market bacon hog is a feature requiring considerable practice in judging. There is danger of too high a degree of fatness, even though the live weight be within the limits that have been mentioned. People who live in the cornbelt experience some difficulty in accepting a properly finished market bacon hog as such when first taking up a study of this type. To them the hog looks considerably underdone. The indications of the proper degree of fatness are difficult to describe. The hog has a well-fed, thrifty appearance, but not a finished look comparable to that of the properly finished lard hog. The flesh is firm and the hog is reasonably well filled out. Soft flesh at the lower part of the hams, at the lower border of the shoulder, or on the jowl, is undesirable because it indicates an over-fat condition and an uneven distribution of the fat. Smoothness and firmness of fleshing are decidedly essential.

The style of the bacon hog should be marked. He should be very active, thus indicating a full muscular development. He should walk without apparent effort. A writhing movement when walking is taken as an indication of weakness in muscling along the back and loin.

The head varies in shape a great deal, depending to a large extent upon the breed, but there is also much variation between individuals belonging to the same breed. Length of snout varies 
with the breed. A long snout is very often associated with a narrow chest, and a very short snout often goes with a heavy jowl and neck. The face should be broad, and the poll should be broad also and come well forward, these being indications of constitutional vigor and feeding qualities. Large, prominent, bright eyes indicate health and constitution. The jowl has very little market value. A heavy, fat jowl denotes too strong a fattening tendency for a bacon animal. Good width across the jowl is desirable, but it should be very trim and neat. Size and carriage of the ear vary according to the breed. A large ear does not indicate lack of quality provided it is fine or thin. Thick, coarse ears denote a thick, coarse skin, which, in turn, denotes coarse-grained flesh.

The neck, while not a valuable part of the carcass, is important as indicating constitution and feeding qualities. A long, thin neck is an indication of deficient constitution and low feeding qualities; while a short, thick neck, with a crest of fat on top will result in a side of bacon that is too heavy at the fore end, which is the cheap end of the side. Moderate length and width of neck are wanted. It is to be expected that mature boars will have heavier necks than sows or barrows.

The shoulders should be light and set in the body smoothly. They should be deep from top to bottom, but not wide from front to rear, and as one looks down on the top of the hog, they should show no greater fullness than the back and loin. Shoulders that have more width from side to side than the rest of the hog are objectionable, but nevertheless should be given preference over a narrow chest in a breeding animal.

The breast should be wide and carry well down between the fore legs and straight out in front to join the lower border of the neck, thus insuring a large chest capacity.

The front legs should be rather long, but not extremely so, straight, strong, with upright pasterns, and carrying the weight full on the toes.

A back of moderate width, very slightly arched, and rounded over the top from side to side represents correct bacon-type development in this valuable part of the carcass. A sagging back or a decidedly arched back is an evidence of weak muscling and consequently of a lack of lean meat along the top where the highest-priced bacon is found. The top of the hog should show a slight arch from head to tail as viewed from the side, the highest point being over the loin. A wide, flat back denotes a high degree 
of fatness such as is wanted in the fat-hog carcass, but not in the carcass of a bacon hog. A very narrow back is an indication of a lack of flesh or lean meat.

The loin furnishes the most valuable part of the side of bacon and therefore should be strongly developed. It should have the same width and form as the back. From shoulder to hindquarter the top of the hog should exhibit a uniform width, uniform arch, and uniform fleshing.

A side that is flat, straight, and deep, with a great deal of length, and carrying a firm, smooth covering of flesh is demanded. The packer likes as long a side as can be had, but the breeder must avoid extreme length because such hogs incline

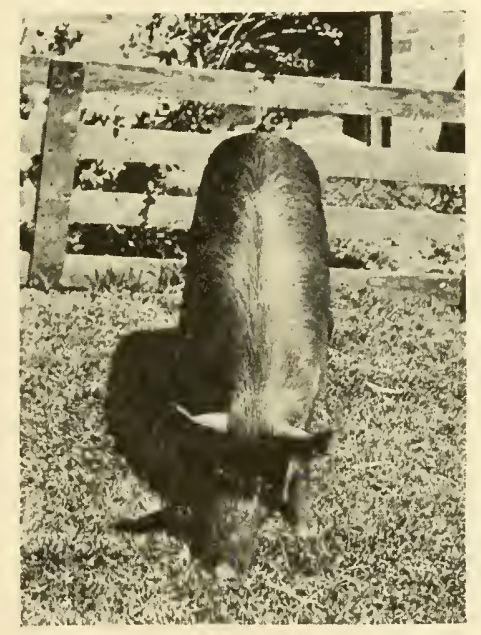

Fig. 92. Correct Bacon Type.

to be narrow and shallow bodied. They lack constitution and feeding qualities to such an extent that they do not make economical gains on feed. The side of the bacon hog constitutes. the most important consideration in judging either breeding or market animals. Score cards for bacon hogs allow more points to the side than to any other part of the animal. When the hog is standing, a straight-edge laid against his side, either vertically or horizontally, should touch every point beneath it. There should be no signs of seams or wrinkles, but a smooth development everywhere. The side should also be firm in fleshing, without any softness just behind the shoulder or elsewhere. 
The flank is important because a high flank injures the appearance of the carcass, necessitates more trimming in order to give evenness to the lower border of the side of bacon, and also is an indication that the belly meat is too thin. When the flank is carried down well, the flesh is usually carried well down on the ham, the belly meat is thick and fleshy, and the development of the side is made more uniform in depth and thickness.

The belly should be straight, trim, firm, thick, and free from flabbiness. This part yields good bacon, but it is not so high priced as that from the loin and back.

The rump should not be broad and flat, which indicates too much fat, but should have the same width as the rest of the top and should be rounding from side to side across the top, the same as the back and loin. It should be long also, and should round slightly toward the tail, but should not be drooping with the tail set low.

A heavy, bulging ham is not an indication of correct bacon type. Such hams must have a great deal of fat trimmed off them in preparing the side of bacon for the market. The ham of the bacon hog should taper toward the hock and should be smooth and firm, especially at the lower part where flabbiness is likely to occur. The flesh should carry well around the bone, inside as well as outside, and should not taper off too suddenly below, but let down well toward the hocks. The ham of the bacon hog is often called the gammon.

The hind legs should be straight and strong, the pasterns upright, and the weight carried full on the toes. 


\section{CHAPTER XXIII.}

\section{THE HOG CARCASS.}

A comparative study of the importance of the various kinds of meat in American, English, French, and German dietaries discloses the fact that civilization is greatly dependent upon the hog and its products. The following table gives the annual per capita consumption of the various kinds of meat in the four countries mentioned, and shows the large contribution of the hog to the meat supply:

\begin{tabular}{|c|c|c|c|c|}
\hline Kind of meat & $\begin{array}{c}\text { United States } \\
\quad(1918)\end{array}$ & $\begin{array}{c}\text { United } \\
\text { Kingdom } \\
\text { (average } \\
1906-1908)\end{array}$ & $\begin{array}{c}\text { Germany* } \\
(1913)\end{array}$ & $\begin{array}{c}\text { France* } \\
(1904)\end{array}$ \\
\hline $\begin{array}{l}\text { Beef ........ } \\
\text { Meal... } \\
\text { Putton and lamb } \\
\text { Pork including lard }\end{array}$ & $\begin{array}{r}\text { Pounds } \\
78.40 \\
7.50 \\
5.30 \\
102.30\end{array}$ & $\begin{array}{r}\text { Pounds } \\
56.00 \\
4.00 \\
26.00 \\
33.00\end{array}$ & $\begin{array}{r}\text { Pounds } \\
31.35 \\
7.25 \\
1.90 \\
71.30\end{array}$ & $\begin{array}{r}\text { Pounds } \\
37.00 \\
8.00 \\
9.00 \\
26.00\end{array}$ \\
\hline Total. & 193.50 & 119.00 & 111.80 & 80.00 \\
\hline
\end{tabular}

*In addition to the above, the consumption of horse flesh amounts to about 1 pound per capita in France, and in Germany 1.9 pounds of goat, horse, and dog meat is consumed per capita.

The British are well known to be partial to beef in their meat dietary, and the Germans to pork, and this is amply substantiated by the table; nevertheless it is seen that the people of the United States consume more beef than the British and more pork than the Germans. The British, however, consume more mutton per capita than any other nationality, and the French come first with veal. The figures show that the consumption of pork, as compared with the consumption of beef, is greater than might be supposed. Americans and Germans consume more pork than beef, but the table shows a different proportion for the English and French. These variations may be due to differences in the way appetites have been cultivated in the various countries, or to differences in the quantities of pork produced and the cost of it.

In the combined slaughter of beef, mutton, and pork in the United States, beef constituted 48 per cent. of the total in 
1909, mutton and lamb constituted only 3.6 per cent., and pork constituted 48.4 per cent. These proportions are practically the same as those recorded for the year 1900. Figures for 1914 show that approximately 54 per cent. of the total dressed weight of meat handled by wholesale slaughtering and meat packing establishments consisted of pork, 38 per cent. of beef, 6 per cent. of mutton and lamb, and 2 per cent. of veal.

The type of hogs found in the several countries varies considerably. In the United States the fat or lard type is produced almost exclusively, this being particularly true of the cornbelt. The stock yards of this country receive practically no bacon hogs; the St. Paul market is something of an exception, although the number received there is comparatively small. We shall,

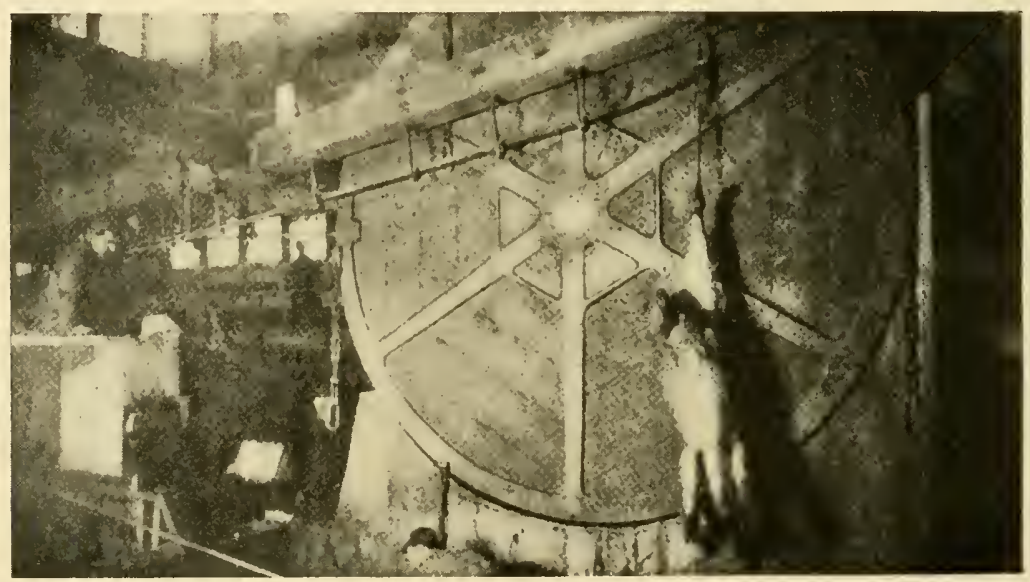

Fig. 93. The Hog Hoist.

therefore, give more attention to the fat carcass than to the bacon carcass.

Slaughtering and dressing.-When the hog enters the packing house, and this applies to both the fat hog and the bacon hog, he passes rapidly through the operations of (1) bleeding, (2) scalding, (3) scraping, (4) singeing, (5) removal of head, (6) disemboweling, (7) splitting, (8) removal of leaf fat and kidneys, (9) facing hams, (10) dry room (four hours), and (11) cooling. This is known as the "packer" style of dressing. The legs, feet, and jowl are left as part of the carcass. An exception is made in the case of pigs and some light hogs intended for the fresh pork trade, these being "shipper" dressed, which means that the 
head is left on, the leaf fat and kidneys in, the hams not faced, and the backbone not split. Some variation also occurs in the manner of splitting the carcass. All dressed hogs are cut open along the underline and through the aitch bone and brisket, but the best heavy carcasses, called loin carcasses, are split through the center of the backbone, while the inferior heavy carcasses, called packing carcasses, are sometimes split on one side of the backbone. Bacon carcasses are usually cut with a knife on each side of the backbone and then split on one side and the backbone taken out, making sides suitable for the English bacon cuts.

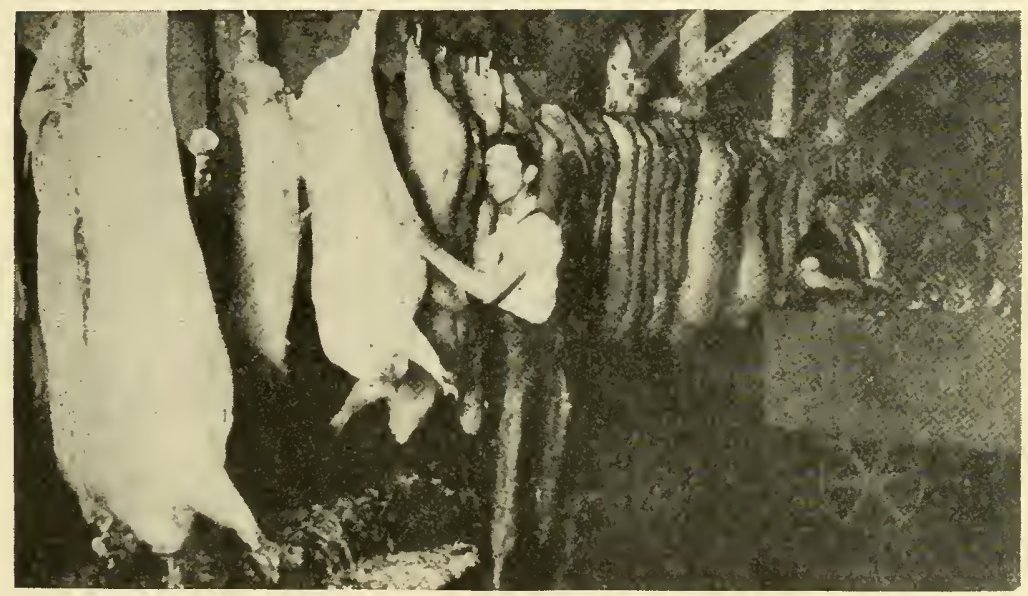

Fig. 94. Dressing Hogs.

The offal and the dressing percentage.-The parts which the hog loses in dressing are the blood, hair, head, viscera, leaf fat, kidneys, and ham facings. The dressing percentage is determined in the same manner as with cattle and sheep. Hogs dressed packer style range in dressing percentage from 68 to 80 per cent., and average about 75 per cent. Hogs dressed shipper style have a dressing percentage about 8 per cent. higher than those dressed packer style, the difference being due to the head, leaf fat, kidneys, and ham facings, which are not removed in the shipper style of dressing. Hogs dressed shipper style easily dress 83 to 85 per cent. Some hogs in the carcass contests at the International Live Stock Show have dressed as high as 89, 89.3 , and 89.6 ; but these were hogs of show-yard quality weighing 417,429 , and 520 pounds respectively, they had been with- 
out feed or water for more than twenty-four hours prior to killing, and were dressed shipper style. The chief factors determining the dressing percentage of a hog are fatness and paunchiness, of which the former is by far the more important.

The average live weight of hogs slaughtered in the United States in 1899 was 218 pounds, the average dressed weight was 170 pounds, and the average dressing percentage was 78 . In 1904, the live weight was 213 pounds, the dressed weight was 163 pounds, and the dressing percentage was 76.5. In 1909, the corresponding figures were 202 pounds, 154 pounds, and

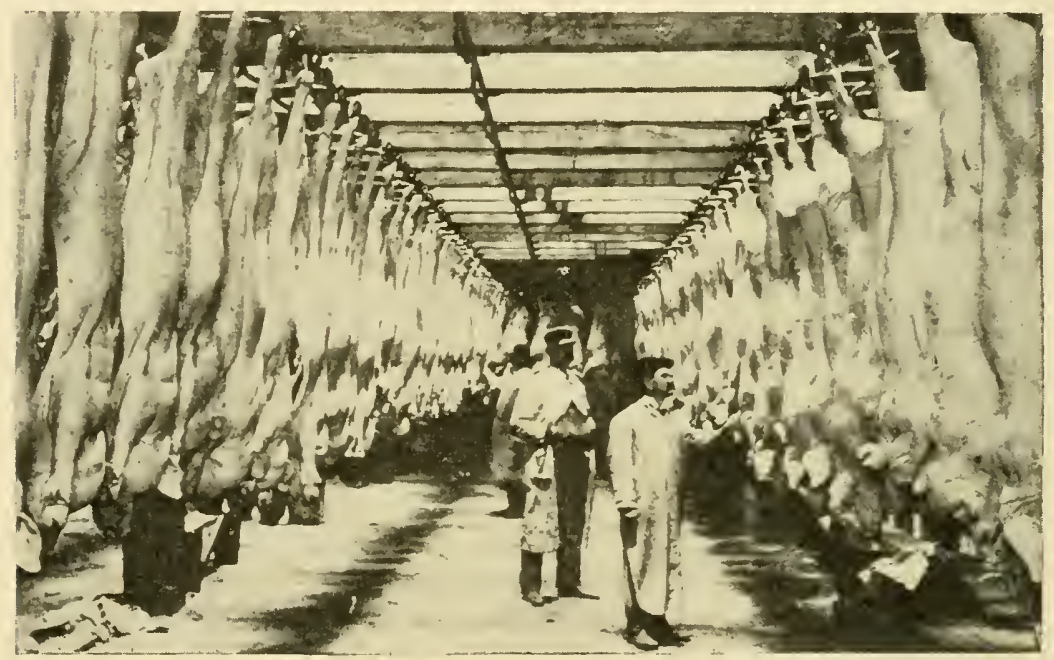

Fig. 95. A View of the Pork Coolers

76.2 per cent.; and in 1914 they were 211 pounds, 159 pounds, and 75.3 per cent.

The wholesale trade in pork.--Only about one or two per cent. of the hogs slaughtered by the large packing houses are sold-as whole carcasses. About three-fourths of the wholesale trade in pork consists of various cured meats and fresh cuts, the remainder consisting principally of lard and a small percentage of sausage and canned meats. Only about twenty per cent. of the domestic trade and five per cent. of the export trade in pork products, other than lard, consists of fresh meat.

The United States Census of 1910 reported the total value of the products of slaughtering and meat packing in the United States to be $\$ 1,631,189,179$. The following list of these products 
is of interest as indicating the importance of pork and the relative value of cured pork and cured beef:

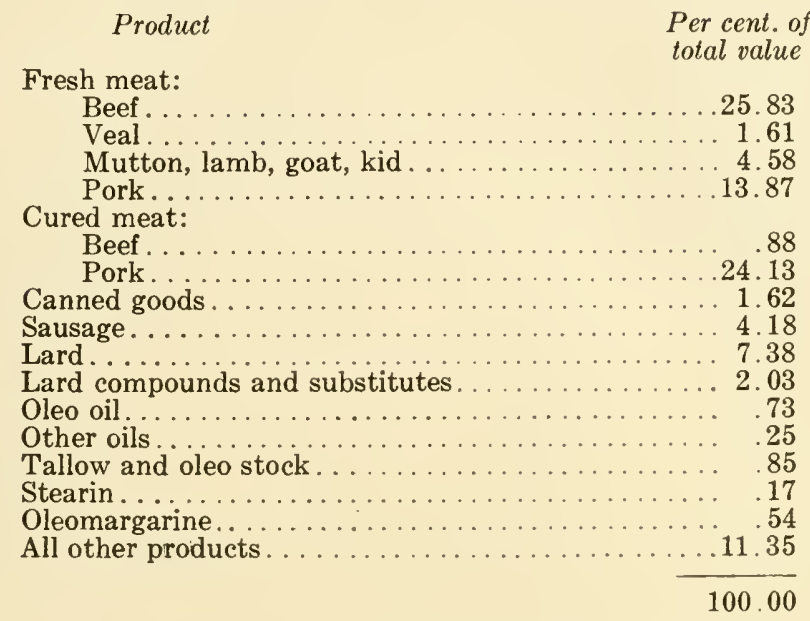

\section{The Fat or Lard-Hog Carcass.}

Wholesale cuts.--After the carcass has been thoroughly chilled it is cut up into shoulders, hams, fat backs, loins, spare ribs, and belly. These wholesale cuts are shown in the drawings which accompany this chapter.

The part labeled "fat back" is a clear layer of external fat containing no lean meat. Studies of the carcasses of cattle and sheep disclose the fact that it is easily possible to feed a steer or a wether too long, and thus make the animal too fat to suit the consumer. One-half to three-fourths of an inch of external fat is all that is wanted on the carcasses of cattle, and for mutton and lamb the desired thickness is proportionate to the requirements for cattle. With fat hogs we find an entirely different state of affairs, for the packer wants a very thick layer of external fat over the top of the hog. This heavy layer of fat constitutes a separate cut known as the fat back, which may be rendered into lard, or dry salted and sold as a dry-salt cut. When manufactured into lard they render 85 to 88 per cent. About one-half of them are sold as a dry-salt cut for which a demand exists in the South and in Europe. Lard is far more valuable than tallow, hence the difference in the packer's attitude toward very heavy fatness in the lard hog as compared with a similar degree of fatness in cattle or sheep. 
The belly contains streaks of lean and is suitable for a "breakfast bacon belly" if the cut is from a light-weight hog. If the hog is heavy, the belly cut is dry salted or pickled and sold as a "dry-salt belly" or as a "sweet-pickle belly," as the case may be.

The following table gives the weights of the various wholesale cuts of pork, the per cent. of live weight included in each cut, the wholesale prices per pound, and the total wholesale price of each cut. This table was compiled from unpublished
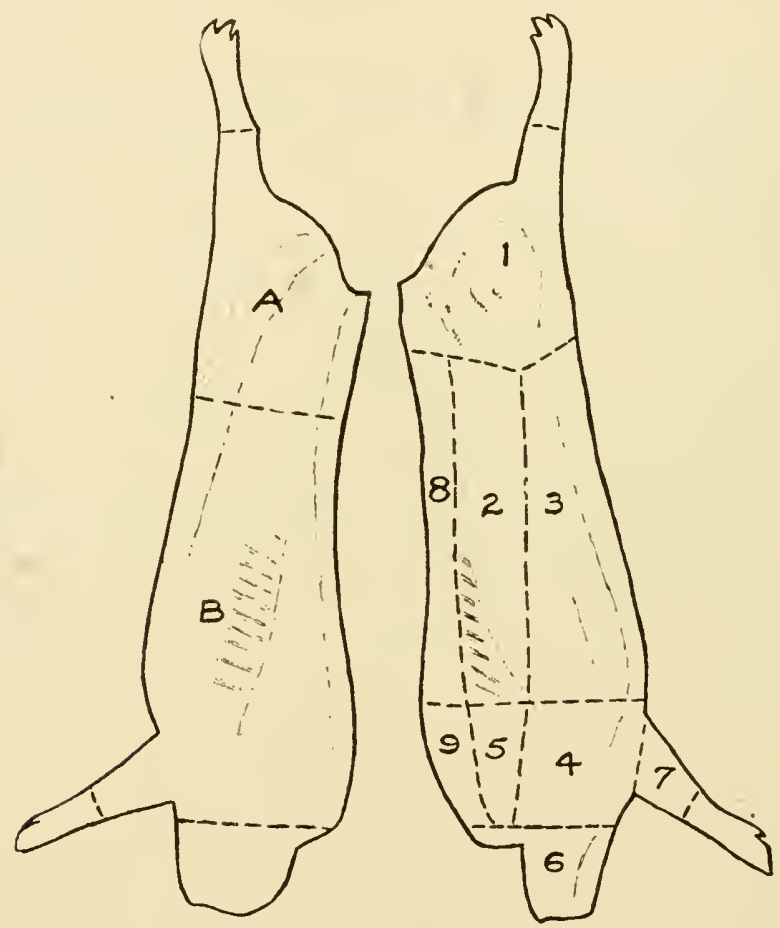

Fig. 96. Wholesale Cuts of Pork.

English Cuts.-A, Long-cut ham; B, long side or middle.

American Cuts.-1, Ham; 2, loin; 3, belly; 4, picnic butt; 5, Boston butt; 6 , jowl; 7 , hock; 8 , fat back; 9 , clear plate; 2 and 8 , back; 2,3 , and 8 , side; 4 and 7 , picnic shoulder; 5 and 9 , shoulder butt; 8 and 9 , long fat back; $4,5,7$, and 9 , rough shoulder.

data of a slaughtering and cutting test conducted by J. M. Evvard of the Iowa Station, in cooperation with Sulzberger \& Sons' Company of Chicago. The test included 24 Duroc-Jersey hogs which averaged 300 pounds live weight and which dressed 
75.19 per cent. If the heads and leaf fat are included, the dressing yield was 81.95 per cent. The following table represents averages of the 24 hogs.

From carcass of hog having live weight of 300 pounds.

\begin{tabular}{|c|c|c|c|c|}
\hline Wholesale cuts & $\begin{array}{l}\text { Weights } \\
\text { of cuts }\end{array}$ & $\begin{array}{l}\text { Per cent. of } \\
\text { live weight }\end{array}$ & $\begin{array}{l}\text { Wholesale } \\
\text { price per } \\
\text { pound }\end{array}$ & $\begin{array}{c}\text { Total value } \\
\text { of cut }\end{array}$ \\
\hline 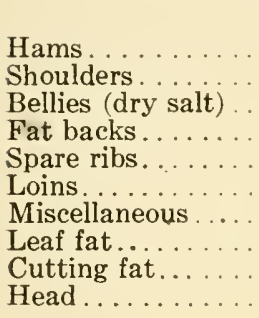 & $\begin{array}{r}\text { Pounds } \\
36.67 \\
45.46 \\
56.70 \\
31.04 \\
1.58 \\
26.92 \\
8.45 \\
8.35 \\
17.77 \\
12.95\end{array}$ & $\begin{array}{r}12.22 \\
15.15 \\
18.90 \\
10.35 \\
.52 \\
8.97 \\
2.82 \\
2.78 \\
5.92 \\
4.32\end{array}$ & $\begin{array}{l}\text { Cents } \\
16.5 \\
12 \\
14 \\
11 \\
10 \\
15 \\
5.5 \\
11.25 \\
10 \\
6.5\end{array}$ & $\begin{array}{r}\$ 6.05 \\
5.46 \\
7.94 \\
3.41 \\
.16 \\
4.03 \\
.46 \\
.94 \\
1.78 \\
.84\end{array}$ \\
\hline Total carcass. & 245.89 & 81.95 & 12.6 & $\$ 31.07$ \\
\hline
\end{tabular}

Note.-The above table includes both sides of the carcass. The shoulder cut is a rough shoulder, including the jowl. "Miscellaneous" includes lean trimmings, tail, neckoones, and rough feet. "Cutting fat" includes small fat trimmings from the hams, fat backs, bellies, and other cuts. It is rendered into lard.

High-priced and low-priced cuts.-There is not much variation in the wholesale price of the various cuts of porkmuch less variation than occurs in the wholesale price of the various cuts of beef, mutton, or lamb. The rib and loin cuts of the beef carcass sell far above the other cuts, and the rib and loin development, together with the development of the round, practically determine the value of the beef carcass. In the fat-hog carcass, values are rather evenly distributed, although the ham may be said to be the most valuable part of the hog. A study of the swine carcass emphasizes the importance of good development in all parts of the hog, and especially is this true of the back, loin, and hams. The top of the hog and the hams hold most of the value of the carcass, but the shoulder and belly are almost equally valuable.

Qualifications of a good carcass.--The value of the fathog carcass depends upon shape, finish, quality, and weight. These various factors will now be discussed.

1. Shape.-The shape desired is one combining great width of side and back in proportion to length of body, straight, even lines, and well-filled hams and shoulders. A neat, trim 
carcass is wanted that is free from prominence on the underline. Hence, barrows are always preferred to sows because sows carry more cheap belly meat, this being expecially true of sows that have had several litters of pigs. Such sows are called "seedy," and they bring a lower price than neat, trim animals that are well tucked up along the belly. The accompanying drawings show the importance of the underline in determining the value of the side cut from a hog. The trimming from a seedy sow goes to the rendering tank and is made into a cheap grade of lard.
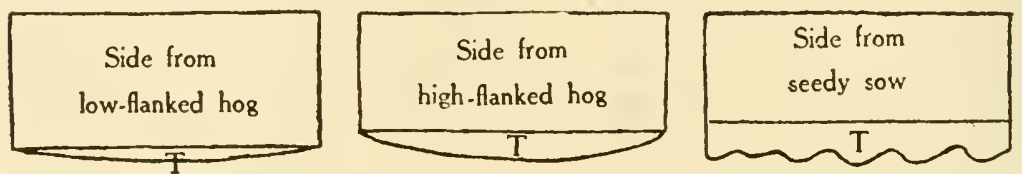

Fig. 97. Effect of Underline on Trimming of Side.

$\mathrm{T}$, trimming.

2. Finish.-This is indicated by the depth and evenness of fat covering the carcass, especially along the back and over the sides; also by the amount and quality of leaf fat. The leaf is the internal fat and includes the kidney fat and extends down to the flanks and "skirt" or diaphragm. It is important that the fat be white and firm. Packers like hogs well fattened because this means a higher yield of lard and a higher dressing percentage. As a rule, the heavier the hog the more fat he carries, because the nearer an animal approaches maturity the more easily he takes on fat. This is shown by the following figures giving the percentage of yields and percentage of parts of carcasses of swine of different live weights. The fat backs were all rendered into lard.

\begin{tabular}{|c|c|c|c|c|c|c|}
\hline $\begin{array}{l}\text { Number of } \\
\text { hogs } \\
\text { slaughtered }\end{array}$ & $\begin{array}{c}\text { Average } \\
\text { live } \\
\text { weight }\end{array}$ & $\begin{array}{l}\text { Side } \\
\text { meat }\end{array}$ & Hams & $\begin{array}{l}\text { Shoulder } \\
\text { cuts }\end{array}$ & Lard & $\begin{array}{l}\text { Total } \\
\text { yield }\end{array}$ \\
\hline \multicolumn{7}{|c|}{ Figures from Boore \& Company, Chicago. } \\
\hline & Pounds & Per cent. & Per cent. & Per cent & Per cent. & Per cent \\
\hline 2107 & 360 & 37.10 & 13.31 & 9.62 & 16.00 & 76.03 \\
\hline & 30 & 36.17 & 13.33 & 9.05 & 15.45 & 74.50 \\
\hline 1215 & 234 & 36.10 & 13.20 & 11.05 & 11.96 & 72.31 \\
\hline 907 & 204 & 34.60 & 13.70 & 10.40 & 11.55 & 70.25 \\
\hline \multicolumn{7}{|c|}{ Figures from Sinclair Packing Company, Cedar Rapids. } \\
\hline 2946 & 293 & 37.94 & 12.74 & 9.10 & 15.09 & 74.87 \\
\hline 4067 & 236 & & 13.52 & 6.58 & & 72.00 \\
\hline 1102 & 232 & 37.76 & 13.38 & 8.42 & 14.21 & 73.77 \\
\hline 1615 & 232 & 38.02 & 13.29 & 8.14 & 13.89 & 73.34 \\
\hline
\end{tabular}


The above figures do not include the small cuttings, tenderloins, tails, pig's feet, cheek meat, etc., which are practically alike for hogs within the weight limits mentioned above. The figures show a marked increase in the percentage of lard yield as the hog matures.

That the hog is by nature disposed to take on more fat than any of the other domestic animals is shown by the following table of analyses made at the Rothamsted (England) Experiment Station. After fasting from eighteen to twenty-four hours the animals were killed and the entire bodies analysed.

\begin{tabular}{|c|c|c|c|c|c|c|c|c|}
\hline Animal & Age & $\begin{array}{c}\text { Live } \\
\text { weight }\end{array}$ & Protein & Fat & $\begin{array}{c}\text { Mineral } \\
\text { matter } \\
(\text { ash })\end{array}$ & $\begin{array}{c}\text { Total } \\
\text { dry } \\
\text { sub- } \\
\text { stance }\end{array}$ & Water & $\begin{array}{l}\text { Contents } \\
\text { of stom- } \\
\text { ach and } \\
\text { intestines } \\
\text { - moist }\end{array}$ \\
\hline & & Lbs. & $\begin{array}{l}\text { Per } \\
\text { cent. }\end{array}$ & $\begin{array}{c}\text { Per } \\
\text { cent. }\end{array}$ & $\begin{array}{c}\text { Per } \\
\text { cent. }\end{array}$ & $\begin{array}{l}\text { Per } \\
\text { cent. }\end{array}$ & $\begin{array}{c}\text { Per } \\
\text { cent. }\end{array}$ & $\begin{array}{l}\text { Per } \\
\text { cent. }\end{array}$ \\
\hline Fat pig. & & 185 & 10.9 & 42.2 & 1.65 & 54.7 & 41.3 & 3.97 \\
\hline Fat sheep & $15 \mathrm{mo}$. & 127 & 12.2 & 35.6 & 2.81 & 50.6 & 43.4 & 6.02 \\
\hline Fat ox... & 4 yrs. & 1416 & $14 . \overline{5}$ & 30.1 & 3.92 & 48.5 & 45.5 & 5.98 \\
\hline Fat lamb. & $6 \mathrm{mo}$. & 84 & 12.3 & 28.5 & 2.94 & 43.7 & 47.8 & 8.54 \\
\hline Fat calf & $8-9 w k s$ & 258 & 15.2 & 14.8 & 3.80 & 33.8 & 63.0 & 3.17 \\
\hline
\end{tabular}

These figures show why the corn crop has formed a closer alliance with hogs than with any other of our domestic animals. The hog requires more fattening food than other animals because he is naturally disposed to take on a very high degree of fatness, and, as has been mentioned, hog fat is far more valuable than the fat of cattle or sheep. Packers desire a covering of outside fat on the carcass of a lard hog that measures from two to six inches in thickness, the requirements varying according to the weight of the carcass.

Armour \& Company's booklet, entitled "Progressive Hog Raising," by E. R. Gentry, contains the following comparison of the merits of a well-fed hog and a poorly fed one:

"Let us take two hogs representing these different grades. One has had good care and has been fed on corn properly supplemented with good forage and high protein feeds. The other has been 'grassed along,' getting a little slop now and then and otherwise allowed to shift for himself. Both are killed and hung in the cooler to chill and harden for forty-eight hours. At the end of this time they come out to be cut up. The cornfed hog is firm, it cuts easily with one stroke of the cleaver or one draw of the knife. There is a good layer of pure white fat 
on the back. The loin cuts out shapely and the flesh is pink and fine grained. The ham has the proper depth of fat and flesh. The belly is the right thickness and properly streaked with lean. It will make high-grade bacon. It is so with all the other cuts. This is a class of hog that makes prime cuts, and so it is a prime hog on the hoof.

"What is the case with the other hog? It comes out of the cooler as soft and flabby as when it went in. It might be left in for weeks and still it would not harden. To break such a carcass up into saleable cuts is next to impossible. It can only be haggled apart. There is a tough rind over the loin and a sheet of gristly fat. After the butcher manages to get the loin out, there is no layer of good white fat on it and the flesh is yellowish and stringy. The belly makes tough, inferior bacon. These cuts cannot be properly cured, as they will shrink away. Even the ham, when smoked, presents a dried-up, unattractive appearance on the market. The result is that the cuts must either be sold at a low price or go to the sausage room or the lard tank. It is not difficult to understand why this hog grades common to inferior."

3. Quality.-A carcass is said to have quality when the outlines are even and smooth, the head and shanks fine, the flesh firm, bright, and smooth grained, the fat white and evenly distributed over the carcass, and the skin smooth, thin, mellow, and free from wrinkles, blotches, or bruises. Coarse or extremely large shoulders, neck, and jowls show lack of quality and are indications of stagginess, and the carcasses of seedy sows grade low because of their coarse quality. Barrows and smooth; clear sows yield carcasses of the best quality.

4. Weight.-While it is true that packers find uses for carcasses of all weights ranging from 20 to 400 pounds, the most valuable carcasses are those weighing 160 to 200 pounds, provided the carcass is at the same time one of good shape, finish, and quality. Such carcasses come from hogs with a live weight of 200 to 260 pounds. Carcasses weighing 160 to 200 pounds yield loins of the proper size and best quality. The general statement may also be made that all carcasses should weigh heavy for their size, thus insuring a high degree of finish or fatness.

\section{Bacon Carcasses.}

The packing house classes the heavier and fatter carcasses as lard hog carcasses, while the lighter, thinner ones are cut up 
into the bacon or English cuts, so called because they are suitable for the English trade. The principal English cuts are Wiltshire sides, Cumberland sides, and long-cut hams. These cuts are also sold under several other names depending on some technical variations in the manner of preparing the side for the retail trade. The Wiltshire side comprises the entire side (half the hog), minus the head, feet, shoulder blade, and hip bone. The

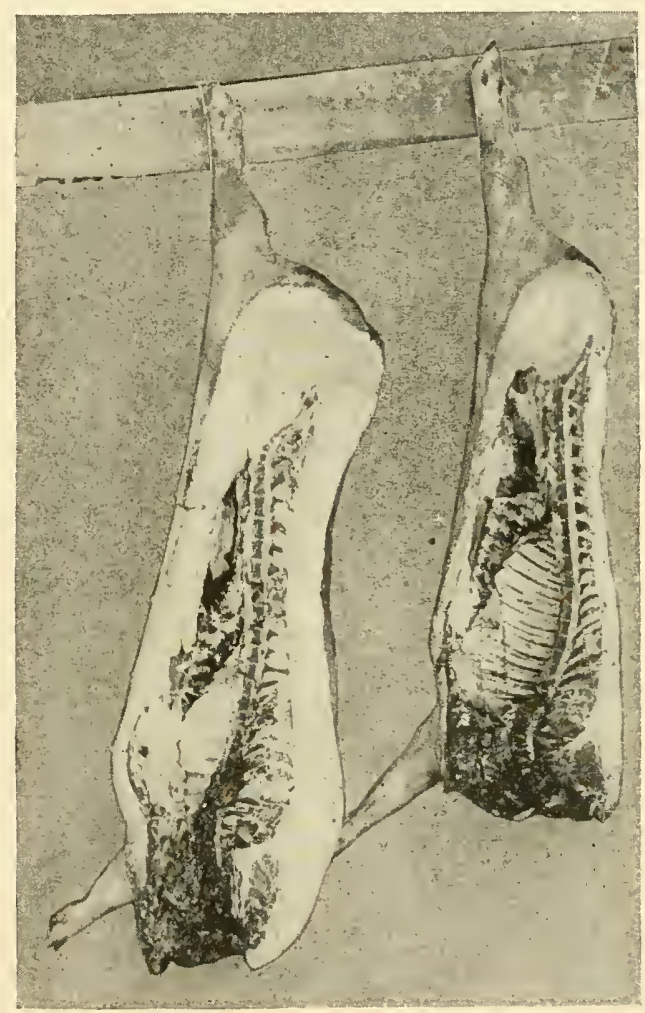

Fig. 98. Fat and Bacon Carcasses Compared.

Note the difference in size, and especially the difference in fatness, between the fat carcass on the left and the bacon carcass on the right.

belly is trimmed smooth and even. These sides average 40 to 70 pounds and are selected especially for thickness of lean meat and a light, even covering of fat from 1 to 2 inches thick, not exceeding $11 / 2$ inches in the best grades. They are made exclusively from choice, lean bacon hogs. The best of these hogs weigh 175 to 190 pounds. The drawings which accompany 
this chapter show a bacon side and indicate its division into the long-cut ham and the long-cut middle or Cumberland.

\section{Classification of Carcasses.}

The classification and grading of hog carcasses is based on the uses to which they are adapted, or in other words, it is based on the products into which they can be converted. Therefore the shape, finish, quality, and weight determine where the carcass will classify and grade. The generally recognized classes and grades* and their respective weights are as follows:

Smooth Heavy, or Heavy Loin Carcasses

Butcher, or Light Loin Carcasse

$240-320 \mathrm{lb}$

Packing Hog Carcasses

$\left\{\begin{array}{l}\text { Heavy .. } \\ \text { Medium } \\ \text { Light... } \\ \text { Choice. } \\ \text { Good ... } \\ \text { Common }\end{array}\right.$

Shippers $160-240 \mathrm{lb}$

$240-400 \mathrm{lb}$

$200-240 \mathrm{lb}$

$100-200 \mathrm{lb}$

Bacon Carcasses

Good

$120-160 \mathrm{lb}$

$110-170 \mathrm{lb}$

$90-110 \mathrm{lb}$

Pigs

$100-200 \mathrm{lb}$

$20-100 \mathrm{lb}$

Smooth heavy, or heavy loin carcasses.-These are from prime, smooth hogs, either barrows or good clear (not seedy) sows. These carcasses weigh 240 to 320 pounds and have four to six inches of fat on the back. The flesh and fat must be deep, firm, and even, the flesh bright colored, the fat white, and the bones not coarse. As the name indicates, such carcasses are especially suitable for making heavy loins, the remainder of the side being made into a heavy fat back and drysalt belly. These carcasses yield a very heavy ham. The per cent. of such carcasses is a very small part of the general supply.

Butcher, or light loin carcasses.-A large proportion of the fresh pork sold in retail markets is pork loins, which are cut into chops and roasts, and light loin carcasses are so named because these cuts can be obtained from them to best advantage. To yield loins of the proper size and quality, a hog carcass should weigh about 160 to 240 pounds and have the same shape, smoothness, and general quality previously described. Thick, firm flesh, smooth, soft skin, and solid, white fat are especially important. The covering of fat on the back should be two to four inches. Barrows and smooth clear sows furnish carcasses of this class. The weights most preferred are 160 to 200 pounds The carcass is cut up into the regular American or fat-hog cuts.

* Ill. Bul. 147. 
Packing hog carcasses.-About one-half of the carcasses in Chicago packing houses are of this class. They are carcasses of mixed hogs of all weights, which are too coarse in quality, rough in shape, and uneven in finish, to be well adapted for fresh pork products or smoked meats and are therefore principally packed in such form as mess pork and dry-salt meats. The hams are sweet pickled and the shoulders made into picnics and Boston butts. The general statement may be made that packing carcasses are inferior carcasses weighing 100 pounds or more which are left after the best carcasses have been sorted out. They are graded heavy, medium, and light according to weight.

Heavy packing carcasses.-These are the carcasses of rough and seedy sows, coarse barrows, boars, and stags averaging 240 to 400 pounds. Common defects of this grade are thick, rough, and wrinkled skin, dark-colored and coarse-grained flesh, soft, oily fat, large bones, and carcass bruises.

Medium packing carcasses.-The only important distinction between this grade and the preceding one is weight. These carcasses weigh 200 to 240 pounds. They are inferior to butcher carcasses in shape, finish, and quality.

Light packing carcasses.-These weigh 100 to 200 pounds. They are too deficient in shape, quality, and finish to be classified as either bacon, butcher, or shipper carcasses. This grade comes mostly from light sows.

Mess pork, which is made from packing hog carcasses, is a simple method of packing cheap pork and was much used in the early days of the packing industry. It is prepared by cutting the side into strips about six inches wide and packing in salt brine in tight barrels (18x29 inches) at 200 pounds net weight of cured pork per barrel or 355 pounds gross. It is shipped principally to the Southern States, northern lumber camps, and South America. Dry-salt meats, the other common product of packing carcasses, are heavy sides, bellies, shoulders, fat backs, and jowls cured in dry salt, pumped with brine, and shipped in coarse salt. They are usually shipped loose, but sometimes are put up in boxes containing 25 to 500 pounds.

Bacon carcasses.-These are suitable for sugar-cured, breakfast-bacon bellies and English meats. Such carcasses have long, deep, smooth sides with a light, even covering of fat. The hams should be full, but lean, and the shoulders light and 
smooth. The flesh must be firm and not "watery," the fat solid, and the carcass very smooth. These carcasses weigh 90 to 170 pounds. The most desirable weights are 120 to 150 pounds. Only a small percentage of Chicago carcasses are of this class.

Choice bacon carcasses. - The depth of back fat is from $11 / 4$ to 2 inches. It must not vary more than $1 / 4$ to $3 / 8$ of an inch over the back and shoulders. Only carcasses of barrows weighing 120 to 160 pounds grade here as a rule.

Good bacon carcasses.-These lack slightly in the essential points of the preceding grade. The thickness of back fat must be 1 to $2 \frac{1}{2}$ inches. The carcasses range in weight from 110 to 170 pounds and come not only from barrows but also from smooth, clear sows.

Common bacon carcasses.-These are decidedly lacking in the prime essentials of the class. They are usually light, unfinished carcasses from "skippy" or "skinny" hogs.

Shippers.-These are similar to butcher hog carcasses in shape and quality, but are lighter in weight and generally not so highly finished. Compared with bacon carcasses they are shorter and thicker bodied, with a deeper and less even covering of fat, heavier jowls, and are younger for their weights. Their chief use is for the fresh retail trade, and they must be fancy in quality. This is the only class of carcasses that is extensively sold as whole carcasses. They are shipped in carlots to eastern points, the greatest demand being in the winter months. They usually weigh 100 to 160 pounds.

Pigs.-These are carcasses of light, young hogs that are comparatively lean and light colored in flesh, with thin, soft skin, soft, red bones, and weighing from 20 to 100 pounds. They are dressed and sold like shippers. Roasting pigs are dressed suckling pigs which are fat and smooth. They are sold like winter lambs direct to hotels and restaurants. The most desired weight is 15 to 20 pounds, but pigs weighing 30 pounds are used.

\section{The Grades of Lard.}

From one-tenth to one-third of the hog carcass is made into lard in large packing houses, the proportion varying with the relative price of lard and grade of hogs. Lard is sold under six different names representing differences in whiteness, grain, flavor, and keeping qualities. Lard is made from leaf fat, fat 
backs, and fat trimmings from ham, shoulder, belly, jowl, and head. Some hams trim fifteen per cent. The highest grade of lard is Kettle Rendered Leaf Lard, made from leaf fat. It is very white in color and finest in grain and flavor of all grades of lard. Then there is Kettle Rendered Lard made mostly from fat backs, with perhaps a small addition of leaf fat. Fat trimmings are also used at times. It ranks second only to the preceding grade. Neutral Lard is made from leaf or back fat at a lower temperature than is required in the manufacture of kettle rendered leaf lard. No. 1 Neutral Lard is made from leaf fat only. It is tasteless, free of acids and impurities, smooth grained, and remains unchanged in odor and color. No. 2 Neutral Lard is made from back fat. It is not as white in color nor as fine in grain as No. 1 and sells at a lower price. Ninety per cent. or more of the lard made at Chicago is known as Prime Steam Lard. It is made from fat trimmings and internal fats. It is darker colored and coarser grained than other grades and is the form in which hog fat can be most economically stored and shipped. It is refined before using. Then there is Refined Lard made from prime steam lard by a bleaching and stirring process. Also there is Compound Lard or Lard Compound, which is a mixture of lard, stearin or other animal fat, and vegetable oil, usually cottonseed oil.

\section{Government Inspection for Disease.}

The first inspection made of animals going to an inspected establishment is ante-mortem or on the hoof. This examination is made on the delivery of the live stock to the packers. Any animals showing symptoms of disease or disabled condition are tagged "U. S. Suspect" and set apart for a more detailed examination. Animals condemned on the hoof are sent to separate establishments provided for such purpose, killed and denatured, after which the product may be used for inedible greases and fertilizer.

Carcasses of hogs which have passed the ante-mortem examination are next inspected immediately after killing, scraping, and partial removal of the head. If any evidence of disease appears the carcass is tagged "U. S. Retained" and sent to the "retained room" for further inspection of glands throughout the carcass. If no suspicious symptoms whatever are discovered, the hog goes back into the meat supply. Another examination 
of all carcasses is made as soon as they are cut open and the viscera exposed. Hams and bacon are inspected during and after curing.

All condemned carcasses and cuts are thrown into a large steam-tight tank under government supervision. Kerosene oil is poured on the meat to prevent any possibility of it ever being offered for sale as fit for human food. The tank is then sealed, steam turned on, and the contents cooked at 280 degrees Fahrenheit for eight hours. The product is then turned back to the packers for soap grease and fertilizer materials.

\section{By-Products of the Hog.}

Packers estimate that practically 70 per cent. of the live hog is merchantable as fresh or cured meat; including lard. Slaughtering and handling involves a shrink of about 10 per cent., which includes the contents of stomach and intestines and loss of weight by evaporation of moisture. The other 20 per cent. is converted into numerous useful by-products. A larger proportion of the hog is edible than of any other food animal, and the value of the by-products is correspondingly less. Among the edible by-products may be mentioned pepsin, derived from hog stomachs; livers, used in the manufacture of liver sausage; and neutral, a specially prepared lard, largely used as an ingredient of oleomargarine. Lard proper is not commonly considered a by-product; it is one of the primary products. Nearly 15 per cent. of the live weight goes into lard. Part of this lard is further processed into lard oil and lard stearin. Lard oil is used for illuminating purposes and as a lubricant. Stearin enters into the manufacture of chewing gum and soft candies.

Brains are packed in cans, frozen, and offered for sale. Tongues are canned or pickled. Hearts go into sausage. Tails, snouts, and ears are rich in gelatin or glue. Kidneys are canned or frozen. Milts or spleens are used as a feed for growing fishes at fish hatcheries. The intestines are cleaned, processed, and made into chitterlings, a food product to be fried like oysters, much favored by colored people. Stomachs are used as sausage containers. Something like 7 per cent. of the weight of the hog is represented in inedible by-products in the raw state which are manufactured into glue, soap, glycerin, blood meal, tankage, curled hair, and fertilizer material. Even the rinds from skinned hams and bacons, as well as the back skin of the hog, are utilized for leather. Nothing is wasted. 


\section{Conclusions.}

The following conclusions may be drawn from the study of the swine carcass and its various products:

1. In order to bring the highest market price, lard hogs must be fat and well tucked up in the underline.

2. The greatest demand is for 200- to 300-pound hogs, and hog growers usually obtain the most profit by fattening and selling their hogs at weights ranging from 200 to 275 pounds.

3. Barrows outsell sows because they carry less cheap meat on the underline.

4. No other animal equals the lard hog in its fat-storing tendency.

5. The production of lard hogs furnishes a logical channel of disposal for corn, because corn is a fattening food and lard brings a much higher price than tallow.

6. Any kind of a hog finds a buyer on the market, but the price paid depends on the kind of carcass the hog will yield.

7. The development of the packing industry has made an outlet for the plainer sorts of hogs which otherwise would be a drug upon the market.

8. No other kind of meat comes so nearly being manufactured by packers as does pork.

9. Indian corn and the American packing industry have combined to develop the American swine industry into a business of mammoth proportions. Corn, properly supplemented, makes pork economically, and pork finds ready sale because packers have discovered many ways of placing pork on the market in attractive and highly palatable form combined with most excellent keeping qualities. 


\section{CHAPTER XXIV.}

\section{HOG MARKETS AND PORK PACKING-PAST AND PRESENT.}

During the first half of the nineteenth century, Cincinnati was the leading pork-packing center of this continent, and this position was maintained until 1863, at which time Chicago took the lead. One by one, other western cities have crowded ahead of Cincinnati until now her rank is fifteenth in the list of American hog-packing cities. That Cincinnati's supremacy was not a permanent one was due to the fact that until the West was settled, live-stock conditions were very unstable, and the logical packing center in 1850 was found to be too far to the east of the center of hog production as it existed twenty years later. With the settling of the cornbelt and the rapid extension of the hog's domain to the westward, Chicago was enabled, by virtue of her location and direct railway connections with the heart of the cornbelt, to gain and hold supremacy as a pork-packing center. The evolution of the gigantic porkpacking business of the United States may be told in brief by first reviewing the growth and development of the business at Cincinnati, and then following it to Chicago at the close of the Civil War.

Early packing at Cincinnati.-In 1833 Cincinnati packed 85,000 hogs. Five years later the number packed in the year had risen to 182,000 head. In 1843 no less than 250,000 hogs were consumed by the numerous packing establishments then doing a thriving business at Cincinnati, and the town was dubbed "Porkopolis," which name was formerly in general use, but is now nearly obsolete. Cincinnati slaughtered 360,000 hogs for packing purposes in 1853, and in 1863 the highest mark was reached, the number that year being 608,457 . The demands of the army were largely accountable for the large number packed during the last mentioned year. Prior to the Civil War, Cincinnati was the center of the finest hog-raising region in the world, including the states of Kentucky, Ohio, and Indiana. It was in this favorable environment and under the stimulus afforded by a large, near-by market that the Poland-China breed originated during the period mentioned. Although Chicago 
took the lead in the number of hogs packed following the war, Cincinnati continued to hold first place for a considerable time so far as the quality of hogs packed was concerned. In 1866 there were fifteen slaughter houses at Cincinnati, some of which employed as many as one hundred hands. One concern slaughtered 60,000 hogs during that year. Measured by the standards of the time, these Cincinnati packing establishments were considered to be gigantic in proportions. In the same year, Cincinnati produced 180,000 barrels of pork, $25,000,000$ pounds of bacon, and 16,500,000 pounds of lard.

Development of packing at Chicago.-The earliest packing or slaughtering done in Chicago was in 1827; in that year Archibald Clybourn erected a slaughter house for the special purpose of supplying the garrison at Fort Dearborn. The trade was mostly local until 1833, when immigration set westward quite strongly, creating a larger demand. During 1835, Mr. Clybourn packed about 3,000 hogs, besides considerable beef, for which a ready market was at hand. This stock had to be picked up at long distances from Chicago and driven on foot to the city. Other men soon engaged in the business which took on larger proportions, the surplus product finding a market in the East. The slaughter houses were mostly located on the south branch of the Chicago river, and into it the offal and filth were drained, which in later years became a nuisance and was prohibited by the city. In 1863 there were 58 different establishments in Chicago doing a general packing business. During the winter of 1853 -' $^{2} 4$, Chicago packed 52,849 hogs, and in 1860-'61 the number packed was 231,335.

During the winter-packing season of 1863-'64, the rank of the largest packing centers and the number of hogs packed by each was as follows: (1) Chicago, 904,159; (2) Cincinnati, 400,000; (3) St. Louis, 200,000; (4) Louisville, 103,996.

Growth of American pork packing.-The pork-packing year ends March 1st and is divided into two seasons--the summer season of eight months, from March 1 to November 1 , and the winter season of four months, from November 1 to March 1. This system came into use before the days of artificial refrigeration, and, although such a designation is no longer necessary it is still adhered to by statisticans. Before 1873, summer packing was not practiced, but it began in September of that year when it is said to have reached the number of 505,500. The total number of hogs packed in the West during the winter 
season, and the cost of hogs per 100 pounds live weight, according to the Price Current-Grain Reporter's special reports* since 1849 and estimates previously, were as follows:

\begin{tabular}{|c|c|c|c|c|c|}
\hline Season & Number & Cost & Season & Number & Cost \\
\hline $\begin{array}{l}1842-' 43 \\
1844-' 45 \\
1849-' 50 \\
1854-' 55 \\
1859-' 60 \\
1864-' 65 \\
1869-70 \\
1874-75\end{array}$ & $\begin{array}{r}675,000 \\
790,000 \\
1,652,220 \\
2,124,404 \\
2,350,822 \\
2,422,779 \\
2,635,312 \\
5,566,226\end{array}$ & $\begin{array}{r}\$ 2.65 \\
2.13 \\
3.37 \\
4.73 \\
11.46 \\
9.22 \\
6.66\end{array}$ & $\begin{array}{l}1879-' 80 \\
1884-' 85 \\
1889-' 90 \\
1894-' 95 \\
1899-' 00 \\
1904-' 05 \\
1909-' 10 \\
1914-' 15 \\
1918-' 19\end{array}$ & $\begin{array}{r}6,950,451 \\
6,460,240 \\
6,663,802 \\
7,191,520 \\
8,675,898 \\
10,456,503 \\
8,725,224 \\
12,559,412 \\
16,877,391\end{array}$ & $\begin{array}{r}\$ 4.18 \\
4.29 \\
3.66 \\
4.28 \\
4.29 \\
4.67 \\
8.30 \\
6.74 \\
17.27\end{array}$ \\
\hline
\end{tabular}

The number of hogs packed in the West during the calendar years, from 1845 to 1918 , were as follows:

\begin{tabular}{|c|c|c|c|}
\hline Year & Number & Year & Number \\
\hline $\begin{array}{l}1845 \\
1850 \\
1855 \\
1860 \\
1865\end{array}$ & $\begin{array}{r}781,000 \\
1,652,000 \\
2,124,000 \\
2,350,000 \\
2,451,000 \\
2,635,000 \\
6,485,000 \\
12,210,000\end{array}$ & $\begin{array}{l}1885 . \\
1890 . \\
1895 . \\
1900 . \\
1905 . \\
1910 . \\
1915 . \\
1918 .\end{array}$ & $\begin{array}{l}11,350,000 \\
16,980,000 \\
15,285,000 \\
23,265,000 \\
25,485,000 \\
25,729,000 \\
30,737,000 \\
35,116,000\end{array}$ \\
\hline
\end{tabular}

Present leading hog-packing centers.-During the fiscal year 1918, swine were slaughtered under Federal meat inspection at 292 establishments in the United States located in 127 cities and towns. From the government reports of animals slaughtered under federal inspection, the following table is constructed, showing the rank of the twenty largest hog-packing cities during the fiscal year 1918:

$\begin{array}{ll}\text { City } & \text { Number of } \\ \text { hogs packed }\end{array}$

1. Chicago . . . . . . . . . 6,692,697

2. Kansas City . . . . . 2 2,775,329

3. Omaha............ 2,132,068

4. St. Joseph ........... 1,772,773

5. National Stock Yards, Ill . . ........... 1,490,954

6. Sioux City . . . . . . . . 1, 1,323,741

7. Indianapolis . . . . . 1,235,443

8. Boston ............. 1,227,496

9. St. Paul .......... 1,190,948

10. Milwaukee............ 1,121,361
City humber of

11. St. Louis . . . . . . . . 1,091,769

12. Cleveland .......... 957,093

13. Detroit.............. 733,424

14. Buffalo ............ 687,642

15. Cincinnati ......... 676,849

16. New York . . . . . . 624,811

17. Fort Worth ....... 601,976

18. Jersey City . . . . . . . 515,134

19. Philadelphia ......... 508,039

20. Newark .......... 483,068

${ }^{*}$ Price Current-Grain Reporter Year Book, 1919. 
Chicago packing at present time.-The number of hogs packed at Chicago* by the leading hog-packing firms in 1916, 1917, and 1918, and the total number packed at Chicago in each of these years was as follows:

1918

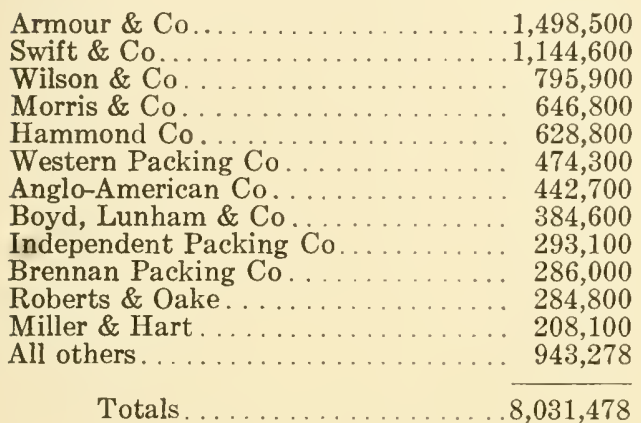

1917

$1,253,000$

788,400

578,000

492,700

420,000

398,200

342,000

272,500

289,400

196,000

195,300

171,000

827,833

$6,224,333$
1916

$1,645,700$

932,000

652,300

596,000

497,100

690,100

465,800

369,700

509,200

320,200

272,600

188,400

984,439

$8,423,539$

By-products from early hog packing.-The Report of the Commissioner of Agriculture for 1866 contains an account of early hog-packing operations which is of interest for comparison with modern methods whereby all by-products of the hog are utilized. The following, written by Mr. Charles Cist, of Cincinnati, appeared in the report for that year:

"I have referred to the remarkable fact, that there was a period in the West when corn would not, in some sections, command six cents per bushel, and in others was of so little value as to be substituted for wood as fuel. Not less extraordinary is the fact, within the knowledge of hundreds now in Cincinnati, that in the early ages of pork packing, say in 1828 , there was so little demand for any portion of the hog, other than hams, shoulders, sides, and lard, that the heads, spareribs, neck pieces, backbone, etc., were regularly thrown into the Ohio river to get rid of them!" The same writer also says: "The slaughterers formerly received the gut fat for the whole of the labor of dressing, wagoning the hogs more than a mile to the pork houses free of expense to the owners. Every year, however, adds to the value of fat, heart, liver, etc., for food and the hoofs, hair, and other parts for manufacturing purposes. Six years since, from 10 to 25 cents per hog was paid as a bonus for the privilege of killing. This was later raised to 75 cents and even to $\$ 1.00$." 
In 1863, hog-packing products consisted of bristles, lard, mess pork, hams, shoulders, bacon, and lard oil used for making candles. The beginning of the immense packing-house by-products industry of modern times was described by an early writer as follows: "Since the Chicago river has ceased to be the sewer for all the offal from the slaughter and packing houses, the owners have been obliged to cart it off to the commons and open fields beyond the city limits at a very heavy expense to them. An enterprising firm has, however, contracted with all the principal firms the present season to carry it all away by the owners paying half the expenses. Instead, however, of carrying it off and throwing it away, they have commenced preparing it for fertilizers. They have provided centrifugal machines, into which they place the refuse from the lard and grease tanks, and throw out all the water, leaving only the solid parts, and that in a pulpy or pulverized condition. In this way they will prepare about three thousand tons the present season, all of which will be shipped east for the manufacture of commercial manures. Another concern is gathering all the bones it can pick up, from which are manufactured large quantities of animal charcoal, and such as are not suitable for that purpose are ground up and sent east, they having shipped the past season over three hundred tons of ground bones alone."

Exports of pork products.-A good idea of the importance of American hog packing to European nations under normal conditions may be obtained from the following table, giving exports of pork products for the fiscal year ending June 30, 1913:

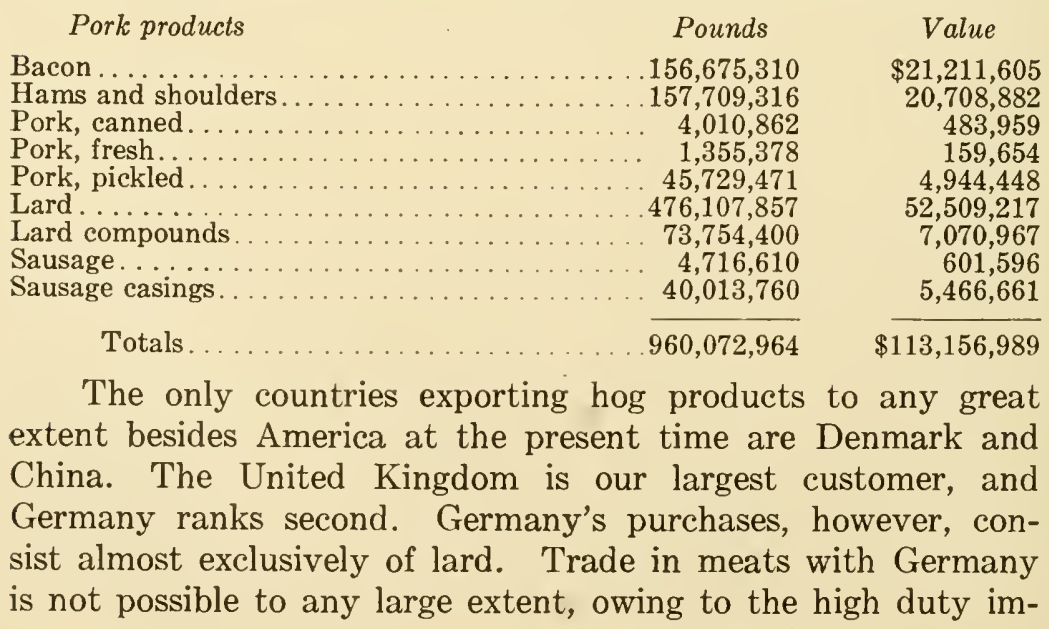


posed. France is a steady importer of lard, and also buys some fat backs, trade in the latter being interfered with by a high duty. We also sell a good many dried sausages to France where this product meets with much appreciation. Italy, Switzerland, Spain, Norway, Sweden, Denmark, Holland, the West Indies, Central America, all countries in South America, Asia, and Australia are buyers of hog products in some form. Some countries buy only the casings for sausage making, but all pay tribute to the American hog in one form or another.

Modern large hog markets.--The census of 1909 estimated that $53,219,568$ hogs were slaughtered in the United States in that year. Census reports indicate that about two-thirds of the hogs marketed in the United States pass through the large central markets, about one-twelfth are sold for local slaughter, and one-third are slaughtered on farms and ranges.

The receipts of hogs* at the principal markets of the country during 1918 were as follows:

\begin{tabular}{|c|c|c|}
\hline $\begin{array}{l}\text { 1. Chicago...... } \\
\text { 2. Omaha..... } \\
\text { 3. Kansas City } \\
\text { 4. St. Louis } \\
\text { 5. Indianapolis } \\
\text { 6. Sioux City . } \\
\text { 7. St. Joseph... } \\
\text { 8. St. Paul..... }\end{array}$ & $\begin{array}{l}8,614,190 \\
.429,533 \\
3,327,722 \\
3,256,400 \\
2,749,976 \\
2,421,166 \\
2,351,013 \\
2,061,390\end{array}$ & $\begin{array}{l}\text { 9. Pittsburg. } \\
\text { 10. Cincinnati } \\
\text { 11. Buffalo... } \\
\text { 12. Cleveland.. } \\
\text { 13. Fort Worth } \\
\text { 14. Louisville.. } \\
\text { 15. Wichita.... } \\
\text { 16. Nashville.. }\end{array}$ \\
\hline
\end{tabular}

As shown by the above figures, Chicago receives more than twice as many hogs as any other market in the country. Of the $8,614,190$ hogs received at the Chicago yards during 1918, $7,643,326$ were slaughtered by Chicago packers, 946,414 were shipped out alive to other points for slaughter, and 24,450 were shipped out for feeding. In addition to the hogs included in the above figures, small packing firms at Chicago, located outside the yards, received and slaughtered 388,152 hogs in 1918.

The growth of the Chicago market is shown by the following list of receipts and shipments of hogs at that point during the years mentioned:

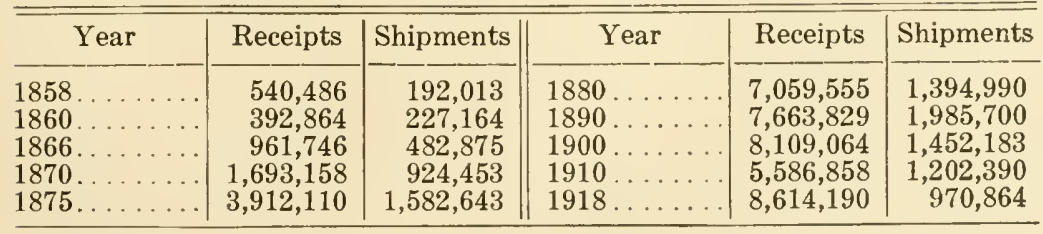

* Year Book of Figures, 1919. 
It is interesting to note that the advent of the refrigerator car, about 1875 , had a marked effect on the proportionate number of hogs shipped. The largest number of hogs received at Chicago in a year was in 1916, when 9,188,224 head were received at the yards proper. If receipts by outside packing firms are included, the figure is raised to 9,528,267. The highest record for a month is credited to January, 1916, when 1,227,508 hogs were received at the yards and enough by outside packers to make the total $1,286,616$. The record week was that ending January 8, 1916, when 334,279 were received at the yards, and

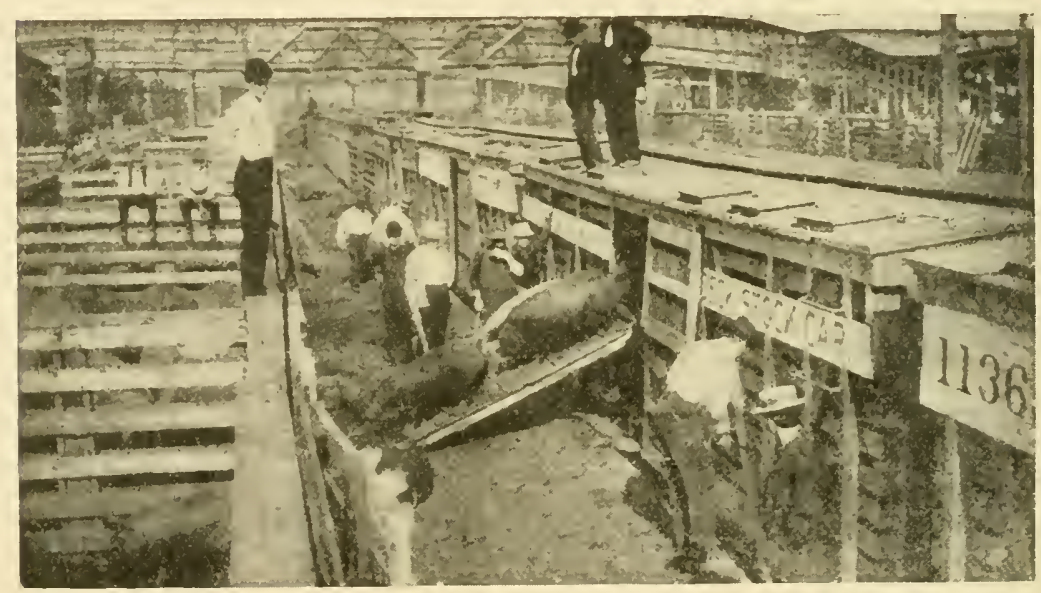

Fig. 99. Unloading Hogs at Chicago.

356,362 in all. On November 29, 1918, the largest day's receipts were recorded, the figures being 96,964 and 101,601 respectively.

The number of hogs marketed annually varies greatly. This fluctuation is caused partly by the ravages of disease, and partly by the fact that if an unexpected or temporary demand springs up, and higher prices rule, great numbers of hogs of inferior size and weight are rushed to market.

Some peculiarities of the hog crop.-The following table gives the monthly average weights of hogs at Chicago during the years from 1907 to 1918 inclusive. The highest monthly average of each year is given in black type, while the lowest monthly average is enclosed in parenthesis: 
Year $1907 \quad 1908 \quad 1909 \quad 1910 \quad 1911 \quad 1912 \quad 1913 \quad 1914 \quad 1915 \quad 1916 \quad 1917 \quad 1918$

\begin{tabular}{|c|c|c|c|c|c|c|c|c|c|c|c|c|}
\hline January. & 223 & 215 & (203) & $(210)$ & 226 & (212) & 226 & (216) & 223 & 195 & (199) & (216) \\
\hline February & 222 & 212 & 204 & 213 & 230 & 217 & 230 & 224 & 224 & 204 & 204 & 231 \\
\hline March... & 228 & 212 & 206 & 218 & 239 & 218 & 240 & 233 & 231 & 14 & 209 & \\
\hline April & 234 & 219 & 212 & 227 & 241 & 227 & 242 & 233 & 233 & 219 & 213 & 242 \\
\hline May & 235 & 218 & 216 & 239 & 242 & 232 & 242 & 236 & 233 & 220 & 217 & 238 \\
\hline Jun & 236 & 217 & 219 & 242 & 236 & 235 & 244 & 237 & 231 & 226 & 225 & \\
\hline July & 240 & 222 & 225 & 246 & 233 & 239 & 243 & 244 & 238 & 231 & 232 & 243 \\
\hline Aug & 250 & 224 & 232 & 255 & 239 & 240 & 233 & 248 & 246 & 232 & 233 & 243 \\
\hline embe & 253 & 219 & 232 & 259 & 224 & 235 & 222 & 242 & 235 & 223 & 231 & 247 \\
\hline Octo & .235 & (207) & 227 & 253 & 212 & 226 & 209 & 229 & 204 & 210 & 212 & 233 \\
\hline Nov & r(209) & 213 & 225 & 232 & (208) & 222 & (207) & 218 & (187) & 195 & 209 & 226 \\
\hline Decemb & 214 & 211 & 214 & 224 & 213 & 223 & 213 & 226 & 190 & (193) & 211 & 223 \\
\hline Average & 231 & 216 & 218 & 235 & 228 & 226 & 228 & 231 & 219 & 210 & 213 & 234 \\
\hline
\end{tabular}

The above table shows that, as a rule, the hogs marketed in August and September are the heaviest of the year, while.the smallest average weights usually occur in the months of November, December, and January. This is due to the fact that the crop of spring pigs arrives on the market mainly in November, December, and January, being held until the hog's share of the corn crop has been utilized in fattening him for the market. The heaviest weights are attained in August and September because of the absence from the market at that time of any considerable number of young hogs. Relatively few hogs are marketed during August and September, but the receipts include a larger proportion of aged hogs than in other months; the result of culling down brood sows after pigs are weaned and before winter begins. Hogs are marketed in much larger numbers in winter than in summer, the heaviest marketing usually occurring in December and January. That the largest receipts occur in December and January and the smallest in August and September is explained by the close dependence of hogs on corn. Hog growers wait until the corn crop can be put on the backs of their hogs before marketing them. This explains the monthly fluctuation in receipts. 


\section{CHAPTER XXV.}

\section{MARKET CLASSIFICATION OF SWINE.}

At Chicago the charge for the yardage of hogs is 10 cents per head. Commission charges for selling hogs are as follows: Hogs in car lots, 20 cents per head; single-deck cars, minimum $\$ 10$, maximum $\$ 12$; double-deck cars, minimum $\$ 15$, maximum $\$ 20$; less than 25 hogs in one car, 40 cents per head. Public inspection of hogs costs 20 cents per car, no fee being charged on ears containing less than twenty head. Corn is $\$ 2$ per bushel.

Following is the classification of swine as used on the principal markets and by newspapers reporting these markets:

\section{Classes}

Prime Heavy Hogs.. . . . . 300-400 lbs ..... None

Butcher Hogs ..........150-300 lbs ...

Packing Hogs ........200-500 lbs...

Light Hogs. . . . . . . 125-220 lbs ...

Pigs

50-125 lbs.

Roughs

Stags

Boars

Feeding Pigs . . . . . . . . . .50-150 lbs.

Roasting Pigs ..........15- 30 lbs.

Governments

Cripples

Dead Hogs
Sub-classes

Heavy Butchers..... 260-300 lbs. Medium Butchers...200-260 lbs. Light Butchers ...... 150-200 lbs. Heavy Packing .....275-500 lbs. Medium Packing....225-275 lbs. Mixed Packing . . . . 200-300 lbs. English Bacon......160-220 lbs. U. S. Bacon ........ 160-200 lbs. Light Mixed .......... 150-200 lbs. Light Light. . . . . . 125-150 lbs

\section{Prime Heavy Hogs.}

This class calls for a prime, heavy, fat-back hog, weighing from 300 to 400 pounds - the extreme of the fat or lard hog type. With the tendency of producers and consumers to favor the lighter hogs, there are not so many prime heavy hogs as formerly. Only the best hogs of these weights classify here. They are usually barrows. They yield a heavy loin carcass.

\section{Butcher Hogs.}

This class is the most numerous and the most popular on the market. Butcher hogs must be very good in quality, correct 
in form, and show evidence of ripeness in condition. They are principally barrows. Barrows sell more readily and at better prices than sows. In a drove of butcher hogs there may be present a few good sows without detracting from the value of the drove. Good young sows are usually kept on the farm for breeding purposes, and poor young sows and old sows will not take on the finish required in the butcher hog class. Butcher hogs yield light loin carcasses and shipper carcasses and are commonly used in the fresh meat trade. This class yields the pork chop, ham, and bacon. They range in age from six to ten months. Except in age and weight, the three sub-classes of butcher hogs are practically the same. The butcher hog

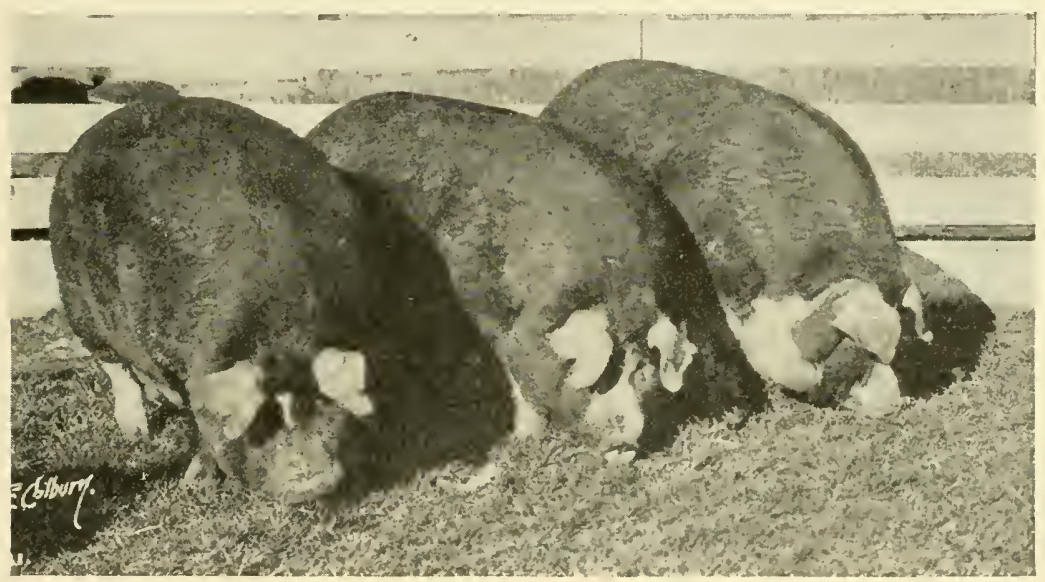

Fig. 100. Prime Heavy Hogs.

carried to sufficient weight becomes a prime heavy hog, but hog growers do not, as a rule, find this practice a profitable one.

\section{Packing Hogs.}

This class ranks next to the butcher class in numbers. These hogs are a poorer sort than butcher hogs, and it is here that we find old brood sows and all other hogs that are heavy enough for this class and not good enough to classify as butcher hogs or as prime heavy hogs. However, it does not include the poorest classes, such as roughs, boars, and coarse stags. This is the class of hogs which, as the name indicates, is of particular importance and interest to the packer. The side meat from these hogs is used principally in the various processes of curing. 
It is made into mess pork, short-cut mess pork, dry-salt sides, and the hams and shoulders are cured. These hogs range in age from nine months upward. A 200-pound packing hog is usually an older hog than a 200-pound butcher hog. Packing hogs differ widely in character. The class includes old sows that bear evidence of once having had pigs, called "seedy" sows, but are fitted in very high condition; good packing hogs, either heavy or medium according to weight; barrows that are not well enough developed and not good enough in form, quality, and condition to go into the butcher hog class, and there may be a mixture of sows and barrows quite varying in quality and condition. Pregnant sows sell with a dockage of 40 pounds.

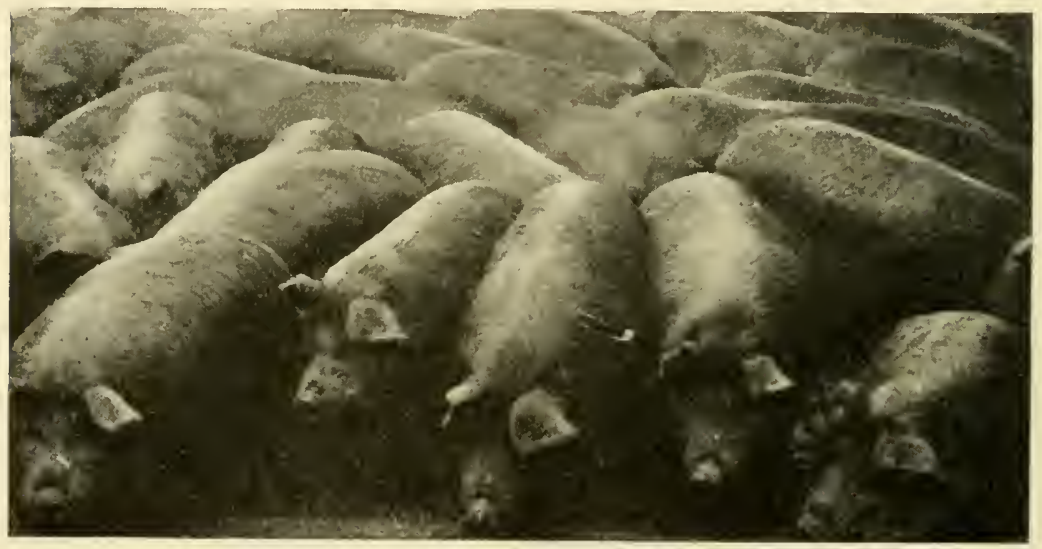

Fig. 101. Prime Butcher Hogs.

Sub-classes of packing hogs.-Heavy packing includes the heavy hogs of the packing hog class, and medium packing includes the lighter hogs. Mixed packing is a sub-class that is somewhat characteristic in itself, for it includes hogs coming from local buyers in the country, and represents hogs of different classes as well as different grades, as the name indicates. There may be heavy packing, medium packing, some light hogs, and even a few butcher hogs in the drove. Many such droves come to the market and are sold to the packer without sorting. In such cases the sorting is done after slaughtering when the carcasses are being cut, the heavy ones being sent one way and the lighter ones another. It is principally mixed packing hogs that furnish a field for operation to the speculator. He buys several carloads of these mixed packing hogs and sorts them into various classes and resells them. 


\section{Light Hogs.}

These are mostly from five to eight months old. It will be noticed that there is some overlapping in weight between this and preceding classes. This class includes hogs that are too light in weight or too lacking in condition or quality to classify as butcher hogs. With the possible exception of some of the English bacon hogs, light hogs are not as heavy as packing hogs. As a class, light hogs have better quality than packing hogs. The light hog class does not include roughs, stags, and boars, which form separate classes. Although alike in weight, hogs of this class vary a great deal in form, quality, and condition. Such being the case, the meat from them is prepared differently, thus making the sub-classes of more importance than in the two former classes. The sub-classes of light hogs

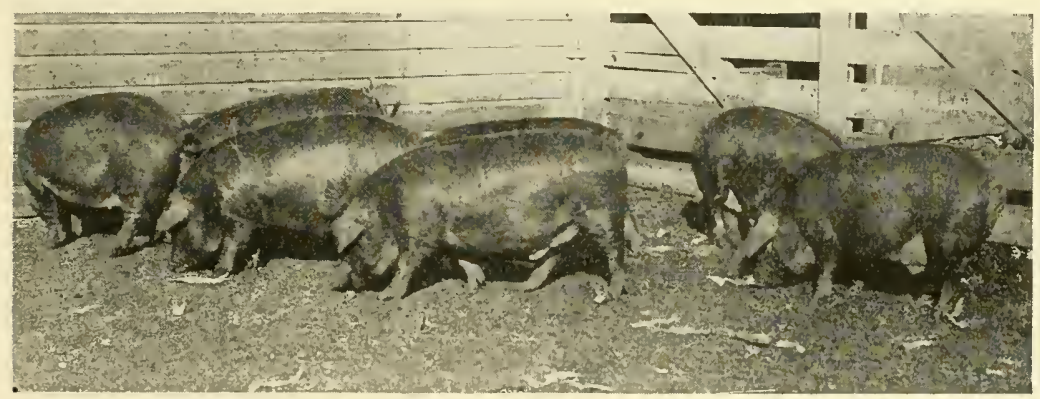

Fig. 102. Choice Butcher Hogs.

are English bacon hogs, bacon hogs of the United States, light mixed hogs, and light-light hogs.

English bacon hogs.-The kind of a hog that is typical of this sub-class of light hogs has already been described in the chapter dealing with bacon hog type. The hog that is representative of this sub-class belongs primarily to Great Britain, Denmark, and Canada. Practically no hogs of this type are received at Chicago. The St. Paul market receives a few. Many hogs are sold on the Chicago and other markets for bacon purposes, but the majority of them are not of true bacon type. This hog must be long in body, deep in side, with comparatively narrow back, narrow and light hams and shoulders, and light muscular neck. As the side of the hog furnishes the best cuts, it is desirable to have the side as well developed as possible in length and depth. This hog must have firm flesh, be well cov- 
ered with lean meat or muscle, and must not have an excess of external fat. The weight must be between 160 and 220 pounds, with weights between 175 and 190 pounds preferred. Such weights insure cuts that are most desirable as to size, flavor, and firmness. A hog smaller than 160 pounds would furnish a side of bacon that would be too thin and watery, while a hog over 220 pounds would yield a side that would be too thick and too fat.

Bacon hogs of the United States.-As there are only a few real bacon hogs produced in this country, the trade is supplied from the lighter hogs of lard hog breeding which show a

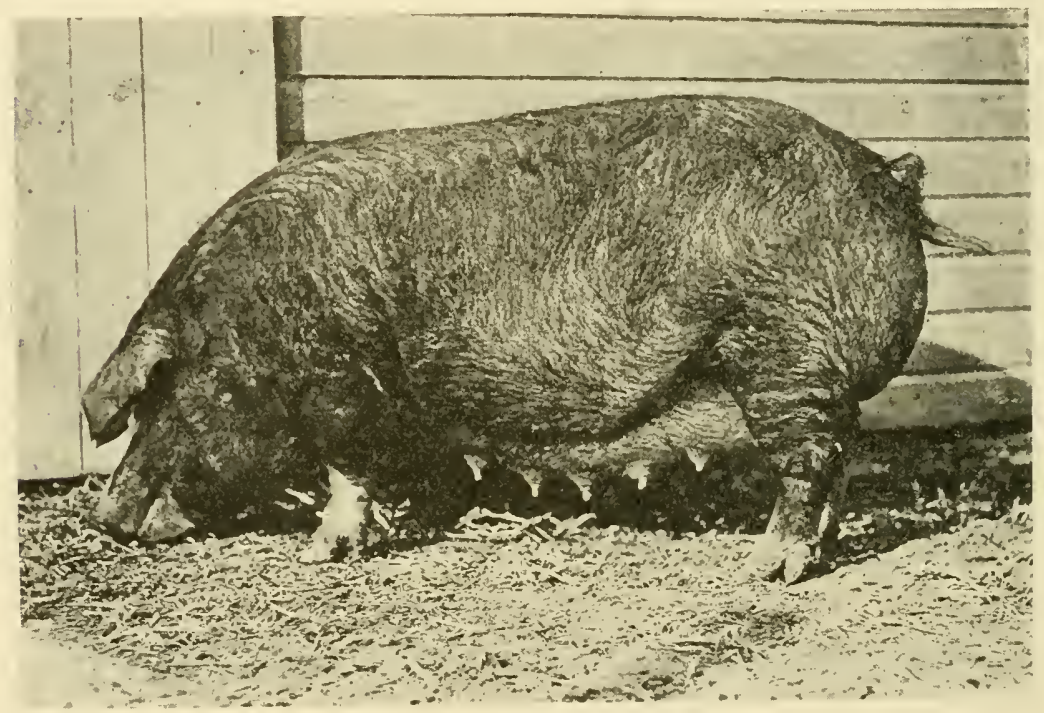

Fig. 103. Packing Sow.

tendency toward the bacon type. In other words, this subclass includes hogs selected from the light hog class that conform as nearly as possible to the bacon type. They weigh from 160 to 200 pounds, and range in age from six to eight months. The bacon made from them is inferior to that made from true bacon hogs and hence brings a somewhat lower price.

Light mixed hogs.-Here we find somewhat of a miscellaneous class quite similar, except as to weight, to mixed packing hogs. This class contains hogs of the light butcher weights that are too poor in quality, form, and condition for butcher hogs It also contains hogs of the same weights as bacon hogs, that. 
are too much of the fat or lard type for bacon. This class, then, is made up of outcasts of two other classes of hogs; in one case it takes the poorer hogs and in the other case the better hogs, considered from the fat or lard hog standpoint. Hogs of this class are used principally for the fresh meat trade and weigh from 150 to 200 pounds. They range in age from five to seven months.

Light-light hogs. - These range in weight from 125 to 150 pounds, and in age from five to six months. They are called "light light" because they are the lightest of light hogs. They are used principally for the fresh meat trade. In the Buffalo market light hogs weighing from 130 to 180 pounds are called "Yorkers." They are so called because they find ready sale on the New York market and are very often shipped there from Buffalo. "Dairies" is another term used in Buffalo, and means hogs that have been fed on slops and refuse from dairies. The flesh of these hogs is not so firm nor will they dress out so well as corn-fed hogs.

\section{Pigs.}

Pigs, as they are considered on the market, range in weight from 50 to 125 pounds, and in age from $3 \frac{1}{2}$ to 6 months. All pigs within these limits bought for slaughter classify here. They are used principally to supply the demand from the cheaper restaurants and lunch counters, and are in greatest demand in winter, being hard to preserve fresh in summer and too young. to cure.

\section{Roughs.}

In this class we find hogs of all sizes that are very coarse, rough, and lacking in condition. They are sometimes called "throwouts." The pork from these hogs is used for the cheaper class of trade for both packing and fresh meat purposes. In market reports, pigs and roughs are frequently classed together; not because they belong in the same class, but because they sell at about the same price.

\section{Stags.}

Stags are hogs that at one time were boars beyond the pig stage and were castrated. They sell with a dockage of 70 pounds. If they are of good quality and condition and do not show too. 
much stagginess, they go in with the various grades of packing hogs. When they are too coarse and staggy in appearance they are sold in the same class as boars.

\section{Boars.}

Boars are always sold in a class by themselves and bring a much lower price than the best hogs on the market at the same time. They sell without dockage. The pork is used to supply the cheaper class of trade and also for making sausage. Boars are not usually marketed until their days of breeding service are over and they are oid and coarse. Many of them are condemned by government inspectors because of sexual odor. They then bring only fertilizer price.

\section{Feeding Pigs.}

During the last few years the prevention of hog cholera by means of the serum treatment has made possible the rapidly growing practice of buying feeder pigs at the large markets. Chicago sent practically no hogs back to farms prior to 1917 , but in that year shipped 45,448 feeder hogs, and in 1918 shipped 24,450. Sioux City shipped 7,715 in 1916, 108,941 in 1917, and 41,004 in 1918. Kansas City shipped 18,183 in 1917, and 174,929 in 1918. St. Paul is the leading feeder hog market with 22,576 in 1916, 231,631 in 1917, and 172,569 in 1918. Thirteen leading markets sent out 139,161 head in 1916, 708,416 in 1917, and 774,011 in 1918. Previously, the purchase of pigs at the markets for feeding purposes was a dangerous practice and was not often attempted. They are now given the preventative treatment for cholera before leaving the market. It is necessary that pigs leaving the Chicago yards shall be inspected for disease by government officials, shall be given the single serum treatment, and shall be dipped. The charge for these services usually amounts to about $\$ 1.50$ per cwt. The commission charge for buying hogs weighing on an average of over 140 pounds per head is $\$ 10$ per car, either single or double deck; hogs averaging 140 pounds or less, $\$ 15$ per car.

Feeder pigs weigh from 50 to 150 pounds, with weights from 90 to 120 pounds most desired, and must be in thrifty, growing condition, but not fat. They should show quality and evidence of good breeding, and should be as uniform as possible in size and appearance. 


\section{Roasting Pigs.}

These are from three to six weeks old and weigh from 15 to 30 pounds. They come to market in small numbers and only during holiday seasons. They are taken direct from their dams, dressed with head and feet on, and served like spring chickens or turkeys. The price varies greatly.

\section{Governments.}

Before hogs are allowed to pass over the scales to be weighed out to the packer, the speculator, the shipper, or any one else who may choose to buy them, they must first pass the scrutiny of a government inspector. All hogs not considered sound in every respect are tagged by this inspector and retained for further examination. Badly pregnant sows, hogs with bunches, boils, etc., also hogs with cuts on the hams and shoulders are retained. These are called "Governments." They are usually bought up by a local dealer and taken to one of the smaller packing houses where they are slaughtered under the supervision of an inspector. If found to be affected so as to make the flesh unfit for human food, they are condemned and tanked. The tank is a large steam-tight receptacle, like a steam boiler, in which the carcass is converted into grease and fertilizer.

\section{Cripples.}

These are hogs that are not able to keep their feet. Weakness of pasterns, feet, and legs is a common fault in lard hogs, especially in those heavily fattened on corn not properly supplemented with protein feeds. Lack of exercise is another cause. Overcrowding of cars and loading and unloading too hurriedly result in a good many crippled hogs. On the market there are far more cripples among hogs than among any other class of stock. Crippled hogs sell to speculators for fully a dollar less per cwt. than they would have otherwise brought.

\section{Dead Hogs.}

These are hogs that died in transit due to overheat, rough handling, over-feeding in hot weather before shipping, and other causes. They are used in the manufacture of grease, soap, and fertilizer. If they weigh 100 pounds or over, they bring the fertilizer price, which is now about $\$ 3.00$ per cwt. If they 
weigh less, they are held in payment of the cost of handling and the shipper gets no return. Actual count of dead stock removed from cars at Chicago, as made by the U. S. Bureau of Animal Industry for a period of two years, showed the number to be 1 out of 2500 cattle, 1 out of 164 calves, 1 out of 526 sheep, and 1 out of 244 hogs.

\section{Hog Prices at Chicago.}

Chicago prices in 1918.*-On Monday, Sept. 16, 1918, two loads of butcher hogs, averaging 214 and 249 pounds respectively, sold at $\$ 20.95$, the highest record for carload lots on the Chicago open market. On the same day 32 head averaging 192 pounds sold at $\$ 21.00$, and ten loads averaging from 194 to 246 pounds sold at $\$ 20.90$. On Nov. 25, 1907, the general average price on the Chicago market was $\$ 3.96$. In 1896 whole droves of packing hogs sold between $\$ 2.70$ and $\$ 3.00$, and the extreme range of prices that year was $\$ 2.40$ to $\$ 4.45$. The very heavy demand for pork products during the World War resulted in new record top prices and new record average prices for all classes of hogs at Chicago in 1918.

Market values of the various classes. - No detailed records are kept of the average prices made by the various market classes of hogs on the Chicago market. The following table gives the yearly average weights and yearly average prices of hogs marketed at Chicago from 1909 to 1918, and also the averages for the entire ten-year period.

\begin{tabular}{|c|c|c|c|c|c|c|}
\hline Year & $\begin{array}{c}\text { Average } \\
\text { weight }\end{array}$ & $\begin{array}{c}\text { Heavy } \\
\text { packing } \\
\text { hogs }\end{array}$ & $\begin{array}{l}\text { Light } \\
\text { hogs }\end{array}$ & Pigs & $\begin{array}{l}\text { Mixed } \\
\text { hogs }\end{array}$ & $\begin{array}{l}\text { All } \\
\text { classes }\end{array}$ \\
\hline $\begin{array}{l}1909 \ldots \ldots \ldots \\
1910 \ldots \ldots \ldots \\
1911 \ldots \ldots \ldots \\
1912 \ldots \ldots \ldots \\
1913 \ldots \ldots \ldots \\
1914 \ldots \ldots \ldots \\
1915 \ldots \ldots \ldots \\
1916 \ldots \ldots \ldots \\
1917 \ldots \ldots \ldots \\
1918 \ldots \ldots \ldots \\
\end{array}$ & $\begin{array}{c}\text { Pounds } \\
218 \\
235 \\
228 \\
226 \\
228 \\
231 \\
219 \\
210 \\
213 \\
234\end{array}$ & $\begin{array}{r}\$ 7.45 \\
8.90 \\
6.70 \\
7.55 \\
8.20 \\
8.20 \\
7.00 \\
9.65 \\
15.20 \\
17.50\end{array}$ & $\begin{array}{r}\$ 7.25 \\
8.90 \\
6.70 \\
7.50 \\
8.45 \\
8.35 \\
7.20 \\
9.45 \\
14.90 \\
17.60\end{array}$ & $\begin{array}{r}\$ 6.55 \\
8.80 \\
6.05 \\
6.40 \\
7.35 \\
7.60 \\
6.60 \\
9.40 \\
14.40 \\
15.57\end{array}$ & $\begin{array}{r}\$ 7.25 \\
8.90 \\
6.70 \\
7.60 \\
8.50 \\
8.30 \\
7.20 \\
9.60 \\
15.10 \\
17.40\end{array}$ & $\begin{array}{r}\$ 7.35 \\
8.90 \\
6.70 \\
7.55 \\
8.35 \\
8.30 \\
7.10 \\
9.60 \\
15.10 \\
17.45\end{array}$ \\
\hline Ten year average... & 224 & $\$ 9.65$ & $\$ 9.65$ & $\$ 8.90$ & $\$ 9.65$ & $\$ 9.65$ \\
\hline
\end{tabular}

* Year Book of Figures, 1919. 
Comparison of the hog market with the cattle and sheep markets brings out strikingly the fact that there is considerable spread in the price of cattle and sheep, and relatively little spread in the price of hogs. A report for any day of the year will substantiate this statement. Between the best cattle and the poorest cattle on the market, there is a tremendous difference in price per cwt., and even between the best and poorest fat steers there is a great difference. The same is true of sheep. The price of cattle and sheep is determined very largely by condition and quality, but hogs sell almost entirely by weight. The condition and quality of hogs vary considerably and affect the price, but do not affect the price to any great degree. Omitting pigs, roughs, and boars, which make up a small percentage of a day's run, one dollar will usually cover the spread on the bulk of hogs sold each day. There are several reasons for the small spread in price of hogs. 1. Packers have discovered and developed methods of curing cuts from the poorer hogs which enable them to put this meat on the market in attractive and appetizing form. This has increased the price of the plainer classes of hogs. 2. Hogs do not vary so much in dressing percentage as cattle and sheep. 3. All hogs are strictly meat animals, whereas the cattle market receives a considerable number of dairy animals, and the sheep market receives a large number of Merinos. 4. Age does not make pork as tough as beef and mutton. Juiciness and color are less variable in pork than in other meats.

In 1915, the U. S. Office of Markets and Rural Organization* conducted an investigation which indicated that 35 per cent. of the hog crop is marketed in the fall, 41 per cent. in the winter, 18 per cent. in the spring, and 6 per cent. in the summer. About 60 per cent. of the annual pig crop is farrowed in March, April, and May, and is sent to market from eight to ten months later weighing from 200 to 250 pounds or over. The largest supply of hogs on the market occurs in November, December, and January. Lowest prices most frequently occur in December and January. Highest prices are usually made in March and April and in September and October, due to the relatively small number of hogs received in these months. Light hogs are normally at a higher price level than heavy hogs during spring and summer when there is a demand for fresh meats, but in the winter packing season heavy hogs bring the highest price

*U. S. Dept. Agr. Report 113. 


\section{CHAPTER XXVI.}

\section{BREEDING FOR THE MARKET.}

Hog raising has always been a profitable and favorite department of farming in the United States. In colonial times pork production was a very simple matter. Hogs were allowed to run wild in the woods where they fed upon roots and natural grasses and fattened upon acorns and beech and hickory nuts, called "mast." The only expense to the farmer was the winter feeding of those too young for market and of those reserved

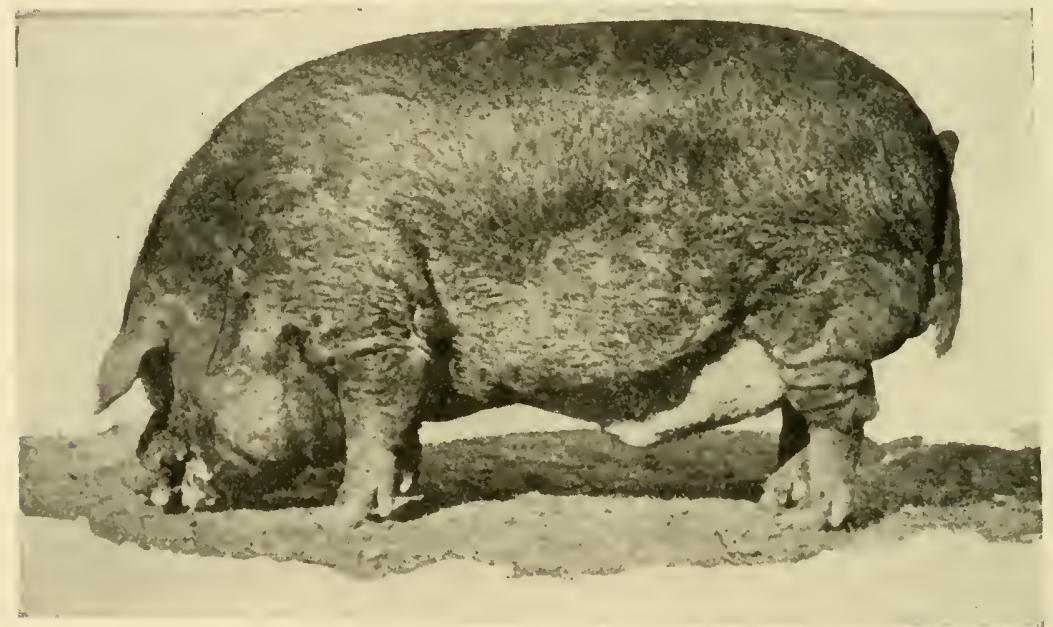

Fig. 104. An Excellent Boar.

Duroc-Jersey boar, Good Enuff Again, Champion at the Ohio State Fair. Owned by W. H. Robbins, Springfield, Ohio. This boar has size, bone, masculinity, a good back, great heart-girth, excellent feeding capacity, smoothness, and quality. He weighed 1000 pounds.

for breeding purposes. Inasmuch as Indian corn was the feed used and as this cereal would not repay the expense of transportation to market until the introduction of railways, it cost very little to produce pork. Even after the organization of the national government and the settling up of the Middle West it was the general impression among farmers that it cost nothing for a man to make his own pork, and for a long time large numbers of dressed hogs were sold in that section of the country 
at prices ranging from seventy-five cents to one dollar per cwt. and were considered sufficiently remunerative at these figures.

As greater areas came under cultivation and the natural forests became more restricted, it was found more profitable and convenient to feed hogs on corn than to turn them out into the woods, as they grew faster and took on more fat. It was at this stage in the development of the American swine industry that pork packing was commenced, and this gave a pronounced impetus to hog production. This was before the days of railroads, and hogs were taken overland in droves to the nearest packing point. Later, when the railroads came, a great saving was effected by eliminating losses due to the giving out of hogs on the route, and pork packing and hog raising received an impulse that has greatly helped to make pork one of the most important staples of the country.

The census found $26,000,000$ hogs in the United States in $1840,33,500,000$ in $1860,47,700,000$ in $1880,57,400,000$ in 1890 , and $62,900,000$ in 1900 . In 1910 the census changed from June 1 to April 15, and the swine enumerators found only 58,200,000. If, however, the number of hogs found on that date increased to the number estimated to exist on the following 1st of June, the swine on farms in 1910 , June 1, probably numbered $69,200,000$. The $58,200,000$ swine found by enumerators April 15, 1910 , had increased, according to estimates of the U. S. Department of Agriculture, to 65,400,000 in 1912, but the unusual prevalence of hog cholera in 1913 reduced the number to $58,900,000$ in 1914. In 1915, the estimated number was $64,600,000$; in $1916,68,000,000$; in $1917,67,500,000$; in $1918,71,000,000$; and in $1919,75,600,000$. From the earliest record there has been a persistent course of increase of swine in the United States.

The United States is the outstanding country of the world in pork production. The leading countries in numbers of hogs, according to the latest available figures, are as follows:

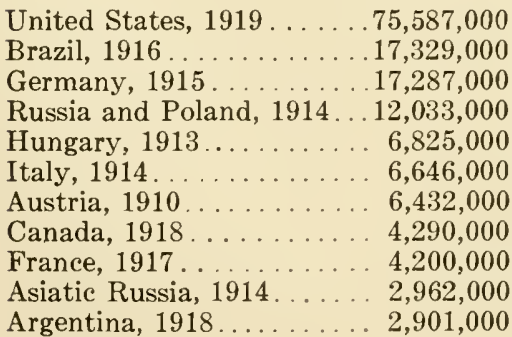

Spain, $1916 \ldots \ldots \ldots \ldots \ldots 2,814,000$

United Kingdom, $1918 \ldots . .2,809,000$

Philippines, $1915 \ldots \ldots \ldots 2,521,000$

Venezuela, $1912 \ldots \ldots \ldots \ldots 1,618,000$

Belgium, $1913 \ldots \ldots \ldots \ldots$. 1,412,000

Roumania, $1916 \ldots \ldots \ldots \ldots 1,382,000$

Portugal, $1908 \ldots \ldots \ldots \ldots 1,300,000$

Netherlands, $1917 \ldots \ldots \ldots 1,185,000$

British South Africa, 1911 . 1,111,000

Sweden, $1917 \ldots \ldots \ldots \ldots \ldots 1,030,000$

Australia, $1916 \ldots \ldots \ldots \ldots 1,007,000$ 
The distribution of hogs (on farms) in the United States on January 1, 1919, was as follows:

North Atlantic Division. .

$3,059,000$

South Atlantic Division

$9,164,000$

North Central, East of Mississippi River

$18,194,000$

North Central, West of Mississippi River.

South Central Division

$27,393,000$

$14,918,000$

Far Western Division

$2,859,000$

Total.... . . .

$75,587,000$

As hogs are now distributed throughout the geographic divisions, the North Central States, extending from Ohio to the western line of Kansas, contain 60 per cent. of the national total; the Southern States, from the Atlantic Ocean to the western line of Texas, have 32 per cent. of the total; the remaining 8 per cent. are in the East and in the Far Western States.

The ten leading states and the number of hogs in each on January 1, 1919, were as follows:
1. Iowa.....
$10,925,000$
6. Nebraska
$5,724,000$
2. Illinois
$4,943,000$
7. Georgia .
8. Minnesota .
$4,250,000$
3. Missouri .
$4,668,000$
9. Kansas .
$4,266,000$
10. Texas
$2,784,000$
5. Ohio....
$2,381,000$

The states of the Mississippi valley play a very important part in the swine growing industry of the world. No other region is so favored as is the corn growing region of the United States.

As previously mentioned, hog production in the United States is closely allied with corn production; in fact, hogs are more closely allied with corn than are any other of our farm animals. Dairy cattle approach hogs in this regard, followed by horses, beef cattle, and sheep in the order named. The writer has determined the average rank of the various states in corn production for the nine-year period from 1907 to 1915 inclusive. Similar average rankings in each kind of live stock were determined for each state, based on the number of animals in each state on January 1, from 1908 to 1916 inclusive. For example, Kansas' average rank in corn during this period was 8th., in hogs, 8th., in dairy cattle, 11th.; in horses, 4th.; in beef cattle, 4th.; and in sheep, 30th. Thus, Kansas' rank in hogs did not vary from her rank in corn; in dairy cattle she varied 3 points from corn; in horses, 4 points; in beef cattle, 4 points; and in sheep, 22 points. If the number of points between hogs 
and corn in each state are added together, we find that hogs varied 196 points from corn in the forty-eight states; dairy cattle varied 233 points from corn; horses, 401 points; beef eattle, 489 points; and sheep, 788 points.

The average rank of the states in corn, hogs, and sheep for the nine years is herewith presented graphically. It will be noticed that in only four states do sheep rank closer to corn than do hogs. These are New Hampshire, Pennsylvania, Michigan, and Wisconsin. In Rhode Island and North Dakota

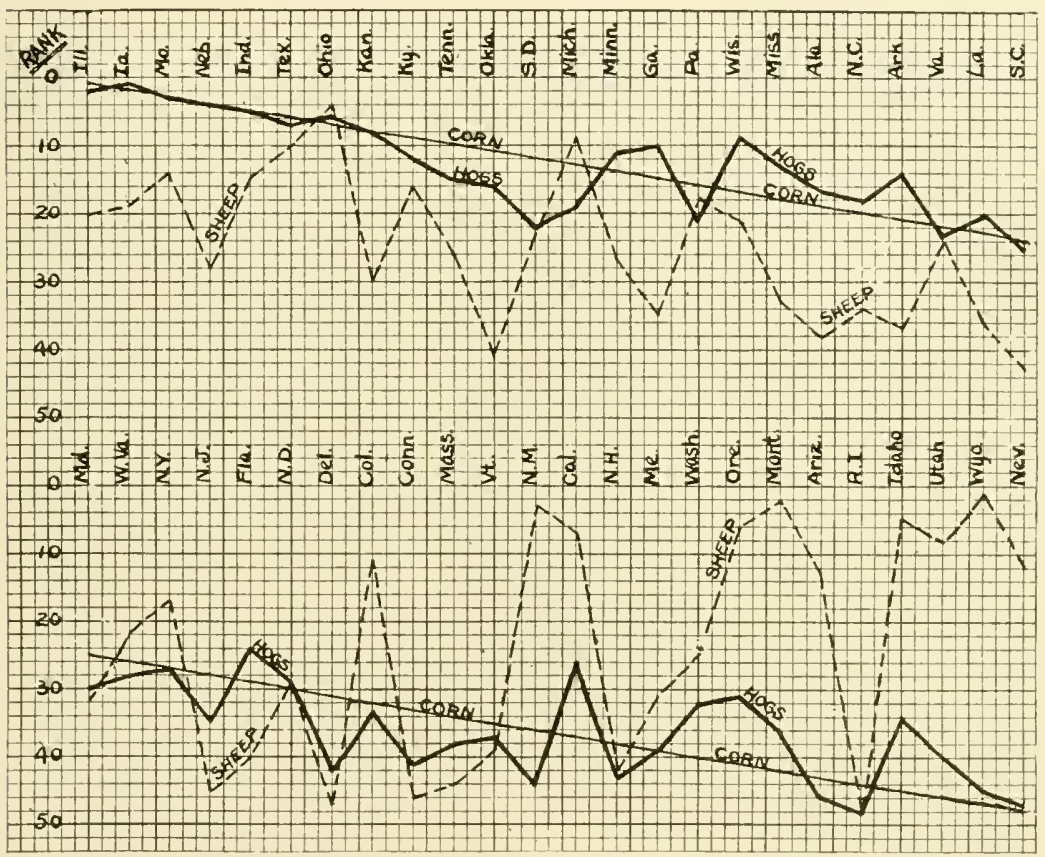

Fig. 105. Pork Production in United States Closely Related to Corn Production.

These graphs show the average rank of the various states in corn production from 1907 to 1915, and in numbers of hogs and sheep on January 1, from 1908 to 1916 inclusive. Hogs are closely related to corn, followed by dairy cattle, horses, beef eattle, and sheep in the order named. Sheep raising has practically no dependence on corn production.

sheep and hogs vary an equal number of points from the rank in corn. In each of the remaining forty-two states, hogs rank closer to corn than do sheep. Notice how closely corn and hogs are associated in the first eight states. There seems to be no correlation between sheep and corn. 
When the United States was settled, swine were brought over from Europe, but conditions here, and especially in the cornbelt, were very different, and the character of the hog was changed to meet the demand as it developed under the different conditions. The new type of hog which was then originated was what is called the fat or lard hog. There were three principal reasons for its development. These were (1) the abundance and good fattening qualities of corn, (2) the home demand for cured meats, and (3) the foreign demand for cheap meats.

1. Corn is a plant native to America, and in the cornbelt can be produced with much less cost than can any of the other grains. The United States produces three-fourths of the world's corn crop. It is a feed comparatively rich in carbohydrates and much lacking in protein. Carbohydrates are used in the animal body for building up fat and to furnish the fuel that is used in the production of physical energy. Protein is that part of a food material that is rich in nitrogen and is used principally to build up muscle or lean meat. Since corn is the principal feed for swine in the United States, it is only the natural consequence that our hogs are of the fat or lard type.

2. In the earlier history of the United States, very few, if any, of the frontier sections had railroad facilities, so could not import fresh meats; neither had they facilities for local production of meats. Then again, these places, and especially the lumber camps, used a great deal of meat, and it had to be of such a nature that it could be hauled long distances on wagons and be capable of long storage after reaching its destination. The most satisfactory meat for this purpose was mess pork. There are two reasons why fat salt pork was better than lean salt pork. (a) Fat pork does not become so salty on being pickled as does lean pork. It is not so thoroughly penetrated by the salt, therefore it is more palatable after long storage than is lean pork, which also requires a larger quantity of salt, and is not so well preserved as is the fat pork. (b) Fat pork was better both from the employer's and the consumer's point of view, because on account of its fatty nature, it contains two and one-fourth times as much energy per unit of weight as does lean pork, therefore making a cheaper article on the bill of fare, also furnishing sufficient energy to the laborer who was toiling hard in cold winter weather. The following table giving analyses and fuel values of a number of common foods shows the high 
fuel value of pork products. It will also be noticed that the foods with the largest fat content have the highest fuel value:

\begin{tabular}{|c|c|c|c|c|c|c|c|c|}
\hline Foods & $\begin{array}{c}\text { Analy- } \\
\text { ses }\end{array}$ & Refuse & Water & $\begin{array}{l}\text { Pro- } \\
\text { tein }\end{array}$ & Fat & $\begin{array}{c}\text { Carbo- } \\
\text { hy- } \\
\text { drate }\end{array}$ & Ash & $\begin{array}{c}\text { Fuel } \\
\text { value per } \\
\text { pound- } \\
\text { calories* }\end{array}$ \\
\hline Lard, refined.... & & $\begin{array}{l}\text { Per } \\
\text { cent. }\end{array}$ & $\begin{array}{c}\text { Per } \\
\text { cent. } \\
\text {. . . . }\end{array}$ & $\begin{array}{c}\text { Per } \\
\text { cent. }\end{array}$ & $\begin{array}{c}\text { Per } \\
\text { cent. } \\
100.0\end{array}$ & $\begin{array}{l}\text { Per } \\
\text { cent. }\end{array}$ & $\begin{array}{l}\text { Per } \\
\text { cent. }\end{array}$ & 4220 \\
\hline Back fat-hog. & 3 & & 7.7 & 233 & $\begin{array}{r}100.0 \\
89.9\end{array}$ & & $\because i$ & 3835 \\
\hline Salt pork ..... & 6 & & 7.3 & 1.8 & 87.2 & & 3.7 & 3715 \\
\hline Bacon, smoked & 13 & 8.1 & 17.8 & 9.6 & 60.2 & & 4.3 & 2720 \\
\hline Mess beef . . . . & 2 & 10.5 & 33.0 & 10.7 & 39.9 & & 5.9 & 1885 \\
\hline Oatmeal.. & 13 & & 7.2 & 15.6 & 7.3 & 68.0 & 1.9 & 1860 \\
\hline Starch ........... & & & & & & $\begin{array}{l}98.0 \\
70.6\end{array}$ & 1.2 & $\begin{array}{l}1825 \\
1660\end{array}$ \\
\hline $\begin{array}{l}\text { Entire wheat flour } \\
\text { Corn meal, bolted. }\end{array}$ & 5 & & 12.1 & $\begin{array}{r}14.2 \\
8.9\end{array}$ & $\begin{array}{l}1.9 \\
2.2\end{array}$ & 70.6 & $\begin{array}{r}1.2 \\
.9\end{array}$ & $\begin{array}{l}1660 \\
1655\end{array}$ \\
\hline $\begin{array}{l}\text { Corn meal, bolted. } \\
\text { Mutton loin, with- }\end{array}$ & 9 & & 12.9 & 8.9 & & 10.1 & & \\
\hline $\begin{array}{l}\text { out kidney and } \\
\text { tallow....... }\end{array}$ & 15 & 14.2 & 40.5 & 12.8 & 31.9 & & .6 & 1585 \\
\hline Bread, white..... & 108 & & 35.4 & 9.5 & 1.2 & 52.8 & 1.1 & 1205 \\
\hline $\begin{array}{r}\text { Beef loin, boneless } \\
\text { strip ......... }\end{array}$ & 6 & & 60.7 & 18.9 & 19.5 & & 9 & 1175 \\
\hline Ribs........... & 28 & 20.2 & 44.9 & 13.6 & 20.6 & & 7 & 1120 \\
\hline Leg of lamb. . & 4 & 13.8 & 50.3 & 15.3 & 19.7 & & .9 & 1115 \\
\hline Round ...... & 44 & 8.5 & 63.0 & 18.7 & 8.8 & & 1.0 & 720 \\
\hline Hens' eggs... & & 10.5 & 66.0 & 13.1 & 9.5 & & 9 . & 645 \\
\hline Apples, fresh..... & 10 & 25.0 & 61.5 & .4 & .4 & 12.4 & .3 & 255 \\
\hline Vegetable soup... & 1 & & 95.7 & 2.9 & $\cdots$ & .5 & .9 & 65 \\
\hline
\end{tabular}

${ }^{*}$ Heat and muscular work are forms of force or energy. The energy is developed as the food is consumed in the body. The unit commonly used in this measurement is the calorie, the amount of heat which would raise the temperature of a pound of water 4 degrees $\mathrm{F}$.

3. There was a foreign demand by the poorer classes of people for cheaper meats than could be supplied by their highpriced bacon industry. This cheaper meat could be supplied in the form of fat pork made from low-priced corn, and at the same time could be furnished at a profit.

From these various causes it is clearly evident that the fat or lard hog of the United States was produced not only because he could be produced more cheaply than the bacon hog, but also because there was a demand for just such a hog.

In the United States the slaughtered swine were 79.8 per cent. of the total stock of hogs on hand in 1900, and 76.9 per cent. in 1910. In 1910, 233 pounds of pork were produced per head of stock of hogs on hand over $31 / 2$ months old April 15. The importance of swine as meat producers is emphasized by these figures.

Size in market hogs. - Some of the weights of hogs marketed at Cincinnati in the early days serve to show rather strik- 
ingly that market hogs, like market cattle, have undergone an evolution from immense weights in the early days to the handyweight market animal of the present time. In 1857 the following records of weights were made on the Cincinnati market:

Number of hogs

$\begin{array}{r}3 \\ 5 \\ 7 \\ 22 \\ 50 \\ 52 \\ 320 \\ 657 \\ \hline 1,116\end{array}$

Net weight

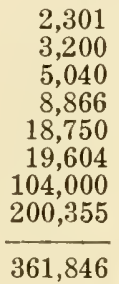

Average per hog

710

640

720

403

375

377

325

305

324

In 1866 these weights were exceeded as shown in the following records for that year:

Number of hogs

$\begin{array}{r}11 \\ 20 \\ 30 \\ 35 \\ 35 \\ 43 \\ 107 \\ 200 \\ 346 \\ 400 \\ \hline 1,227\end{array}$

Net weight

$\begin{array}{r}6,732 \\ 15,452 \\ 15,180 \\ 15,785 \\ 15,712 \\ 15,738 \\ 43,014 \\ 71,800 \\ 139,092 \\ 150,000 \\ \hline 488,505\end{array}$

Average per hog

\begin{tabular}{l}
612 \\
772 \\
506 \\
451 \\
449 \\
366 \\
402 \\
359 \\
402 \\
375 \\
\hline 398
\end{tabular}

Of the lot of twenty included above it was said: "The lot of twenty, raised and fed for market in our county (Hamilton County, Ohio) has certainly no parallel in the wide world, none of the hogs exceeding 19 months of age, and generally running from 15 to 16 months old."

Wren and Schaffer of Middletown, Ohio, packed in 1870 a lot of thirty-eight Poland-China hogs averaging 613 pounds gross at 21 months old, all fattened by one man in Butler County. Following are records of a large number of hogs (Poland-Chinas) raised in Butler County, Ohio, and sold to packers in 1870:

\begin{tabular}{|c|c|}
\hline $\begin{array}{l}\text { Number of } \\
\text { hogs }\end{array}$ & $\begin{array}{r}\text { Average } \\
\text { weigh }\end{array}$ \\
\hline $\begin{array}{l}80 \ldots \\
40 \ldots \\
38 \ldots \\
48 \ldots \\
42 \ldots \\
40 \ldots\end{array}$ & \\
\hline
\end{tabular}

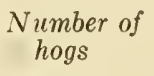

20

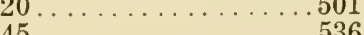

$45 \ldots . \ldots 536$

$75 \ldots \ldots \ldots \ldots \ldots 3$

$60 \ldots \ldots \ldots \ldots \ldots+\ldots \ldots$

$40 \ldots \ldots \ldots \ldots \ldots \ldots$

$12 \ldots \ldots \ldots \ldots 73$ 
There is record of one lot of 30 Poland-Chinas marketed in 1870 that averaged gross 384 pounds at eleven months of age, while another lot of ten of the same breed and age marketed in that year averaged 410 pounds gross.

The immense weights of earlier times were made possible by cheap corn, by the premium paid for heavy hogs by packers in those days, and by selecting hogs of great weight for breeding purposes. During late years the tendency has been to market handy-weight hogs, and fewer heavy hogs appear on the market each year. This change has been brought about by the high price of corn, by improved methods of packing which permit hogs of less fatness and lighter weight to find favor with packers, by the general tendency on the part of the consumer to favor light cuts, and by the growing demand for bacon in place of the old-fashioned, heavy, salt meats. The breeder also has played a part in this change to the handy-weight market hog, by giving preference to hogs of quality and smoothness over those of large size and tending toward roughness and lack of quality. In recent years some breeds actually deteriorated because of the fact that most of the breeders went too far in the matter of securing quality and refinement in their animals and failed to keep up enough size and constitution to suit the practical hog grower. This mistake was realized and today the effort is being made to get back on safer ground by breeding for all the size possible and yet maintain a proper degree of quality in the animal. The ideal hog for the farmer is a medium-weight hog, or a hog slightly above what would be called medium weight, possessing desirable quality, smoothness, and symmetry.

Selection of breeding stock.-The points which should receive particular attention in selecting hogs for breeding purposes are (1) size, (2) feeding capacity, (3) constitution and vigor, (4) quick maturity, (5) strength of back, legs, pasterns, and feet, (6) quality, (7) breeding qualities, (8) uniformity of type, and (9) ancestry.

1. Under present conditions, the most profitable stage for the grower to market lard hogs is between 200 and 275 pounds. Nevertheless, hogs used for breeding purposes should have plenty of size combined with desirable type and early maturity. If the breeding stock is of large size, the pigs will be growthy and will attain marketable weights in quick time. The cheapest gains are made during the growing period. This is shown by the following compilation presented by Henry and 
Morrison* which summarizes over 500 American feeding trials with more than 2,200 hogs:

Weight of hogs

Pounds feed for 100 pounds gain

$100-150$ pounds

$150-200$ pounds

$200-250$ pounds

$250-300$ pounds

$300-350$ pounds

.437 pounds

482 pounds

.498 pounds

511 pounds

.535 pounds

The risk of loss from disease is lessened in marketing younger hogs, and the farmer gets a quicker turnover of his capital.

The most profitable hog is one that inherits the ability to grow to large size, but which will fatten if desired long before the limit of growth is reached. It is desirable, therefore, to set the standard for matured weight as high as is consistent with proper form, quick maturity, and quality. For boars in high condition, the standard may be set at 800 pounds or over without necessarily sacrificing other desirable qualities. Sows in high condition should weigh not less than 600 pounds. By proper selection and by improved methods of feeding and management, these weights may be equalled or surpassed. It is not desirable to keep breeding stock in high condition, but the term "breeding condition" has such a variable meaning that it cannot be used satisfactorily as a basis for weights. In breeding condition, boars and sows will weigh considerably less than 800 pounds and 600 pounds respectively, but they should have enough size of frame and capacity for taking on flesh to enable them to reach these weights if they were fed to high condition.

2. Feeding capacity is indicated by length, depth, width, and fullness of middle. Some degree of paunchiness may be accepted as evidence of feeding capacity. A wide head, prominent poll, well-developed jaw, a mild eye, and a short neck are further indications of a good feeder.

3. Constitution and vigor are indicated by width and depth of chest, a large heart-girth, good spring of rib, large feeding capacity, and a strong appetite. A general appearance of strength and ruggedness without coarseness, an active walk, a bright, open eye, a healthy skin, and abundant, glossy hair are other evidences of constitution, thrift, and vigor.

4. A quick-maturing hog is one that makes a fast growth, yet can be fattened off at market weight. Such hogs are ready

* Feeds and Feeding, p. 569. 
for market in quick time and at low cost. This quality is possessed in greatest degree by hogs descended from breeding stock of large size that are broad backed, deep, full-made, and not too long of body and legs. Some hogs will grow big enough and weigh well for their age, but, lacking the proper form, they do not fatten readily and cannot be finished at desired market weights.

5. A low back is a bad fault in a breeding animal. It is a weakness which is as liable to be transmitted to offspring as any other good or bad quality. The boar should stand on

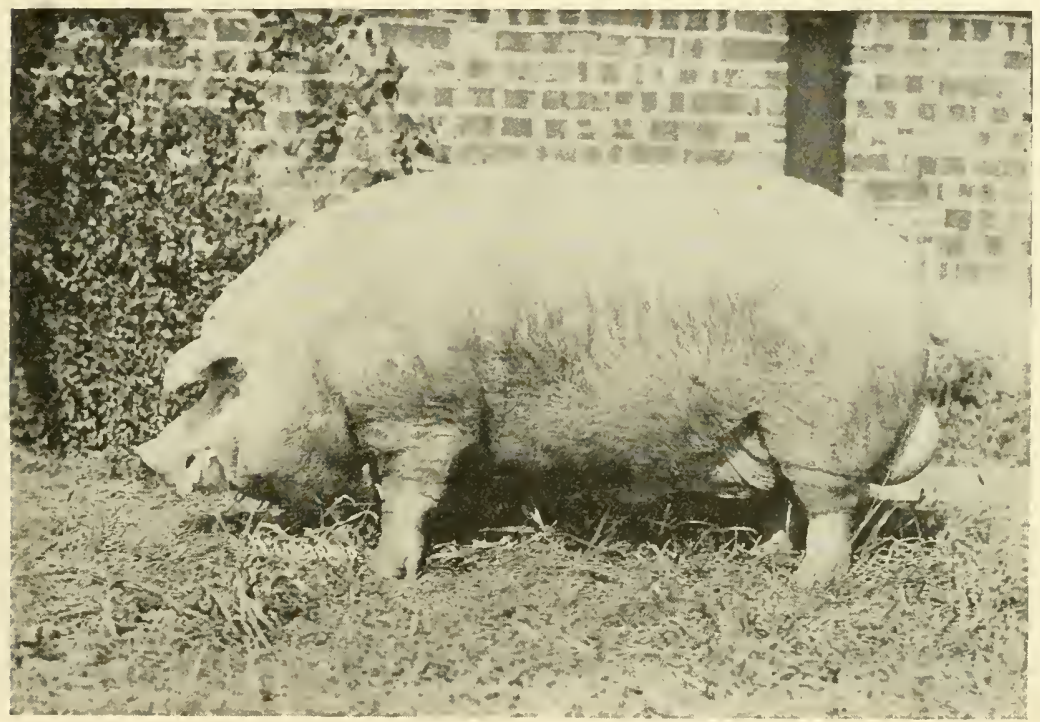

Fig. 106. Good Type in the Breeding Boar.

Chester White boar, Champion at the Iowa State Fair in 1913. Owned by Mr. A. B. Somerville, Monroe, Ia.

large, strong bone, this being one evidence of masculinity, but extremely large, rough bone, covered with a thick, puffy skin is undesirable, indicating coarseness. The breeding sow should show greater refinement of bone than the boar, yet it should be amply sufficient to sustain not only her weight but also the added weight imposed by pregnancy and large litters. Fine shank bones are not objectionable because they are liable to be fractured by the weight of the sow, but because extremely fine bone is associated with small, weak tendons and ligaments which permit the pastern to drop down and the toes to spread apart, 
thus making the legs weak and greatly lessening the usefulness of the animal. Proper feed during the growing period and sufficient exercise are other factors which have much to do with the strength of feet and legs. Sickled hind legs, bowed-out hocks, inbent knees, and other deformities should be avoided, particularly in selecting a boar.

6. A reasonable degree of quality, as indicated by smoothness of form and flesh and by trimness of appearance, is something of an evidence of good breeding and must be shown in breeding stock if it is to be shown in their pigs on the market. The butcher desires a very high degree of quality and refine-

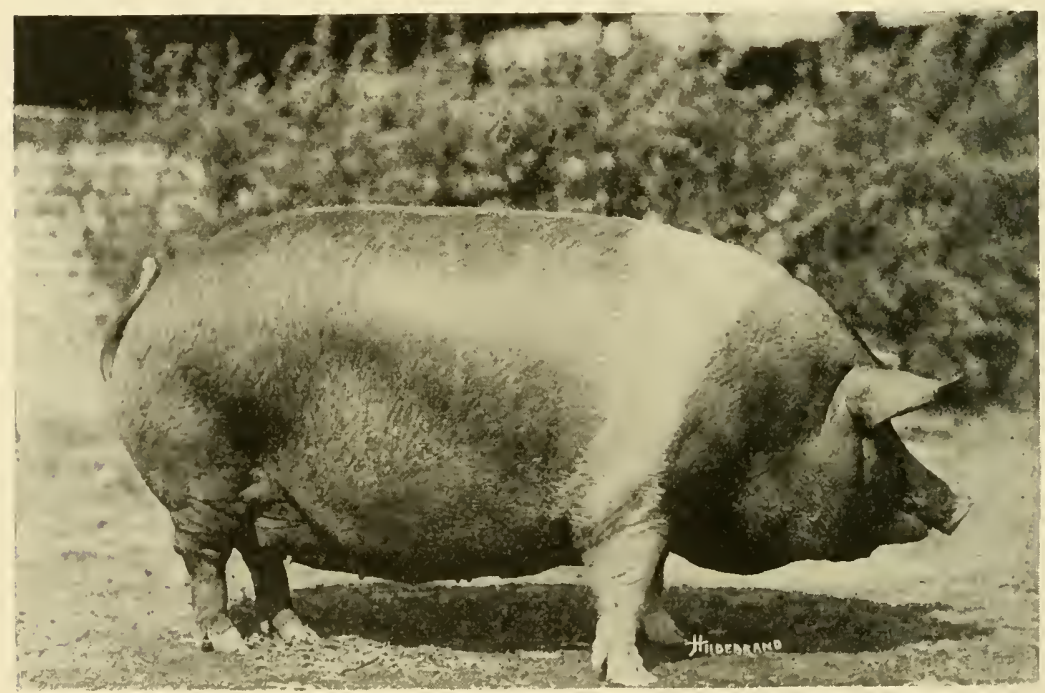

Fig. 107. Good Type in the Breeding Sow.

Hampshire sow, Gloria 2d., Champion at the Iowa State Fair in 1914. Owned by Mr. Russell Yates, Palo, Ia.

ment in head, ear, hide, hair, bone, and fleshing, but does not pay enough premium for it to justify the producer in emphasizing quality too strongly. As pointed out near the end of the preceding chapter, the value of a hog on the market is determined very largely by his weight, without much regard to fatness and quality. However, a fair degree of quality is characteristic of the easy-feeding, quick-maturing hog. The breeder should select for as much quality in breeding stock as may be had without sacrifice of proper size, constitution, and strength of bone. 
The skin over the shoulders of mature boars is thicker and heavier than on sows or barrows. This character is called the shields, and was a highly useful feature in the wild boar as a protection in fighting. The wild boar has transmitted this character in greater or less degree to his domesticated descendants. In some instances the thickening and hardening of the skin is so great as to produce pronounced callouses, and these are objectionable. A smooth shoulder is desired in the boar as well as in the sow and barrow.

7. Great variation in prolificacy exists between individual sows of the same breed. There are also some rather marked differences between breeds. The number of pigs per litter varies from one to sixteen or more, but with good management is usually from six to ten and under ordinary farm conditions averages about seven or eight. It is well to remember, however, that it is the number of pigs raised, rather than the number farrowed, which is most important. Sows that are irregular breeders, difficult to get in pig, not prolific, poor sucklers, or that lie on their pigs should be sent to market. Short-middled sows of the chunky type are usually lacking in prolificacy and milking qualities. Size, stretch, roominess and a mild disposition are essential to good brood sows. Their udders should include twelve or more well-developed glands and teats.

Masculine, vigorous boars are quick and sure breeders. Motherly- or matronly-looking sows are the most satisfactory breeders and best mothers.

8. The breeding herd should be kept as uniform in size, form, color, and other points as possible in order that the pigs may acquire a finish at about the same time and present a uniform and attractive appearance in the feed-lot and on the market.

9. A good ancestry back of a young boar or sow is the best possible guarantee that it will develop into a useful breeding animal. Between two hogs equal in individuality, one the best pig from a poor litter and a poor ancestry, and the other the worst pig from a good litter and a good ancestry, there is almost certain to be a marked advantage in favor of the latter as a breeder. Particularly in selecting boars is it important to buy from a good herd, and to select pigs from a large litter, a good litter, a good sire, and a good dam. In other words, try to get prolific and producing blood, blood that will breed on. In breeding for the market, the sows should be purebreds or high grades. None other than a good purebred boar should 
be used on any herd. In hogs, as in other stock, the sire is at least half of the herd.

The sow may be bred when eight months old, farrowing her first litter when twelve months old. If well fed and cared for, she will raise two litters per year, though many breeders believe that better results are obtained if the sow raises one litter per year, or at most three litters in two years. The average duration of pregnancy in swine is 114 days. Boars eight to ten months old may be used on a few sows if they are well developed for their age and well fed. A mature boar will breed one sow a day, or from thirty to forty sows during the breeding season.

With no other kind of live stock is there practiced so much mixing of breeds and cross-breeding as in the breeding of hogs for the market. It is very commonly believed that by crossing a boar of one breed upon sows of another breed, more vigorous and growthy offspring will result. While there is no serious criticism to be made against such a method so far as the first cross is concerned, it invariably happens that if this policy is followed up and further crossing and mixing is resorted to, a variety of shapes and colors is presented that is most unattractive as compared with a bunch of hogs possessing good uniformity. In the majority of cases it will be most profitable to pick out one of the standard breeds of hogs and stick to that breed year after year. If this is done there need be no lack of vigor in the offspring if the parent stock is selected with due care as to constitution and vigor. 


\section{PART FOUR.}

\section{HORSES.}

\section{INTRODUCTION.}

For centuries the horse has been a faithful servant of man in the capacity of a burden bearer. "From remotest ages he has come with man, side by side, in the glory and achievements of the white race. In all the darings and doings of the Saxon, wherever countries were to be conquered, battles fought, and the banner of Britain carried round the world, wherever has been a footprint, there also was the hoof-beat."* As compared with other domesticated animals, the horse is peculiar in his relation to man, for he is valuable on account of his ability to do work and not because he furnishes a tangible product useful as food or otherwise. It is his athletic ability which makes the horse useful.

None other of our domestic animals occupies as important a place in the economy of things as does the horse; if all the horses were suddenly taken from the nations of the world, agriculture, business, and commerce would be seriously impaired and we would soon be in a state of famine. Consider the vast number of horses in use on farms, on city streets, on country roads, in armies, and for numerous pleasure purposes, such as riding, driving, racing in harness and under saddle, hunting, and polo. We could give up any of the other domesticated animals with much less serious results, and this in spite of the advent and improvement of the automobile, motor truck, and tractor, and their wide use at the present time.

The horse may be said to be a locomotive which consumes hay and grain instead of coal. $\mathrm{He}$ is self-feeding, self-controlling, and self-reproducing, and is at the same time a very efficient motor. Farmers who use horses may be compared to the engineer who operates a motor. Farmers who breed horses may be compared to the manufacturer of motors. No man can manufacture or operate a motor with real success

* John Trotwood Moore, in The Gift of the Grass. 
unless he understands its construction, the importance of its various parts, their strength or weakness, and their relation to one another. No man can learn the construction of a motor by studying its exterior only; he must take it apart and study the various parts, and then put them together again. Then he must put it in motion and study the action of the various levers, pulleys, and springs, in order that he may know the location of weaknesses and at what points the most wear comes. Knowing these things, he can manufacture a motor of high efficiency, or, operating one, he can obtain from it the greatest amount of work with least danger of injuring the machine. Hence we see how important is a knowledge of the anatomy of the horse as a basis for the study of types of horses and the requirements and capabilities of each type.

It is not possible to develop a good judge of any kind of live stock by teaching simply what to look for in an animal. A mere description of parts or points is not sufficient. The student wants to know why certain things are desirable in an animal, and why certain other things are undesirable. $\mathrm{He}$ must know the "why" of each point if he is to value each point properly and put emphasis where it belongs. This is especially true in learning to judge horses. No matter how carefully the points to be looked for in feet and legs are described, the student cannot recognize the importance of these parts and know what constitutes a first-class foot and leg, unless he has a fairly good idea of their anatomy and physiology. In the pages which follow, the writer has, therefore, given considerable attention to some of the essential features of horse anatomy before entering upon a description of the various types and market classes of horses.

\section{Definition of Horse Terms.}

Stallion.-Breeding male.

Mare.-The female.

Colt.-A young stallion.

Filly.-A young mare.

Foal.-Colt or filly under one year old.

Weanling.-A weaned foal.

Gelding.-Unsexed male, castrated under two years old. The best age to castrate colts is at one year old after they have been on pasture a few weeks but before fly-time. In the cornbelt the best time to castrate is the latter part of May. 
Stag.-Unsexed male, castrated when mature or so far advanced toward maturity that masculinity is plainly evident in head and neck. This constitutes coarseness in a horse for harness or saddle use.

Yeld mare.-A mare that has not raised a foal during the season; a dry mare. 


\section{CHAPTER XXVII.}

\section{BRIEF ANATOMICAL STUDY OF THE HORSE.}

In all animal life the cell is the structural and functional unit. A tissue is a collection of similarly differentiated cells. A number of tissues grouped together form an organ. The body is an aggregation of organs. We feed a horse to produce tissue and to produce energy. The systems of organs are seven in number. They are (1) skeletal, (2) muscular, (3) digestive, (4) respiratory, (5) genito-urinary, (6) nervous, and (7) integumentary.

Skeletal system.-The skeletal system is important as it largely determines the conformation of the horse. The skeleton of the horse is composed of a number of bony segments, most of which exist in pairs. The divisions of the skeleton are (1) head, (2) neck, (3) trunk, and (4) limbs. The head consists of numerous bones, mostly flat, united by sutures which gradually undergo obliteration with age. The lower jaws are strong and in each jaw there are six molar teeth (24 in all). Twelve of these are temporary-three in each jaw, and known as the 1st, 2nd, and 3rd molars, while the 4th, 5th, and 6th are permanent. There are also six incisors in the upper and six in the lower jaw, all of which are temporary and are entirely replaced by the time the animal is $4 \frac{1}{2}$ years old.

The vertebral column is a chain of 54 to 56 irregular bones (vertebræ) extending from skull to end of tail. There are seven cervical (neck) vertebræ, 18 dorsal (back), 6 lumbar (loin), 5 sacral (croup), and 18 or 20 caudal (tail) vertebræ. From above, the spinal column exhibits a concave cervical curve, a convex dorsal curve, a nearly straight lumbar region, and the sacro-caudal curve is concave below. The 3rd, 4th, and 5th dorsal vertebr: have the highest spines which form the withers.

There are 18 pairs of ribs, 8 of which are true and 10 false. The 8 true pairs join the 8 segments of the sternum or breast bone. The 7 th or 8 th ribs are longest. There is no collar bone (clavicle) as in man, and the fore limbs are not attached to the trunk but are connected by intervening muscles. The hind limbs are united to the trunk by the pelvic girdle which, in reality, is composed of three segments on each side. 
Muscular system.-The horse comprises a great number of systems of levers represented in the bones and joints, each supplied with a system of muscles which furnish the power. Muscles exert a force in only one way, and that by shortening, giving a pull. For this reason muscles are arranged in pairs, as illustrated by the biceps and triceps which move the forearm in man. The flexor muscles are always inside the joint and the extensors outside. The theory has been advanced that the shortening of muscles is due to a change in the form of the muscular cell from an elongated form to one nearly round

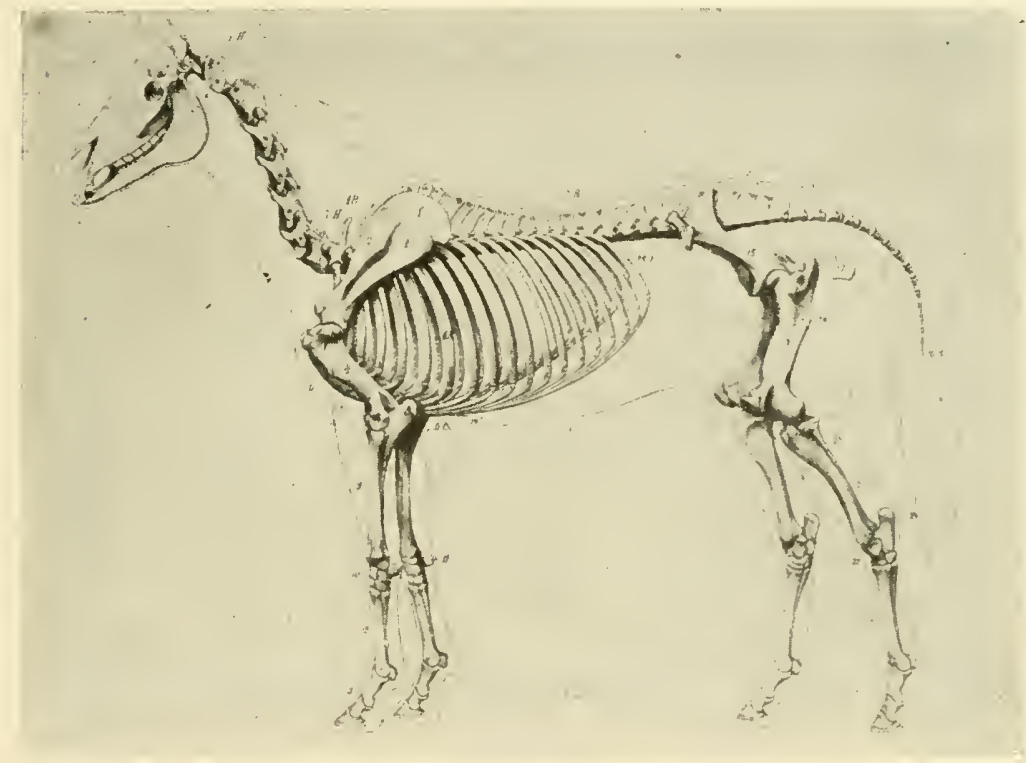

Fig. 108. Skeleton of the Horse.

This illustration shows the location of the bones and the degree to which the skeleton and the muscle influence the form.

when stimulated by nerve action. Muscles act through very short distances and upon the short end of levers composing the animal frame. Acting in this way, speed and distance are gained with a corresponding reduction in the magnitude of the force. Because muscles are able to act only through very short distances, it is necessary for them to act upon the short end of the levers in order that sufficiently rapid movement may be gained. 
The muscular system obtains its maximum development in the horse, and upon the excellence of this, beauty of conformation largely depends. Especially is this latter true of the neck and hindquarters. The muscles of the back and loin are the largest in the body. There are no muscles below the knees and hocks-only their tendinous prolongations. The first muscle under the skin almost covers the entire body and is the one that enables the animal to shake flies or any irritating foreign substance off its skin.

Digestive system.--The tongue is small as compared with that of the ox. The gullet is long and has a very small opening into the stomach. The capacity of the stomach is small, holding between 3 and 4 gallons, while the stomach of the ox holds 30 to 40 gallons. But the small size of the organ is compensated for by the large size and capacity of the intestines which hold twice that of the ox. The large intestine has a capacity of about 20 gallons, and the small one 12 gallons. The liver is large, as are also the kidneys.

Respiratory system.- The respiratory organs are well developed, and comprise the nasal cavities, the larynx, the trachea, the bronchial tubes, and lungs. The heart is large and four chambered, and the blood vessels are large and have strong, thick walls. Thus is the horse well fitted for his athletic life.

Nervous system.-The nervous system is well developed and comprises the brain and spinal cord. There are 12 pairs of nerves which take origin from these structures.

Integumentary system.- The hair or coat is shed in the spring and autumn, except that of the mane and tail which is permanent. There are both sweat glands and sebaceous glands in the skin, but the former are practically absent from the limbs.

In judging horses, the judge takes into consideration many matters relating to the structure and interior of the animal, as well as the exterior. A wide, deep middle and a broad muzzle, for example, indicate great digestive capacity; a large nostril and large chest show capacity for respiration; a silky coat and fine skin are normal qualities of the integument, while alertness and gracefulness of movement are evidences of good nervous control.

The horse differs from a mere machine in that he is largely capable of guiding his own movements without aid from his driver. Training accomplishes much in this regard, but the less a horse is possessed of intelligence and nervous control, the 
less he is automatic as a motor, and the more he becomes dependent upon his driver.

\section{Anatomy of the Fore Limb.}

From the top downward, the bones of the fore limb are as indicated in the accompanying diagram. The fore limb is composed of a scapula (or shoulder blade) which is articulated to the humerus (or arm) by a ball-and-socket joint, and the arm in turn articulates with the radius by a hinge joint. The lower end of the radius rests upon the upper row of the carpal bones of which there are 7 or 8 in the horse, corresponding to the wrist in man. Below the carpus (knee) is the large meta-

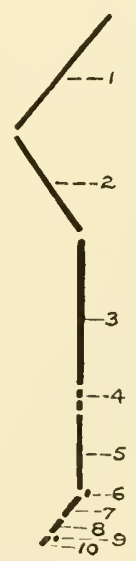

Fig. 109 Bones of the Fore Leg.

1, Scapula; 2, humerus; 3 , radius and ulna; 4 , seven or eight carpal bones; 5 , cannon bone and two splint bones; 6 , two sesamoid bones; 7 , large pastern bone; 8 , small pastern bone; 9 , navicular bone; 10 , coffin bone.

carpal (or cannon) bone, and articulated with the back of it are two slender rods of bones-the small metacarpal (or splint) bones. The lower end of the large cannon bone forms a hinge with the first phalanx (or large pastern bone), which is followed by the second phalanx (or small pastern bone), and then the third phalanx (or coffin bone), the two last named being enclosed within the hoof. In addition to these, at the articulation between the cannon and the large pastern bone are two small bones, known as the sesamoids, while at the back of the coffin joint there is a small bow-shaped bone, known as the navicular, which is frequently the seat of disease. 
The bones are held together by ligaments. Tendons are similar in character to ligaments, but differ in that they join muscle to bone.

The scapula, humerus, and radius and ulna are enclosed in heavy muscles which move them. There are no muscles about the knee and the parts below. Instead, long tendons pass down from the muscles above, thus connecting the power with the levers of the lower part of the limb. Hence there are only bones and tendons below the forearm, together with some very important ligaments which hold the bones in proper relation to one another. These ligaments are very strong elastic cords. The lower limb moves when the muscles exert a pull

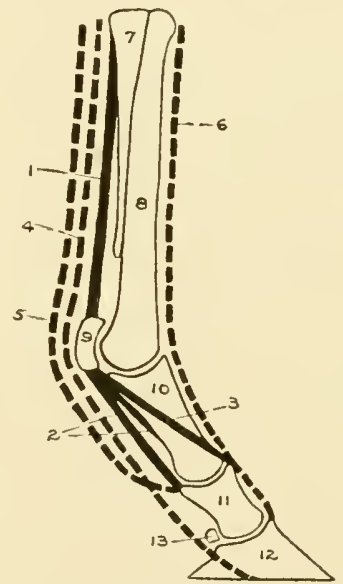

Fig. 110. Fore Leg from Knee to Ground.

Showing the bones, ligaments, and tendons. 1, Suspensory ligament; 2 , inferior sesamoid ligaments; 3 , branch of suspensory ligament; 4, flexor tendon of foot; 5 , flexor tendon of pastern; 6 , extensor tendon; 7 , splint bone; 8 , cannon bone; 9 , sesamoid bones; 10 , large pastern bone; 11 , small pastern bone; 12 , coffin bone; 13 , navicular bone.

on their tendons, which are likewise strong and elastic. The tendons and ligaments of the fore limb are shown in the accompanying drawing. The long ligament from fetlock to knee is the suspensory ligament. It supports the fetlock.

\section{Anatomy of the Hind Limb.}

The hind limb consists of the femur (or thigh bone) which is the largest in the body and articulates below with the tibia and also with the patella (or knee cap). The hock is composed 
of six bones which may be divided into two sets, each having a purpose of its own. One group of four small bones (tarsals), arranged in two rows and resting on the head of the cannon, are united together and to adjacent bones by short, powerful ligaments, and so close is the union that the movement of one bone upon another is reduced to a simple gliding action of very limited degree. Though slight, this movement is of much importance in breaking the jar communicated to this joint when the horse is in action. Above the small tarsal bones are two larger bones, the astragalus and calcaneus, as shown in Fig. 112.

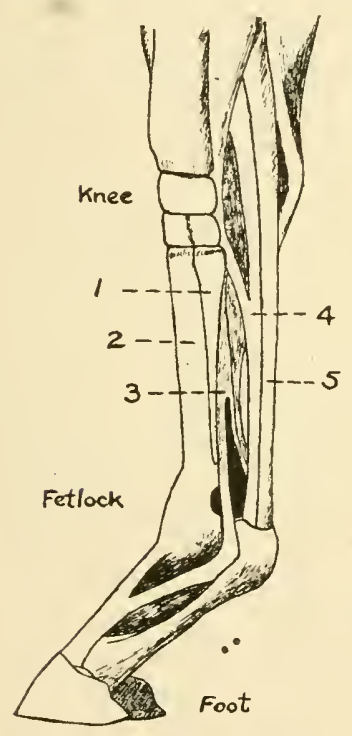

Fig. 111. Bones, Tendons, and Ligaments of the Fore Leg.

1 , Splint bone; 2 , cannon bone; 3 , suspensory ligament; 4 , flexor tendon of foot; 5 , flexor tendon of pastern.

To the calcaneus is attached the strong tendon known as the tendon of Achilles. By means of it the muscles above exert a powerful pull upon the hock joint, producing extension of the joint. This is the principal means of the horse's propulsion. The knob-like end of the calcaneus (to which the tendon attaches) forms the point of the hock. In some instances the pull upon the hock has been great enough to produce a fracture of this bone.

Sometimes a diseased condition is brought about by the ossification into one mass of some or all of the bones of the hock. This is called a bone spavin and is a serious unsoundness because it destroys the important gliding action of the tarsals, stiffens the joint, and often causes lameness. 
The parts below the hock are similar in structure to those below the knee.

The skeletons of man and horse compared show striking similarity, and at some points rather marked variation and difference in proportionment of parts. There are seven or

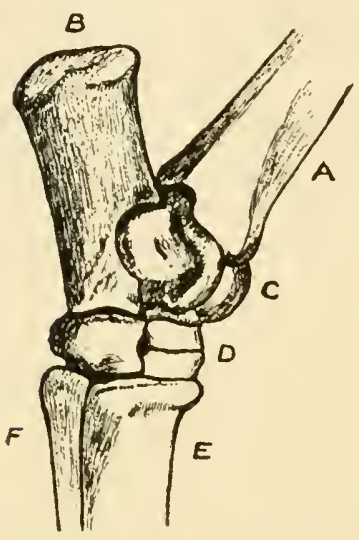

Fig. 112. Bones of the Hock.

A, Tibia; B, calcaneus; C, astragalus; D, tarsals; $\mathrm{E}$, cannon bone; $\mathrm{F}$, splint bone.

eight bones in the knee of the horse. The horse's knee corresponds to man's wrist. The bones below the horse's knee correspond to those beyond man's wrist. Following is a comparison of the bones and parts of the fore and hind limbs of the horse with the arm and leg of man:

Fore Limb of Horse

\section{Parts}

Shoulder

Arm

Forearm

Knee

Cannon

Pastern and foot 1st, 2nd, and 3rd

Hoof phalanges

\section{Scapula}

Humerus

Radius and ulna

7 or 8 carpals

3 metacarpals

Hind Limb of Horse

Parts

Croup

Thigh

Stifle

Gaskin

Hock

Cannon

Pastern and foot

Hoof
Bones

Ilium, ischium, and pubis

Femur

Patella

Tibia and fibula

6 tarsals

3 metatarsals

1st, 2nd, and 3rd phalanges

Arm of Man

Parts

Shoulder

Arm

Forearm

Wrist

Palm

Fingers

Finger nails

\section{Bones}

Scapula and clavicle

Humerus

Radius and ulna

7 carpals

5 metacarpals

(Thumb-2 bones

Other fingers - 3

bones

\section{Leg of Man}

Parts

Pelvis

Thigh

Knee

Calf

Ankle

Instep

Toes

Toe nails

\section{Bones}

Ilium, ischium,

Femur and pubis

Patella

Tibia and fibula

8 tarsals

5 metatarsals

\{ Great toe -2 bones

Other toes -3 bones 
The following drawing makes clear the comparison between the hind limb of the horse and the foot of man.

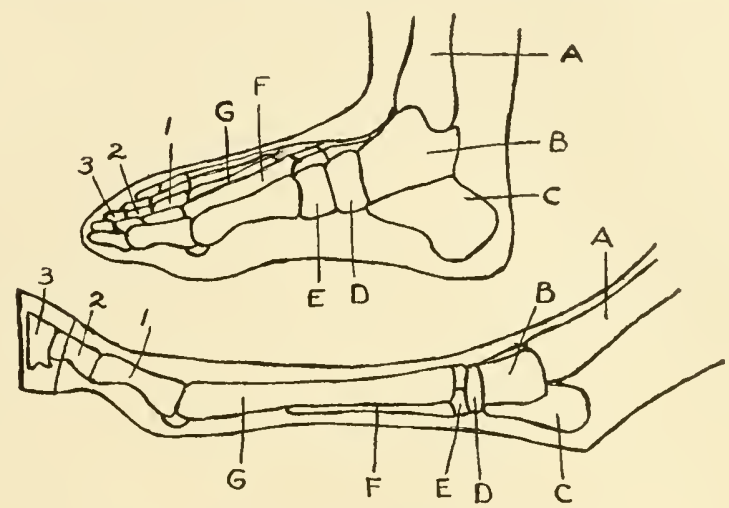

Fig. 113. Man and Horse Compared.

Bones of the human foot and hind leg of horse compared. A, Femur; B, astragalus; C, calcaneus; D and E, small tarsals; F and G, metatarsals; 1,2 , and 3 , first, second, and third phalanges.

\section{Anatomy of the Foot.}

The foot is not a mere block of horn, but is a composite structure made up of particular parts, each with a certain work to perform. There is an old saying, very full of truth, "No foot, no horse." A knowledge of the structure of the foot is very essential in learning to judge horses.
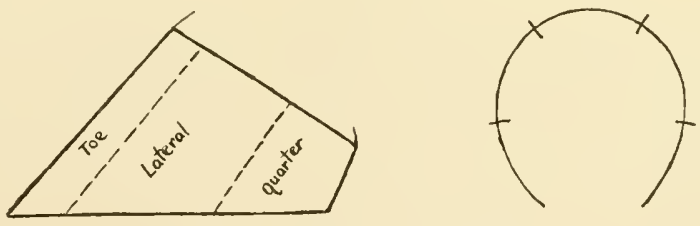

Fig. 114. Exterior of the Hoof.

Showing division into toe, laterals, and quarters.

The exterior of the foot may be divided into five parts, each including one-fifth of the circumference. These are the toe, laterals, and quarters.

From the interior outward, the parts of the foot are the coffin bone, lower end of the small pastern bone, navicular bone, extensor tendon, flexor tendon, lateral cartilages, plantar cushion, pododerm or foot-skin, and the hoof. The foot also has its blood vessels and nerves. 
Bones.-The bones of the foot and pastern are four in number, three of which-the long pastern, short pastern, and coffin bone-placed end to end form a continuous straight column passing downward and forward from the fetlock joint to the ground. A small accessory bone, the navicular bone, lies crosswise in the foot behind the coffin joint, enlarging the joint surface. The short pastern projects about $1 \frac{1}{4}$ inches above the hoof and extends about an equal distance into it.

Tendons and ligaments.-The extensor tendon of the toe passes down the front of the pastern and attaches to the top and front of the coffin bone. The outer branch of the suspensory ligament attaches to the tendon a short distance above this point. The flexor tendon of the foot passes down between the

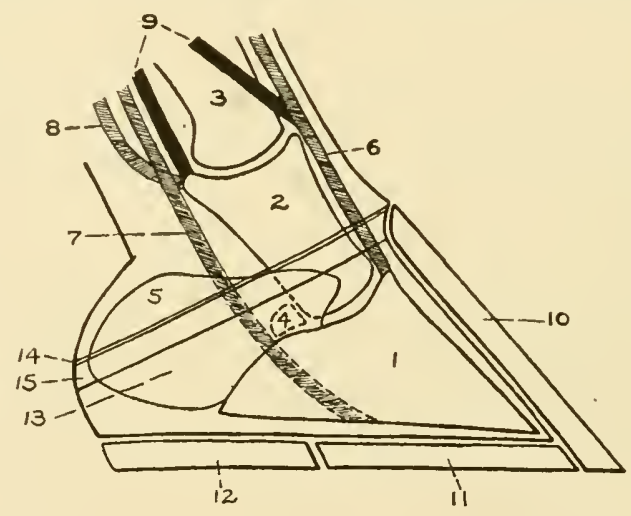

Fig. 115. Diagram Showing Structure of Foot.

1, Coffin bone; 2, small pastern bone; 3, large pastern bone; 4 , navicular bone; 5 , lateral cartilage; 6 , extensor tendon; 7 , flexor tendon of foot; 8 , flexor tendon of pastern; 9 , branches of suspensory ligament; 10, wall; 11, sole; 12, frog; 13 , indicates location of plantar cushion between the lateral cartilages; 14 , perioplic ring; 15 , coronary cushion.

heels, glides over the under surface of the navicular bone, and attaches to the under surface of the coffin bone. The bones of the foot are held together by powerful short ligaments.

Lateral cartilages and plantar cushion.-The elastic tissues of the foot include the lateral cartilages and the plantar cushion. The lateral cartilages are two plates of gristle, one on either side of the foot, extending from the wings of the coffin bone backward to the heels and upward to a distance of an inch or more above the edge of the hair, where they may be felt by the fingers. When sound, these plates are elastic and yield readily to moderate finger pressure, but from various causes 
they may undergo ossification, in which condition they are hard and unyielding and are called sidebones. The plantar cushion is a wedge-shaped mass of tough, elastic, fibro-fatty tissue filling all the space between the lateral cartilages, forming the fleshy heels, and serving as a buffer to disperse shocks. It extends forward underneath the navicular bone and flexor tendon, and protects these structures from injurious pressure from below.

Pododerm (or foot-skin).-The pododerm or horn-produc. ing membrane is merely a continuation of the derm, or true skin. It covers the foot inside the hoof, just as a sock covers the human foot inside the shoe. It differs from the ordinary external or "hair" skin in having no sweat or oil glands, but, like it, is richly supplied with blood vessels and sensitive nerves. The functions of the pododerm are to produce the hoof and unite it firmly to the foot.

The hoof and how it grows.-The horny shell, called the hoof, which covers and protects the foot, is made up of three parts, (1) the wall and bars, (2) the sole, and (3) the frog.

Each part of the hoof is grown by some particular part or parts of the pododerm. In general it may be said that the horn of the hoof is made up of tubules or shafts of horn which grow from papillæ the same as does hair. These tubules are cemented together by non-tubular matter corresponding to dandruff exfoliated by the skin. In fact, so pronounced is the similarity in growth of horn and hair that coarse hair, especially on the legs and coronet, is associated with horn of coarse texture. Therefore the more coarse and brittle the hair about the coronet, the more porous, brittle, and weak will be the formation of the horny hoof.

The wall horn consists of three layers known as (1) the outer or perioplic layer, (2) the middle or coronary layer, and (3) the inner or laminous layer. The perioplic layer is very thin. It is varnish-like in appearance and forms the surface or crust of the wall. Its function is to preserve the moisture of the foot and to absorb moisture. A horse working in sand or dust usually has this outer layer worn away. The coronary layer forms the real basis of the wall. At the heels it is deflected forward to form the bars of the hoof. The angle between the wall and bar is thickened and is called the buttress. The function of the bars is to react against contraction of the heels. The inner or laminous layer of the wall horn is not tubular. It 
is called laminous because it has the appearance of the leaves of a book. There are 500 to 600 of these laminæe which extend from the top of the hoof to the sole. It is less thick than the coronary layer, but, like it, is deflected forward at the heels to help form the bars.

Growth of the wall.-At the lower end of the pastern, running along the edge of the hair from one heel around the toe to the other heel, is a narrow ridge of pododerm, $\frac{1}{16}$ to $1 / 8$ of an inch wide, called the perioplic ring. It consists of papillæ, which are microscopic nobs or nodules, and from each papilla a shaft of horn grows downward, forming the periople of the wall. Like the periople, the coronary layer grows downward from a band of pododerm at the top of the hoof. This band is

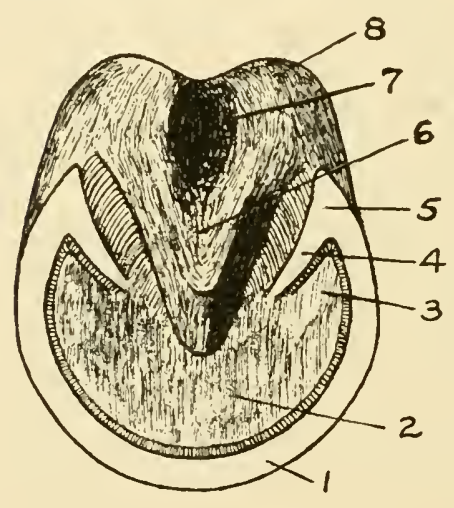

Fig. 116. The Parts of the Hoof.

1 , Wall; 2 , sole; 3 , branch of the sole; 4 , bar; 5 , buttress; 6 , frog; 7 , cleft of the frog; 8 , bulbs of the heels.

called the coronary cushion, and it lies just below and parallel to the perioplic ring. At the heels it is deflected forward where it produces the horn of the bars. The laminous horn is produced by that part of the pododerm known as the fleshy laminæ; these laminæ extend up and down between the coronary cushion and the sole. The fleshy laminæ of the pododerm and the laminous layer of the wall horn dovetail together, thus holding the hoof securely to the foot.

The sole horn is circular in shape except that it is notched at the rear where it receives the bars and horny frog. It is naturally concave below and is bounded at its edge by the wall and bars. It is very brittle, non-elastic, and easily penetrated. The sole horn is produced by the fleshy sole, which is that portion of the pododerm covering the entire under surface of the foot excepting the fleshy frog and bars. 
The horny frog does not come in contact with the sole horn except at its apex. It is tough, elastic, and rather soft horn. The upper part of the horny frog has an elevation or ridge and on the bottom there is a corresponding notch or groove. The horny frog grows from the fleshy frog, which is that part of the pododerm just above the horny frog.

The preceding discussion of the parts of the hoof and pododerm may be summarized as follows:
1. Wall $\left\{\begin{array}{l}\text { Perioplic layer, produced by perioplic ring. } \\ \text { Coronary layer, produced by coronary cushion. }\end{array}\right.$
2. Sole, produced by fleshy sole.
3. Frog, produced by fleshy frog.

All parts of the hoof grow downward and forward $w$ th equal rapidity, the rate of growth being largely dependent up 11 the amount of blood supplied to the pododerm. Abundant and regular exercise, good grooming, moistness and suppleness of the hoof, going barefoot, plenty of good food, and at proper intervals removing the over-growth of the hoof and regulating the bearing surface-all these, by increasing the volume and improving the quality of blood flowing into the pododerm, favor the rapid growth of horn of good quality. Lack of exercise, dryness of the horn, and excessive length of the hoof hinder growth. The average rate of growth of the hoof is about onethird of an inch a month. Irregular growth often occurs. This is almost always due to an improper distribution of the body weight over the hoof,- that is, an unbalanced foot. One authority on this subject says:- "If breeders were more generally cognizant of the power of overgrown and unbalanced hoofs to divert the lower bones of young legs from their proper direction, we might hope to see fewer knock-kneed, splay-footed, pigeon-toed, cow-hocked, interfering, and paddling horses."

Characteristics of a healthy foot.-A healthy foot is equally warm at all parts, and is not tender under pressure with the hands. The coronet is soft and elastic at all points and does not project beyond the surface of the wall. The wall is straight from coronet to ground, so that a straight-edge laid against the wall from coronet to ground parallel to the direction of the horn tubules will touch at every point. The wall should be covered with the outer varnish-like layer of horn called the periople, and should show no cracks or clefts. Every hoof shows "ring formation," but the rings should not be strongly marked 
and should always run parallel to the coronet. Strongly marked rings are evidence of a weak hoof, but when limited to a part of the wall are evidence of previous local inflammation. The bulbs of the heels should be full, rounded, and of equal height. The sole should be well hollowed out, the frog well developed, the cleft of the frog broad and shallow, the spaces between the bars and the frog wide and shallow, the bars straight from buttress toward the point of the frog, and the buttresses themselves so far apart as not to press against the frog. A hoof cannot be considered healthy if it presents reddish, discolored horn, cracks in the wall, bars, or frog, thrush of the frog, contraction or displacement of the heels. The lateral cartilages should yield readily to finger pressure. Some horsemen object to a white hoof, believing it to be less durable, but a white hoof is as good as a dark-colored one. Horn of good quality is fine grained and tough, while poor horn is coarse grained and either too mellow and friable or hard and brittle. 


\section{CHAPTER XXVIII.}

\section{SOME IMPORTANT FACTS CONCERNING THE HORSE.}

Base of support.-The horse's legs are his base of support, just as the table legs support the table. The longer the legs, the less stable the base of support. The smaller the base of support, the less stable it will be. The less stable the base of support, the greater the speed of the horse; while the greater the stability, the greater the power for draft. The base of

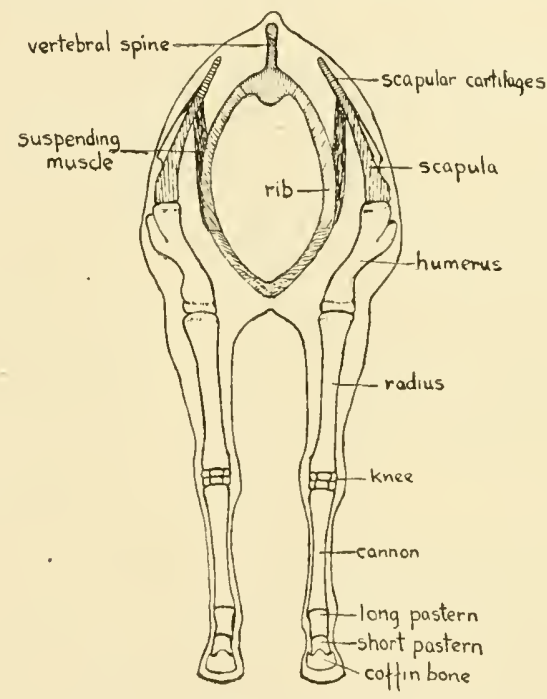

Fig. 117. Attachment of Fore Leg to Body.

Cross-section through chest, showing the bones of the fore leg and the muscular attachment of leg to body.

support of any object will be most stable when it comes directly beneath the center of weight. In horses the center of weight is far forward, lying immediately behind the shoulders. Thus the fore legs support much more of the weight of the horse than do the hind legs, in fact it is the function of the forequarters to support, and of the hindquarters to propel. This is the more clearly shown when we examine the anatomy of the horse, for we find that the hind legs are attached to the trunk by the strong ball-and-socket joint, while the fore legs are not directly attached 
to the trunk but are connected by intervening muscles which form a sort of sling which suspends the body between the two fore legs. The muscle attaching the fore limb to the trunk is called the serratus magnus. It is an enormous triangular muscle which originates on the upper part of the internal surface of the shoulder blade and spreads out like a fan on the sides of the chest and neck and ends on the cervical vertebræ and first eight or nine ribs. The drawing presented herewith shows a front view of the muscular attachment of the scapula to the neck and trunk.

When the horse is standing, the base of support is represented by a rectangle the corners of which are the horse's feet. In the walk, the base of support is triangular, for then only three feet touch the ground. In the trot or pace, only two feet touch the ground, and the base of support will be represented by a line. In the run or gallop, the base of support is a point. Thus as speed increases there is a corresponding decrease in stability.

The horse in motion.-We have seen that the horse is rather unstable because the center of weight lies almost over the fore legs. Hence the fore legs answer the purpose simply of a support to the horse's weight when he is in motion. If we could replace the fore legs with a wheel, we would have an equally efficient motor.

When a man walks, he leans forward in order to throw the center of his weight ahead of his base of support. This causes him to begin to fall forward, and indeed he would fall if he did not advance his foot and so bring his base of support once more under, or nearly under, the center of weight. Walking is simply a succession of interrupted falls. The same is true of the horse. In walking he pushes backward against the ground with his hind feet and causes his center of weight to tip forward. The result is that he begins to fall, and if he did not advance a fore foot he would land on his head. By stepping forward he again assumes his equilibrium and immediately tips his weight forward again by propelling with his hind legs. Walking is simply the repetition of this performance over and over again.

In the trot and the gallop or run, there is the same backward thrust with the hind feet and the same recovery with the fore feet, but the thrust is much greater, the stride is longer, and the shock and effort in the recovery are increased in proportion. 
In 1897, Tod Sloan, a famous American jockey, went to England to ride. He practiced the same seat which all American jockeys use and with which all Americans are familiar. Its peculiar feature is that the jockey sits as far forward on the horse as possible. When Sloan appeared on English race courses he was severely ridiculed, for at that time English jockeys were not familiar with our methods and it was thought Sloan was trying to attract attention to himself by adopting a ridiculous position on his horse. Race-going people laughed at him until it was noticed that he was enjoying unusual success at winning races. Sloan rode twenty winners during his first season in England, forty-three the next, and in 1899 he was first past the post with no fewer than one hundred and eight horses. In the same year, two other Americans, the brothers Lester and Johnny Reiff, also had eighty-two victories to their credit. The methods of these American jockeys were soon copied by most of the English riders, but the Americans continued to pile up a remarkable record of successes, culminating in three successive Derby triumphs-Lester Reiff's in 1901, Martin's in 1902, and Maher's in 1903. During eight years ending in 1905, the eight or nine American jockeys who appeared in England for one or more seasons divided among them, in retainers, winning fees, and etceteras, fully a million dollars. Their work made a new chapter in English turf history.

No sooner had Sloan shown ability to win consistently than people began trying to find out the secret of his success. They could see that he carried himself as far forward on his horse as possible, and so these questions arose:-Does a man seated near the neck of a horse enable the animal to travel faster than one seated near the tail? If so, why? As for the first question, Sloan gave it a practical answer by his consistent winnings. The second question was also finally answered.

A horse to move forward at all must thrust at the earth, and the chief force of this thrust comes from his hind legs. If the center of weight of horse and rider is just over, or close to, the thrusting power, naturally it diminishes the efficiency for speed, for instead of thrusting the horse forward, a large portion of the muscular energy is wasted in lifting the weight of the jockey at every stride. The drawing below and the words which follow will make this clear.

The farther forward the center of weight is, the longer is the line from hind foot to center of weight, called the line of 
thrust, and the more nearly will this line approach the horizontal. As a horse has to raise himself vertically with each bound, it is naturally a matter of very great importance whether he has to lift a dead weight or a weight which throws forward. A jockey on the horse's neck adds to the forward weight, and this moves the center of weight still further forward and places still more weight on the fore legs and equally less on the hind legs. The longer the angle of thrust, the easier and therefore the faster the horse will go, for his power will then be utilized almost exclusively in a horizontal thrust resulting in speed, and little of his energy will be consumed in simply raising weight to let it fall again. It is the same as a man pushing a wheelbarrow;

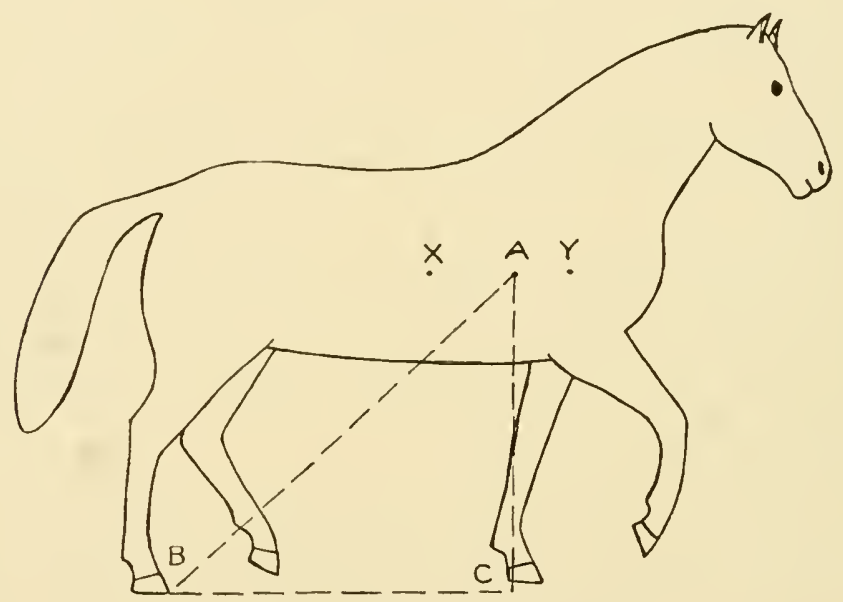

Fig. 118. The Horse in Motion.

$\mathrm{A}$, Center of weight; $\mathrm{AB}$, line of thrust; $\mathrm{ABC}$, angle of thrust; $\mathrm{Y}$, center of weight when rider is over neck of horse; $\mathrm{X}$, center of weight when rider sits near the tail.

if the load is near the handles it must be raised at each step, while if the load is over or near the wheel the man does not expend so much energy in a lift at each step, but can use all his force at pushing straight ahead.

Where the wear comes.-From what has been said concerning the function of the fore legs in supporting most of the horse's weight, we can readily understand that the horse is more apt to tire, exhaust, and ruin his fore legs than his hind ones. It is common to see men driving their horses at speed when going down hill, thinking that the horse is doing little 
or nothing because the vehicle follows without having to be pulled. This is a decided error, for in going down hill still more weight is thrown on the fore legs, and if the animal is made to descend at speed he hammers his fore legs severely, and often stumbles and falls. Because of the hammering to which the fore legs and feet of the horse are subjected, and because of the great strain coming upon the hock joint due to its prominent part in propulsion, the feet and legs constitute a most vital part in every type of horse, and special attention should be given to front feet, front pasterns, the hocks, and the set or position of the hind legs when judging.

Hoof mechanism. - When the horse places his foot on the ground, expansion occurs, especially at the heels When the foot is raised there is contraction. The plantar cushion, being soft, transmits force or motion in all directions more or less equally (as a liquid). It cannot move downward to any great degree, hence it spreads or diffuses laterally, and so the heels expand. When the horse places his foot on the ground there occurs:-(1) Contraction of the hoof at the toe-wall coronet; (2) sinking of the sole, especially at its branches; (3) expansion of the heels; (4) sinking of the bulbs of the heels. These four movements constitute what is known as the "hoof mechanism." The health of the foot is dependent on the normal and free hoof mechanism, and it should not be hindered by improper shoeing or other causes. Hoof mechanism breaks concussion and assists circulation. Concussion is shock and counter-shock. These shocks must be diffused, and this is cared for laterally in the foot by its changes in form.

Absorption of concussion.-Every step at the walk or trot means a big concussion between the ground and the front foot of the horse. Were it not for certain arrangements for the absorption of this shock or jar, the horse would soon be made worthless. Hoof mechanism is, as we have seen, one of the means of scattering the shock, acting in much the same way as a pneumatic tire on a vehicle. Another safe-guard is found in a sloping pastern, which acts in much the same manner as the spring under a carriage. Then there is the angle between humerus and forearm, and also between scapula and humerus, which also act as springs. A sloping shoulder is useful in the same way.

If you have ever ridden in a farm wagon over a rough road, standing on your heels, you can appreciate the tremendous wear 
which comes on the legs of a horse with poor feet, straight pasterns, and straight shoulders. Then if you shifted your weight to your toes and bent your knees slightly, you found that your teeth stopped chattering and your hat remained on your head.

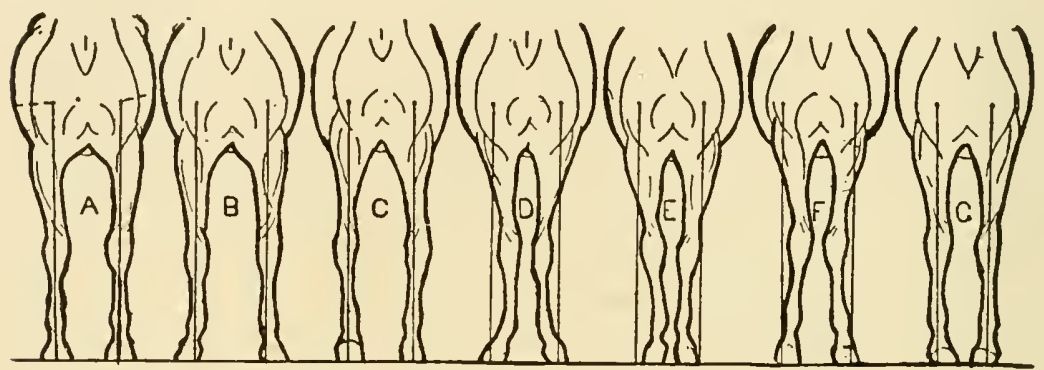

Fig. 119. Front View of Fore Legs.

A vertical line downward from the point of the shoulder should fall upon the center of the knee, cannon, pastern, and foot. A, Ideal position; B, toes out; C, bow legged; D, narrow chested and toes out; E, stands close; F, knock kneed; G, pigeon toed.

In other words, your change in position changed the column of bones supporting your weight from a straight, vertical column to a broken one with angles which acted as springs and absorbed the jar. It is just so with a horse having good feet and nicely sloping shoulders and pasterns.
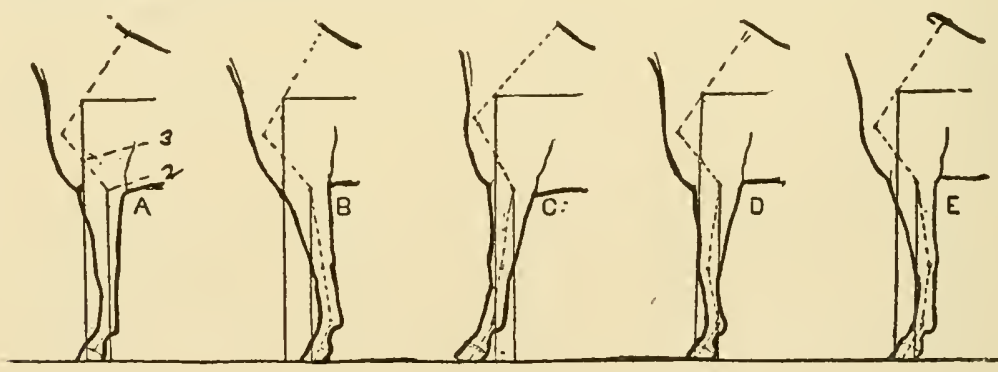

Fig. 120. Side View of Fore Legs.

A vertical line downward from the center of the elbow joint should fall upon the center of the knee and fetlock joints and meet the ground back of the heel. A, Ideal position; B, camped under; C, camped out; D, knee sprung; $\mathrm{E}$, calf kneed.

\section{Defective conformations of the legs and effects on action.-} A line around the hoof on the ground gives the area of the base of support of that leg. If the center of the base of support of the leg is not directly under the center of the weight falling on that leg, the side of the foot nearest the point directly under 
the center of weight will be compelled to do more than its share of the work. Therefore the leg of the horse should be so set that the center of the base of support comes directly under the center of the weight it bears. The fore legs should be so placed
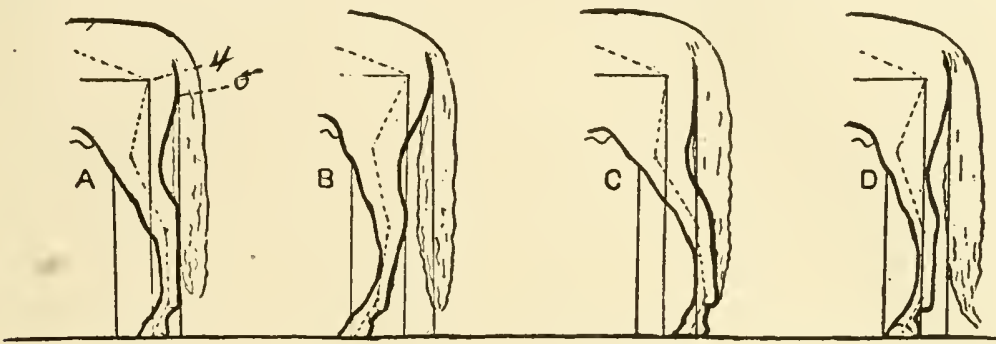

Fig. 121. Side View of Hind Legs.

A vertical line downward from the point of the buttock should touch the reariedge of the cannon from hock to fetlock and meet the ground some little distance behind the heel. A, Ideal position; B, stands under; C, camped out; $\mathrm{D}$, hind leg too straight.

under the body that, when viewed from in front, a perpendicular line dropped from the point of the shoulder will divide the leg and foot into lateral halves. When viewed from the side, a perpendicular line dropped from the middle of the forearm where it joins the body should divide the leg from body to fet-
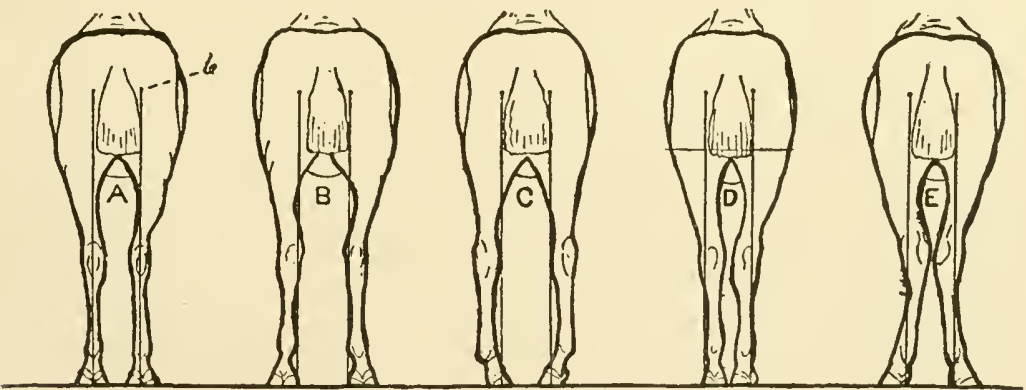

Fig. 122. Rear View of Hind Legs.

A vertical line downward from the point of the buttock should fall upon the center of the hock, cannon, pastern, and foot. A, Ideal position; B, stands wide; C, bow legged; D, stands close; $\mathrm{E}$, cow hocked.

lock into lateral halves and strike the ground just back of the heel.

When the horse assumes his natural position, the hind legs should be so placed that, when viewed from the rear, a perpendicular line dropped from the point of the buttock will divide 
the leg and foot into lateral halves; and when viewed from the side, this line should touch the rear edge of the cannon from hock point to fetlock and meet the ground some little distance back of the heel.

The direction and slope of the axis of pastern and foot are very important. When the leg is viewed from the front or side, the axis of the pastern and the axis of the foot should be identical. As viewed from the front, the toe should point directly forward. This insures an even distribution of weight to both sides of the foot and also trueness of action. As viewed from the side, the axis of the front pastern and foot should meet the ground at an angle of about 45 degrees. This angle affords the best combination of strength and springiness.

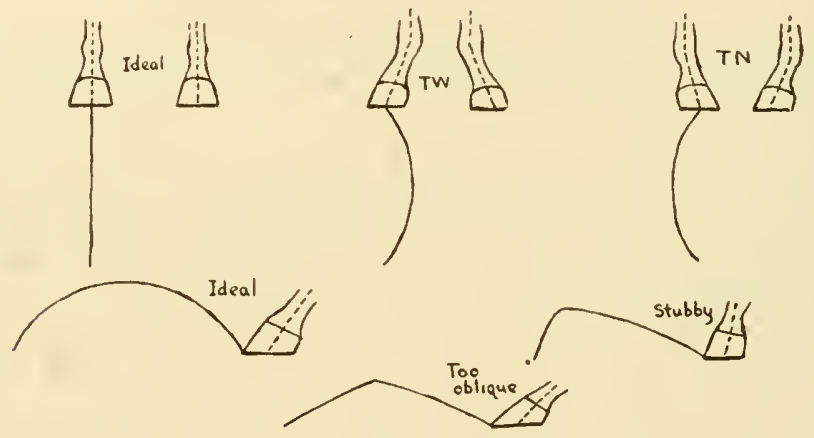

Fig. 123. Defects in Fore Legs and Their.Effect on Action.

When moving toward or from you, the feet of the horse should appear to have only one motion, which should be vertically up and down. This is very essential in every type of horse. Height of action in any type should be great enough to clear the ground by a reasonable distance, so as to prevent stumbling and insure length of stride. The carriage horse is required to go higher than this for reasons which will be explained in connection with the description of that type. The essentials of good action are (1) straight line action, (2) long stride, and (3) foot should be picked up with snap. Defects in conformation and placing of feet and legs result in defects in action. Only when the legs are correctly proportioned and properly placed can good action result. Correctness of action depends also upon temperament, strength of muscling, height over withers as compared with height over hips, and general symmetry and proportionment of parts. The most common 
defects in the shape and position of the legs are shown in the accompanying drawings.

A horse that is "base wide" or "toe wide" in front, swings the leg inward when in action. A "base narrow" or "toe narrow" conformation results in the horse swinging his feet outward, or "paddling" as it is called. (See accompanying drawings.) Horses that naturally stand wide at the hocks will travel the same way (wide), which is very undesirable. When the hind legs are bowed outward, the hocks spread still further outward when the stress comes upon them in action, and usually the foot leaves the ground with a twisting motion which wears out shoes and is otherwise undesirable. Any deviation from trueness in the flight of the foot wastes energy, detracts from the appearance of the horse in action, and the horse may strike himself, called interfering, which often causes blemishes, lameness, and stumbling.

Viewed from the side, a nicely sloping foot and pastern leave the ground easily and describe the are of a circle at every step. Straight or stubby pasterns and feet result in a short, stubby way of going that is stilted and non-elastic. A toosloping pastern and foot are not nicely carried, but are brought out straight to a point in front and then slapped upon the ground. (See accompanying drawings.) Other defects of action will be discussed in connection with the various types of horses.

Bent or sickle hocks. - This defect is often difficult for beginners to detect. It is often possible to pose a horse so as to hide this fault unless one knows exactly how to detect it under all conditions. When a horse with a sickle hock stands in a natural position, the defect is easily seen. A vertical line downward from the point of the buttock may then touch the point of the hock, but below that point the cannon slopes forward instead of following the vertical line, and the hind foot is placed too far forward. (See B in Fig. 124, and note that this is not the same defect as B in Fig. 121.) Some horses are very slightly sickled and some are very crooked indeed. Such a conformation is decidedly objectionable because bent hocks are not as stout as straight hocks at a hard pull or at work of any kind, and furthermore the crooked shape of the hock and leg brings an added strain on the hock joint. The sickle hock often develops a curb, and is also subject to other unsoundnesses.

In showing horses, it is common to stretch them out on their legs to a slight extent, so as to raise the head and neck, level 
up the croup, and increase the slope of the front pasterns. A horse in such a position is more apt to hold it than a horse standing naturally, and for all these reasons it is practiced by horsemen. It also has the advantage of covering up defects in the set of the legs, particularly a sickle hock. If a horse with sickle hocks is stretched or "camped out" a bit, his hind cannons become vertical, and the novice is likely to overlook the fact that the line of his cannons, even though it is vertical, points back of his buttock, often to a considerable degree. (See $\mathrm{C}$ in accompanying drawings, and note that this is not the same as $\mathrm{C}$ in Fig. 121.) It is only by noting carefully the direction of the lines indicated in the accompanying drawings that one can detect this fault.

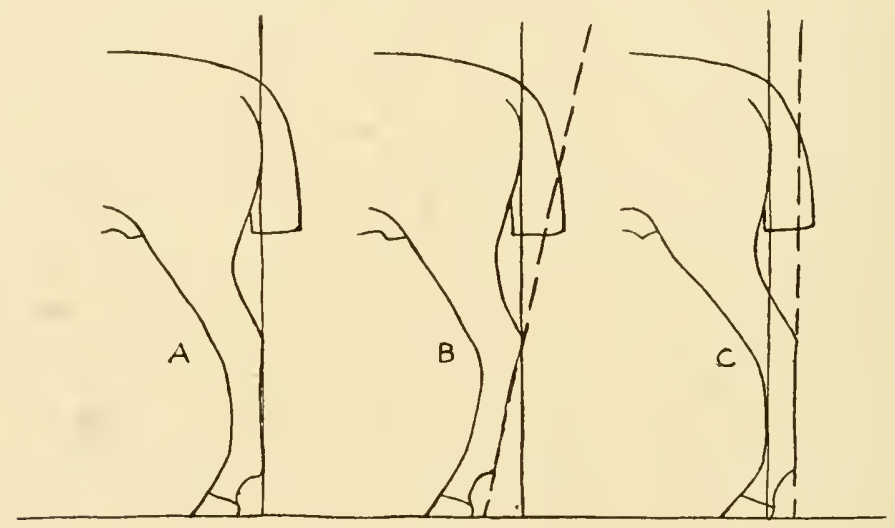

Fig. 124. Sickle Hock.

A, Hind leg of a horse of correct conformation; B and C, two positions of the hind leg of a horse with a sickle hock; $\mathrm{B}$, in a position easily exposing the defect; C, in a position in which the defect is not so apparent.

Determination of age from the teeth.-The age of the horse is easily determined up to and including the fifth year by an examination of the incisor teeth, of which there are three pairs in the upper jaw and three pairs in the lower. All of these incisors are temporary or milk teeth up to two years of age. At birth none of the temporary teeth have cut the gums, but at one year they have all appeared and the middle and intermediate pairs are in wear, but the corner pairs are not fully in wear. At two years, all of the temporary teeth are in wear. At $21 / 2$ to 3 years, the middle pair above and below are shed, and are replaced by permanent incisors. These are broader, heavier teeth, and have a rather rough or corrugated surface, whereas 
the surface of the milk teeth is smooth. At $31 / 2$ to 4 years, the intermediate pair of permanent incisors appears in each jaw. At $4 \frac{1}{2}$ to 5 years, the corner pair of milk teeth above and below are displaced by permanents, and the horse may be said to have reached maturity.

After five years the age is not so easily determined, nor are the indications so accurate. We rely mostly upon changes in appearance shown by the wearing surfaces of the teeth to tell us the age beyond five years. The wearing surface of new permanent teeth has a long, narrow cup or depression running across it transversely. The rims of these cups disappear through wear, leaving two distinct rings of enamel, one around the margin of the tooth, and the other around the cup. With wear, the cup becomes smaller, more oval or rounding in shape, and more shallow, until it is finally worn almost completely away. Continued wear exposes the tip of the pulp canal or cavity in the center of the tooth, and the exposed tip of this canal appears between what is left of the cup and the front of the tooth. The exposed pulp cavity is called the dental star.

At six years, the middle pair in the lower jaw are usually worn level and the wearing surface tends to become oval in form. The central ring of enamel is plainly evident, but is smaller than at five years, indicating considerable wear. The lower corner teeth, which at five years showed little or no wear, now usually show wear, the edge surrounding the cup being much less sharp and shell-like. The canine teeth, which first appeared at four years are now completely out. At seven years, the lower intermediates are also levelled on the wearing surface and the ring of central enamel becomes wider from before backward, and shorter from side to side. A hook or swallow tail is often present on the upper corner teeth because they are broader than the lower corners and do not wear down evenly. At eight years, all the lower teeth are levelled and the dental star appears upon the center and intermediate pairs, showing between the front border of the tooth and the front border of the central enamel.

At nine years, the hook or swallow tail on the upper corners has often disappeared. The lower centers are round; their central enamel has a triangular form; and their dental star is narrower and more distinct. The center pair of the upper jaw are usually levelled. At ten years, the changes previously mentioned become more marked, and the upper intermediates are 
usually levelled. At eleven years, the central enamel of the upper corner teeth becomes elliptical and tends to disappear. The lower teeth now show much wear, the central enamel forms a small ring only, very close to the back border of the tooth, while the dental star becomes narrower and also approaches the back border. At twelve years, all of the lower teeth are round, and sometimes the central enamel has disappeared, in which case the wearing surfaces show only a small yellowish spot which is the dental star. At fifteen years, the swallow tail, which reappeared at ten years, is still in evidence, the teeth tend strongly toward a triangular shape on the wearing surface, and other indications of age become marked. At twenty-one years, the swallow tail is gone again, and all indications of wear are very marked. After ten or eleven years and on up to thirty or more, only general indications serve as a guide to the age. The horseman knows that the teeth change from oval to threesided with age, and that they project or slant forward more and more each year. In very old horses these features are very marked.

In determining the age, a regular procedure should be followed. First open the lips and determine whether the teeth are temporary or permanent. Unless they are all permanent it is usually unnecessary to open the mouth. If they are all permanent, the wearing surfaces of the lower incisors should be carefully examined first, and then the wearing surfaces of the upper incisors. Also note the profile or slant of the teeth, and the presence or absence of the hook or swallow tail on the upper corner teeth.

Mere description here will not enable the student to become adept at determining age. Actual practice and the study of many mouths are necessary in order to master this subject.

Determination of the height of horses.-The height of a horse is determined by measuring the vertical distance from the highest part of his withers to the ground. The unit in which the height of horses is expressed is the hand. A hand is four inches. A horse measuring 60 inches high is thus said to be 15 hands high; a horse measuring 63 inches is said to be "fifteen, three," meaning 15 hands, three inches, written 15-3; and one measuring 65 inches is 16-1 hands high. The dividing line in height between horses and ponies cannot be definitely fixed, but is about 14 hands. Ponies vary in height from 14 hands down to 8 hands or even less, while horses vary from 14 hands 
up to 18 hands and over. With practice the height of horses may be estimated very closely without the aid of a measuring standard. A person who knows the exact height from the ground to the level of his eyes, and also the exact height from the ground to his chin, can step up to the shoulder of a horse, locate the highest bony part of the withers, and estimate the height very easily. 


\section{CHAPTER XXIX.}

\section{ORIGIN OF THE TYPES OF HORSES.}

The history of the horse dates back to 4000 B. C. Several wild species existed in Europe and Asia from very remote times, but it was in Asia Minor and Egypt that the horse was first domesticated and made to serve man. He was taken thence to Greece, Rome, and Arabia; thence to more remote parts of Europe and Asia, particularly to Spain, France, and England; and thence to America and Australia.

For a long time the horses used by the early European tribes and nations were small, semi-wild animals, and no effort was made to improve them by breeding. They were simply native wild horses, captured, tamed, and put to use, and their size and strength was not great enough to permit them to be ridden. They were used principally in warfare, harnessed to chariots. However, there were horses of black color and much greater size and weight native to the region in Western Europe now called Flanders, and these were taken south and east, just as the horses of Asia Minor and Egypt were taken north and west. The infusion of the blood of this large Flemish horse increased the size of European horses and made them suitable for riding and other purposes. Better feed and care also contributed to this result.

The development and progress of the horse was parallel with the development of civilization and a prominent factor in it. The horse was first used for military purposes; next, in ceremonies, both religious and civil; third, in the agricultural and commercial pursuits of nations; fourth, in connection with the pastimes and sports of nations.

First saddle horse. - The Arabian horse was the first breed of live stock developed by man. This horse is a saddle type and was developed by the nomadic tribes of the desert for use in warfare. The exact origin is unknown, but the great age of the breed is shown by a legend which says that it is descended from five mares in the stud of King Solomon. It seems to have descended directly from the wild Libyan horse native to Northern Africa-most excellent of all known wild varieties of the horse. The Arabian has for centuries possessed such equisite quality, 
refinement, intelligence, spirit, docility, and beauty as to make him universally admired and famous. He was taken to England at the close of the seventeenth century and was used in founding the English Thoroughbred and also the Norfolk Trotter which later became the Hackney. In Russia he helped produce the Orloff Trotter, and the Percheron breed of France is also thought to owe some of its excellence to Arab blood in its foundation. Inasmuch as the Yorkshire Coach Horse, Cleveland Bay, American Trotting Horse, American Saddle Horse, and the Morgan are all sprung largely from the Thoroughbred, every breed of light horses carries the blood of the Arab in greater or less degree.

Turk, Barb, and Spanish horses.-The Turk, or Turkish horse, found in portions of European Turkey, but principally in Asia Minor, was of considerable importance in the seventeenth century, but it has deteriorated very much since then. The Barb is a native of the Barbary States, whence its name. It is found in its greatest perfection among the Moors, who introduced the Barb blood into Spain during their rule in that country, and so improved the Spanish horse that for several centuries it occupied the first place throughout Europe. Spanish horses of this stock brought to America by the Spaniards are regarded as the progenitors of the wild horses once common to Mexico and California.

Origin of the running horse.--In later times, England became the center of horse breeding and the nursery of most of the present-day breeds. One of the first types of horses developed in England was the running horse, the sport of racing having been fostered there from an early date. Long before an Arabian, Barb, or Turk stallion set foot on English soil, a strain of running horses of considerable excellence had been developed, hence the Oriental stallions which were later imported cannot be given more than half the credit for founding the running horse or Thoroughbred. The Thoroughbred owes. his origin jointly to the native running mares of England and to the Arabian, Barb, and Turk stallions imported at the close of the seventeenth century.

The Great Horse or War Horse.--The first type of English horse was the "Great Horse" or "War Horse" used during the Crusades and up to about the year 1600 to carry the warriors clad in their suits of heavy armor. A knight in heavy armor, together with the armor for his horse, weighed about 
400 pounds, hence the necessity for a big, strong horse. The native English horse was small, and in order to increase the size and strength, Flemish stallions were imported from Normandy, and for nearly 500 years English breeders centered their attention on the matter of size. With the appearance of gunpowder and firearms in warfare, armor was made useless and the heavy war horse gave way to much lighter animals with more speed.

Origin of draft type.-When displaced in warfare, the ponderous war horse did not become extinct, but was put to work at tilling the soil. Prior to this, field labor had been performed solely by oxen, and the ox continued in use as a draft animal even after horses were introduced for farm work. The war horse thus became an agricultural horse and in time was utilized as the foundation of the British draft breeds-the Shire and Clydesdale-just as the Percheron breed was built up from the heavy diligence horses used in France in the early days when roads were deep in mud. The railroad later displaced the diligence horse and he found a place on the farm. When a demand arose from cities for a horse suited to moving heavy freight through the streets, these agricultural horses in England, Scotland, France, and Belgium were bred larger, heavier, and better to meet the new demand, and thus originated the draft breeds as we know them today - Shire, Clydesdale, Percheron, and Belgian. This occurred in the first part of the nineteenth century.

The hunter.-Fox hunting in England dates back to early times, and there has long existed a demand for a type of horse specially adapted to this sport. Strange to say, no breed of hunters has ever been developed, the demand being supplied by Thoroughbreds and grade Thoroughbreds showing the hunter type.

The carriage horse.-The modern type of carriage horse originated less than fifty years ago. Prior to this, there was a succession of types dating from the time the most primitive carriages came into use centuries ago. Hence the term carriage horse may be used in a restricted sense or in a broad general sense, and the carriage horse may be said to be an ancient type or a modern one, according as the term is used. The primitive carriage horse was a semi-wild pony, and he was harnessed to a couple of long poles, fixed at one end to the pony's neck, the other end dragging on the ground beneath the load. Next in 
the evolution of the modern carriage came the sledge, and later came a sledge mounted on rollers. In time the rollers were improved to the present form of an axle and wheels. All this was before the Christian era. Centuries more elapsed before anything deserving the name of carriage was built.

Carriages were first used by the nobility of England about the beginning of the thirteenth century, but the roads were so bad and the vehicles so heavy that they were of little service until the end of the sixteenth century. The first coaches in England and America were objected to because they were said to obstruct the narrow ways, impede traffic, and endanger foot passengers. It was about 1660 that the present custom of driving for pleasure and show in Hyde Park, London, was established. But it was not until more recent times that driving became a real pleasure, for carriage springs were not invented until about 1665 and in their first form appear to have been crude and inefficient. Toward the middle of the eighteenth century, great and rapid improvement was begun in highways, vehicles, and horses, so that the the rate of travel was increased from 4 or 5 to 12 miles per hour. Then came the railway, displacing the road coach and consigning the carriage horse to the realm of pastime and pleasure exclusively.

The first English carriage horse was the old black cart horse, or shire horse as he was called, heavy, ungainly, with a big head and shaggy fetlocks. He was descended from the old-time war horse, and hence was of Flemish blood. They were so slow that the footmen could easily go ahead when necessary and engage lodging at the next inn. As highways were improved and carriages made lighter, the cart horse was crossed with the Thoroughbred in order to secure lighter and faster animals for carriage use. In this way originated the Cleveland Bay and Yorkshire Coach Horse - two breeds of heavy carriage horses.

The carriage horse as we know him today is comparatively a new type in both Europe and America. He is a mediumsized animal with outstanding beauty and attractiveness in both form and action. The demand for such a horse did not arise until city streets were improved and carriages made elegant and comfortable, so that driving became a pleasure rather than a painful necessity. Increase in wealth during the past halfcentury and the creation of a larger leisure class of people also helped to create a demand for this special type of horse. From 
what was called the Norfolk Trotter, which was a fast-trotting, plain, serviceable, moderate-sized horse formerly used by English farmers as a road horse (and used by them under saddle), there was developed in England the Hackney, which is today the foremost breed of carriage horses. The Norfolk Trotter originated at about the same time as the Thoroughbred, being the result of crossing Arabian and other Oriental sires on mares showing aptitude for the trotting gait, just as the Thoroughbred resulted from the crossing of these same sires on native running mares of proven ability on the turf. Although the Hackney is the only true breed of carriage horses, other breeds not infrequently produce individuals of this type which help to supply the demand.

The polo pony.-The game of polo was introduced into England in 1874, and to America two years later. This sport calls for an active, rugged pony of about 14-2 hands, and those which best serve the purpose are small-sized or dwarf Thoroughbred horses. A breed of polo ponies is now being developed in England.

The horse in America.-From an equine standpoint, history repeats itself to a considerable degree in America and also records the creation of at least two new and distinct types of horses. There were no horses on this continent at the time of its discovery, hence American horse history dates from 1492. The first horses were brought to this continent by Cortes and Ferdinand De Soto. Cortes used but few horses in his conquest of Mexico, some of which undoubtedly became the progenitors of the wild horse of the western plains. Similarly, horses abandoned by De Soto near the Texas border no doubt survived and were the principal foundation of the American wild horse.

In colonial times, the most common type of horse was a small saddle horse measuring not more than 14 hands. These were the descendants of the small, unimproved European horses brought over by the first settlers and were of no particular breed or breeding. This little colonial saddle horse was indispensable as a utility animal, being practically the sole means of transportation in those early times. He was likewise a source of amusement and recreation, being used in running matches of short distances. For this latter purpose, however, the little saddler soon gave way to the English Thoroughbred imported quite extensively by the early settlers of the Carolinas and Virginia. 
Field labor was performed by oxen, except in Pennsylvania and New York where Flemish horses had been introduced from Holland. This Flemish horse was, as we have already seen, a large and rather ungainly animal, and when the colonies expanded westward, this horse was used to haul freight over the mountains from eastern ports to Pittsburg and Wheeling. It required 12,000 wagons annually, each pulled by four or six horses, driven tandem, to carry on the vast freighting business which developed, and the freight bill amounted to $\$ 1,500,000$ in a year. The wagons were called Conestoga wagons, and the horses were given the same name. With the coming of the railroad and the river boat, the Conestoga horses and wagons were quickly displaced and no further efforts were made to breed heavy horses in America until very recent times. The blood of the Conestoga was absorbed into the common stock of the country and the type became extinct. Thus we see that colonial horse stocks were of three types only:-(1) the little saddle horse, (2) the Thoroughbred, and (3) the Conestoga.

Origin of the roadster type.-With the opening of roadways, vehicles were quickly brought into use, so quickly indeed that the so-called roads over which they were driven were little more than clearings through the woods with here and there a "corduroy" of logs to make passable some marshy spot. The roads were first improved in the more thickly settled parts of the country, and it was thus about Philadelphia that the roadster type of horse was originated at the beginning of the nineteenth century in response to the demand for a horse suitable for road driving and harness racing. The American trotting horse or roadster was derived from four sources: (1) the English Thoroughbred, (2) the Norfolk Trotter, (3) the Arab and Barb, and (4) certain pacers of mixed breeding, By selecting and breeding for speed at the trot, the American Trotter has been developed and today may be called a true breed, although the individuals composing it show considerable divergence in type. In Vermont the Morgan horse was developed. The Morgans descended from one horse, Justin Morgan, whose sire was a Thoroughbred, but whose dam was of unknown breeding. While often regarded as a distinct breed, they really constitute one family of the American Trotter.

American Saddle Horse.-At the time roads were being improved in the East, Kentucky and the West were still a country of bridle paths only. The blue-grass region of Kentucky is 
splendidly adapted to the production of light horses, and it was principally in that state and Missouri that the American Saddle Horse breed originated and developed. Kentucky was settled in 1775 , and as early as 1802 it was said that "almost all of the inhabitants employ themselves in training and ameliorating the breed of horses." The American Saddle Horse originated from crosses of the Thoroughbred upon pacers of mixed breeding which had been brought from Canada. Considerable Morgan blood entered into the making of the breed also. Starting with these materials, a type of saddle horse possessing great intelligence and beauty was established. These horses are taught five or more distinct gaits, and as a result of years of selection and breeding, there is today a natural inclination on the part of the American Saddle Horse to show these gaits, which include not only the walk, trot, and canter, but also the rack, running walk, fox trot, and slow pace.

The general-purpose horse.-When the railway displaced the Conestoga horse, many farmers attempted to produce what was styled "the horse of all work." By this was meant a general-purpose horse useful to wagon, plow, or under saddle. The early agricultural papers were full of advice to farmers that such a type be bred, and fair associations encouraged the movement by offering prizes for this class of horses. From 1840 to 1850 the "horse of all work" was the horse of the day. About 1850, the first draft stallions were imported from Europe, but they were not brought over with the idea of producing draft horses in this country, but to breed to the small native mares, with which this country was well supplied, in order to produce a general-purpose horse. Prior to this there were some attempts to produce such a horse by crossing the Thoroughbred and the Conestoga, but the progeny possessed most of the defects of both parents and were utterly unsuited for farm use or anything else. By 1870, breeders had come to realize that there is more profit in producing specialized types of horses useful for special purposes, rather than a single general-purpose type not capable of doing anything well. Thus, although articles still appear occasionally in farm papers advising the production of a generalpurpose horse, and although some county fair associations persist in offering prizes for this ancient type, the general-purpose horse died a natural death a half-century ago. Let him rest in peace.

The draft type in America.-About 1870, there arose a strong demand from cities for a heavy horse, and since that 
date hundreds of Percheron, Belgian, Shire, and Clydesdale stallions and mares have been imported to America annually for the purpose of breeding heavy horses fitted for the work of moving heavy loads over city streets-in other words, draft horses. America developed no draft breed of her own. After the Conestoga disappeared we had no heavy horses to use as a foundation for such a breed, and when the demand arose in this country several European countries had draft breeds ready formed which we borrowed from them.

The carriage horse in America.-In America, as in England, the modern carriage horse is a recent addition to our types of horses. The more wealthy families among the early settlers of the Carolinas and Virginia kept coaches for use on state and social occasions, but the so-called roads were so miserable that driving was in no wise a pleasure. Most of the carriages in use in the early days were stage coaches which did the work now done by railways. In 1812, the fare from Philadelphia to Pittsburg over the national turnpike, 297 miles, was $\$ 20$ by coach, and it required six days to cover the distance. Crosses of the Flemish horse of New York and Pennsylvania with the little saddle horse gave the well-knit, sizeable horses required on these early coaches. With the growth of towns and cities, carriages became common, but the horses used would not today be classed as carriage horses although they were of a serviceable kind. Driving for pleasure and pastime, which in later years became so popular with city people, did not begin until after the Civil War, in fact it was not until 1880 that the modern type of carriage horse came into use. From that date forward, there was a large and increasing demand for smoothly-turned, high-stepping, well-mannered horses, weighing from 1,000 to 1,200 pounds. The animals which supplied this demand were for the most part recruited from the ranks of the American Trotter and American Saddle Horse, although our very choicest carriage animals have been English Hackneys. Since 1900, the automobile has displaced a great many carriage horses, especially those of mediocre quality, but there still exists a demand for animals of show-yard quality for which good prices are paid.

Effects of mechanical inventions on horse types. - The invention of firearms resulted in a change in the type of the cavalry horse from the old-time heavy war horse to a lighter animal with more speed. The displaced type did not become extinct, but was put to use in the fields. The invention of the railway 
and steamboat and the building of canals restricted the horse's field of usefulness by displacing the stage coaches and the Conestoga horses and wagons. The Conestoga type then became extinct, being mingled and absorbed into the common stock of the country. In France the diligence horse was gradually developed into the Percheron breed. The application of electric power to street railways in 1888 closed a channel of disposal for thousands of cheap horses such as were used on the old-time horse cars, and the perfection of the bicycle and the fad for cycling which followed led many to believe a horseless age was at hand. But the street car horse was not a profitable animal to produce, and many who took up the bicycle never owned a horse anyway. Horses came into greater demand and brought higher prices than ever before.

Next came the automobile, the motor truck, and the tractor and again a horseless age was predicted. It is a fact that the motor is the strongest mechanical competitor the horse has had to meet, and while it is impossible at this time to say with exactness what the effects will be on horse production, enough time has elapsed to show that the horse yet has an important place on city streets and on roadways, as well as on the farm. The automobile, motor truck, and tractor are not only doing the work that is also done by horses, but they are doing work which the horse cannot do. In other words, the motor has to a large extent created its own necessity. There is, on the other hand, a vast amount of horse work of various kinds which cannot be done by motors. The horse and the motor each occupy fields of their own, the margins of which overlap to some extent, and here competition between the horse and motor is keen. The carriage horse and roadster have felt this competition most.

Many large business firms have sold their draft horses and installed motor trucks, only to discover that the short haul may be made more economically with horses, and they have therefore reinstated horse equipment along with their motor trucks. Farmers have found that tractor manufacturers are over-enthusiastic regarding the tractor's ability to displace the horse upon the farm. The horse's place in the realm of sport is undisturbed by the automobile. Saddle horses, including the hunter and polo pony, are in great demand, while racing in harness and under saddle continues to prosper throughout the country. 
Classification of the breeds. - The various breeds of horses may be classified according to type as follows, mention also being made of the place of origin of each breed:

Draft Type

Percheron............ France

Belgian . . . . . . . . Belgium

Shire ............. England

Clydesdale . . . . . . . . Scotland

Suffolk. . . . . . . . England

Roadster Type

American Trotter ..... United States Morgan ........... United States

Orloff Trotter . . . . . Russia
Carriage Type

Hackney ............ England

Cleveland Bay ......... England

Yorkshire Coach . . . . . England

French Coach..........France

German Coach.........Germany

Saddle Type

American Saddle Horse. . United States Thoroughbred ......... England

Arabian ............. Arabia 


\section{CHAPTER XXX.}

\section{DRAFT TYPE.}

The first question which presents itself is-What is a draft horse? A draft horse is a horse adapted to the work of pulling heavy loads at a walk. The farmer who produces draft geldings for sale looks to the city for a purchaser, for in the cities the greatest demand is found, and the big, heavy drafter there finds ready sale at a good figure. The conditions of street traffic in large cities demand the hauling of the largest possible loads. Distances are great and delays waste much time. At street crossings, bridges, and at railway crossings, minutes are lost that in a day count up to hours. At sidings and warehouses, it is a lucky chance if a team can get up to its door or car without waiting for one or more wagons to be loaded or unloaded ahead of it. There is thus a natural tendency for teamsters to haul big loads in order to move the freight, and this makes big horses necessary. Furthermore, big wagons, big loads, and big horses enable merchants to move the goods with less equipment and fewer drivers, and lessen expenditures for shoeing, feed, stabling, harness, and repairs. There is thus a tendency toward big horses and big loads in all cases where quick delivery is not imperative, and where loading and unloading are done at one or a few points. The heavy loading of wagons has gone so far that many cities have placed restrictions upon the size of loads, in order to protect draft animals from abuse. In Chicago, the maximum load for a single horse or mule is 3,500 pounds, and when two or more horses are hitched together, the maximum is 4,000 pounds per animal.

We must bear in mind that the drafter is not only adapted to pulling heavy loads at a slow gait, but that this work is done on hard pavements in the city. The draft horse not only does the hardest kind of work required of horses, but he works under conditions which put his feet and legs to a severe test. The drafter may be said to be the real business horse, whereas the carriage horse, roadster, and saddle horse are largely used for pleasure purposes.

In order to do the work required of him, the draft horse must possess the following qualifications-(1) weight, 
strength, (3) true, snappy action, (4) endurance and durability, (5) feeding capacity, and (6) good disposition.

Weight.-This is decidedly essential. The heavier the horse, the more adhesion he has to the ground. When a horse is working in harness, the traces tend to lift the fore feet off the ground, and for this reason a heavy horse is able to use his weight to good advantage. In stage-coach days it was a common trick for the driver to throw a bag of meal across a horses' back, or get upon a horse himself, in case the coach got into a place where a hard pull was necessary. By so doing, his team was often able to start the load without other assistance. The added weight produced more adhesion between the feet and the ground, thus enabling the animal to exert all his strength at a pull, instead of uselessly "scratching gravel" when trying to start.

Standing on a hard surface, a man of 200 pounds weight can easily outpull a man of 150 pounds in a tug-of-war, for the reason just explained. If the 150-pound man take another man upon his shoulders and back, however, he can defeat his opponent who outweighs him by 50 pounds. The man on the shoulders of the 150-pound contestant adds nothing to the muscular power at that end of the rope, but rather lessens it; but the added weight and the increase in adhesion permit the full strength of muscles to be more nearly exerted, and the 200-pound man is readily defeated.

The horse moves a load by (1) simply leaning against the collar, and (2) by muscular strength. Thus, weight has a second advantage in that it takes the place of some of the muscular energy, for the weight of a heavy horse more nearly offsets the weight of the load than does the weight of a smaller horse, and every extra pound thrown against the collar means a corresponding reduction in muscular force required in moving the load. Then, too, as a rule, the larger the horse, the stronger he will be.

To sum up, weight in the draft horse has three values(1) It gives the feet more adhesion with the pavement or ground, so that the muscular power may be applied to the collar, (2) by offsetting some of the weight of the load, it lessens the amount of muscular exertion required, and (3) as a rule, the heavier the horse, the stronger he will be. Some horses make up for a lack of weight by their superior ambition and courage. 
Strength.-This is a matter of muscling. Draft horses must be very muscular throughout, especially in the hind. quarters. When judging drafters, fat should not be mistaken for muscle.

Action.-Action that is straight and true insures conservation of energy and sure-footedness. The action should also be snappy; this enables the animal to get over the ground rapidly, and shows a willing disposition. Action is also valuable as an index to the way the horse is put together; true action can result only from proper placing of the feet and legs, in fact, from a proper proportionment of all parts, and their proper relation to one another. Correct action, showing trueness, snap, and length of stride, results from a rather rare combination of proper structure, muscling, and temperament. Therefore, good action is not only valuable in itself, but is good evidence of merit in the entire make-up of the horse.

Endurance and durability.- Endurance means the ability to do the day's work without fagging. Durability means the ability to work day after day without breaking down under the strain. Endurance is concerned mostly with wind, muscling, and feeding capacity, while durability depends mostly upon the feet and legs. Some first-hand hor'ses last but six months, or even less, on city streets. Others last as long as fifteen years, and, in some cases, even longer. If a draft horse goes to pieces quickly when put to work, he is a considerable loss to the owner. Feet and legs are the parts most liable to prove defective. Lack of wind is a common fault. The horse with a short rib seldom stands up to hard labor very long. Buyers refuse to invest much money in horses that are shallow bodied and cut up high in the flank, such animals being poor feeders.

Feeding capacity. - The horse is comparable to a locomotive. He consumes hay and grain for fuel. Other things being equal, the greater the amount of fuel consumed, the greater the work that can be done. The drafter should be a good feeder.

Disposition.-To be of great usefulness, a draft horse must be a prompt, willing worker that will be pleasant to handle, active, and quick to respond to commands, yet quiet and docile.

\section{DETAILED DESCRIPTION OF THE TYPE.}

General appearance.-The form of the draft horse is low set, broad, deep, massive, compact, symmetrical, and stylish. He should have a short back and a long underline. He must 
weigh not less than 1,600 pounds, and ton horses are the sort to keep in mind as draft horses. Weights over a ton are not uncommon. It has been estimated, on the basis of weights and prices for horses at the large markets, that every 100 pounds above 1,500 adds $\$ 25.00$ to the horse's value. As to height, drafters usually stand from 16 to 17 hands at the withers. The height over the hips should be no greater than at the withers, as this detracts from the symmetrical appearance, throws more weight upon the forequarters, and makes the action stilted and heavy. Although the short-legged horse is more powerful, the

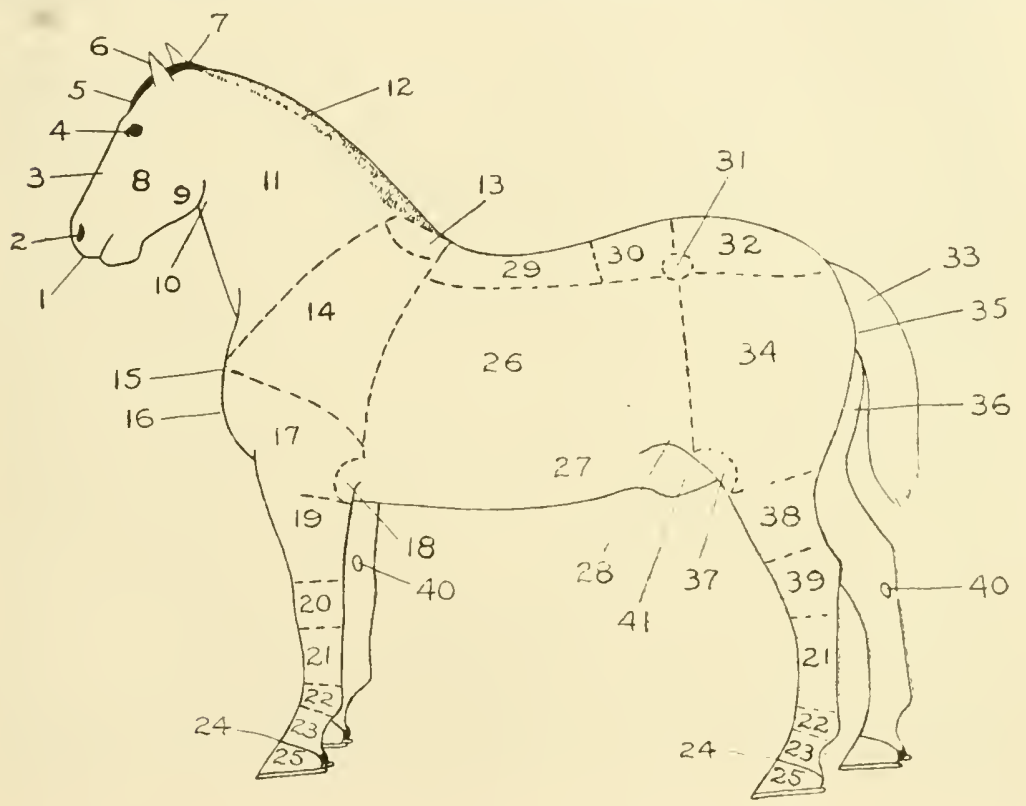

Fig. 125. Points of the Horse.

$\begin{array}{ll}\text { 1. Muzzle } & \text { 12. Crest } \\ \text { 2. Nostril } & \text { 13. Withers } \\ \text { 3. Face } & \text { 14. Shoulder } \\ \text { 4. Eye } & \text { 15. Point of shoulder } \\ \text { 5. Forehead } & \text { 16. Breast } \\ \text { 6. Ear } & \text { 17. Arm } \\ \text { 7. Poll } & \text { 18. Elbow } \\ \text { 8. Cheek } & \text { 19. Forearm } \\ \text { 9. Jaw } & \text { 20. Knee } \\ \text { 10. Throttle } & \text { 21. Cannon } \\ \text { 11. Neck } & \end{array}$

22. Fetlock joint 32. Croup

23. Pastern 33. Tail

24. Coronet 34. Thigh

25. Foot 35. Point of buttock

26. Ribs 36. Quarters

27. Belly 37. Stifle

28. Flank 38. Gaskin

29. Back 39. Hock

30. Coupling 40. Chestnut

31. Hip 41. Sheath

horse with slightly more length of leg will take a longer stride, and may therefore be more useful. Some buyers also prefer a 
certain degree of height in the drafter because they use wagons with a high top or cover, and a short-legged horse would not be in harmony with such vehicles. At this point, it may be mentioned that a great many firms desire horses which are not only able to do their work successfully, but which also have considerable style and beauty that will attract attention on the streets and help to advertise the firm and its business. To this end, a great deal of money is invested in vehicles nicely designed and ornamented, which are horsed with animals that add to, rather than detract from, the appearance of the turnout. Buyers keep the vehicle in mind when buying horses.

Quality and substance, as shown in head, hair, hoofs, bone, and joints, should be preeminent. Substance refers particularly to the size of the bone as shown in cannons and joints, while quality refers to the fineness of texture of all parts. Quality associated with substance insures good wearing qualities. Quality is shown in bone that is hard and smooth, joints that are well defined, or clean, and cannons and pasterns that are entirely free from meatiness. As previously explained, it is objectionable for a horse to be meaty in his knees or hocks or in the parts below them. The term "clean," as applied to the hocks, knees, cannons, ankles, and pasterns, means that these parts are entirely free from meatiness, swelling, or other unnatural development, so that the natural structure is sharply and clearly defined. Clean legs are one of the best and most important evidences of good quality. The cannons of some draft breeds have more or less long hair, called "feather." If it is fine and "pily," rather than coarse and curly, it indicates quality, for fine hair seldom covers rough, coarse bone. The entire coat, including mane and tail, also indicates quality if the hair is soft and fine. The horse with quality will have a head of medium size, a neat ear, a trim muzzle, and a chiseled appearance about the face and jaws. He also has hoofs of fine texture which will wear well, and his joints are less subject to bony diseases.

Head.-The size of the head should be proportionate to the size of the horse. A pony head is not the right sort for a draft horse, and a barrel head indicates coarseness and lack of good breeding. Every line and feature should be distinct,there should be a chiseled appearance that indicates character, quality, and good breeding. Great width between the eyes and a broad, full forehead show intelligence. The eye should be large, bright, clear, and very prominent, to insure good vision, 
for the horse should be able to see where he is stepping. The nose and muzzle should be broad, indicating a good feeder. The nostrils should be large (but not permanently distended), to provide easy breathing. Trim lips that are thin show quality and refinement. Strong cheeks, and jaws that are wide across underneath, provide good grinding ability for proper mastication of feed. The ears should be of fine texture and medium size, and should be set well up toward the poll and carried alert.

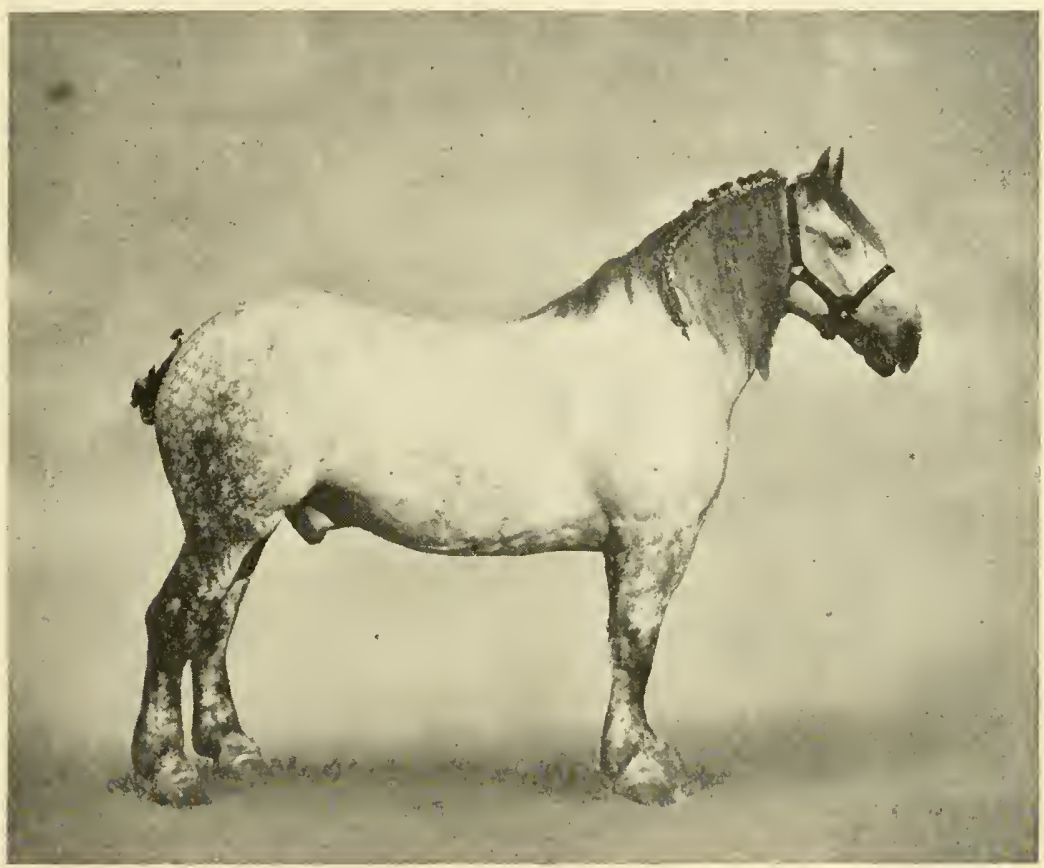

Fig. 126. The Draft Type.

Big Jim, four times champion draft gelding at the International. Mr. J. H. S. Johnstone, of the Live Stock World, wrote the following regarding Big Jim when announcing his death in 1910: "There never was a prouder stepper in harness, and there never was a big one that held himself together and went at his work in a more sprightly manner. His size was immense2,385 pounds - and not one of his competitors ever approached him in that regard. Personally I do not expect to see his like again."

Ears set down on the side of the head and carried in a lopping fashion decidedly injure the appearance. The expression of the eye and the carriage of the ear are good evidences of the temperament and disposition. The head should be of medium 
length, and, as viewed in profile, the face line should be rather straight. A Roman face line indicates a strong, determined will, and is not desirable.

Neck.-The neck of the draft horse should be at least medium long, and should be very muscular, with some degree of crest or arch to the top. The crest should be pronounced in the stallion, but not so excessive as to break over to one side. At the junction with the body, the neck should be very deep, but at the throttle it should be very trim and rather cut up underneath, with no fullness or thickness there to bring pressure on the windpipe. The head and neck should be carried well up, to insure good vision, lighten the forehand, and improve the appearance.

Shoulders.-The shoulders should be very deep, muscular, and have much slope. An upright shoulder results in transmission of shock, and also in shortness of stride. A sloping, muscular shoulder that is laid in snugly is conducive to good action. Frequently, the shoulders are too open and prominent, so that the horse does not stand over his legs as he should. Such horses do not take a straight stride, but swing their legs outward when in action.

Withers.-The tops of the shoulder blades should come well together so that the withers may be well defined, though muscular, and not as sharp as in the lighter kinds of horses.

Breast and chest.- The breast should be very wide and very muscular. The chest should be full, wide, and deep, to provide room for heart and lungs. The horse is an athlete, and large lungs and good heart action are very essential. A contracted heart-girth shows lack of constitution. There is no such thing as too much heart-girth or chest capacity.

Arm.-The arm should be very muscular, and should be thrown forward to give slope to the shoulder.

Forearm.-The forearm should be powerfully muscled, so that as viewed from the side it appears very broad next to the body, tapering to the knee. No muscles are present below the knees and hocks, hence the action is dependent upon the muscles above these joints.

Knee.-The knee must be broad from every point of view, and must be deep from top to bottom. This provides a large joint, indicating strength. The knee must also be straight, so as to set the leg straight below the body. There must be no meatiness about the knee or any of the joints or parts below, 
for, as has been stated, all muscles end above the knee and are attached to the parts below by tendons. Meatiness about the knee interferes with the working of the tendons, and lessens the free and easy flexion of the joints. Hence the knee should be clean, flat across the front, and well defined. 'This is essential.

Cannons.-The cannons should be short and clean, with the tendons large and set well back from the bone. As viewed from the side, there should be good width, and the cannon should be flat instead of round. As one passes the hand along the cannon bone, it should feel smooth, hard, and dense. The skin and hair covering it should be fine. Between the bone and the tendons there should be well-marked depressions or grooves. Meatiness about the cannons is as objectionable as it is about the joints, and for similar reasons. The cannons furnish one of the best means of determining quality. Clean, flat, smooth cannons have bone that is composed of fine cells, and that is flinty in character. Coarse, rough bone is made up of large cells, and is porous and spongy. Too much refinement of bone is often found in the draft horse. On the other hand, large bone is frequently found which is very lacking in quality. There should be a combination of substance with quality. It is possible to make up in quality a certain lack of substance, but not the contrary.

Fetlock joint. - The fetlock joint should be wide from front to back, clean, and well defined.

Pasterns. - The pasterns should be oblique to relieve concussion, and should show reasonable length. A slope of about forty-five degrees is desired. More slope than this tends toward weakness. The pasterns should show plenty of substance, yet be clean, and should spread out or expand at the lower end into wide, round, open hoof-heads or coronets.

Feet.-The old saying, "No foot, no horse," is full of truth. A draft horse of excellence in all respects except feet is as worthless as a fine building on a flimsy foundation. When it is considered to what great stress the foot of the draft horse is subjected, the wonder is that feet last as long as they do on hard pavements. Driven against cobblestones and brick by the great weight of the body above, the fore feet undergo repeated shocks which soon batter to pieces feet that are defective. The foot should be large, to afford a large bearing surface. When viewed from front or side, the axis of the foot should coincide with the axis of the pastern. The hoof should appear dense, 
waxy, and smooth, indicating toughness and durability. The form of the hoof should be round. Inasmuch as the wall of the hoof grows out from the coronet or hoof-head, the size and shape of the foot will depend largely upon the size and shape of the hoof-head, which should therefore be large and round. A foot that is large on the ground and cramped and small at the hoof-head has too much flare of the wall to provide strength, and is not a good foot. The sole should be concave, as this means strength. Flatness of sole is a common fault among draft horses. The bars should be strong, to insure against contraction of the heels, and the frog should be large and elastic. The heels should be very wide and fairly high, and the fore feet should be symmetrically made and uniform in size and shape. The position of the feet and legs should be as described in Chapter XXVIII.

Ribs.-The ribs should be well sprung and deep, giving a wide, deep body. Such a conformation provides a strong middle-piece, gives the necessary weight to the animal, and indicates good digestive capacity, as well as ample room for heart and lungs. The distance from the last rib to the hip should be short, and the flank should be deep. Horsemen speak of a deep, full flank as a "good bread basket," and in certain sections of the country where a business is made of feeding drafters for market, care is taken to select animals for feeding that have deep, full middles, for the other kind are poor feeders and cannot easily be made fat. The horse that is cut up high in the flank is said to be "wasp-waisted," "tucked-up," or "washy." When put to work, such horses show lack of endurance or stamina, for they do not consume enough feed to replace the energy expended in doing hard labor; hence they become very thin in flesh, and are unable to do hard work for many days in succession. The middle of the draft horse in good flesh should be very large, and as round as a dollar.

Back.-The back forms the connection between the power, which is in the hindquarters, and the point of application of this power, which is the shoulder. A short, rather straight, broad back that is heavily muscled affords the strongest conformation. A short, wide back is not only more rigid than a long, narrow one, but also brings the power closer to the collar; it is therefore much desired because of its mechanical advantage over the long, rangy conformation.

Loin.-The loin is usually called the "coupling." It lies just in front of the hips, and includes those vertebræ which 
have no ribs below them. The loin, like the back, should be short, broad, and heavily muscled.

Hips.-Beginning with the hips and continuing throughout the hindquarters, we are dealing with the location of those muscles which furnish power for draft, hence we want an appearance of great massiveness everywhere. It used to be thought that the draft horse did his work simply by falling against the collar, thus bringing his weight to bear, and consequently that his forequarters ought to be as heavy as possible; it was no harm if his shoulders were straight, and as for his hindquarters, it did not matter much what they were. But this idea has been exploded and it is now known that he pulls by muscle more than by weight, and much more by the muscles of his hindquarters than by those of his forequarters. So we want the hips of the drafter to be wide and heavily muscled, yet smooth.

Croup.-A very broad and long croup gives the greatest area for the laying on of muscle. It should also be fairly level from hips to setting on of tail. A steep croup not only detracts from the appearance, but is also usually associated with shortness of croup, weakness of coupling, and crooked hind legs. The croup should be covered with heavy, massive muscles.

Tail.-The tail should be attached high, and should be full haired and well carried.

Thighs. - The thighs should be very wide and should bulge with muscle, and the quarters should be very deep and heavy. The stifle should likewise be heavily muscled, and there should be great width through the hindquarters from stifle to stifle. Viewed from the side, the thigh should be very wide from stifle to end of body.

Gaskins. - The gaskins, like the forearms, should be very wide and bulging with muscle.

Hocks. - Suppose we have a pair of ton horses hitched to a big load. When the word is given to start, the horses extend and lower their heads, lean against the collar, crouch down behind by bringing their hind feet forward and flexing their hocks, and then the pull of the powerful muscles of the hindquarters extends the hock joint and straightens the hind leg, thus bringing great pressure against the collar, and the load moves. The point to be remembered is that an enormous strain comes upon the hock, and if there is any weakness in that joint it is certain to cause trouble. The hock must be large, clean, wide both 
ways, and deep, and the point of the hock should be prominent. It should be straight from top to bottom. Hocks that are badly sickled, bowed outward, or cow hocked are not stout enough to match the strength of the muscles above. They thus limit the power of the horse and are likely to become unsound. Fleshiness and puffs are distinctly objectionable. Thick, meaty hocks are too common in draft horses. A clean appearance, so that every angle and line of the joint is apparent, is very much desired.

Cannons, pasterns, and feet.-The requirements for hind cannons, pasterns, and feet are almost identical with those in front. However, the hind cannons are always longer and usually broader than the front ones. Also, the hind pasterns are seldom so sloping, and the hind feet are not quite so large or round. There is less concussion behind than in front, but the stress is much greater at the pull, hence it is proper that hind pasterns and feet be a little more erect, in order to provide the necessary strength of conformation.

From what has been said above, the value of a properly set hind leg, as viewed from behind, is emphasized. If the horse is "bow legged," his legs will prove weak when the strain is put upon them. Walking on a crooked hind leg is comparable to driving a bent nail. The force of the hammer bends the nail instead of driving it into the wood, and a crooked hind leg bows outward instead of remaining rigid and transmitting full force against the collar.

Symmetry.- Now that the details of the drafter's conformation have been described, a word may be added regarding symmetry or proportionment of parts. The fact is that some horses are good in their various parts, yet fail to present a good appearance. What they lack is symmetry. The head may be good, and the neck may be good also, but the two may be joined at an angle which injures the appearance. The neck may not rise from the shoulders as it should. The feet may be good, but may be too small to be in proportion to the size and weight of the animal. The top line from head to tail may be an irregular line full of angles, whereas it should be gracefully curved. The hips may be wide, which is desirable, yet they should not be wide out of all proportion to the rest of the body, so as to be ragged and prominent. Seemingly small factors such as these may or may not affect the horse's usefulness for work, but frequently they constitute the difference between a 
plain animal and one of show-yard character, between which there is a great difference in price. One horse looks as though he were made up of a lot of different-sized parts which do not fit well together, while the other seems cast from a carefully prepared mould. Standing in natural position, the symmetrical horse carries his head and neck well up, so that the face line, shoulder, and pastern all slope at nearly the same angle; the croup is fairly level from hips to tail, the tail is set high, and all parts of his conformation are so proportioned as to give him a well-balanced appearance.

On the matter of type.-To present the best appearance, the drafter should not be over-drafty in type; that is, shortness of leg and compactness and width of body should not be carried

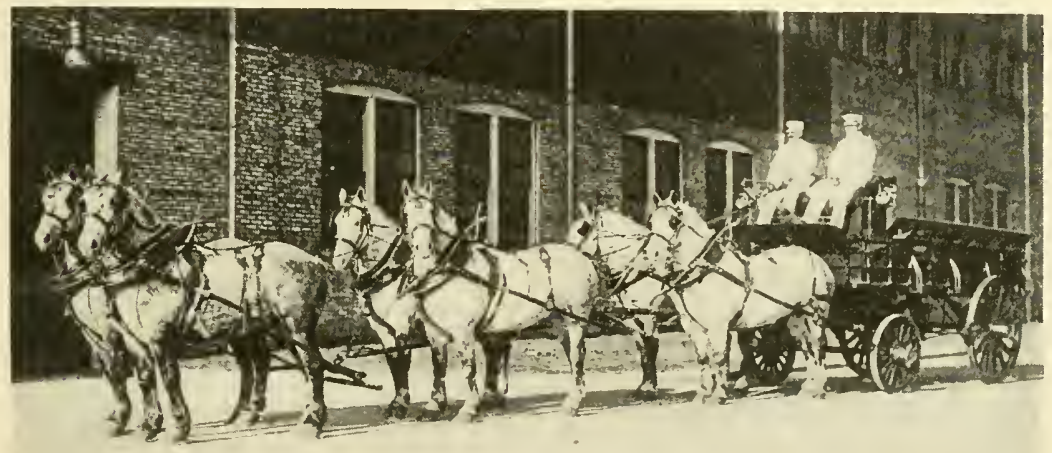

Fig. 127. Heavy Drafters in Harness.

This is the famous team of grays which was invincible at the leading shows a few years ago. They were shown in both the United States and Great Britain. Big Jim was the near wheeler in this team. Owned by Armour \& Company of Chicago.

to the extreme. This type of horse is sometimes referred to as the "Poland-China drafter." A certain degree of length of leg, length of neck, and length of underline is necessary, not only for the sake of looks, but also because it actually makes the horse more useful. He takes a longer step, and will do more work in a day than the extremely pudgy type of horse. On the other hand, we certainly do not want a horse that is all length and style. We must aim at the middle ground, selecting for as much style as may be had without sacrifice of any of those qualities which make the draft horse useful for his work. 
Action.-The action of the draft horse should be true, snappy, and bold. As you see him going or coming, the movement of the legs should be straight in the line of motion, the feet being carried true, with no paddling or irregularity of gait. Walking away from you, he should move with enough snap to give you the flash of his shoe at every step. As you view him in action from the side, he should show length of stride and enough height of action to clear the ground safely at each step. High knee action is not essential; in fact, carriage horse action in a draft horse means useless expenditure of energy. However, there should be a strong, free movement of knees and hocks, without dragging or stiffness. The walk is the real gait of the draft horse, and an active, snappy, springy walk, with trueness and length of stride, is the prime essential so far as action is concerned. However, the trot often magnifies defects in gait so that they are more easily seen, and in show and sale rings drafters are shown at both gaits. The stride in the trot should be long, true, springy, steady, and business-like, with a certain degree of height of action to insure against stumbling. Horsemen like a bold way of going that indicates willingness and courage in the horse.

In action, the hocks should pass close together, so close in fact that they nearly brush each other. Some horses go so wide behind that a wheelbarrow could be put between the hind legs and scarcely touch them. Any tendency to spraddle behind is one of the greatest, if not the greatest, defect which the drafter can exhibit, so far as action is concerned.

The study of action is one requiring close attention. The observer must take into consideration every movement of the horse. Attention must be given not only to the movement of the feet and legs, but also to the carriage of the head and neck and the entire body. The head should be carried well up, giving a stylish appearance and a good outlook, and the top of the horse should be carried level and true, without any rolling or wobbling motion from side to side, and without any indication of lameness. The front and hindquarters should act in unison, and the legs should be kept well under the body as the horse travels, showing no tendency to drag the hind legs, and especially the hocks, out behind the body. When kept up underneath as they should be, and when all the motions of the horse are in unison, we say that he moves in a collected manner. As before stated, perfection in action can result only when there is a com- 
bination of proper conformation and strength, and a willing disposition.

Common defects in the action of draft horses are (1) going wide at the hocks, (2) swinging the fore legs outward, called "paddling," (3) swinging in, (4) striking supporting leg with foot of striding leg, called "interfering," (5) twisting striding leg around in front of supporting leg, called "winding," "plaiting," or "rope walking," (6) short, stubby stride, (7) low, skimming action, called "daisy cutting," (8) unsteadiness of gait, (9) striking sole or heels of fore foot with toe of hind foot, called "forging," (10) excessive lateral shoulder motion, called "rolling," (11) lack of energy or snap, and (12) lameness.

Color.-It is commonly said that a good horse cannot have a bad color. By this is meant that color is disregarded if the horse suits otherwise. Some colors, however, are very generally disliked, and still other colors are not liked by some persons. For instance, duns, flea-bitten grays, white horses, very light grays, and spotted horses are universally discounted, either because they are hard to groom, hard to match, or because the color is unsightly. Dark colors, such as dark or steel gray, dark dappled gray, dark bay, dark brown, dark chestnut, dark roan, and black, are given preference. Dark dappled grays are well liked by buyers, and some firms will accept no other color because the flash gray color attracts attention to their turnouts. It is not uncommon for business houses to adopt some color as a sort of trademark, on account of the advertising value. However, color is of less importance in draft horses than in any other type. This is true because the drafter is a business horse, whereas other types are valued mostly for pleasure purposes.

Finish.-The term "finish" refers to fatness and to the condition of the coat. The horse market discriminates in price to a considerable degree between the fat drafter and the thin one, and it is surprising what an improvement is made in some horses by the addition of fat. Fatness adds to the weight, improves the form and spirit, and provides the necessary reserve store of energy to carry the horse through the first few weeks in the city during adjustment to city sights, sounds, loads, pavements, stables, and other new conditions. Although fat is important in the horse for sale or show, the judge must learn to distinguish between fat and muscle, and must not be deceived as to size of middle, spring or rib, or length of back and croup. The coat should be well groomed, so as to give the animal a sleek appearance. 


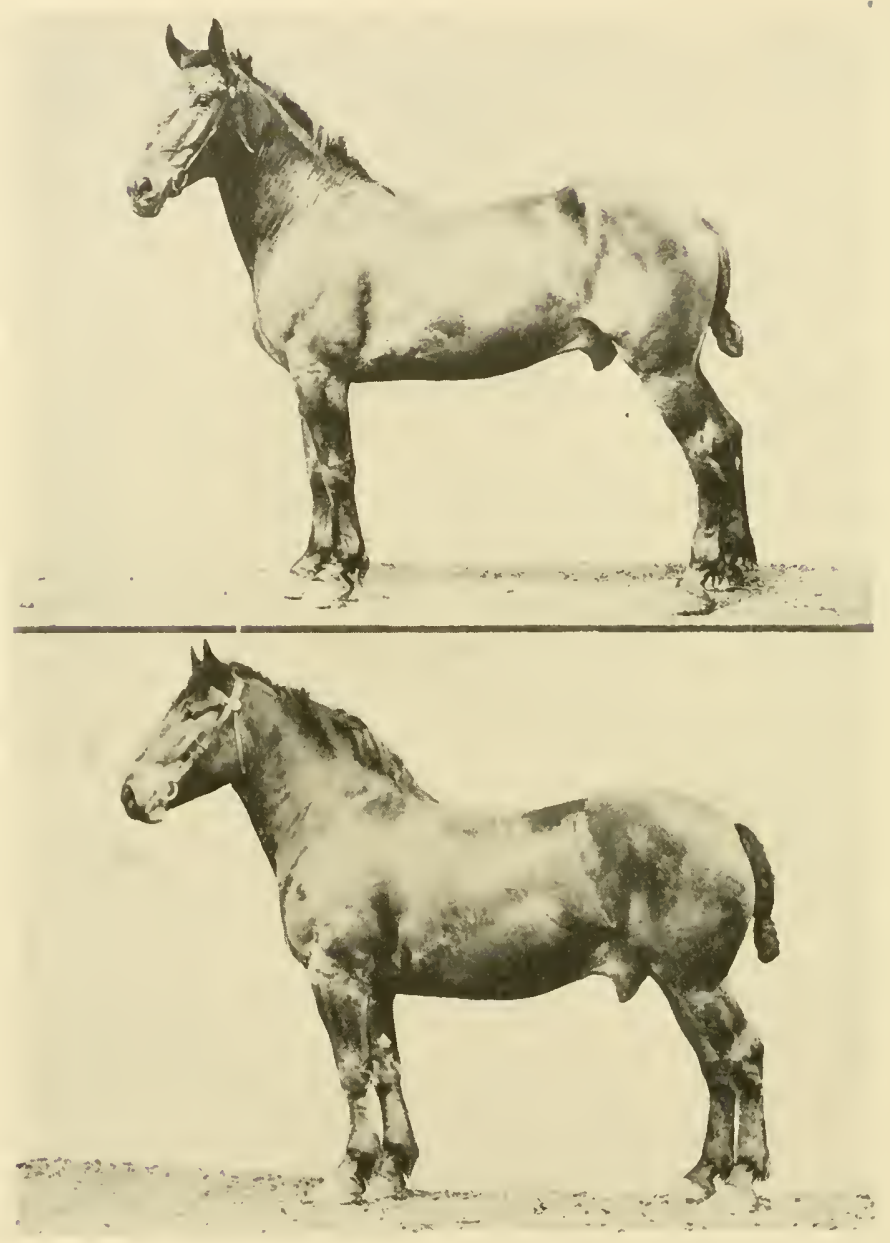

Fig. 128. Before and After Fattening.

A gelding fattened by Mr. B. E. Carmichael of the Ohio Experiment Station. Fattening shortened the back, filled out the coupling, smoothed the hips, lengthened and levelled the croup, rounded out the middle, gave crest to the neck, transformed his angular lines into pleasing curves, and changed his worried expression of eye and ear to one of contentment, alertness, and spirit. The feet and legs, however, are not improved during the fattening period.

It might be assumed from these pictures that fat will transform the head, neck, and entire top of a horse from inferior to excellent. However, when fat this gelding does not have the big middle which a fat horse should have, neither does he show just the right lines and proportions. It is difficult to recognize the merits of a thin animal, and it is almost as difficult to see the faults of a fat one. The above pictures strikingly illustrate these facts. 
Weight for age.-Draft horses that are properly fed and cared for usually reach at least 50 per cent. of their matured weight at 12 months of age; 75 per cent. at 24 months; 85 per cent. at 36 months; 95 per cent. at 48 months; and 100 per cent. at 60 months. On this basis the horse that is to weigh a ton at maturity should weigh not less than 1000 pounds at 12 months, 1500 pounds at 24 months, 1700 pounds at 36 months, 1900 pounds at 48 months, and 2000 pounds at 60 months. These are general averages. Variations will occur depending on feed, care, breed, sex, and individual. Belgians and Percherons mature somewhat earlier than Shires and Clydesdales. Mares and geldings mature quicker than stallions, but do not as a rule make as heavy weights at maturity. Some highly-fed colts and fillies make the weights mentioned at 12 and 24 months and then stop growing so soon that they fall considerably below a ton at maturity. This is especially true of yearlings and twoyear-olds that have a compact, low-set form and finished appearance like a mature horse, instead of the growthy, rugged appearance characteristic of youngsters that ultimately reach real draft horse size and weight. 


\section{CHAPTER XXXI.}

\section{THE CARRIAGE OR HEAVY-HARNESS HORSE.}

The modern carriage horse is almost exclusively a pleasure horse. His name implies his use. $\mathrm{He}$ is put before various kinds of pleasure vehicles, ranging from the light runabout to the heavy coach. Because he wears heavy leather, in contrast

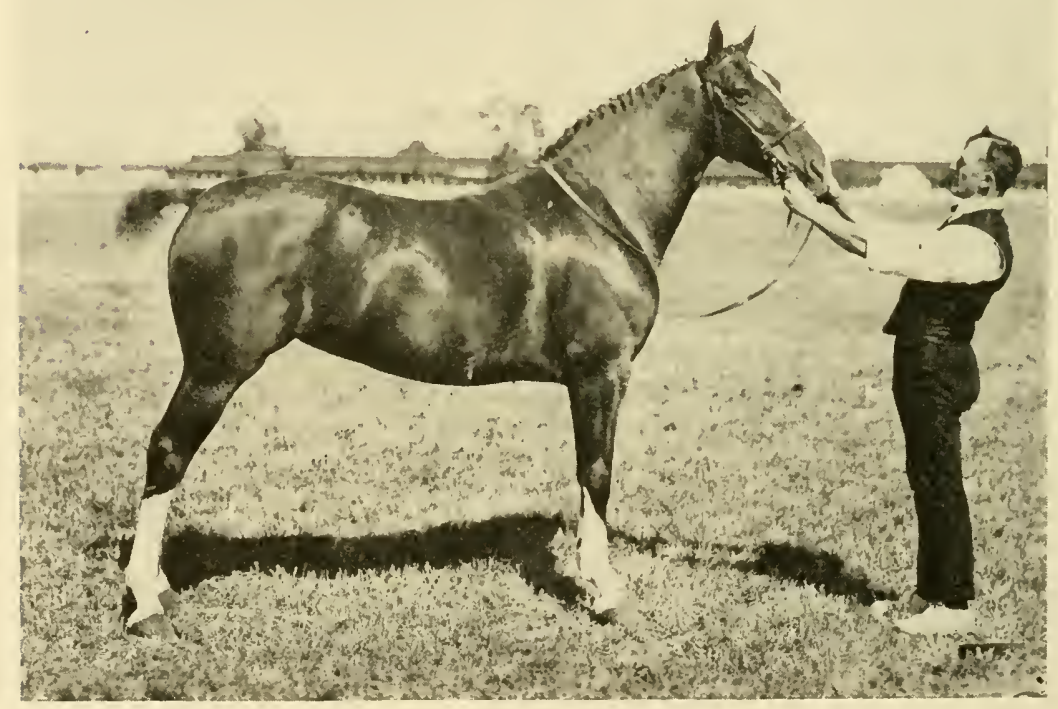

Fig. 129. Carriage or Heavy-Harness Type.

Hackney mare, Queen of Diamonds, imported and owned by the Truman Pioneer Stud Farm, Bushnell, Ill.

to the harness worn by the roadster, he is also called the heavyharness horse. It is apparent that there should be a wide range in the size and weight of carriage horses, in order to meet the widely varying demands of the various vehicles and uses to which this horse is put. In other respects, all carriage horses are very nearly alike. 
The value of the carriage horse is determined by (1) beauty of conformation, (2) action, (3) manners, (4) temperament, (5) color, (6) endurance and durability.

Beauty of conformation. - The conformation of the carriage horse must show beauty, style, symmetry, and finish. Being a pleasure horse, it is the ability not only to do certain work which determines value, but to do this work gracefully, and to present, while standing or in action, a picture of pleasing appearance. Everything is sidetracked for appearance in the breeding of this horse. Attractiveness of form is not restricted to any one type of horse, but it brings the highest price when found in the carriage horse. The value of the drafter is very largely measured by the amount of work he can do; the value of the light-harness horse is largely measured by his speed; the value of the saddle horse depends not only upon his appearance, but also upon his knowledge of the gaits and his ability to carry his rider with comfort and ease; the value of the carriage horse depends chiefly upon his appearance and general attractiveness of form and action.

Action.-Here again, beauty is the thing sought at the expense of other qualities. The carriage horse must not only go level, true, and collected, but he must go very high-the higher the better. With this end in view, he is bred, fed, shod, trained, bitted, and driven with a view to securing as much height of action as possible - not because it makes him more useful for his work, but because it makes him more pleasing to look upon. A certain degree of height of action is necessary in all horses, in order to secure length of stride and to prevent stumbling; such action signifies freedom of movement of joints and muscles, and indicates willingness and spirit. But the carriage horse is asked to go higher than this, even though it means added wear and tear on feet and legs, and a great amount of energy to accomplish the result. Beauty is given first consideration.

Manners.-Working in crowded streets, where driving requires considerable care, it is easily apparent that, with proper conformation, action, and durability, the carriage horse will not furnish real pleasure unless he has manners. Furthermore, if he fails to respond to commands, possesses a strong will that rebels at these commands, or fails to act quickly, his lack of manners may result disastrously to the occupants of the carriage. He must be so thoroughly trained and familiar with the com- 
mands of his driver that the execution of whatever is asked will be done involuntarily, unhesitatingly, and instantly. Every command of word, whip, or rein must be received intelligently, and intelligently acted upon by the horse.

Temperament.-The sanguine or nervous temperament is the one desired in carriage horses, for without it we cannot

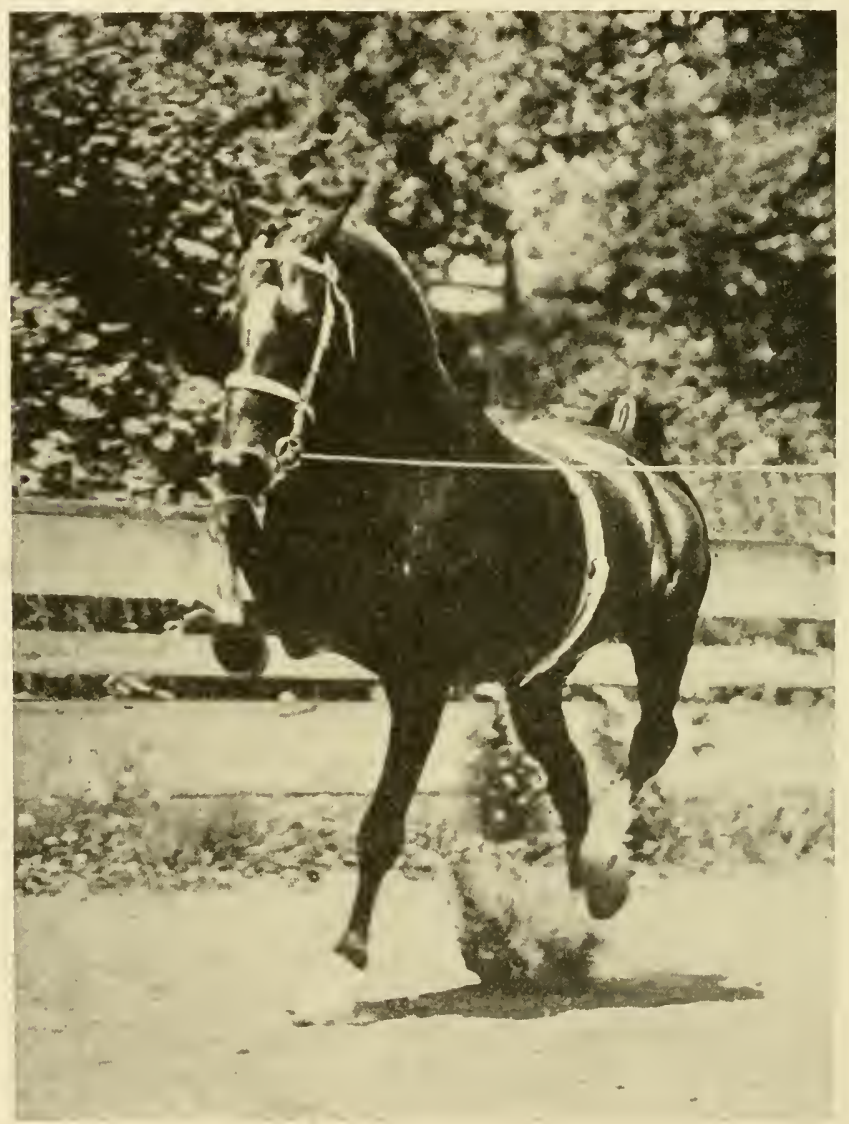

Fig. 130. The Heavy-Harness Type in Action.

Hackney pony, Irvington Model, bred and owned by Mr. W. D. Henry, Sewickley, Pa.

expect that degree of action which is required, nor that quickness of response to commands which is essential. There are other types of horses which should possess the sanguine temperament to even a greater degree than the heavy-harness horse; these are the speed types, the trotter and the runner. 
Color.-With the possible exception of the saddle horse, color is of more importance in heavy-harness horses than in any other type. The dark solid colors are preferred, as being in proper accord with the elegant vehicles drawn by this horse. White ankles are often favored, because a horse so marked has his action emphasized and easily seen. Grays, roans, and light colors are heavily discounted or even rejected, except for certain special restricted uses, such as sporting tandems, road fours, or cross-matched pairs, and in horses for ladies' use, even the white markings are discriminated against. True elegance and good taste are wanted, and this excludes colors that are flashy and calculated to attract undue attention.

Endurance and durability.-The carriage horse is required to make only short trips at a moderate pace. Endurance is not so essential, therefore, as in other types. However, durability, which means wearing quality, is of great importance. Extremely high action makes necessary the best of feet and legs. Durability is almost entirely dependent upon the amount and quality of bone, and the structure and texture of feet.

We may make a final summing up of the foregoing points by saying that the carriage horse is one specially fitted to work before pleasure vehicles, over short distances, at a moderate pace, wearing heavy leather; and that to be in keeping with the handsome vehicles which he moves, he must show beauty and attractiveness of form and action that will add to, rather than detract from, the appearance of the turnout.

\section{DETAILED DESCRIPTION OF THE TYPE.}

General appearance.-Compactness and fullness of form are required, in order that the horse may fill his harness properly and be in proper keeping with the vehicles before which he is put. He must possess great smoothness of conformation, with all his lines curving rather than angular. He must appear snugly put together. Although it is not desired that he stand on very short legs, it is essential that he be not leggy, or what is termed "weedy," in appearance. Medium length of leg is required, to give proper action and lend him style and symmetry. The height ranges from 14 to 16-1 hands, and the weight from 900 to 1,300 pounds. As previously stated, size and weight are of rather minor importance. However, big horses that are good ones are harder to find than smaller ones, hence size is of some importance, especially in breeding animals. The greatest 
demand is for horses standing from 15 to 16 hands. Quality is indicated in bone, joints, hoofs, hair, head, and smoothness of form. As the subject of quality has been fully discussed in connection with draft horse type, lengthy description is unnecessary here. Quality is valuable in the carriage horse because it assures durability, and because refinement and smoothness add beauty to the horse.

Head.-The head should be refined and well proportioned with every feature sharply defined. The forehead should be broad, and the eyes should be large and prominent. Strong

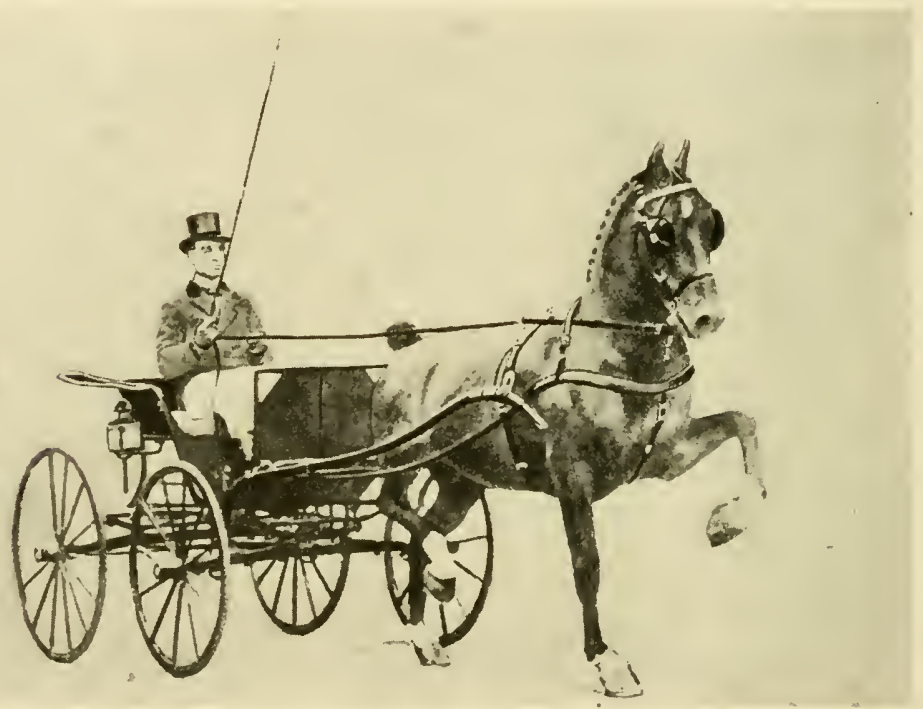

Fig. 131. The Carriage Horse in Harness.

Compare this picture with Fig. 134, and note the difference in height of action, type of vehicle, and weight of harness. This is the noted Hackney mare, Bountiful, owned by Judge W. H. Moore of Chicago.

jaws and a wide muzzle are desired, yet the muzzle must be trim, the lips thin, and the entire head free from any appearance of coarseness. The nostrils should be large. The ears should be fine and placed close together near the poll, turning in slightly at the tips. The attachment with the neck must be clean and graceful. The appearance of the head should indicate intelligence, alertness, and quality.

Neck.-Length of neck is very essential. It should be gracefully arched and bear considerable muscle,--enough muscle 
to lend fullness and strength, but not so much as to give an appearance of heaviness or coarseness. The upper border of the neck should be fine along its entire length. Ewe necks are very unattractive and undesirable. The neck should blend nicely with the shoulders. The shape and carriage of the head and neck have much to do with making the animal a real carriage horse, or a plain, inferior sort. Without a high-class front, no horse can qualify as a heavy-harness horse of superior type.

Shoulders.-Long, snugly laid shoulders, that have a decided slope and are well muscled, are wanted. The withers should be well set up and should show refinement.

Chest.-The chest should be moderately wide and very deep. The breast should be carried out prominently, and be rather muscular.

Middle. - The middle of the horse should be round, full made, short on top, and long below. This calls for long, wellarched ribs. The back, and especially the loin, should be thickly muscled and short, giving strength and a smooth, finished appearance. Depth of flank is essential, for the sake of appearance and keeping qualities.

Hips.--The hips should be smooth. Prominent hips in the carriage horse are decidedly faulty, because they detract from the smoothness of form which is so much desired.

Croup.-A long, level, fairly broad, well-muscled, and smoothly turned croup is the most attractive and the best indication of strength. A short, steep croup, commonly designated a "goose rump," is very objectionable. The tail should be attached high and carried out from the quarters. Carriage horses usually have the tail docked and set.

Thighs and quarters.-Full, muscular development of thighs, quarters, and gaskins gives the desired plumpness of form and necessary strength.

Legs.-Superior quality of bone, associated with substance, should be evident in the cannons. The arm should be very muscular. The forearm should be muscular and long. The knee must be wide both ways, deep, and flat across the front. It should be clearly defined in all its lines, which means an absence of meatiness. The hocks should be wide from front to rear, broad across the front from side to side, and deep from top to bottom. The point of the hock should be prominent, and the rear edge of the joint below the point should be straight, 
or very slightly incurving. Roughness or coarseness of bone about this joint, puffiness, or meatiness are looked upon with suspicion as indicating weakness. The cannons, both front and rear, as viewed from the side, should be broad and flat, with the grooves between the cannon bone and tendons easily seen and felt. The broad, flat appearance results when the tendons are placed well back from the bone, and when the legs are free from meatiness. Smooth, hard, flinty bone and clean tendons are necessary. Straight, strong fetlock joints are essential. The front pasterns should slope at an angle of about 45 degrees, and be long enough to give elasticity of stride, yet show sufficient substance to insure strength. Proper position of the legs is of greater importance in this type than in draft horses. So much of the value of the horse depends upon action, and so much of action depends upon proper position of the legs and feet, that great attention should be given to this point. The legs must come straight down and the toes point straight ahead, to insure true action.

Feet.-The size of the foot should be proportionate to the size of the horse. Roundness and size of hoof-head, width at the heels, and height at both heel and toe are important. The discussion regarding the sole, bars, frog, denseness of horn, etc., as given in connection with draft horse type, applies here with equal force.

Action.-The requirements of action in the carriage horse are-(1) trueness, (2) height, (3) length of stride, (4) collection, (5) elasticity, (6) boldness and power, (7) gracefulness of movement, and (8) moderate speed. The walk must be snappy, quick, and business-like to a marked degree. But it is at the trot that action is wholly revealed. The flight of each foot must be straight and true. The fore foot should be carried forward and high up, as if following the rim of a rolling wheel, and the stride should be long. The foot meets the ground easily and without apparent jar, in fact, the step appears elastic, and the meeting with the ground seems to send the foot on again as though it were made of rubber. The foot, pastern, cannon, and forearm cannot accomplish this alone. There must also be freedom of action of the arm and shoulder. Every movement must show grace and style, and the whole attitude of the horse should be one of combined courage and power.

Proper folding of the knee meets only half of the requirement. Associated with this, there should be a decided flexing 
of the hock. The hind foot will leave the ground with snap and free movement of pastern, and the hock will be carried, not backward, but upward toward the dock, to accomplish which the hock must be flexed very decidedly. If the action of the hind leg is as described, the hind foot clears the ground by considerable distance, and the hocks do not drag out behind the horse. Many heavy-harness horses swing the hind legs back and forth with but slight flexing of the hocks. Such action has a straggling appearance that is in marked contrast to the high and collected action of a horse possessing proper action.

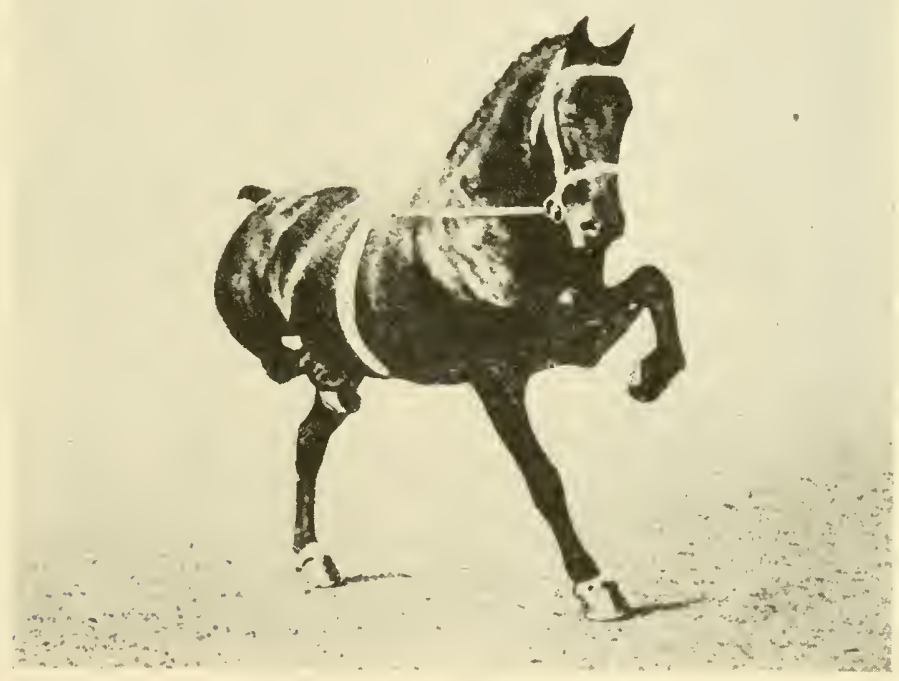

Fig. 132. Sensational Action.

Little Ruby, a Champion Hackney pony stallion, owned in England.

There should also be unison of movement between fore and hind legs.

As pointed out in the description of the draft horse, excellence of action results only when there is a combination of proper conformation of body and legs, correct position of feet and legs, sufficient muscle, proper temperament, and abundant spirit. Action is so valuable in the heavy-harness horse that breeders and dealers often resort to artificial means to secure it in horses which are deficient in their movement. Heavy 
shoes produce height of action. Stimulants are sometimes given to put spirit into the horse; these have only a temporary effect, and when used at all are mostly used with show horses. Short chains are sometimes fastened to the feet of young horses, to teach them to lift their feet high. Exercising over rough or freshly plowed ground, or in straw, is also a common practice, to induce lifting of the knees and hocks. The toe is allowed to grow out long, adding weight to the foot and requiring more energy on the part of the horse in breaking over as he takes a stride, so that when he does break over, the extra force tends to carry the foot higher and farther away. Action produced by any such methods as these is known as artificial action, in contrast to natural action bred in the horse. Artificial action is usually discovered without difficulty. The practiced eye detects that the horse is not doing his work with ease and pleasure. There seems to be a straining of muscles, a "tied up" way of going, and a lack of steadiness that is never seen in the natural actor. Artificial action results in quick tiring of the horse; it is not an unusual spectacle to see such horses come into the show ring with high action which rapidly disappears until the legs drag, if the horse is called upon to do much work, while the natural actor goes high from start to finish.

On the other hand, no matter how natural it may be for a horse to go high, he still requires proper shoeing, bitting, training, and driving, in order that his inherent ability may be developed. Even after the horse is "made," as the saying goes, if he is placed in the hands of an inexperienced reinsman, unskilled in driving heavy-harness horses, the result will be an absolute failure. The trained carriage horse responds superbly under the guidance of the master reinsman. Given proper aids from word, whip, and rein, the horse instinctively responds with the best performance of which he is capable.

Speed.-This is not important in heavy-harness horses; only a moderate degree of speed is wanted. 


\section{CHAPTER XXXII.}

\section{THE ROADSTER OR LIGHT-HARNESS HORSE.}

The roadster or light-harness horse is distinctly an American type, or strictly speaking, it is a breed-the American Trotter or Standardbred. The light-harness horse is a pleasure horse exclusively; his domain includes the regular race tracks, where he is used for professional racing, and also the city speedways and snowpaths, and country roadways, where amateur racing and road driving are indulged in by men who admire the trotting horse and seek recreation in the open air.

The light-harness type and the sport of harness racing originated in and about Philadelphia at the beginning of the nineteenth century, at which time roads were improved and made suitable for pleasure driving. This type is the result of Yankee skill and genius applied to horse breeding. The American Trotter is a wonderful production, and closely rivals the running horse in point of speed. Large numbers have been exported to Europe, especially to Russia, Germany, and Austria, where harness racing is becoming increasingly popular.

This type is styled "light-harness type" because, on both road and track, the horse works in light-weight harness that is quite in contrast to the heavy leather worn by the heavyharness horse. The harness is light because the vehicles to which this horse is put are very light in weight. In professional racing, the bike sulky is used, which weighs from 27 to 35 pounds; in matinee racing, the vehicle used is a light speed wagon, having four wheels but of the same general construction as the sulky, and weighing only 65 to 68 pounds. On the road, the hitch is to a light wagon weighing about 175 pounds, which may have a top much like the common piano-box buggy. For snow racing, a specially constructed speed sleigh is used, weighing a little less than 100 pounds.

The extensive use of the light-harness horse in professional racing is well known, and there has also been a large demand for this horse in amateur racing. Many Americans have derived great pleasure from owning and driving fast trotters. Driving clubs have been organized in many cities and towns for the conduct of matinee racing during the summer and fall, and 
sometimes during the winter months as well. This is done purely from love of the sport, the prizes being ribbons and trophies, and not purses as in professional racing. Hundreds of good horses, some of them holders of world's records, have been purchased by men who never competed for cash prizes; for example, Lou Dillon, The Harvester, and Uhlan were owned by Mr. C. K. G. Billings who never raced his horses for money.

The value of the light-harness horse is based upon (1) speed, (2) stamina or endurance, (3) durability, and (4) beauty of conformation.

Speed.-Whether in use on or off the track, the light-harness horse is prized very largely for his speed. For racing purposes, he is required to show 2:30 speed at the trot, or 2:25 at the pace, before he is considered a light-harness horse in the true sense of the word; for road use he should be able to do at least ten miles within an hour. A light-harness horse without speed is as useless for the purpose intended as a drafter without size, or a carriage horse without action and beauty. The ability to "get there" is the thing for which this horse is bred and trained. The world's trotting record is now 1:58 (which means one minute and fifty-eight seconds for the mile) and is held by Uhlan, a gelding. The world's pacing record is $1: 551 / 4$, held by the stallion Dan Patch. The world's trotting and pacing records* and the years when they were established are as follows:

\section{Trotting}

\begin{tabular}{|c|c|}
\hline 1 mile. . & Uhlan (1912) . . . . . . . \\
\hline 2 miles . . . & The Harvester (1910) . . . . . . . \\
\hline 3 miles... . . & Nightingale $(1893) \ldots \ldots \ldots \ldots \ldots \ldots 6: 551 / 2$ \\
\hline 4 miles. & Senator L. (1894) . . . . . . . . . . . 10:12 \\
\hline 5 miles... . & Zambra $(1902) \ldots \ldots$ \\
\hline 10 miles... . & Pascal $(1893) \ldots$ \\
\hline allion... & Lee Axworthy (1916) . . . . . . \\
\hline [are... & Lou Dillon (1903) . . . . . . \\
\hline elding. & Uhlan $(1912) \ldots$. \\
\hline earling ... & Airdale (1912).. \\
\hline Two-year-old & The Real Lady (1916)... \\
\hline Three-year-old & The Real Lady (1917). \\
\hline Four-year-old. & Peter Volo (1915) ..... \\
\hline Five-year-old & Lee Axworthy (1916). \\
\hline der saddl & Country Jay (1909)... \\
\hline & hlan and Lewis Forrest (19 \\
\hline
\end{tabular}

*Horse Review Harness Racing Guide, 1918. 
Pacing

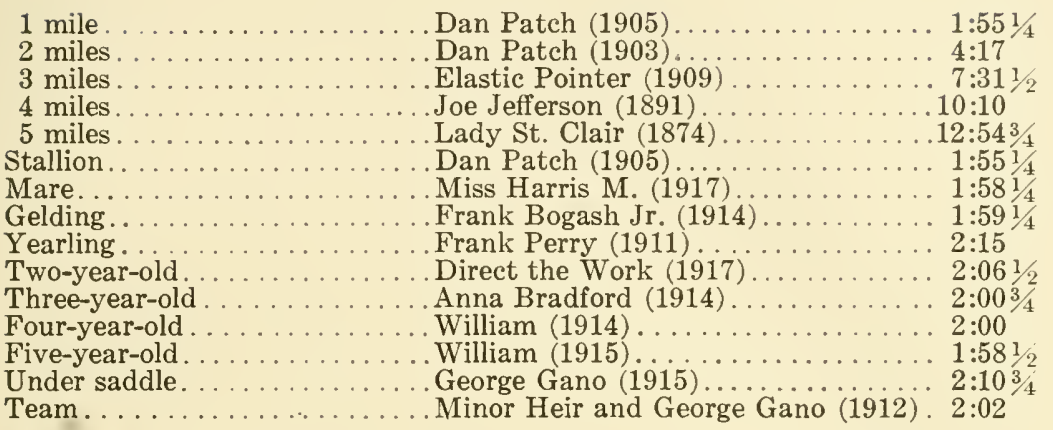

Stamina or endurance.-Most racing, both amateur and professional, is at mile heats over half-mile or mile tracks. Some races are two in three, and some three in five, heats. Not until some horse has succeeded in winning the necessary two or three heats is the race decided. For this reason, some races extend into very gruelling contests. Some horses show a wonderful burst of speed for a quarter of a mile or so, and then quit. These horses are said to "lack bottom," by which is meant a lack of stamina or endurance. Stamina means ability to go a mile at speed, and to repeat the mile, two, three, or more times, with intermissions of not less than 25 minutes. To accomplish this requires heart and lungs of the first order, together with a welldeveloped muscular system. On the speedway and snowpath, there is a great deal of brush racing, that is, racing over short distances of varying lengths, depending on the wishes of the drivers and the ease or difficulty in passing opponents. This is usually not so severe as a regular racing program, provided the horse has been properly conditioned and trained. Horses which have more stamina than speed must depend on their ability to wear down their more speedy rivals, in order to win a heat or race. This they do by repeated scoring for a start, or through the good fortune of having a race extended out to extra heats-what is termed a split-heat race. Other horses, with more speed than stamina, must be driven to win from the start of the race, avoiding unnecessary scoring and endeavoring to win the required number of heats in short order.

Durability. - It is readily apparent that the work required of the light-harness horse is of such a nature as demands the best of feet and legs. This type of horse has a decided advantage over the carriage horse and drafter, in that he works 
on a much more yielding footing, yet the high rate of speed puts his feet and legs to a very severe test, and many horses with speed and stamina have their usefulness and value greatly lessened because of failure to keep sound when called upon to go through a strenuous racing campaign or do a large amount of work on the road. Some very noted horses and some families of trotters have been notably lacking in this respect.

Beauty of conformation is a comparatively small factor in determining the value of light-harness horses for racing purposes. Some breeders have placed considerable emphasis on the matter of looks and attractiveness, but in general it may be said that beauty in the light-harness horse, while appreciated whenever it occurs, has not been fully emphasized by breeders, because they have been catering to the demand of the race track, and that demand is for speed above everything else. In selecting roadsters strictly for road driving, however, speed is not so important as endurance and the ability to make a long drive in creditable time, and for this work a horse of attractive, finished appearance is highly desirable. A big, strong, well-made horse, with quality, a well-carried head and tail, light mouth, good manners, excellent feet and legs, and a long stride, is the sort best suited for road driving. For the various kinds of racing, however, speed, stamina, and durability are the almost exclusive requirements.

\section{DETAILED DESCRIPTION OF THE TYPE.}

General appearance.-There is considerable variation in the general appearance of the light-harness horse. This is a result of breeding for speed alone. Speed is the only characteristic which all light-harness horses possess with reasonable uniformity. To be sure, selection and breeding for speed have resulted in fixing a sort of general type upon this horse. Certain things are necessary in the conformation of the horse to enable him to go fast. Acknowledging this, there is yet opportunity for rather wide differences in appearance. In selecting animals for breeding purposes, the basis of selection has been speed almost to the exclusion of other qualities. S. W. Parlin, Editor of the American Horse Breeder, has written the following on the subject of breeding trotters: "When choosing between two animals for breeding purposes, one of which is a very attractive animal, but known to be lacking in inheritance from animals that were race winners at some gait, and a less attractive one, 
that has a rich speed inheritance on both sides, it will always be safer to take the less attractive one that has the richer inheritance."

The above outlined practice, while correct enough in breeding for the track, is responsible for the wide variation in appearance found among light-harness horses. A few breeders have bred for beauty and speed combined. Mr. C. J. Hamlin, who during his lifetime maintained a world-famous breeding and

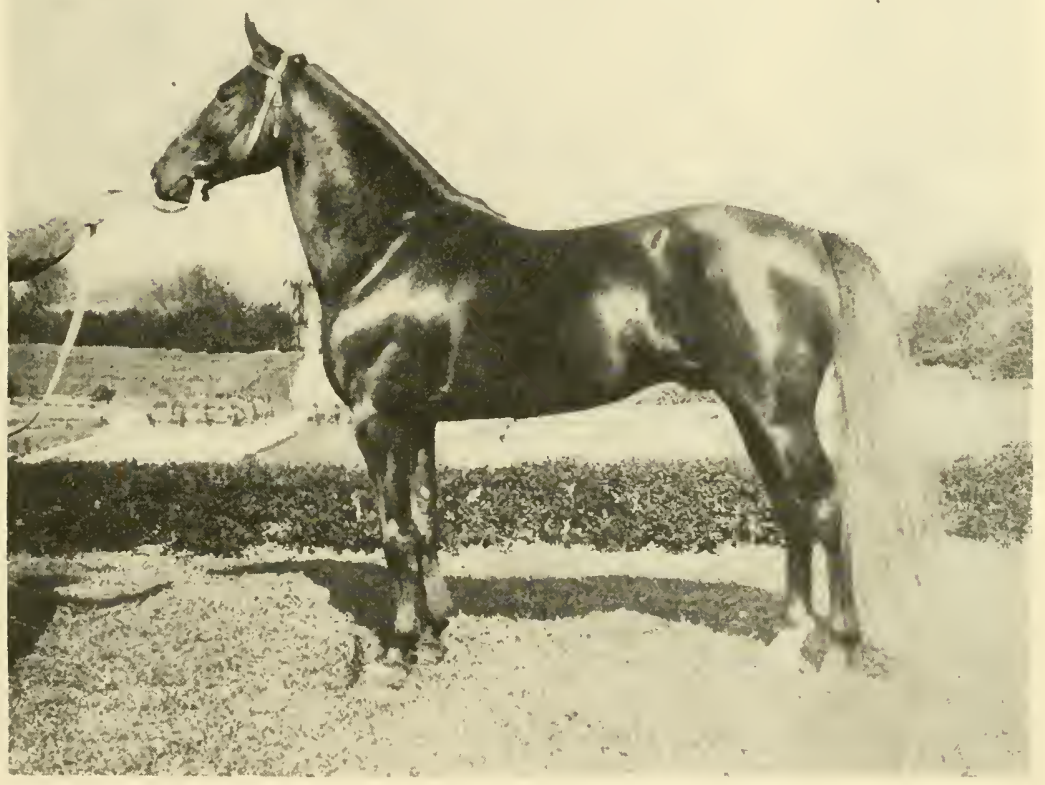

Fig. 133. Roadster or Light-Harness Type.

Azoff, 2, 2:141/4; son of Peter the Great 2:071/4 and Dolly Worthy 2:271/4, by Axworthy $2: 15 \frac{1}{2}$. Owned at Thompson Farm, Libertyville, Ill., Hon. John R. Thompson, Proprietor.

training plant at East Aurora, N. Y., used to say- "When you go into a ball room, you would rather choose as a partner a beautiful woman who can dance well than a homely one who can dance equally well." He used this illustration to show his attitude in the production of the roadster. Mr. Hamlin successfully combined speed with size, soundness, style, and elegance of form. 
In breeding for speed alone, certain other characters are bound to be impressed also. Speed in the light-harness horse is associated or correlated with refinement, endurance, and courage. Size, symmetry, and beauty are not correlated with speed except in the most general way. The light-harness horse varies in weight from 800 to 1,250 pounds, and in height from 14-2 to 16-1. Weights from 950 to 1,150 pounds and heights from 15 to 16 hands are most common. This type is rather upstanding, leggy, long, deep, narrow, and angular. Quality is shown by clean, smooth, dense bone; sharply defined tendons and joints; fine skin and hair; small ears; fine-haired mane and tail; hoofs of smooth, dense horn; and a chiseled, blooded-looking head. The temperament must be decidedly sanguine, which brings courage, willingness, and promptness, with no sluggishness.

Head.- The head should be refined and well proportioned, with a straight face line, a fine muzzle, large nostrils, and thin, trim lips. The eyes should be large, prominent, clear, and bright. The forehead should be high, broad, and full. The ears should be fine, pointed, set close, and carried alert.

Neck.-A long, lean neck, with a fine throttle, is desired. Ewe necks are common. A straight neck, or one with slight arch, is preferable.

Shoulders.-Long, smooth, sloping shoulders, fitted close together, and forming high, refined withers at the top, are most desirable.

Middle.-A deep rib, without much arch, is associated with desirable light-harness type. The chest gets its capacity from depth, rather than from width. A straight, mediumshort, well-muscled back and loin are essential. The underline is long, and the flanks should be well let down.

Hips. - The hips should be fairly wide, yet smooth. This type does not present as smooth a hip as the carriage horse. A little prominence of hip is not very objectionable, but if this is so pronounced as to give a rough appearance it is undesirable.

Croup.-A long, level, fairly broad, muscular croup is best suited to this type. Defective croups are common. The tail should be attached high and well carried.

Thighs and quarters.-Long, muscular thighs give speed. Well-muscled quarters are necessary for strength.

Legs.-Length of leg is necessary for speed, yet there should be proper proportion between length of leg and size of horse. 
A shallow body set up high on very long legs is not a good type. Yet it is just as essential that the light-harness horse have length of leg to secure speed, as it is that the draft horse have a short leg to secure great power. However, the length must come above the knees and hocks as much as possible. The arm should be muscular, and carried well forward, while the forearm should be long and muscular, with a nice tapering to the knee. This provides room for the long muscles associated with speed. The knees must be clean, bony, straight, broad, deep, and strongly supported. The cannons should be broad, with large, clean tendons set well back from the bone. Straight, wide fetlock joints and strong, sloping pasterns of good length are very necessary. The fore leg must be straight, and the toe should point directly forward, to insure trueness of action. A long, muscular gaskin is an important requirement. This brings the hocks far below the point of the buttock, which is essential in securing speed. Clean hocks that are wide, deep, straight, with prominent point, and well supported below are very necessary. The hind legs must be set straight, with the toes pointing straight ahead. Sickle-shaped hind legs are rather too common.

Feet.-The best of feet are necessary. Although this type is usually afforded an easy footing, nevertheless the tremendous concussion puts the feet to severe strain when the horse travels at speed. At high speed, a stride of 19 or 20 feet is attained. Imagine the force of the concussion when a 1,000-pound horse strides 20 feet in less than half a second, as is the case when the horse is trotting at a two-minute gait. The feet should be welldeveloped, uniform in size, point straight forward, and slope at the same angle as the pastern. The horn of the hoof should be dense and smooth, the sole should be concave, the bars strong, the frog large and elastic, and the heel wide and open.

Gait.-Both pacers and trotters are found among lightharness horses. These gaits differ from each other in that the pace is a lateral motion in which the fore and hind leg of the same side act together, while the trotter moves diagonally. A change of a few ounces in the weight of a shoe often transforms the gait. Many horses hold records at both gaits. The pacing gait is about three seconds faster for the mile than the trot, but it is not so popular with horsemen as the trotting gait, especially for road driving. With the pace there is often associated a decided rolling of the body, which is disliked, the pull on the vehicle is jerky, and the pacer does not work well in the 
mud or where the going is heavy. The natural pacer also frequently possesses a steep croup, short underline, and sickleshaped hind leg.

Action.-The walk should be true, quick, elastic, and regular. The trot, in order to be fast without undue tiring of the horse, must be straight and true, with regular, even, long stride. Height of action is of little importance; in fact, the less knee and hock action the better. It is only important that the foot clear the ground, accompanied by enough action of knee and hock to secure length of stride. There should be no hitching or unsteadiness of gait, and no great tendency to break when going

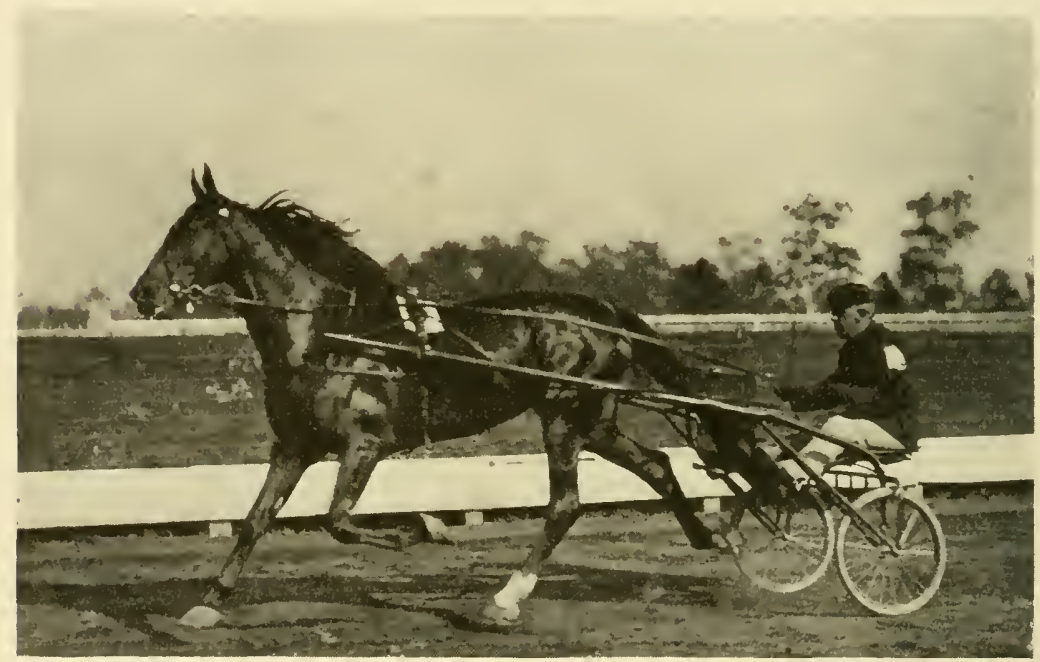

Fig. 134. The Light-Harness Horse in Action.

The Harvester, 2:01, Ex-Champion trotting stallion, driven by $\mathrm{Mr}$. Ed Geers. Owned by Mr. C. K. G. Billings of New York City.

at speed. The action should be what is sometimes termed "frictionless," giving one the impression of a perfect mechanism that can travel at greatest speed with least expenditure of energy. It is apparent that much of the success of the light-harness horse depends upon good action, and good action, in turn, is dependent largely upon proper position of the legs. Defects in conformation result in knee knocking, speedy cutting, overreaching, and other faults of action.

Common defects in the action of light-harness horses are (1) swinging the fore feet inward, instead of carrying them 
straight away, (2) a stride in which extension is more marked than flexion, and in which the heel of the foot strikes the ground first, called "pointing," (3) pause in flight of foot before foot reaches ground, called "dwelling," (4) striking sole or heels of fore foot with toe of hind foot, called "forging," (5) striking supporting leg with foot of striding leg, called "interfering," (6) hitting front of hind foot, above or at line of hair, against toe of fore foot as it breaks over, called "scalping," (7) the trotter at speed often goes rather wide behind, and he sometimes strikes his hind leg, above the scalping mark, against the outside of the breaking over fore foot, called "speedy cutting," and (8) "cross-firing," a fault in pacers corresponding to forging in trotters.

Condition.-The condition of the light-harness horse is in marked contrast to the types previously described. When in desirable racing condition, there seems to be a total absence of fat from the muscles. A clean-cut, sinewy appearance indicates proper racing trim. For hard use on the road, a fat horse is almost equally objectionable. The fat horse is soft, sweats easily, and tires quickly. However, proper condition is not secured by giving short rations. The roadster should be well fed, and kept in proper condition by lots of exercise.

Color.-A study of the American Trotting Register, which is the stud book in which Standardbred horses are recorded, indicates that the colors per thousand horses are as follows:605 bays, 140 chestnuts, 130 browns, 85 blacks, 25 grays, 13 roans, and 2 duns. The first four colors-bay, chestnut, brown, and black-are liked best. Grays, roans, and duns are not so popular. 


\section{CHAPTER XXXIII.}

\section{THE SADDLE HORSE.}

Any horse used for riding might be called a saddle horse. But there is a certain type of horse best suited to carrying a man in safety and comfort, and this is the type to bear in mind when thinking of saddle horses. The horse of all pioneer peoples is the saddler. In new countries, before the opening of roads, the saddle horse is of greatest usefulness. When the country becomes settled and roadways are opened and improved, other types of horses quickly appear, and there is less and less real necessity for the saddle horse; but the saddler never disappears from any community, because he is highly prized as a horse for pleasure and recreation.

When roads were being opened in the states along the eastern seaboard, and the roadster began to gain popularity, Kentucky, Missouri, and the West were yet a country of bridle paths, and there the saddle horse was held in high esteem. In 1818 , a traveller through the Kentucky blue-grass region reported that "the horse, 'noble and generous,' is the favorite animal of the Kentuckian, by whom he is pampered with unceasing attention. Every person of wealth has from ten to thirty, of good size and condition, upon which he lavishes his corn with a wasteful profusion." Besides Kentucky and Missouri, the states of Virginia and Tennessee have been intimately connected with saddle horse development in America. These four states produce many excellent saddle animals annually.

Today, saddle horses are used in a business way by the cavalry of the United States Army and National Guard, by the mounted police of the larger cities, by cattle drovers in rural districts, by cattle buyers and salesmen at the large live-stock markets, by ranchers in the West, and by overseers and managers of large plantations and farms in the South, East, and Central West. However, the high prices for saddle horses are paid by people to whom the saddler is a pleasure horse. In city parks and on country roads are to be seen many excellent saddle horses, used strictly for pleasure and recreation.

All good saddle horses possess a general type which we may call "saddle type," but the uses made of saddle horses are 
so varied that several varieties or sub-types of the saddle horse exist, each possessing a distinct type of its own. The most important of these sub-types are (1) the five-gaited saddler, (2) the three-gaited horse, (3) the hunter, and (4) the polo pony. All of these are pleasure horses. The running horse or race horse, the cavalry horse, and the western cow pony are other sub-types adapted to certain special uses, but the following discussion is confined to the four first mentioned. A brief description of the cavalry horse will be found in the chapter dealing with market classes of horses.

\section{The Five-Gaited Saddle Horse.}

The five-gaited saddle horse is also known as the American Saddle Horse, this being the name of the breed which supplies practically all horses of the gaited class. To classify as a five-gaited horse, the saddler must have at least five gaits, four of which must be the walk, trot, canter, and rack; in addition to these four, the horse must have one or more of three slow gaits - the running walk, fox trot, and slow pace. The gaited saddler is the horse that has made Kentucky and Missouri famous. In his native home he is looked upon with great admiration, and bred and trained with great care.

General appearance.-The gaited horse wears a natural mane and tail, in contrast to the other types of saddle horses. The breeders of this type lay stress upon loftiness of carriage, airiness of movement, refinement, intelligence, docility with high spirit and courage,-withal, great beauty in every detail of conformation, without any sacrifice of those qualities which insure durability and creditable performance of the work demanded of a saddle horse. A leading Kentucky breeder presents the points of the typical five-gaited saddle horse in the following brief paragraph*:-

"The typical saddle horse does not differ materially from other light horses in conformation. The characteristics peculiar to the type are a long, clean neck, sloping pasterns and shoulders, withers moderately high and narrow, a short and compactly coupled back, smoothly turned quarters, and a well-set, highcarried tail. In action there should be promptness, ease, and precision in going from gait to gait, and absolute straightness and evenness in each. The rack should be smooth, swift, and

* Bit \& Spur, September, 1912, p. 22. 
without side motion of the body or legs, the trot should be fast and without offensive flashiness, the canter should be slow with no increasing speed, the flat-footed walk should be springy and reasonably fast, while the running walk, or fox trot, should be easy and comfortable and equal to about five miles an hour."

Gaits.-In a wild state the natural gaits of the horse were four in number - the walk, trot, pace, and gallop or run. Under domestication these gaits have been variously modified and additions made for saddle purposes. These additions and modifications are largely the result of the selection for breeding purposes

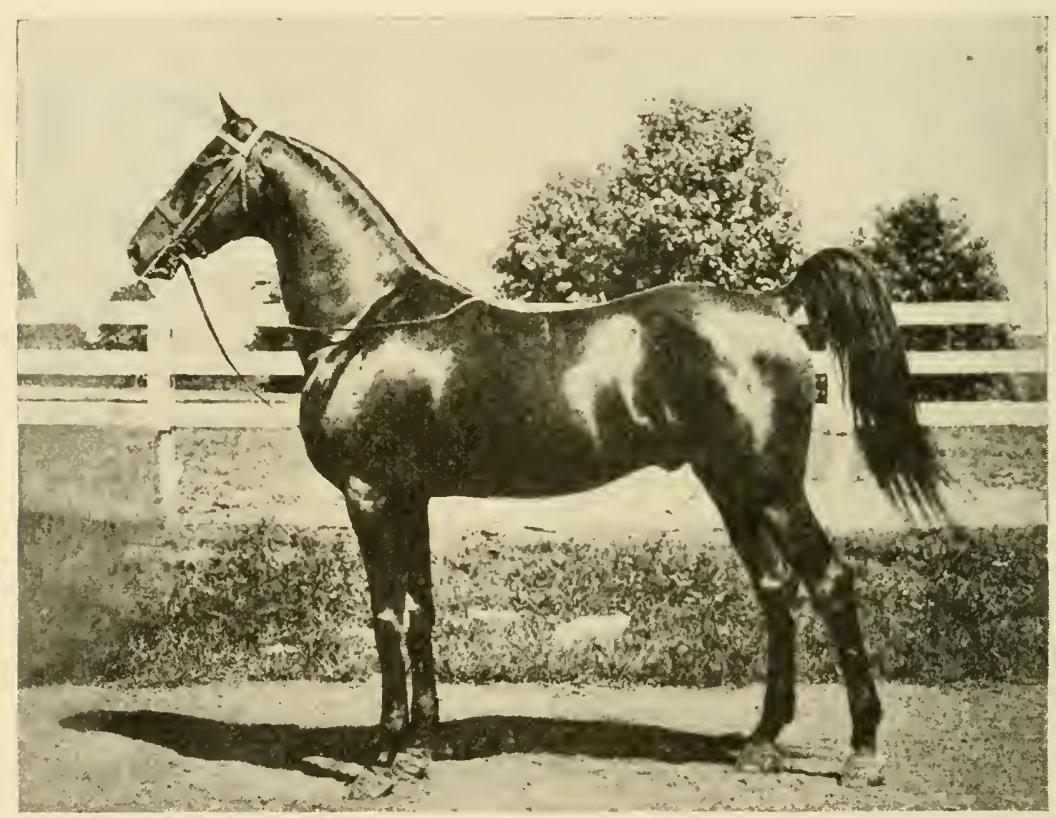

Fig. 135. Five-Gaited Saddle Horse.

The noted prize-winning stallion, Kentucky's Choice. Owned by Mrs. R. Tasker Lowndes, Danville, Ky.

of those animals most readily acquiring the desired gaits when trained to them. The gaits desired in the five-gaited type of saddle horse are as follows:

Walk.-The flat-footed walk should be springy, regular, and reasonably fast.

Trot.-This is a diagonal gait, the off fore foot and near hind foot striking the ground together, the body being then propelled forward from this support and sustained by the near 
fore foot and off hind foot. It is a "two-beat" gait. The trot should be fast, with only moderate height of action, extreme knee action being undesirable. Many otherwise excellent saddle horses cannot trot well, "pointing" and coming down on their heels, instead of exhibiting a well-balanced trot.

Canter.-The canter is a restrained gallop. It is slower than the gallop and easier to ride. With proper training, the horse easily acquires this gait. It should be slow, with no in-

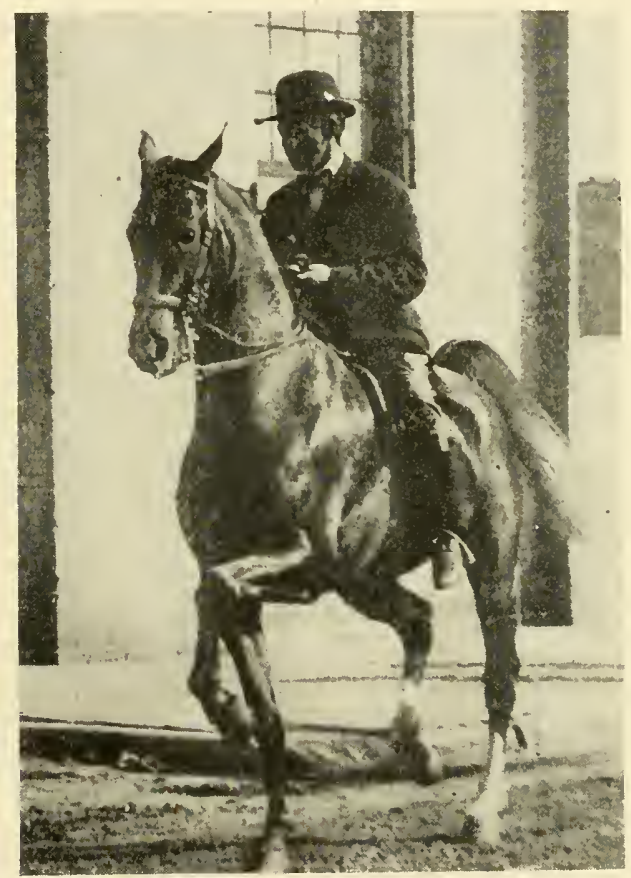

Fig. 136. The Saddle Horse in Action.

Edna May, undefeated five-gaited mare, ridden by Mr. Mat S. Cohen, Lexington, Ky. Owned by Mrs. R. Tasker Lowndes, Danville, Ky. This picture shows correct degree of knee and hock action and proper carriage of head and tail.

creasing speed. The canter is not considered perfect until the horse can perform it at a rate no faster than a fast walk. To "canter all day in the shade of an apple tree" is a saying sometimes used to describe the canter of a highly trained saddler that can canter very slowly and in a small circle. A well-trained horse will change lead in the canter, and start with either foot leading, at the will of the rider. 
Rack.-This is a four-beat gait, each foot meeting the ground singly, all the intervals being equai. Hence it is sometimes called "single foot." This gait may be distinguished by the ear alone, because the foot-falls are rapid enough to produce a characteristic clatter. The rack is taught by urging the horse with the whip or spurs and restraining by the curb. This breaks up the movement of a slow gait, and the restraint is sufficient to prevent a free trot or canter, so that the horse flies into a rapid four-beat gait. The rack is easy for the rider, hard for the horse. It is showy, and some horses can perform it at great speed. This gait has been officially named the "rack" by the American Saddle Horse Breeders' Association, hence the name "single foot" should not be used. It should be smooth, swift, and without side motion of the body or legs.

Slow pace.-The slow pace, sometimes called the "stepping pace," is the true pace so modified that the impact on the ground of the two feet on a side is broken, the hind foot touching first, thus avoiding the rolling motion of the true pace. The slow pace is a comfortable and attractive gait. Many trainers do not favor it, for the horse easily falls into the habit of taking the true pace which is not a desirable saddle gait because it is rough and uncomfortable. The true pace is the worst gait a saddle horse can possess; the rider cannot rise to it and save himself as in a trot.

Fox trot.-The fox trot is a slow, short-striding trot. It is not so popular as the running walk. It is a broken-time gait and difficult to describe. Some riders, when asked to exhibit the fox trot, simply restrain their horses to as slow a trot as possible, seeking to pass that off as a fox trot, but the true fox trot is not accompanied by restraint.

Running walk.- This is a slow gait, as are also the slow pace and fox trot. The running walk is faster than a flat-foot walk and is taught by gently urging the horse out of the ordinary walk, but restraining him from a trot or rack. It is intermediate between the walk and rack. The movement of the legs is more rapid than in a walk, but in about the same rhythm. The true running walk is usually characterized by a bobbing or nodding of the head, and, in some instances, by a flopping of the ears, in unison with the foot-falls. It is an all-day gait, easy and comfortable to both horse and rider, and equal to six miles an hour or more. It is, however, not as showy or attractive as the other gaits. 


\section{The Three-Gaited Saddle Horse.}

This type is also styled the "walk, trot, canter horse," and the "park hack." This is the horse which conforms to English fashions, whereas the five-gaited saddler is exclusively an American type.

General appearance.-The walk, trot, canter horse usually has his mane pulled and his tail docked and set, in accordance

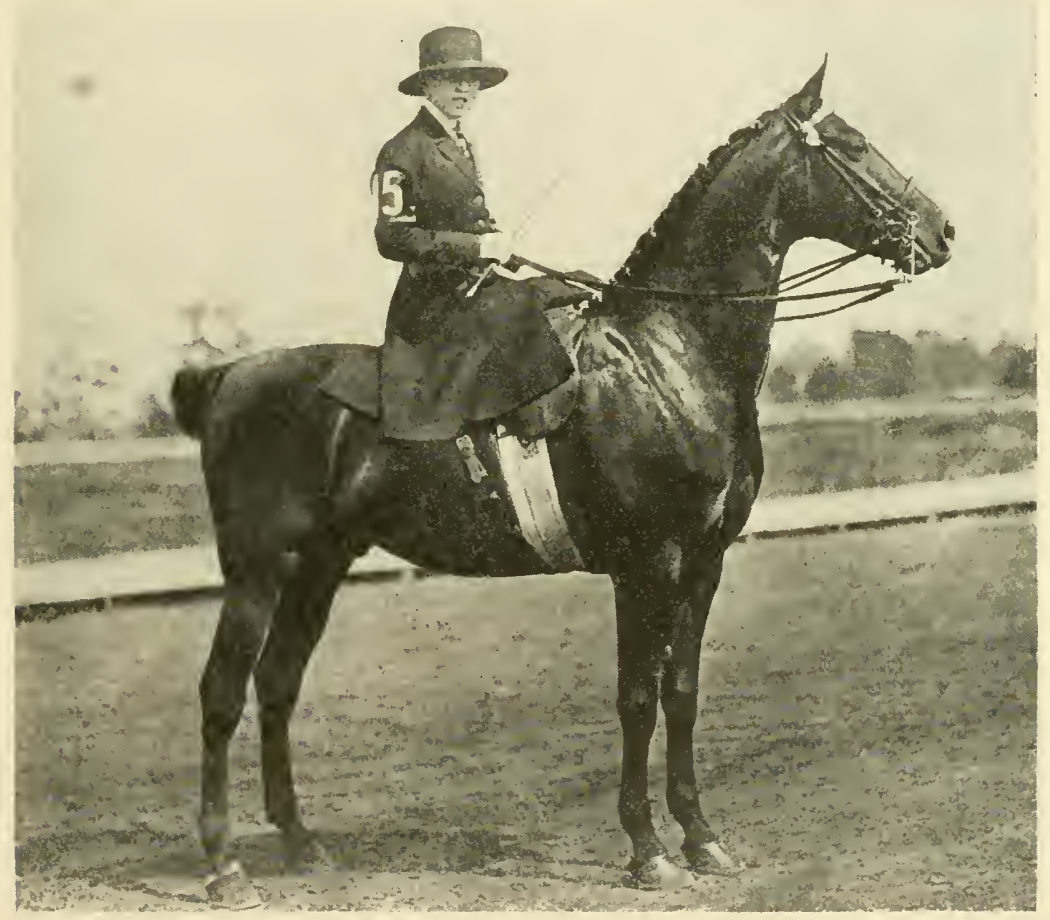

Fig. 137. The Three-Gaited Saddle Type.

Connoisseur, an excellent type of walk, trot, canter horse. Owned by Mr. Wm. Ritter, Columbus, Ohio.

with English fashion, whereas the five-gaited horse wears a full mane and tail. Otherwise, the two types have much the same general appearance. Most three-gaited saddlers are American Saddle Horses which, for one reason or another, are marketed as three-gaited horses. There are also quite a number of walk, trot horses which are of Thoroughbred breeding, and some have a strong infusion of the blood of the American Trotter. In such 
cases, the head and tail are not carried so high, and there is not the evidence of style in form and action which characterizes the horse that is of American Saddle Horse breeding.

Gaits. - This horse must show three gaits, and three only; these are the walk, trot, and canter. It is as objectionable for a three-gaited horse to show more than the gaits mentioned as for the five-gaited horse to know less than five gaits.

While many people have adopted the walk, trot, canter horse in preference to the five-gaited type because they accept English horse fashions as law, there is still another reason why the American type with its five or more gaits is not favored by all riders. The reason is that there is no advantage in having a horse with all the gaits unless the rider is skillful enough to keep them distinct. If the man is less instructed than the horse, a sad confusion of paces is apt to result. A well-mouthed, wellsuppled horse, with a good trot and a good canter is more useful to the ordinary rider than is one of the highly accomplished gaited saddlers; hence the popularity of the three-gaited horse, especially in the larger cities. Saddle horse breeders recognize this state of affairs and annually send to market a large number of three-gaited animals, as well as large numbers of five-gaited horses.

Outside of the matter of gaits, the requirements for the five-gaited and three-gaited types are so nearly identical that one discussion will suffice for both.

\section{REQUIREMENTS OF THE SADDLE HORSE.}

The essential points to be looked for in a saddle horse are (1) beauty of conformation, (2) sure-footedness, (3) comfortable seat, (4) best of manners, (5) knowledge of the gaits, (6) endurance and durability, and (7) dark solid color.

1. Beauty of conformation.-Attractiveness of form and action is almost, if not quite, as valuable in the saddle horse as in the carriage horse. People who ride for pleasure take as much pride in the ownership of an attractive animal as do the owners of carriage horses.

2. Sure-footedness. - Saddle action must, first of all, be safe and sure. A horse inclined to stumble is dangerous, and cannot be highly valued for saddle purposes.

3. Comfortable seat.-Though a horse be sure-footed, he will not be of much use or value for saddle work unless he 
gives his rider a pleasant ride. Rough-gaited horses are not useful saddle horses.

4. Manners.- The intimate relation between horse and rider calls for the very best of manners. Conduct that would be tolerated from a horse in harness may be very disagreeable if the horse is under saddle. The very nature of the use to which the saddler is put makes manners one of the prime essentials.

5. Knowledge of gaits. - To a considerable extent the value of the saddle animal is measured by his knowledge of the gaits. As this is largely a matter of training, it is placed fifth in the list of requirements. There must be no mixing of gaits; each gait must be distinct, and the horse should change gaits promptly and easily at the signal from the rider.

6. Endurance and durability. - This implies a good middle and enough substance combined with quality of bone and joints to insure good wearing qualities. Although a pleasure horse and hence not asked to do extreme labor, nevertheless real pleasure does not come to the rider who knows his horse to be delicate in bone, or otherwise liable to injury, if called upon to do hard work.

7. Color.-Dark colors are much preferred, including bay, brown, chestnut, and black. Flashy colors such as dapple gray, roan, dun, cream, white, and parti-color are too conspicuous for ordinary saddle use.

\section{DETAILED DESCRIPTION OF SADDLE TYPE.}

Size and weight.-These are quite variable depending on the character of the work and the weight of the rider. The height is usually from 15-1 to 15-3 hands, and the weight from 1,000 to 1,150 pounds. A gaited horse of 15-1 hands and 1,000 pounds is termed a "lady's saddler," or if a walk, trot, canter horse, a "lady's hack;" but for heavier riders larger animals are required, some men needing a horse standing over 16 hands and weighing 1,200 pounds or even more. For the sake of comparison the heights and weights of the various sub-types of saddle horses are here given:

\section{Type}

Five gaited.

Three gaited

Hunter....

Cavalry....

Polo pony.
Height

$15-16$

$14-3-16$

$15-2-16-1$

$15-16$

$14-14-2$
Weight

900-1200

$900-1200$

$1000-1250$

$950-1200$

$850-1000$ 
Conformation.- The saddle horse is considered by many people to be the most stylish, beautiful, and finished of all horses. The principal requirements in conformation are (1) a long, refined neck, (2) nicely sloping pasterns and shoulders, and (3) moderately high and refined withers. The lines of the head should be cameo-like in sharpness and clean-cutness. An ideal saddler will naturally have a head showing an unusually kind disposition and high intelligence, for the intimate relation between horse and rider demands the best of manners in the horse and thinking ability on both sides. The head should be set at the right angle on a very long, refined, nicely arched neck. Unless there is lots of horse in front of the saddle, the appearance is spoiled, and a horse with a short, straight, heavy neck is not easily controlled. There should be easy flexion of jaw and neck, and this is possible only with a long, refined neck, properly arched. However, a "weedy" neck, that is, one lacking in muscular development, is not wanted. Much attention must be given to the slope of pastern and shoulder, for straight pasterns and shoulders are more objectionable in the saddle horse than in any other type because they are almost certain to make the horse a hard rider. Height and refinement of withers are necessary for a similar reason. Horses that are low in the forehand are not comfortable to ride. Furthermore, the saddle cannot be made secure on round, flat withers, this being particularly true of the side saddle. The extension of the shoulder into the back and shortness and strength of coupling are very important. A straight or roached back does not afford an easy ride; there should be a certain degree of springiness, without any weakness or sway-backed conformation. The saddle horse is somewhat upstanding, and the head and tail should be smartly carried.

Refinement and finish.-The saddle horse should possess a high degree of quality, and lots of smoothness from end to end. There should be greater refinement of head, ear, and bone than in the heavy-harness type of horse. The shoulders should be well laid in, and the hindquarters smoothly turned. The smoothness of the typical saddler is in marked contrast to the angular appearance of the roadster. Rotundity of body is a highly desirable feature. Levelness of croup is more important in the saddle horse than in any other type; if a horse has a steep croup, the defect is magnified a great deal when the saddle is placed upon his back, and he presents a plain appearance. 
Action.-The action should be energetic, elastic, of moderate height, and especially there should be trueness of motion in all gaits. Gracefulness and ease of action are very desirable. A springy step resulting from sloping pasterns and shoulders is more essential in the saddle horse than in any other type. A straight-shouldered and -pasterned horse gives one a ride like a carriage without springs. Collected action, by which is meant harmony or unison of movement between fore and hind legs is necessary for gracefulness and comfort. It also means that the legs will be kept at all times under the weight, thus permitting of quick turns or any other evolutions desired. Collected action is largely a result of properly training the horse, and skill on the part of the rider. By pressure of the leg, or use of the whip or spur, the horse is kept alert, with the hind legs well under the body, while the hands bring sufficient pressure on the mouth to restrain the movement slightly, arch the neck, and secure a slight yielding of the jaw. If the action is not collected, the horse moves awkwardly and executes sudden commands in a clumsy fashion.

Temperament and disposition.- The temperament should be sanguine, as in all other light horses. The disposition should be kind, willing, honest, and courageous. There should be docility with high spirit and animation. 


\section{CHAPTER XXXIV.}

\section{THE HUNTER AND POLO PONY.}

The hunter and polo pony differ rather markedly from the two types of saddle horses described in the preceding chapter, largely because they are required to do work of a highly specialized nature in which performance is of greater importance and beauty less valued than with the gaited horse and park hack. Hence, the hunter and polo pony are given separate consideration in order that their peculiarities of type and requirements may be better emphasized.

\section{The Hunter.}

The hunter is the type used in following the hounds in fox hunting. He must be up to carrying his rider at good speed over long distances across country, jumping fences and ditches when called upon to do so. Like the park hack, this is an English type.

Although the American demand for this horse is somewhat limited, the supply is still more so, resulting in high prices being paid for green horses of the hunter stamp. In England the demand is great, and American horses of hunter type have been much sought after by exporters. The English people have invested many millions of dollars in the sport of fox hunting. There is an increasing demand for hunters in this country, and the demand will continue to grow because fox hunting, besides being a most healthful and invigorating amusement, is also a fashionable and popular sport in many sections of the country. It is estimated that within twenty-five miles of New York there are six hundred to eight hundred hunters in daily use, and that the suburbs of New York and Philadelphia total nearly fifteen hundred such animals. Many are well worth over $\$ 1,000$, and a great majority are worth $\$ 400$ to $\$ 500$ each. It is probable that this census represents from $\$ 750,000$ to $\$ 1,000,000$ worth of horses for hunting. In Canada there are hundreds of excellent hunters, and the sport is on the increase. The Central West of the United States is beginning to take up fox hunting, several hunt clubs having been organized in that section during the last few years. 
From the nature of the work, the hunter must be a horse of more size, ruggedness, and constitution than the other types of saddle horses. He must be a stayer at hard work, a jumper, and a horse of courage and decent manners. His bone must be of good size and of the right quality, and there must be an evidence of strength throughout his conformation. Otherwise he cannot long withstand the hardships of the hunting field.

Height and weight.-With reference to height, much will depend upon circumstances. Weight-carrying hunters are always more difficult to procure, and command higher prices. Short, light-weight men prefer 15-2 hands to 15-3, but height is quite subsidiary to conformation. Where fences are high, tall horses are necessary, but conformation must not be sacrificed to this. Some hunters are nearly 17 hands. Hunters are classed as light, middle, and heavy weight according to their size and weight. Most of the hunting horses in use range in height from 15-2 to 16-1 hands, and in weight from 1,000 to 1,250 pounds.

General appearance.-The general appearance of the hunter should be that of a thin-skinned, big-boned, small-headed, fineshouldered, deep-chested, clean-legged animal, with a neatly turned, compact body, and having a facial expression of great keenness, docility, and quick perception.

Head.-The head should be refined; the forehead straight; the eyes large and prominent; the ears erect and thin; and the skin covering the head and face should also be thin, rendering the various prominences upon the skull easily apparent. The high-class hunter should have a mild, keen, and extremely intelligent expression.

Neck.-The neck must be long, narrow towards the poll, and the head should be carried obliquely, a lofty carriage being undesirable in the hunter. As the shoulders are approached, the neck should increase in width, be of moderate thickness, and clean along its upper border, with a closely-cropped mane. Many hunters are very weedy in the neck, and if this is the case, the horse is unable to recover himself in the event of a fall, as the muscles of the neck materially assist in raising the forepart of the body in its attempt to regain balance.

Withers. - The upper border of the neck should pass into high withers, and most of the best hunters are high in this region. 
Shoulders.--When judging hunters, attention must be fixed upon the shoulders, not only while the horse is at rest, but also when jumping, as good shoulder action is one of the most important points in a hunter. In action it must be free and full, yet fine, because if the shoulders are logged up with muscles (heavy shoulders), the free action is interfered with when jumping.

Chest.-The chest must be deep; in fact, it is self evident that a hunter should be "well-hearted" in order to provide plenty

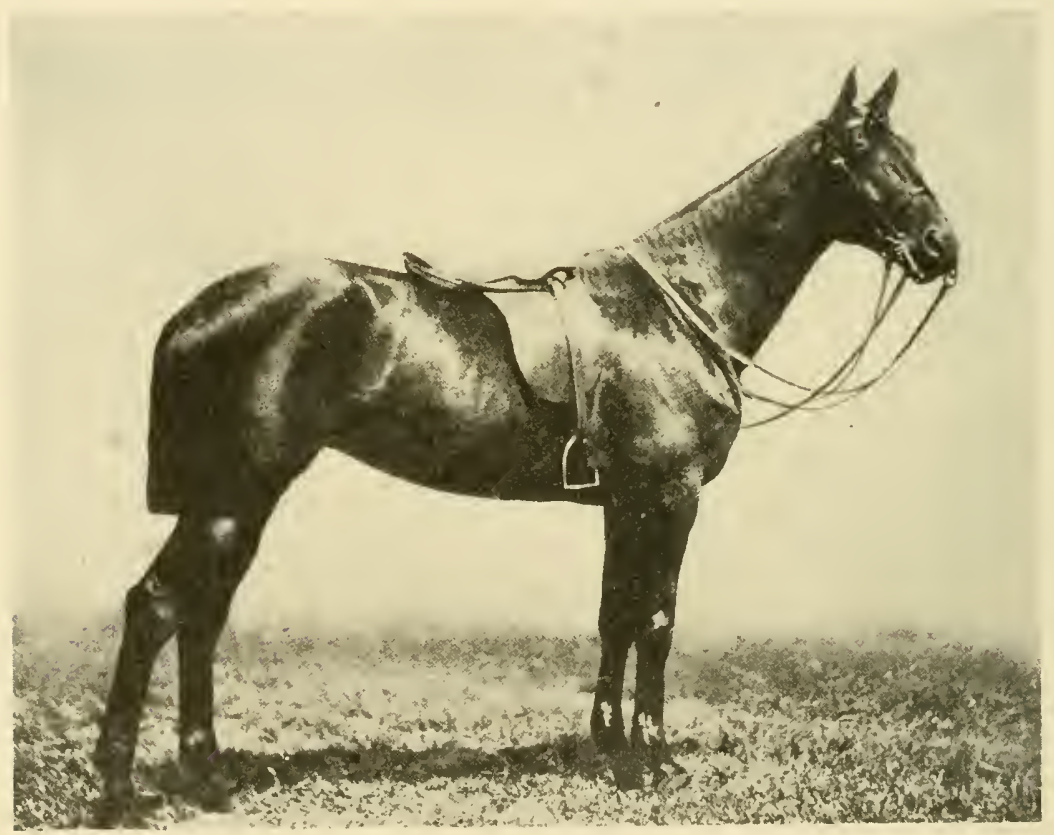

Fig. 138. A Typical Hunter.

Surprise, a winner at the Royal Hunter Show and many other shows in England. Owned by Sir Merrick Burrells.

of space for the free play of heart and lungs under extreme exertion. Width of chest is not required and often means bulky shoulders.

Ribs.-A slightly flat side is desirable, though the ribs must not be short, otherwise the horse becomes "tucked up" or "washy" in appearance.

Back, loin, and croup.--The back and loin should be of medium length, and the latter must be broad and clothed with 
powerful muscles, passing into neatly turned quarters-the so-called "goose rump" being of objectionable conformation.

Arms and knees. - The arms should be strong and powerful; the forearms of good breadth above and ending below in broad-jointed, clean knees. A stiff knee is certainly detrimental, as is also low daisy-cutting action, as such horses cannot freely flex and extend their joints during the leap.

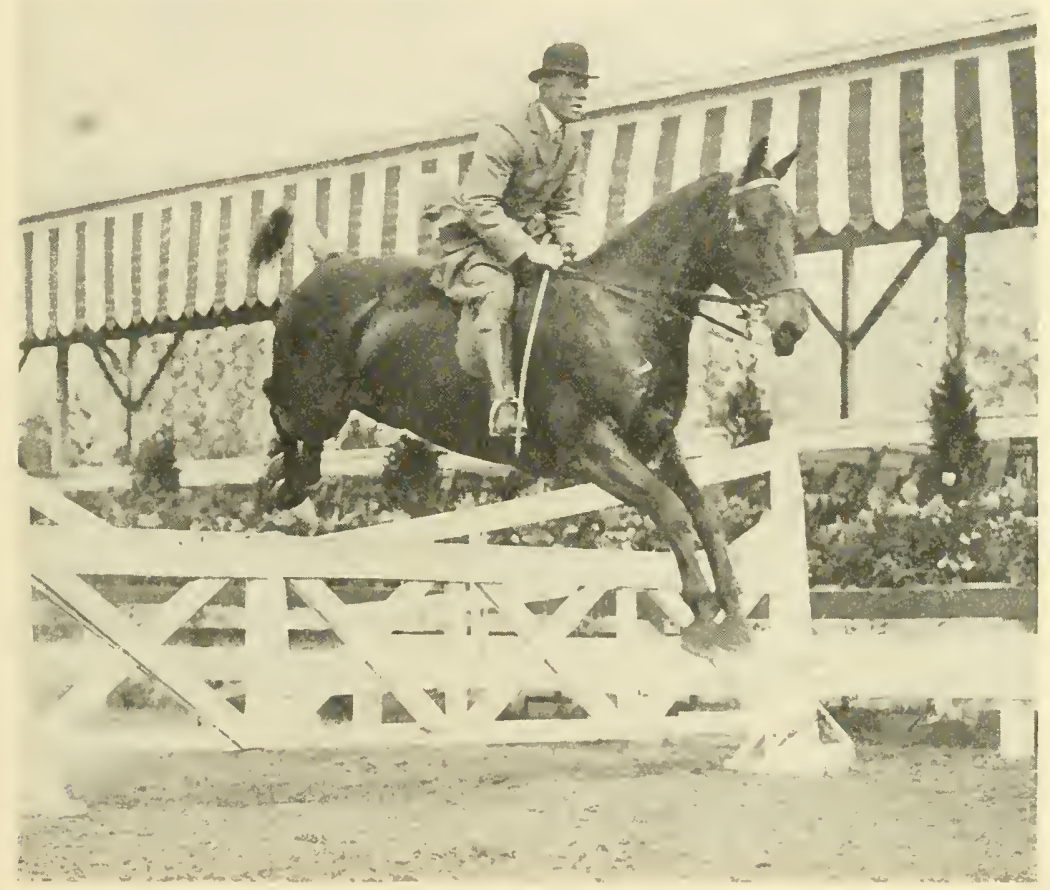

Fig. 139. The Hunter in Action.

Mr. Edward B. McLean's Alarms jumping at the National Capitol Horse Show at Washington, D. C., in 1914, ridden by Mr. Louis Leith.

Thighs and hocks.- The first and second thighs must be neatly turned, and clothed with powerful muscles. Particular attention must be paid to the hocks and to hock action; the hock joints must be broad, deep from front to back, clean in outline, and covered with thin skin.

Cannons, fetlocks, and pasterns.-The cannons, fetlocks, pasterns, and feet demand special examination. The so-called "clean" legs are indispensable, and every horseman knows the 
meaning of this term. If a hunter's legs are of this description, there is little fear that they will fill up after a heavy day's work. Associated with cleanness must be considerable substance. The fetlocks must be capable of full flexion. The ideal pastern is one with a moderate degree of slope, broad in front, deep from front to back, and well rounded at the sides. It should be covered with thin skin. Pasterns that are too long, too oblique, or light in the bone, are of bad conformation; and short, upright pasterns are extremely objectionable for very evident reasons.

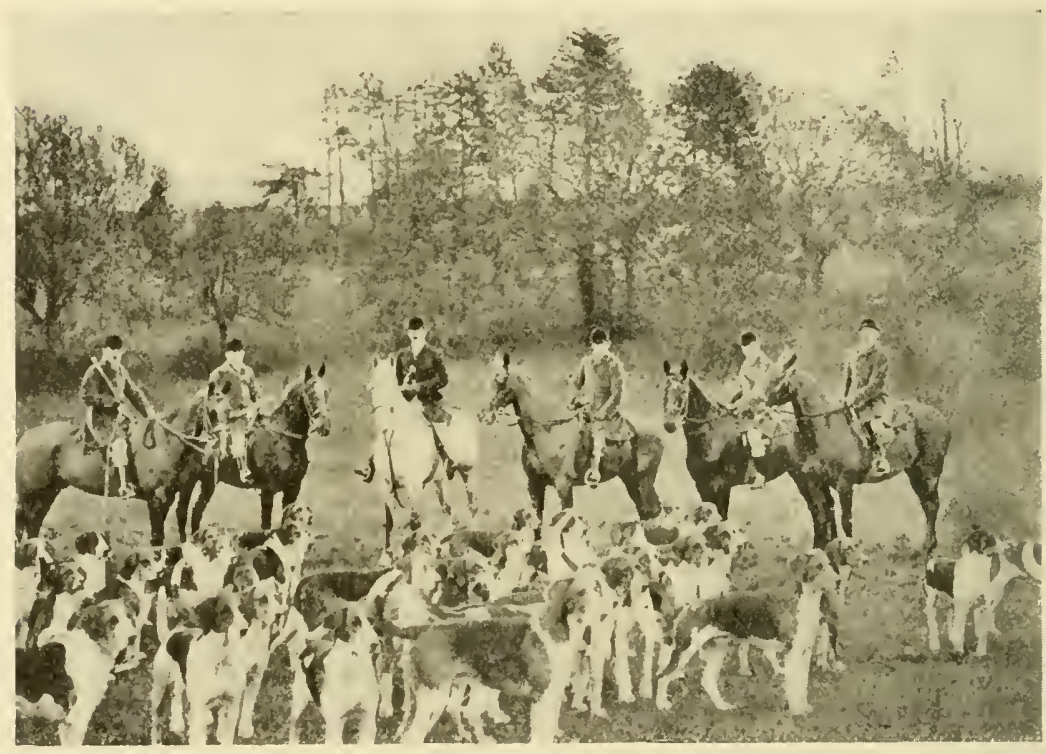

Fig. 140. A Hunt Team and Pack of Fox Hounds.

Feet.-The feet must be concave on their lower surface, proportionate in size, of good shape, well open at the heels, neither contracted nor cracked.

Color.-In selecting a hunter, color seldom plays any part, and in the hunting field are horses of almost every color. Bay, brown, light or dark chestnut, and gray are the principal colors, more especially bay and brown, with either white or black points.

Disposition.-This is of great importance in order to insure the safety of other horses, the hounds, and the rider. Some hunters are tremendous pullers, in fact, defy all attempts to hold them. There is great difference in temperament and dis- 
position - one hunter will rush at his fences in a reckless and headstrong way, and another will even walk to his jump and clear it in a businesslike manner. It is because so many Thoroughbreds have bad dispositions, that horses having a small amount of draft blood are often more desirable as hunters than are those of straight Throroughbred breeding.

Production of hunters. - There is no breed of hunters. They are largely of Thoroughbred breeding, about seven parts Thoroughbred and one part cold (draft) blood being a generally accepted formula in breeding hunters. This proportion is secured by mating a three-quarter-blood mare with a Thoroughbred stallion of correct type to get hunters. The infusion of cold blood gives greater size and ruggedness and a better disposition, but is said to lessen to some extent the staying qualities and gameness of the animal. Some most excellent hunters have come of straight Thoroughbred breeding. Ireland has long enjoyed a wide reputation for the rearing and sale of the best hunting horses --the name "Irish hunter" carrying the idea of super-excellence in this type of horse, even if some so named were in reality bred in places far removed from the Emerald Isle.

\section{The Polo Pony.}

Modern polo is largely a rich man's game. It is played with four mounted men on a side, the object being to drive a wooden ball between goal posts at the ends of a field 300 yards long and 120 to 150 yards wide. Each player carries a longhandled mallet of regulation design. It is a very fast game for both ponies and men, requiring quickness and precision.

History of polo.--Polo existed in Persia and Turkey before the tenth century. Thence it spread to Central Asia, Thibet, and Central India, being found at Calcutta in the fifteenth and sixteenth centuries. It is said to have also existed in Japan a thousand years ago. English officers returning from India, in 1874, started polo at the Hurlingham Club, Fulham, England. Hurlingham has since been recognized as the great center of the sport, and the rules it has laid down have been accepted as authority in every country except America, where a few changes in these rules have been made.

The game was introduced into this country in 1876, and from a small start made in that year it has steadily grown in favor. In 1911 there were 42 civilian clubs and 38 military 
posts in this country where polo was played. The game is now played the world over. When first introduced into this country, the ponies used were 13-2 hands high; from these, very tall men almost touched the ground with their feet. Larger and faster ponies were found more advantageous, and the standard was fixed at 14 hands. It has since been raised to 14-1, and again to 14-2, the present standard. The rules limit the height of ponies to 14-2 hands or under, but this rule is not strictly enforced; the modern game is played at such high speed that only big 14-3 to 15-hand Thoroughbred or three-quarterblood ponies are considered good enough for important matches. The range in weight is from 850 to 1,000 pounds.

Demand for good ponies.-It is a thoroughly established fact that a player is no more proficient than his pony. The question of suitable mounts has been troublesome to American players from the very first. There was a time when western cow ponies made acceptable mounts for the game. They were brought to the East by the carload and sold at very moderate prices. A small percentage of these developed into really good polo ponies. As competition became keener, the demand for better and better ponies became more imperative, and today the cow pony has been replaced by what is virtually a Thoroughbred horse of small size. In almost every case, the best modern ponies were sired by a Thoroughbred stallion. English ponies used for polo have always carried more or less Thoroughbred inheritance; they are bred in the purple, trained two years, and carefully housed and fed.

Five years ago a number of American ponies were valued at $\$ 1,000$, and for some imported English ponies up to $\$ 2,000$ had been paid. At a sale in England, in 1898, a pony named Sailor, brought $\$ 3,750$. In 1909 the American team which went to Hurlingham to compete for the world's championship was enabled to win largely because of the excellence of their ponies. These ponies were English-bred, and were reported to have cost high prices ranging up to $\$ 5,000$. The American victory brought as much credit to English pony breeders as it did to the playing ability of the American team. In championship contests, four to six ponies are used by each player and some players məintain a big string of ponies from which to make selections for games.

What constitutes a good polo pony?-The polo pony must combine speed with weight-carrying ability. He must be 
wiry, agile, and under proper training must acquire ability to quickly start, stop, and wheel. He must have a light mouth. $\mathrm{He}$ must be intelligent and learn to like the game and follow the ball. The disposition must be such as insures a level head, doggedness, docility, courage, and quickness. Much depends on the rider; there is danger of the pony becoming a puller if the rider is deficient, and some ponies become ball-and-mallet shy by being struck accidentally on the head and legs. A pony that pulls hard or becomes wild in a fast scrimmage, or swerves off the ball, is useless in first-class polo.

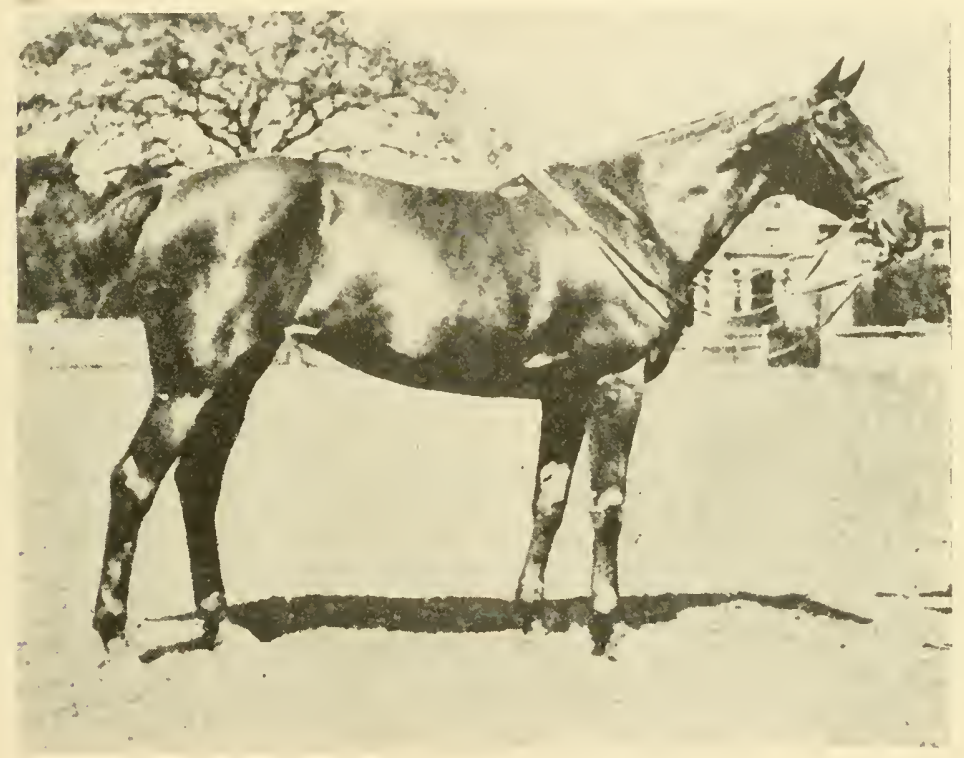

Fig. 141. Polo Pony of Excellent Type.

Owned by Mr. L. Waterbury and ridden by him when a member of the American team which won the International Cup from England.

The game calls for lots of endurance and wearing quality, hence the conformation of middle, hindquarters, feet, and legs largely determines a pony's adaptability for the game. The object of breeders is to produce a pony 14-2 hands high, able to carry from 168 to 200 pounds for ten minutes in a fast game.

The polo pony should be built like a weight-carrying hunter. His head should be well set on, wide between the jaws, with plenty of room at the throttle. He should have a big, clear, sound, prominent eye; small, pricked ears, indicative of alert- 
ness; a well-formed, well-arched, and muscular neck; a fine, sloping shoulder; not too fine at the withers, and his breast should be ample and in proportion to the remainder of the forequarters. His forearms should be big and powerful, the knees wide, particularly good under the knee, with a short cannon. The fetlocks should be large and clean, the pasterns well supplied with bone, and of proper slope and strength. The foot should be of good size, smooth, nicely shaped, the heels open, and the frog well developed and elastic.

He should be deep from withers to sternum, and fairly wide through the chest; he should be short in the back, well coupled, ribbed close up to the hip, with plenty of muscle be-

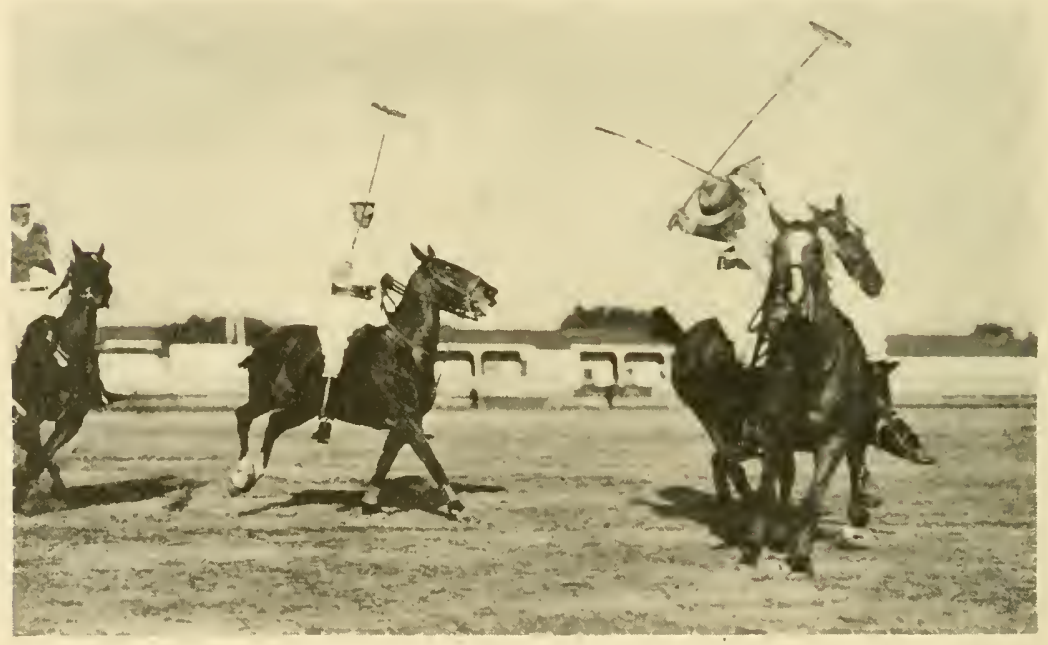

Fig. 142. The Polo Pony in Action.

hind the saddle. His thighs and quarters should be big and powerful, carrying down into the gaskin in well-defined masses of muscle, and the gaskin should bulge with muscle also. The hock should be broad and flat, with the natural prominences clean-cut and well developed. The tendon of Achilles should be well defined and powerful. There should be great bone below the hock, and in other respects the hind leg should be similar to the fore one.

Production of polo ponies.-At present the only method of producing ponies such as the modern game demands is the mating of polo pony mares with a Thoroughbred stallion of approved type. However, a very large percentage of get is 
over height, and only a small percentage of foals that are of proper size have the conformation and disposition to become polo ponies. Evidently the breeding of this pony is not a proposition for the general farmer, but only for the specialist who makes a special study of the requirements of players and of methods of production. In Texas and other western states are a few ranches which make a business of breeding these ponies and training them, being equipped with polo fields for this purpose. Beginning with western cow ponies, they have graded up their pony stock by the use of dwarf Thoroughbred sires until the present stocks are practically of straight Thoroughbred breeding. England has taken up the production of polo ponies in a more systematic manner than have we in this country. In 1893 they formed the Polo Pony Stud Book Society, thus laying the foundation for pedigrees and for the establishment of a breed. The name of the society was later changed to the Polo and Riding Pony Society. Beginning in 1895, annual shows have been held by this organization, and enough progress has been made in breeding to indicate that in time a true breed of ponies for polo will be established. When this is accomplished, the production of polo ponies will not be so difficult or uncertain as it is today. 
CHAPTER XXXV.

\section{MARKET CLASSES OF HORSES.}

The present rank and importance of the various horse markets is shown by the following figures giving the receipts for 1918:

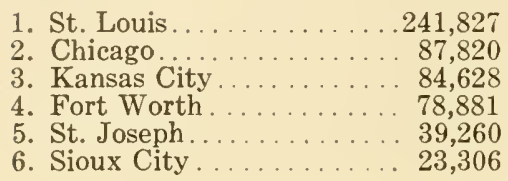

Total
7. Omaha

8. Indianapolis .

9. Denver..... .

10. Oklahoma City

11. Wichita...

12. St. Paul
$.22,212$

19,608

14,599

12,678

10,782

6,541

642,142

Auction rules.-At the large horse markets, horses are sold at auction under certain rules which are well known and understood by all horsemen who buy or sell at these markets. As the horse comes into the auction ring, a clerk on the auctioneer's stand displays a placard on which appears in large letters the rule under which the animal will be sold, such as "Sound," "Serviceably sound," "At the halter," etc. The rule under which the horse is sold is a guarantee made by the seller to the buyer. The buyer has until noon of the following day to refuse the horse, if upon examination and trial he finds that the animal is not as represented.

The definitions of the principal rules which govern the sale of horses are given below. Exceptions to these rules may be announced from the auction stand, pointing out the defects, in which case they are recorded and go with the horse.

1. Sound.--Perfectly sound in every way.

2. Serviceably sound.-Virtually a sound animal, barring slight blemishes which do not interfere with his usefulness in any way. His wind and eyes must be good, but a spot or streak in the eye which does not affect the sight will be considered serviceably sound as long as the pupil of the eye is good. He must not be lame or sore in any way.

Ill. Bul. 122, Market Classes and Grades of Horses and Mules, by R. C. Obrecht, has been used as the basis for much of this chapter and Chapter XXXVIII. The student will find it well worth while to refer to this bulletin, especially for the excellent illustrations which it contains. 
3. Wind and work.-The only guarantee this carries with it is that the animal has good wind and is a good worker.

4. Work only.-He must be a good worker, but everything else goes with him. No other guarantee than to work.

5. Legs go.-Everything that is on the animal's legs goes with him; nothing is guaranteed except that he must not be lame or crampy. He must, however, be serviceably sound in every other respect.

6. At the halter.- Sold just as he stands without any recommendations. He may be lame, vicious, balky, a kicker, or anything else. The purchaser takes all the risk. The title only is guaranteed.

Market requirements. - The factors that determine how well horses sell upon the market are soundness, conformation,

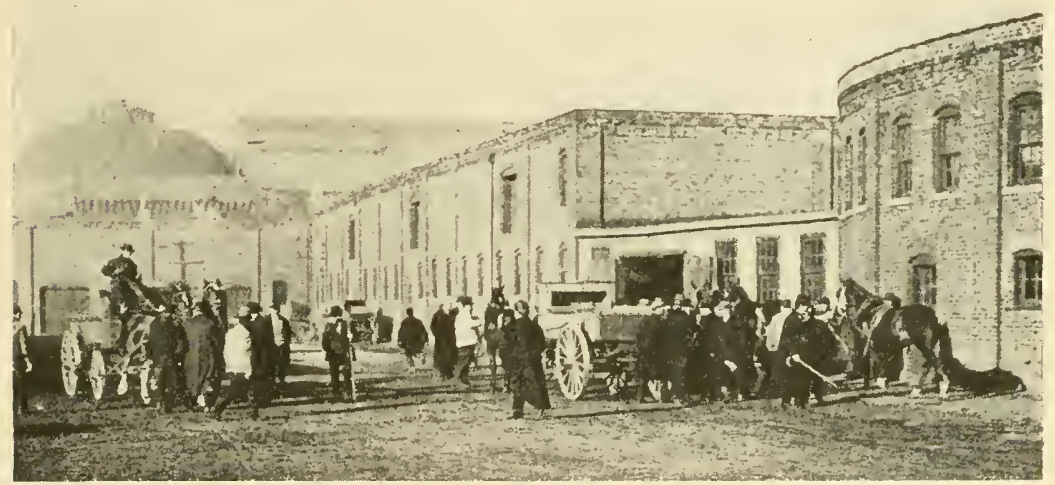

Fig. 143. Horse Market at Union Stock Yards, Chicago.

Winding and trying-out horses immediately after purchase. If the horse is found to be not as represented when sold, the buyer has the privilege of returning him to the seller.

quality, condition, action, age, color, training, and style. These, together with some minor considerations, are discussed below.

Soundness. - The market demands that a horse be serviceably sound, by which is meant one that is as good as a sound horse so far as service is concerned. He may have slight blemishes, but nothing that is likely to cause lameness or soreness in any way. He must be good in wind and eyes, but may have small splints and puffs, and a little rounding on the curb joint. Broken wind, thick wind, sidebones, unsound hocks such as curbs, spavins, and thoroughpins, large splints, and buck knees are discriminated against. 
Conformation.-If a horse is to do hard work, with a minimum of wear, and give the longest possible period of service, he must possess a conformation indicative of strength, endurance, and longevity, the indications of which are good feet, a good constitution, good feeding qualities, good bone, and symmetry of conformation. Conformation has been discussed fully in connection with the various types described in preceding chapters, and no further discussion is necessary here.

Quality.-Quality in a horse is of great importance, as has already been emphasized. A horse lacking in quality is a comparatively cheap animal.

Condition.-To be appreciated on the market, a horse must be fat and possess a good coat of hair, which gives him a sleek appearance. Condition is most important in draft, chunk, and wagon horses. When a green horse goes to the city, he loses weight during the first few weeks until he becomes used to the new conditions, and it is a decided advantage if he enters city work carrying a high finish. When a horse is fed to a high state of fatness, it invariably improves his spirit and style, as well as his form and weight. In some individuals, fat covers many sins. The man who sends his horse to market in finished form is offering the animal in most attractive condition. Condition is a very important item of value on the horse market.

Action.-Action has been fully discussed in preceding chapters. We have seen that the requirements vary according to the type of horse, and that action is always a very important item of value, in some instances being as important a factor as any in determining the value of the horse.

Age.-Horses sell best from five to eight years old. Heavy horses, such as drafters and chunks, sell best from five to seven years old, but a well-matured four-year-old in good condition will find ready sale. Carriage, saddle, and road horses sell better with a little more age, because they do not mature so early and their education is not completed as soon as that of heavy horses. They are most desired from five to eight years old.

Color.-As a rule, the color of horses is of secondary importance, provided they possess individual excellence. Previous discussions of the various types have shown that color is of more 
importance in pleasure horses than in those used for business and utility purposes.

Training and disposition.--Every class calls for a horse of good disposition and well educated for his work. Mere "greenness" in a drafter, however, does not affect the price much if he is free from vice and bad habits, but carriage and saddle horses must be thoroughly schooled in order to realize good values.

Sex.-Sex is not of great importance in the market. However, geldings sell better than mares for city use, as there is some liability of mares being in foal, and if not, the recurrence of heat is objectionable. For farm use and southern trade, mares are preferred, because farmers buy horses with the expectation of breeding them.

Breed.-The breed to which a horse belongs has but little or no influence upon his market value as long as he has individual excellence.

Style and freshness.-If able to shape themselves well in harness, very plain horses often make a stylish showing, and this increases their value materially. They should be spirited and energetic, which generally comes from being well fed. They should be well groomed, the hair being short and sleek, lying close to the body, and possessing a luster which indicates health. Clipping of the foretop and legs should not be practiced in the case of heavy horses, as it is an indication of staleness or second-hand horses. The presence of the foretop and feather leaves no doubt as to freshness from the country. The feet should be in good condition and of a good length hoof, which is necessary to hold a shoe.

Breeders make no real effort to supply some of the market classes of horses, either because the demand is very limited or the price too small. Such classes are supplied by careless breeding, by the mixing of types, and by the misfits which result even when the breeding of horses is conducted as carefully as possible.

The classification outlined below includes not only those classes of horses which are regular commodities on the large horse markets, but also other more rare and valuable classes which are only to be had from certain dealers and breeders who cater to an exclusive trade not represented at the large markets: 
Classes

DRAFT HORSES

CHUNKS

WAGON HORSES

CARRIAGE HORSES

ROAD HORSES

SADDLE HORSES

MISCELLANEOUS
Sub-classes

Height
Hands

Weight

Pounds

(Heavy Draft. . . . . . 16 to $17-2$

Light Draft. . . . . . . . 15-3 to $16-2$

Loggers. . . . . . . . . . 16-1 to $17-2$

(Eastern Chunks.......15

Farm Chunks...........15

Southern Chunks....... 15

to 16

to $15-3$

to $15-3$

(Expressers........... 15-3 to 16-2

Delivery Wagon.........15 to 16

Light Artillery ........ 15-2 to 16

Heavy Artillery .......16 to 17

Fire Horses.......... to $17-2$

Coach Horses.........15-1 to 16-1

Cobs............... 14-1 to 15-1

Park Horses . . . . . . . 15 15 to $15-3$

Cab Horses. . . . . . . . . 15-2 to 16-1

$\left\{\begin{array}{l}\text { Runabout .........14-3 to } 15-2 \\ \text { Roadsters } \ldots .15 \text { to } 16\end{array}\right.$

Five-Gaited Saddler ...15 to 16

Hunters........... 15-2 to 16-1

Cavalry Horses . . . . . . . 15 to 16

Polo Ponies..........14 to $14-2$

1750 to 2200

1600 to 1750

1700 to 2200

1300 to 1550

1200 to 1400

800 to 1250

1350 to 1500

1100 to 1400

1150 to 1300

1400 to 1700

1200 to 1700

1100 to 1250

900 to 1150

1000 to 1150

1050 to 1200

900 to 1050

900 to 1150

900 to 1200

900 to 1200

1000 to 1250

950 to 1200

850 to 1000

$\left\{\begin{array}{l}\text { Feeders } \\ \text { Range Horses } \\ \text { Ponies } \\ \text { Plugs } \\ \text { Weeds }\end{array}\right.$

\section{Draft Horses.}

A full description of draft type has already been presented, so that it is only necessary to mention the chief distinctions between the three sub-classes, Heavy Draft, Light Draft, and Loggers.

Heavy draft.-These are the heavier weights of the draft class; they stand from 16 to 17-2 hands high, and weigh from 1750 to 2200 pounds.

Light draft.-The light drafter is similar in type to the heavy drafter, but is smaller; they stand from 15-3 to 16-2 hands, and weigh from 1600 to 1750 pounds. While 15-3 hands is accepted as the minimum height for light drafters, it should be understood that a 15-3-hand horse is less desirable than a taller horse, and he borders closely on the class known as eastern chunks.

Loggers. - These are horses of draft type that are bought for use in the lumbering woods. This trade demands com- 
paratively cheap horses, yet wants them big and strong. Because of the prices paid, the trade is usually compelled to take the plainer, rougher horses of the heavy draft class, and some are slightly blemished or unsound, such as "off in the wind," small sidebones, curbs, wire marks, etc. Loggers should stand from $16-1$ to $17-2$ hands, and weigh from 1700 to 2200 pounds.

\section{Chunks.}

Usage has fixed the name of this class, which is significant of the conformation of the horse, rather than the use to which he is

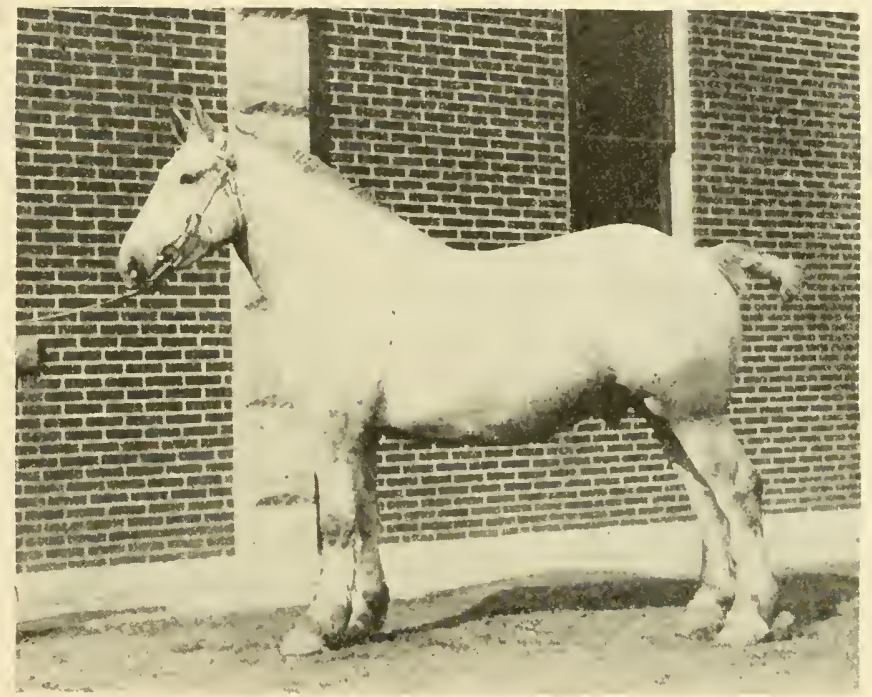

Fig. 144. Eastern Chunk.

put. However, the prefixes given in the sub-classes are rather indicative of his use. Chunks are divided into three sub-classes, Eastern, Farm, and Southern.

Eastern chunks.--At one time, this class was known as Boston chunks, but as the trade has widened to other cities they are known by the general name of eastern chunks. They are most generally used in pairs or three abreast to do the same work as draft horses; but may be used in pairs, in a four-in-hand, or in a six-in-hand team. The eastern chunk may be briefly and accurately described as a horse of draft horse type in all respects except size and weight. $\mathrm{He}$ is, then, a little drafter. $\mathrm{He}$ is usually a little more blocky and compact than the true 
drafter. He stands from 15 to 16 hands high, usually not over 15-3, and weighs from 1300 to 1550 pounds, depending upon size and condition. Being required to do his work mostly at the walk, his action should be similar to that of the draft horse.

Farm chunks.-Horses of this class may be found on the market at all seasons of the year, but during the spring months they form an important feature of the trade. They are bought to be used on the farm, and are in most urgent need during the season when crops are being planted. They are usually of mixed breeding, draft blood predominating, and are commonly known among farmers as "general-purpose" animals. Mares are more generally taken than geldings. For this class, low-set, blocky horses are wanted, not so heavy as the eastern chunks. Farm chunks are usually lighter in bone, and often slightly blemished or unsound. In general, the typical farm chunk should be a moderate-sized, all-round good individual, standing from 15 to $15-3$ hands high, and weighing from 1200 to 1400 pounds. Being lighter horses than the eastern chunks, they should be a little quicker and more active. The varied use to which horses are put on farms requires ability to trot readily if necessary. However, since the walk is their most important gait, they should be good walkers and do it with ease and rapidity.

Southern chunks. - In some markets these are termed "southern horses," or "southerns." They are small horses that are taken by dealers to large southern cities and sold to southern planters for tilling their lands and for driving and riding. The southern farmer does not cultivate deeply, and the soils are light, consequently he does not require very large horses. However, each year the trend of the market is for larger horses for this trade. Southern chunks are small horses standing from 15 to $15-3$ hands high, and weighing from 800 to 1250 pounds. They are rather fine of bone, possessing an abundance of quality, and are more rangy in conformation than any of the other chunks, having more of the light horse blood. Many of them are similar to the cheaper horses used on the light delivery wagons of cities. They should have good action. The southern chunk is comparatively a cheap horse.

\section{Wagon Horses.}

This class includes horses useful for quick delivery. The demand is from cities and towns. These horses must be closely coupled, compactly built, with plenty of constitution and stamina. 
They must be good actors, have a good, clean set of legs, with plenty of bone and quality, and a good foot that will stand the wear of paved streets. The sub-classes are Express Horses, Delivery Wagon Horses, Light Artillery Horses, Heavy Artillery Horses, and Fire Horses. Their breeding is a mixture of draft and light bloods. They are neither light nor heavy horses, but may be termed middle-weights.

Express horses.--Express horses are used by express companies to collect and deliver goods to and from railroad stations. Different companies use horses of slightly different size and weight. For instance, if the business of a company is centrally

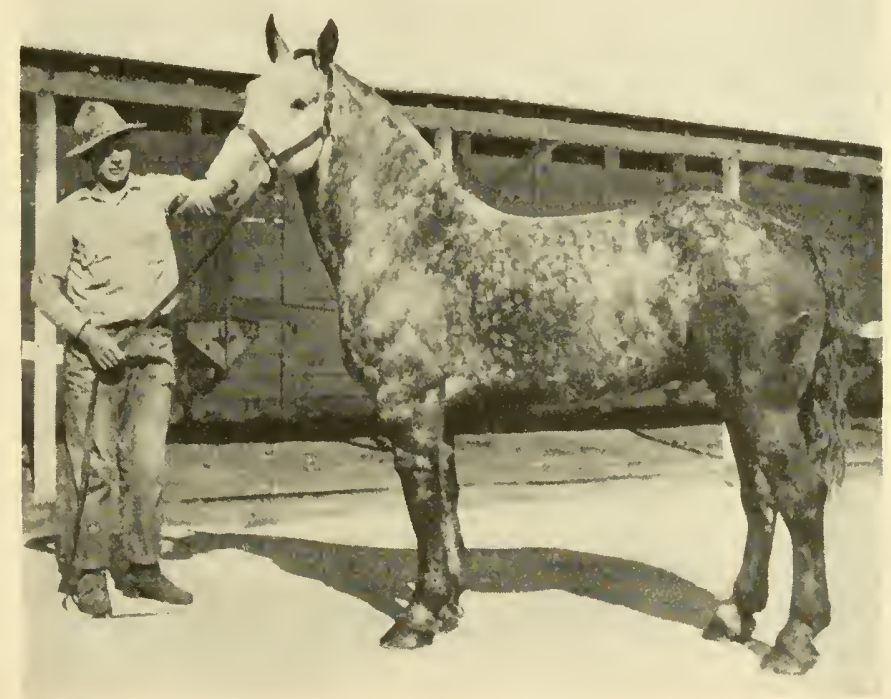

Fig. 145. Express Horse.

located in a city, and depots are not far apart, they use larger horses and load heavier; if the business is done in the outlying parts of a city, and the depots are a considerable distance apart, lighter horses with more action are wanted. They are used singly or in pairs, and the size of the horse will depend on the weight of the wagon. The lightest ones are called "money horses," as they are hitched to the lightest wagons to deliver valuables, this kind of work demanding quick service.

The typical expresser is rather upstanding, deep bodied, and closely coupled, with good bone and an abundance of quality, energy, and spirit. He should stand from 15-3 to 16-2 
hands high, and weigh from 1350 to 1500 pounds in good flesh; the average express horse is 16 to $16-1$ hands high, and weighs around 1400 pounds in working condition. His head should be neat, his neck of good length, and his crest well developed. His shoulder should be obliquely set, coupled with a short, well muscled back and a strong loin. His croup should be broad, rounding, and well muscled, his quarters deep, and thighs broad. He should not be goose rumped, nor cut up in the flank. His underpinning should be of the very best, his cannons broad and clean, and his hoofs of a dense, tough horn.

The express horse is required to do his work both at the walk and trot, the latter being the principal gait. He should be quick and active, and should keep his feet.well under him and throw enough weight into the collar to move a heavy load at the walk, or a lighter load at the trot. As in the previous classes, he should be a straight-line mover, with possibly a little more knee and hock action.

Delivery wagon horses.-Generally speaking, delivery wagon horses are not as large as expressers, and not as high-grade animals; most mercantile firms are not such liberal buyers as the express companies, and consequently they get a cheaper grade of horses. However, this is not always true, as some of the large department stores, whose deliveries serve as an advertisement, will pay more for the very best than express companies, thus getting very choice animals. The conformation requirements are practically the same as for express horses, except they are not quite so large, standing from 15 to 16 hands, and weighing from 1100 to 1400 pounds. The action requirements are the same as for express horses, though some are not as good actors. The demand for delivery wagon horses comes from all kinds of retail and wholesale mercantile houses, such as meat shops, milk houses, grocery houses, dry goods firms, and hardware merchants, for use on light wagons for parcel delivery. Some of the coarser, rougher ones are used on the huckster wagons, junk wagons, sand wagons, and by contractors for cellar excavating, street cleaning, railroad grading, or almost any kind of rough, heavy work.

Light artillery horses. - These conform rather closely to the better grades of delivery wagon horses of the same weight. The following specifications, prepared under the direction of the Quartermaster General of the United States War Department, clearly set forth the requirements. 
"The artillery horse for light and horse batteries must be sound, well bred, of a superior class, and have quality; of a kind disposition, well broken to harness, and gentle under the saddle, with easy mouth and gaits, and free and prompt action at the walk, trot, and gallop; free from vicious habits; and otherwise to conform to the following description: A gelding of specified color (no white or gray horses will be accepted), and in good condition, from 5 to 8 years old at time of purchase; height from 15-2 to 16 hands; weight from 1150 to 1300 pounds, depending on height. Horses otherwise satisfactory which fall short of, or exceed, these limits of weight by not more than 50 pounds, due to temporary conditions, may be accepted.

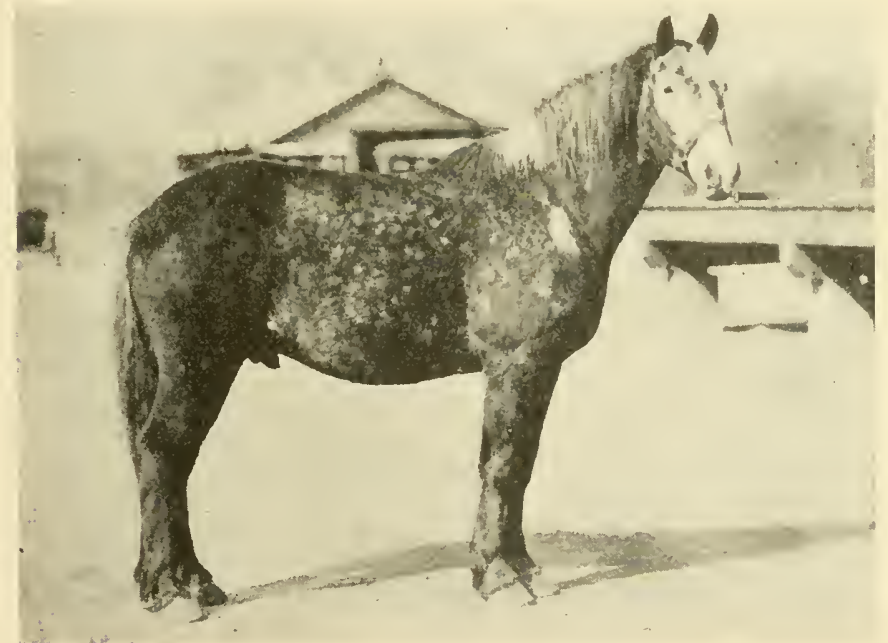

Fig. 146. Light Artillery Horse.

"The artillery horse for light and horse batteries is required for quick draft purposes, and should be heavy enough to move the carriage ordinarily by weight thrown into the collar rather than by muscular exertion. Long-legged, loose-jointed, longbodied, narrow-chested, coarse, and cold-blooded horses, as well as those which are restive, vicious, or too free in harness, will be rejected."

Heavy artillery horses.--The U. S. Army specifications for artillery horses for siege batteries are as follows:

"A gelding conforming to the above specifications for horses for light and horse batteries, except that the animal should be from 16 to 17 hands high, and weigh from 1400 to 1700 pounds, 
depending on height. A smart, active, draft horse, with plenty of bone and substance, and enough quality to insure staying power in fairly fast work, is required for this service."

The work of the heavy artillery horse is much heavier and slower than that of the light artillery horse, and the type demanded in the horse is quite different. Here it is a question of power rather than of speed, and the heavy artillery horse is in fact a light draft horse, though some fall somewhat short of the weight desired in light drafters. Heavy artillery horses might properly be classed with draft or chunk horses, but for

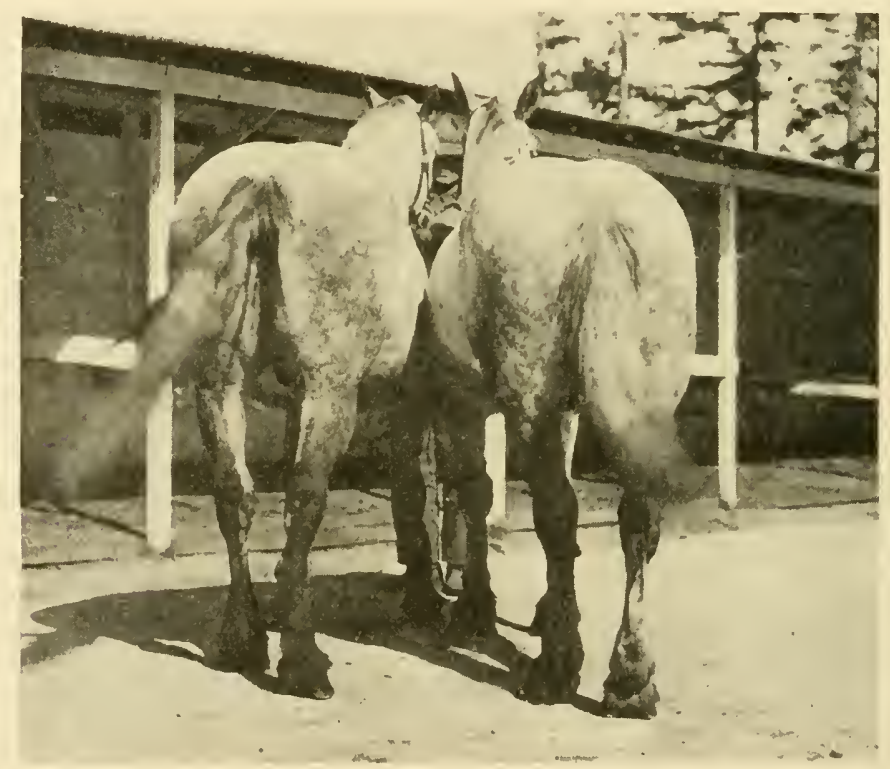

Fig. 147. Heavy Artillery Horses.

convenience are included in the same general class as the light artillery horses.

The demand for artillery horses is rather spasmodic, at some times being much greater than at others. Contracts are given to the lowest responsible bidder to supply them in large numbers at a specified time. Because of the rigid examination and requirements of official inspectors, some men have lost money in filling contracts.

Fire horses.--The fire horse is more rangy in conformation than the expresser, he being required to throw weight into 
the collar and often to take long runs. The requirements are very rigid, as will be seen by the specifications set forth by Mr. Peter F. Quinn, former Superintendent of Horses of the Chicago Fire Department:

"The work required of a horse best suited to fire department services necessitates almost human intelligence. Such a horse must not only be well bred, sound in every particular, quick to observe, prompt and willing to respond to every call, but as well, ambitious to discharge his numerous and unusual duties under constantly differing surroundings. In selecting, the first requisites are tractability, good feet and legs, with bone and hoof of the best texture, a short, strong back, and wellproportioned fore- and hindquarters, well covered with firm,

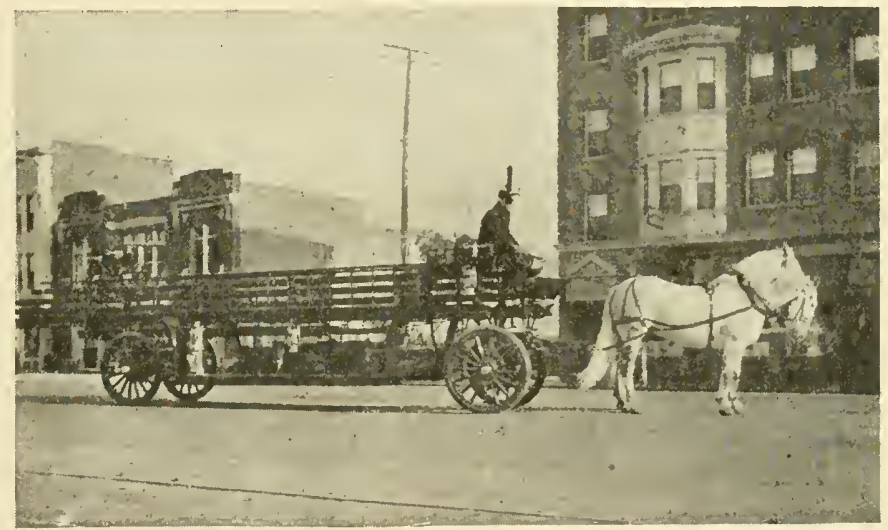

Fig. 148. Fire Horses.

elastic muscles. For heavy engine companies and heavy hookand-ladder trucks, a gelding of uniform and hardy color, in good condition, from five to seven years old, standing 16 to 17-2 hands, and weighing from 1500 to 1700 pounds should be selected. Hose-carriage horses, same age; weight from 1200 to 1400 pounds; height, 15 to 16-2 hands."

The demand for fire horses is very limited, coming from fire companies of cities. There are usually enough horses in the general supply to meet the demand.

\section{Carriage Horses.}

The chapter dealing with carriage horse type presents a detailed description of the general class known as carriage horses, 
and while this general class is subdivided into at least four smaller groups, known as Coach, Cob, Park, and Cab Horses, nevertheless the differences between them relate mostly to size and weight, and practically the same conformation, style, and action is desired in all four sub-classes. Keeping carriage horse type in mind as applying to all four groups, only a few remarks are necessary in order to give the reader a correct idea of each subclass.

Coach horses.-Coach horses may be described as carriage horses of large size. They should stand from 15-1 to 16-1 hands high, and weigh from 1100 to 1250 pounds. The weight is not so important as the size. The essential thing is to get a horse that looks right before the large, heavy vehicle to which he is hitched. For instance, the most desirable height in horses for a park drag, body break, or heavy coach is 15-3 to 16 hands, and they should weigh around 1150 to 1200 pounds. For a light brougham, a pair of 15-2 hand horses, weighing 1100 pounds is more appropriate. A hearse requires black horses from 15-3 to 16-1 hands high, weighing 1200 to 1250 , and without white markings. White horses are also used to some extent by undertakers.

The demand for coach horses comes from wealthy men who maintain stables of fine horses and equipages for pleasure driving. They are hitched singly, in pairs, unicorn (sometimes called a spike, as one horse is hitched to the end of the pole, ahead of a pair), four-in-hand, and six-in-hand, to coaches, breaks, park drags, etc. A large percentage of coach horses have a predominance of American Trotting Horse blood, while a few are produced from the imported coach breeds; but since many of the imported so-called coach horses possess the common fault of grossness and coarseness, as a class they do not possess the requirements demanded by the American markets.

Cobs.-Cobs differ from coach horses in size and in the use to which they are put. They are driven singly, in pairs, or tandem, usually by ladies, though they may be used by gentlemen as well. Cobs stand from 14-1 to 15-1 hands high, and weigh from 900 to 1150 pounds. The strongest demand comes for horses 14-3 to 15 hands high, and weighing from 1000 to 1100 pounds. Being essentially a lady's horse, solid colors are wanted, without flash markings. They are usually hitched to a light brougham, phaeton, or some carriage that is not intended for carrying more than four. 
Park horses.-The park horse, sometimes called the gig horse, is neither a large nor a small carriage horse, but is a carriage horse of medium size. Many coach and cob horses meet the requirements for park horses so far as size and weight are concerned, yet cannot correctly be classed as park horses. This is because the park horse represents the cream of the carriage horse class. He is a higher-priced horse than either the coach or cob horse. He has the same conformation and action as they, but his conformation is more perfect, his action higher and more sensational, and his style and elegance more outstanding. They are hitched to a cart or gig, or may be driven tandem to the latter vehicle. They are also driven in pairs before mail phaetons and victorias. The limits for height and weight are 15 to $15-3$ hands and from 1000 to 1150 pounds, the most desirable height being $15-1$ to $15-2$ hands, and the weight from 1000 to 1100 pounds. It is readily apparent that the park horse is difficult to produce. Some are of Trotting Horse breeding, a few have been produced by crossing Hackney stallions on Trotting or Thoroughbred mares, but the best are of pure Hackney breeding; the latter method is attended by greater certainty of good results than any other method of production.

Cab horses. - The cab horse is a comparatively cheap horse, and the requirements are not so rigid as for coach, cob, or park horses. They are used on cabs, coupes, hansoms, and other vehicles for public service in cities. They are much the same type as the coach horse, in fact many of them are the discarded and lower grades of the coach sub-class. Cab horses stand from 15-2 to 16-1 hands high, and weigh from 1050 to 1200 pounds. The demand comes from livery and transfer companies.

\section{Road Horses.}

This class includes Runabout Horses and Roadsters. Runabout horses occupy an intermediate place between typical roadsters and carriage horses, but on account of their action, conformation, and the use to which they are put, may be more properly classed as road horses.

Runabout horses.-A runabout horse is a rather shortlegged horse, standing from 14-3 to 15-2 hands high, and weighing from 900 to 1050 pounds. His head should be neat, ear fine, eye large and mild, neck of good length and trim at the throttle. The neck should be of medium weight, not quite so heavy as that of the coach horse, and not so light and thin 
as that of the roadster. The shoulder should be obliquely set, the withers high and thin, the back short, well muscled, and closely coupled to the hips by a short, broad loin. The barrel should be deep and round, the ribs well sprung, and the chest deep; the croup should be long and the hips nicely rounded. The legs should be well placed and heavily muscled, the bone broad and clean, and the pasterns of good length and obliquely set, joined to well-shaped feet. The runabout horse is not quite so stockily built as the cob, being not so heavy in neck and crest, not so full made and rotund in body, and not so heavy in quarters. The action is more moderate than that of a cob;

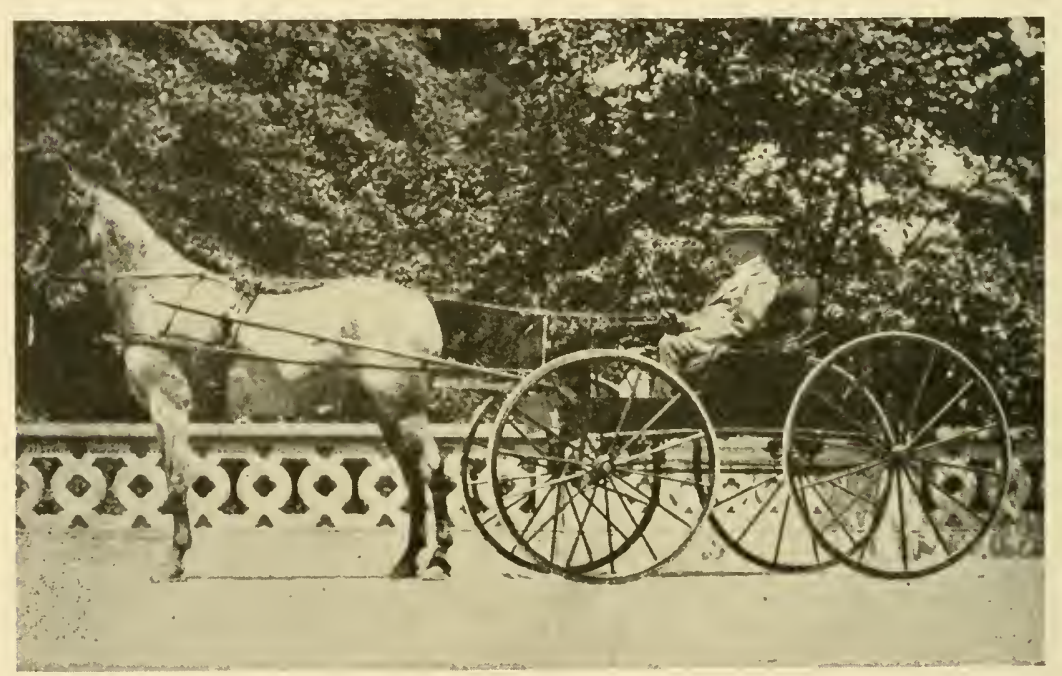

Fig. 149. Runabout Horse.

he does not need to be as high an actor, but should have more speed. The action should be bold, frictionless, and straight, such as is conducive to speed and beauty of form.

The demand for runabout horses is for single drivers. They are used in cities and elsewhere on runabouts and driving wagons. They are of more or less mixed breeding, the predominating blood being that of the American Trotting Horse.

Roadsters.-The chapter dealing with light-harness or roadster type sets forth the requirements for roadsters in form, action, and speed, and discusses the uses to which they are put. No further discussion is needed here. 


\section{Saddle Horses.}

The saddle horse class includes the five sub-classes known as Five-Gaited Saddlers, Three-Gaited Saddlers, Hunters, Cavalry Horses, and Polo Ponies. All of these, with the exception of the cavalry horse, have received full consideration under the subject of types of horses in preceding chapters. Space need be given here only to a description of the cavalry horse.

Cavalry horses.-The Quartermaster General of the War Department has sent out the following specifications as the requirements for an American cavalry horse:

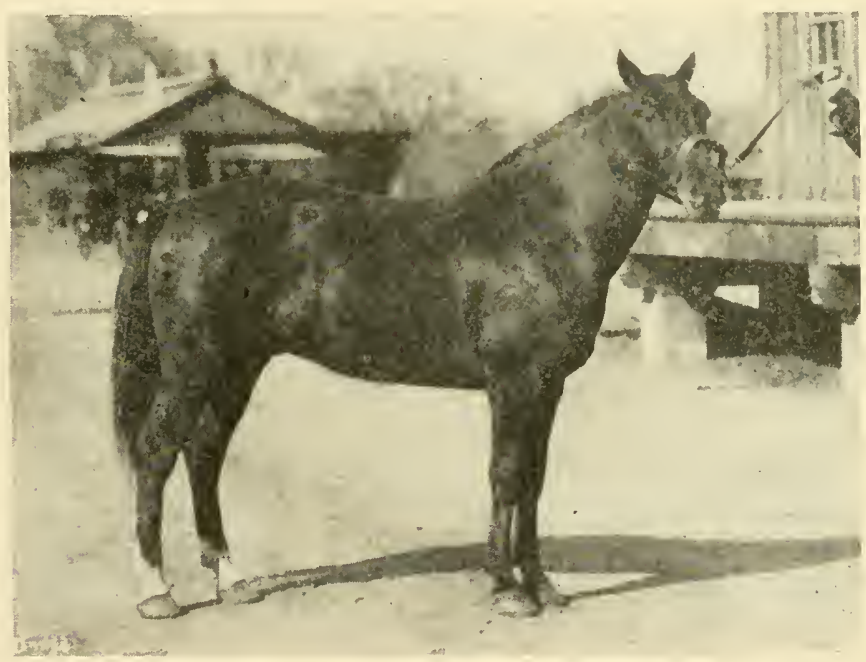

Fig. 150. Cavalry Horse.

"Each horse will be subjected to a rigid inspection and any animal that does not meet with the requirements should be rejected. No white or gray horses will be accepted. The mature horse must be sound, well bred, of a superior class, and have quality; gentle and of a kind disposition; well broken to the saddle, with light and elastic mouth, easy gaits, and free and prompt action at the walk, trot, and gallop; free from vicious habits; and otherwise to conform to the following description: A gelding of specified color, in good condition, from 5 to 8 years old at time of purchase; weighing from 950 to 1200 pounds, depending on height, which should be from 15 to 16 hands." 
Cavalry remounts for the United States War Department are purchased as needed through contract orders, the contract being let to the lowest responsible bidder. In filling orders, dealers are often obliged to educate many of the recruits to the saddle, in order to meet the specific requirements.

\section{Miscellaneous Horses.}

Feeders.-Feeders are horses thin in flesh which are purchased to be put in condition and resold. They may belong to any of the above classes, but the practice is more generally applied to draft horses, chunks, and wagon horses. The old adage, "a little fat covers a multitude of defects," is still true;

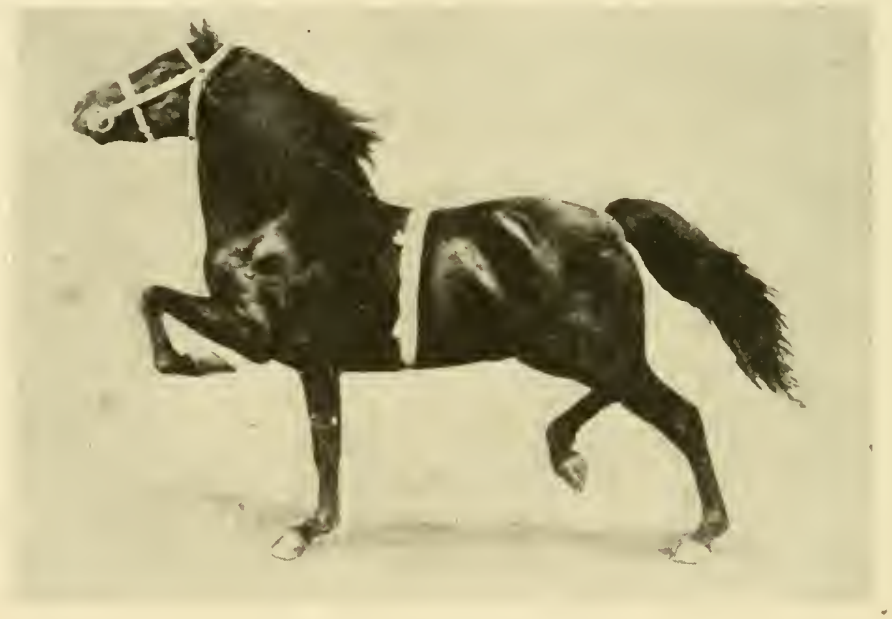

Fig. 151. High-Class Pony.

King Larigo, Champion Shetland pony stallion at the Panama-Pacific Exposition and Champion at the Iowa State Fair for five years. Owned by Mr. Geo. A. Heyl, Washington, Ill.

the value of flesh when put on thin horses can hardly be appreciated, unless one has seen them fleshed and placed again on the market.

Range horses.--During certain seasons of the year, there may be found on the market horses bred and reared on the range, commonly known as "range horses." They are divided into two general classes, light and heavy, according to the predominance of light or draft horse blood. For the sale ring, each of these classes is divided into carlots as follows: "colts," meaning weanlings; "ones," the yearlings; "twos," the two- 
year-olds; "dry stuff," the three-year-olds and over, those not suckling foals; and "mares and colts," the brood mares with foals at foot. In the aution ring, the price is stated per head and the buyer takes the entire lot. Most of the range horses find their way to the country, where they are usually broken; when educated, they may be returned to the market and may fill the demand for some of the commercial classes.

Ponies.-Ponies of various grades and breeding are frequently found on the market, and are usually bought for the use of children and ladies. The characteristics distinguishing ponies from horses are not easily described. The principal distinguishing feature is that of height, a pony being 14 hands or under. But there are dwarf horses that do not have pony blood or characteristics that come within these limits. Other pony characteristics are a deep body with rounding barrel, heavily muscled thighs and quarters, croup not drooping, and width well carried out, all of which the small horse does not usually possess. The neck is often short and heavy, though this is not a desirable quality. Ponies are essentially children's horses, and they must be kind and gentle in disposition, with as much spirit as is compatible for their use. There are no special requirements for weight, the limits being quite wide. They should be straight-line movers, and the more knee and hock action they possess, the higher prices they will bring, other things being equal. The Indian pony, or "cayuse" as he is sometimes called, is larger; he is a descendant from the native range stock, and is classed on the market as a range pony.

Plugs.-Plugs are worn-out, decrepit horses with but little value. This class is too well known to need description.

Weeds.-Weeds are leggy and ill-proportioned horses lacking in the essential qualities, such as constitution and substance. They have little value for service of any kind.

\section{Prices for Horses at Chicago.}

Prices of the various classes compared.-Prices during 1918 averaged as follows upon the Chicago market,* figures for preceding years being given for comparison:

* Year Book of Figures, 1919. 
Class

1918

Draft horses

Southern chunks $\ldots \ldots \ldots \ldots \ldots \ldots$

Express horses............... 170

Carriage horses (pairs) ........ 425

Drivers .................... 165

Saddle horses............... 190

General use.

$\begin{array}{rrrrr}1917 & 1916 & 1915 & 1910 & 1902 \\ \$ 215 & \$ 210 & \$ 203 & \$ 200 & \$ 166 \\ 100 & 96 & 88 & 87 & 57 \\ 175 & 169 & 166 & 161 & 135 \\ 450 & 470 & 473 & 473 & 450 \\ 165 & 160 & 164 & 172 & 145 \\ 190 & 187 & 179 & 177 & 151 \\ 150 & 146 & 155 & 144 & 117\end{array}$

The above is a rather incomplete report, but it is all that is available. The total value of all horses received at Chicago in 1918 was $\$ 16,246,700$, and their average value was $\$ 185$. The average was $\$ 185$ in $1917, \$ 180$ in $1916, \$ 180$ in $1915, \$ 183$ in $1914, \$ 188$ in 1913 , and $\$ 179$ in 1912 . In connection with these figures it should be remembered that many of the best loads of horses from the cornbelt are taken directly to the eastern cities for sale, being gathered by country buyers who consign them to eastern dealers. 


\section{CHAPTER XXXVI.}

\section{HORSE BREEDING.}

This is a broad subject which may be considered and discussed at length from many points of view. Only brief treatment is possible here, however, in which the most common mistakes in horse breeding are pointed out and their remedies briefly discussed. This is written from the standpoint of the farmer who desires to breed horses in a moderate or small way for the profit there is in it.

Horse production on the small farm. - The advantages of intensive farming have been widely discussed for a number of years. Intensive farming is farming on a small scale, but doing it perfectly, hence realizing the largest possible return on a moderate investment. Horse production on a small scale, as discussed here, is similar to intensive farming. It means the ownership of one or two pairs of high-class brood mares, preferably purebreds, which are used to do part or all of the farm work, and which are given the very best care and attention. They are bred only to high-class stallions of the same breed as themselves, and during pregnancy they are well cared for, well fed, and not overworked. As foaling time draws near, they are watched carefully and assistance is given if necessary. They foal on clean bedding in a clean stall, or, better still, at pasture, and the foals are immediately treated to prevent navel ill. The foals are given the best of care and are carefully trained, being halter broken as early as possible and made gentle by proper handling. They are kept growing after they are weaned, and in due time are carefully and thoroughly educated in harness or under saddle, as the case may be. This is intensive horse production.

Intensive horse raising therefore means keeping a few extra-good brood mares, and each year producing a few extragood foals which may be grown out by the breeder or sold as weanlings or yearlings to be developed by someone else. The first costs under this plan are not necessarily less than where a large number of the average kind of brood mares are kept. Good brood mares cost considerable, but they are the only kind on which large profits may be made. If this plan seems im- 
practicable because purebred mares are expensive, why not reach the same end by buying a weanling or yearling filly of the desired breed, growing out this filly to breeding age, and retaining her best filly foals for breeding purposes? In this way, given a few years' time, it is easily possible to get on an intensive footing with as many mares as are required.

We have had enough of the average kind of horse production in this country; in fact, far too much of it. It has been demonstrated beyond all doubt that it pays much better to

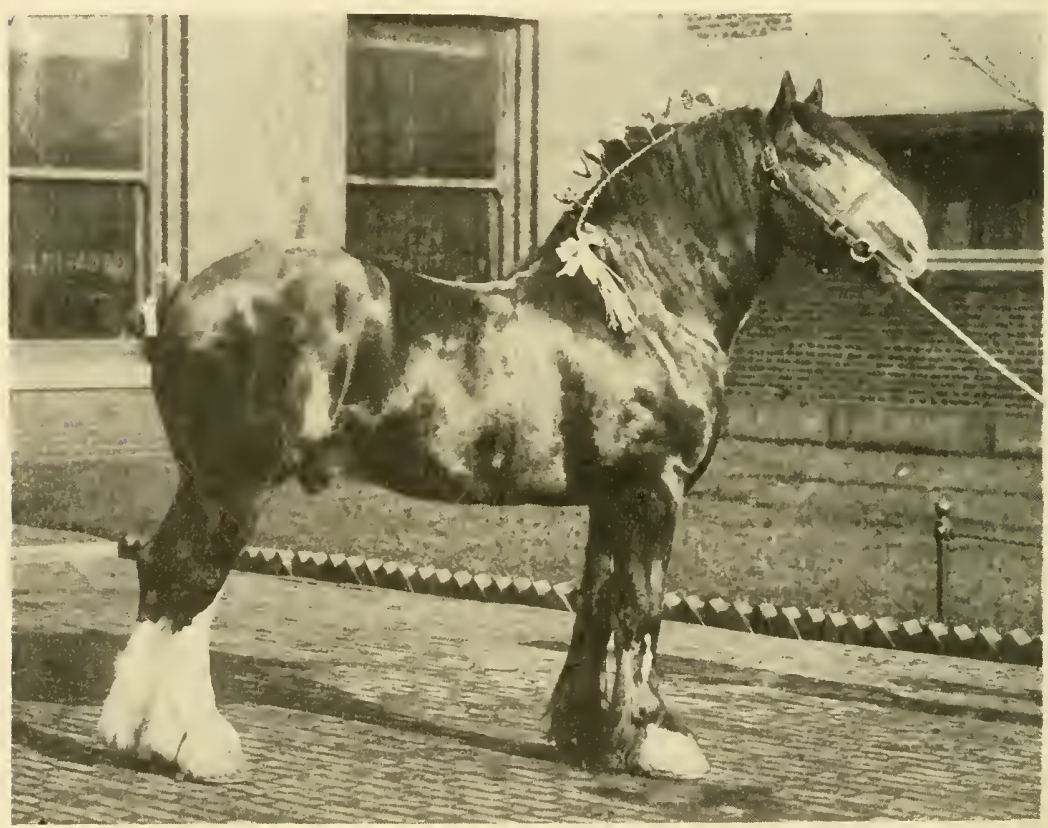

Fig. 152. Correct Type in the Draft Stallion.

Fyvie Baron, Champion Clydesdale stallion at the 1913 International. Owned by Conyngham Bros., Wilkesbarre, Pa. Note his maculinity, quality, style, symmetry, correct position of legs, nice pasterns, and good feet.

keep a few extra-good brood mares and raise carefully a few good foals, than it does to keep a lot of cheap mares and produce a lot of cheap horses, without feed enough to give any of them a fair chance. Today the tendency is for the cheap horse to bring less, and for the good horse to bring more than ever before. The motor has helped to bring about this condition, and the writing on the wall should be heeded. 
The writer once visited a farm where he was shown a sixteenyear-old grade draft mare of good type and individuality. On the same farm were five good mares, all out of the aged mare mentioned. Other of her numerous offspring had been sold at good prices. The mare had made the farmer money and was still making it, for at the time of this visit she had a fine filly foal by her side. But the owner was not satisfied. "Think how much more money I would have made," said he, "if I had begun with a purebred registered mare. If the old mare had been purebred and registered, the value of every one of her foals would have been easily doubled, and it wouldn't have cost a cent more to raise them." The lesson to the young breeder is clear,-start right, even if it means starting slowly by buying one young registered filly, and from her building up a breeding stud of fine mares.

The farms of the Middle West and East are well adapted to the intensive plan of horse production, because most of the farms are not large, and usually the teaming is done by the owner himself, or by one or two hands who are always under close observation. On big farms, with incompetent and everchanging help, if valuable brood mares are kept, they are liable to be injured if used to do the farm work. The writer is not one of those who advocate keeping brood mares in idleness. They will be healthier and will produce stronger foals if worked in moderation. The plan should call for working the brood mares, but not working them as hard as we work geldings or mules. Let them earn their board, and board them well. They may be worked well up to foaling time if care is taken not to back them to a heavy load, or put them to a hard strain. Mares have been hurriedly unhitched and unharnessed while cultivating corn or doing some other moderate work, and have foaled thrifty, well-developed foals, the equal of any. But such mares have been well fed and cared for during pregnancy, and they should be given as long a vacation on pasture after foaling as the farm work will permit.

The most profitable horse breeding in France, Belgium, England, Scotland, and America is done on the intensive plan, on farms of moderate or small size, by farmers who are good practical horsemen with a taste for doing things well. There is ample room in the United States for much more horse raising on this plan, and we have always had too many inferior mares, too many cheap stallions, and too many cheap horses hunting buyers. 
Choosing a type to breed.-What type of horse shall the farmer breed? The answer depends upon how much capital is available to put into the business, upon the personal qualifications of the breeder, and also upon his personal preference as to type. To some extent, the choice will depend upon the location of the farm, and upon the crops that can be grown. It will ordinarily require more capital to engage in the breeding of light horses than in the breeding of draft horses. Light horses especially require more expensive equipment to accom-

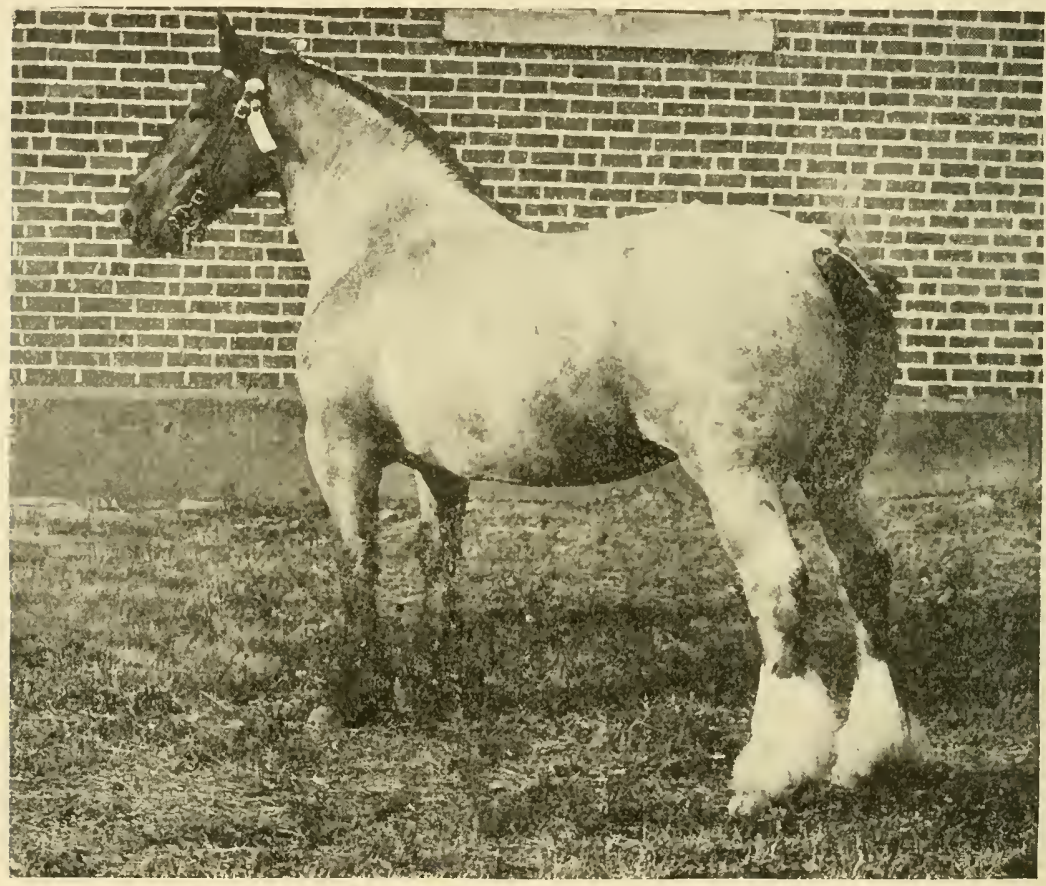

Fig. 153. Correct Type in the Draft Mare.

Coldham Surprise, Champion Shire mare at the 1913 International. Owned by Mr. Geo. M. McCray, Fithian, Ill. Note her roomy middle, faultless top line, symmetrical form, abundant muscling, and large bone. She has ruggedness and strength combined with quality and femininity.

plish the training and finishing without which they sell at comparatively moderate prices. Because of temperament and disposition, some men are more successful with one type of horse than another. The man who intends to engage in the breeding of horses should ask himself the following questions regarding any or all types he may have under consideration. 1. Am I 
familiar enough with the type and the methods of its production to know what I am striving to produce and how to produce it? 2. Provided I can produce the type successfully, how can I dispose of my animals, and what are the chances of realizing full value for my stock? 3. Are my buildings, fences, land, and crops adapted to the production of horses, and if not, can I remedy the shortcomings?

Advantages of draft type.-In the majority of cases, the best type for the farmer to produce is the draft horse. It has many advantages. The brood mares are much better suited to do the work of the farm than are any of the light horse types. Practically no special training is needed to make the drafter ready for market, and he is marketable at a younger age than is ordinarily true of the types of light horses. If he is kept free from wire cuts and other blemishes, and is fat and well groomed when offered for sale, he should realize full value. The carriage horse or saddler, on the other hand, requires months of handling in order to give him a good mouth and develop his action or gaits, as the case may be. Furthermore, a wire cut or other blemish is much more serious with these types than with the drafter. They require more care and attention from birth to selling time, and require a greater age to finish them for market. It is also true that there are fewer misfits in breeding draft horses than with any other type of horse, in other words, results are more certain and sure. The production of draft horses fits into general farming better than the production of any of the light horse types. For these various reasons, the draft horse is of greatest interest to most farmers, and is most frequently selected by farmers who take up horse breeding.

Light types require greater skill.--Let it be understood, however, that the foregoing arguments are not intended to discourage the breeding of types other than the drafter. The point is that carriage, saddle, and roadster horses are more difficult to produce than drafters, and but few persons, comparatively, are qualified to breed them successfully. The production of light horses requires a higher order of skill both in breeding and salesmanship than does the production of the draft horse, and when this is supplied, light horse breeding is a profitable enterprise. Hence the selection of the type to breed should be governed largely by the ability of the man who is to supervise the breeding, provided, of course, he is to work under conditions not unfavorable to the type he is best qualified 
to produce. Failures in horse breeding, as in most other things, usually have been due to the man believing himself capable of doing things for which he was not qualified.

Perhaps in no other field have so many breeders found themselves mistaken regarding their abilities as in the breeding of the trotting horse. This type appeals strongly to the majority of Americans, and many farmers and others have believed that they knew a safe and sure system of breeding for speed. Even in the best of hands, the breeding of trotters is very doubtful as to results, and only a small percentage of the foals ever attain anything noteworthy on the turf. Speed is an elusive quality dependent on such a rare combination of good qualities in the animal as to make results in breeding very

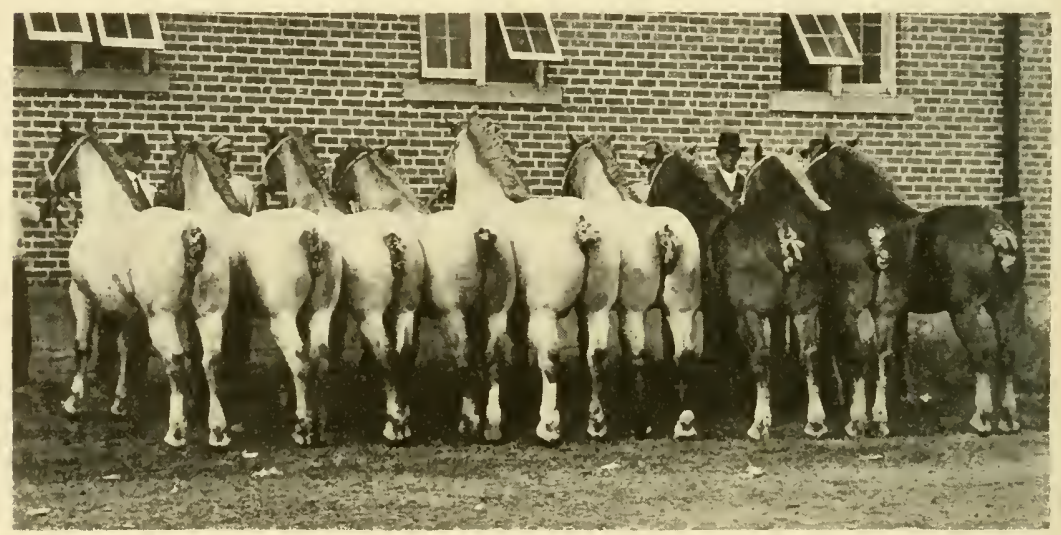

Fig. 154. A Highly Successful Sire.

Undefeated Belgian stallion, Farceur, and eight of his get. This group contains the first and second prize get of sire, Iowa State Fair, 1915 and 1916; the first prize futurity filly and champion mare at Iowa in 1916; the world's champion group at the Panama-Pacific Exposition in 1915; the first, second and third prize two-year-old fillies and champion mare at the International, 1916. Owned by Mr. Wm, Crownover, Hudson, Ia. Farceur was sold in 1917 for $\$ 47,500$ to Mr. C. G. Good, Ogden, Ia.

uncertain, and it should be understood that only a few men possess the special qualifications necessary to success in breeding this type of horse, and that only the wealthy, who are willing to accept the pleasure and fascination of the undertaking as partial remuneration for the capital invested, can ordinarily afford to take up this difficult art. A few men of moderate means have made a success with trotters by selling yearlings as "prospects" to be developed in the hands of some one else, but even this method is uncertain as to results financially. 
Pony breeding offers a good field for profit to those who are in a position to reach the trade for Shetland, Welsh, or Hackney ponies. The breeding of polo ponies, however, is as yet a very uncertain undertaking comparable to breeding trotters.

Selecting a breed.--After the type of horse has been chosen, it is next in order to decide what breed of that type shall be selected. The choice of a breed is not so serious or important a matter as the selection of a type or the selection of the individuals which are to compose the stud. It will depend largely upon the personal fancy of the breeder, although in some types of horses in certain localities, one breed may be so much liked or another breed so much disliked as to make it advisable for the new breeder to conform to the choice of the community, if it is possible to do so. He can then profit from the experience and advice of his neighbors, he will benefit from a greater number of local sales of his stock, and there will be more stallions to select among when mating his mares. After deciding what type shall be produced, the mistake is sometimes made of selecting a breed to work with which does not rightly belong to that type. For example, efforts are sometimes made to produce the carriage type from trotting-bred stock, or from a saddle breed, and while many excellent heavy-harness horses have sprung from these breeds, they have been largely in the nature of accidents in breeding, and ordinarily they cannot be produced in this way with enough regularity to make such a plan of breeding advisable.

Selecting the individuals.-We now come to the matter of selecting the individuals which are to compose the stud. First of all, they must be sound; and this is a matter to which many farmers pay too little attention. Buyers offer the best prices for sound stock, and the farmer has too frequently sold his young mares that were sound, and has retained those with sidebones, ringbones, spavins, curbs, etc., for breeding purposes. This is radically wrong and a very short-sighted practice. Soundness is of very vital importance in every type of horse, and especially in animals used for breeding purposes. The individuals should also be true representatives of the type to which they belong. Whether or not the brood mares should be purebred depends on the amount of capital available and on the type of horse selected. If possible, it is preferable that they be purebred, registered mares. However, some very profitable work in producing drafters for the market has been done 
with good grade draft mares. In such cases, these mares have shown excellent draft type, even though they were not eligible to registry. Purebred draft mares cost considerably more to buy, but have the very great advantage of having their foals eligible to registry, and hence of greater market value. In breeding carriage, saddle, and roadster horses, it is essential in most cases that purebred mares be used.

Well-developed feminine character and a good disposition are fundamental qualities in a brood mare, as such mares are usually more regular breeders, better mothers, and more easily handled and worked than are mares of masculine appearance or mean, vicious, or highly nervous disposition. The brood mare should have a long underline, and a deep, full-made, roomy middle.

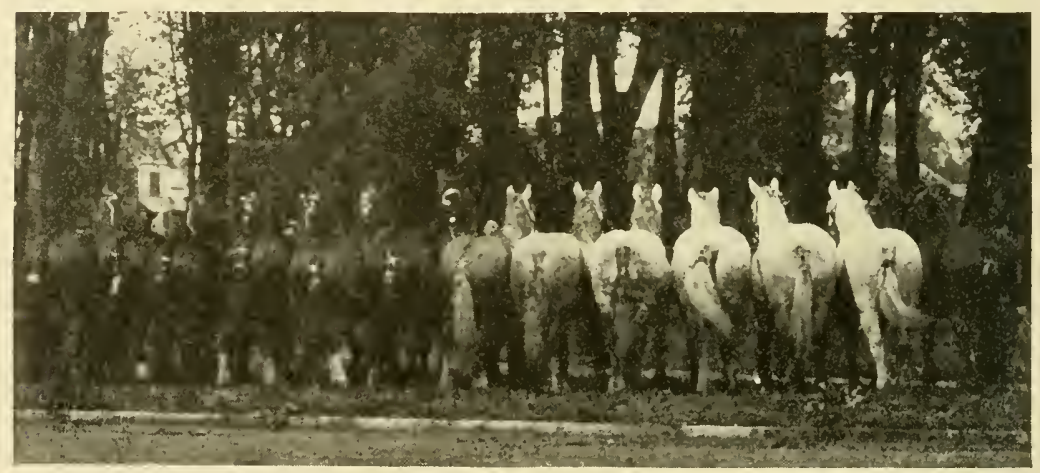

Fig. 155. Blood Will Tell.

Grade Shire mares shown at the Bushnell, Ill., horse show in 1914, all bred and owned by Mr. Jonas McGrew, Walnut Grove, Ill. All of these mares, and the dams and grandams of some of them, were sired by Shire stallions imported by the Truman Pioneer Stock Farm, Bushnell, Ill.

Well-developed draft fillies may be bred when two years old; others should not be bred until three years old. The duration of pregnancy in mares is quite variable, but averages about 340 days. A two-year-old stallion may breed 8 or 10 mares in the season, a three-year-old from 25 to 30 , and a four-year-old from 40 to 50. The breeding season lasts from 100 to 115 days, and it is important not to use the stallion too heavily at any time. A two-year-old may safely be allowed to cover one mare every five days; a three-year-old, three a week; a four-year-old, three every two days; and a mature horse should be limited usually to two covers daily, and perhaps occasionally he may make three. 
A sound, purebred stallion that is true to type and a good individual in every way is the only kind worthy of patronage. If there is no such horse in the community, it will pay to ship the mares a long distance to reach such a one. If possible, it is always best to patronize a stallion that has proved himself a sure breeder and a getter of good foals. There would not be the great number of unsound, mongrel, and inferior stallions standing for public service if there did not exist a demand for them on the part of mare owners. There can be only one explanation so far as the owner of the mare is concerned, and that is the saving in the amount of the service fee; but no more shortsighted practice can be followed, it having been demonstrated in almost every community that the added value of the foal from a high-class stallion, as compared with the foal by a cheap horse, repays the extra service fee many times over. It costs little more to raise a good foal than an inferior one, and the foal by the cheap stallion is not ordinarily a profit maker. So many breeders have shown a lack of judgment in this matter, and horse stocks have deteriorated to such an extent in some states on account of the large number of mares bred to cheap horses, that stallion laws have been enacted which debar unsound stallions from public service, and require that placards be posted on the stable door telling whether the stallion is a purebred, cross-bred, grade, or mongrel. Every state needs a law of this kind, modified to suit its needs.

Results of careless breeding.-Another evil in need of remedy is the too common practice of mixing the types of horses. Heavy mares are mated with trotting stallions in order to produce an animal for road use, or with no particular idea in the mind of the mare owner except to "get a colt." Light-weight, light-boned mares, without any semblance of draft qualities, are mated with draft stallions in the hope of getting a draft foal, or again simply to "get a colt." The results of such breeding are to be seen on every hand in the country, and a visit to any large horse market reveals the fact that a large percentage of the animals offered for sale are of no particular type or market class, because they have a variegated ancestry, the result of indiscriminate crossing of heavy and light horses. One is at a loss sometimes to know by what method some market offerings were produced. The result is a lot of cheap horses adapted to no particular work, which net the producer a loss in most cases and seldom yield a profit. Breeders must learn to stick to type. 
The experience of all successful horse breeders teaches no other lesson more forcibly than this.

Pedigree not always an indication of merit.-In the minds of many people, the words "purebred," "registered," and "imported" have a charm much greater than they deserve. Far too often, glaring faults of individuality or even serious unsoundness are passed with light criticism because the animal in question is eligible to one or more of these fascinating names. After all, one must conclude that there is something in a name. It is a fact that some purebred horses are practically worthless for breeding purposes. If an animal is purebred and registered, its value is very greatly increased, provided it is a good individual of useful type; but if the animal is decidedly faulty in conformation, or has serious unsoundness, its pedigree and registration number are of small account, and the animal is of little or no value for breeding purposes.

Feed and care.-Every successful breeder is a good feeder and caretaker, for no matter how excellent the ancestry of a foal may be, its inherited good qualities cannot reveal themselves unless the foal is provided with good quarters and plenty of the right feed with which to build up and grow. Feed and care are fully as important as parentage in producing good horses.

Summary.-In conclusion, therefore, follow the intensive rather than the extensive plan of horse production; select the type to breed after careful study of the situation; select a breed which truly belongs to that type; select sound individuals possessing a high degree of individual excellence; breed to a strictly high-class, purebred stallion, regardless of the amount of his service fee; if there is no such stallion in the immediate neighborhood, ship the mares whatever distance is necessary to reach a high-class horse; patronize a tried and proven sire if possible; stick to a definite line of breeding - do not mix the types indiscriminately; raise a class of foals that merit plenty of good feed and care, and supply the same; be conservative in your judgment and appreciative of the fact that the breeding of horses is an enterprise which repays careful study of all departments of the business.

\section{A Few Statistics.}

The United States, with 21,534,000 horses and 4,925,000 mules on January 1, 1919, has over 25 per cent. of the world's 
horses and over 50 per cent. of the world's mules. During the World War, or from 1914 to 1918 inclusive, the United States exported $1,054,000$ horses, valued at $\$ 219,459,000$, and 357,255 mules, valued at $\$ 70,926,000$.

Spain is the only country which has more mules than horses.

The average value of horses in the United States in 1919 was $\$ 98.48$, while the average value of mules was $\$ 135.59$. These figures include all ages. Utah was the only state in 1919 which reported a higher average valuation for horses than for mules.

Iowa, with 1,567,000 head, had more horses in 1919 than any other state. The other leading states in order of rank were Illinois, Texas, Kansas, Nebraska, Missouri, Minnesota, Ohio, North Dakota, and South Dakota. These ten states have a little more than half of the horses of the country.

The leading mule-owning states are Texas, Missouri, Georgia, Mississippi, Arkansas, Alabama, Oklahoma, Tennessee, Kansas, and Kentucky, in the order given, while no mules were reported in 1919 from Maine, New Hampshire, Vermont, Massachusetts, Rhode Island, and Connecticut. Six states own more mules than horses, these being North Carolina, South Carolina, Georgi a, Alabama, Mississippi, and Arkansas. 


\section{CHAPTER XXXVII.}

\section{THE MULE.}

The various breeds of the ass belong to one species known as Equus asinus. The various breeds of the horse belong to a distinct species known as Equus caballus. The male ass is called a jack, and the female a jennet. The cross of a jack on a mare produces a hybrid known as a mule. The cross of a stallion on a jennet produces a hybrid known as a hinny. Although it is often stated that the hinny and mule differ in appearance, the hinny tending to be more like a horse and the mule tending more toward the type of a jack, there is no difference in type and appearance between them. Very few hinnies are produced, as jennets are in such demand for producing jacks that they are seldom bred to stallions. Mules and hinnies do not breed, being infertile. As the saying goes, "the mule has no pride of ancestry, and no hope of posterity."

Breeds of jacks. - A number of breeds have been imported to the United States, including the Catalonian, Poitou, Maltese, Andalusian, Majorcan, and Italian. American breeders have made various crosses of these breeds and have developed by selection the so-called American Jack, which may be considered a distinct breed.

Best type of jack. - The best jack for mule breeding is one having as much size, weight, and substance as possible, without coarseness. He should stand 16 hands or over. Very few jacks exceed 16-1 hands and 1150 pounds. He should be lengthy and wide in form, with a straight, strong top, a well-shaped head, large and well-set ears, straight legs showing plenty of bone, feet of good size, shape, and texture, and a rather fine, glossy coat of hair. He should be active and show considerable style and spirit. The best color is black with light nose and belly, as a jack of this color will get the best-colored mules out of mares of all colors.

Best mares for mule breeding.-Mares standing 15-3 to 16-1 hands, and showing some evidence of draft blood, yet having good finish and quality, produce the best mules. These mares weigh from 1350 to 1500 pounds. The mare should have a roomy middle, and she should also have large, wide, and good feet. 
The mule.-Big, heavy mules bring the highest price if they show smoothness and good quality. The very best stand 16-3 to 17-2 hands and weigh 1600 to 1700 pounds. Few reach 1800 pounds. Mules do not weigh as heavy for their height as horses. Mules are judged by practically the same standards as horses.

The mule and horse compared.-Mules are more surefooted than horses, pick their way more carefully, and look out for themselves better than a horse. Mules are more intelligent than horses, and are more apt to learn to refuse or avoid hard

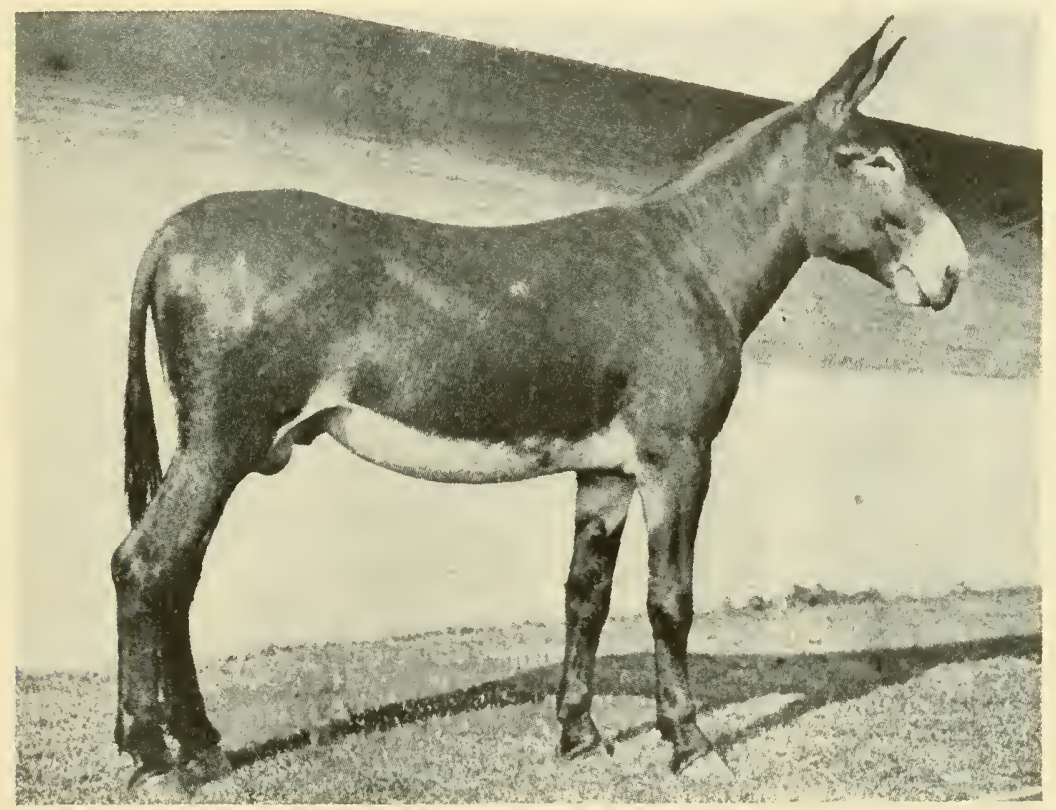

Fig. 156. Correct Type in the Jack.

Limestone Monarch, Champion at the Missouri State Fair in 1912, and Reserve Champion at the Panama-Pacific Exposition in 1915. Height 15-3 hands; weight, 1212 pounds. Bred and owned by Mr. L. M. Monsees, Pettis County, Mo.

or unpleasant work. When a mule gets tangled up in wire or into some other predicament, he usually stands quietly until released, whereas a horse often becomes excited and struggles even though he lacerates his legs and body and punishes himself very severely. Mules usually accept their lot and plod along at their work without wasting energy in fretting or nervousness, while worry rather than work often keeps a horse thin. Mules are less sensitive than horses; they accept more abuse and rough handling, and get along better under an incompetent driver. 
Mules stand hot weather better than horses. Mules are less subject to digestive troubles and founder. A mule will not gorge himself as a horse often does if he gets into the feed bin or has access to too much feed. The mule's foot has a very thick, strong wall and sole which enables the foot to endure the shock and concussion on hard pavements particularly well. Mules are less subject to foot troubles which cause lameness, and their feet are less affected by continuous shoeing. Mules are usually stabled more cheaply than horses. They are often

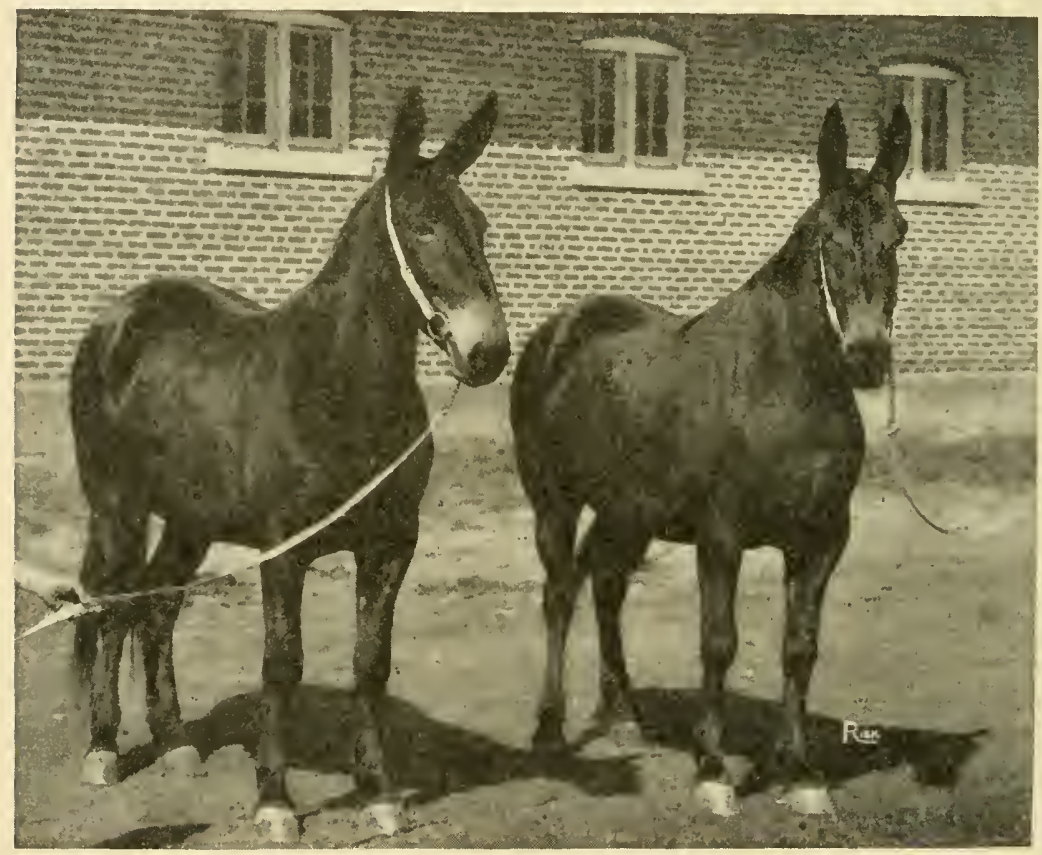

Fig. 157. Prize-Winning Mules.

Champion pair of mules at the Iowa State Fair, 1915, six years old, weighing 1600 and 1620 pounds. The off mule (on the left of the picture) was champion mule of the show. Owned by F. L. Hutson \& Son, State Center, Ia.

kept in sheds or pens in which a number are turned loose together. Aged and second-hand mules sell better than aged and second-hand horses. Mules require less veterinary attention and are less often incapacitated for work than horses. Mules once worked together as a team are harder to separate than horses. This may be an advantage, or it may in some cases prove a detriment. Mules are more uniform in form and color than horses, and are easier to match into teams. 
On the other hand, the mule has some shortcomings as compared to the horse. He has not the weight for the heaviest draft work. Because of the small size of his foot he is more apt to slip on pavements at a hard pull. Furthermore, the mule's habit of pushing directly forward against the collar, instead of crouching and lifting like a draft horse at a hard pull, also results in slipping on pavements. Mules do not work well in soft ground. The small foot of the mule does not bear him up, and he is usually much more timid under these conditions than is the horse. Mules will avoid a muddy spot or puddle of water if they can. The wilfulness and trickiness of many mules and their lack of spirit makes it less of a pleasure to drive the average mule than the average horse. The mule has a harder mouth. Too often it takes a gag bit to hold him and a black-snake whip to make him go. Mules are not adapted to use in the artillery, as they are gun-shy, usually lack speed, and do not respond to commands quick enough. They are not so dependable as horses in an emergency.

Mr. George E. Wentworth, Superintendent of the Chicago Union Stock Yards Horse Market, in an interesting article* entitled "Why Use Adulterated Horses?" discusses the place of the mule in warfare as follows: "They say the mule can stand more heat, but cavalry regiments in South America, south Africa, Arabia, India, China, or Morocco are not mounted upon the sure-footed, swift, enduring, and patient mule. The Cossacks did not pursue Napoleon from Moscow on the backs of mules, nor did the men of Marion and Sumpter, Stuart or Sheridan win their victories astride the progeny of a jack. The Crusaders panoplied in full armor, fought Saladin and his Emirs over the dry and arid dusty deserts of Palestine mounted upon Norman and Arabian horses. Armies trust live weight to horses, dead weight to mules."

As mules do not breed, there is no opportunity for profit to the farmer from this source. The mule's inability to breed is something of an advantage in the city and in the army, as there is always the danger of a mare being in foal when she is purchased, and if she is it causes trouble and annoyance in a city stable or in the army; she must either be sold or kept idle for a time. From all standpoints, however, the mule's failure to breed is a detriment as compared to the horse.

*The Horseman \& Spirit of the Times, Aug. 4, 1914. 


\section{CHAPTER XXXVIII.}

\section{MARKET CLASSES OF MULES.}

The mule market is of more recent origin than the horse market, but has developed into a large business. Whereas horses are usually sold at public auction, mules are usually sold at private sale, being sold singly, in pairs, or in any number to suit the needs of the buyer. When large numbers are wanted of a uniform height and weight, they are most often sold at a fixed price per head and the salesman gives a guarantee as to age, soundness, and other requirements. When an order is placed for mules of different sizes or for different market classes, they will ordinarily be figured individually, or in pairs.

Market requirements. - The market requirements for mules are similar to those for horses. They should be sound, of a desirable age and color, well fleshed, and sleek in coat; and should possess abundant quality and a strong conformation. They should also have good action. These requirements are discussed in detail below.

Soundness. - Mules should be serviceably sound. Blemishes are objectionable, though not in the same degree as with horses. They should be sound in eyes and wind, and should be good workers. The most common and serious unsoundnesses are large spavins, puffs, sidebones, defective eyes, and unsound wind.

Age.-The most desired age is from four to eight years; however, there are exceptions in some classes, as noted below.

Condition.- The appearance is greatly improved if mules are marketed carrying flesh enough to round out their middles. Sleek, glossy coats of hair are often estimated to be worth ten dollars. The flesh should be smooth, not lumpy or rolly. The value of flesh on mules is about equal to that on draft horseswhich is twenty-five cents per pound with a good grade of horses.

Quality.--Refinement of head, hair, bone, joints, and hoofs is an evidence of good bone and wearing qualities.

Conformation.-All mules should have a large chest, long shoulder, deep barrel, straight short back with as much spring of rib as possible, a broad loin, and a long level croup. The underline should be comparatively straight, the rear flank well 
let down, and the thighs and quarters heavily muscled. The legs should evidence both substance and quality, the feet should be large, wide at the heel, and sound, and the hoofs should be smooth. The form, muscling, and set of legs should be approximately the same as in horses. The head of the mule is a good index of his disposition and temperament; it should be of good size, yet clean-cut as an evidence of quality. The forehead should be broad and flat, and the nose slightly Roman,

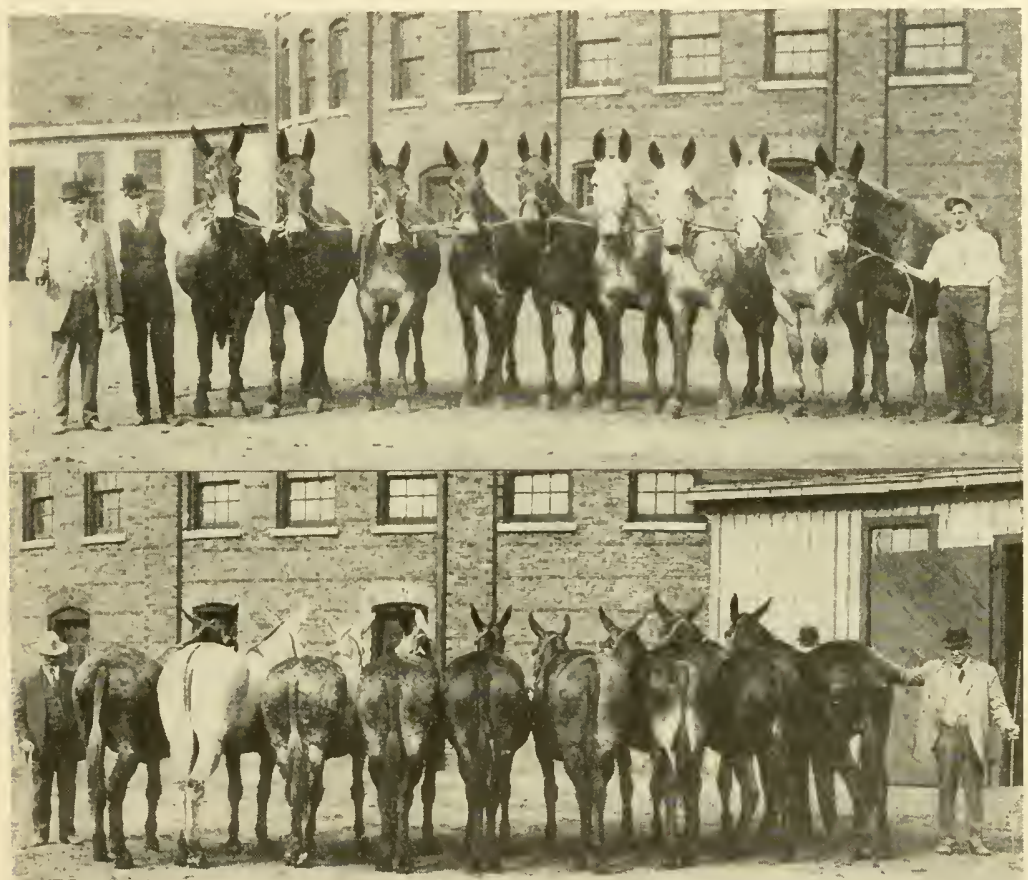

Fig. 158. High-Class Draft Mules.

which indicates stamina and strength. If the head is as described, the animal is usually considered to be a more reliable and agreeable worker than one not possessing these characteristics. The ears should be long, thin, tapering, and carried erect; the neck should be long, with moderate crest, and should join the shoulder smoothly. The mane should be roached, and the tail clipped in the regular manner with not too short a bush.

Color.-All mules of solid color, except white, are in good demand, though color is not an important factor. Dapple 
grays are popular in the draft class, but as a general rule, bays, browns, and chestnuts are most desirable, while flea-bitten grays are discriminated against.

Action.-Action counts for very little in market mules. They should show vigor and energy in their movements and be straight-line movers. They should not be lame or crampy, nor defective in action because of badly set legs.

The market classes of mules are determined by the use to which they are put, but in order for a class to exist there must

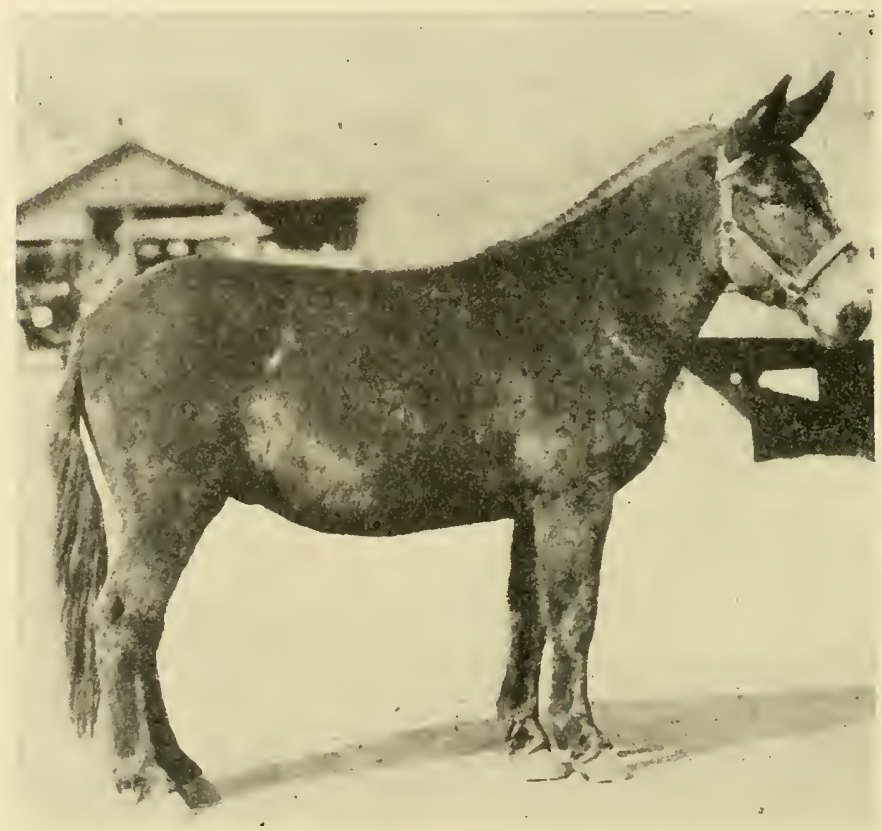

Fig. 159. Mining or Pack Mule.

be a demand for considerable numbers of a definite type. In the St. Louis market, which is the largest mule market in the world, there are six market classes which are as follows:

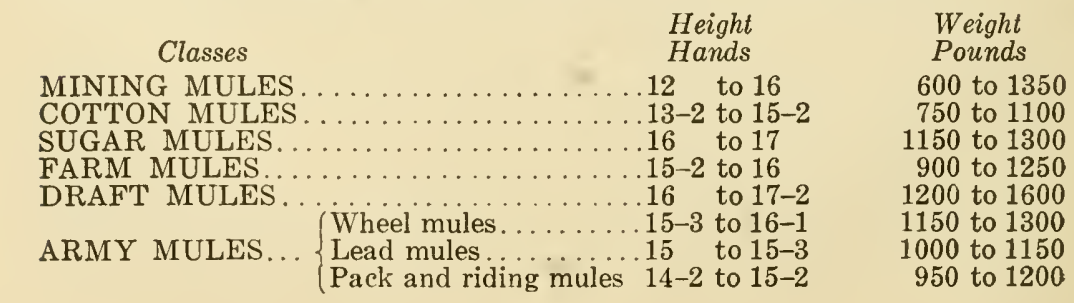


Mining mules.--These are purchased for use in mines, principally to haul cars of ore or coal to the hoisting shafts. They are rugged, deep bodied, short legged, compactly built, and have heavy bone and large feet. They stand from 12 to 16 hands high, and weigh from 600 to 1350 pounds. Those used down in mines are termed "pit mules," and the height of these is limited by the depth of the vein worked. Ages from 5 to 8 years are most preferred, but a well-developed four-yearold, or a well-preserved ten-year-old, is often accepted. Geldings are much preferred to mare mules for this trade. Bad wire marks on the feet are severely discriminated against, as

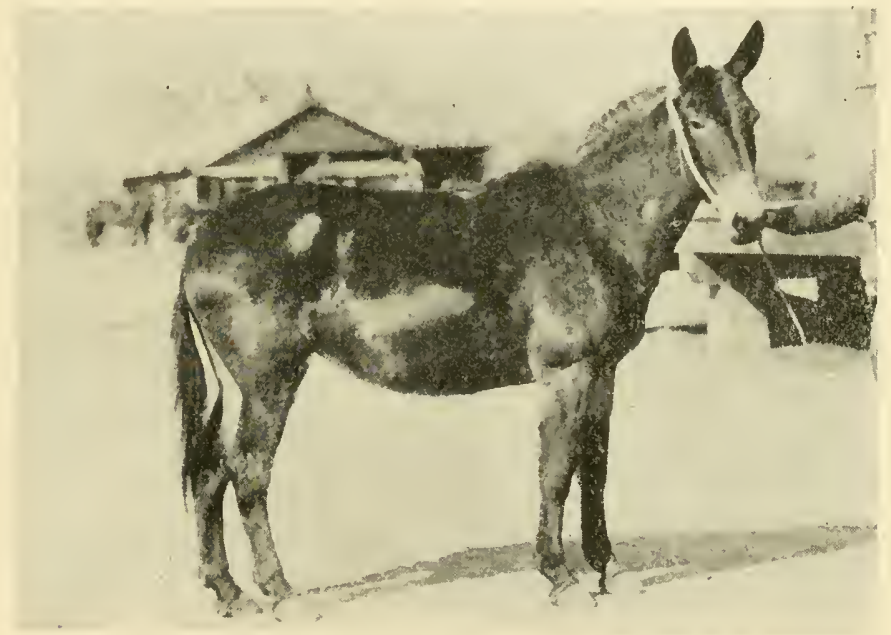

Fig. 160. Cotton or Lead Mule.

they are likely to become sore from contact with sulphur and other chemicals in the mine. The demand for miners is strong and constant throughout the year, and comes from all sections where mines are operated.

Cotton mules.-Cotton mules are very similar to mining mules in size, but are lighter boned and not so compactly built. They should have small, neat heads, and possess much quality and finish. Their feet are smaller and bodies proportionately lighter. Cotton mules stand from 13-2 to 15-2 hands high, and weigh from 750 to 1100 pounds. They are most desired from 3 to 7 years old, but may find ready sale up to 12 years of age. Mare mules sell better than geldings in this class. The trade begins about the first of September and continues good 
throughout the fall and winter months, then gradually decreases until after the cotton crop is planted, or about April. From this time until the following fall, the demand is light. Cotton mules are used by cotton growers to plant, cultivate, and harvest the cotton crop, but a great many such mules are also taken to cities for use on delivery wagons and other purposes.

Sugar mules.-These are mules especially adapted for use on the sugar farms of Georgia, Louisiana, and other southern states. Sugar mules are taller, larger, more breedy looking, better finished, and have heavier bone than cotton mules. The feet should be large in proportion to the bone. They stand

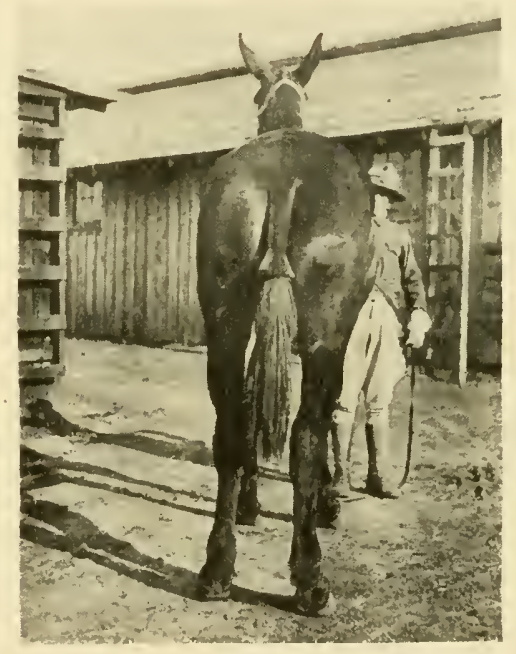

Fig. 161. Sugar Mule.

from 16 to 17 hands high, and weigh from 1150 to 1300 pounds. Mare mules from 3 to 6 years old are most desired for this trade. As sugar mules are larger and possess more quality and finish than cotton mules, they sell for a little more money. The trade begins in August, and usually ends in February. They are in greatest demand in September, October, and November.

Farm mules.-Mules purchased for use on farms in the central states are known on the market as farm mules. They are less uniform in type than the other classes, as farmers like to buy animals that show promise of further development. Farm mules are usually from 15-2 to 16 hands high, and from 3 to 6 years old, four-year-olds being preferred. They are often 
plain looking and thin in flesh, though possessing good constitution, bone and feet, and showing indications of a good outcome when well fed and cared for. Many of them are worked for a time, then fattened and returned to the market. When resold, they may be taken as miners, sugar mules, or cotton mules. The strongest demand for farm mules occurs during the late winter and spring months.

Draft mules.--Draft mules are large, heavy-boned, heavyset mules, with plenty of quality. They are purchased to do heavy teaming work. Many are used by contractors doing railroad grading, and consequently they are often spoken of as

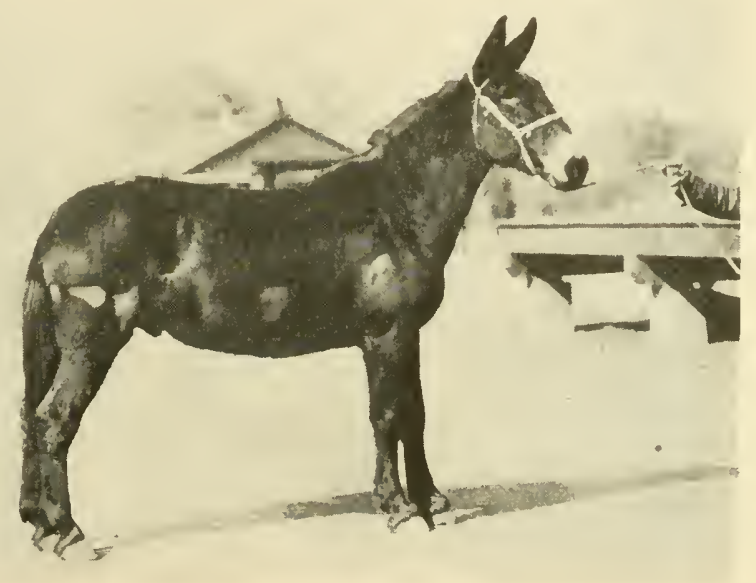

Fig. 162. Farm or Wheel Mule.

railroad mules. They are especially demanded for heavy teaming work in cities in warm climates, where they are preferred to horses because they are said to be hardier, able to stand the hot sun better, and not subject to as many ills. Draft mules stand from 16 to 17-2 hands high, and weigh from 1200 to 1600 pounds and upwards. They should combine weight and strength. They should be large, rugged, heavily boned, and strongly muscled. The feet should be large, the back short and strong, the middle deep and closely coupled, the croup fairly level, and the thighs and quarters massive. They are most desired from 5 to 8 years old, and little preference is shown regarding sex. The demand is strong and quite constant the year round. 
Army mules. - The demand for mules in the army is very limited and the class is not important except in time of war. In the recent World War, the American mule played a very important part, and large numbers were purchased at the various markets. Three classes are required, these being wheel mules and lead mules used in four-in-hand teams on army wagons for transport work, and pack and riding mules.

Wheel mules.-Government specifications call for mules that are "sound, well bred, and of a superior class; of a kind disposition, free from vicious habits, gentle, and well broken to harness, with free and springy action at the walk and trot; and otherwise to conform to the following description: A mare or gelding of uniform and hardy color, in good condition, from 3 to

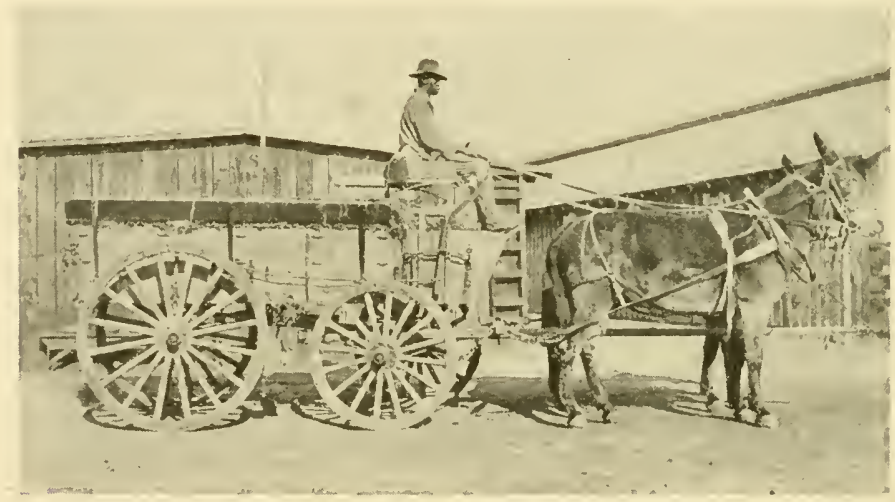

Fig. 163. Small Pair of Wheel Mules to Army Wagon.

8 years old. Three-year-old mules will be purchased only when exceptionally fine individuals." Wheel mules stand 15-3 to 16-1 hands high, and weigh from 1150 to 1300 pounds.

Lead mules.-These are of the same general description as the wheelers, but are smaller animals. They should stand 15 to 15-3 hands high, and weigh from 1000 to 1150 pounds.

Pack and riding mules.-Pack and riding mules stand from 14-2 to 15-2 hands, and weigh from 950 to 1200 pounds. They must be of stocky build, with a stout neck, short, strong back, good coupling, large deep barrel, and good feet and legs, with ample bone. The pack mules must be particularly deep in the middle and strong backed, as they carry a long pack saddle which fits well down on the sides of the mule, and they carry from 300 to 350 pounds. Pack mules are used for trans- 
port work in very rough or wooded country where wagons cannot be used. The demand for these mules is limited.

Plugs.-These are worn out, cheap mules that have but little value. They are usually unsound in one or more respects, very plain and rough in form, and many are of advanced age.

Export mules.-The export trade in mules has increased during recent years. Large shipments have been made to South Africa, Philippine Islands, and Cuba. The size and type of these mules varies, depending on the use to which they are put and the country to which they are sent. Some are used for army service, some for agricultural purposes, some for heavy teaming, and some in mines. Hence the term "export mule" is a trade name which is not restricted to any particular kind of mules. 


\section{CHAPTER XXXIX.}

\section{UNSOUNDNESS IN THE HORSE}

Soundness is a very vital factor in determining the value of a horse, and a knowledge of unsoundness is very essential to success in breeding. Brief description of the most common unsoundnesses has been deferred until the close of the discussion of horses in order that the student may learn to fix his attention, first of all, on type. The matter of soundness, while important, is often overemphasized by beginners. Presented here at the close, such information should serve as an important supplement to preceding discussions of the types and market classes of horses and mules.

If a horse is unsound, his unsoundness may be accounted for in one or more ways: (1) he may have had a natural weakness in conformation or structure which predisposed him to the unsoundness; (2) he may have been strong in conformation, but forced to do extreme labor which was beyond the power of the animal machine to endure; (3) the unsoundness may be the result of a bruise, blow, cut, or other injury; (4) unsoundness may result following a diseased condition of some part of the body, and (5j lack of proper care, as, for example, failure to keep the feet in proper balance so as to distribute the weight and wear equally over the various parts of the foot and leg, may bring on unsoundness. In the horse for work, it matters little which of the above explanations applies; he is unsound, and the horse market fixes his value according to the nature of the unsoundness, without regard to the reason why the horse has it. In the horse intended for breeding purposes only, unsoundness should not be considered a serious detriment unless it is explained by the first of the possibilities listed above. For example, it is wiser to breed to a horse having a naturally strong hock which, because of accident or extreme work, has developed a bone spavin, than it is to breed to a sound horse having a weakly formed hock which is free from bone spavin only because it has never been put to the test of even moderate work. It is often difficult, however, to determine with accuracy the reason for an unsoundness, and in all such doubtful cases the unsoundness should be looked upon with suspicion and the horse rejected for breeding purposes. 
Certain unsoundnesses are ordinarily referred to as "hereditary," on account of their marked tendency to reappear in succeeding generations. More correctly, however, it is some weakness of conformation that is transmitted which predisposes the members of the family to one or more unsoundnesses. Considerable difference of opinion exists among well-informed persons as to the hereditary transmission of some unsoundnesses.

A number of minor troubles which are not unsoundnesses are here given brief mention, because of the frequency with which they are met and to satisfy curiosity regarding them. Treatment is briefly mentioned in some cases for a similar reason. Many minor troubles are important because they blemish a horse. A blemish merely detracts from the appearance of an animal, whereas an unsoundness interferes with his working capacity. Many unsoundnesses are blemishes as well. A study of the ills to which the horse is heir shows that his eyes, legs, and wind are the seats of unsoundness.

Blindness.-Any defect of sight is a serious defect in a horse, and eye trouble always furnishes grounds for rejecting horses for unsoundness. Inspecting a horse for blindness requires expert knowledge of the diseases of the eye, and, although the average horseman ean in many cases discover defective eyes, no horse is safely passed as sound in eyes except by a wellqualified veterinarian. Severe weeping, partially closed eyelids, sunken eyes, inability to bear strong light, a cloudy appearance of the cornea, unnatural or dull color, failure of the iris to contract to a considerable degree when brought from darkness to light, too active. play of the ears, failure to blink when an object is passed close to the eye-these and many other conditions give evidence of defective vision. (See also cataract and periodic ophthalmia.)

Blood spavin.-Blood spavin is situated in front and to the inside of the hock, and is merely a varicose or dilated condition of the vein passing over that region. It occurs directly over the point where the bog spavin is found, and is sometimes confused with the latter. It constitutes a blemish rather than an unsoundness.

Bog spavin.-This is a round, smooth, well-defined swelling in front and a little inward of the hock. On pressure it disappears to reappear on the outside and just behind the hock. It is caused by a weakness in the synovial sacs of the joint, accompanied by a hyper-secretion of synovial fluid or joint oil. 
Bog spavins are more often blemishes, rather than unsoundnesses. They are classed as the latter only when they are well developed or cause lameness. Slight cases are described as merely "a little full in the hocks." Treatment consists of rest, blistering, cauterization, and the use of pressure pads and peculiar bandages.

Bone spavin.-This is a bony growth of variable size in the hock, which may or may not make itself visible on the exterior. It most often occurs at the inner and lower border of the hock, but may arise on the upper part, or on the outside of the hock. In some cases, no outward signs of spavin are perceptible; these are called "occult" spavins. Care should be taken not to mistake a prominent development of the inner and lower border of the hock, natural in some animals, for a

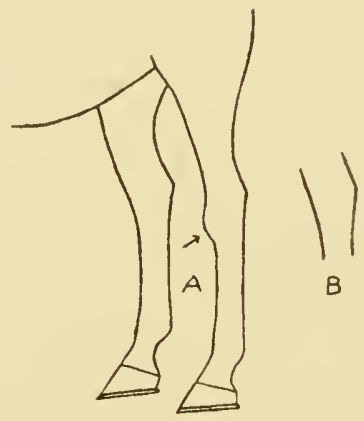

Fig. 164. Bog Spavin.

A, Bog spavin; B, sound hock.

spavin. Hocks that are narrow or tied in below are subject to bone spavin, as are also those of coarse structure.

Bone spavins affect one or more of the six bones of the hock. The spavin usually represents an effort on the part of nature to repair the joint. Spavins are caused by sprains, by violent efforts in jumping, galloping, trotting, or pulling, by slipping or sliding, and other similar causes. This is classed as an hereditary unsoundness. It is one of the most serious unsoundnesses of horses; it causes lameness and stiffens the joint. As with sidebones and ringbones, the size of the spavin is not a safe index of its seriousness. An excellent test for spavin lameness consists in lifting the affected leg off the ground for one or two minutes, holdins the foot high so as to flex all the joints. Then start the animal off in a trot, when the lameness will be greatly intensified if it is caused by spavin. Treat- 
ment consists of complete rest for a month or more, blistering, the use of proper medicaments, firing, and special operations on the joint. Firing produces a small scar, and when this is present the spavin is called a "jack."

Broken wind or heaves.-This condition is denoted by a characteristic hollow cough, short, and something like a grunt, which once heard is easily recognized a second time. Inspiration is performed normally, but expiration is abnormal, being double, or what is commonly called the "double lift." The first portion of the expiration expels the air as normally, and the second apparently squeezes the remainder of the air from the lungs in a gradual manner, seemingly with more or less voluntary exertion. When such an animal is put to work, there is also a wheezing noise with the breathing. From a commercial standpoint, a broken-winded horse has practically
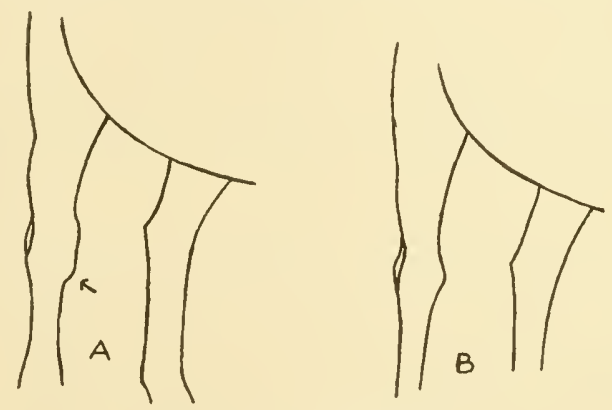

Fig. 165. Bone Spavin.

A, Bone spavin; B, sound hock.

no value, yet he may continue to work fairly well. The cough is sometimes disguised by unprincipled persons through the administration of such substances as shot and grease; but this is only temporary. The abnormal breathing cannot be concealed. In some cases of broken wind, the air vesicles of the lungs have been found, after death, ruptured; the right side of the heart enlarged, and the walls of the stomach dilated, though this is not always true. A predisposition to this disease may be inherited. In doubtful cases of broken wind, give the animal all the water he will drink and then ride or drive him uphill. This will bring out the symptoms if the disease is present.

There is great diversity of opinion as regards the exact cause of heaves. It is usually associated with disorder of digestion, or to an error in choice of feed. Feeding on clover 
hay or damaged hay or straw, too bulky food, and keeping the horse in a dusty atmosphere or a badly ventilated stable produce or predispose to heaves. Horses brought from a high to a low level are predisposed.

Capped elbow.-This is commonly termed "shoe boil," and consists of a bruise at the point of the elbow, generally caused by the heel of the shoe when the horse is lying down, and sometimes from other causes. The continued irritation leads to the production of a tumor at the point of the elbow. The skin may be broken, and slight suppuration very often occurs. The cause must be removed, and the animal provided with a leather or rubber ring around the fetlock while in the stall. The remainder of the treatment is surgical. Capped elbow may cause severe lameness, but it is usually a blemish only.

Capped hock.-This is quite common and may or may not constitute unsoundness. It is the result of a bruise, either continuous or intermittent, and may appear suddenly or gradually. Such bruises may be received in shipping by train or boat, or by the habit some animals have of kicking against the sides of the stall, or at fences, or even in harmess. The skin, bursa, or the bone may be involved in capped hock. Usually it is the skin, which becomes very much thickened over the point of the hock. It is in every case a blemish. Treatment consists of hot and cold applications and blistering.

Cataract.-When the lens of the eye becomes so cloudy or opaque as to present a white or grayish color, the eye is said to be affected with cataract, which is a practically incurable form of blindness. A blow over the eye and other causes bring it on. It is rather common, particularly in aged horses.

Chronic cough.-A permanent cough accompanying broken wind, glanders, and other diseases constitutes an unsoundness.

Cocked ankles or knuckling.-This is a partial dislocation of the fetlock joint, in which the position of the bones is changed, the pastern becoming more nearly perpendicular. While it is not always an unsoundness, it nevertheless predisposes to stumbling and to fracture of the pastern. Young foals are frequently subject to this condition, and in the great majority of such cases the trouble disappears in a few weeks without treatment. Horses with erect pasterns often knuckle as they grow old, especially in the hind legs. All kinds of hard work, particularly in hilly districts, are exciting causes of this trouble. It is also caused 
by improper shoeing, in which the toe is made too long and the heel too low, thus producing inflammation and retraction of the tendons. Lastly, it is caused by disease of the suspensory ligament or of the flexor tendons, whereby they are shortened, and by disease of the fetlock joint. It is one of the worst faults a horse can possess, and it greatly affects the value and the price. Treatment varies depending on the cause of the trouble. Relief may be secured by so shoeing as to shorten the toe and elevate the heels, thus relieving the tendons. In extreme cases, the tendons may be operated on to secure relief. Firing and blistering effect a cure in some instances.

Contracted feet.-Contraction of the feet is not a diseased condition in itself, but is a symptom of such and leads to trouble. Contraction is due to a removal of the full functions of the foot, such as is the case in lameness, removal of frog pressure, defective shoeing, etc. Contraction occurs more especially at the heels, and more frequently in the fore feet than in the hind ones. Veterinarians look upon this condition as constituting unsoundness. Treatment is not of much avail, but going barefoot or wearing a special shoe to spread the heels will help to alleviate the condition.

Corns. - A corn is a bruise to the fleshy sole, and is manifested by a reddish discoloration of the horny sole beneath the bruise. It usually occurs upon the inner quarter of the fore foot. A corn very often causes severe lameness, and is a cause of unsoundness. The treatment consists in paring, special shoeing, poulticing, keeping the part thoroughly clean, and a few weeks' rest.

Cracked heels. - This condition is denoted by an inflamed state of the skin, which becomes broken, and, if severe, may cause lameness. They are frequent in the horse, especially following a frost, the moisture from the thaw favoring this. It is similar to chapped hands, and fissuring is favored by the movements in the hollow of the heels. Treatment consists of the application of a soothing liniment applied daily with tow and bandage.

Curb. - This is an unnatural prominence of variable size, located on the posterior border of the hock, four or five inches below the point of the hock. It is easily detected by viewing the joint in profile. It is caused by a sprain of the tendon which passes over that part, or of the strong ligament located there. Hocks that are sickled, coarse, and thick in appearance, or that 
are too narrow from front to back at their base, most often develop curbs. Violent efforts in heavy pulling, high jumping, or slipping are often the direct cause of curb. Curbs do not often cause lameness, or, if they do, it is usually during the formative stage. Legally it is an unsoundness, although it is not much of a detriment, especially in horses for slow work. Curbs are much less serious than bone spavins, ringbones, sidebones, cocked ankles, and stringhalt. Treatment in the early stages consists of cold applications to relieve the acute inflammation. When the first stage has passed, blistering, frictions with ointments, and firing are often used with good success.

Fistula. - This is an ulcerous lesion found at the withers. Fistulas follow as a result of abscesses, bruises, wounds, or longcontinued irritation by the harness or saddle. The pus burrows and finds lodgment deep down between the muscles. The horse becomes incapacitated for work for a considerable period. Most
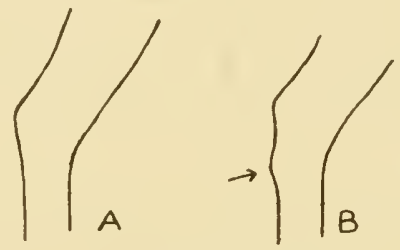

Fig. 166. Curb.

A, Sound hock; B, curb.

cases are curable. The treatment is largely surgical; the animal should be placed in the care of a competent veterinarian as soon as the condition is discovered. After the fistula is healed, a scar usually remains in the region of the withers. A horse that has had fistula is liable to subsequent attacks of the same trouble.

Founder or laminitis. - This is a simple inflammation of the fleshy laminæ within the hoof. Being exceedingly vascular, the laminæ are subject to congestion, and, being enclosed within the hoof, there is very little room for the relief' of the congestion. The animal suffers most agonizing pain. Cc: cussion is one of the most common causes. Another is overfeeding on grain, causing indigestion, irritation of the alimentary tract, and inflammation of the fleshy laminæ through sympathy. Other causes are unusual excitement, bad shoeing, over-exertion, exhaustion, rapid changes of temperature, or any other agencies of an over-supply of blood, to the fleshy laminæ, resulting in 
congestion and inflammation. But it is the after-effects which are of most interest to us here. The disease sometimes becomes chronic, and this seriously affects the secretion of the horn. The toe of the hoof turns up, the heels become longer than natural, while the hoof near the coronet is circled with ridges like those of a ram's horn. These ridges are wide apart at the heel, and close together in front, and are due to periods of interference with the growth of horn simultaneous with the inflammation of the fleshy laminæ. Because of the high heel and turned-up toe, the leg knuckles at the fetlock joint. Usually, accompanying these defects, the sole is found to be thin, convex, and weak, and will stand but little wear. Because of the convexity, the diseased tissues bear unusual weight, and such animals are generally incurable cripples.

Grease.-This is not an unsoundness, but is such a troublesome and common complaint that brief mention is here given. It is a skin disease appearing nearly always in the hind cannons. Draft horses are more subject to it than light horses. Some individuals are predisposed to it-those with coarse skin and coarse feather. Other horses have it as a form of parasitic mange, denoted by a greasy condition of the skin, congestion of the skin, erect hair, and offensive odor due to discharge from the sores. There is a constant itching and the horse rubs the part, producing thickening and wrinkling of the skin. Treatment varies. Half an ounce of Fowler's solution of arsenic night and morning in the feed, burning with hot iron, applying hot linseed poultices, dressing with lead lotion, giving a mild physic, decreasing amount of feed allowance-all these furnish good methods of treatment.

Hip down.-This is a fracture of the point of the hip, often caused by the animal striking the part against the door post of the stable. It causes a flatness and sometimes the broken piece of bone may be felt. It is best detected by standing squarely behind the animal and viewing it across the hips. It constitutes a blemish.

Navicular disease.-Navicular disease is a chronic inflammation involving the navicular bone, the navicular bursa, and the flexor tendon of the foot. It is brought on by repeated bruising. Light horses are affected much oftener than heavy horses. The hind feet are seldom affected. It is practically never found in mules. One-third of the weight falling on the leg is sustained by the little bow-shaped navicular bone, and 
the bone in turn is supported by the flexor tendon of the foot. (See Fig. 115.) Such defects as an insufficient plantar cushion, a small frog, and contracted feet predispose the horse to navicular disease. In this way the disease may be hereditary, as these predisposing causes may be transmitted to offspring. High knee action, fast work, and hard pavements also endanger a horse from this disease. Dry stables, heavy pulling, and bad shoeing also tend toward the development of this trouble. In the early stages of navicular disease, the animal at rest points the affected foot forward and rests it on the toe, with the fetlock and knee flexed. In the lameness which develops, the affected leg takes a short stride, and the toe strikes the ground first. The disease is progressive and incurable, rendering the animal practically valueless, but not entirely useless on soft ground. To relieve the pain, neurotomy may be performed, an operation in which the sense of feeling is destroyed in the foot by cutting out pieces of the nerve at the fetlock. Navicular disease is one of the most serious unsoundnesses.

Periodic ophthalmia or moonblindness.-This is a disease affecting the eyes of horses, probably caused by a germ. It is quite commonly called moonblindness, because it was thought at one time that the moon had some influence on the cause of the disease. There is undoubtedly an hereditary predisposition to the disease, but there are few cases to indicate that the disease itself is transmitted from parent to offspring, but rather the foal is born with a weakness of the eyes, transmitted by the stallion or dam. Other predisposing factors are low, swampy pastures, poorly ventilated or insufficiently lighted stables, over-feeding, etc.

The disease comes on with an inflammation usually of one eye. The transparent portion of the eyeball becomes bluish or white in color, most noticeable in the lower part. The eye is kept half closed on account of pain produced by light. Often this is associated by a swelling of the eyelids and reddening of the membrane lining them, with a discharge of tears over the face. There is no indication of an injury or more severe inflammation at one point than at another. In one to two weeks these symptoms disappear and the eye may be practically normal to all general appearances for a period of usually one to three months, when another attack occurs more severe than the first. After a few attacks have come and gone, the eye has a bluish appearance, looks cloudy instead of clear, the eyeball is 
shrunken, retracted in the orbit, and the lens develops a cataract. After having destroyed one eye, the disease frequently affects the other, and the history of the first is repeated.

Poll evil.-Poll evil is a fistula upon the poll of the head, and in no sense differs from fistulous withers except in location. It is caused by blows, bruises, and chafing by the halter or bridle.

Ringbone.-This is a bony growth at the coronet or on the pastern, in either the front or hind legs. It is called "ringbone" because it often grows around the coronet so as to form a ring, although in a large number of cases the growth takes the form of a lump on the pastern, rather than that of a ring at the hoof-head. This disease may result from severe work in early life, from bruises, blows, or sprains, or from improper shoeing. Ringbone often follows an abscess of the coronet, or a deep-punctured wound. It is also classed as an hereditary unsoundness, horses with short, upright pasterns being pre-

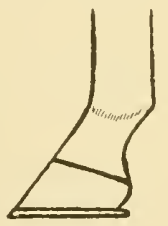

A

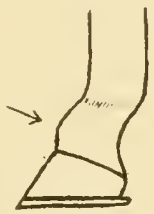

B

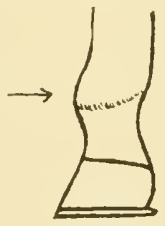

C

Fig. 167. Ringbone and Cocked Ankle.

$\mathrm{A}$, Sound; B, ringbone; $\mathrm{C}$, cocked ankle.

disposed. Ringbones often cause lameness which may disappear with exercise, returning again when the animal is cooled. They may or may not stiffen the joint. The size of the ringbone is not so important as its position. If it is located so as to interfere with the movement of the tendons behind or in front of the foot, it is a very serious trouble. Prevention of ringbones consists in keeping foals well nourished, and keeping the hoofs in balance. Curative measures consist of so shoeing as to straighten the axis of the foot and pastern as viewed from the side; blistering, followed by a few weeks of rest; and point firing in two or three lines over the ringbone. When these measures do not relieve lameness, the only recourse is nerving.

Roaring or thick wind.-Horses that make a loud, unnatural noise in breathing are said to have thick wind, or to be roarers, excepting those which manifest this trouble because 
of a severe sore throat. Any obstruction of the free passage of air in some part of the respiratory tract may cause roaring; occasional causes are nasal polypi, thickening of the membrane, pharyngeal polypi, deformed bones, paralysis of the wing of the nostril, etc. However, chronic roaring is caused by paralysis of the muscles of the larynx, thus permitting the cartilage and vocal cord to lean into the tube of the larynx. The noise is made during inspiration, and in far-advanced cases may be produced also during expiration. A horse is tested for roaring by putting him to severe exertion, as the sound is usually made only when at work. Roaring is a serious unsoundness because it incapacitates an animal for severe work, and it is a serious blemish because the noise is unpleasant. It is classed as an hereditary disease. Treatment varies depending on the exact cause, and includes a course of iodide of potassium in the early stages of the disease, or, in advanced cases, operating on the larynx.

Grunting.-When a pass is made at a horse with a stick, or he is otherwise startled, and he grunts, he should be further tested for roaring. It is a common thing for a roarer to grunt, although grunters are not always roarers. Such animals should be given a severe test of wind. Pleurisy and rheumatism will cause grunting, which ceases when the animal recovers from the disease.

Whistling.-This is only a variation of the sound emitted by a roarer. It may be temporary, due to a severe sore throat.

Sand crack.-Sand crack is a splitting of the wall of the hoof, beginning at the coronet, and commonly at the inner or outer quarter in the fore feet or at the toe in hind ones. It is due to imperfection in the growth of horn. It may cause lameness through sensitive parts being nipped by the crack. It constitutes unsoundness. The treatment is rest and cutting a notch transversely below the crack. If there is lameness the crack may be clasped. The shoe may be seated out below the crack, relieving pressure.

Sidebones.-Sidebones are formed by the ossification of the lateral cartilages of the foot, so that they become hard and unyielding, instead of soft and elastic. (See Fig. 115.) This disease is most common in heavy horses. They are found more often in the front feet than in the hind ones, and the outer cartilage is more often affected than the inner one. In the hind feet they are of little importance, since they cause no lameness. 
In the front feet they may or may not cause lameness, usually the latter; however, they always lessen the natural expansion of the heels and often result in shortening of the stride. When lameness is present, the horse comes out of the stable stiff and sore, but with exercise the gait shows improvement. Sidebones are caused by sprains, bruises, blows, and other injuries; and by high-heeled shoes, high calks, and short, upright pasterns. The size and prominence of a sidebone is not an index to the damage it may produce. Treatment is not of much account. It consists in using cold-water bandages, then blistering or firing. Neurotomy (nerving) is often practiced to relieve lameness. This is classed as an hereditary unsoundness. It is a serious form of unsoundness, but is not so serious as bone spavin, ringbone, roaring, or blindness.

Splint.-A splint is a variable-sized bony enlargement on the cannon bone, usually on the inside of the upper two-thirds of the front cannons. The button-like enlargements at the lower end of the splint bones should not be mistaken for splints. Splints occasionally cause lameness; if so, they constitute an unsoundness. They are more detrimental in horses used for fast work than in heavy horses used for slow work. In the great majority of cases, splints are only minor blemishes. Many horses have them. Splints often appear in young horses and may be absorbed shortly afterwards without treatment. The chief cause of splint is concussion. Other causes are sprains and injuries or blows on the cannon bone. No treatment should be given, as they but rarely cause trouble. Blistering and firing are sometimes practiced.

Sprung knees or buck knees.-This defective conformation may be congenital or the result of heavy labor at too early an age, there being retraction of the flexor tendons of the parts below the knee. While not an unsoundness, it detracts from the usefulness and value, especially in saddle horses. Horses with badly sprung knees may fall even when standing at rest and unmolested. (See D in Fig. 120.)

Stringhalt. - This disease comes under the general heading, chorea, or St. Vitus dance. It is manifested by a sudden, involuntary jerking up of one or both hind legs when the animal is walking or trotting. It may be very slight in some horses, but increases with age. In some the affected leg is caught up very violently and high, and then lowered equally sudden and forcible. It is more often associated with a nervous disposition 
than with a sluggish one. It is an incurable disease and very considerably lessens the price. It is best detected by causing the animal to back, or turning him around in his tracks first one way and then the other.

Swollen legs.-A swollen leg usually indicates disease, the causes being many. It is also not uncommon in old horses, or those having a sluggish circulation. It is not an unsoundness, but detracts from the appearance and is highly undesirable. Treatment consists in giving laxatives, saltpeter, and moderate exercise.

Thoroughpin.-This is similar to bog spavin; it is a swelling occurring at the back and on top of the hock in that part known as the "hollows." It is due to weakness of the capsular ligament and to hyper-secretion of synovial fluid. It is round and smooth, and most apparent when viewed from behind. The swelling is usually on both sides and a little in front of the hamstring. When pressed on one side, further distention occurs on the opposite side. It seldom causes lameness. Treatment is the same as for bog spavin. Thoroughpin is not a serious ailment, being usually only an eyesore, although many horsemen consider it an unsoundness.

Thrush.-This is a disease of the cleft of the frog which may cause lameness. It is usually the result of negligence, the result of uncleanliness. The cleft of the frog becomes suppurating and moist, and there is a very rank odor. Treatment consists in washing, disinfecting, drying, dusting with a little calomel, and packing. This must be repeated daily until the part becomes normal.

Windgall or road pufi.- Joints and tendons are furnished with sacs containing a lubricating fluid called synovia. When these sacs at the fetlocks become distended by reason of an excessive secretion of synovia, they are called windgalls. They form a soft, puffy tumor about the size of a hickory nut or walnut. They are sometimes found in young horses, but are most common in horses used for hard labor, especially on pavements. They may be accompanied by lameness, but if not, they are classed merely as blemishes. As a rule, no treatment is necessary in young horses. Older animals may be treated by resting, coldwater douches and bandages, and blistering. 


\section{INDEX.}

Action, effects of conformation on, 366-9.

slope of pastern on, 369 . essentials of, 368 .

(For action of various types see chapters on draft, carriage, road, and saddle horses.)

Age, in selecting feeder steers, 97-100. from teeth, cattle, 39 .

horses, 370-2. sheep, 202.

to breed ewes, 240 . heifers, 137. mares, 464. sows, 344 .

castrate calves, 26 . colts, 346 . lambs, 193. pigs, 281.

dock lambs, 193.

Alveoli of udder, 157-8.

American horses, origin of, 378-81. Jack, 468.

Merino, 245-53.

Saddle Horse, origin of, 379-80. type of, 419-22.

-type hog, description of, 282-9.

Anatomy of horse, 348-60.

Arabian horse, origin of, 374-5.

Army mules, 478-9.

Artillery horses, 446-8.

Ass, 468.

Auction rules, 438-9.

Australian plan of handling wool, 277-8.

Automobile, effect on horse industry, 382.

Baby beef, 87-91.

advantages and profits, 126 .

on the market, 110.

Bacon hog carcass, 306-8.

hogs, English, 325-6.

U. S., 326.

-producing countries, 290.

production, feeds used in, 290-1.

-type hog, description of, 290-6.

Barb horse, origin of, 375 .

Barrow, definition of, 281.

Base of support of horse, 361-2.

Bate, John J., early beef exports by, 82 .

Beef, ageing or ripening, 49. block or side, 49 .
Beef, Continued.

breeding cattle, weight for age, 131.

cow, type desired in, 133-7.

breeds, 25 .

internal fat of, 68 .

bull, importance of a good, 128-30 number of cows bred to a, 133.

type desired in, 128-33.

carcass, 40-56.

classes and grades of, 54-5.

cutters and canners, 49 .

differences due to sex, 54 .

good and inferior compared, 48.

grading, 53-4.

how produced, 46-7.

shape of, 50.

thickness of fat on, 50-2. flesh in, 50 .

variations in, 44-5.

weights of, 49-50.

cattle breeding for market, 12537.

prices, high and low months, 124.

shrinkage in transit, 81.

consumption in various countries, 297-8.

corned; introduction of, 80 .

cow, type desired in, 133-7.

cuts, prices of, 44. weights of, 44 .

cutting, 43 .

demands of butcher, 48-9. consumer, $48-9$.

exports of, 23 . pioneer, 82.

grain of, 53 .

heifers, age to breed, 137.

making, value of type in, 63-70. marbling, 50-2.

pounds produced per head of stock cows, 125 .

production, baby, advantages of, 126.

in cornbelt, outlook, 126.

factors for success in, 137.

see Calves, Carcass, Cattle, and Feeders.

sire, price to pay for, 129 . type desired in, 131-3. 
Beef, Continued.

steer vs. dairy steer, $63-70$. vs. beef heifer, 91-3.

type, definition of, 25 . description of, 27-39.

wholesale cuts of, 42-4.

Blindness, 481.

Block beef, 49 .

Blood meal, source of, 212. spavin, 481.

supply to udder, 159-60.

Boar, definition of, 281. number of sows bred to, 344 .

type desired in. 337-44.

Boars, on the market, 328.

Bog spavin, 481-2.

Bone spavin, 482-3.

Bones, flintiness of, in beef carcass, 53 . of cattle, changes due to age, 46-7 size of, in beef carcass, 53 .

Break-joint of lambs, 208-9.

Breed, a factor in selecting feeder steers, 103-4.

of horses, selecting a, 463 .

type, definition of, 25 .

Breeding bucks, on market, 232.

ewes, on market, $230-2$.

for milk production, 172-9. the market,

cattle, 125-37.

hogs, 332-44.

horses, 457-67.

sheep, 235-44.

sheep class, 230-2.

Breeds of cattle, 25.

beef, internal fat of, 68 .

dairy cows, differences in milk of, $160-1$

horses, 383.

origin of, 374-83.

jacks, 468 .

sheep, 192.

swine, 281.

classification of wool of, 267.

Broken wind, 483-4.

Brood mares, selection of, 463-4. working, 459 .

Buck, definition of, 193.

Buck knees, 491.

Bucks and stags, 226.

breeding, on the market, 232 .

Bull, definition of, 26 .

Bulls and stags, on the market, 113. feeder, 117.

Bull's Head Stock Yards, Chicago, 76.

Butcher cattle, 112-3. hogs, 322-3.

By-products from slaughteringcattle, 57-62.

hogs, $312,317-8$.

sheep, $212-3$.

Cab horses, 451.

Calf, definition of, 26 .
Calves, charges for selling at Chicago, 83.

manner of dressing, 42 .

number slaughtered in U. S., 72. value, and weight, at Chicago, 71.

prices of, at Chicago, 122-4.

see Cattle and Veal calves.

slaughter at markets, locally, and on farms, 72.

of, in percentage stock of cows, 125.

yearlings, and older cattle, for feeding, 97-100.

Canner carcasses, 49.

cattle, 114-5.

Canter described, 421.

Capped elbow, 484. hock, 484.

Carbonization of wools, 271 .

Carcass, bacon hog, 306-8.

beef, discussion of, $40-56$. cutter and canner, 49. differences due to sex, 54 . for side or block use, 49 .

good and inferior compared, 48.

grading, 53-4.

heifer vs. steer, 51.

how produced, 46-7.

shape of, 50.

thickness of fat on, 50-2. of flesh in, 50 .

variations in, $44-5$.

classes and grades, beef and veal, 54-5.

hog, 308-10.

sheep and lamb, 207.

goat, 209-10.

hog, discussion of, 297-310.

sheep or lamb-

discussion of, 203-10.

qualifications of a good, 207-9.

weights, beef, 49-50.

hog, 308 .

lamb, 208 .

sheep, 208.

veal, 55 .

Carloads, number of animals per car, 78-9.

Carpet wool, 259-60.

Carriage, evolution of, 376-8.

horse class, 449-51.

in America, 381.

origin and development of, $376-8$.

type, description of, $400-8$.

Casings, for sausage, 212.

Castration, best age for calves, 26 .

colts, 346 .

lambs, 193.

Cataract, 484 . pigs, 281. 
Cattle breeding in West, status in various states, $129-30$.

business today, 83-4.

by-products from slaughtering, $57-62$.

charges for selling at Chicago, 83 . dressing percentage of, 41-2.

early, 85-7.

fashions in, 85-94.

feeding, advantages of, 105 margin in, 96-7. source of profit in, 96 .

hides, average weight and value of, 57.

hoofs, value of, 58 .

horns, value of, 58 .

how classified and graded on market, 119-22.

market receipts, 71-2.

marketing, by seasons, 72 .

markets, American, 71-84. development of large, 74-5. early, 73 .

number slaughtered in U. S., 72 . to each inhabitant, 125.

value and distribution in U. S., 125-6.

value and weight at Chicago,

offal, 41. 71 .

prices at Chicago, 122-4.

highest and lowest months see Calves. on market, 124.

shipments by rail, early, 75 . methods of, early, 74-5.

shrinkage of, in transit, 81 .

slaughter at Chicago, $72,80$. markets, locally, and on farms, 72 .

of, in percentage stock of cows, 125 .

slaughtering, 40-1.

special advantage of, on farm, 26 .

terms, definition of, 26 .

weights of early, 85-7.

Caul of sheep, 204-5.

Cavalry horses, 453-4.

Chicago, Bull's Head Stock Yards, 76. cattle market, 71.

slaughter at, 72,80 .

sources of receipts, 79 .

charges for buying hogs, 328 .

corn, 322 .

hay, 83.

public inspection of hogs, 322.

selling cattle and calves, 83 . hogs, 322 .

sheep and goats, 215 .

yardage, cattle, 83 .

hogs, 322 .

sheep and goats, 215.
Chicago, Continued.

development of meat packing at, 315 .

early cattle trade, $75-6$.

hog market, 319-20. growth of, 319-20.

-packing firms, 317.

hogs slaughtered at, 317 .

packing plants, owners of, 80 .

prices for cattle and calves, 122-4. hogs, 330 .

horses, 455-6.

sheep and lambs, 233-4.

see Union Stock Yards, Chicago.

sheep market, 214-5. slaughtered at, 214-5.

zone system of marketing at, $72-3$.

Chitterlings, 312 .

Chunk horses, 443-4.

Cincinnati, early hog packing at, 314.

Circulation of blood to udder, 159-60.

Class, market, definition of, 106.

Classes and grades of carcassesbeef, $54-5$.

hog, 308-10.

mutton and lamb, 207.

Classes and grades of cattle, 106-24.

hogs, $322-31$.

horses, 438-56.

mules, 472-9.

sheep, 215-34.

wool, 262-7.

Classes, average prices at Chicagocattle, 122-4.

hogs, 330.

horses, 455-6.

sheep, 233-4.

Classes of Merinos, 251-3.

Classification of fine-wool sheep, 251-3.

see Market classes.

types and breeds of horses, 383 .

types and breeds of sheep, 192.

wools, 259-67.

Clothing and combing wools, 258-9, 262-7.

Coach horses, 450 .

Cob horses, 450 .

Cocked ankles, 484-5.

Colostrum, 162.

Colt, definition of, 346 .

Combing and clothing wools, 258-9, 262-7.

Commission charges, Chicagobuying hogs, 328 .

selling cattle, 83 . hogs, 322.

sheep and goats, 215.

Conestoga horses, 379 . 
Contracted feet, 485 .

Corn and hogs closely related, 334-5. beef, 80 . charges for, at Chicago market, 322 .

Corns, 485.

Cotton mules, 475-6.

Cough, chronic, 484.

Cow, definition of, 261.

Cows, fat, on the market, 113. see Beef cows and Dairy cows. stock and feeding, 117.

Cracked heels, 485 .

Crippled hogs, 329.

Cross-bred, definition of, 127.

Cumberland side, 307-8.

Curb, 485-6.

Cuts, see Wholesale cuts.

Cutter carcasses, 49.

Cutters and canners, 114-5.

Cutting beef, 43 .

Dairy breeds, 25 . differences in milk of, 160-1.

bull, importance of a good, 172-6. selection of a, 176-8. type desired in, 151-4.

cattle breeding, 172-9.

cow, type desired in, 138-51.

cows, method of judging, 138-40. notable tests of, 164-6. number, value, and distribution in U. S., 172.

testing, value of, 175 .

variations in usefulness of, 164-71.

world's record-holding, 1667.

farming, advantages of, 178-9.

steers, for beef, 63-70. why lacking thick flesh, 68-9

temperament, 150 .

type, definition of, 25 . description of, 138-54.

Dead animals, numbers removed from cars at Chicago, 330 .

Dead hogs, 329-30. sheep, 233.

Delivery wagon horses, 446 .

Depilatory, 269.

Digestive system of horse, 350 .

Docking lanbs, best age for, 193 .

Draft horse in America, 380-1. mare, selection of, $463-4$. mules, 477.

stallion, selection of, 465 .

type, advantages of, to farmer, 461.

description of, 384-99.

origin of, 376.

weight for age, 399 .

Dressing calves, 42 . cattle, 40-1.
Dressing, Continued.

hogs, 297-8.

percentage, average of

calves, 42 .

cattle, 42.

hogs, 299-300.

sheep and lambs, 205.

of cattle, 41-2.

hogs, 299-300.

sheep, 205.

see Slaughter.

sheep and lambs, 204-5.

Dual-purpose breeds, 25.

cattle, profits from, 184-7. utility of, 180-2.

type, definition of, 25 . description of, 182-4.

Dyeing woolen goods, 259 .

Eastern chunks, 443-4.

Eastman, Timothy C., early beef exports by, 82 .

Eckles, C. H., investigation of variation in milk production, 167 70 .

English bacon hogs, 325-6.

Escutcheon of dairy cattle, 149-50.

Ewe, definition of, 193.

mutton breeding, type desired in, 240-3.

Ewes, age to breed, 240.

fat, 226 .

feeder, 230.

number to breed to one ram, 240 .

Export mules, 479.

Exports of beef, 23

pioneer, 82 .

of pork products, 318-9. wools, 272-3.

Express horses, 445-6.

Farm chunks, 444.

mules, 476-7.

Farming, live-stock, advantages of, 21 . vs. grain, 19 .

Fashions in market cattle, 85-94.

Fat, color of, in beef, 52-3.

cows on the market, 113.

heifers on the market, 109, 113.

internal, in steers of different breeds, 68 .

percentage in cuts of beef, 48 .

steer class, 107-10.

storage in bodies of cattle, 47 .

thickness of, in beef carcass, $50-2$.

Fatness, effect of feed on, in steers, $37-8$.

Federal inspection for disease, 79 .

Feed, charges for, at Chicago, 83. effect on composition of milk, $170-1$.

required for gains in hogs, 339-40. steers, 52 . 
Feeder bulls, 117.

cattle, decline in production, 126. sale of, by seasons, 95 . sub-classes and grades, 1157. where bought, 95 .

ewes, 230.

horses, 454 .

pigs, 328

sheep and lambs, 226-30. sale by seasons, 226 . where bought, 226-7. steers, selection of, 95-105. wethers, 230 .

Feeding cattle, advantages of, 105 .

Feeds, fertilizing value of, 20 .

Feet, contracted, 485 .

Fertility, soil, maintenance of, 20 .

Fertilizer, source of, 212.

Fill of cattle on market, 42 .

Filly, definition of, 346 .

Fine-wool sheep, breeds of, 192. type, description of, $245-54$.

Fire horses, 448-9.

Fistula, 486.

Five-gaited saddle horse, 419-22.

Fleece of fine-wool sheep, 250. mutton sheep, 198-202. see Wool. tying, 275-6.

Fleeces, buck, 276 . cotted or matted, 276. grading, 262 .

Flesh, effect of feed on, in hogs, 290-1. steers, $36-8$ thickness of, in beef carcass, 50 . why dairy steer lacks, 68-9.

Fleshing, natural, in feeder steers, 102.

Foal, definition of, 346 .

Foods, analyses and fuel values of, 337 .

Foot of horse, anatomy of, 355-9. characteristics of a healthy, 35960.

Fore leg of horse, anatomy of, 351-2.

Founder, 486-7. attachment of, 361-2.

Four-tooth, definition of, 193.

Fox trot described, 422.

Free-martin, definition of, 26.

Gains by hogs of different weights, 339-40.

steers for different periods, 52 .

Gaits of horse described, 420-2.

trotting and pacing, 415-6.

Gammon, 296.

Gelding, definition of, 346 .

General-purpose horse, 380 .

Gestation period of cattle, 137.

horses, 464 .

sheep, 240 .

Gilt, definition of, 281.
Glue, 58, 212, 312 .

Goat carcasses, 209-10. skins, value of, 212.

Goats and kids-

charges for selling at Chicago, 215 .

number slaughtered in U. S., 214.

on the market, 233.

slaughter at markets, locally, and on farms, 214

Governments, 329.

Grade animal, definition of, 128.

dairy cows compared with scrub dams, $173-5$.

market, definition of, 107.

Grading carcasses, beef, 53-4.

hog, 308-10.

mutton and lamb, 207.

Grease, 487. see Market classes

Great Horse, origin of, 375-6.

Grunting, 490.

Guenon, Francois, escutcheon theory of, 149.

Hams, long-cut, 307-8.

Hand, definition of, 372 .

Hay, charges for, at Chicago market, 83.

Heaves, 483-4.

Heavy-harness type-

description of, $400-8$.

see Carriage horse.

Heifer beef, compared with steer beef, 91-3.

carcasses, preferred in England, 51.

definition of, 26 .

fat, on the market, 109, 113.

Height of horses, determining, 372-3.

Hides, cattle, average weight and value of, 57 .

see Skins.

High grade animal, definition of, 128 .

Hind leg of horse, anatomy of, 352-5.

Hinny, 468. attachment of, 361 .

Hip down, 487.

Hock, anatomy of, 352-4.

Hocks, bent or sickle, 369-70.

Hog by-products, 312, 317-8.

carcass, classes and grades of, 308-10.

discussion of, 297-310.

U. S. Retained, 311.

wholesale cuts of, 301-3.

crop, peculiarities of, $320-1$.

fattening ability of, 305 .

marketing, numbers and prices by seasons, 321 .

markets and pork packing, 31421. 
Hog markets, Continued.

present leading, and receipts, 319 .

-packing centers, leading present, 316.

firms at Chicago., 317

past and present, 314-21.

prices at Chicago, 330 .

-producing states, 334 .

product importing countries, 318 9.

exports of, 318-9.

high fuel value of, 336-7.

-raising countries, leading, 333.

see Pigs, Pork, and Swine.

slaughter, compared with cattle and sheep, 297-8.

at markets, locally, and on farms, 319

terms, definition of, 281 .

yardage charges at Chicago, 322 .

Hogs and corn closely related, 334-5.

boar class of, 328 .

breeding for the market, 332-44.

butcher, 322-3.

charges for buying at Chicago, 328.

cripples, 329.

selling at Chicago, 322.

dead, 329-30.

dressing percentage of, 299-300.

English bacon, 325-6.

feed for $100 \mathrm{lbs}$. gain, 339-40.

feeder pig class, 328 .

governments, 329 .

heavy and light, demand and prices for, 331 .

increase in numbers of, 333 .

light, 325-7.

light light, 327. mixed, 326-7.

market classes and grades of, 322-31.

number, value, and distribution in U. S., 334 .

numbers packed in various years, and cost, 316 .

offal of, 299-300.

packing class of, 323-4.

pig class of, 327 .

prime heavy, 322 .

public inspection of, at Chicago, charge for, 322.

roasting pig class, 329 .

rough class, 327.

seasonal marketing of, 331 .

see Hog, Pig, Pork, and Swine.

selection for breeding purposes, 339-44.

sell largely by weight, 331 .

size in market, 337-9.

slaughter in U. S., in per cent. total stock, 337 .
Hogs, Continued.

slaughtering and dressing, 298-9.

stag class, 327-8.

U. S. bacon, 326 .

weights of, in early times, 337-9.

marketed at Chicago

by months, 320-1.

Hoof, and how it grows, 357-9. mechanism, 365 .

Hoofs, cattle, value of, 58 .

Horns, cattle, value of, 58 .

Horse, age of, from teeth, 370-2.

anatomy of, 348-60.

and mule compared, 469-71.

base of support of, 361-2.

breeding, 457-67.

conformation concerned in action, 366-9.

digestive system of, 350 .

effects of mechanical inventions on, 381-2.

foot of, anatomy of, 355-9.

fore leg, anatomy of, 351-2.

height of, determination of, 372-3.

hind leg, anatomy of, 352-5.

hock, anatomy of, 352-4.

important facts concerning the, $361-73$.

in America, 378-81.

motion, 362-4.

integumentary system of, 350 .

market auction rules, 438-9. requirements, $439-41$.

markets, receipts in $1918,438$.

muscular system of, 349-50.

nervous system of, 350 .

prices at Chicago, 455-6.

respiratory system of, 350 .

skeleton of, 348 . compared with man, 354-5.

terms, definition of, 346-7.

utility of, 345 .

where wear comes in, 364-5.

Horses, number, value, and distribution in U. S., 466-7.

Hot-house lambs, 232.

Hunter horse, description of, 428-33. origin of, 376. production of, 433 .

Imports of wools, 272-3.

Inspection, federal, for disease, 79, 311-2.

Inspection of hogs at Chicago, charge for, 322 .

Integumentary system of horse, 350 .

Interfering, 369 .

Jack, best type of, 468 .

Jacks, breeds of, 468 .

Jennet, the, 468 .

Judging dairy cows, two methods of, $138-40$. 
Kemp, 201, 274.

Knuckling, 484-5.

Lamb, definition of, 193. recent demand for, 203 see Mutton and Sheep.

Lambs, fat, 218-23. feeder, 227-9.

hot-house, 232. spring, 219-20. throw-out, 233.

Laminitis, 486-7.

Lard, grades of, 310-1. hog carcass, 301-6. hogs, feeds used with, 283.

-type hog, description of, 282-9. reasons for developing in U. S. 336-7.

yield from hogs of different weights, 304 .

Lateral cartilages, 356-7.

Lead mules, 478 .

Lean meat, color of, in beef, 52 . percentage in beef cuts, 48 .

Legs of horse, anatomy of, 351-5. attachment to body, 361-2. defects in conformation, 366-70. swollen, 492.

Light-harness type, description of, 409-17.

Light hog class, 325-7. see Roadster.

horses, require skill in breeding, 461-3.

light hogs, 327.

mixed hogs, 326-7.

Live-stock farming, advantages of, 21 . vs. grain farming, 19 .

comparison of erop yields, 126 .

Locomotion in the horse, 362-4.

Loggers, 442-3.

Loretta D., record of, 166.

Manure, value of, 20.

Marbling in beef, 50-2.

Mare, best type of, for horse breeding, 463-4.

definition of, 346

mule breeding, 468 .

working the brood, 459 .

yeld, definition of, 347 .

Margin in cattle feeding, 96-7.

Market cattle, how classed and graded, 119-22.

class, definition of, 106 .

classes and grades of cattle, 10624.

horses, $438-56$. mules, 472-9. sheep, 215-34. swine, $322-31$. wool, 262-7.
Market classes, Continued.

average prices of -

$$
\begin{aligned}
& \text { cattle, 122-4. } \\
& \text { horses, 455-6. } \\
& \text { sheep, 233-4. }
\end{aligned}
$$

swine, 330 .

demands, importance of, to breeder and feeder, 21.

grade, definition of, 107.

receipts, cattle, 71-2.

horses, 438.

sheep, 214.

swine, 319 .

requirements for horses, 439-41. mules, 472-4.

Marketing, seasonal variations in, cattle, 72.

hogs, $321,331$.

sheep, 214.

wool properly, 276-7.

zone system of, at Chicago, 72-3

Markets, American cattle, 71-84.

hog, 319-20.

horse, 438 . sheep, 214.

development of large, 74-5.

early cattle, 73 .

hog, past and present, 314-21.

Mast, 332 .

Meat consumption in various countries, 24, 297-8.

industry, three eras in, 80.

packing, development at Chicago, 315 .

production, in U. S., in 1909, 24. world total, 24 .

Merino, classes of, 251-3.

importance of the, in U. S., 245.

type, description of, 245-54.

Milk cistern, 157.

cows, see Dairy cows.

ducts, 157-8.

effect of feed on, 170-1.

mirror, 149-50.

nature and composition of, 160-1.

production, breeding for, 172-9. cause of variation in, 167-70. in U. S., in 1918, 24-5. of average dairy cow, 164 .

secretion, 155-63. stimuli to, 163.

veins, 148-9.

wells, 149 .

yield per cow in 1918, 24-5.

Milkers and springers, 119.

Milking qualities, importance of, in beef cows, $135-6$.

Mining mules, 475.

Mohair, 278.

Moonblindness, 488-9.

Morgan horse, origin of, 379.

Motor, effect of, on horse industry, 382. 
Mule, 468-71.

and horse compared, 469-71.

best type of, 469 .

Mules, market classes of, 472-9.

requirements for, 472-4.

number, value, and distribution in U. S., 466-7.

Muscle, effect of feed on, in steers, 36 .

Muscular system of horse, 349-50.

Mutton and lamb carcass, 203-13.

consumption in various countries, 297-8.

wholesale cuts of, 206.

breeding ewe, type desired in, 240-3.

ram, type desired in, $237-40$.

carcass and pelt, 203-13.

classes and grades of, 207.

qualifications of a good, 207-9.

wholesale prices of, 207.

pounds produced per head of stock ewes, 237.

recent demands for, 203 .

sheep, breeds of, 192 .

class, 218-26.

increase in numbers in U.S., 236.

type, description of, 194-202.

Native sheep, characteristics of, 216.

Navicular disease, 487-8.

Nervous system of horse, 350 .

Noils, 258.

Norfolk trotter, origin of, 378 .

Offal of cattle, 41.

hogs, $299-300$.

sheep, 205.

Oleo oil, source of, 213.

Oleomargarine, manufacture of, 57-8.

Origin of breeds of horses, 374-83. types of horses, $374-83$.

Pace, slow, described, 422.

Pacing gait described, 415-6. records, 411.

Pack and riding mules, 478-9.

Packing hogs, 323-4.

-house by-products from cattle, $57-62$.

hogs, $312,317-8$. sheep, 212-3.

industry, development of, 79-80. three eras in, 80 .

plant, the modern, 82-3.

plants, owners of, at Chicago, 80 . pork, past and present, 314-21.

Paddling, 369.

Park horses, 451.

Pasterns, slope of, effect on action, 369.
Pedigree, dangers of, 178 .

important in swine breeding, 343-4.

value of, in selecting dairy bull, 176-8.

with performance, 176-8.

Pelt of sheep, value and use of, 210-2.

Periodic opthalmia, 488-9.

Pigs, on the market, 327.

feeding, 328 .

roasting, 329 .

see Hog, Pork, and Swine.

Pluck, 205, 212.

Plug horses, 455. mules, 479 .

Pododerm, 357.

Poll evil, 489.

Polo, history of, 433-4.

pony, description of, 433-7. origin of, 378 . production of, 436-7.

Ponies, 455.

Pony breeding, 463.

Population, agricultural, 23-4. of U. S., 23-4.

Pork, consumption of, in various countries, 297-8.

exports of, 318-9.

high fuel value of, 336-7.

importing countries, 318-9.

packing, development at Chicago, 315.

past and present, 314-21.

produced per head stock of hogs, 337.

products, exports of, 318-9.

value of, $300-1$.

salt, fat, and lean compared, 336 . wholesale cuts of, 301-3.

trade in, $300-1$.

Pregnancy, duration of, in cows, 137. ewes, 240

mares, 464 .

sows, 344 .

Prices at Chicago, for cattle, 122-4. hogs, 330 .

horses, 455-6.

Prime heavy hogs, 322 . sheep, 233-4.

Prolificacy in swine, 343.

Purebred, definition of, 127.

Rack described, 422.

Railroads, early shipments of cattle by, 75 .

Ram, definition of, 193.

mutton breeding, type desired in, 237-40.

number of ewes to breed to, 240 .

Rambouillet, 253-4.

Range cattle breeding, in various states, 129-30.

on the market, 110-2. 
Range breeding, Continued. horses, $454-5$.

sheep, 216.

Receipts at leading marketscattle, 71-2.

hogs, 319 .

horses, 438 .

sheep, 214.

Records, fastest trotting and pacing, 410.

highest, by dairy cows, 166-7.

value of, in breeding for beef, 137 . dairy cattle, 175 .

Refrigeration, artificial, 81.

Refrigerator car, 80-1.

Renick, George, cattle feeding operations of, 73-4.

Respiratory system of horse, 350 .

Ringbone, 489 .

Road horse class, 451-2. puff, 492.

Roadster type, description of, 409-17.

Roaring, 489-90. origin of, 379 .

Roasting pigs, 329.

Roughs, 327 .

Rudimentaries of bull, 154.

Runabout horses, 451-2.

Running horse, origin of, 375 . walk described, 422 .

Saddle Horse, American, origin of, 379-80.

class, 453-4.

first, origin of, $374-5$.

type, description of,

Sand crack, 490.

$$
\text { 418-27. }
$$

Sausage casings, 212.

Scouring wool, 270-1.

Scrub animal, definition of, 127.

Secretion of milk, 155-63.

Sex differences in beef carcasses, 54 .

Shadybrook Gerben, record of, 166 .

Shearing sheep, 255.

hand vs. machine, 276.

Shearling, definition of, 193.

Sheep and lambs, marketing by seasons, 214. number slaughtered in U. S., 214.

at Chicago, number, value, and weight of, 214.

branding with paint, 275 .

breeding for the market, 235-44. breeds, 192. wool of, classified, 267.

by-products from slaughtering, 212-3.

carcass, 203-10.

caul, 204-5.

charges for selling at Chicago, 215.
Sheep and lambs, Continued.

dead, 233.

dressing, method of, 204-5. percentage of, 205.

industry in U. S., in early times, 235-6.

increase in numbers in U. S., 236. market classes and grades of, 215-34.

markets, 214-5. in U. S., 214.

most profitable kind to grow, 193. native and western, $216-8$.

number, value, and distribution in U. S., 236.

offal, 205.

pelts, value of, 210-2.

prices at Chicago, 233-4.

highest and lowest months, 234.

raising, advantages of, 189-91. present status of, 189 .

see Lamb and Mutton.

shearing, 255.

skins, value of, 212 .

slaughter at markets, locally, and on farms, 214.

by Chicago packers, 214-5. in per cent. stock of ewes, 237.

slaughtering, 203-4.

terms, definition of, 193.

types of, 191-3.

Shoddy, 259.

Shoe boil, 484 .

Shote, definition of, 281.

Shrinkage of beef cattle in transit, 81 . wools, 267.

Sickle hocks, 369-70.

Sidebone, 490-1.

Skeleton of horse, 348.

man and horse compared, 354-5.

Skins of goats, value of, 212 .

sheep, value of, 212 .

Slaughter at Chicago, number of calves, 80 . cattle, 72,80 . hogs, 317 . sheep, 214-5.

Slaughter in per cent. of breeding stock-

cattle and calves, 125 . sheep and lambs, 237.

market, local, and farm-

of cattle and calves, 72 .

goats and kids, 214 .

hogs, 319.

sheep and lambs, 214.

of hogs in per cent. of total stock, 337.

pork compared to beef and mutton, 297-8.

see Dressing. 
Slaughtering and dressing cattle, 40-1. hogs, 298-9. sheep, 203-5.

Sloan, Tod, his method of riding, 363 . Soil fertility, maintenance of, 20 .

Southern chunks, 444.

Soundness in breeding ewes, 231.

Sow, age to begin breeding, 334 . definition of, 281.

type desired in, 339-44.

Spanish horse, origin of, 375. Merino, 245.

Spavins, 481-3.

Spayed heifer, definition of, 26.

Spaying heifers, reasons for, 93-4.

Splint, 491.

Spring lambs, 219-20.

Springers, 119.

Sprung knees, 491.

Stag, definition of, $26,193,281,347$.

Stags, 327-8. and bulls on market, 113 .

Stallion, definition of, 346 . type desired in, 465 .

Standardbred horse, origin of, 379 . see Roadster.

Stearin, 58, 312.

Steer class on market, 107-10. definition of, 26.

Steers, changes in due to feeding, 36-8. gains in different feeding periods, 52.

see Cattle and Feeder.

weights at various ages, 39 .

Stepping pace described, 422.

Stock and feeding cows, 117.

Stocker and feeder cattle-

decline in production, 126.

sale by seasons, 95 .

see Feeder.

sub-classes and grades of, 115-7.

where bought, 95 .

Stomach worm of sheep, 217-8.

Stringhalt, 491-2.

Sugar mules, 476 .

Suprarenalin, 213.

Sweetbreads, 58.

Swine, advantages of raising, 279-80. breeds of, 281 .

see Hog, Pig, and Pork.

types of, 280.

Swollen legs, 492.

Teats of dairy cow, 147.

structure of, 157.

Teeth as indication of age of cattle, 39 . horses, 370-2.

Temperament, dairy, 150 . sheep, 202. discussion of, 150 .
Tests of dairy cows at expositions, 164-6.

value of, 175 .

Texas and western range cattle, 110-2. long-horn cattle, $110-1$.

Thick wind, 489-90.

Thoroughbred, origin of, 375 .

Thoroughpin, 492.

Thyroidin, 213.

Three-gaited saddle horse, 423-4.

Throw-out lambs, 233.

Thrush, 492.

Top, 258-9.

Tractor, effect of, on horse industry, 382.

Transportation, early methods of, $73-4$.

Tripe, 212.

Trot, fox, described, 422 .

Trotting gait described, 415. horse, origin of, 379 . records, 410.

Turk horse, origin of, 375 .

Two-shear, definition of, 193.

Two-tooth, definition of, 193.

Type, definition of, 25.

of horse to breed, choice of, 460-1. value of, in beef making, 63-70.

Types of cattle, 25 .

horses, 383.

effects of mechanical inventions on, 381-2. origin of, 374-83.

sheep, 191-3.

swine, 280.

Udder of cow, structure of, 155-7. dairy cow, 146-7.

Union Stock Yards, Chicagocharges for buying hogs, 328 . corn, 322 .

hay, 83.

inspection of hogs, 322 .

selling cattle and calves, 83 . hogs, 322. sheep and goats, 215.

yardage of cattle, 83 . hogs, 322 . sheep, 215 .

description of, $76-8$.

founding of, 76 .

growth as hog market, 319-20.

prices for cattle and calves, $122-4$. hogs, 330 .

horses, 455-6.

receipts, cattle, 71 . sheep, 233-4.

hogs, 319-20.

horses, 438.

sheep, 214.

sources of, 79 .

see Chicago. 
Unsoundness in the horse, 480-92.

U. S. bacon hogs, 326 .

Variations in usefulness of dairy cows, 164-71.

Veal calves, 118-9.

consumption in various countries, 297-8.

pounds produced per head of cows, 125.

see Calves.

Walk, running, described, 422.

Wagon horses, 444-9.

Walk, trot, canter horse, 423-4.

War Horse, origin of, 375-6.

Weanling, definition of, 346 .

Weeds, 455.

Weight, dressed, average of calves, 42 . cattle, 42 .

hogs, 300 .

lambs, 205.

sheep, 205.

for age, beef bulls and cows, 131 . draft horses, 399 .

lard hogs, 289.

steers, 39.

importance of, in draft horses, 384-5.

live, average of slaughtered calves, 42 .

cattle, 42 .

hogs, 300 .

lambs, 205.

sheep, 205.

of hogs, most profitable, 339 .

Weights of early cattle, 85-7.

hogs, 337-9.

hogs at Chicago, by months, $320-1$.

horses, 442

Western range cattle, 110-2.

breeding in various states, 129-30. receipts at Chicago, 71.

Western sheep, characteristics of, 216 . prices at Chicago, 233-4.

Wether, definition of, 193 .

Wethers, fat, 225-6.

feeder, 230 .

Wheel mules, 478.

Whistling, 490.

Wholesale cuts of beef, 42-4. mutton and lamb, 206.

Wiltshire side, $307-8$. pork, 301-3.

Windgall, 492

Wool, Australian plan of handling, $277-8$.

black, 270,276 .

buck fleeces, 276 .

burs in, 275 .

carbonization of, 271.

character, 274.

clip of world, 271.

consumption per capita, 255.
Wool, Continued.

cotted or matted, 276.

dyeing, 259.

factors determining value of, 273-6.

fiber, strength of, 275. structure of, 255-7.

fineness of, 257.

frowzy, 268.

grading, 262 .

imports and exports, 272-3.

market classes and grades, 262-7

marketing properly, 276-7.

markets in America, 273.

packing, 276.

painted, 275 .

pooling by growers, 278 .

pounds per pound of cloth, 259 .

prices of scoured and raw, 274 .

-producing states, 272.

production in U. S., 271-2.

pulling, 269-70.

scouring, 270-1.

see Fleece and Wools.

shearing, hand vs. machine, 276.

shrinkage, 272, 273-4. of various grades, 267.

sorting, 268-9.

tags, 275.

tying fleece, 275-6.

wet, 275 .

Woolens and worsteds, 258-9.

Wools, American, how to improve, 277.

and wool growing, 255-78.

bright and semi-bright, 260 .

carpet, 259-60.

classifications of, 259-67.

clipped and pulled, 259.

combing and clothing, values of, 262.

domestic and territory, 259-61. classes and grades of, 262-7.

Ohio, 260.

see Fleece and Wool.

washed, unmerchantable, and unwashed, 261-2.

World's record dairy cows, 166-7.

trotting and pacing records, 410-11.

Worms, stomach, of sheep, 217-8.

Worsteds and woolens, 258-9.

Yardage charges at Chicagocattle and calves, 83 . hogs, 322.

sheep and goats, 215 .

Yearling sheep, fat, 224-5. feeders, 229 .

Yeld mare, definition of, 347.

Yolk, 200. secretion and composition, 257-8.

Zone system of marketing at Chicago, $72-3$. 




